


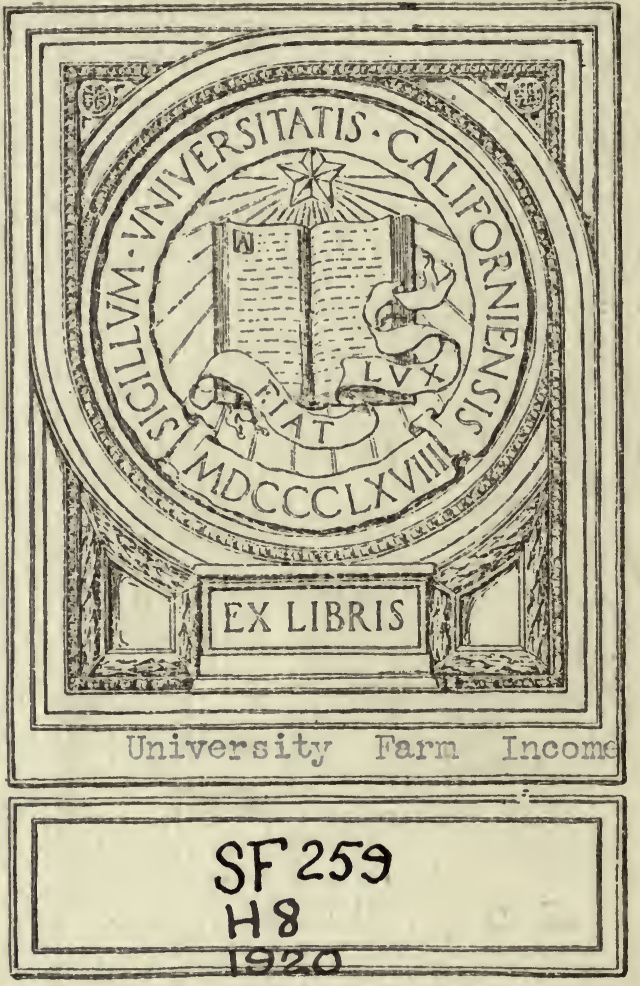

U.C.D. LIBRARY 



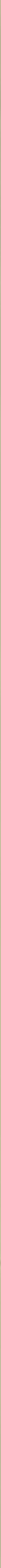




TO THE MEMORY

of

MY FATHER

This Volume is Dedicated 
COPYRIGHT, 1920

O. F. HUNZIKER 


\title{
Condensed Milk and Milk Powder
}

\author{
T H I D E D I T I O N \\ REVISED AND ENLARGED
}

PREPARED FOR THE USE OF

Milk Condenseries, Dairy Students and Pure Food Departments

\author{
By \\ OTTO F. HUNZIKER, B. S. A., M. S. A. \\ Author of "The Butter Industry" \\ Formerly Professor of Dairy Husbandry, Purdue University \\ and
}

Chief of the Dairy Department of the

Indiana Agricultural Experiment Station

LaFayette, Indiana

Now Manager Manufacturing Department and Director Research Laboratory Blue Valley Creamery Co.

Chicago

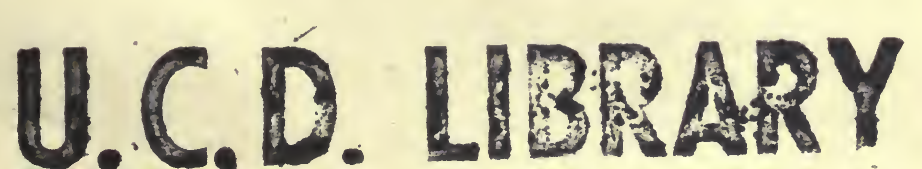


Unimfarm 


\section{P R E F A C E}

This book treats of the various phases of the condensed milk and powdered milk industry. It discusses every step in the process of manufacture, following the milk from the farmer's door to the finished product in the pantry of the consumer. The processes of condensing and desiccating milk, skim milk, buttermilk and whey are given special attention and the defects of the product, their causes and prevention are explained in detail.

The inception of this publication is the result of innumerable and persistent calls for definite and reliable information on the subject of condensed milk and milk powder, from manufacturers in this country and in foreign lands; from parties contemplating embarking in the business; from national and state experiment stations which are oftentimes called upon to investigate condensed milk defects; from dairy schools desiring to give instruction on the subject; from national and state pure food departments, seeking information concerning the possibilities and limitations of manufacture, in their efforts to formulate and enforce standards and laws ; and from commercial chemists in need of reliable methods of analyses of these special dairy products.

The information contained in this volume represents the author's experience, covering a period of twelve years, in the practical manufacture of condensed milk, as expert advisor to milk condensing concerns in the United States, Canada and Australia, and as visitor of condensed milk and milk powder factories in this country and in Europe.

It is the author's hope that the information contained herein may serve as a guide to manufacturers, investigators, teachers and food authorities, alike; that it may assist in a better understanding and wider dissemination of the principles, phenomena and facts involved in the processes of manufacture; and that it may lift the obstructing veil of unnecessary secrecy which has hovered over these 
industries since their beginning, curtailing their development and depriving them of much of the light of advanced science to which they are justly entitled and which they need for their greatest development for the lasting benefit of the producer, manufacturer and consumer alike.

Purdue University, March, 1914.

O. F. HUNZIKER.

\section{PREFACE FOR THIRD EDITION}

Since the issuance of the First and Second Editions of this treatise many changes have taken place in the various phases of the Condensed Milk Industry. Old processes have been modified and improved, new processes have been invented; the equipment used for manufacture has undergone changes, new tests have been devised for the determination of the composition of the finished products and the entire status of the industry has yielded to an unexpected, unforeseen and important evolution.

Of the most outstanding new features in this edition may be mentioned the chapters on Directions for the Standardization of the Sterilizing Process, Evaporated Milk Control, Use of the Mojonnier Viscosimeter, Manufacture of Condensed Buttermilk and Buttermilk Powder, New Patents and Processes for the Manufacture of Milk Powders. Important additions have also been made to the chapters on History of the Industry, Volume of Output, Markets, Exports, Imports, Cost of Manufacture, Standardization of Condensed Milk, and Prevention of Condensed Milk and Milk Powder Defects.

In preparing this Edition, the author has endeavored to completely revise the old edition, incorpoarting in the revised edition the many changes which the tooth of time has wrought and to bring this treatise in all its important phases up-to-date.

O. F. HUNZIKER.

Chicago, Ill., September, 1920. 


\section{CONTENTS}

\section{PART I \\ CONDENSED MILK}

Definition

Chapter I

History and Development-Invention of process; development of industry; annual output in U. S., 1899-1920; annual output in other countries; list of condenseries by states............. Pages 17-29

\section{Chapter II}

Essentials of Suitable Locations for Condenseries-Milk supply; water supply; transportation facilities; sewage disposal.

Building and Equipment-Material of construction; floors, walls and ceilings; ventilation; drainage; general plan of factory; list of equipment; economic arrangement of machinery; sanitary arrangement of machinery............................ 29-43

\section{Chapter III}

Milk Supply-Basis of buying milk; comparative prices paid for milk in 1914 to 1918 in the four large condensing territories in U. S.; quality; control of quality; inspection at condensery; acid tests of milk; boiling test; sediment test; fermentation tests.

Factory Sanitation-Effect on patrons; on wholesomeness of product; on marketable properties; how to keep factory in sanitary condition; can washing; care of milk in factory prior to condensing ............................................. 43-58

PART II

\section{MANUFACTURE OF SWEETENED CONDENSED MILK}

\section{Definition}

\section{Chapter IV}

Heating-Purpose; temperature; manner; advantages and disadvantages of different methods.

Addition of sugar-kinds of sugar; beet sugar; quality and amount of sugar; mixing the sugar.............................. 59-68

\section{Chapter V}

Condensing-Description of vacuum pan; types of coils; arrangement of coils for maximum rapidity of evaporation.

Condensers-Surface condenser; barometric condenser, wet-vacuum spray condenser; care of condenser; expansion tank; catch-all.

Vacuum Pump-Science and practice of evaporating in vacuo.

Purpose of condensing in vacuo; relation of pressure to boiling point; relation of altitude to atmospheric pressure; relation of steam pressure in jacket and coils, water in condenser, temperature in pan and vacuum, to rapidity of evaporation.

Starting the Pan.

Operating the Pan.

Prevention of accidents................................. $68-96$ 


\section{Chapter VI}

Striking or Finishing the Batch-Definition; ratio of concentration; methods; appearance to eye.

Beaumé hydrometer; temperature correction of Beaumé; specific gravity of sweetened condensed milk at different degrees Beaumé; sampling the batch; drawing off the condensed milk.

Cooling-Methods; equipment; effect on product.........Pages 96-110

Chapter VII

Filling-In barrels; in cans; filling machines.

Sealing-Kinds of seals; soldering devices; solder; soldering flux; gas supply ................................... 110

PART III

\section{MANUFACTURE OF UNSWEETENED CONDENSED MILK EVAPORATED MILK}

Definition

\section{Chapter VIII}

Quality of fresh milk; standardizing milk.

Heating the Milk.

Condensing.

Striking.

Beaumé hydrometer; temperature correction of Beaumé; calculation of specific gravity from Beaumé reading; standardizing evaporated milk .................................... 117-124

\section{Chapter IX}

Homogenizing-Purpose; principle of homogenizer; Gaulin homogenizer; Progress homogenizer; Viscolizer; operation of homogenizer

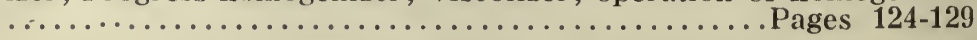

Cooling-Holding tanks.

Chapter $\mathrm{X}$

Filling-Filling machines; venthole cans.

Sealing-Sealing machines; can testers.................... 129-136

Chapter XI

Sterilizing-Purpose; sterilizers; loading the sterilizer; uniform distribution of heat; cans with tell-tale thermometers; temperature and time exposure; qualifications of processer; rapid and uniform cooling; fractional sterilization; standardization of properties that influence behavior of evaporated milk toward heat of sterilization; Mojonnier method of evaporated milk control; Mojonnier equipment; preparation of bicarbonate of sodium solution; preparation of sample cans for sterilizer; sterilizing sample cans; testing sample cans for viscosity; Mojonnier viscosimeter; importance of proper viscosity; factors that influence the viscosity and their correlation to sterilizing process; the correct viscosity for evaporated milk; adding sodium bicarbonate to batch; adjusting sterilizing process to different sizes of cans; Should bicarbonate of soda be used?

Shaking-Purpose; methods; speed of shaker. 
Chapter XII

Plain Condensed Bulk Milk-Definition; quality of fresh milk; heating; condensing; superheating; striking; ratio of concentration; cooling ......................................... 1626

\section{Chapter XIII}

Concentrated Milk-Definition; apparatus needed; operation of Campbell process; advantages and disadvantages of process.Pages $166-168$

\section{Chapter XIV}

Condensing Milk by Continuous Process-Buflovak rapid circulation evaporator; description; operation.

The Continuous Concentrator-Description; operation.

The Ruff Condensing Evaporator-Description; operation; quality of product from continuous machines...............Pages 168-176

\section{Chapter XV}

Condensed Buttermilk-Composition of buttermilk; manufacture; removal of whey by gravity; concentration by centrifugal separation; evaporation in vacuo; equipment necessary.

Operation-Ripening of buttermilk; preheating; condensing; concentration; testing for density; condensing buttermilk by film process; packing; storage; composition of condensed buttermilk; markets; annual output in U. S.

Condensed Whey or Primost....................... 176-185

\section{PART IV}

\section{FROM FACTORY TO CONSUMER}

\section{Chapter XVI}

Packing-Stamping and inspecting of cans; labeling; labeling machines; wrinkles and rust spots on labels; capacity of labeling machines.

Packing in Cases-Marking the cases; casers; packing for export ....................................... 185-191

\section{Chapter XVII}

Storage-Purpose; effect of storage temperature; advisability of storing.

Transportation Pages 191-194

\section{Chapter XVIII}

Markets-Consumption of condensed milk and fluid milk; market prices; exports and imports........................... 194-200

\section{Chapter XIX}

Chemical Composition and Standards of Condensed Milk-Sweetened condensed milk; water, solids, fat, proteids, milk sugar, sucrose, ash, specific gravity.

Evaporated Milk-Water, solids, fat, proteids, milk sugar, ash; composition of milk fats in evaporated milk; soluble and insoluble curd in evaporated milk.

Plain Condensed Bulk Milk.

Condensed Milk Standards................................ 200-211 


\section{Chapter XX}

Sanitary Purity of Condensed Milk.

Digestibility.

Vitamine Properties.

Water-soluble Vitamines-Fat-soluble vitamines; anti-scorbutic vitamines; effect of heat of process on vitamines......Pages 211-217

\section{Chapter XXI}

Cost of Manufacture-Gencral discussion; cost of sweetened condensed milk; cost of evaporated milk............. Pages 217-222

\section{PART V}

\section{CONDENSED MILK DEFECTS, THEIR CAUSES AND PREVENTIONS}

Classes of Defects.

\section{Chapter XXII}

Defective Sweetened Condensed Milk-Detailed discussion of the following defects: Sandy, rough or gritty, settled, thickened and cheese, lumpy, white and yellow buttons, blown or fermented, rancid, putrid, brown, metallic...................... 222-252

\section{Chapter XXIII}

Defective Evaporated Milk-l)etailed discussion of the following defects: Curdy, grainy, separated or churned, blown or fermented, brown, gritty, metallic............................ 25ages

\section{Chapter XXIV}

Adulterations of Condensed Milk-Skimming, addition of animal and vegetable fats; imitation condensed milk; annual output of ; addition of commercial glucose; addition of bicarbonate of soda and other alkalies, addition of cream of tartar, addition of starch

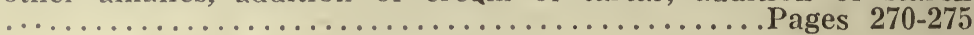

\section{PART VI}

\section{MANUFACTURE OF MILK POWDER}

Definition

\section{Chapter XXV}

Kinds.

History and Development; Annual Production.

Description of Different Processes-Doug-drying processes; Wimmer process; Campbell process; Film-drying processes; Just process; Hatmaker process; Gathmann process; Passburg process; Ekenberg process; Govers process; Buflovak process; Spray-drying processes; Percy process; Stauf process; McLachlan process; Merrell-Merrell-Gere process; Rogers process; Gray processes; Dick process ............................................. 275-303 


\section{Chapter XXVI}

Commercial Manufacture of Milk Powder by Spray Process-Preheating; precondensing; heating of air; spraying and desiccating; desiccating chamber; spray nozzles; spray pumps; hot air intake and discharge; recovery of desiccated milk; bolting, packing ..................................... Pages 203-315

\section{Chapter XXVII}

Composition and Properties of Milk Powders-Chemical composition of milk powders; factors affecting composition; soluof manufacture; markets; annual output..........Pages $315-330$

\section{Chapter XXVIII}

Dried Buttermilk-Composition of buttermilk powder; annual output; manufacture; markets.

Dried Whey.

Malted Milk-History of malted milk industry; manufacture of malted milk; keeping quality; markets; annual output.

Federal Standards for Milk Powders and Malted Milk...Pảges 330-335

\section{PART VII}

STANDARDIZATION, TESTS AND ANALYSES OF MILK, CONDENSED MILK AND MILK POWDER

\section{Chapter XXIX}

Standardization-Purpose; standardizing fluid milk; standardizing the finished product; standardizing the sucrose in sweetened condensed milk .................................... $335-342$

\section{Chapter XXX}

Chemical Analyses-Milk; specific gravity; total solids; ash; total nitrogen; albumin and casein; milk-sugar; butterfat.

Sweetened Condensed Milk-Specific gravity; total solids; ash; proteids; milk-sugar; butterfat; sucrose.

Evaporated Milk-Specific gravity; total solids; solids tables; ash; proteids; milk-sugar; butterfat.

Milk Powder-Total solids; ash; proteids; milk-sugar; sucrose; butterfat ....................................... $342-365$

\section{Chapter XXXI}

Mojonnier Test for Fat and Solids-Equipment; directions; determination of per cent fat and total solids in milk, skimmilk, buttermilk, sweetened condensed milk, evaporated milk, condensed bulk milk, milk powder and malted milk................. Pages 365-374

\section{Chapter XXXII}

Bacteriological Analyses-Sampling; dilutions for numerical counts; plating; media for total counts, acidifiers, liquefiers and yeast and molds; incubation; making counts; qualitative determinations.

Legal Standards for Dairy Products by States.........Pages 374-379 



\section{ACKNOWLEDGMENTS}

The author desires to express his appreciation and gratitude to Borden's Condensed Milk Co. for cuts showing portrait of Gail Borden and interior and exterior views of milk condensing factories; to the Alpine Evaporated Milk Co. for cut showing portrait of John B. Meyenberg; to the Helvetia Milk Condensing Co., and to Horlick's Malted Milk Co. for biographic data relating to the early history of the industry; to Mr.Wm. T. Nardin, Attorney, for extensive statistics on milk prices; to Mojonnier Bros. Co. for valuable data relating to the manufacture of evaporated milk; to Mr. C. E. Fenlon, Vice President of the Rico Milk Products Co., for valuable information relating to cost of manufacture and details of operation; and to the manufacturers and dealers of machinery and supplies related to the industry, for their many cuts for illustration in the text and for their generous contribution of advertisements, whose kindly and active co-operation made possible the issuance of this publication. 


\title{
Complete Milk Condensing Unit
} for

\author{
Dairy Schools \\ and Experimental Laboratories
}

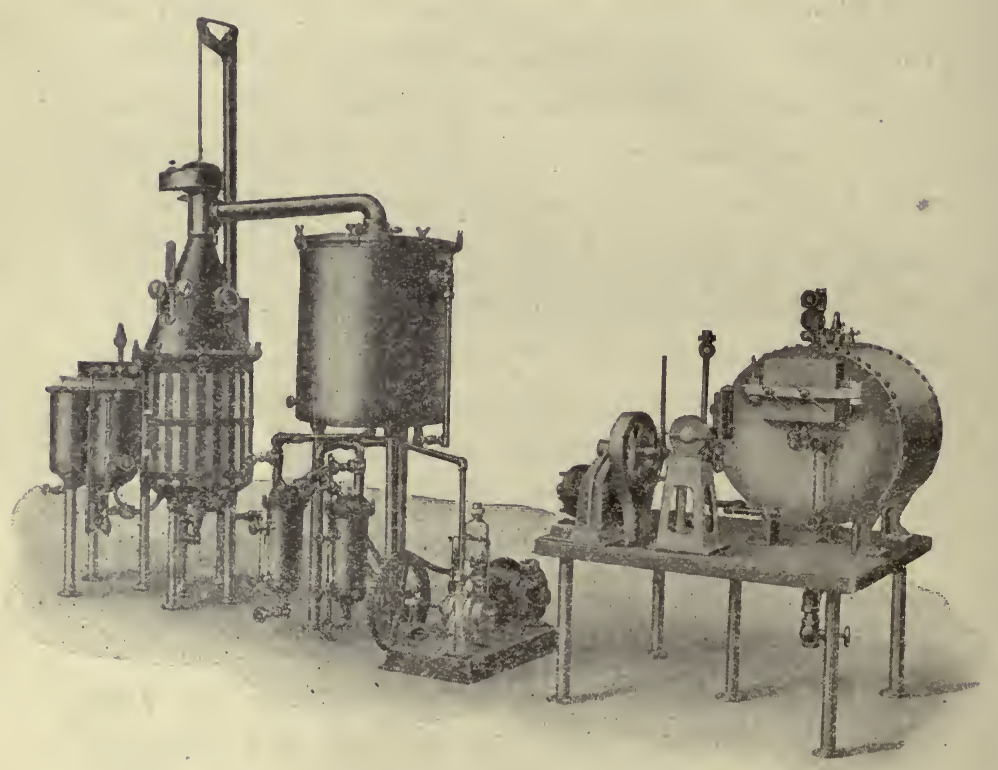

The dairy school is the manufactory of dairy knowledge, the clearing house of dairy thought, and the distributory of the dairy gospel 


\title{
PART I. CONDENSED MILK
}

\author{
CHAPTER I. \\ DEFINITION.
}

Condensed milk is cow's fresh milk from which a considerable portion of the water has been evaporated and to which sucrose may or may not have been added.

There are chiefly two classes of condensed milk, namely, sweetened and unsweetened. Both reach the market in hermetically sealed tin cans intended for direct consumption, and in bulk, intended for bakers, confectioners and ice cream manufacturers.

A portion of the condensed milk on the market is made from the chief by-products of milk, skim milk and buttermilk. Condensed skim milk supplies the same markets as condensed whole milk sold in bulk. Condensed buttermilk furnishes a valuable hog and chicken feed. It has, also, been recommended for medicinal purposes, and of late years it has found extensive use in bakeries and for the manufacture of diverse prepared foods.

\section{HISTORY AND DEVELOPMENT OF INDUSTRY.}

Invention of Process.-Conclensed milk is the child of the nineteenth century. Its origin does not date back far, and its innovation and rapid development stand in sharp contrast to those of the manufacture of butter and cheese, industries to which reference is made in the Old Testament ${ }^{1}$ and the evolution of which has been very gradual. Notwithstanding the newness of this product, its manufacture has assumed such proportions that today it occupies a prominent place among the leading branches of dairy manufactures.

The condensed milk industry was introduced at about the

1 Book of Genesis, C. 18, V. 8: "And he took butter and milk and the calf he had dressed and set it before them."

Book of Job, C. 10, V. 10. "Hast thou not poured me out like milk and curdled me like cheese." 
same time as the factory system of the butter and cheese industry; although, for many years before the invention of a successful process of condensing milk, methods had been sought to preserve milk.

The American, Gail Borden, the inventor of the manufacture of condensed milk, is said to have experimented some ten years before he finally decided that a semi-fluid state, produced

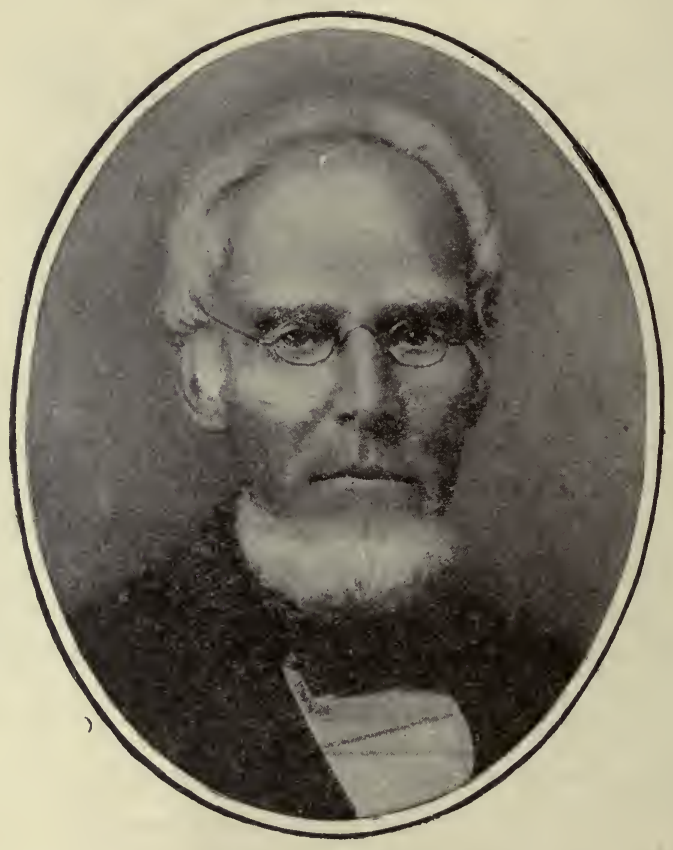

Fig. 2. Gail Borden

by evaporation in vacuo, was the best form of preservation. He first applied for a patent in 1853, but it was not until three years later that the Patent Office appreciated the originality and value of his claim sufficiently to grant him a patent. In August, 1856, he was awarded a patent on his process, both by the United States and by England.

In his application Mr. Bordon says:"

"I am aware that sugar, and various extracts, have been and

1 "A Brief Sketch of Gail Borden," by S. L. Goodale, Secretary Maine State Board of Agriculture, 1872. - Courtesy of Borden's Condensed Milk Company. 
are now concentrated in vacuo under a low degree of heat, to prevent discoloration or burning. I do not claim concentrating milk in a vacuum pan for such a purpose, my object being to exclude the air from the beginning of the process to the end, to prevent incipient decomposition. This is important and I claim the discovery."

The claim, United States Patent No. 15,553, August 19, 1856 , is in the following words:

"Producing concentrated sweet milk by evaporation in vacuo, substantially as set forth,- - the same having no sugar or other foreign matter mixed with it."

Since the introduction of the process of milk condensing, inrented and patented by Borden, numerous modifications of the process, as well as entirely different processes, have been invented in this country and abroad. The most characteristic among these are: condensation by refrigeration, by centrifugal force, by boiling under atmospheric pressure, by passing hot air over or through milk, etc. Most of these new processes have not proved commercially satisfactory, with the result that the principle of the process, originally invented by Gail Borden. and which consists of condensing the milk in vacuo to a semifluid liquid, is still made use of in the manufacture of the great bulk of condensed milk produced, both in this country and abroad.

While the claim of the patent granted Gail Borden was that of "producing concentrated sweet milk by evaporation in vacuo without the admixture of sugar or other foreign matter," records show that Gail Borden manufactured sweetened condensed milk, sold under the famous Eagle Brand label as early as 1856. The first advertisement by Borden of unsweetened condensed milk was recorded in Leslie's Weekly, May 22,1858 . It reads as follows:

"Borden's Condensed Milk. Prepared in Litchfield County, Conn., is the only milk ever concentrated without the admixture of sugar or some other substance and remaining easily soluble in water. It is simply Fresh Country Milk, from which the water is nearly all evaporated, and nothing added. The Committee of the Academy of Medicine recommend it as 'an 
article, that, for purity, durability and economy, is hitherto unequalled in the annals of the milk trade.'

"One quart, by the addition of water, makes two and a half quarts,--equal of cream, five quarts rich milk and seven quarts good milk.

"For sale at 173 Canal Street, or delivered at dwellings in New York or Brooklyn at 25 cents per quart."

Development of Industry.-The beginning was small, the process crude and the product imperfect. Not until the strennous years of the war of Secession did the value and useful-

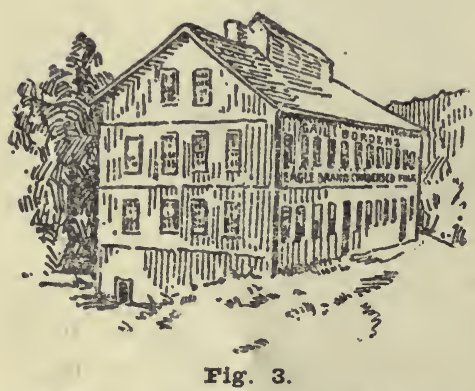

The first condensed milk factory in America, Wolcottville, Conn. ness of condensed milk as a commodity become fully recognized. During the Civil War there was a great demand for this product and from that time on the industry grew with great rapidity.

The first factory was operated by Gail Borden in Wolcottville. - Litchfield county, Connecticut, in the summer of 1856 , but disappointed in not obtaining means, nothing was accomplished. A second attempt was made at Burrville, five miles distant, in 1857 . hy a company consisting of the owners of the patent. A small quantity of milk was here successfully condensed and its introduction into New York began. Although admitted by all to be superior to any before made, it was slow in meeting with sales proportional in magnitude to the expenses incurred. Yielding to the monetary revulsion of that year the company suspended operations, leaving Mr. Borden liable for bills drawn, on. which he was sued.

It was not until February, 1858, when Mr. Borden (with the other owners of the patent) associated himself with Jeremiah Milbank, Esq., who advanced money to revive the business, that he could be said to enjoy adequate means to develop his invention and at which time the New York Condensed Milk Company was formed. Abandoning Burrville, the new company established work on a more extensive scale in Wassaic, Duchess county, New York, in 1860. In 1865, extensive works were erected at 
Elgin, Illinois. Borden's Condensed Milk factories today number upwards of fifty, extending from Maine to Washington State as well as into Canada. The New York Condensed Milk Company was incorporated in New Jersey in 1860 and in New York in 1870. This company was succeeded by Borden's Condensed Milk Company which was incorporated in New Jersey in 1899.

In the sixties of the last century, the Anglo-Swiss Condensed Milk Company was organized in Switzerland under the leadership of Charles A. Page, then United States Consul at Zurich. Switzerland, and his brother George H. Page, and with the assistance of Swiss and English capital. The first factory of that company was built and operated in 1866 at Cham, Lake

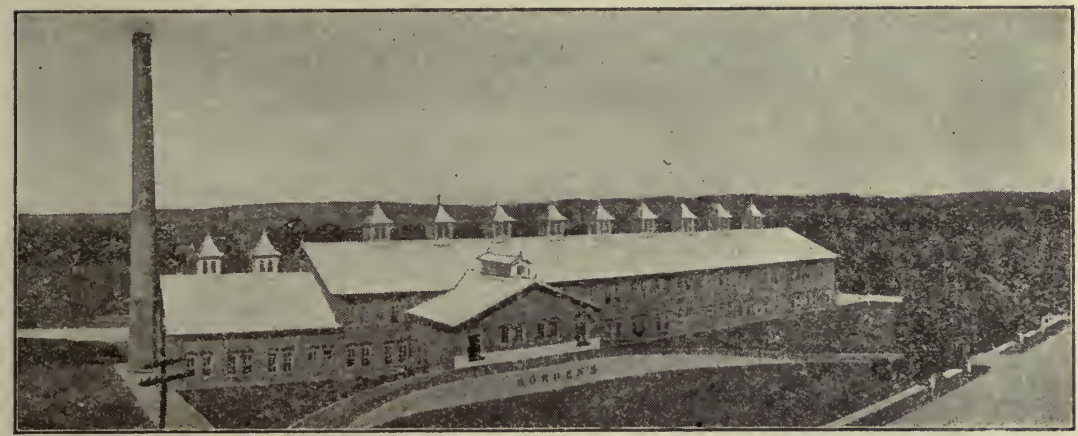

Fig. 4. Factory of Borden's Condensed Milk Co., Randolph, N. $\mathbf{Y}$.

Zug, Switzerland, under the direction of George H. Page, who was its president until 1898, when he died.

This company prospered and grew rapidly in Europe. In the eighties of the last century it invaded the United States, where it built and operated several large factories in New York, Wisconsin and Illinois. The American factories were managed by David Page and William P. Page, brothers of George H. Page. In 1902 the Anglo-Swiss Condensed Milk Company sold its entire American interests, factories and business, to Borden's Condensed Milk Company. In 1904 the Anglo-Swiss Condensed Milk Company consolidated with Henry Nestle, of Vevey, Lake Geneva, Switzerland, another successful manufacturer of condensed milk. The company which is now known as the NestleCham Condensed Milk Company, is operating some twenty large 
condensed milk factories in European countries, with headquarters at Cham, Switzerland.

$\mathrm{Up}_{\mathrm{p}}$ to the early eighties of the last century, sweetened condensed milk was the only condensed milk that was put on the market and sold in hermetically sealed cans, while unsweetened condensed milk was manufactured and sold open, largely direct to the consumer, in a similar way as market milk. The purity

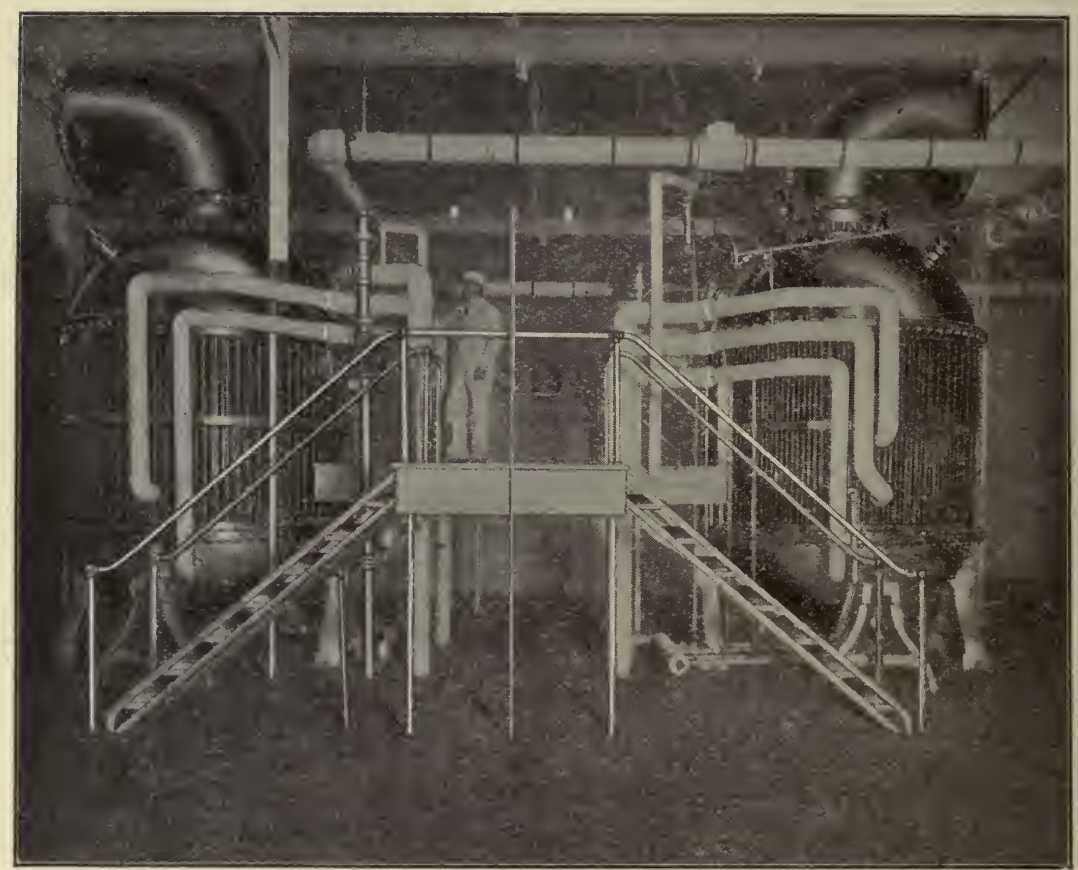

Fig. 5. Pan Room in Factory of Borden's Condensed Milk Co.

and keeping quality of this unsweetened condensed milk, however, were greatly superior to market milk.

Early in 1885 the Helvetia Milk Condensing Company was organized at Highland, Illinois. This company confined its efforts exclusively to the manufacture of evaporated milk (unsweetened condensed milk, sterilized by heat and sold in hermetically sealed cans). While, for several years before the organization of this company, the possibilities of producing a sterile unsweetened condensed milk were essayed in laboratory 
investigations by scientists, and while simultaneously with the commencement of operations of this company, several other companies experimented on this form of condensed milk, the Helvetia Milk Condensing Company was the first organization that succeeded in producing a marketable unsweetened condensed milk that was sterile and would keep indefinitely.

The rudiments of the

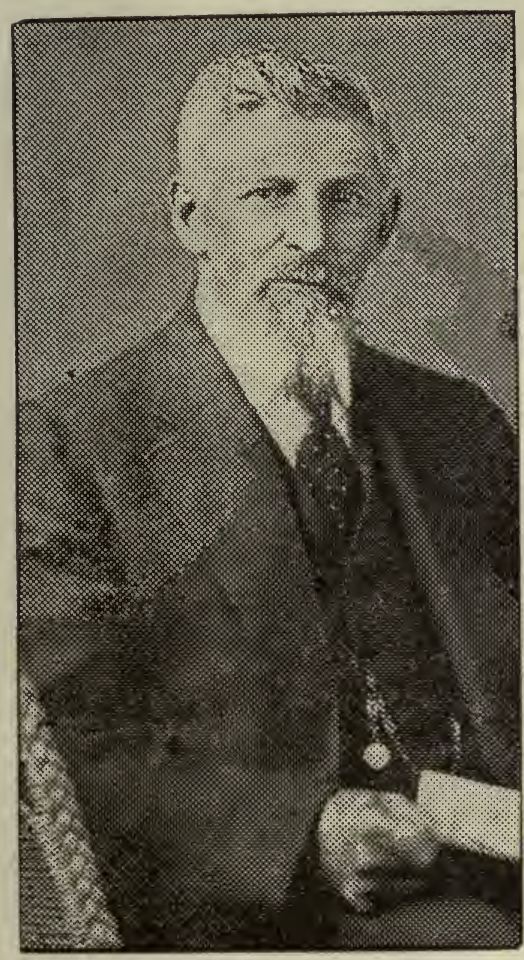

Fig. 6. John B. Meyenberg process of evaporated, sterilized milk were introduced by Mr. John B. Meyenberg, a native of Switzerland, who formerly was operator in the mother plant of the AngloSwiss Condensed Milk Co. at Cham, Switzerland. Mr. Meyenberg, being a man with an inventive turn of mind, experimented on the evaporation and sterilization of milk, during the years 1880 to 1883 . As the result of these experiments he decided that it was possible to preserve milk: without the aid of sugar. Migrating to this country, he applied for, and was granted a patent on his idea of preserving milk by sterilization, by the United States Government in 1884 (Patent No. $308,422)$, and again in 1887 (Patent No. 358,213). Mr. Meyenberg was also granted patent rights (Patent No. 308,421) on apparatus for preserving milk.

Attracted to Ifighland, Illinois, by reason of its large Swiss population, on the representations of Mr. A. J. Pagan, a leading Highland citizen, who brought Mr. Meyenberg to Highland and introduced him to the community, Mr. Meyenberg associated himself with Mr. John Wildi, then a merchant of Highland, who 
at once took a leading part in the organization of the Helvetia Milk Condensing Co., early in the year 1885. Mr. Meyenberg served as the technical manager for the first year, after which he severed his connections with his company and became engaged in the promotion of other evaporated milk factories in the middle west, and on the Pacific Coast. Mr. Meyenberg died in 1914.

During the first year of its existence, operations of the Helvetia Milk Condensing Company were suspended a number of times, both on account of difficulties encountered in the technique of successful manufacture and also for financial reasons. In an endeavor to place the company on a technically and commercially successful basis, the board of directors took charge of the work with Mr. Louis Latzer as technical manager, and the first half of the second year was mostly deroted to experimental work. During the third year, interruptions in the operations were only slight and after that the company operated continuously and successfully until the panic of 1893, which.marked the last suspension of business and which was due to the strained commercial conditions that prevailed throughout the country.

The first board of directors of this company was composed of Dr. Knoebel, John Wildi, George Roth, Fred Kaeser and Louis Latzer, with Dr. Knoebel as president and Mr. Wildi as secretary and treasurer, and business manager. In $1888 \mathrm{Mr}$. Latzer became president, which position he is holding to the present day. In $1907 \mathrm{Mr}$ Wildi severed his connection and organized the John Wildi Evaporated Milk Co. with headquarters in Columbus, Ohio. Mr. Wildi died in 1910.

The early development and the vicissitudes through which this pioneer company in the evaporated milk business passed are most instructively expressed by its president, Mr. Latzer:

"Very little of the product turned out the first two years would now pass as standard goods. About the third year, after more knowledge of the physical and chemical properties of milk and after the introduction of the practice of fractional sterilization, had solved the keeping properties and had improved the physical condition of the product, we felt that the industry had come to stay. After we had gained more knowledge and experience, and a lower standard of the product was adopted by the 
industry, the practice of fractional sterilization was abandoned for economic reasons.

"The commercial part of the business also had its trials and tribulations in introducing a new and comparatively inferior product of comparatively high cost, and to overcome the prejudices of both the trade and the medical profession.

"The problem thus confronting the company was to improve the product, decrease its cost and improve selling methods at the least possible cost."

At first this unsweetened condensed milk, of relatively thin consistency and pregnant with the cooked flavor resulting from its exposure to high sterilizing temperatures, failed to appeal to the public, who had become accustomed to the use of the sweet, thick and semi-fluid sweetened condensed milk. But of late years the demand for, and the manufacture of this product. evaporated milk, has increased rapidly, until today, in this country, its output by far exceeds that of sweetened condensed milk.

Originally this unsweetened sterilized condensed milk was labeled and sold under the name of "Evaporated Cream." The Federal Food and Drugs Act of 1906 caused the name "Evaporated Cream" to be changed to "Evaporated Milk."

A further important step in the development of the manufacture of condensed milk occurred with the introduction of the Continuous Concentrator, which machine was developed by the By-Products Recovery Co., of T'oledo, Ohio. 'This company was organized in 1913 and their machine and process are covered by numerous United States patents. The principle upon which the Continuous Concentrator is constructed and operates is as follows :

"To rapidly move a film layer formation within a cylinder having a heated surface, having means for escaping vapors and means for keeping the surface bright and clean, circumferentially and from the point of inlet to the point of outlet."

Another type of the film principle of continuous concentration is represented in the Ruff Condensing Evaporator, manufactured by the Cream Production Co., Port Huron, Mich.

The Continuous Concentrator in its present improved form has reached a state of perfection that renders this machine appli- 
cable for the commercial manufacture of the diverse forms of condensed milk and milk by-products.

The simplicity and economy of the equipment involved, the simplicity and rapidity of the process and the fact that no water is required for condensing the escaping vapors, are decided advantages over the condensation in vacuo. Already the demand for these concentrators among condenseries and ice cream factories is very great. This process lends itself admirably to the establishment and operation of small local condenseries and milk shipping stations where milk is condensed and then shipped for packing and sterilization to concentration plants.

Annual Output of Condensed Milk in the United States 1899-1919, Inclusive.

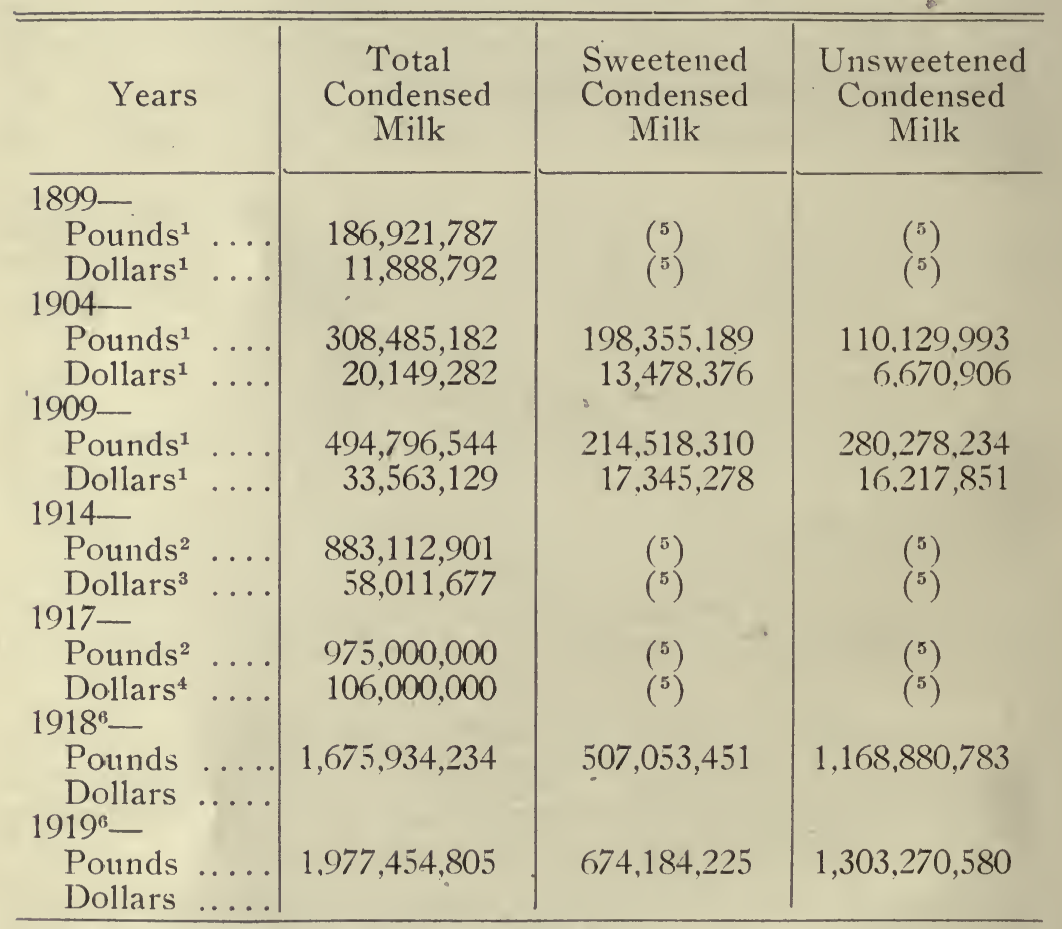

1 United States Census Report for 1910.

Inited States Dairy Division, by Correspondence.

${ }^{8}$ Value estimated at $\$ 3.40$ per case.

Value estimated at $\$ 5.50$ per case.

$\checkmark$ Not reported separately.

"Potts, R. C.. U. S. Bureau of Markets, February 17, 1920, and "The Market Reporter," U. S. Bureau of Markets, Vol. 1, No. 13, March 27, 1920. 
In this country, as well as in Canada, Europe, Australia and New Zealand, the condensed milk industry grew rapidly. Every succeeding decade marked the organization of new companies and the erection of new factories until today, there are milk condensing factories in nearly every civilized country within the dairy belt.

The above figures may serve to empliasize the rapid growth which the condensed milk industry in the United States has enjoyed during the last decade. The total output of condensed milk in 1919, both sweetened and unsweetened, but not including "filled" condensed milk such as condensed goods modified with vegetable fats, nor condensed butternilk and uncondensed sterilized canned milk, was 1,977,454,805 pounds, at an estimated value of approximately $\$ 200,000,000$. Calculating the ratio of concentration at 2.5 to 1 , this output represents the utilization of approximately 4,944,000,000 pounds of fluid milk. In 1917. when the total output of condensed milk was $975,000,000$ pounds, representing the utilization of about $2,437,000,000$ pounds of fluid milk, the total production of milk in the United States was estimated at about $84,611,350,000$ pounds of which 2.9 per cent were manufactured into condensed milk. Reliable figures are not as yet available of the total production of milk in the United States for the year 1919. Tt is estimated however, to be about 90,000,000,000 pounds. On the basis of the above estimate, about 5.4 per cent of the total milk produced in the United States during the year 1919 was manufactured in to condensed milk.

A new and unprecedented impetus was given the condensed milk industry in America by the advent of the World War. The concentration of the product, its wholesomeness and high food value, the serviceableness of its package and its great keeping quality rendered it indispensable as a food for the army and navy, as well as for the civilian population of the warring nations in its dire need for food. In this great crisis in which the food supply of the nations of the earth was playing a most important role, condensed milk has proved its worth and the demand for this commodity has increased to tremendous proportions. This demand has been readily responded to by the industry on the American continent and has resulted in a vast increase of the 
output of condensed milk and in the erection of many new and large factories within the short span of the war.

The tremendous increase in the volume of condensed milk manufactured in this country in 1919 is due in part also to the rapidly growing consumption of ice cream and soft beverages of which ice cream is a constituent, as the result of national prohibition. Conservative estimates place the increase of condensed bulk milk supplied to ice cream factories at 15 to 20 per cent over previous years.

In 1899, there were in operation in this country about fifty factories manufacturing condensed milk, distributed over fourteen different states, New York and Illinois leading the list by over 50 per cent. In 1904, the Government estimated the total number of condenseries in operation at eighty-seven. In 1914 , there were in the United States over two hundred milk condensing factories, distributed over twenty-three different states. And in 1918 Government statistics place the total number of condenseries at 322, distributed over 30 different states as shown on the following table:

Distribution of Milk Condensing Factories in United States ${ }^{1}$ in 1920.

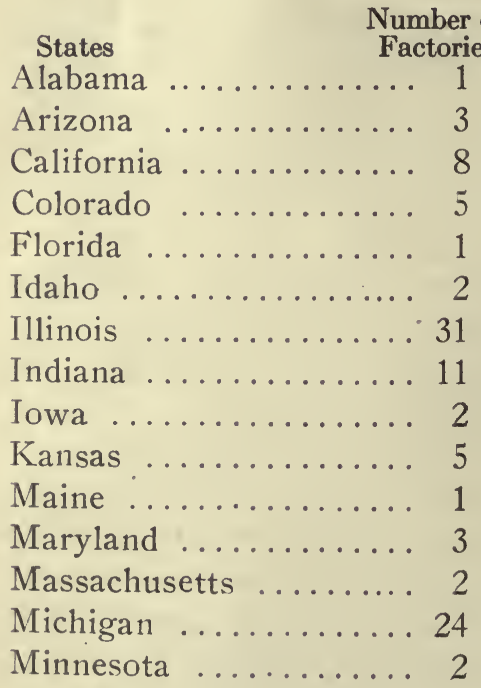

\begin{tabular}{|c|c|}
\hline \multicolumn{2}{|r|}{$\begin{array}{l}\text { Number of } \\
\text { Factories }\end{array}$} \\
\hline Missouri & \\
\hline Nebraska & ... 2 \\
\hline New Hampsh & $\ldots$ \\
\hline New Jersey & $\ldots 5$ \\
\hline New York & .. 68 \\
\hline North Dakot & $\ldots \quad 1$ \\
\hline Ohio..... & ... 30 \\
\hline Oregon .... & $\ldots 5$ \\
\hline Pennsylvania & . 37 \\
\hline Rhode Island & .. 1 \\
\hline Utah ...... & $\cdots$ \\
\hline Vermont ... & $\ldots$ \\
\hline Virginia ... & .. \\
\hline Washington & . . 19 \\
\hline Wisconsin . & 40 \\
\hline Total 30 & \\
\hline
\end{tabular}

${ }^{1}$ Potts, R. C., U. S. Bureau of Markets, 1920. 
Other countries in which the condensed milk industry has made rapid progress are: Canada, Australia, New Zealand, Switzerland, Germany, England, Ireland, Holland, Sweden, Norway, Austria, Japan and India. The annual output of some of these countries is reported below.

Annual Output of Condensed Milk in Different Countries. ${ }^{1}$

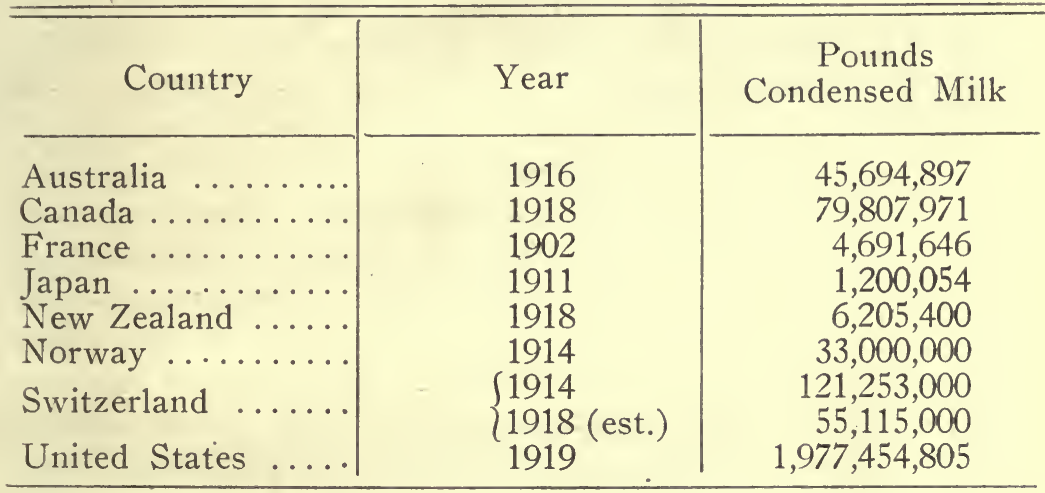

Chapter II.

\section{ESSENTIALS OF SUITABLE LOCATIONS FOR MILK CONDENSING FACTORIES.}

Unlike the establishment of creameries and cheese factories, the building of condenseries and the installing of the necessary machinery involve the investment of large capital. There is need of a substantial building and of expensive machinery. The supplies are numerous and must be purchased in larger quantities before the returns from the sale of the manufactured product are available. It is estimated that, it takes from three to six months before the condensed milk reaches the consumer. This holds true especially in the case of canned goods. The fixed expenses also are comparatively heavy, and do not materially change with a decrease or increase in the milk supply.

All of these facts emphasize the importance of locating the factory in a territory most suitable for economic manufacture,

1 Pirtle, T. R., Statistician, U. S. Dairy Division, February 12, 1920. 
to guard against heary loss which would naturally resuit in localities unfavorable to the industry.

The chief factors to be considered in this connection are:

Milk supply

Water supply

Transportation facilities.

Other conditions.

Milk Supply.-A large supply of milk with possibilities for extending the milk supply territory is the first essential. The condensery must have milk to do business. The locality in which it is located must be adapted for the production of large quantities of milk; it must be a dairy country where reasonably large herds are kept. Other things being equal, the larger the milk supply, the lower the cost of manufacture. Where the milk supply drops below fifteen thousand pounds of milk daily, profitable manufacture becomes difficult. Territories of gathered cream creameries are usually not very desirable. The farmers generally have small herds and are not inclined to haul their milk daily. They prefer to take their cream to the creamery once or twice per week, or whenever it is convenient for them to do so. Again, they appreciate the feeding value of the skim milk and depend on the skim milk to raise their young stock and pigs. When they take their milk to the condensery, there is no skim milk nor buttermilk left for feeding purposes.

The presence of whole milk creameries and cheese factories renders a locality most attractive for the establishment of milk condenseries. The farmers usually have reasonably large herds, they are accustomed to take reasonable care of their milk and to haul it to the factory daily, and the condensery prices are generally high enough ahove the creamery or cheese factory prices to induce the farmers to patronize the condensing factory.

Territories in close proximity of large consuming centers, though dairying may have reached a high state of development, are not desirable, owing to the continuous and growing demand for fresh milk. Competition of this kind means high prices, which no business tactics are capable of modifying.

Water Supply.-The value to the milk condensing plant of a generous and never-failing supply of clean, cool water cannot 
be overestimated. The folly of erecting condenseries without first ascertaining the water supply has in some instances compelled milk.condensing companies to abandon new plants, merely because of lack of water.

In addition to the water used in the boilers and for washing purposes, large amounts of water are necessary for condensing and for cooling the condensed milk. It is estimated that the condensation of one pound of fresh milk requires about three gallons of water at ordinary temperature, although this amount of water may be considerably reduced by the use of condensers of maximum efficiency.

The water must be pure. In spite of all precautions, it will come in contact, more or less, with the milk. Though all apparatus and utensils holding and conveying milk and condensed milk may be thoroughly steamed after rinsing with water, there are untold channels through which the milk may become contaminated with polluted water. Frequently, while the milk is condensing, the vacuum pump accidentally stops. If the processor fails to immediately shut off the water supplying the condenser. water will pour back from the condenser into the milk in the vacuum pan. In the case of filthy, polluted water, the entire batch may be ruined. Again, the pan is usually rinsed between batches and, if the water used is unclean, it will contaminate the milk of the succeeding bath. Finally, when the heavy 40-quart cans filled with condensed milk are set into the cooling tank. water frequently splashes over into the cans. Here again the quality of the condensed milk in jeopardized, unless the water used is pure.

The water must be cold. The colder the water the more satisfactory is the operation of the vacuum pan and the smaller the volume of water required to condense a given volume of milk. If the temperature of the water used in the condenser rises much above 65 degrees $\mathrm{F}$., the process of condensing may become difficult, according to the type of pan and condenser used. Cold water is essential, also, for the prompt and proper cooling of the condensed milk.

Transportation Facilities.-It is essential that the factory have access to one or more railway lines.

While, for reasons discussed under "Milk Supply," it is not 
advisable to erect a factory in ton close proximity to large consuming or railway centers, it is equally undesirable to choose a condensery site where transportation facilities are poor.

Where access to one railroad only can be had, the factory is at the mercy of that road. Experience has shown that monopoly of transportation usually means a low standard of efficiency of service and high freight rates. ${ }^{1}$ On the other hand, competition involves a struggle for the survival of the fittest, and it offers the public all the inducements that business ingenuity and enterprise can produce. Where two or more transportation companies are after the business of the same manufacturing concern. they will generally leave nothing undone in the way of accommodations and low rates to please the manufacturer. The result is that the manufacturer enjoys the advantages of efficient service, good accommodations and reasonable freight rates. ${ }^{1}$

This is a factor which the condensery cannot afford to overlook, as the freight charges are a very conspicuous item in the expense account of the milk condensing business. A part of the fresh milk may have to be shipped to the factory by rail, all the finished product must leave the factory by rail and the condensery is dependent on the railway for its raw materials and supplies, such as sugar, tinplate, solder, box shooks, barrels, labels. oil, rnsin, gasoline, coal, etc. Prompt and efficient transportation is essential. Undue delays may cause the condensery serious inconvenience and loss, and may result in the cancelling of important orders.

Other Conditions. - The removal of the sewage of the factory is important. It may be possible for the factory to connect with the town or city sewer, in which case the problem is easily solved. Where this is not possible, a site along a creek, river. pond or lake may offer effective means to take care of the condensery sewage. Where no such natural depository is available, the elevation of the site should be sufficient to carry off the sewage far enough from the factory to insure the plant against foul odors and unsanitary conditions. In the absence of all of these avenues for the disposal of the sewage, a properly laid-out sys-

1 The matter of freight rates is now largely regulated by the Federal Department of Transportation. 
tem of septic tanks with efficient filter beds may serve the purpose.

Where possible, it is advisable to take advantage of hillsides, affording natural means to arrange and operate the factory onthe gravity plan.

\section{BUILDING AND EQUIPMENT.}

Material of Construction.-Since the establishment of a milk condensing factory involves the investment of considerable capital, those willing to invest must have faith in the permanency of the business. For a permanent business, a building substantially constructed is the most cconomical. Most of the factories belonging to the most reputable concerns are built very substantially. However, there are in this country condensing factories in the construction of which cheapness was the governing factor.

It is beyond the realm of this volume to furnish detailed specifications and plans for the construction of condensed milk factories. Such information would be of comparatively little value, as such details must of necessity vary with locality, capacity of prospective plant, type of equipment, system of operation and preferences of individual owners. Such details are best decided on and worked out for each individual factory separately and when needed. There are a few fundamental principles, however. which apply to all factories and to which attention may be briefly called here.

Floors, Walls and Ceilings.-Stone, brick, concrete, concretesteel, according to availability, are satisfactory materials of which to construct a condensery. Intersecting walls or partitions are best constructed of similar material. If constructed of wood, they should rest on concrete, brick or stone, built up at least two feet from the floor, or the lower two feet of which partitions should be wainscoated with an approved quality of cement plaster.

All floors of the main building should be of cement, great care being taken that the foundation of these floors be of uniformly hard material, thoroughly tamped and avoiding soft spots. The concrete bed should be at least four inches in depth, consisting of one part of cement, two parts of sand and four parts 
of gravel. The sand should be sharp building sand and the gravel should be washed pebbles, ranging in size from one-half to one inch. The top dressing should be not less than one inch thick, consisting of one part of cement and one and one-half parts of sharp building sand. It should be carried up on the walls and partitions at least two inches, forming a sanitary cove. After finishing, the floors should be allowed to harden for at least two weeks. 'This will greatly prolong their life. It is advisable to use cement hardener such as Master Builders' cement, or Lapidolith, etc., which will help to make these floors more nearly wear-, water-, dust- and crack-proof. It is difficult to keep the condensery in sanitary condition. and to protect the product against contamination, unless the floors of the factory are and stay free from cracks and holes.

Ventilation.-A proper and effective system of ventilation is another very important and too often entirely neglected factor in the planning of the condensed milk factory. This applies to all parts of the plant where work is being done, but it is especially essential in rooms where free steam escapes. The ventilating system should be adequate to afford ready and quick escape of steam, to remove foul air and to facilitate the regulation of temperature. Unless free steam does promptly find an exit from the factory rooms, it condenses on the walls and ceilings, making them sweat profusely, causing corrosion of the walls and ceiling, deterioration of motors and other similar equipment, and molding of supplies; this is especially the case during the winter months. The removal of foul air and the control of the temperature of the air are essential for the comfort, health and efficiency of the employes.

The system of ventilation that will accomplish efficient ventilation will of necessity vary with the type of plant and arrangement of equipment. Gravity ventilation is, under average conditions, inadequate to produce satisfactory results in factories, like milk condenseries, where there is bound to be much escape of free steam. The exchange of air is not rapid enough to remove the steam before it condenses on the walls and ceilings, especially in cold weather. It is, therefore, advisable to provide for some form of forced ventilation. Under certain conditions of construction an air flue connecting with the smoke stack may 
furnish all the ventilation needed. ${ }^{1}$ Under many other conditions, however, it is necessary to hood that equipment from which free steam escapes in large volume, such as can washers, and can sterilizers, hot wells, etc., and to draw the steam away through ducts of adequate size by one or more motor fans located in the outside wall or ceiling.

Drainage.-All floors of the manufacturing rooms should slope to facilitate rapid drainage. A fall of one-eighth inch per foot is usually sufficient. Large water-sealed floor drains should be sufficiently numerous and well placed in all rooms to rapidly carry off water. The surface of these floor drains should be about one-half inch below that of the adjoining floor, so as to catch the water readily. In the larger rooms open drainditches in the cement floor, six to eight inches wide and covered with perforated iron plates, are preferable to bell-traps. They may be placed along the walls or elsewhere. They should be not more than forty feet apart and have a fall of one-eighth inch to the foot, with the floor sloping toward them. It is generally most convenient to have all the drain pipes enter into one large sewer pipe not less than ten inches in diameter, for a condensery receiving about fifty thousand pounds of milk daily, which should dispose of all the factory sewerage. It is advisable to place the main sewer pipe outside the building and to have it terminate in a "clean-out." This will afford more ready access in case the sewer is stopped up.

General Plan of Factory.-Most of the condensing factories are either one- or two-story buildings. In the case of two-story buildings the first floor is usually devoted to the boiler and engine rooms, vat room, well room, filling, sealing and packing rooms. On the second floor are installed the pan room, store room for sugar and box shooks, the tinshop and possibly the offices. A basement is sometimes provided and used for the storing of condensed milk.

Fig. 7 illustrates a floor plan of a milk condensing factory with a capacity of fifty thousand pounds of milk daily. All operating rooms are located on one floor. The arrangement of machinery permits of the handling of the milk on the gravity

${ }^{1}$ In this case there should be an inner and outer stack with an air space between which connects with the air flue, 
plan or with pumps, according to the topography of the site and the elevation of the rooms. The receiving room floor and the platform which accommodates the vacuum pans, should be seven to eight feet above the main floor. In order to take care of storage of water, sugar, tin cans, barrels and box shooks, there should be a second floor over the well room and the filling, sealing and sterilizing room. The ceiling of these rooms should be not less than sixteen feet above the floor.

The rooms are so arranged as to necessitate the minimum expenditure of machinery, conveyors and labor. All work rooms open on the railway switch, and the storage room is accessible by two elevators. The well room, where most of the steam is needed, is next to the boiler room, so as to minimize condensation in the steam pipes. If the main steam pipes are properly insulated, this arrangement should furnish the vacuum pans with dry steam. The floor in the boiler room should be two feet below the main floor, in order to give additional fall for the condensation water from jacket and coils of the vacuum pans to the boiler feed tank.

The partition between the receiving room and testing room is equipped with a cabinet, opening on both sides so that the sample bottles can be placed on the shelves in the receiving room and taken off the shelves in the test room.

From the weigh cans on the receiving platform the milk runs direct into the hot wells, which are sufficient in number to conveniently divide the milk into batches and to heat the milk with the least possible delay. The capacity of the vacuum pumps is angmented by their close proximity to the vacuum pans and the hot wells and by the fact that the water supply tanks are overhead. The space to be evacuated is confined very largely to the vacuum pan only, the milk has to be lifted by the vacuum pump but a few feet and the water runs into the condenser by gravity.

From the well room the condensed milk is transferred to the tanks on the platform over the filling machines. The evaporated milk is pumped from the cooling coils through the wall and the sweetened condensed milk is raised to the platform in ten-gallon cans on the elevator, or is forced by a pressure pump into the tanks feeding the filling machines. The sealing benches are equipped with self-heating soldering coppers. In the place of the 


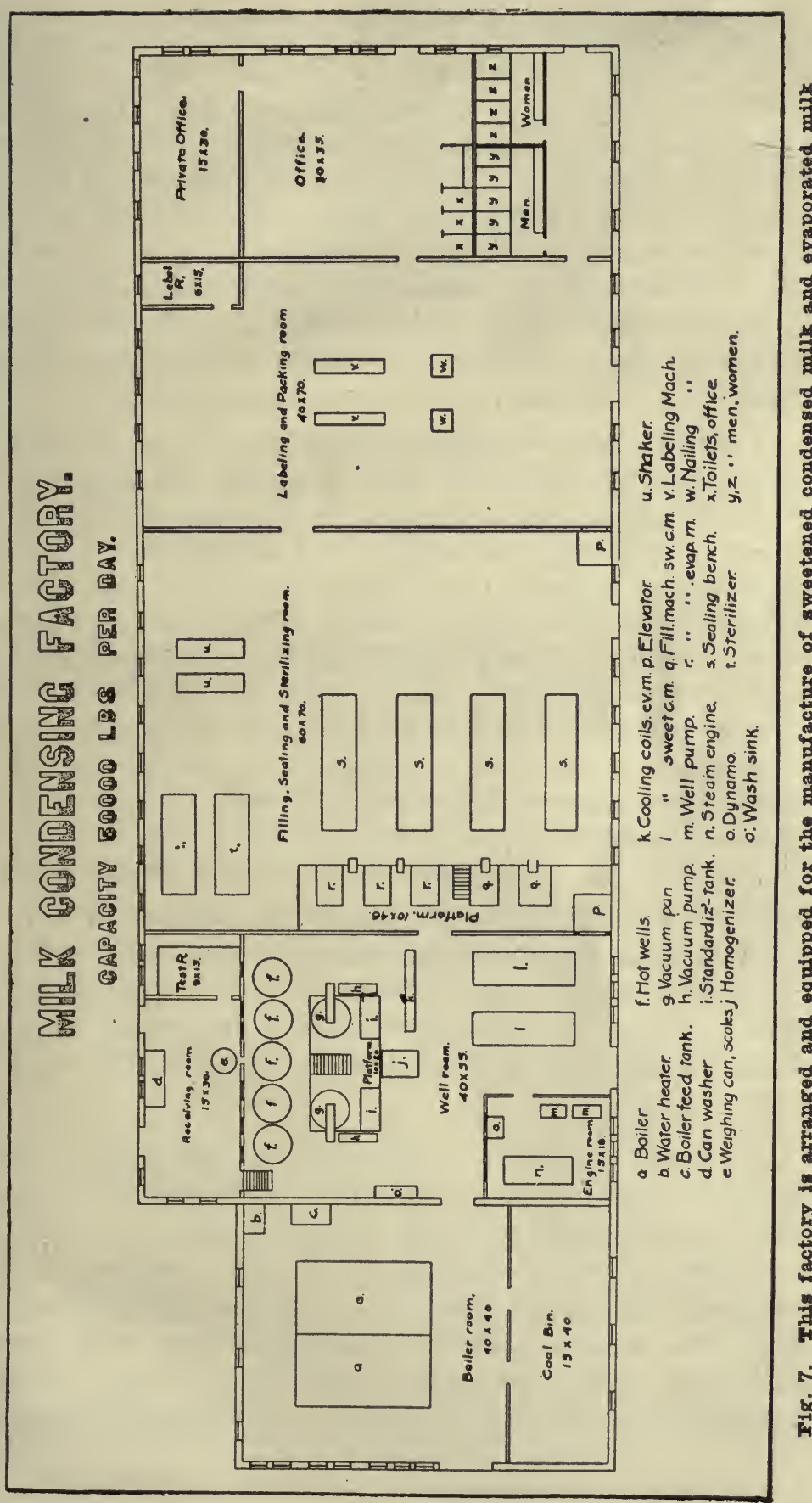


soldering benches and hand coppers, automatic sealing machines may be installed. The sterilizers and shakers are conveniently placed to take care of the sealed evaporated milk. The tin cans for the sealing room and the box shooks for the packing room are brought down from the storage room overhead on the elevator. The labeling and packing room, equipped with the labeling and box nailing machines, provides for considerable storage of the finished product. Additional storage at a moderate and uniform temperature might be provided for by a basement under the packing room. A label stock room furnishes satisfactory storage for the labels.

In case the factory manufactures its own tin cans, a tinshop, equipped with the necessary machinery (see list of machinery and equipment) should be located in as close and convenient proximity to the filling and sealing room as possible. A suitable place is directly opposite the filling room with the railway track separating the latter from the tinshop. The tinshop should have two outside doors, opening out on the track, and its machinery should be so arranged that the tin plate can be unloaded from the car at one door, is moved back through the machinery and appears again in the form of finished cans at the other door. directly opposite the filling room and ready for the reception of the condensed milk. Instead of erecting a separate building for the tinshop, the latter may also be conveniently installed in the second story directly over the filling room.

Where natural gas and gas from municipal corporations is not available, one or more gasoline gas generators should be installed. These gas generators contain inflammable material and should, therefore, be located at a reasonable distance from the main building.

The tendency in factory construction today is to do away with all partitions between operating rooms, having all manufacturing and packing rooms in one large space. In this case it is customary and economical to place the vacuum pan and condensed milk storage tanks on an elevated platform and installing the hotwells, coolers, vacuum pump, milk pumps, homogenizer, filling and sealing machines, sterilizers, labeling and packing machines on the main floor, which also provides 
the necessary space for the stock of supplies and of canned goods.

List of Equipment.-The following is a list of the principal machinery and equipment needed in an up-to-date condensery with a capacity of fifty thousand pounds of milk daily:

\section{BOIIER ROOM}

Boilers with a total capacity of $400 \mathrm{H}$. P.

1 boiler feed tank.

1 boiler feed pump.

1 boiler water heater.

\section{FNGINE ROOM!}

$140 \mathrm{H}$. P. engine.

2 well pumps, 150 gallons per minute each.

180 light dynamo.

Pipe and thread-cutting tools, anvil and forge.

\section{RECEIVING ROOM}

2 1000-pound weigh cans, "low down" style.

2 6-beam milk scales, or other weighing arrangement.

1 can-washing machine with steam and water jets and air blower for drying the cans.

1 milk sample bottle rack.

\section{HEATING AND CONDENSING DEPARTMENT}

6 5000-pound capacity jacketed kettles with revolving agitators and superheating device.

16 -foot vacutim pan

17 -foot vacuum pan or continuous concentrators.

2 vacuum pumps

2500 -gallon standardizing vats on scales.

1 6-cylinder homogenizer.

1 internal tube cooler, capacity 5000 to 8000 pounds per hour, for cooling evaporated milk, or

1 submerged coil cooler, or

2 36-can cooling vats with cans, cross bars and paddles complete, or

1 In case municipally generated electricity is available, there is no need of a Dynamo and much of the equipment may be supplied with direct drive by motors. This would obviate the installation of a steam engine. 
2 5000-1bs. circular conling vats with vertical coils for cooling sweetened condensed milk, or 1 submerged coil cooler with high pressure pump and two 5000-gallon glass enameled holding tanks with agitators, for both evaporated milk - and sweetened condensed milk.

1 wash tank.

1 elevator.

1 2-beam platform scale.

1 truck.

\section{FILIING, SEALING AND STERILIZING DEPARTMEN8}

4 200-gallon condensed and evaporated milk vats. ${ }^{1}$

2 filling machines for sweetened condensed milk.

2 filling machines for evaporated milk.

4 soldering benches, $5 \times 20$ feet, with 10 self-heating soldering coppers each, or

1 or more sealing machines with can-testing baths, the number depending on type and capacity of machine used.

2000 wooden trays holding 24 16-ounce cans each.

2 sterilizers, capacity 75 to 100 cases each, complete with iron trays.

1 double shaker.

2 trucks.

\section{IABEIING AND PACKING DEPARTMENT}

2 labeling machines with casers

2 nailing machines.

2 trucks.

\section{TESTING ROOM}

2 24-bottle Babcock testers, with one gross of standard milk test bottles and accessories, complete. Equipment for chemical and bacteriological analyses of milk, milk products and sugar.

Usual equipment.

\section{OFICES}

\section{TOIIET ROOMS}

Usual equipment.

${ }^{1}$ Not needed if well room is equipped with large holding tanks. 


\section{OVIRHEAD STORAGE ROOM}

150,000 -gallon water tank. This tank is preferably located outside of factory.

1 4-beam platform scale for sugar.

\section{ADDITIONAI EQUTPMENT}

1 gasoline gas generator (complete), needed in absence of access to natural gas or municipal gas.

1 15-ton ammonia compressor, with ammonia and brine pipe lines, circulating pump and brine tank.

\section{TIN SHOP}

Needled in case cans are manufactured at the factory.

2 squaring shears.

2 body cutting machines.

2 lock seamers.

6 presses.

2 crimping machines.

2 soldering floats.

1 can tester with vacuum pump.

1 can wiper.

1 lathe with tools.

1 gasoline gas generator, complete.

$125 \mathrm{H}$. P. engine or motor.

200 can crates.

Economic Arrangement of Machinery.-In the arrangement and connection of the machinery, economy of manufacture and sanitation of the product should receive serious consideration. The machinery should be so arranged as to reduce to the minimum the space, pumps, pipes and conveyors needed. Pumps, conveyors, pipes and fittings are expensive, and the space saved by judicious arrangement of the stationary machinery may be used to advantage for other purposes.

Human muscle is the most expensive form of motive power. Wherever muscle can be replaced by machinery and where, by intelligent arrangement of the machinery, innecessary steps and handling can be avoided, the cost of manufacture is reduced.

The matter of insulation of ammonia, brine, steam and water pipes is an important item as related to the economy of fuel. 
For proper and economical insulation the following types of pipe covering are recommended:

\section{Ammonia and Brine Lines.-}

1st layer of tarred felt.

2nd layer of 1 " thick hair felt.

3rd layer of tarred felt.

4 th layer of $1^{\prime \prime}$ thick hair felt.

5 th layer of tarred felt.

6th layer of wove-felt paper.

7 th layer of 8-oz. canvas jacket, sewed on.

8th layer of sizing and one coat of lead and oil paint.

Each layer of hair felt must be securely wound with twine. Each layer of all material should be coated with hot asphalt, applied while hot, excepting layers, 6,7 and 8 .

Special seals must be made at all flanges and fittings, and such flanges and fittings must be insulated independently. This arrangement will prevent damage to adjoining coverings, should fittings spring leaks.

Before applying pitch or asphalt, the necessary precautions must be taken to have the pipes thoroughly dry and the asphalt or pitch must be hot.

Steam Lines.-Air cell asbestos covering, or covering of equal insulating and lasting quality, one inch thick on pipes, and fittings, to be built up of asbestos cement to a corresponding thickness; smoothly finished and neatly canvassed, with metal bands at $18^{\prime \prime}$ intervals. Before putting on the metal bands the covering should receive two coats of asbestos cold water paint.

Cold Water Lines.-Covering of wool felt, tar paper lined, sectional, one inch thick on pipes; fittings to be built up to a corresponding thickness with one inch hair felt, the entire line should be neatly finished with a graded mixture of Portland cement and asbestos cement, and canvas-jacketed and equipped with metal bands at $18^{\prime \prime}$ intervals. Before putting on the metal bands, the covering should receive two coats of asbestos cold water paint.

Sanitary Arrangement of Machinery.-Milk pumps, milk pipes, milk troughs and other milk conveyors are, at best, ene- 
mies of sanitation. They should be avoided wherever possible. The gravity system of conveying milk should be used in preference to the pumping system. Milk pipes should be short and accessible; all vats sould be of sanitary construction; woorenjackets should not be tolerated; all seams in the vats and kettles should be well flushed with solder; milk pumps should be brass lined; all milk pipes should be of black iron pipe made. smooth on the inside by sandblasting, or of galvanized iron or copper heavily tinned over on the inside: long lines of milk pipes should be equipped with unions at short distances; crosses or sanitary couplings should be used in place of elbows, in order to render all sections of the milk pipes easily accessible to flue brushes.

CirAptFr III.

\section{MILK SUPPLY.}

Basis of Buying Milk.-The prices which the condensery pays the patrons are not usually governed by any board of trade. They do not even necessarily follow the quotations of the butter and cheese market, though they naturally bear a more or less definite relation to them. In normal times condensery prices average from about twenty to fifty cents higher per hundred pounds of milk than those paid by creameries and cheese factories.

The relation between condensery prices on the one hand and creamery and cheese factory prices on the other, varies principally with the market demand for the finished product and the season of the year.

The greater the demand and the brisker the market for condensed milk, the greater usually is the difference in price for whole milk. Thus, during the war the export demand for condensed milk was very great. This resulted in an extreme rise of prices which condenseries offered for milk over those paid by creameries and cheese factories, at least in so far as exportation was not too greatly limited by shortage in shipping facilities.

It is customary for the condenseries to pay the highest differential over and above creamery and cheese factory prices in 
winter, during the time of low supply, and to drop prices very close to those of creameries and cheese factories in summer, during the flush of the milk producing season. Nardin ${ }^{1}$, assembled comparative milk prices paid by condenseries and creameries and cheese factories in the four main condensed milk-producing sections of this conntry, Illinois, New York and Pennsylvania, Wisconsin, and the Pacific Coast States, for the years 1914 to 1918 inclusive. These prices have been summarized in the following table. They show that in some instances condensery prices exceeded creamery and cheese factory prices by over one dollar, while there were times in summer when condensery prices even dropped slightly below creamery and cheese factory prices.

Formerly condensery prices were announced by the respective concerns from three to six months in advance. Of late years this practice has been more and more abandoned and quotations are issued in advance for one month only. The Midwest Milk Manufacturers, representing the milk dealers, market milk plants and condenseries in the Chicago milk district and the middle western states, confer on the price to be paid for milk for the succeeding month, toward the close of the preceding month, and announce these prices for the coming month.

Generally speaking, and as Nardin points out, "the price in Illinois is subject to prices of fresh milk distributed in Chicago and St. Louis. Prices in New York and Pennsylvania have been subject to the influences of the New York Dairymen's League, and the price of fresh milk for distribution in the City of New York. The Wisconsin price is most largely influenced by butter and cheese prices. The Pacific Coast is, on account of freight rates, somewhat isolated from the rest of the country, and the production of evaporated milk on the coast has been larger in proper to the demands for fresh milk for distribution in coast territory, than perhaps in any other part of the country."

The milk condenseries, as a whole, have been slow in adopting the butterfat content of milk as their basis for payment. Even up to a few years ago most condenseries were paying for the milk on the one hundred weight basis and some factories

${ }^{1}$ Nardin, Wm. T., Memorandum on Federal Trade Investigation of Milk Manufacturers, 1918. 
Comparison of Whole Milk Prices Paid by Milk Condenseries in the Four Large Condensing Territories in the United States, with Whole Milk Values Based on Market Prices of Butter and Cheese.

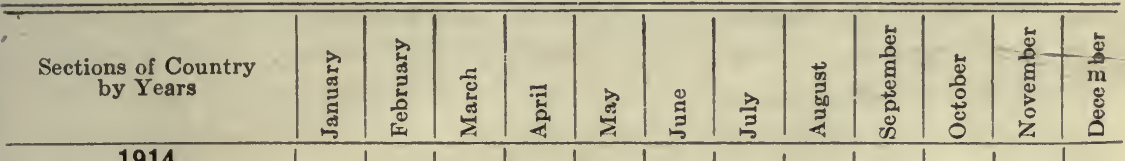

Illinois:

1914

\begin{tabular}{c|c|c|c|c|c|c|c|c|c|c|c|c} 
Mean condensery price & 1.96 & 1.87 & 1.72 & 1.52 & 1.31 & 1.22 & 1.45 & 1.56 & 1.60 & 1.77 & 1.79 & 1.82 \\
Value in butter \& cheese & 1.34 & 1.27 & 1.25 & 1.17 & 1.14 & 1.12 & 1.10 & 1.19 & 1.17 & 1.15 & 1.21 & 1.21
\end{tabular}

New York and Pennsylvania:

\begin{tabular}{l|l|l|l|l|l|l|l|l|l|l|l|l|} 
Mean condensery price. & 1.96 & 1.76 & 1.73 & 1.41 & 1.24 & 1.19 & 1.35 & 1.50 & 1.64 & 1.89 & 2.01 & 1.90
\end{tabular}

\begin{tabular}{l|l|l|l|l|l|l|l|l|l|l|l|l|l|l} 
Value in butter \& cheese & 1.34 & 1.27 & 1.25 & 1.17 & 1.14 & 1.12 & 1.10 & 1.19 & 1.17 & 1.15 & 1.21 & 1.21
\end{tabular}

Wisconsin:

\begin{tabular}{l|l|l|l|l|l|l|l|l|l|l|l|l|} 
Mean condensery price & 1.87 & 1.82 & 1.79 & 1.62 & 1.40 & 1.28 & 1.43 & 1.47 & 1.50 & 1.72 & 1.77 & 1.80
\end{tabular}

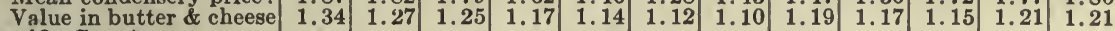

Pacific Coast:

\begin{tabular}{|l|l|l|l|l|l|l|l|l|l|l|l|l|} 
Mean condensery price. & 1.73 & 1.69 & 1.66 & 1.58 & 1.42 & 1.45 & 1.51 & 1.65 & 1.74 & 1.69 & 1.71 & 1.61
\end{tabular}

\begin{tabular}{l|l|l|l|l|l|l|l|l|l|l|l|l} 
Value in butter \& cheese & 1.34 & 1.27 & 1.25 & 1.17 & 1.14 & 1.12 & 1.10 & 1.19 & 1.17 & 1.15 & 1.21 & 1.21
\end{tabular}

Illinois : 1916

\begin{tabular}{l|l|l|l|l|l|l|l|l|l|l|l|l|} 
Mean condensery price. & 1.85 & 1.83 & 1.72 & 1.51 & 1.27 & 1.20 & 1.35 & 1.47 & 1.50 & 1.66 & 1.77 & 1.81
\end{tabular}

Value in butter \& cheese

New York and Pennsylvania:

Mean condensery price. Value in butter \& cheese

Wisconsin:

Mean condensery price.

Value in butter \& cheese

Pacific Coast:

Mean condensery price

Value in butter \& cheese

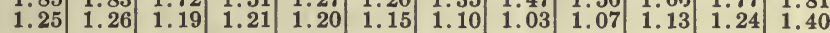

Illinois :

$$
1916
$$

Mean condensery price.

Value in butter \& cheese

\section{New York and}

\section{Pennsylvanis:}

Mean condensery price.

Value in butter \& cheese

Wisconsin:

Mean condensery price.

Value in butter \& cheese

Paciflc Coast:

Mean condensery price.

Value in butter \& cheese 1917

Illinois:

Mean condensery price Value in butter \& cheese

New York and Pennsylvania:

Mean condensery price. Value in butter \& cheese

Wisconsin:

Mean condensery price.

Value in butter \& cheese

Pacific Coast:

Mean condensery price.

Value in butter \& cheese 1918

Illinols :

Mean condensery price.

Value in butter \& cheese

New York and

Pennsylvania:

Mean condensery price .

Value in butter \& cheese

Wisconsin:

Mean condensery price.

Value in butter \& cheese

Paciflc Coast:

Mean condensery price.

\begin{tabular}{l|l|l|l|l|l|l|l|l|l|l|l}
1.95 & 1.75 & 1.72 & 1.41 & 1.19 & 1.15 & 1.30 & 1.52 & 1.61 & 1.87 & 2.00 & 2.05
\end{tabular}

\begin{tabular}{l|l|l|l|l|l|l|l|l|l|l|l}
1.25 & 1.26 & 1.19 & 1.21 & 1.20 & 1.15 & 1.10 & 1.03 & 1.07 & 1.13 & 1.24 & 1.40
\end{tabular}

\begin{tabular}{l|l|l|l|l|l|l|l|l|l|l|l}
1.82 & 1.82 & 1.70 & 1.45 & 1.30 & 1.22 & 1.40 & 1.43 & 1.48 & 1.65 & 1.74 & 1.72
\end{tabular}

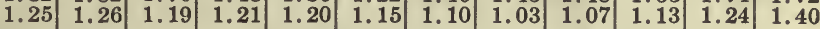

\begin{tabular}{l|l|l|l|l|l|l|l|l|l|l|l}
1.51 & 1.51 & 1.35 & 1.30 & 1.22 & 1.29 & 1.38 & 1.39 & 1.41 & 1.50 & 1.54 & 1.59
\end{tabular}

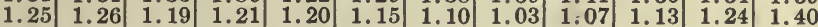

\begin{tabular}{l|l|l|l|l|l|l|l|l|l|l|l}
1.82 & 1.74 & 1.63 & 1.64 & 1.46 & 1.34 & 1.52 & 1.67 & 1.67 & 1.98 & 2.12 & 2.25
\end{tabular}

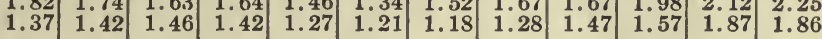

\begin{tabular}{l|l|l|l|l|l|l|l|l|l|l|l}
1.94 & 1.93 & 1.74 & 1.50 & 1.36 & 1.27 & 1.43 & 1.62 & 1.80 & 2.42 & 2.53 & 2.57
\end{tabular}

\begin{tabular}{l|l|l|l|l|l|l|l|l|l|l|l}
1.37 & 1.42 & 1.46 & 1.42 & 1.27 & 1.21 & 1.18 & 1.28 & 1.47 & 1.57 & 1.87 & 1.86
\end{tabular}

\begin{tabular}{l|l|l|l|l|l|l|l|l|l|l|l|}
1.78 & 1.72 & 1.69 & 1.67 & 1.52 & 1.42 & 1.50 & 1.60 & 1.67 & 1.95 & 2.15 & 2.35
\end{tabular}

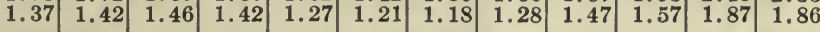

\begin{tabular}{l|l|l|l|l|l|l|l|l|l|l|l}
1.65 & 1.66 & 1.64 & 1.53 & 1.52 & 1.47 & 1.52 & 1.62 & 1.69 & 1.80 & 1.92 & 1.98
\end{tabular}

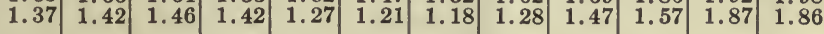

\begin{tabular}{l|l|l|l|l|l|l|l|l|l|l|l}
2.25 & 2.12 & 2.05 & 2.37 & 2.13 & 1.92 & 2.20 & 2.38 & 2.52 & 3.00 & 3.18 & 3.28
\end{tabular}

\begin{tabular}{lllllllll|l|l|l|l|l}
1.76 & 1.84 & 1.99 & 2.04 & 2.02 & 1.88 & 1.93 & 2.01 & 2.21 & 2.19 & 2.14 & 2.19
\end{tabular}

\begin{tabular}{l|l|l|l|l|l|l|l|l|l|l|l}
2.49 & 2.44 & 2.32 & 2.24 & 2.21 & 2.12 & 2.39 & 2.83 & 2.91 & 3.00 & 3.77 & 3.52
\end{tabular}

\begin{tabular}{l|l|l|l|l|l|l|l|l|l|l|l}
1.76 & 1.84 & 1.99 & 2.04 & 2.02 & 1.88 & 1.93 & 2.01 & 2.21 & 2.19 & 2.14 & 2.19
\end{tabular}

\begin{tabular}{l|l|l|l|l|l|l|l|l|l|l|l}
2.36 & 2.25 & 2.12 & 2.29 & 2.21 & 1.93 & 2.27 & 2.45 & 2.43 & 3.19 & 3.32 & 3.22
\end{tabular}

\begin{tabular}{ll|l|l|l|l|l|l|l|l|l|l|l}
1.76 & 1.84 & 1.99 & 2.04 & 2.02 & 1.88 & 1.93 & 2.01 & 2.21 & 2.19 & 2.14 & 2.19
\end{tabular}

\begin{tabular}{l|l|l|l|l|l|l|l|l|l|l|l}
2.06 & 2.01 & 2.02 & 2.09 & 2.14 & 2.19 & 2.32 & 2.27 & 2.58 & 2.67 & 2.67 & 2.81
\end{tabular}

\begin{tabular}{l|l|l|l|l|l|l|l|l|l|l|l|}
1.76 & 1.84 & 1.99 & 2.04 & 2.02 & 1.88 & 1.93 & 2.01 & 2.21 & 2.19 & 2.14 & 2.19
\end{tabular}

\begin{tabular}{l|l|l|l|l|l|l|l|l|l|l|l}
3.28 & 3.15 & 2.95 & 2.67 & 2.10 & 1.90 & 2.32 & 2.80 & 2.98 & 3.42 & 3.74 & 3.83
\end{tabular}

\begin{tabular}{l|l|l|l|l|l|l|l|l|l|l|l|}
2.24 & 2.40 & 2.16 & 2.00 & 2.01 & 2.01 & 2.11 & 2.19 & 2.48 & 2.78 & 2.77 & 3.09
\end{tabular}

\begin{tabular}{|l|l|l|l|l|l|l|l|l|l|l|l}
3.90 & 3.68 & 3.40 & 2.65 & 2.61 & 2.00 & 2.29 & 2.85 & 3.16 & 3.78 & 3.96 & 4.17
\end{tabular}

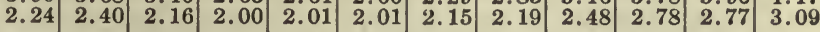

\begin{tabular}{l|l|l|l|l|l|l|l|l|l|l|l}
3.28 & 3.13 & 2.88 & 2.59 & 2.21 & 2.07 & 2.32 & 2.80 & 2.98 & 3.40 & 3.74 & 3.84
\end{tabular}

$\begin{array}{llllllllllllll}2.24 & 2.40 & 2.16 & 2.00 & 2.01 & 2.01 & 2.15 & 2.19 & 2.48 & 2.78 & 2.77 & 3.09\end{array}$

\begin{tabular}{l|l|l|l|l|l|l|l|l|l|l|l}
2.84 & 2.81 & 2.66 & 2.35 & 2.27 & 2.28 & 2.50 & 2.81 & 3.12 & 3.30 & 3.41 & 3.51
\end{tabular}

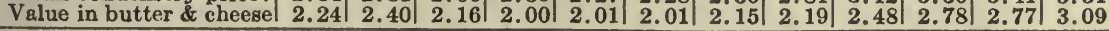


were still clinging to the custom of buying milk by the quart, using the yardstick for remnant cans. Other factories paid a stated price per hundred weight for all milk testing say 4 per cent fat and over and made corresponding reductions for milk containing less than 4 per cent fat. Still others paid a premium for milk testing above 4 per cent fat. A few concerns only bought milk on the straight butterfat basis.

As far as the condensery is concerned it is entirely feasible to pay for all milk strictly on the butterfat basis. Milk rich in fat, and therefore rich in solids, yields more condensed milk than milk poor in fat. To pay by the hundred weight, regardless of quality is a practice which discriminates in favor of breeds of low-testing milk and against breeds of high-testing milk. This practice has, in fact, had the result that in the milk supply territory of these condenseries the breeds and individuals of cows producing low-testing milk were encouraged and developed until they largely predominated, at the expense of breeds of cows producing high-testing milk. This situation in turn was responsible for the popular, though erroneous impression, that milk from the Holstein, Ayrshire and Brown Swiss breeds is better suited for milk condensing purposes than milk from the Channel Island breeds.

Within the last half decade, during which the condensed milk industry has experienced so great a development, the great majority of American condenseries have abandoned their old way of paying for milk by volume, or weight only. Many condensing concerns are now buying their milk on the straight butterfat basis and nearly all of the other condenseries pay for their milk on the basis of a standard fat content, penalizing the farmer by lower prices for milk that falls below a specified per cent of fat, and giving him a bonus for milk in which the per cent of fat is over the standard figure specified. Thus for example the price quoted may apply to $100 \mathrm{lbs}$. of 3.5 per cent milk with an added differential of say 4 cents for each one tenth per cent fat above 3.5 per cent and a deducted difierential of 4 cents for each tenth per cent fat below 3.5 per cent.

In countries, where one breed overwhelmingly predominates or where the predominating breeds all yield milk of similar richness and where the freshening of the majority of cows is fairly 
evenly distributed over the twelve months of the year, the milk generally continues to be bought on the basis of its weight or volume, and not by test. Under these conditions the objection of not paying on the butterfat basis is, in part at least, removed.

The great bulk of the milk supply reaches the condensery by wagon or by motor truck. Usually part of the cost of trans-

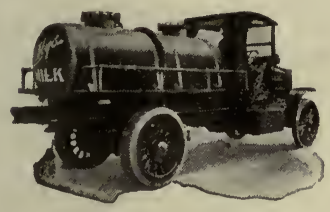

Fig. 8.

Glass-lined steel tank on truck for transporting fluid milk to condensery

Courtesy of The Pfaudler Co. portation is borne by the factory and part by the farmer. Some milk condensing concerns operate concentration points to which the milk is hauled by the patrons, and from which it is hauled to the factory in large glass-lined tanks mounted on motor trucks. Shipments by rail are less common in this country, the nncertainty of rail transportation, with its frequent delays, jeopardizes the quality of the milk. Payments for the milk are generally made monthly.

Quality.-The quality of the fresh milk is the first and most important factor to be considered. The milk condensing factory, ignoring this fact and accepting milk from unsanitary dairies and careless dairymen, is bound to pay the penaity for such neglect sooner or later.

Polluted milk and milk that has not been cooled promptly and to a reasonably low temperature on the farm, may pass through the process successfully, if it is not too sour. The condenser milk made from it, though, is inferior in flavor and keeping quality, and usually shows signs of deterioration and decay before it reaches the consumer. The risk of handling such milk is very great; it may result in total loss to the manufacturer. The trouble may and often does begin before the process is completed. Unclean, abnormal, or partly fermented milk, when subjected to the process, is prone to curdle and whey off; the condensed milk becomes lumpy and shows other defects. This is especially true where superheating is practiced and where evaporated milk is made.

Milk that has received the best of care on the farm may be detrimental to the interests of the condensery, if it comes from cows less than thirty days before their parturition, or from fresh 
cows within the first seven days after calving, or from cows otherwise in abnormal condition. Such milk is often abnormal in its chemical properties, and, when subjected to high temperatures, undergoes changes that make its manufacture into a marketable condensed milk difficult.

Control of Quality.-Every well managed milk condensing factory plays the part of an educator in the production of sanitary milk. The condensery ustually issues a set of rules, setting forth specifically the conditions under which the milk coming to the factory shall, or shall not be produced. Copies of these rules, which are generally a part of the contract, are placed in the hands of all patrons. The condensery employs one or more dairy inspectors whose business it is to see that the rules are rigidly enforced. These rules cover, in general, the following principal points:

1. Cows.-The milk must come from healthy cows. Milk from cows that are diseased, or that have a diseased udder, or that are otherwise in poor physical condition, will be rejected.

2. Feed and Water.-Do not feed weeds, roots, or other feed stuffs possessing strong and obnoxious odors; such as onions, garlic, turnips, cabbage, wet distillery slops, decayed, musty or sour silage, or other fermented feed.

3. Lactation Period.-Reject all milk from cows less than thirty days before, and of the first seven days after calving.

4. Milkers and Milking.-Milk with clean, dry hands into clean utensils and remove the milk to the milk room immediately after drawn.

5. Straining.-Strain the milk in the milk room through a fine wire mesh strainer ( 80 to 100 meshes to the inch). Do not use cloth strainers.

6. Cooling.-Cool the milk to 60 degrees $F$. or below and keep it at that temperature until it reaches the factory. Do not mix the warm morning's milk with the cold night's milk; cool the morning's milk before mixing, or send it to the factory in separate cans.

7. Care of Utensils.-Rinse with cold water, wash with warm water and washing powder, and rinse with boiling water 
all milk utensils thoroughly after use; keep them in a clean place between milkings. Do not store the milk on the farm in cans that have not been washed by the factory.

8. Stables.-Whitewash the stable twice every year and remove manure daily. (Some condenseries furnish spray pumps for applying whitewash.)

Inspection of Milk at the Condensery.-At the condensery the milk is subjected to rigid inspection by a man who is, or should be, an expert on milk inspection; every can is examined. Warm milk and milk that is tainted, or smells slightly sour should be rejected.

Inspection of Milk by Sense of Smell and Taste.-In most cases the milk is inspected with reference to odor. The inspector quickly raises the cover of each can to his nostrils. The odor in the cover is typical of that in the can. If it is "off," the can is rejected. An experienced man on the platform can, by the use of this method, tell with much accuracy, whether the milk should pass or not.

Inspection of Milk According to its Temperature.-The temperature is also noted. This need not be done with the thermometer in each case. By placing his hand on the body of the can, or by noting the warmth of the air and odor in the cover immediately after removing it, or by the. presence or absence of small particles of butter floating on the surface of the milk, the inspector can readily tell if the milk has or has not been properly cooled. A correct thermometer should always be on the platform for guidance.

Inspection of Milk by the Use of Acid Tests.-Since the degree of acidity, or the sweetness of the milk, is one of the chief factors that determines its fitness for condensing purposes, tests that rapidly and accurately determine the per cent of lactic acid in the fresh milk, are of great service.

Some concerns have adopted a definite acid standard of milk, rejecting all milk containing more than the maximum per'cent of acid of their standard, and they test every can of milk received with an acid test. This method insures sweet milk in the fac- 
tory, provided that the alkaline solutions used are correct. This work involves considerable expense, however, and unless the solution is carefully prepared and made up fresh often, its use may yield misleading results. Again, when the acid test is performed on the milk of each can, the acceptance or rejection of the milk depends altogether on the per cent of acid it contains. Although milk may be otherwise unfit for use, it will pass, as long as it is low in acidity. Experience has shown that, while it is necessary for the condensery to decide on a maximum acidity of milk above which all milk be rejected, the nose and the palate of the experienced inspector are better criterions tnan the acid test alone, as to the fitness of milk for condensing. Acid tests are valuable in the case of uncertainty and suspicion as to the quality of any given can of milk. All milk containing .18 per cent lactic acid or more is dangerous for condensing purposes.

\section{Acid Test for Daily Use, Where Each Can of Milk is Tested.}

Stock Solution.-Weigh out two hundred grams of sodium hydrate C. P. and add distilled water to make up one liter. Keep tightly stoppered.

Solution for Daily Use.-Mix 4 c.c. of stock solution with 991 c.c. of distilled water, and add 5 c.c. of phenolphthalein indicator. The indicator is prepared as follows: dissolve one gram of dry phenolphthalein in 100 c.c. of 50 per cent alcohol. Each cubic centimeter of the prepared alkaline solution neutralizes .01 per cent lactic acid, 18 c.c. of the prepared solution, therefore, neutralize .18 per cent lactic acid, when a 17.6 c.c. pipette is used for measuring out the milk.

Making the Test.-With the Babcock pipette, measure 17.6 c.c. into a white cup. With a small dipper, holding exactly 18 c.c., pour 18 c.c. of the prepared solution into the cup; stir or shake. If the mixture remains faintly pink, it contains less than .18 per cent acid and will pass; if it turns white, it contains more than .18 per cent acid and should be rejected or subjected to additional tests.

The stock solution should be standardized by a chemist. The prepared solution should be made up daily. Both solutions 
should be kept in glass bottles, tightly corked. The bottle containing the stock solution should be glass-stoppered.

The Boiling Test.-Inspection by Heating. The heating to the boiling point of samples of suspicious milk furnishes a most reliable means to determine the fitness of stich milk for condensing. In many instances milk may satisfactorily pass the other tests and yet it may not be in condition to stand the heat to which it will be subjected in the process. If it curdles, when boiled, it is obviously unfit for use. This test shows more than the acid test above. By its use the operator is able to detect milk otherwise abnormal, such as milk containing colostrum, etc., or the proteids of which are unstable for other reasons.

Making the Test.-The boiling test is simple and can be manipulated rapidly. A sample of the questionable milk is taken into a small dipper. The dipper is held up against a steam jet turned down into the milk. Direct steam is turned into the milk until it comes to a boil. If flakes or specks of curd cling to the sides of the dipper, the milk is unfit for use.

An alcohol lamp or gas burner on the platform may be used for heating the sample. In this case a few cubic centimeters of the milk are discharged with an ordinary pipette into an oruinary test tube, such as are in common use in the chemical laboratory and can be obtained from the drug store. The tube is held over the flame and the milk comes to a boil in less than a minute. If the milk is in good condition the sides of the glass tube remain perfectly clear. If it curdles upon heating, the sides of the tube show fine specks of the curd. The appearance of these specks condemns the milk.

In the case of milk intended for evaporated milk, the boiling test is not sufficiently severe to reveal the fitness of the milk for the sterilizing process. For the reliable detection of undesirable milk for this purpose, the use of the pilot sterilizer or test sterilizer is recommended. Suspicions samples of milk are filled into tins, the tins are sealed and placed into the pilot sterilizer where they are given the same process of sterilization as is used for the finished product. Milk that withstands this sterilization can be depended upon to also pass safely through the process of manufacture. Milk that curdles in this test steriliza- 
tion obviously shows its unfitness, the cause of which should be promptly investigated and removed.

Fig. 9.

\section{The Sediment Test.-This} test shows the relative amount of dirt present in milk. One-half pint is passed through a small circle of absorbent cotton and the amount of mechanical impurities present in the milk is indicated by the color of the cotton after filtration. In order to hasten the filtration, the milk is forced through the filter under slight pressure; this is accomplished by a rubber bulb attachment to the apparatus, as shown in the accompanying Fig. 9.
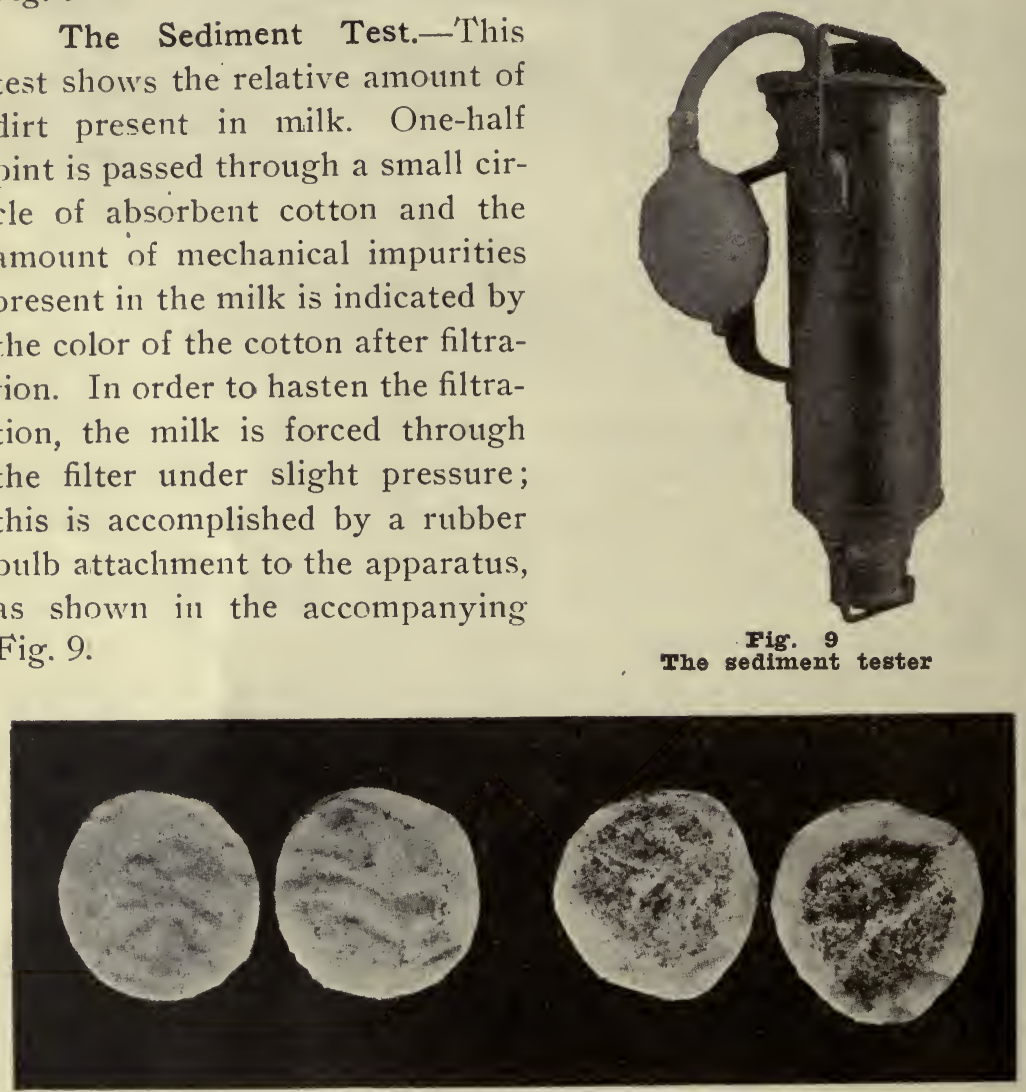

Fig. 10. Cotton Iilters

Clean milk

Dirty milk

If the cotton retains a white or creamy color, the milk is relatively free from filth. Milk produced under unsanitary conditions stains the cotton brown or black.

These cotton filters may be pasted on a sheet of paper similar to a milk sheet, arranged so that the circles are placed opposite the respective patron's name or number. When shown to the patrons who come to the factory, they furnish a most effective object lesson to them. When the milk reaches the factory on 
route wagons or by rail, cards similar to Figure 11 may be mailed to the patrons. The evidence is so conclusive that even the nost obstinate patron cannot help admitting his guilt and can usually be induced to "clean up."

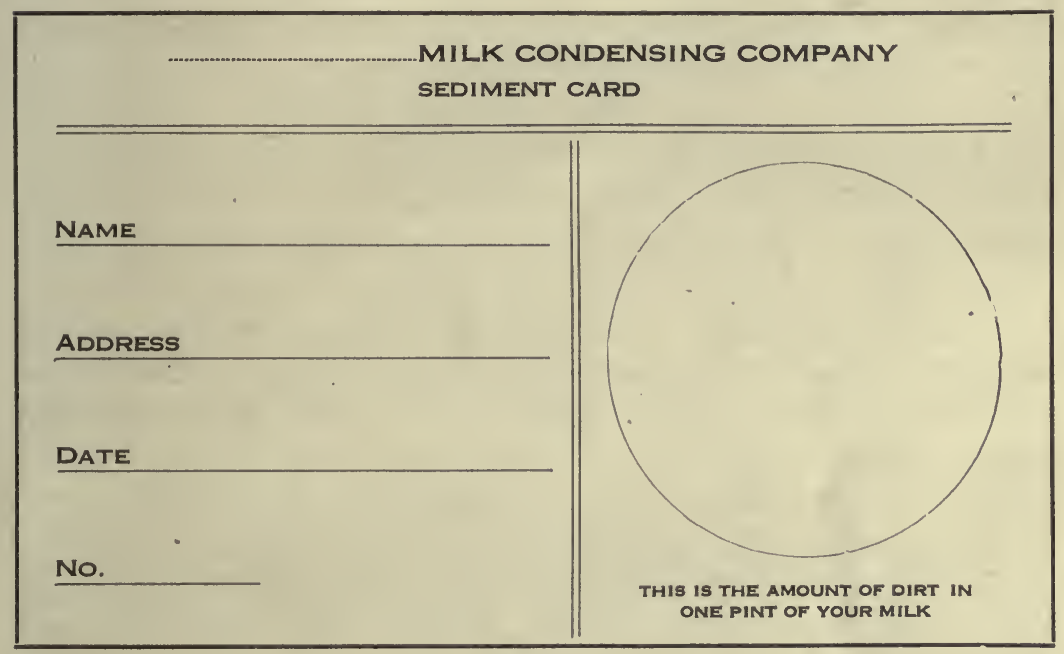

Fig. 11

Fermentation Tests. - These tests are of great value in the rapid determination of the kind of hacteria with which the milk from individual patrons is contaminated. Glass tubes are filled one-half full of milk from each patron. These tubes are set in a constant water bath at 100 degrees $\mathrm{F}$. and the changes which milk undergoes are noted after six, twelve and twenty-four hours.

A solid curd with a clear whey indicates that lactic acid bacteria are the chief organisms and that the milk has been produced under cleanly conditions. These organisms are killed when the milk is heated in the hot wells. Such milk therefore is safe, unless it contains excessive acid, as shown by acid test.

A curd with gas holes, or that which is torn to pieces in the tubes, shows the presence of gas-producing germs. These come largely from manure and other filth. Among these are Bacillus coli communis, the natural inhabitant of the colon of the animal, and butyric acid organisms which are spore bearers. The latter especially may give rise to serious milk defects, causing "swell 
heads." Patrons sending such milk should be looked after at once.

If the curd dissolves. or no curd is formed and the milk changes into a transparent liquid, it usually is contaminated by germs from the dust of hay and bedding, or polluted water. To this class of organisms belong Bacillus subtilis, Bacillus fluorescens liguifaciens, Plectridium foetidım, Bacillus putrificus, etc. Some of these are violent gas producers and most of them are spore-bearers. They are the cause of the most disastrous milk defects. Dairies from which such milk comes should be vigorously inspected and all milk from them should be rejected, until the patrons have learned how to furnish sanitary milk.

Milk that remains unchanged for twenty-four hours when subjected to the fermentation test, suggests that it contains some preservative. It is possible, however, for milk produced under ideally sanitary conditions to remain normal and unchanged even at these high temperatures for several days. Where milk comes to the factory in bulk as is the case in the condensery, samples showing abnormal keeping quality should be regarded with suspicion, and the respective dairies should receive immediate and - thorough inspection.

Tests for Butterfat and Specific Gravity.-In the factories where the milk is not paid for on the butterfat basis, composite samples should be taken daily, to be tested for fat and specific gravity, at regular intervals of from two to four weeks, in order to detect possible adulterations by skimming or by the addition of water. For specific directions for the Babcock test, the use of the lactometer and tests for preservatives see Chapter XXX "Chemical Tests and Analyses of Milk and Milk Products."

\section{FACTORY SANITATION.}

In the previous paragraphs, special emphasis was placed on the great importance of a good quality of fresh milk. It is equally essential that the factory be kept in exemplary condition as to cleanliness and sanitation. This is necessary because of its effect on the:patrons and on the wholesomeness and marketable property of the finished product.

Effect on Patrons.-It does not take the watchful eye of the intelligent patron, who daily comes to the factory, very long to 
learn, whether the manufacturer gives his milk as good care as he gave it on the farm. A good example set by the factory will mean much toward instilling the patron with ambition to do likewise on the farm. Shiftlessness is a contagious disease, to which the average farmer is very susceptible. It is, therefore, inconsistent for the factory to issue and enforce rules of sanitation for the dairy farmer when, within its own walls, all principles of sanitation are violated.

Effect on Wholesomeness of the Product.-Uncleanliness and filth interfere with the wholesomeness of the product. Condensed milk made in a factory ignoring sanitation, may contain certain products of decay which are poisonous to the human system. Again, it may contain germs of infectious diseases and thus become the cause of widespread epidemics of these diseases and possibly claim many victims. As a matter of common decency and of duty to the commonwealth, the condensery should pay close attention to cleanliness in all operations.

Effect on the Marketable Property of the Product.-Again, uncleanliness in the factory is bound to bring financially disastrous results. The seriousness of the disaster is greatly augmented by the fact that the consequences of neglect are usually not apparent until after the goods have reached the market. The pollution of condensed milk with impurities and filth in the factory, shortens the life of the product Such condensed milk is of very poor keeping quality. It may reach the market and the consumer in condition that causes it to be rejected, resulting in a complete loss to the manufacturer. The manufacturer allowing such conditions to exist, is usually the last man to realize and admit that he is at fault; which renders attempts to locate and stop such defects exceedingly difficult. Furthermore, instead of helping to build up the trade and to advertise the brand, he demoralizes it.

How to Keep Factory in Sanitary Condition.---Cleanliness in the factory is absolutely essential. The milk vats should be rinsed with plenty of water and scrubbed and steamed thoroughly, as soon as possible after use. 'The copper kettles and vacuum pans should be rinsed, then scoured with sandpaper or emery cloth, then rinsed and steamed thoroughly. The milk pipes should be scoured by running fluc brushes through, flush- 
ing them with clean water and steaning them until they are scalding hot. In the case of milk pipes of excessive length, they should be well flushed with hot alkaline water. Milk pumps should be taken apart every day and freed thoroughly from all remnants of milk. The water in the cooling tanks should be changed as often as is necessary to insure clean water in them at all times. The homogenizer should receive special attention, all its valves should be thoroughly cleaned and steamed daily. The cooling coils should be scalded before use. The filling machines for evaporated milk should be freed from all milk, rinsed and steamed thoroughly and no remnants of milk should be allowed to stick to the valves. The filling machines for sweetened condensed milk should be emptied and completely washed, at least once per week, and protected from dust and flies by covering them when not in use. The tin cans should be stored in a clean room and every precaution should be taken to guard against their defilement from dirt, dust, insects and mice. Where possible they should be sterilized before use.

All vats, kettles, milk conveyors, vacuum pans, milk pumps, and all machinery coming in contact with milk, should be flushed and steamed again in the morning, as soon as the condensery opens. The sugar chute should be kept clean, care being taken that no damp or wet sugar remains in it. Special attention should be given to the washing of the farmers' cans. After washing with brush and hot water containing some good washing powder, they should be thoroughly rinsed, then steamed until they are hot. If possible they should be dried by an air blast.

The floors and walls of the factory should be kept in sanitary condition. Accumulated rubbish should be removed and sewers and drains should be disinfected at regular intervals.

Can Washing.-Another extremely important, and often woefully neglected feature, relating to the effective management of the patron from the standpoint of high quality of milk, is the condition of the milk cans which the factory returns to the patron.

The patron is bound to lose his interest in taking painstaking care of his milk when the cans returned to him by the factory are filthy and foul-smelling. Nor need the factory expect the milk, it receives in such cans, to be either of high quality for condensing or wholesome. And yet an astounding proportion of con- 
densery cans reach the farmer in condition, unfit to receive and ship milk in.

Proper can washing consists of four essential operations, namely, washing, rinsing, steaming and drying.

The cans should be washed until all remnants of milk are removed. They should be rinsed with hot water until all of the dirty wash water is flushed out. They should be steamed until "piping-hot," and they should be dried until "bone-dry."

There is now admirable equipment available on the market for accomplishing these four important purposes, affording adequate facilities to enable the condensery to return to the patron cans that are clean, sterile and dry.

Care of Milk in the Factory Prior to Manufacture.-The problem of so handling the milk in the factory, from the time it arrives until it is heated preparatory to cvaporation, is an important one, that has received much careful consideration by the foremost condensed milk men. Since bacteriological analyses have shown that, under favorable temperature conditions, the micro-organisms present in milk are capable of doubling in number once every twenty minutes, it is essential that the milk either be heated to high enough temperatures to restroy germ life, or be cooled to a temperature low enough to stop growth and multiplication, as soon as possible.

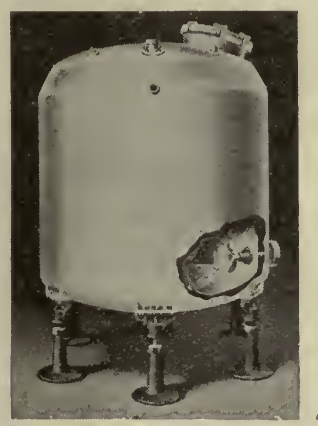

Iig. 12.

Glass-lined tank for cooling and holding milk before manufacture

Both practices are feasible, but to heat the large volumes of milk that arrive at the factory, all within a few hours, would tax the equipment of the factory under average conditions very heavily. And unless the condensery were equipped with very large vacutum pan capacity, much of this heated milk would have to lie idle in the forewarmers for hours, avaiting its turn for condensation. This would be undesirable and might prove harmful to the quality of the finished product.

Courtesy of The Pfaudler Co.

Efforts have, therefore, been made, especially within recent years, to provide a practical and economical method of cooling 
the milk as soon as it arrives and of holding it at a low temperature until ready for heating and condensing. This has led to diverse practices, such as running the milk over a surface coil cooler into a jacketed tank, or cooling it by running it into a large tank equipped with cold air blowers, or cooling the milk in large vats equipped with revolving coils, etc.

One of the later methods for refrigcrating the milk consists of the use of large, usually circular, glass enameled steel tanks. These tanks are completely surrounded on their sides and bottom by a cold water or brine jacket and are equipped with a milk distributing derice that causes the inflowing milk to be sprayed by gravity against the top of the sicles of the tank and to percolate in a thin layer down the sides. In this manner the cooling is instantaneous, the entire sides of the tank being surtounded by the cooling medium. It is ained to cool the milk to about 40 to 45 degrees $F$. and to hold it at this temperature until ready for manufacture.

'These glass enameled tanks have many advantages; they minimize the initial cost of the necessary equipment, reducing the number of costly vacuum pans, and forewarmers, required; they cut down labor cost, because they reduce the equipment to fewer pieces to operate and to clean; they are of such construction that they are easily and quickly cleaned and readily kept in proper sanitary condition, the smooth and pore-free enamel yields more readily to the brush than copper surfaces; they avoid all possibility of chemical action of the milk on metal and, therefore, are a reliable safeguard against the development of metallic flavor in the milk.

The use of these large holding tanks also facilitates the standardization of the milk for fat and solids not fat. For detailed directions on standardizing see Chapter XXIX. 


\title{
PART II. MANUFACTURE OF SWEETENED CONDENSED MILK
}

\author{
CHAPTER IV.
}

\section{DEFINITION.}

Sweetened condensed milk is cow's milk, condensed at the ratio of $2 \frac{1}{3}$ to $23 / 4$ parts of fresh milk to 1 part condensed milk. It contains considerable quantities of sucrose, usually about 40 per cent, to preserve it. It is of semi-fluid consistency and reaches the market in hermetically sealed tin cans, varying in size from eight ounces to one gallon, and in barrels similar to glucose barrels, holding from three hundred to seven hundred pounds of condensed milk. When made properly, sweetened condensed milk will keep for many months, but is best when fresh.

\section{HEATING.}

Purpose.-The first step in the process is to heat the milk to near the boiling point. There are three chief reasons for which the milk is heated, namely, to destroy most of the bacteria, yeast, molds and other organized and unorganized ferments, to facilitate the solution of the sucrose, and to prevent the milk from burning on to the heating surface in the vacuum pan.

Destruction of Ferments.-When the fresh milk arrives at the factory it contains micro-organisms in varying numbers and of different species. In some cases disease-producing bacteria may be present, rendering the milk dangerous to the health and life of the consumer, were it not heated to temperatures high enough to destroy these germs. Again, milk may contain bacteria, yeast, molds and enzymes that cause it to undergo undesirable fermentations which, if allowed to pass into the condensed milk, may tend to shorten the life and impair the wholesomeness and marketable properties of the latter. 
Solution of Sucrose.-It is very essential that all the cane sugar which is added to the milk be completely dissolved, in order to lessen the tendency of the sugar to form large crystals in the finished product. Undissolved sugar crystals in condensed milk act in a physical way much as bacteria in fluid milk do in a bacteriological way. They multiply rapidly, and such condensed milk usually precipitates its sugar before the product reaches the market. The presence of excessively large sugar crystals makes the product gritty and causes the formation of a sediment in the bottom of the cans; this is objectionable to the consumers. When the milk is heated to the proper temperature before condensing, the solution of the cane sugar is facilitated and the tendency toward grittiness is minimized.

\section{Prevention of Burning Milk on Heating Surface.-If cold} milk comes in contact with a steam-heated surface and is not agitated vigorously, it bakes or burns onto this heating surface. The milk in the vacuum pan is heated or kept hot by means of the steam jacket and coils. These racliators are charged with steam under pressure and consequently give off a high degree of heat. If cold milk is drawn into the vacuum pan, the milk remains calm for a considerable length of time. During this time it is bound to bake or burn on the heating surface, giving the product a burnt flavor, causing it to contain brown specks and retarding the process of evaporation. If the milk is hot when it enters the pan, the reduced pressure in the pan causes it to boil violently at once, avoiding all danger of sticking to and burning on the heating surface and making possible maximum rapidity of evaporation.

Temperature.-In most factories the milk is heated to from 180 degrees $F$. to 200 degrees $F$. This temperature is sufficient to accomplish the three purposes. Heating the milk to the boiling point tends to give it a rather pronounced cooked flavor, which is objectionable. However, in the case of danger of contamination of the milk with resistant types of undesirable bacteria, it may become necessary to practice boiling the milk.

Manner of Heating.-Thorough, efficient and rapid heating of large volumes of milk to temperatures near the boiling point is a problem that requires careful consideration. The tendency 
of the milk to stick to the heating surface is a permanent obstacle and efforts to overcome this frequently result in sacrificing thoroughness of heating.

A variety of methods and numerous different types of machincs are used for this purpose in the different milk condensing factories. Some use large copper kettles in which the milk is heated by turning steam direct into the milk. Others use jacketed copper kettles equipped with a revolving agitator. The milk is

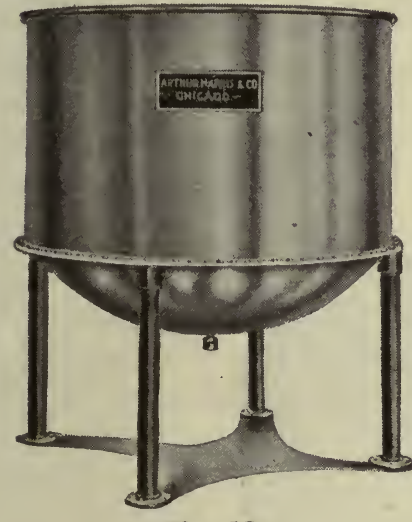

Iig. 13.

The hot well or forewarmer

Courtesy of Arthur Harris \& Co. heated by turning steam under pressure into the jacket and the burning of the milk is prevented by keeping the milk in constant motion. In this case the milk is usually heated to about 170 degrees $\mathrm{F}$. by the jacket and from there on the temperature is raised to that desired, by turning steam direct into the hot milk. Still others are heating the milk by means of large continuous pasteurizers in which case hot water or steam serves as the heating medium. The milk passes in a thin layer between two water-heated surfaces, one of which is revolving. In some factories the milk is forced through a series of pipes inclosed in a hot water or steam jacket.

Finally, in some condenseries a combination of the continuous pasteurizer and the plain or jacketed kettle is used. The milk is heated to nearly the desired temperature in the pasteurizer. From there it flows into the kettle, where the heating is completed. This method insures efficient heating and, at the same time, if operated properly, it prevents scorching of the milk on the heating surface.

Advantages and Disadvantages of Different Methods of Heating.-In most factories in this country the first named method is used. Steam is turned direct into the milk until it boils up. This is the oldest and most primitive method. While very simple in operation, this method has some objections. At 
best, much of the steam used condenses in the milk, increasing the amount of water that has to be evaporated. It, therefore, prolongs the process of condensing and increases the cost of manufacture. This is especially true where the boilers are located at some distance from the hot wells and the steam pipes are not well insulated, causing the steam to be "wet," and when the milk to be heated is cold. It is estimated that the amount of extraneous water thus added to the milk increases the bulk of the milk by about one-sixtl of its original volume. The steam is often associated with impurities, such as cylinder oil from the engine, boiler compounds used in the boilers, scales from the insile of the pipes, etc. 'These various impurities cannot possbily improve, but may seriously injure the quality of the milk. It is generally conceded by those who have given this matter careful

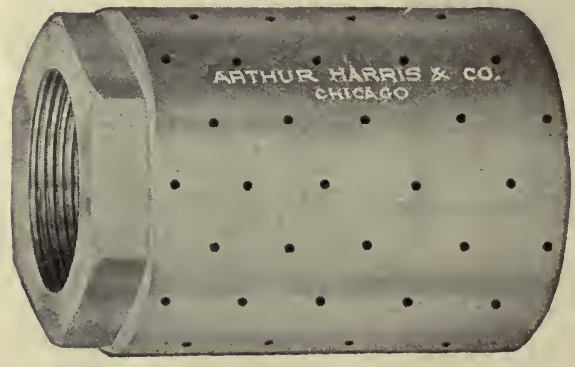

Fig. 14. Steam rosette for heating milk

Courtesy of Arthur Harris \& Co.

thought, that the turning of steam direct into the milk shortens the life of the product and causes it to develop a stale flavor, which may degenerate into an oily flavor. The same defect is noted also when cream is heated by turning steam into it. The prolonged exposure of the milk to the condensing process, as the result of the addition to the milk of considerable quantities of condensed steam, is an additional objection.

From the above discussion it is obvious that the heating of the milk by bringing it in direct contact with free steam has some objections. Just to what extent this practice jeopardizes the quality has not been very conclusively demonstrated. But it is recommended that the heating with direct steam, if it must be practised, be confined to the last stages of the heating process, 
that is, that the milk be heated to pasteurizing temperature, 170 degrees $\mathrm{F}$. or thereabout, by the use of a continuous pasteurizer, or a jacketed kettle, or other similar means, and that from there on only to the desired temperature, direct steam be used.

\section{ADDITION OF SUGAR.}

Considerable quantities of sucrose are added to the condensed milk for the purpose of preserving it.

Kinds of Sugar.-In order to convey to the milk preservative properties, that kind of sugar must be used which does not reádily undergo fermentation and which has the power of inhibiting bacterial activity when dissolved in a concentrated solution. Glucose could be purchased at a very low cost, but it is not suitable for this purpose, since it is, in itself, very unstable and fermentable. It has no preservative qualities, even in concentrated solutions. Sucrose, saccharose, or cane sugar, $\mathrm{C}_{12} \mathrm{H}_{22} \mathrm{O}_{11}$, properly refined, ferments with difficulty in concentrated solutions, and has the power of retarding the growth of bacteria and other ferments ordinarily present in sweetened condensed milk. It is, therefore, very satisfactory and useful in this connection.

Beet sugar, which is chemically indentical with cane sugar, is used in E,uropean countries very largely in the place of cane sugar. On the continent the beet sugar industry is an important factor. With the climate adapted to the growing of sugar beets and the labor relatively cheap, beet sugar can be secured by the European condenseries at lower cost than cane sugar. In America, where the annual sugar cane crop is large and where the high cost of labor renders the expense of growing sugar beets relative ly high, there is practically no difference between the price of cane sugar and beet sugar. 'When American beet sugar was used in the condenseries during the infancy of the beet sugar industry, this sugar was found undesirable, often giving rise to fermented condensed milk. It was then supposed by the condensed milk men that beet sugar contained yery resistant sporebearing bacteria, which followed the beets from the soil into the refined sugar. This conclusion is highly improbable, as the temperatures and chemicals employed in the process of beet sugar making are prohibitive of the passage of living bacteria 
from the soil to the finished sugar. It is possible, however, that the standard of refinement of American beet sugar, during the earlier days of its manufacture, was low and that some of the beet sugar on the market may have contained small amounts of acid, invert sugar and other impurities, ingredients of such a nature as to render the sugar prone to give rise to fermentation and, therefore, condemn its use in the milk condensery.

While the beet sugar on the market today appears to have reached a very high state of refinement and is, according to the best authorities, equal in purity to cane sugar, it is still shunned by the American condenseries, which insist that nothing but cane sugar will do. However, whenever a shortage occurs of the sugar cane crop in the West Indies, raw European beet sugar is imported into the United States and it all emerges from our seaboard refineries as "pure cane sugar." It is not improbable, therefore, that the sugar supply of many American condenseries today consists at times largely of beet sugar, though it is purchased under the name of cane sugar.

There is no good reason why the best refined beet sugar, manufactured today in this country and elsewhere, should not give fully as good results for condensing purposes as the same quality of cane sugar. Tests made at the California Agricultural . Experiment Station ${ }^{1}$ led to the conclusion that the two kinds of sugar, cane sugar and beet sugar, were equally valuable for canning and identical in their behavior when of the same fineness of crystallization.

Beet Sugar Cannot be Detected from Cane Sugar.-While the raw sugar from the two different sources, the sugar cane and the sugar beet, takes on the character of the impurities from which it has not yet been freed (the raw product of the sugar cane is pleasant in flavor, the raw product from the sugar beet is acrid and disagreeable in flavor), the sucrose or so-called pure cane sugar, can be and is crystallized out, and in every case the sugar is identical in chemical composition, appearance and properties. "By no chemical test can the pure crystallized sugar from these two different sources be distinguished."'2 1913.

1 California Agricultural Experiment Station, Circular No. 33.

${ }^{2}$ United States Department of Agriculture, Farmers' Bulletin No. 535, 
Quality of the Sugar.--Since the sugar, sucrose, is added for the purpose of preserving the condensed milk, it is obvious that none but the best quality of refined sucrose is admissible. Low grade sucrose is a product dangerous to the condensed mitk business. It is apt to contain sufficient quantities of acid and invert sugar, to give bacteria and yeast an opportunity to start fermentation. When once started, the destruction of the product is almost inevitable. In years of failure of the cane sugar crop. when the prices of sucrose soar high, condenseries yield frequently to the temptation of buying lower grades of sugar. The result invariably is an abnormally large output of condensed milk that "goes wrong."

It is very important that the sugar in the factory be stored where it will keep dry. Sucrose has hygroscopic properties. When exposed to an atmosphere saturated with moisture it absorbs water. In damp storage it is prone to become lumpy, moldy and frequently sour. When these precautions are neglected there is danger of defective condensed milk, causing the cans on the market to swell, due to gaseous fermentation.

Adulteration of sugar with foreign admixtures, such as white sand, white clay, starch, or lime dust is rare, and occurs usually only in pulverized sugar. For the detection of these adulterants, add a spoonful of the suspicious sugar to a glass of hot water and stir. Pure sugar will dissolve completely, while most of the common impurities are insoluble and will settle to the bottom.

The purchase of coarsely granulated sugar is an effective safeguard, insuring freedom from these adulterants. Powdered sugar should not be used in the condensery.

Amount of Sugar.-The amount of sucrose used varies in different countries, with different manufacturing concerns, in different factories of the same company and at different seasons of the year. The normal variations range between twelve and eighteen pounds of sucrose per one hundred pounds of fresh milk. Most factories use about 16 per cent.

It is not advisable to overstep the limits above indicated. Condensed milk serves as a substitute for fresh milk. The more sucrose it contains, the greater is the difference in composition and properties between the condensed milk and the fresh milk. 
Sucrose is not as readily digested as the other ingredients of milk; therefore, the presence of excessive amounts of cane sugar in condensed milk tends to reduce its digestibility and its wholesomeness as a food. Again, while normal milk is a well-balanced food in itself, the presence of large amounts of care sugar in it causes this equilibrium to be disturbed, the condensed milk being excessively ricl in carbohydrates and relatively poor in proteids. These facts are specially significant where condensed milk is used for infant feeding and by persons with weak digestion.

On the other hand, sweetened condensed milk depends for its preservation on the sucrose. This class of condensed milk is not sterile and is prevented from rapipd deterioration by the preservative action of the sucrose only. Therefore, the smaller the anount of sucrose it contains, the greater the danger from the activity of ferments and the lower its.keeping quality.

The relative prices of cane sugar and of fresh milk also govern the amount of cane sugar used in many factories. In summer, milk prices are low and sugar prices are high, while in winter the relative prices are reversed. Hence there is a tendency on the part of the manufacturer to use less sugar in summer than in winter.

Again, the amount of cane sugar used varies according to the kind of market for which the condensed milk is intended. Milk put on the market in hermetically sealed cans is generally exposed to more unfavorable conditions and is older by the time it reaches the consumer than milk sold in barrels. It is customary to use about sixteen pounds of cane sugar for every one hundred pounds of fresh milk for canned goods, and about twelve to fourteen pounds of cane sugar for barrel goods.

Finally, there is a strong tendency in some localities for sweetened condensed milk made in May and June, to thicken rapidly and become cheesy with age. This can easily be prevented by the use of more cane sugar in the milk manufactured during these months. (See Chapter XXII on "Condensed Milk Defects.”)

A more accurate method of determining the amount of sugar that should be added to the original milk in order to secure a 
definite desired percentage of cane sugar in the finished product. is to accurately test and standardize the original fluid milk for fat and solids not fat and then calculate the pounds of sugar to be added on the basis of the eotal pounds of fat or of solids present. For detailed directions see Chapter XXIX on "Standardization."

Mixing the Sugar.-The sugar is added to the hot milk before the latter enters the vacuum pan. In some factories a separate tank is provided for this purpose. Small portions of the hot milk are allowed to flow into this tank. To these the sugar is added. This tank is called the sugar well. It is usually equipped with a mechanical reversible stirrer, moving to and fro on an eccentric, to facilitate the solution of the sugar. The milk from the heater and from the sugar well runs into a tank sunk into the floor of the well room, the ground well, from which the mixed sweetened milk is drawn into the vacuum pan. In other factories the sugar well and ground well are one and the same tank, into which the milk runs direct from the heater. In this case it is advisable to set a wire mesh strainer (sixty to eighty meshes to the inch) over the sugar well. The sugar is placed into this strainer, a little at a time; the hot milk from the heater passing into and through the strainer dissolves the sugar. A paddle or stick should be used to stir the sugar in the strainer. For greater convenience and economy of labor, the sugar barrels and scales are placed on the floor over the well room. The sugar is transferred to the strainer below through a sugar chute which may be equipped at the lower end with an adjustable cutoff to regulate the sugar coming down. Or the kettles, hot wells or sugar wells in which the sugar is added to the milk, are sunk into the floor sufficiently to facilitate the emptying of the sugar barrels direct from the floor into the milk. In this case no sugar chute.is needed. Other factories dissolve their sugar in boiling water in a separate tank, and draw this syrup into the vacuum pan together with the hot milk. This is a very commendable practice, as it minimizes the danger of undissolved sugar crystals escaping into the pan. Moreover, this watery syrup can be boiled without danger of giving the milk a cooked flavor. 


\section{Chapter V.}

\section{CONDENSING.}

From the ground well in the well room the sweetened milk is drawn into the vacuum pan, where it is condensed under reduced pressure. The vacuum pan is usually located on the second floor over the well room, or in the well itself, in which case it is elevated above the floor six to eight feet. The vacuum pan is connected with the vacuum pump, which should be installed near the pan.

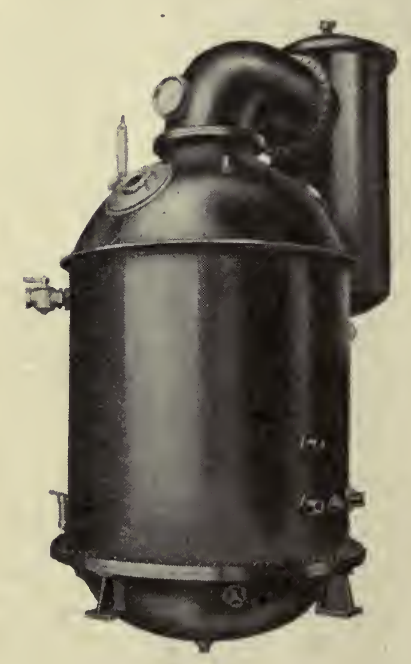

Fig. 15.

Vacuum pan and condenser Courtesy of Groen Mfg. Co.

Description of the Vacuum Pan. -The vacuum pan is a retort in which the milk is heated and evaporated in partial vacuum. The origin of the term "pan" has not been satisfactorily explained. In the early and experimental days of the manufacture of condensed milk, the milk was evaporated in open kettles, called pans. It is probable that the name of this primitive apparatus was passed on to the more perfected machinery now in use.

The vacuum pans are constructed of copper, iron, steel or bronze Practically all of the vacuum pans used for condensing milk are made of copper throughout; they are of various styles and sizes. The predominating size used in milk condenseries is the "six-foot pan." By the term six-foot is meant a retort measuring six feet in diameter.

There are two general types of vacuum pans on the market; pans that are relatively wide in diameter and shallow in depth, and pans of relatively narrow diameter and which have a deep body. Both types are claimed, by their respective manufacturers, to have special advantages, such as ease of operation, uniformity of action, economy of fuel and of water, and rapidity of evapora- 
tion; the opinions of the users of these pans are also at variance concerning their relative merits.

The advocates of the wide, shallow pan claim that this type

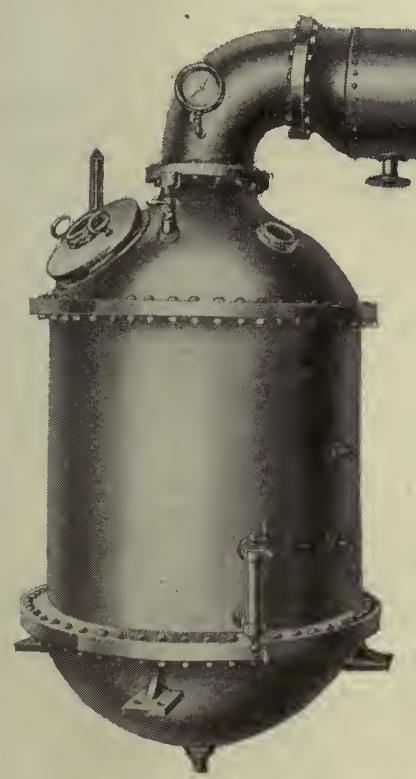

Fig. 16

Vacuum pan and condenser

Courtesy of

Arthur Harris \& Co.

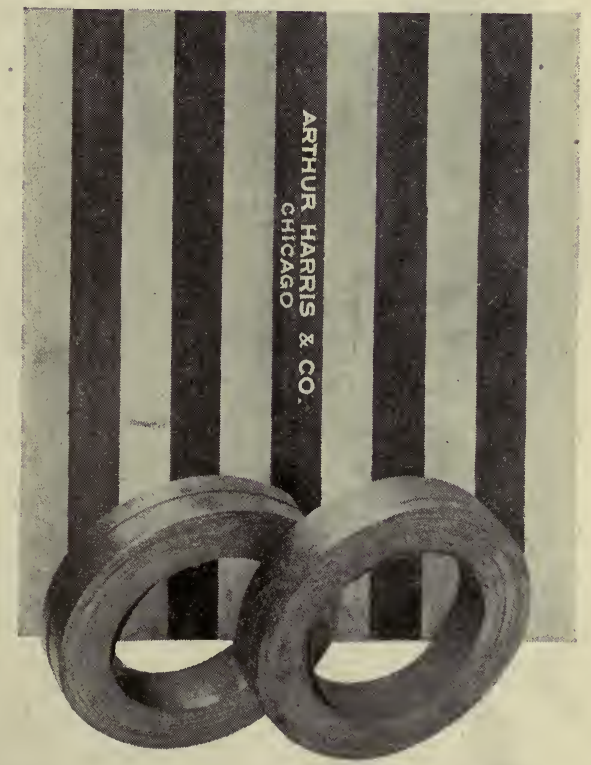

Fig. 16-A. Covering and insulation for vacuum pans

Courtesy of Arthur Harris \& Co. 
of pan makes possible such an arrangement of the heating surface as to take care of the maximum amount of milk with the minimum depth of milk over the heating surface and that this arrangement is most desirable. They hold that because the wide and shallow pan offers a larger area of evaporating surface, it therefore makes possible more rapid evaporation than the narrow, deep pan. They further emphasize that in the wide, shallow pan, the milk boils more quietly, is under better control and is less apt to be carried over into the condenser and lost, than in the narrow, deep pan.

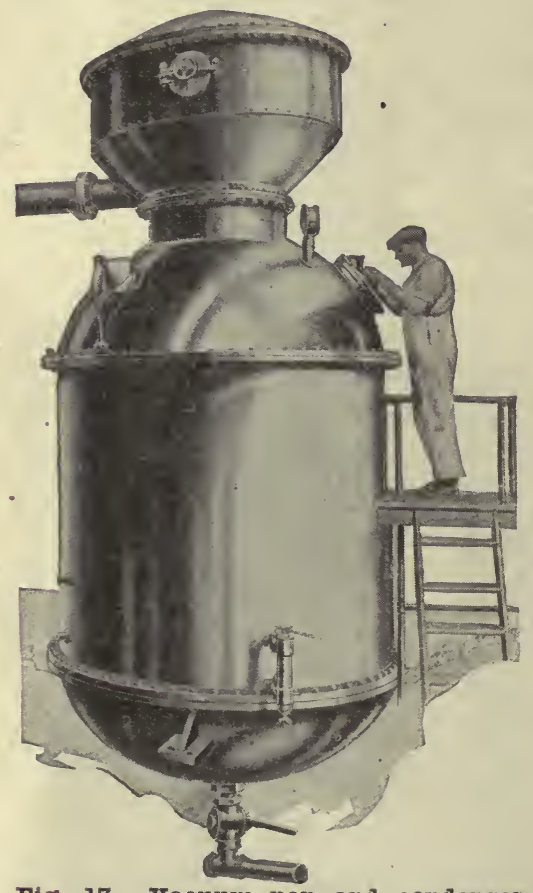

Iig. 17. Vacuum pan and condenser

Courtesy of Mojonnier Bros. Co.

The advocates of the narrow, deep pan claim that their type of pan increases the rapidity of evaporation because it causes the milk to pass over the heating surface more rapidly. When the pan is in operation, the boiling milk travels from the center of the bottom toward the periphery where it rises, rolls over the coils, and returns to the center. It is claimed that a pan with a shallow jacket, such as the narrow, deep pans have. causes the milk to roll over higher, especially if the coils are close to the periphery and leave plenty of vacant space in the center of the pan. This, in turn, means more rapid circulation of the milk, causing it to pass over the heating surface at greater speed. and oftener, which naturally enables the milk to utilize more heat and, therefore, to evaporate more quickly. Because in such pans the milk rolls over higher, they require a sleeper body.

Experience has demonstrated that for maximum rapidity of evaporation, other factors being the same, maximum rapidity of 
circulation of the milk over the heating surface is indispensable. It is further obvious that the rapidity of evaporation is in direct relation to the area of the heating surface.

Rapidity of circulation of the milk demands that there beno hindering counter currents and that the milk be permitted to circulate with maximum freedom in one direction. This can best be accomplished by leaving a large open space in the center for the milk to return to the bottom after it has boiled up and over the coils from the periphery.

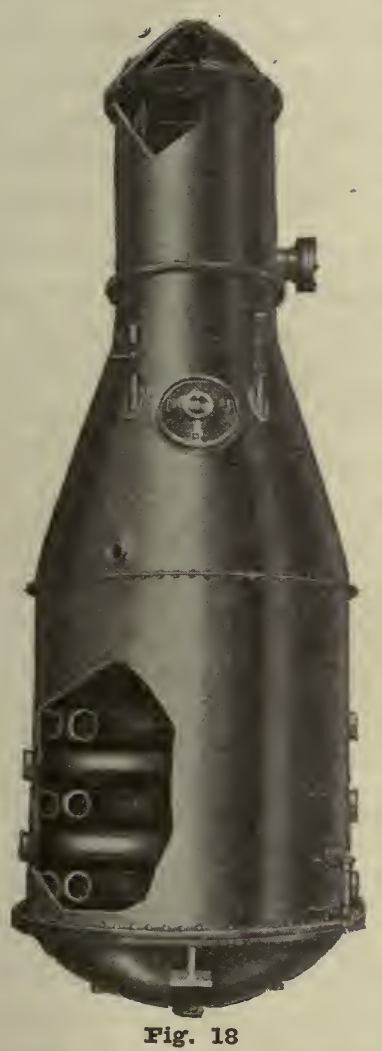

Vacuum pan and condenser Courtesy of C. E. Rogers

In order to have the coils so arranged as to permit this maximum and unhindered circulation of the milk, the pan must have a certain height or depth, so as to admit the necessary heating surface.

With the growing recognition of these principles, vacuum pan manufacturers are therefore more and more tending toward the style of pan with a tall body in proportion to its diameter.

The vacuum pan consists of four main parts, namely, the jacket or bottom, the body or vapor belt, the dome and the condenser.

The Jacket forms the bottom of the pan. The inside wall is copper, the outside cast iron. It generally is concave, the curve varying in different types of pans from a depth of a few inches to two and one-half feet. The steam space in the jacket between inner and outer walls is about two inches wide. It is equipped with two steam inlets and one or two steam outlets. In some pans some or all of the steam outlets of the coils also exhaust through the jacket.

In the center of the bottom there is an opening, from two to three inches in diameter, for the discharge of the condensed 
milk, fitted with a valve. In the case of pans that have no special "striking" or sampling cup, this discharge is equipped with two valves and a short nipple between valves, to make possible the sampling of the condensed milk while the pan is in operation.

The Body or Vapor Belt represents the main part of the pan. It is cylindrical, of varying height and is equipped with copper coils which have their outlets either through the jacket or the walls of the body. Their upper ends connect, through the body of the pan, with the main steam line. Most pans are equipped with two to three or more coils located at different elevations. Since steam should be turned into the coils only when they are covered with the milk, it is desirable to have several short independent coils rather than but one large one. This will give a larger range of the quantity of milk that can be condensed and increases the speed of evaporation. The coils vary in diameter from about three to six inches. The upper and outer coils are the larger ones. The diameter and length of the coils necessarily vary with and are limited by the capacity of the pan. The shorter each individual coil, and the greater the number of independent coil sections and the greater the total heating surface, consistent with maximum rapidity of circulation of the milk and with easy access to all parts of the jacket and coils, the better. Other things being equal, the more square feet of heating surface, the less steam pressure, by the gauge, is required to furnish the necessary heat for maximum evaporation. This is important because high steam pressure in the jacket and coils means exposure of the milk to high temperature, which is undesirable. The heating surface should be sufficient to make possible the complete condensation of the steam in the jacket and coils. If the heating surface is inadequate, more steam has to be turned into the jacket and coils, in order to secure the necessary heat for rapid evaporation, than will condense; free steam will blow through and ont of the coils, resulting in uneconomic and wasteful use of fuel, and jeopardizing the quality of the product. The presence of numerous but short coils also increases the intensity of heat-transmission, as practically all of the steam is condensed in the uppermost convolution of each coil. There is a considerable variation in the area of the heating sur- 
face in different makes of pans, ranging from about 120 to 205 square feet, in the case of six foot pans.

In the latest improvement in coils each independent coil makes only one turn in the pan and the inner and outer coils have the same inlet and discharge and are placed on the same level. This permits of the installation of a larger number of independent coils, each placed at a different level. In this manner the coils can be utilized to better advantage. This is especially significant when the rolume of milk in the pan is very small, making pos-

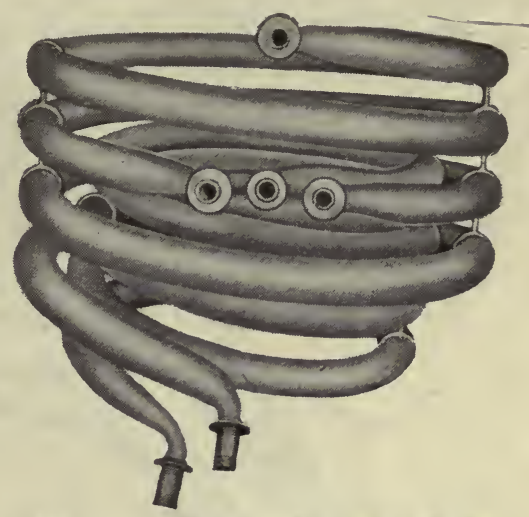

Fig. 19. Steam coils in Harris pan Courtesy of Arthur Harris \& Co. sible the operation of the lower coils independent of the upper coils and thereby avoiding the danger of burning the milk, which inevitably occurs when the heated coils are not completely submerged. This arrangement increases the heating efficiency of the pan, heat can be turned on the lowest coil almost immediately after starting operation, and toward the end of the batch, when the milk again boils low, some of the coils are still covered and can be used. The shorter length of these coils from inlet to exhaust also makes possible the simultaneous utilization of a greater volume of steam. These combined features materially increase the rapidity of evaporation and augment the capacity of the pan. These improved coils have the further advantage that their exhausts do not have to be carried through the jacket, but pass through the body of the pan.

Jacket and coils are connected independently with the direct steam main from the boiler. Each connection at the pan should carry a valve and a steam gauge on the pan-side of the valve. The main steam line and connections leading to pan should be properly insulated by proper pipe coverings, in order to supply the pan with as dry steam as possible.

The drips or discharge ends of the jacket and coils are connected with the boiler feed water tank. If the pan has sufficient 
heating surface and is operated properly, the drip ends of the jacket and coils should discharge warm water on!y, and not free steam. The jacket and coils should be free at the drip or discharge ends so that all condensation water may be quickly and continuously removed. This is necessary in order to make the most economical use of the steam and to secure high efficiency of evaporation. In order to guard against hack pressure the drips may be equipped with suitable check valves.

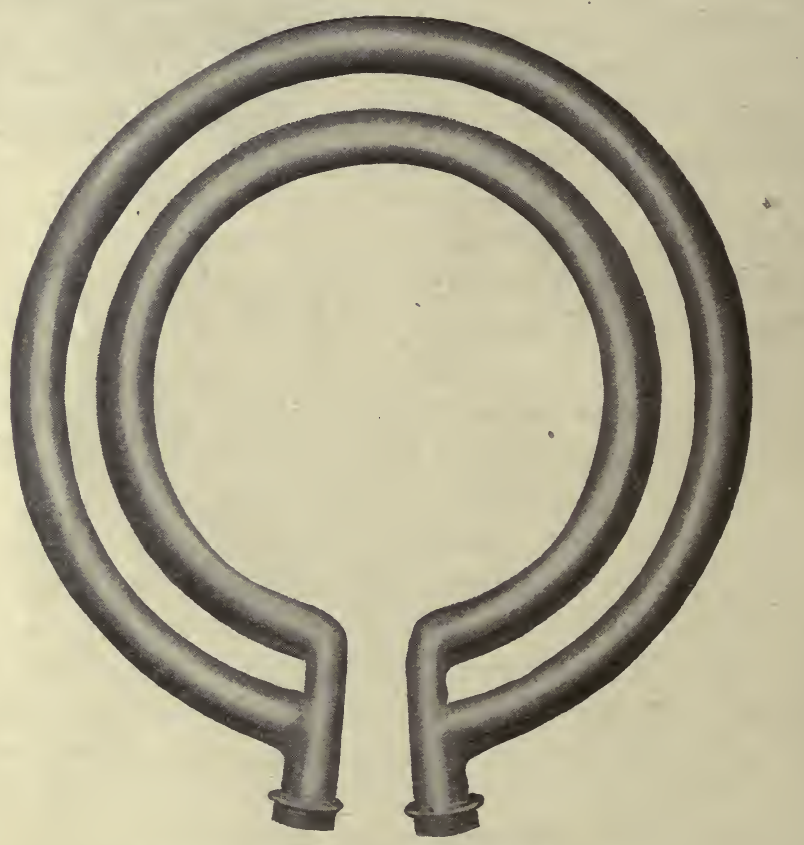

Fig. 20. Steam coils in Rogers pan Courtesy of C. E. Rogers

Through the walls of the body of the pan also enters the milk draw pipe. This pipe connects with the hot well and through it the milk rushes into the pan. Immediately outside of the pan the milk pipe should be equipped with a valve to regulate the inflow. The size of the milk draw pipe and valve is governed by the capacity of the pan; usually two to three inches in diameter. Inside of the pan the milk pipe should be turned down. If this provision is not made, the milk shoots straight across the 
pan atomizing into a,dense spray, which is partly drawn over into the condenser, causing loss of milk.

The body of the pan also usually carries, near its lower portion, a sampling cup, or striking cup, which facilitates the sampling and testing for density, of the contents of the pan while the pan is in operation.

A suitable, permanent covering should be provided for the body of the pan for insulation against heat radiation. This will not only economize finel and speed evaporation, but it will also

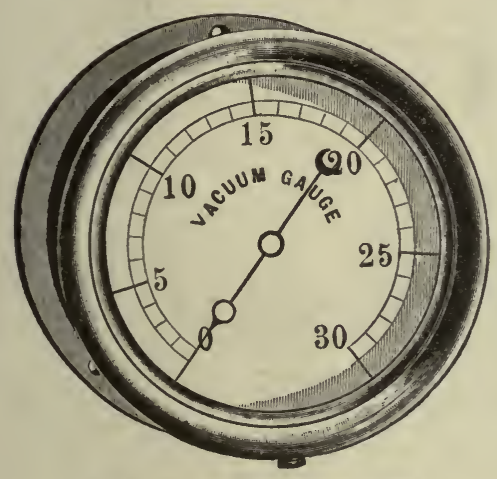

Fig. 21. Vacuum gauge assist in keeping the pan room reasonably cool.

The Dome rests on top of the body of the pan. It is equipped with a manhole, manhole cover, thermometer, vacuum gauge, sight glasses, lights, blow-down valve or vacuum breaker. The man hole measures $\mathrm{about}$ fourteen to eighteen inches in diameter. It is closed by a solid brass cover with a well-fitting, ground surface flange. The cover carries a five-inch spy-glass or sight-glass through which the operator watches the boiling milk in the pan. The stem of the thermometer is enclosed in a brass casing and reaches to near the bottom of the pan. Some processors prefer a short thermometer which registers the temperature of the vapors instead of that of the milk. As both, the milk and the vapors are subjected to the same pressure, their respective temperatures are the same. The vacuum gauge connects with the interior of the pan, and indicates the number of inches of vacuum. A mercury column may be used in the place of the vacuum gauge. In the rear of the dome there are two sight glasses. Through these the interior of the pan is illuminated by means

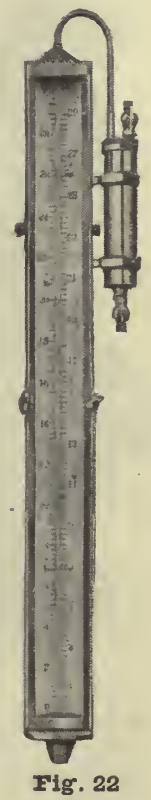

Mercury Column Courtesy of C. E. Rogers 
of lamps, gas or electric lights. The "blow-down" valve, or vacuum breaker, serves to admit air into the pan in order to "break" the vacuum. This is necessary for readily drawing off the finished condensed milk. It is further needed to prevent the contents of the vacuum pan from being drawn over into the condenser, whenever the milk rises above a safe level.

A further accessory of the dome may be an automaotic milk sampler. The sampler tube is carried through the wall of the dome and extends to near the bottom inside of the pan. Where this tile projects through the dome it is equipped with motor, piston pump, striking cup and hydrometer. The striking cup at its upper end terminates in a . small chamber equipped with a sight-glass through which the operator notes the position of the hydrometer.

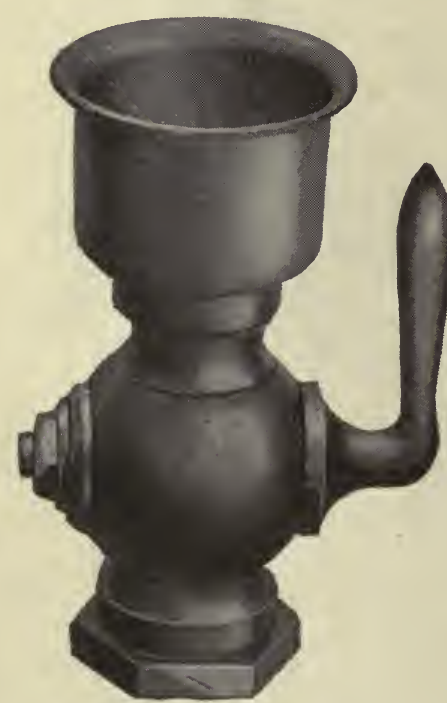

Fig. 24.

vacunm breaker or blow-down valve
Courtesy Arthur Harris \& Co.
The Condenser. -The condenser is

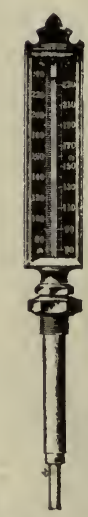

Fig. 22

Thermometer for vacuum pan

Courtesy of Arthur Harris \& Co. that portion of the condensing apparatus in which the vapors, rising from the boiling milk in the pan, are condensed to water. The condenser is attached to the dome of the pan. There are three types of condensers in use, the surface condenser, the barometric condenser and the wetvacuum spray condenser.

The Surface Condenser consists of a tube cylinder filled with brass tubes, mounted on a receiver. The water used for cooling circulates outside of the tubes and the vapors pass through the tubes, where they are chilled and condensed. This condenser has the advantage of enabling the operator to note the amount of condensation and to measure the amount of water actually condensed. The receiver at the bottom of the condenser should be 
so arranged that it can be drained at will and without interfering with or retarding the operation of the pan.

The Barometric Condenser consists of a vertical cylinder of iron or brass, equipped with a spray jet, through which the cool-

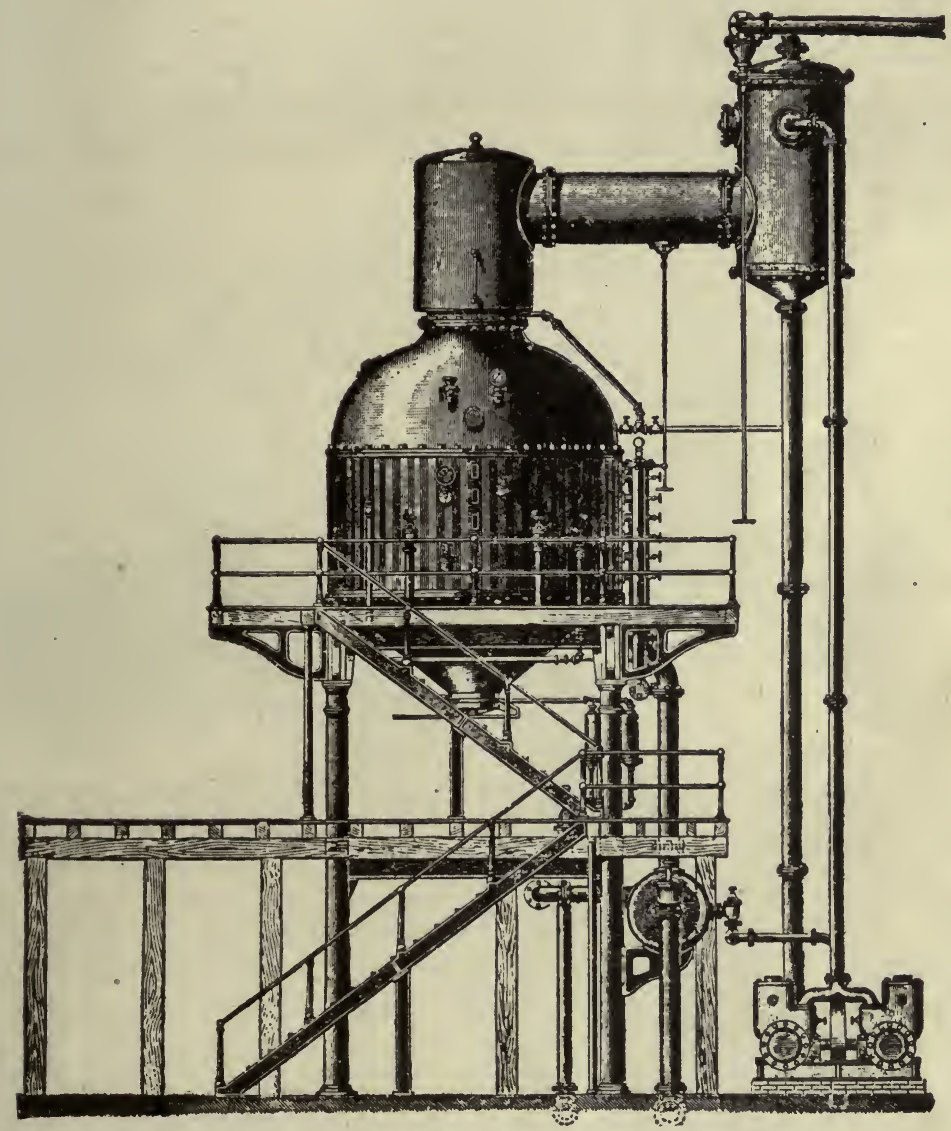

Fig. 25. Vacuum pan with dry vacuum barometric condenser Courtesy of Arthur Harris \& Co.

ing water enters the condenser. The vapors being drawn over from the violently boiling milk in the pan, are condensed by passing through this spray of cold water. This condenser discharges its water into a tight cistern in the ground. The condenser is placed so that its bottom flange is about thirty-five 
feet above the water level of the cistern in which the discharge pipe from the condenser terminates. The height of the condenser depends on the barometric pressure of the location where it is installed. The lower the altitude and, therefore, the higher the atmospheric pressure, the higher must the condenset be above the cistern. At the sea level, the atmospheric pressure sustains a water column about thirty-four feet high. This water column in the discharge pipe seals the vacuum and at the same time permits the water from the spray and the condensation water to escape automatically. The cistern in which the water column terminates should be of sufficient size to hold about one-third more water than the capacity of the entire length of the discharge pipe calls for and should have a large overflow into the sewer. When the pan is in operation and a uniform vacuum is maintained, the level of the water column remains constant and the excess water from the condenser overflows from the cistern into the sewer.

\section{The Wet-Vacuum Spray} Condenser consists of a huge hollow cylinder of brass or iron, usually, but not necessarily, horizontal.

The horizontal spray condensers are usually equipped with a perforated spray pipe, placed lengthwise in the cyl-

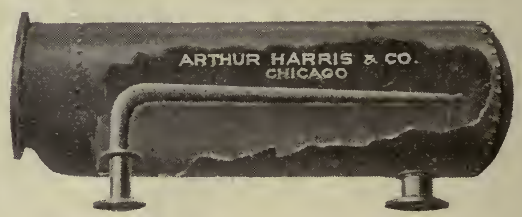

Fig. 26. Wet-Vacuum horizontal spray condenser

Courtesy of Arthur Harris \& Co. inder. This spray pipe should run close to the top side of the cylinder, so as to give the spray that escapes from the holes on the upper side of the spray pipe a chance to strike the top of the horizontal cylinder with force and to become atomized. The spray pipe connects at the end nearest the pan with the pipe supplying the cooling water. When the pan is in operation, a shower of cold water issues forth from the perforations of the spray pipe as the result of the rediced pressure in pan and condenser. The force with which the water escapes these perforations is further augmented by the fact that in most cases the water supply tank is located higher than the condenser. The hot vapors arising from the boiling milk in the pan are drawn over into the condenser, where they come in contact with the 
cold water spray and are condensed. The bottom of the condenser cylinder, at the end farthest from the pan is connected with the suction end of the vacuum pump through which the water and the condensed vapors in the condenser escape. Manholes with covers should be provided at the top and end of the condenser cylinder to facilitate the cleaning out of the condenser.

In the vertical spray condenser the condenser cylinder is upright. located either on top of the pan or at some distance, as is the case, for instance, where a catch-all is installed between

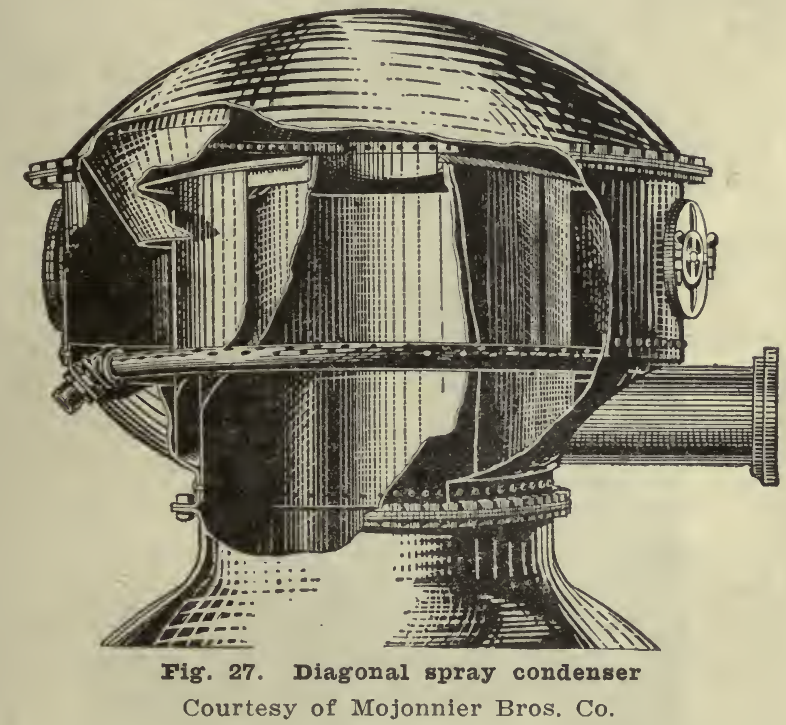

pan and condenser. The interior arrangement of the vertica! condenser varies somewhat with the different makes. One type of vertical condenser widely used in American condenseries consists of a double insulated vapor tube resting on top of the pan. This insulated tube is surrounded by and connects with a spray chamber, which terminates at its top in a perforated metal plate. and which has an opening in the side near the bottom that connects with the vacuum pump supplying the suction and that permits the escape of the condensed vapors and cooling water. The cooling water enters at the top of the condenser. Immediately underneath the water inlet it strikes a metal cone or umbrella which prevents the water from running into the vapor tube, and 
distributes it evenly over the perforated spray plate. The vapor rises into the vapor tube of the condenser and is drawn over into the spray chamber surrounding it, where the vapor is condensed by the spray of water issuing from the perforated spray plate which tops the spray chamber and which contains a large number of very small holes. As the water falls through these openings by gravity, the spray is uniform and constant and does

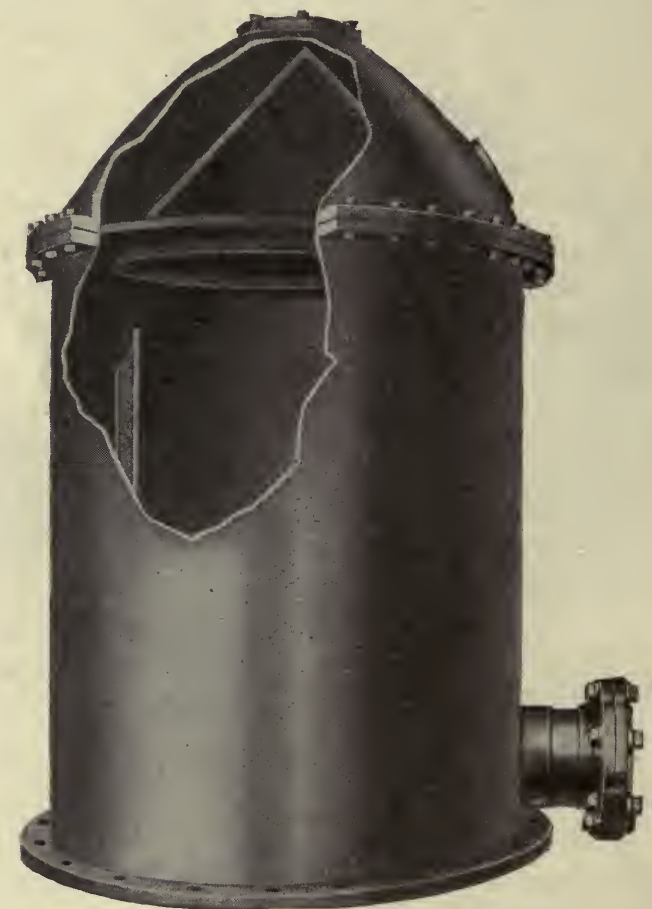

Fig. 28. Vertical spray condenser

Courtesy of C. E. Rogers

not depend on the amount of water used, nor does it require water pressure on the condenser. A complete sheet of spray always is formed, through which the vapors must pass, regardless of the amount of water used, a fact which assists in the efficient use of the water and in rapid and complete condensation of the vapors. Manholes with covers are located at the top to facilitate the cleaning of the spray plate. 
In another type of vertical spray condenser the insulated vapor tube in the center is surrounded by a spray chamber of much greater width, and the water spray starts near the bottom of the chamber from perforations in a circular coil. The perforations are so located that the spray slants upward and outward. As it strikes the periphery of the condenser, it is deflected downward and toward the center. It is claimed that in this case two sheets of spray are formed, through which the vapors must pass. Baffle plates extend downward and outward from the top of the vapor tube preventing any of the spray from entering the vapor tube. Manholes with covers are provided at the sides to make possible easy cleaning of the condenser.

Instead of the condenser being attached direct to the dome of the vacuum pan, the condenser may form a part of the vacuum pump. This arrangement is feasible both in the case of the wetvacuum spray condenser and in the case of the surface condenser.

The chief difference between the wet-vacuum condenser and the barometric condenser is that in the wet-vacuum condenser the water from the condenser passes through the vacuum pump, while in the barometric condenser the water does not pass through the vacuum pump, but goes direct into the sewer and the vacuum is sealed by the barometric water column. So far as practical experience has shown, there is no material difference in the efficiency between these two types of condensers. The water column of the barometric condenser helps somewhat to maintain a uniform racuum. It necessitates, however, the installation of the pan inconveniently high and requires somewhat more expensive machinery than is the case with the wet-vacuum condenser. The chief difference between both of these systems and the surface condenser is that, in the wet-vacuum and barometric condensers the condensed vapors mix with the cooling water, while in the surface condenser the condensed vapors are collected and carried off separately and without mixing with the cooling water. In the case of condensing liquids, the vapors of which are of commercial value, the surface condenser must be used. The surface condenser, however, is of relatively small capacity and the cooling water cannot be utilized as economically as in the case of the other systems. Where large quantities of vapors are to be handled and the vapors have no commercial 
value, as is the case in condensing milk, the barometric and wetvacuum condensers are best suited; if properly constructed, their operation utilizes the cooling water most economically.

Care of the Condenser.- In the operation of the spray and jet condenser, special attention should be paid to the condition of the spray pipe, or spray plate. Especially, when the water used contains much organic matter, as is the case with water from a creek, pond or lake, there is a tendency of the spray equipment beçoming filled and coated with slimy organic matter, causing the perforations to clog. This renders the distribution of the spray irregular and the control of the pan difficult. It causes great waste of water because much of the water is discharged from the condenser and lost without coming into direct contact with the vapors. The water is, therefore, not utilized economically and the difference between the temperature of the vapors and the discharge of the condenser is excessive. In order to avoid this the condenser should be cleaned out thoroughly at least once a week, or oftener if necessary, to keep the pores of the spray pipe or plate free from obstructions. It is advisable to install condensers equipped with a manhole, properly located, otherwise access to the spraying arrangement is not sufficiently convenient to insure frequent inspection and thorough cleaning by the average operator.

The Expansion Tank, Catch-All, or Milk Trap.-This is a tank frequently installed between the dome of the pan and the condenser. Its purpose is to collect and reclaim any milk that may be carried over from the pan and to prevent its escape and loss through the condenser.

If the pipe through which the milk enters the pan is turned down and its end is carried to near the bottom of the pan, so as to avoid the formation of excessive milk spray, if the pan is operated carefully and if the milk is kept at a reasonably low level, there is very

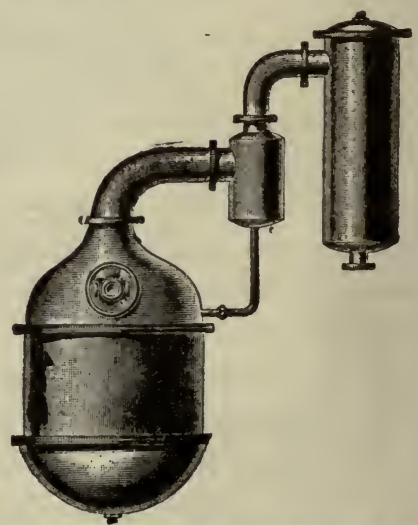

Fig. 29. Vacuum pan with milk trap

Courtesy of Arthur Harris \& Co. 
little danger of milk being carried over into the condenser in quantities sufficient to be of any consequence. Under these conditions the installation of a special milk trap between the pan and the condenser for the purpose of collecting the escaping milk spray and carrying it back to the pan is, therefore, an unnecessary expense.

If the pan is small in comparison to the amount of milk to be condensed, and if it is forced beyond its intended capacity so that the milk boils up high, there usually is considerable loss of milk, as indicated by the foaminess and milky color of the exhaust of the vacuum pump. In such cases the mechanical loss' of an average size batch may amount to several hundred pounds of milk. In order to not lose this milk, a milk trap or catch-all may be installed between the pan and the condenser. The vapors laden with the milk spray enter the trap near the top. The spray drops to the bottom of the trap, while the vapors are drawn over into the condenser, where they are condensed as usual. This trap may be constructed of sufficient size so as to serve as a reservoir to collect all the milk that is carried over, and at the conclusion of the process the contents of the trap are drawn from the bottom and are condensed with the next batch; or the bottom of the trap may be connected with the pan so that the milk thus carried over flows back into the pan automatically. In this case a small trap only is necessary.

It should be understood that the milk trap is only a remedy and not a preventive. Where the capacity of the pan is in proportion to the amount of milk to be condensed, as it should be, and where the pan is operated properly, the trap is unnecessary. The trap is an additional piece of apparatus to be kept clean. Unless it is so constructed that access can be had to all parts of its interior and unless it really is kept clean at all times, it may become a serious source of contamination.

The Vacuum Pump.-The vacuum pump is, strictly speaking, not a part of the vacuum pan, but its intimate connection with the pan makes it

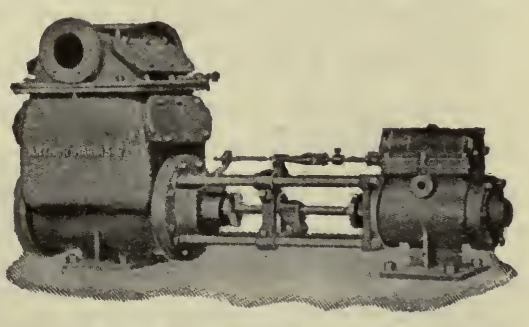

Fig. 30. Wet-vacuum pump Courtesy of Arthur Harris \& Co. 
necessary to briefly consider it at this point. The suction end of the vacuum pump is connected with the condenser. The vacuum pump exhausts the pan, forming a partial vacuum. There are principally two types of vacuum pumps used in the milk condensery, the dry-vacuum pump and the wetvacuum pump. The dry-vacuum pump is used in the factories with the dry-vacuum system, i. e., where the cooling water and the condensation water escape to the sewer direct and without passing through the vacuum pump, as is the case with the surface condenser and the barometric condenser. The wet-vacuum pumps are used with the wet-vacuum system, where the cooling water and the condensation water pass through the cylinder of the pump. The dry-vacuum pumps have the advantage of permitting the operation of the machine at a higher piston speed than the wet-vacuum pumps in which the water must be displaced at the end of each stroke. The cylinders of the dry-vacuum pump are cooled by water jackets. The initial cost of the dry-vacuum pumps, however, is greater than that of the wet-vacuum pumps.

The efficiency of the vacuum apparatus depends very largely on the vacuum pump. Rapid evaporation at a relatively low temperature necessitates the maintenance of a high vacuum. The type, material, construction, workmanship, installation and operation of the vacuum pump should be such as to insure the maximum efficiency.

The pump should be placed on a good foundation and as near the vacuum pan as practicable in order that the full benefit of the vacuum may be realized. The suction pipe and all connections must be tight. The suction pipe must be of the size directed by the manufacturer, as short as possible and with few and easy bends. The grade of the suction pipe should be uniform in order to avoid air pockets.

The water should be turned into the condenser before the vacuum pump is started. The pump should not run at a higher speed than is necessary to secure the required vacuum. Excessive speed means high steam consumption and heavy wear and tear on the pump. The amount of water supplied to the condenser should be regulated to suit the requirements. Ordinarily, and with a vacuum of twenty-five to twenty-six inches, the 
temperature of the condenser discharge should be about 110 degrees F. A lower temperature would cause excessive and uneconomic use of water unless the available water has a temperature lower than is the case in the average American condensery (50 to $60^{\circ} \mathrm{F}$.). The basin on the vacuum cylinder should be kept filled with water to prevent admission of air to the cylinder through the stuffing box, and the spray pipe, jet, or spray plate in the condenser should be inspected often to make sure that the perforations are not clogged. The stuffing box of the cylinder should be well packed with a good quality of packing and the steam cylinder well oiled. Start the pump slowly. Belt-driven

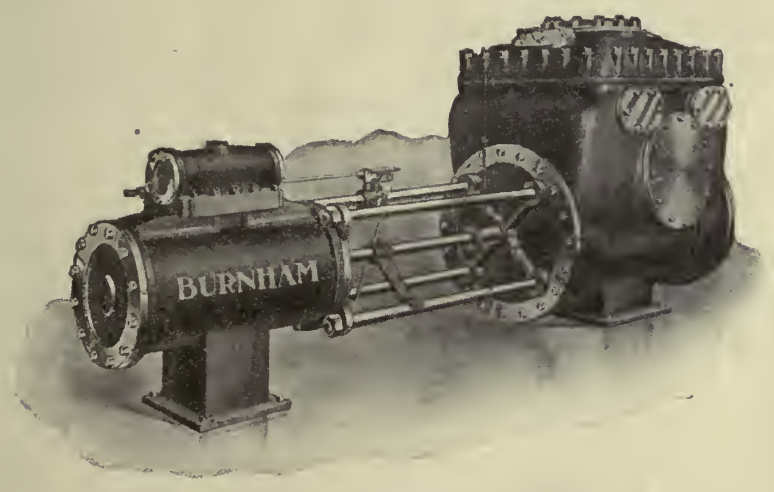

Fig. 31. Wet-vacuum pump

Courtesy of Union Steam Pump Co.

pumps, especially those equipped with a fly-wheel, insure greater uniformity of speed than direct-acting, steam-driven pumps. Steam-driven pumps should be furnished with a high grade governor. The vacuum pump should have a capacity proportionate to the size of the vacuum pan, amount of heating surface, steam pressure and temperature of condensing water.

\section{Science and Practice of Evaporating in Vacuo.}

Purpose of Condensing in Vacuo.- The important advantages gained by evaporating milk under reduced pressure, or in vacuo, are : economy of evaporation, rapidity of evaporation, low temperature and large capacity of apparatus. All of these features are essential in the successful condensing of milk. 
Rapid evaporation cannot take place until the milk is brought to the boiling point and is kept there until evaporation is completed. Under atmospheric pressure and at the sea level, the boiling point of water is 212 degrees $\vec{F}$., the boiling point of milk is very slightly higher, about 214 degrees $F$. Evaporation of milk under atmospheric pressure in an open kettle, however, is a relatively slow process, requiring a long time and large apparatus. Furthermore, exposure of the milk to 212 to 214 degrees F. long enough to complete evaporation would render the product unsuitable for market. The properties of some of its ingredients are altered, the product would assume a dark color and a marked cooked flavor as the result of the effect of heat. All of these objections are minimized and partly avoided by lowering the boiling point of milk. These objections, however, do not apply to evaporation under atmospheric pressure by film treatment, as is the case with the Continuous Concentrator described in Chapter XIV.

Relation of Pressure to Boiling Point.---The temperature at which milk boils depends on the pressure to which it is exposed. 
The table below shows the boiling point of water at pressures ranging from atmospheric pressure at the sea level (14.72 pounds per square inch) to a complete vacuum.

Boiling Points of Water at Different Vacua. ${ }^{1}$

\begin{tabular}{|c|c|c|c|c|}
\hline $\begin{array}{l}\text { Absolute pres- } \\
\text { sure per } \\
\text { square inch }\end{array}$ & $\begin{array}{l}\text { Vacuuminches } \\
\text { of mercury } \\
\text { column }\end{array}$ & $\begin{array}{l}\text { Vacuum milli- } \\
\text { meters } \\
\text { of mercury } \\
\text { column }\end{array}$ & $\begin{array}{l}\text { Temperatures } \\
\text { of boiling } \\
\text { point of } \\
\text { water, F. }\end{array}$ & $\begin{array}{l}\text { Temperatures } \\
\text { of bolling } \\
\text { point of } \\
\text { water, C. }\end{array}$ \\
\hline 14.720 & 0.00 & 00 & 212.00 & 100.00 \\
\hline 14.010 & 1.42 & 36 & 209.55 & 98.5 \\
\hline 13.015 & 3.45 & 88 & 205.87 & 96.8 \\
\hline 12.015 & 5.49 & 139 & 201.96 & 94.3 \\
\hline 11.020 & 7.52 & 191 & 197.75 & 91.9 \\
\hline 10.020 & 9.56 & 243 & 193.22 & 89.5 \\
\hline 9.020 & 11.60 & 295 & 188.27 & 86.75 \\
\hline 8.024 & 13.63 & 346 & 182.86 & 83.7 \\
\hline 7.024 & 15.67 & 398 & 176.85 & 80.5 \\
\hline 6.024 & 17.70 & 450 & 170.06 & 76.8 \\
\hline 5.029 & 19.74 & 502 & 162.28 & 72.5 \\
\hline 4.029 & 21.78 & 553 & 153.01 & 67.2 \\
\hline 3.034 & 23.81 & 605 & 141.52 & 60.8 \\
\hline 2.034 & 25.85 & 657 & 126.15 & 52.3 \\
\hline 1.040 & 27.88 & 708 & 101.83 & 38.7 \\
\hline .980 & 28.00 & 712 & 100.00 & 37.8 \\
\hline .735 & 28.50 & 724 & 90.00 & 32.2 \\
\hline .544 & 28.89 & 734 & 80.00 & 26.7 \\
\hline .402 & 29.18 & 741 & 70.00 & 21.1 \\
\hline .294 & 29.40 & 747 & 60.00 & 15.6 \\
\hline .216 & 29.56 & 751 & 50.00 & 10.0 \\
\hline .162 & 29.67 & 754 & 40.00 & 4.4 \\
\hline .127 & 29.74 & 756 & 32.00 & \\
\hline
\end{tabular}

1 By courtesy of the Buffalo Foundry \& Machine Company. 
The pressure or, correctly speaking, the vacuum, is expressed in terms of inches of mercury which the atmospheric pressure sustains. The mercury column is not a direct measure of the pressure, but it shows the difference between the atmospheric r,ressure and the absolute pressure in the vacuum chamber. The atmospheric pressure at the sea level is 14.7 pounds per square inch. It sustains a mercury column in an absolute vacuum of 30 inches at 62 degrees $F$., and of 29.922 inches at 32 degrees $F$. The absolute vacuum may be calculated by multiplying the atinospheric pressure by the factor 2.04. In case there is only a partial vacuum the mercury column sustained is lowered to the extent of the absolute pressure in the vacuum pan. The absolute pressure may be calculated as follows:

Example: The actual racuum in the pan is 25 inches at the sea level. What is the absolute pressure?

$\frac{14.7 \times(30-25)}{30}=2.45$ pounds of absolute pressure per sq. inch.

Relation of Altitude to Atmospheric Pressure.-At altitudes higher than the sea level, the atmosplieric pressure is reduced and the mercury column is lowered, though the absolute pressure in the vacuum pan may be the same. Therefore, in factories located at high altitudes the mercury column will show fewer inches of vacuum at a given temperature and with a given absolute pressure.

The following table shows the barometric reading in inches of mercury column and the atmospheric pressure in pounds per square inch at different altitudes: 
Barometric Reading Corresponding with Different Altitudes. ${ }^{1}$

\begin{tabular}{c|c|c|c|c|c}
\hline $\begin{array}{c}\text { Barometric } \\
\text { reading in } \\
\text { inches of } \\
\text { mercury }\end{array}$ & $\begin{array}{c}\text { Atmospheric } \\
\text { pressure in } \\
\text { pounds per } \\
\text { square inch }\end{array}$ & $\begin{array}{c}\text { Altitude } \\
\text { above sea } \\
\text { level in feet }\end{array}$ & $\begin{array}{c}\text { Barometric } \\
\text { reading in } \\
\text { inches of } \\
\text { mercury }\end{array}$ & $\begin{array}{c}\text { Atmospheric } \\
\text { pressure in } \\
\text { pounds per } \\
\text { square inch }\end{array}$ & $\begin{array}{c}\text { Altitude } \\
\text { above sea } \\
\text { level } \\
\text { in feet }\end{array}$ \\
\cline { 2 - 6 } 30.0 & 14.72 & 0 & 23.5 & 11.54 & 6412 \\
29.7 & 14.60 & 264 & 23.0 & 11.30 & 6977 \\
29.5 & 14.47 & 441 & 22.5 & $11: 05$ & 7554 \\
29.2 & 14.35 & 710 & 22.0 & 10.80 & 8144 \\
29.0 & 14.23 & 890 & 21.5 & 10.56 & $874 ;$ \\
28.7 & 14.11 & 1163 & 21.0 & 10.31 & 9366 \\
28.5 & 13.98 & 1347 & 20.0 & 9.81 & 10648 \\
28.2 & 13.86 & 1625 & 19.0 & 9.32 & 11994 \\
28.0 & 13.74 & 1812 & 18.0 & 8.82 & 13413 \\
27.5 & 13.50 & 2285 & 17.0 & 8.33 & 14914 \\
27.0 & 13.26 & 2767 & 16.0 & 7.84 & 16506 \\
26.5 & 13.02 & 3257 & 15.0 & 7.35 & 18201 \\
26.0 & 12.77 & 3758 & 14.0 & 6.86 & 19996 \\
25.5 & 12.53 & 4268 & 13.0 & 6.37 & 21891 \\
25.0 & 12.27 & 4787 & 12.0 & 5.88 & 23886 \\
24.5 & 12.03 & 5318 & 11.0 & 5.39 & 25981 \\
24.0 & 11.78 & 5859 & & & \\
\hline
\end{tabular}

1 By courtesy of the Buffalo Foundry \& Machine Company. 
In the following table may be found the altitudes of various cities in the United States:

\section{Altitude in Feet of Various Cities in the United States.}

By Courtesy of United States Department of Agriculture.

Akron, Ohio .......... 940

Albany, N. Y. ......... 22

Atlanta, Ga. ............1032

Baltimore, Md. ........ 92

Birmingham, Ala. ......600

Boston, Mass. ......... 16

Buffalo, N. Y. ........ 583

Burlington, Vt. ........ 112

Butte, Mont. ...........5555

Charleston, S. C. ...... 12

Chattanooga, Tenn......6 672

Chester, Pa. ......... 22

Chicago, Ill. . ........ 590

Cincinnati, Ohio ....... 490

Cleveland, Ohio ........ 582

Dayton, Ohio ......... 740

Denver, Colo. ...........5183

Dallas, Tex. .......... 430

Des Moines, Iowa ...... 805

Detroit, Mich. ........ 588

Duluth, Minn. ......... 609

Houston, Tex. ........ 46

Indianapolis, Ind. ..... 708

Ithaca, N. Y. .......... 411

Kansas City, Mo. ...... 750

Knoxville, Tenn. ...... 890

L.exington, $\mathrm{Ky} . \ldots \ldots \ldots .955$

Little Rock, Ark. ...... 264
Los Angeles, Cal. . . . . . . 267

Louisville, Tenn. ....... 453

Memphis, Tenn........ 256

Milwankee, Wis. ....... 593

Minneapolis, Minn. ..... 812

New Haven, Conn. ...... 10

New Orleans, La. ....... 6

New York City ......... 54

Oklahoma City, Okla. .... 1197

Omaha, Neb. ...........1016

Philadelphia, Pa....... 42

Phoenix, Ariz. .........1082

Pittsburgh, Pa. ........ 743

Providence, R. I. ....... 11

Richmond, Va........ 51

Rochester, N. Y. ...... 510

St. Louis, Mo. ........ 455

Salt Lake City, Utah ...4238

San Francisco, Cal. ..... 15

Santa Fe, N. M. ......6952

Seattle, Wash. ......... 10

South Bend, Ind. ....... 717

Spokane, Wash. ..........1908

Tampa, Fla. .......... 15

Washington, D. C. .... 25

Wichita, Kan. ........1294

Vicksburg, Miss. ...... 196 
According to $\mathrm{Kent}^{1}$ the relation of altitude to atmospheric pressure per square inch is as follows:

\section{Altitude}

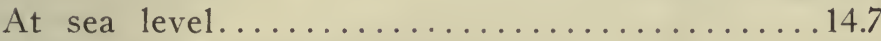

$\frac{1}{4}$ mile above sea level.................... 14.02

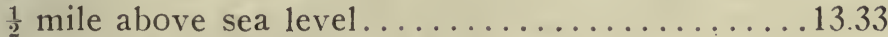

$\frac{3}{4}$ mile above sea level.................. 12.66

1 mile above sea level...................12.02

$1 \frac{1}{1}$ miles above sea level................... 11.42

$1 \frac{1}{2}$ miles above sea level................. 10.88

2 miles above sea level................. 9.80

"For a rough approximation we may assume that the pressure decreases one-half pound per square inch for every 1,000 feet of ascent."

The absolute pressure in the pan of a factory located at Omaha; Neb., with an altitude of 1,016 feet above sea level, and condensing in an actual vacuum of twenty-five inches, would then be as follows:

Atmospheric pressure $=14.7-.5=14.2$ pounds per square inch.

Absolute vacuum $=14.2 \times 2.04=28.97$ inches.

Absolute pressure $=\frac{14.2 \times(28.97-25)}{28.97}=1.95$ pounds per square inch.

Relation of Steam Pressure in Jacket and Coils, Water in Condenser, Temperature in Pan and Vacuum, to Rapidity of Evaporation.-The temperature of the vapors in the vacuum pan depends directly upon the pressure or vacuum under which they are generated. The more nearly complete the vacuum and, therefore, the lower the pressure, the lower is the temperature, and, other conditions being the same, the more rapid the evaporation. The pressure in turn is governed by the capacity of the vacuum pump, the tightness of the joints, the steam pressure in jacket and coils and the amount and temperature of the water in the condenser.

'Mechanical Engineer's Pocket-Book, p. 581. 
With a low capacity vacuum pump, or a pump running irregularly, or too slow, or too fast, and with leaky joints, the vacuum will always be low, and the pressure and temperature relatively high. Under these conditions the pan is difficult to operate and evaporation is slow.

With the above conditions under control and properly adjusted and with a given area of heating surface and arrangements of it for proper circulation of the milk, the temperature and the rapidity of evaporation depend on the steam pressure in the jacket and coils and on the amount and temperature of the water used in the condenser.

Twenty-five pounds of steam pressure in the jacket and coils has been found to be about the maximum that can safely be used. With this steam pressure the milk coming in direct contact with the heating surface is exposed to about 267 degrees $F$. and there is a tendency for some of it to bake or burn on, which is undesirable. The walls of the jacket and coils are also subjected to considerable strain, since they are surrounded by an almost complete vacuum. Then again, if the pan has the proper amount of heating surface the capacity of the condenser and the water supply are in most cases insufficient to take care of and condense the vapors arising from the boiling milk in the pan, when the steam pressure in jacket and coils approaches or exceeds twentyfive pounds. Most condenseries operate their pans with five to fifteen pounds of steam pressure in jacket and coils. In the operation of some pans not more than ahout five pounds steam pressure can be used economically in jacket and coils, because the use of more steam causes the steam to blow through and out of the coils.

Aside from the principle of construction the capacity of the condenser used in milk condenseries is very largely dependent on the water supply. Whenever the condenser is forced beyond its capacity, by using excessive steam in jacket and coils, the vacuum drops, the temperature rises and the process of evaporation is retarded.

The higher the vacuum the more rapid the evaporation. A rise in the steam pressure in the jacket and coils increases the 
rapidity of evaporation only as long as enough water passes through the condenser to maintain a high vacuum. As soon as the steam pressure in the jacket and coils reaches the point where the water in the condenser fails to promptly reduce the vapors, the vacuum drops, the temperature in the pan rises and evaporation is checked.

The condensing of milk requires immense quantities of water; experience has shown that it takes from one to three gallons of water to condense one pound of fresh milk, the exact amount depending on the construction of the condenser and the temperature of the water. The water supply is one of the weakest links in most condenseries, so that economy of water is one of the important factors to be considered. The steam pressure in the jacket and coils should, therefore, be so regulated as to make it possible to maintain the maximum vacuum consistent with reasonably economic use of water. With a vacuum of twenty-five inches the temperature in the pan is about 135 degrees $F$., the temperature varying somewhat with the altitude of the factory. In some condenseries the temperature of the pan is kept at 150 degrees $\mathrm{F}$. This practice may economize the water a trifle better, but the rapidity of evaporation is considerably lower.

Condensing at temperatures lower than 130 degrees F., without reducing the steam pressure in the jacket and coils, increases the rapidity of evaporation, but taxes the water supply beyond the reach of most condenseries. So much water has to be used in the condenser that it is not used economically, as is shown by the relatively low temperature of the water discharging from the condenser. The temperature of the condenser discharge bears a direct relation to the temperature of the vapors in the pan. Observations made in various factories and under different conditions by Hunziker and others showed that the condenser discharge was anywhere from 5 to 25 degrees $F$. lower in temperature than the vapors in the pan, the difference averaging about 15 degrees $\mathrm{F}$.

The smaller the difference in temperature between the condenser discharge and the vapors in the pan, the more economic is the use of the water and vice versa. It is not advisable under 
average conditions to so operate the pan that the temperature of the condenser discharge drops below 110 degrees $F$., because of the wasteful use of water under such conditions.

The condensing of one pound of milk requires about one pound of steam and ten to twenty-five pounds of water. The number of heat units used for condensing in vacuum is practically the same as that required by èvaporating in open pans. In order to use the steam economically the pan should be so operated as to make possible its complete condensation by the time it leaves the jacket and coils. Whenever so much steam is used that it blows through and out of the jacket and coils without being condensed, there is great waste of fuel. For further details on this point see "Description of the Vacuum Pan."

Starting the Pan.-Before drawing the milk into the pan, the pan should be thoroughly rinsed with water, then steamed until the temperature rises to about 180 degrees $F$. or above. Then the manhole cover is put in place, all the air valves are closed, water is turned into the condenser and the vacuum pump is started. When the vacuum gauge shows over twenty inches of vacuum, the pan is ready for the milk.

Operating the Pan.-The valve of the milk pipe leading to the pan is now partly opened. The milk enters the pan automatically as the result of the reduced pressure in the pan. When the milk covers the jacket, steam is gradually turned into the jacket. As each coil becomes submerged in milk, the coils are charged with steam. At no time should steam be turned on the jacket and coils when they are not completely covered with milk, as such action would cause the milk to stick to and burn on the heating surface, the milk would assume a burnt flavor, it would become permeated with black specks and the evaporation would be retarded. On the start, but a few pounds of steam pressure should be used in the jacket and coils, to avoid burning, owing to the presence in the milk of considerable air. As the milk becomes more concentrated and settles down to uniform boiling, the steam pressure may be gradually increased until it reaches the maximum. The maximum pressure permissible must be governed by the amount of heating surface, the capacity of the vacuum pump and the temperature and amount of water available for 
use in the condenser. Under average conditions about fifteen pounds of steam pressure may be safely used.

During the early stages of the process, when the milk is of low density, the evaporative duty is high, probably about twentyfive to thirty-five pounds per square foot of heating surface with ten pounds of steam pressure. This gradualiy decreases and is lowest toward the end of the process.

When enough milk is in the pan to completely cover the jacket and coils, the milk intake should be reduced and regulated in accordance with the rate of evaporation. The milk is drawn into the pan continuously, but only as fast as it evaporates. It should be kept as much as possible at a constant level, and this level is preferably as low as is consistent with complete covering of the upper most coil.

In order to secure maximum rapidity of evaporation, the vacuum pump should run at the proper speed and its operation should be uniform, a uniform vacuum and temperature should be maintained and the milk should be prevented from rising to an abnormally high level in the pan.

Prevention of Accidents.-The operator should pay strict attention to the pan in order to avoid loss of milk due to accidents. He should watch the water supply and govern its use accordingly. If the water supply becomes exhausted, air is liable to be drawn into the pan through the condenser. This will cause the milk to drop suddenly and then rise in a body, threatening to escape throngh the condenser. Whenever air in considerable quantities is allowed to enter the pan while in operation; be it as the result of lack of water, or through any other cause, or when the vacuum pump is allowed to stop and live steam is turned into the milk in the pan. as is the case when the milk is superheated, the escape of milk may be avoided by immediately shutting the steam inlet to the jacket and coils, by closing the milk intake and by slightly opening the blow-down valve whenever the milk rises dangerously high. By skillful manipulation of the blow-down valve until the milk again settles down to uniform boiling, loss can be avoided and the process can be continued in the normal way. 
By the time all the milk is in the pan, condensation is nearly completed, and from ten to twenty minutes further boiling usually gives the milk the desired density. Toward the end of the process the steam pressure in jacket and coils should be reduced to about five pounds or less. When the milk approaches the desired density, it is comparatively heavy and viscous and boils less vigorously. It therefore is more directly exposed to the heating surface. In the case of excessive steam pressure, its quality is jeopardized. If the batch is small so that the level of the milk drops below some of the coils, steam to the exposed coils should be turned off entirely.

\section{Chapter VI.}

\section{STRIKING OR FINISHING THE BATCH.}

Definition.-When the boiling milk in the vacuum pan approaches the desired degree of concentration, the batch is "struck." The term "striking" is applied to the operation of sampling the condensed milk and testing the sample for density. This term very probably referred, originally, to the meaning of "striking the batch right," that is, stopping the process at the proper time, or when the milk is neither ton thick nor too thin. It then expressed the result of the operation, while now it is used to mean the operation itself.

Ratio of Concentration.-Sweetened condensed milk intended for canned goods has a specific gravity of 1.28 to 1.30 . This density is reached usually when the ratio of concentration is about $2.5: 1$, i. e., 2.5 parts of fresh milk are condensed to one part of condensed milk, assuming that about sixteen pounds of sucrose have been added to every one hundred pounds of fresh milk.

Occasionally the ratio of concentration is based on the proportion of water evaporated, in which case it is obviously much higher than when based on the amount of milk required to make one pound of condensed milk, because the added cane sugar takes the place of its own weight of water, and thereby acts as a diluent of the condensed milk. Thus let us assume that 16 
pounds of cane sugar are added to every 100 pounds of fresh milk and that it takes 250 pounds of fresh milk to make 100 pounds of sweetened condensed milk, 100 pounds of sweetened condensed milk, therefore, contain $16 \times 2.5=40$ pounds of cane sugar. Using the sugar-free finished product as the basis for calculation, then, the ratio of concentration would be:

$$
\frac{250}{(100-40)}=4.17 \text { to } 1 \text {. }
$$

Instead of giving the ratio of concentration, this basis of calculation determines the ratio of evaporation only. The results are, therefore, erroneous and misleading. It does not materially matter whether the diluent in the condensed milk is water or cane sugar, or both; the really important factor is the per cent milk solids in the condensed milk as compared with the per cent solids in the original fresh milk, and this relation is solely determined by the amount of fluid milk required to make one pound of condensed milk, or by the true and actual ratio of concentration. If it takes $2 \frac{1}{2}$ pounds of fresh milk for every pound of condensed milk, then the ratio of concentration is obviously 2.5 to 1 and not 4.17 to 1 .

Methods.- To know just when the proper degree of concentration has been reached is difficult and requires experience. It is here where the processor can easily make or lose his wages. There are various indications reminding the observant processor that the milk in the retort is nearly "done," viz., time consumed for condensing, time elapsed since all the milk has been "drawn up," amount of condensed milk left in the pan and, most of all, the appearance and behavior of the boiling milk itself. Milk that has been sufficiently condensed assumes a glossy, glistening linstre, it boils over from the periphery towards the center, forming a small nucleus or puddle of foam in the center of the pan. An experienced and observant operator knows within a few minutes when the milk is condensed enough. This does not mean, however, that he should wait until the last minute before he "strikes" the batch, for even the most skillful and experienced 
processors are easily deceived by the mere appearance of the condensed milk through the sight glass.

The degree of concentration may be more accurately determined by taking a sample from the pan and testing it by various methods, such as by weighing a definite quantity of condensed milk on a sensitive scale, by the use of a resistance apparatus, or viscosimeter, or by the use of a specially constructed hydrometer. Of these the Beaumé hydrometer has been found the most suitable to use under average factory conditions.

Mechanical devices and instruments, such as above enumerated can be depended upon, when all conditions influencing the specific gravity of the product, such as chemical composition and temperature, are under control. Their successful use renders careful and accurate standardization of the milk for butterfat, solids not fat, and sucrose indispensable. Without standardization of the component ingredients of milk the result of the use of these devices may prove erroneous and misleading.

The operation of these devices must also be simple and rapid, for when the boiling and rapidly evaporating milk in the pan approaches the proper density, quick action is essential. One minute over or under condensing may cause the milk to be either too thick or too thin for the market, and may necessitate the "rerunning" of the entire batch.

In the absence of a satisfactory instrument for rapid determination of the concentration, and particularly in the absence of a carefully standardized product, the experienced eye and the good judgment of the processor are all essential. The following factory methods have been found applicable and reasonably reliable.

Determination by Appearance to the Eye.-Draw a sample from the pan into a tin dipper, lower the dipper into a pail of ice water or snow. Stir the condensed milk with a metal-back thermometer until the condensed milk is cooled to 70 degrees $F$. Note the thickness of it. Or, finish the batch at a constant temperature, say 120 degrees F. Draw a sample into a tin cup and note the thickness by examining the milk when pouring from 
a teaspoon. The transparency of the milk when thus held against the light and the manner in which the milk piles up in the cup furnish a practical index to its density. The last method is preferable becatuse of its greater rapidity. For best results the use of a Beaumé hydrometer, especially constructed for sweetened condensed milk, graduated to from 30 to 37 degrees B. and with subdivisions of one-tenth degrees is recommended.

Use of Beaumé Hydrometer.-Beginners and inexperienced operators do well to take numerous samples from the batch in the operating pan and to start sampling early, so as to avoid over-condensing. No definite figure at which the Beaumé hydrometer should be read can be stated that would show the proper density under all conditions. The Beaumé reading of sweetened condensed milk of the proper concentration varies with such factors as per cent of fat, per cent of sucrose and per cent solids, ratio of concentration and temperature of the condensed milk when the reading is taken. However, for general guidance. it may be stated that condensed milk of a concentration of $2.5: 1$, made from fresh milk of average richness and containing sucrose at the ratio of sixteen pounds of sugar per one hundred pounds of fresh milk, will show a Beaumé reading of about 33.5 degrees $F$. at 60 degrees $F$., or about 32 degrees B. at 120 degrees F. Sweetened condensed skim milk containing approximately 40 per cent sucrose will show a Beaumé reading at 60 degrees $\mathrm{F}$. of about 37 degrees B., or about 35.5 degrees B. at 120 degrees $F$. If it is intended to use more sugar $(44 \%)$ and to limit the per cent milk solids to 28 per cent, whole milk is condensed until the Beaumé hydrometer at 130 degrees F. shows $31 \frac{1}{2}$ degrees B. Skimmed sweetened condensed milk containing 28 per cent milk solids and 42 per cent

Fig. 32. Beaumé hydrometer for sweetened condensed milk

Courtegy

C. J. Tagliabue Mfg. Co. sucrose tests about $34 \frac{3}{4}$ degrees B. at 130 degrees F. 
Correction of Hydrometer Reading for Temperature.-The Beaumé hydrometers used in American condenseries are graduated to give correct readings at 60 degrees $F$. If the readings are to be correct, or if it is desirable to convert them into specific gravity, the condensed milk should have a temperature of 60 degrees $\mathrm{F}$. Where this is not convenient, the observation may be made at any temperature convenient and the reading corrected as follows:

When the temperature is above 60 degrees F. multiply the difference between the observed temperature and 60 degrees $F$. by the factor .025 and add the product to the observed reading of the Beaumé hydrometer. When the temperature of the observed reading is below 60 degrees $F$. the corresponding product is deducted.

Example: Beaumé reading at 120 degrees $\mathrm{F}$. is 31.2. Corrected reading is $31.2+[.025 \times(120-60)]=32.7$.

The specific gravity may be calculated when the Beaumé reading is known, by using the following formula:

Specific gravity $=\frac{144.3}{144.3-\text { B. }} ; B .=$ Beaumé reading.

Example: Beaumé reading, at 60 degrees $\mathrm{F}$. is 33.1 .

$$
\text { Specific grvity }=\frac{144.3}{144.3-33.1}=1.2976
$$

In the following table are assembled figures showing the specific gravity of sweetened condensed milk of different Beaumé degrees, varying from 28 degrees $B$. to 37.8 degrees $B$. 
SWEetened Condensed Milk-Striking

101

Specific Gravity of Sweetened Condensed Milk of Different Beaumé Degrees.

\begin{tabular}{|c|c|c|c|c|}
\hline $\begin{array}{c}\text { Beaume at } \\
60 \text { degrees F. }\end{array}$ & $\begin{array}{l}\text { Specific } \\
\text { Gravity }\end{array}$ & $\begin{array}{c}\text { Beaumé at } \\
60 \text { degrees F. }\end{array}$ & $\begin{array}{c}\text { Specific } \\
\text { Gravity } \\
\end{array}$ & \\
\hline 28.0 & - 1.2407 & 33.0 & 1.2965 & \\
\hline .2 & 1.2428 & .2 & 1.2988 & \\
\hline .4 & - 1.2449 & .4 & 1.3011 & \\
\hline .6 & 1.2471 & .6 & $\therefore \quad 1.3034$ & \\
\hline .8 & 1.2493 & .8 & $\quad 1.3058$ & \\
\hline 29.0 & 1.2515 & 34.0 & 1.3082 & \\
\hline .2 & 1.2536 & .2 & 1.3106 & \\
\hline .4 & 1.2558 & .4 & 1.3130 & - \\
\hline .6 & 1.2580 & 6 & 1.3154 & \\
\hline .8 & 1.2602 & .8 & 1.3178 & $\cdot$ \\
\hline 30.0 & 1.2624 & 35.0 & 1.3202 & \\
\hline .2 & 1.2646 & .2 & 1.3226 & \\
\hline .4 & 1.2668 & $=.4$ & 1.3250 & \\
\hline .6 & 1.2690 & .6 & 1.3274 & \\
\hline .8 & 1.2713 & .8 & 1.3299 & \\
\hline 31.0 & 1.2736 & 36.0 & -1.3324 & \\
\hline .2 & 1.2758 & .2 & 1.3 .348 & \\
\hline .4 & 1.2780 & .4 & 1.3372 & \\
\hline $.6=$ & 1.2803 & .6 & 1.3397 & \\
\hline .8 & 1.2826 & $\cdot 8$ & 1.3422 & \\
\hline 32.0 & 1.2849 & 37.0 & 1.3447 & \\
\hline .2 & 1.2872 & .2 & 1.3472 & \\
\hline .4 & 1.2895 & .4 & 1.3497 & \\
\hline .6 & 1.2918 & .6 & 1.3522 & \\
\hline .8 & 1.2941 & .8 & 1.3548 & \\
\hline
\end{tabular}


Sampling of Batch.-The samples can be drawn from the pan by operating the two valves at the bottom explained under "Description of Vacuum Pan." While the milk is condensing, the partial vacuum in the pan makes impossible the drawing off of the sample by simply opening the outlet. Instead of causing the milk to come out, air would rush in with violent force and would cause the milk in the pan to be thrown over into the con-

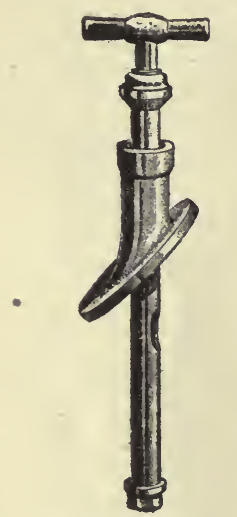

Fig. 33. A convenient device for sampling the condensed milk in the pan

Courtesy of Arthur Harris \& Co.

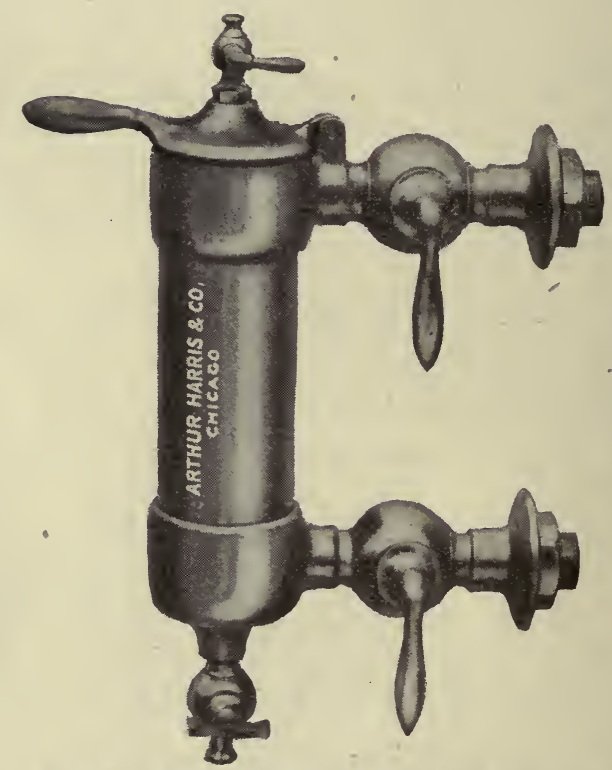

Fig. 34. A convenient device for sampling condensed milk in the pan Courtesy of Arthur Harris \& Co.

denser, besides dangerously jolting the machinery. For this reason the outlet is equipped with two valves, both of which are closed during the condensing process. For taking samples, open the upper valve. This allows the condensed milk to run into the nipple between the two valves. Now close the upper valve and open the lower one. The milk will run out freely. The first sample should be rejected, as it may contain water caught in the nipple.

For greater convenience and increased rapidity of sampling, especially constructed sample cups or striking cups, attached to the side of the body of the pan may be used. These striking cups 
are now made of such size that the hydrometer can be operated in them, rendering the use of a separate hydrometer cylinder unnecessary. The latest invention for facilitating the sampling and striking is the automatic milk striker designed by Mojonnier Bros. Co., Chicago. This ingenious contrivance consists of a motor-driven piston pump. The suction tube carrying the piston extends from the dome of the pan into the boiling milk. This tube projects at its upper end through the wall of the dome and overflows into a hydrometer cylinder. This cylinder carries at its upper end a chamber permitting unhindered motion of the hydrometer and the end of this chamber which faces the operator is equipped with a sight glass and a light. In the cylinder reposes a Beaumé hydrometer. Whenever the operator desires to know the density of the condensed milk in the pan, he starts the motor. The pump immediately fills the cylinder and the hydrometer shows the density or Beaumé reading.

Drawing off the Condensed Milk.-As soon as the evaporation is completed, the steam is shut off from the jacket and coils, the water valve is closed, the vacuum pump stopped and the vacuum broken by opening the "blow-down" valve. The manhole cover is then removed and the vacuum pump started again in order to remove the hot air over the milk. The milk is drawn into 40 -quart cans or into tanks or cooling vats. The condensed milk should be drawn from the pan as rapidly as possible to prevent its superheating while in the pan. In some factories a wire mesh or cloth strainer is attached to the outlet of the pan, so that the condensed milk is strained before it runs into the cans. This practice is unnecessary and objectionable, as it tends to retard the removal of the milk from the pan.

\section{COOLING.}

The sweetened condensed milk, as it comes from the vacuum pan, has a temperature of about $115^{\circ} \mathrm{F}$. to $130^{\circ} \mathrm{F}$. If it were allowed to cool naturally, or on its own accord, i. e., if no effort were made to cool it promptly, it would superheat and this would cause it to become thick and cheesy in a short time. It is, therefore, essential that it be cooled at once. Formerly this was done by drawing the milk from the pan into 40 quart cans, setting these filled cans in tanks with ice water and stirring the condensed milk with a stick. 
This was a very crude method, it involved much hard work and time, and the quality of the product was poor. It was soon found that the imperfect hand stirring caused excessive sugar crystallization, which made the milk sandy. The sudden chilling and irregular stirring of a saturated sugar solution like sweetened condensed milk are favorable to the formation of sugar crystals. Where the stirring is imperfect and irregular, all the milk is not kept in sufficient motion to insure uniform and gradual cooling. The milk next to the side of the cans is chilled too abruptly, favoring the formation of crystals. Vigorous stirring in itself is conducive of sugar crystallization.

Later the hand stirring was completely superseded by mechanical stirring, paddles closely scraping the sides of the cans being used. Instead of setting the paddles in motion, they are stationary and the cans revolve. The principle is similar to that of the vertical ice cream freezer. Heavy iron tanks, with a capacity of twelve to forty-eight 40-quart cans, are used for this purpose. The bottoms of these tanks are equipped with a system of $\operatorname{cog}$ wheels, set in motion by means of a gear at one end of the tank. The wheels have a diameter large enough to carry one can each. The cans are set on these wheels, the paddles are inserted and fastened to cross-bars and the power started. The cans should be heavily constructed to stand rough usage, without suffering indentations. Cans with irregular, depressed, or bulged sides cause the paddles to do poor work. Such cans should be slipped over a wooden horn, or other contrivance, and the indentations hammered out with a mallet. The paddles are held stationary by cross-bars and are forced against the periphery of the cans by springs. Attention should also be paid to the pivots on which the $\operatorname{cog}$ wheels rest. If they are warped, the wheels do not run true, so that it is not possible for the paddles tc scrape the sides of the cans properly.

The sweetened condensed milk should be cooled gradually. Sudden chilling should be avoided. This is best accomplished by warming the water in the cooling tank to about 90 degrees $F$., before the cans are set in. The cans are then allowed to revolve for fifteen to twenty minutes before any cold water is turned into the tank. After that, cold water is turned in slowly until the temperature of the milk has fallen to abont 70 degrees $F$. The 


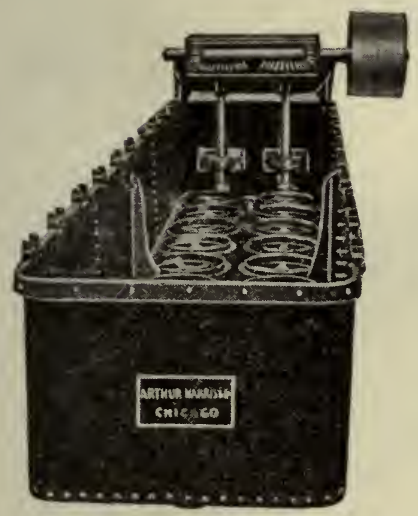

Fig. 35. Cooling tank for sweetened condensed milk Courtesy Arthur Harris \& Co.

entire time of cooling should last about two hours. The cans should revolve slowly, rapid stirring enhances-the precipitation of sugar crystals. In order to scrape the sides of the cans efficiently, when the cans revolve slowly, (about five revolutions per minute) it is advisable to use two paddles in each can, scraping the cans at opposite sides. When the milk is sufficiently cooled the cans are stopped, the paddles lifted out, scraped and removed, and the cans taken out of the tank. This method of cooling sweetened condensed milk is still in vogue in the majority of condenseries. It is obviously crude, laborious and time-consuming.

In some factories the condensed milk is transferred from the pan direct into large tanks and is sub-. sequently cooled by pumping it with a high pressure pump through a series of coils submerged in cold water. This method is labor and time-saving and the objectionable features of agitation are aroided. On the other hand, there is danger of too rapid chilling, which tends toward excessive sugar crystallization and the production of rough, sandy and settled milk.

Within recent years the use of circular tanks

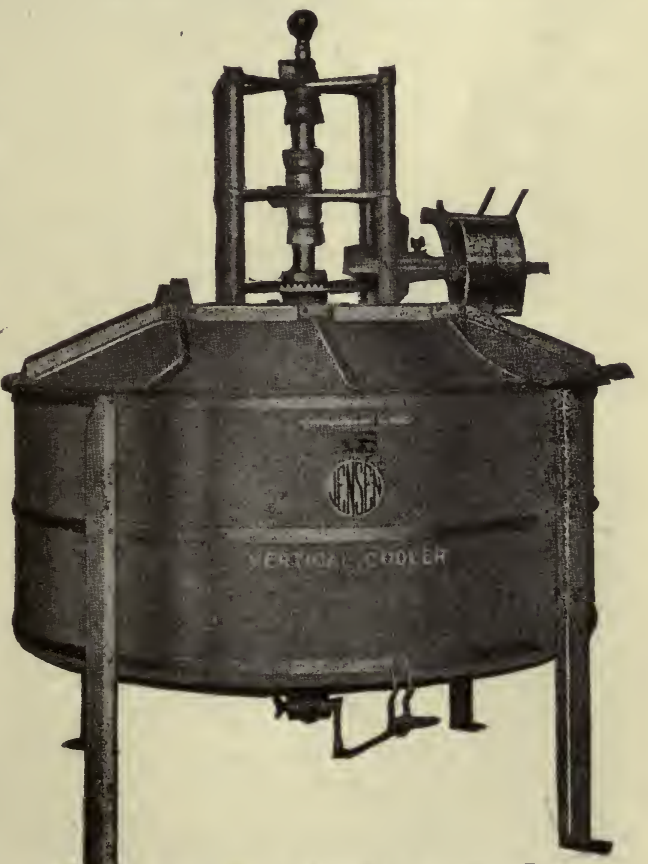

Fig. 36. Vertical coll cooler

Courtesy of Jensen Creamery Machinery Co. 
with jacket and vertically suspended, revolving coil, has been adopted in numerous factories with most satisfactory results, and this method of cooling this viscous product promises to assist in solving the cooling problem. Rectangular vats with horizontal coils, which also have been tried for this purpose, however, are less desirable, as they tend to cause the condensed milk to foam excessively. This foaming is caused by the fact that the horizontal coil revolves into the milk, beating air into it. In the case of the circular tank, the vertical suspended coil when revolving moves upward, out of the milk, thus avoiding incorporation of air and excessive foaming. The circular vat with the suspended vertical coil has the further advantage that the condensed milk does not come in contact with bearings and glands, these parts being entirely detached from the vat.

A still more recent method of cooling sweetened condensed milk consists of a combination of the use of the submerged coil and subsequent slow agitation. The equipment for this method consists of a vertical or horizontal tank, equipped with a submerged coil. This coil should have a diameter of about $1 \frac{1}{2}$ inches and a length of from 600 to 700 -feet, the length needed depending on the temperature to which it is desired to cool the condensed milk and the temperature of the cooling water. The coil is usually of regular, so-called sanitary pipe (copper pipe tinned on inside) or it may be black iron pipe preferably sandblasted on inside.

The submerged coil connects at its intake with a high pressure pump and at its outlet with one or more large enameled steel holding tanks (capacity 11sually 5,000 gallons). Each of these holding tanks is equipped with a powerful motor-driven, vertically slanting agitator, also enameled. The agitator revolves at a speed of about 12 R. P. M.

In the operation of this method of cooling, the hot sweetened condensed milk is drawn from the vacuum pan, preferably by gravity, into a standardizing vat mounted on scales. When all the condensed milk of one and the same batch has been transferred to this tank it is accurately weighed. The weight of the original fluid milk is then divided by the weight of the condensed milk. This yields the exact ratio of concentration. If 
the concentration is in excess of that desired, the product is standardized by the addition of the accurately calculated necessary amount of distilled water.

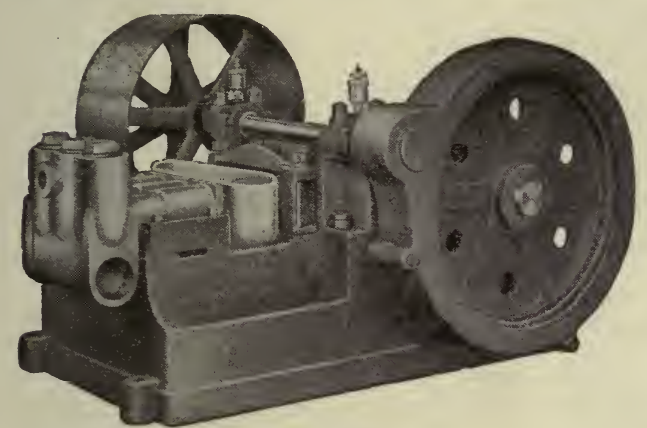

Fig. 37.

High pressure pump for sweetened condensed milk

From this standardizing tank the hot c onde n s ed milk is forced by means of the high pressure $\mathrm{pum} \mathrm{p}$ through the submerged coil in the cooling tank. The water supply to this tank is automatically regulated by a thermostat, so as to cool the condensed milk to the desired tempera-

ture (usually 65 to 75 degrees $\mathrm{F}$.).

The condensed milk remains in the submerged coil about six minutes, i. e., six minutes elapse from the time it enters the coil till it reaches the exit. From here the now cool condensed milk flows to the holding tank where it is slowly agitated for several hours.

Experience has demonstrated that this method of cooling and agitating sweetened condensed milk is very effective in preventing the production of sandy and settled milk. It appears that the great viscosity of the sweetened condensed milk causes the milk, in its passage through the coil, to be subjected to the least damaging agitation. The center of the column of the milk moves forward slightly faster than the portion nearest the walls of the coil. This results in a rolling or curling motion, producing sufficient and yet not excessive agitation.

The subseqent slow agitation of the cooled condensed milk in the holding tanks for a considerable period of time, further assists in the preservation of a smooth product. It enhances the formation of very small crystals at the expense of larger crystals, thereby minimizing the tendency toward coarseness and insuring a uniformly smooth product that is not prone to yield a sugar sediment. 


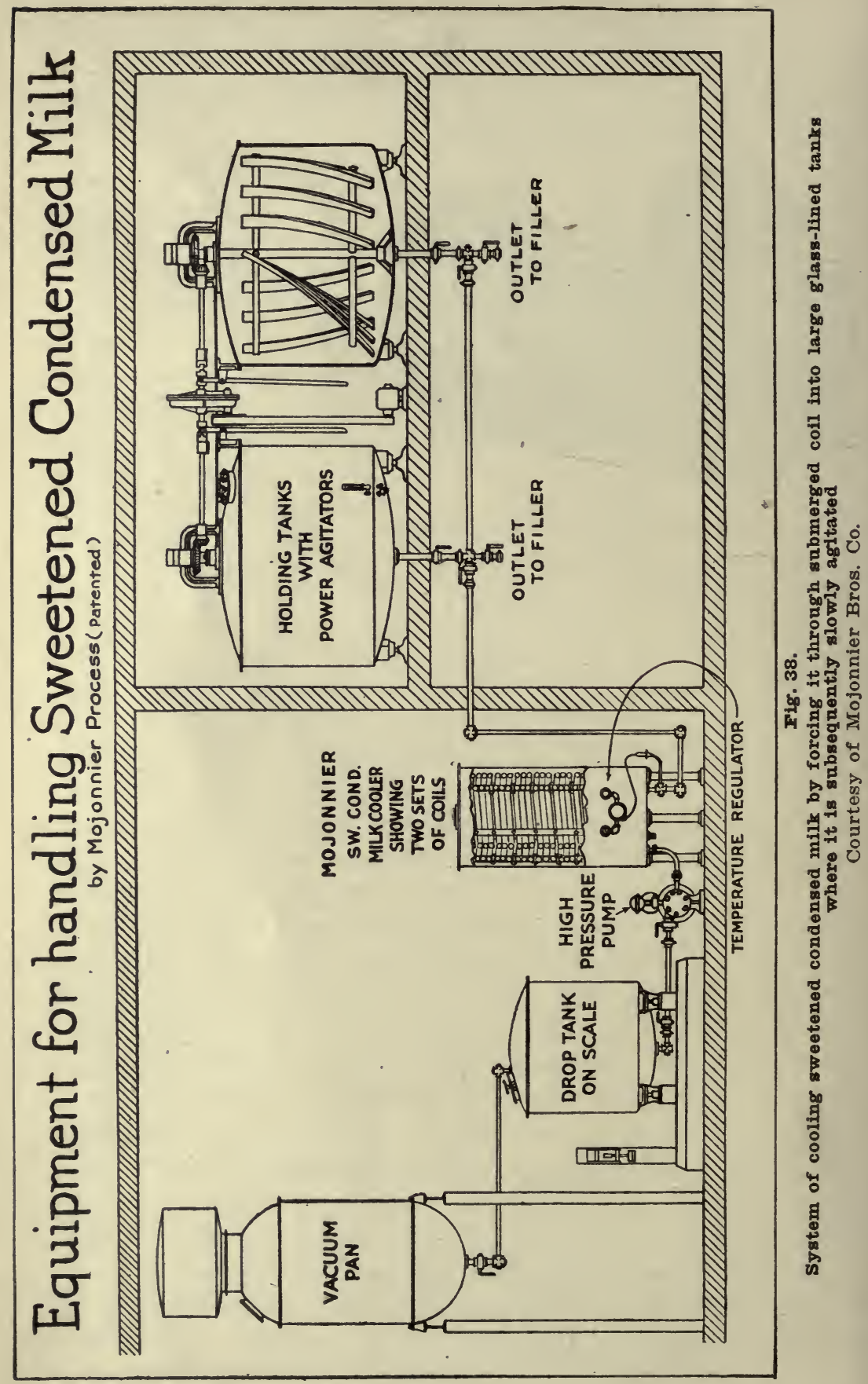


The pressure required to pump the sweetened condensed milk through the cooling coil and up into the holding tanks varies from about 800 to 1200 pounds, and the pump used for this purpose must be strong enough to develop a pressure of at least 2,000 pounds, which may be required to start the flow through the coil after the milk has stood idle for some time and has become chilled.

This method, in addition to its labor-saving feature, and to its efficiency in avoiding sandy and settled condensed milk, has the further important advantage, that the product is protected against contamination with bacteria, mold, and other impurities from the air, etc., the product being under seal until it reaches the filling machine, or until it is packed into barrels in the case of bulk goods. This method, therefore, should be particularly adapted for efforts to produce an article that does not develop "buttons" with age. See also Chapter on "Defects of Sweetened Condensed Milk."

The chief criticism that may be raised against this method lies in the question of cleaning the cooling coil. From the standpoint of bacterial contamination it may safely be said, however, that the danger of such contamination is remote. After the product of one day's make has passed through the coil, the coil is sealed by valves and there is no reason to doubt that the condensed milk remaining in the coil till next day's operation, is not just as well protected against all contaminating influences, as if it were sealed in tin cans. It is advisable, however, to completely empty and rinse and steam the submerged coil at regular intervals of say once per week. This is especially desirable in the case of a copper coil, in order to guard against an excessive accumulation of copper salts which would tend to lend the product a metallic flavor and to jeopardize its wholesomeness. In the case of a black iron coil, sand-blasted on inside, the effect of the action of the acid and sugar of the milk is negligible. However, when not filled with condensed milk the iron coil should be kept filled with clean water to prevent excessive rusting. 


\section{Chapter VII.}

\section{FILLING.}

The sweetened condensed milk is put on the market in barrels and in hermetically sealed tin cans.

In Barrels.-Barrels, similar to glucose barrels, are generally used. They hold from three hundred to seven hundred pounds of condensed milk. New barrels should be used for this purpose. Barrels paraffined, or coated with sodium silicate, on the inside are most satisfactory, as they are more apt to be free from mold spores. Old glucose barrels are dangerous to use, as they often contain decaying remnants of glucose, which cause the condensed milk to ferment. The new barrels are steamed out and drained thoroughly. The filling is facilitated by the use of a large galvanized iron funnel with a discharge one and one-half inches in diameter, or an ordinary milk pail with a nipple one and onehalf inches in diameter in the bottom of the pail. When filled, a double layer of cheese cloth is placed over the bunghole, and the bung is driven in level with the staves. The barrel goods are sold to bakeries and candy factories.

In Cans. - The canned goods are intended for the retail market. The cans used hold from eight ounces to one gallon of condensed milk. Most makes of tin cans for sweetened condensed milk have a s mall opening, three-eighths to threefourths inch in diameter through which they are filled. The cans known and sold under the trade name "sanitary can" are filled before the top

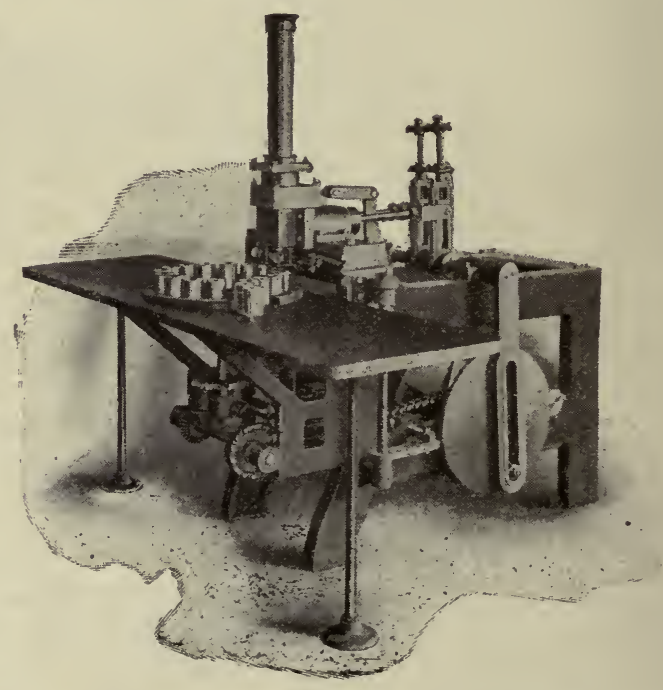

Fig. 39.

Filling machine for sweetened condensed milk Courtesy of Schaefer Mfg. Co. 
is crimped on. Sweetened condensed milk is of a semi-fluid, viscous and sticky consistency. The successful and rapid filling of the cans without spilling the milk over the top of the can is, therefore, somewhat difficult. If done by hand the work is very slow. For this reason many ingenious machines have been devised which are more or less efficient in "cutting off" the milk without "slobbering." The filling machines now in use vary from the primitive hand filler, in which the condensed milk is "ground out" by the turning of

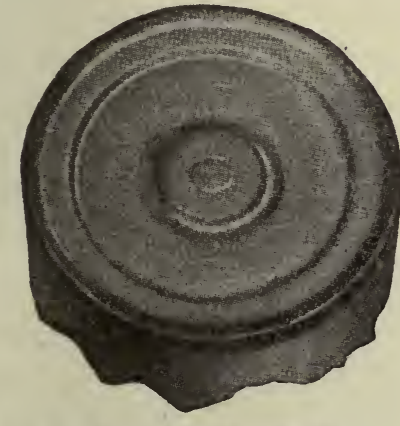

Fig. 40. The solder seal

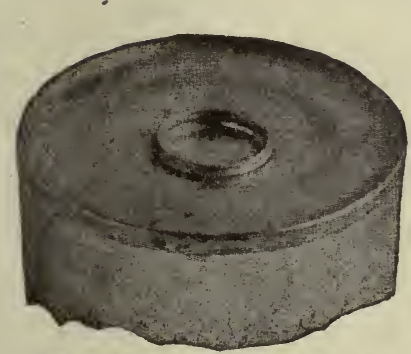

Fig. 42. The Gebee seal

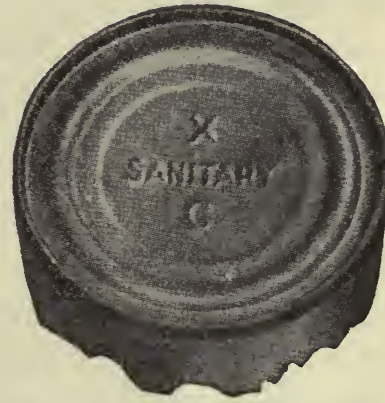

Fig. 41. The Sanitary can

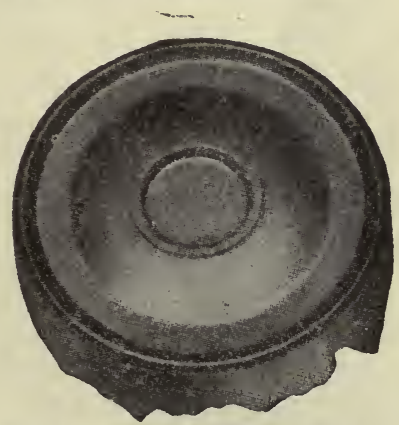

Fig. 43. The McDonald seal

a crank by hand, to the most perfect forms of automatic filling machines. In these filling machines, all parts coming in contact with the condensed milk are constructed of brass. They usually are equipped with a reservoir, receiving tank, or hopper, which has an automatic feed, usually a floating device attached to a valve, which regulates the inflow according to the discharge. The discharge is adjustable to fill any size can with a remarkable degree of accuracy, except gallons which are usually filled by 
hand. Machines of this type will fill from twenty-five thousand to thirty thousand cans per day (ten hours).

These machines are of complex construction and must receive proper care. It is best to clean them thoroughly after each day's work. But, since their inlet and discharge are closed hermetically, the complete washing may he done once per week only, without seriously disturbing their efficiency or impairing the product. For thorough cleaning, the filler should be dissected, removing all detachable parts, such as valves, pistons, tubes, etc. When freed from all remnants of condensed milk, the parts should be scalded, dried and replaced in the machine. In order to guard against all possible contamination by remnants of wash water, it is advisable to reject the first few cans of milk of the next filling. When not in use, the filling machine should be covered with clean cloth, or oil cloth, to protect it from dust and flies, etc.

As soon as the cans are filled, they should be "capped." If allowed to stand open, dust, dirt and flies, or other insects are prone to reach their interior, and the prolonged exposure of the condensed milk to the air and light causes the surface to crust over and to develop a tallowy flavor.

\section{SEALING.}

Kinds of Seals.-The seal must be air-tight and firm enough to prevent its breaking during the rough treatment to which the cans are exposed in transportation. There are several methods of sealing the cans, depending largely on the construction of the can. Most of the cans used are sealed with solder. There is a groove, around the opening, the periphery of the cap fits into this groove and the latter is filled with solder. In the case of cans which are sealed without solder, the cap or the entire end of the can is crimped onto the can so as to make a hermetical seal. The McDonald seal with the friction cap, the Gebee seal with the burr cap, and the Sanitary can seal with the top of the can crimped on after filling, are the chief types of solderless seals. In the case of the McDonald seal, a tightly fitting cap with a wide flange is pressed into the opening. The "capped" can passes under a series of steel rollers pressing the flange firmly against the top of 
the can. This seal is very simple, but is not very strong and not hermetically tight. In the case of the Gebee seal, a rim projects around the opening of the can. After the cap is inserted, it is crimped over this rim by means of a series of revolving dies. This seal is reasonably strong but not hermetically tight. The Sanitary can is entirely open at one end when filled. The cover or end is crimped around the periphery of the body of the can by means of revolving dies. This seal is reasonably strong and usually hermetically tight. The chief advantages of the seals without solder lie in the saving of labor and the reduction of the cost due to the omission of solder.

\section{Soldering Devices and Machinery.} -The sealing of all solderless seals is done by specially constructed sealing machines.

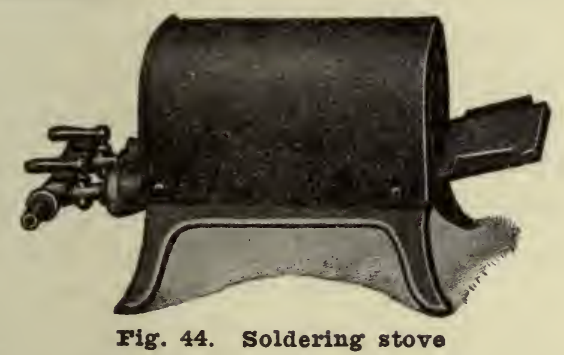

Courtesy of Arthur Harris \& Co.

For seals with solder there are several machines on the market but much of this work is as yet done by hand. For this, different types of soldering coppers are in use and the copper tips are heated in soldering stoves or pots. Some soldering coppers have hollow circular tips with a diameter equal to that of the cap used. The hollow tip is telescoped by a rod which holds the

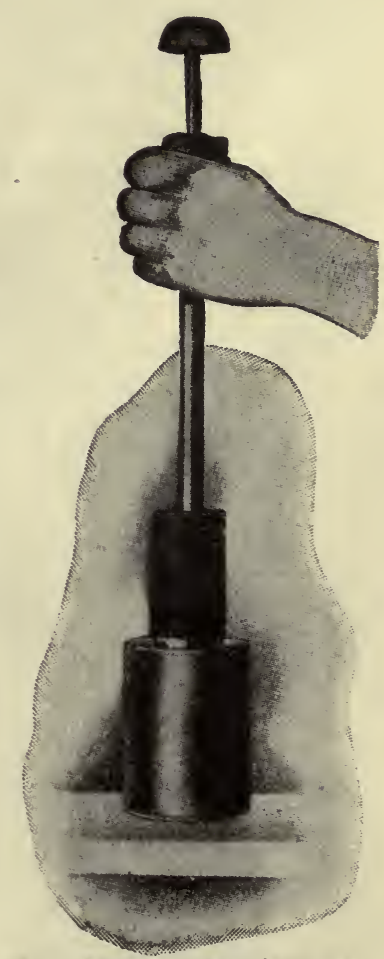

Fig. 45. A convenient device for soldering by hand cap in place and the periphery of the tip fits into the groove of the opening of the can, where it melts the solder. A rapid, neat and leakless seal can be made with this instrument.

Ordinary soldering coppers with a blunt point, such as are in 
general use by the tin smith, are not very satisfactory. Unless they are drawn out and filed down into a fine point, their use is not conducive of neat work, progress is comparatively slow and leakers are often numerous. When gas is available the automatic soldering copper may be used to advantage. In this tool the copper tip, which is long and slender is automatically heated by a current of gas passing through the handle and burning at the copper tip. The handle of the device is connected with the gas and air pipes by means of flexible rubber tubing. No time is lost waiting. for the copper to heat and the flame can be so regulated that the temperature of the copper tip is right and uniform. This is important, because perfect work is impossible unless the coppers have the proper temperature.

Machine-soldering is now rapidly replacing hand-soldering. The principle of the older types of soldering machines consisted of revolving discs on which the tin cans were placed. The cap was held in place by a vertical rod pressing on it. The solder was applied by hand, the hot soldering copper was held over the groove in the can while the cans revolved. This method had no particular advantage over the hand soldering. There was little, if any, saving of time and the quality of the work was not much, if any, better.

There are now on the market newer types of soldering machines, most ingeniously constructed and their operation in factories with large outputs economizes labor and time.

Solder.-The solder used for sealing should be of standard composition. In this country, canning establishments are prone to use a very poor quality of solder. It contains from 45 to 55 per cent lead. Lead is a poisonous metal; its use in the canning industry should, therefore, be regulated by law. In Germany, the law requires that solder used in tin cans for food products must not contain over 10 per cent of lead.

Where the sealing is done by hand the solder is most conveniently used in the form of thin bars or wire. The wire is usually bought already cut up in segments, each segment furnishing solder enough to seal one can. In the newer types of soldering machines the solder wire is automatically fed from spools. 
The smaller the opening of the can, the less solder is necessary to complete the seal. An opening smaller than three-eighths of an inch in diameter, however, cannot conveniently be used, owing to the difficulty of filling the can with this viscous product. The essential points of satisfactory sealing are: no "leakers," neat work, rapid work, small amount of solder. Aside from the size of the opening of the can, the amount of solder used depends on the experience of the sealer. Beginners usually make an uneven seal, waste much solder, and have many "leakers." This is largely due to their ignorance of the proper soldering temperature of the copper. An experienced sealer will use from two to three pounds of solder per thousand tin cans with moderatesized openings. He will seal from fifteen hundred to twenty-five hundred cans per day.

Soldering Flux.-.The use of solder requires the application of soldering flux, to prepare the surface of the tin for the solder. The flux always precedes the solder. When the hot solder is applied, some of the flux is bound to sweat through, between cap and can, gaining access to the interior of the can. The common practice of using zinc chloride or other similar acid fluxes, which are highly poisonous, therefore, cannot be too strongly condemned. Their presence in the can may jeopardize the health and life of the consumer, as well as the marketable properties of the product. There are other fluxes which are absolutely harmless, and which, if properly used, give satisfactory results. Dry, powdered resin, or resin dissolved in alcohol or gasoline, are of this class. Ammonium chloride, while used in most tin shops, is not as well suited for this purpose.

Gas Supply.--A plentiful and steady supply of gas is very essential. Where natural gas or gas from a municipal corporation is not available, the factory must rely on its own generator. For the needs of the condensery a gasoline gas plant seems suitable. Gasoline gas is produced by forcing atmospheric air over or through a body of gasoline. The mixture of air and gasoline vapors forms the gasoline gas. The gas generators in use consist chiefly of carburetor, air pump or blower, and regulator. The carburetor usually has a series of cells, connected with one another by means of a system of syphon tubes. The 
interior of each cell is partitioned off with heavy cotton wicking This wicking absorbs the gasoline by capillary attraction. The air, passing through the fine meshes of wicking, comes in contact with a large surface of gasoline.

The following are some of the essential points to be observed in the installation and operation of gas generators of this type: Sink the carburetor low enough (three to five feet below the surface of the ground if necessary) to permit the gas pipe to slant from the factory to the carburetor. If the gas pipe is horizontal, or inclined toward the factory, condensation water may collect in the pipe, obstructing the free passage of gas. This causes the gas either not to be available at all, or to reach the stoves in irregular gusts, which is equally unsatisfactory. Where the gas pipe slants toward the carburetor, the condensation water flows back into the carburetor, causing no obstruction. Use gasoline of the best quality only. Cheap grades form a residue and clog the generator. The gasoline is best bought in iron barrels; this prevents unnecessary loss by evaporation, which occurs in wooden barrels, especially in summer. The cells should not be filled more than two-thirds full; too much gasoline reduces the gas-generating capacity of the carburetor. If, during extremely cold weather, the carburetor refuses to generate gas, the injection of a pint of wood alcohol through the blow pipe into the cells, usually remedies the trouble. The gas plant and gasoline storage should be located in a separate building and at a reasonable distance from the main building, in order to minimize danger from fire. 


\title{
PART III
}

\section{MANUFACTURE OF UNSWEETENED CON- DENSED MILK EVAPORATED MILK}

\author{
Chapter VIII.
}

\section{DEFINITION.}

There are three kinds of unsweetened condensed milk on the market, namely, evaporated milk, formerly called evaporated cream, plain condensed bulk milk and concentrated milk.

Evaporated milk is cow's milk condensed in vacuo at the ratio of about two to two and one-half parts of fresh milk to one part of condensed milk. It is of the consistency of thin cream and reaches the market in hermetically sealed cans varying in size from eight ounces to one gallon. Evaporated milk is preserved by sterilization in steam under pressure. When properly made, it will keep indefinitely, but is best when fresh.

\section{QUALITY OF FRESH MILK.}

In the manufacture of evaporated milk the physiological normality and the chemical purity and sweetness of the fresh milk are factors even more important than in the case of sweetened condensed milk. A uniformly satisfactory and marketable product cannot be manufactured, unless the milk is normal and pure in every respect. The reason for this largely lies in the fact, that defects the fresh milk may have, are greatly magnified and intensified by the high sterilizing temperature to which the evaporated milk is subjected. While, from the biological point of view, contaminations of this milk are largely rendered harmless by sterilization, defective fresh milk cannot be made into a marketable product, becausc such milk usually does not survive the process.

It should be understood that any condition or factor that, in the slightest degree, increases the tendency or ability of the 
casein to curdle, tends toward the formation of a hard, unshakable coagulum during sterilization, and makes the manufacture of a marketable product difficult. Abnormal milk of this type may come from cows approaching parturition, or too soon after calving, or milk from cows suffering from disease, generalized or local, or from cows in poor and abnormal physical condition, which may be brought about by poor care, over-feeding, feeding the wrong kinds of feed, or feed in poor condition, exposure to abnormally hot weather and flies, or any other condition which disturbs the physiological functions of the animal and thereby affects the physical, chemical, and physiological properties of the milk; or it may be due to improper care of the milk, causing it to be excessively contaminated with germ life, or to be relatively high in acid. All such milk renders the quality of the finished product uncertain and may result in heavy loss.

In view of these facts it is obvious that the greatest care should be exercised on the receiving platform, inspecting every can of milk, using the most reliable means, as recommended in Chapter III on "Control of Quality," to detect suspicious milk, and rejecting all milk that fails to reach the sanitary standard adopted by the factory.

Standardizing.-In order to insure in the finished product the percentage relation of fat to solids not fat that meets with the Federal Standard or with any other standard desired, the fluid milk should be accurately standardized. For this purpose each batch of fluid milk must be correctly tested for per cent fat and per cent solids not fat. On the basis of these tests, the amount of cream or skim milk which it is necessary to remove or to add, as the case may be, can then be readily calculated. For detailed directions on standardizing the milk to any desired standard see Chapter XXIX on "Standardization."

\section{HEATING THE MILK.}

The equipment for heating the milk should be such as to enable the factory to heat the milk with the least possible delay so as to avoid the development of acid, or to make possible the prompt cooling of the milk upon its arrival to a temperature at which bacterial development is checked. In the manufacture of evaporated milk, the batches of condensed milk in the vacuum 
pan must be relatively small. This milk foams more in the pan than the heavier sweetened condensed milk. This factor reduces therefore, the capacity of the pan. If the milk is not cooled upon arrival, but is transferred immediately to the hot wells, it is advisable to use numerous small wells, rather than but one or a few large ones. These small wells fill rapidly and the milk can be heated without delay. This system makes it possible to render the bacteria inactive and harmless practically as soon as the milk arrives, minimizing the danger of acid formation. ${ }^{1}$

Steam may be saved if the milk is forewarmed by running it through coils inclosed in a chamber of exhaust steam, but the coils increase the labor and difficulty of cleaning. It is best to heat the milk to as near the boiling point as possible and hold it there for five to ten minutes, provided that the capacity of the factory warrants this delay. In this heating the casein of the milk is somewhat changed. There occurs partial, though invisible, precipitation, and the higher the temperature to which the milk is heated, the more pronounced is this change. This change is desirable, because the casein thereby surrenders, to a limited extent, its power and tendency to form a firm curd in the sterilizer. See also Chapter XI on "Sterilizing."

\section{CONDENSING.}

The same apparatus, the vacuum pan and pump, is used for condensing the milk, and the process of condensing is principally the same, as in the case of sweetened condensed milk. The fresh milk is condensed at the ratio of two to two and onehalf parts of fresh milk to one part of condensed milk. In some factories it is customary to superheat the milk in the pan before it is drawn off, i. e., the steam to the jacket and coils is shut off, the water valve is closed, the vacuum pump is stopped and "Iive" steam is passed into the condensed milk. When the vacuum has dropped to about six to eight inches, and the temperature has risen to 180 to 200 degrees $\mathrm{F}$. the superheating is stopped, the steam is turned off, the vacuum pump is started again, and the condensing is completed. The superheating is frequently also done after the evaporated milk has been drawn

${ }^{1}$ See also Cooling Milk and Standardization. 
from the pan. In this case, the process of evaporation is usually carried slightly beyond the desired density of the finished product, the evaporated milk is drawn from the pan into an open vat or kettle where steam is turned direct into the milk until the superheating is completed, which is indicated by its greater consistency and the slightly flaky condition of the curd. Then water is added to the superheated evaporated milk to bring the product back to the desired density.

The chief purpose of superheating is to partly precipitate the curd. This minimizes the danger of the formation of too hard a curd in subsequent sterilization. It also lends the body of the milk the appearance of greater consistency, gives it a more creamy character and assists in the prevention of subsequent fat separation. The superheating of evaporated milk is not essential for the production of quality and marketable properties, but it is looked upon by many manufacturers as a safeguard against such defects as curdiness and fat separation. It is not improbable that its advantages are much overestimated, and in most factories the superheating process in entirely omitted.

The condensing of milk for the purpose of manufacturing evaporated milk may be done also in the absence of the vacuum pan, by the use of the "Continuous Concentrator," the construction and operation of which are described in Chapter XIV on "Condensing by Continuous Process."

\section{STRIKING.}

The striking, or sampling and testing for density, of evapor. ated milk, is more easily accomplished than that of the sweetened condensed milk. When this product has nearly reached the proper density, it is not viscous and syrupy, containing no cane sugar. It resembles in consistency rich milk or thin cream and has a specific gravity of 1.05 to 1.075 at 15.5 degrees C. or 60 degrees $\mathrm{F}$.

Samples are drawn from the vacuum pan as described under sweetened condensed milk and the density can be readily determined by means of a hydrometer. Beaumé hydrometers, registering from 5 to 15 degrees B., are generally used. As it is important that the determinations be accurate, the hydrometer 
should be sensitive and its scale should be subdivided into tenth degrees. The batch should be "struck" at a uniform temperature, say 120 degrees $F$., so as to avoid misleading readings of the hydrometer. A difference of a few tenths degrees Beaumé affects the behavior of the evaporated milk in the sterilizer very appreciably. If the density is too great the product may badly curdle during sterilization. If the density is too low the evaporated milk may be below the legal standard. It is advisable for the operator to use a pail of water of the proper temperature, when he strikes the batch, so that he can adjust the temperature of the milk in the hydrometer jar readily and quickly, and need not depend entirely on the temperature of the milk in the pan which may change several degrees while he is engaged in the operation of striking. The hydrometer jar containing the sample of evaporated milk is set into the pail of hot water of the desired temperature, the hydrometer is inserted in the jar and the reading is taken.

While the Beaumé hydrometers should be used at the temperature for which they are graduated, which is 60 degrees F., they answer all practical purposes at any other temperature: at 120 degrees $\mathrm{F}$. for instance. The chief essential is to take the reading at some uniform and definite temperature and read the Beaumé at that same temperature in the case of every batch. In that way the results are comparable. The operator soon learns that at a given temperature the evaporated milk of proper density shows a certain Beaumé reading. When the reading is higher or lower, the milk has either been condensed too much or not enough. The use of the automatic "striker" described under "Striking Sweetened Condensed Milk," practically solves the control of the temperature of the sample taken.

The same formula, however, cannot be used under all conditions. No rule-of-thumb method of determining the density can therefore be established. Aside from the degree of condensation, the specific gravity of the milk varies with locality, season of year, quality of milk, etc. This means that what is the proper Beaumé reading in one locality, or at one season in the same locality, may be entirely wrong in another locality, or at other seasons in the same locality. If uniformity in the density and behavior of the batches of evaporated milk is to be secured 
throughout the year, the operator must watch the behavior of his milk from day to day and from season to season and he must modify the Beaumé reading in accordance with the changing conditions. This is one of the all important stages of manufacture, where relentless and careful study and watchfulness are indispensable.

In order to make absolutedy sure that the density of the evaporated milk is right, it is advisable to get it just as near right as possible in the pan and then draw the milk from the pan into a standardizing vat, large enough to accommodate the entire batch or several batches. The operator then tests the milk again and this second estimation he can perform more carefully, because he is then relieved of the responsibility of attending to the operation of the vacuum pan. If the evaporated milk happens to be a trifle too heavy he can dilute it with distilled water until the Beaumé reading is just right. See also "Standardization," Chapter XXIX. For maximum uniformity and accuracy ef results of determination with the Beaume hydrometer, or by other means, it is essential that the percentage relation of fat to solids be uniform from batch to batch. This uniformity requires standardization of each batch.

\section{Correction of Beaumé Reading at Temperatures} Other than 60 Degrees F.-At a temperature of 120 degrees $F$. the Beaume reading of the finished batch of standard evaporated milk may vary between about 6 and 8 degrees B., according to season of year and locality. At 60 degrees $F$. the Beaumé reading is approximately 1.88 degrees $B$. higher.

If it is desired to record the Beaumé reading at the correct temperature, i. e., 60 degrees $F$., and Fig. 46. Mfg.Co. 
60 degrees $\mathrm{F}$., multiply the difference between the temperature of the observed reading and 60 by the factor .0313 and add the product to the observed reading.

Example: Beaumé at 120 degrees F. is 6.8 ; what is the reading at 60 degrees $F$.?

Answer: $6.8+(60 \times .0313)=8.68$ degrees $\mathrm{B}$.

The corrected Beaumé reading is 8.68 degrees $B$. When the temperature at which the reading is made is below 60 degrees F., multiply the difference between the temperature of the observed reading and 60 by the factor .0313 and subtract the product from the observed reading.

Calculation of Specific Gravity from Beaumé Reading.-In order to record the density of the evaporated milk in terms of specific gravity, instead of Beaumé degrees, the following formula may be used:

Specific gravity $=\frac{145.5}{145.5-\mathrm{B}} ; \mathrm{B}=$ Beaumé reading at 60 degrees $F$.

Example: Beaumé reading at 60 degrees $\mathrm{F}$. is 8 degrees B. What is the specific gravity?

$$
\text { Specific gravity }=\frac{145.5}{145.5-8}=1.0582
$$

Standardizing Evaporated Milk.-As previously suggested it is advisable to carry the condensing process slightly beyond the concentration desired, so as to enable the operator to readily standardize it to the exact point desired by the addition of a small amount of distilled water.

As soon as condensation is completed the contents of the pan are drawn into a standardizing vat resting on scales. The evaporated milk is accurately weighed; the degree of concentration is calculated by dividing the weight of the original fluid milk by the weight of the evaporated milk, and the amount of water necessary to bring the solids and fat to the exact standard desired is calculated, and added to the evaporated milk. If it is desired to further check these results, or instead of weighing the evaporated milk, it may be tested for fat and solids, and the degree of concentration may be calculated by dividing the per cent of fat or of solids in the evaporated milk by the per cent of fat or of solids, respectively, in the fluid milk. For de- 
tailed directions on calculations of concentration and on exact method for standardizing, the reader is referred to Chapter XXIX on "Standardization."

\section{Chapter IX.}

\section{HOMOGENIZING.}

Purpose.-The object of homogenizing is to avoid the separation of the butterfat in the evaporated milk after manufacture.

The butter fat is present in milk in the form of minute globules. These fat globules are lighter than the rest of the ingredients of the milk. They, therefore, show a strong tendency to rise to the surface and to form a layer of thick cream in the cans. When these cans are subsequently subjected to agitation, as is the case in transportation, this cream churns, forming lumps of butter. This tendency of evaporated milk to separate in storage and churn in transportation is especially noticeable with milk rich in fat and in which the large fat globules predominate. In Jersey and Guernsey localities, it is more difficult, therefore, to manufacture evaporated milk that does not separate, than in Holstein and Ayrshire localities. While separated and churned evaporated milk is perfectly sound and in every way as valuable as a food, as it would be without this separation, it does not sell in this condition. It is rejected on the market.

This tendency toward fat separation can be minimized and frequently entirely prevented by increasing the viscosity of the evaporated milk. This can be accomplished by superheating the milk in the pan or after it leaves the pan, and by prolonging the sterilizing process, raising the heat very slowly or stopping the reel of the sterilizer at certain stages of the process. However, there are conditions when even these precautions do not permanently avoid separation of the fat. In such cases, the proper use of the homogenizer furnishes a reliable means to guard against this difficulty.

Principle of the Homogenizer.-The principle of the homogenizer is to force the milk under high pressure through exceedingly small, microscopic openings. By so doing the fat globules are broken up so finely that they fail to respond to the gravity 
force, they cannct rise to the surface and therefore remain in homogeneous emulsion. The value of the homogenizer lies in removing the fundamental cause of this separation. It reduces the fat globules to such small size that their buoyancy, or gravity force, is not great enough to overcome the resistance of the surrounding liquid.

The earlier theories concerning the action of the homogenizer were that the milk had to pass through openings so minute, that the fat globules, in order to be able to pass through, were crushed, torn and divided into much smaller units, hence their fine state of division in the homogenized milk.

Later study of the principles of homogenization has revealed facts and probabilities which do not bear out the earlier assumptions. Men who have subjected the construction and operation of homogenizers to intensive study claim, that the openings or orifices through which the milk passes in the machines in commercial use when operating at capacity, range in size from about .003 inch to $.01 \mathrm{inch}$. If these findings are correct, then it is obvious that the fat globules and even clusters of fat globules can pass through the homogenizer as entire units and without being broken up, for the average fat globule measures about .0001 inch in diameter.

It is not improbable that the homogenizing action is very similar in its atomizing cause and effect, as that which takes place in the spray-drying process, only the homogenizing action is more intensive because of the smaller size of the openings through which the milk must pass. The atomized spray in the spray-drying process is formed, not in the spray nozzle, but as soon as the pressure is released, or-as soon as the milk escapes from the nozzle.

In the case of the spray-drying process, the atomized spray is discharged into a medium of heated air, while in the homogenizing process, the atomized spray is discharged into a liquid medium, milk.

The degree of fineness of the atoms in either case depends. on the speed with which the liquid passes through the orifice; the higher the speed the finer and more minute the atoms. And the speed of passage in turn depends on the degree of pressure and the size of the orifice. The greater the pressure and the 
finer the opening, the faster the milk travels through the orifice; and in the case of the homogenizer, the finer the division of the fat globules in the homogenized milk

The tendency of fat globules to separate out in homogenized evaporated milk is further reduced by the fact that the homogenizer also alters the physical condition of the casein, making it more viscous and thereby increasing the resistance which the fat globules must overcome in their upward passage.

The exact changes which the casein undergoes are not well understood, but it is not improbable that either the high pressure or the vibration, or both, to which the milk is subjected in the homogenizer, bring about a molecular rearrangement of the casein. Possibly these factors cause the lactic acid which is increased due to the concentration of the evaporated milk, to remove calcium from the casein, leaving a part of the casein as free casein which is a solid, and a part of the casein as casein lactate which is in a colloidal state and which is readily hydrolized.

The fact remains that, when the homogenizing is done under relatively high pressure, or when done in a homogenizer carrying a spring-loaded valve which tends to vibrate or pound the constituents of the milk, the resulting homogenized milk increases in thickness, is more susceptible to the curdling acting of the heat in the sterilizer and is more prone to "feather" or curdle when poured into hot coffee.

The essential features of an efficient and reliable homogenizer are: A high class, high pressure, sanitary milk p u $\mathrm{m} \mathrm{p}, \quad$ a resistance valve or similar homogenizing arrangement made from material which will not wear nor rust, and a means for a c c u r ately adjusting this valve.

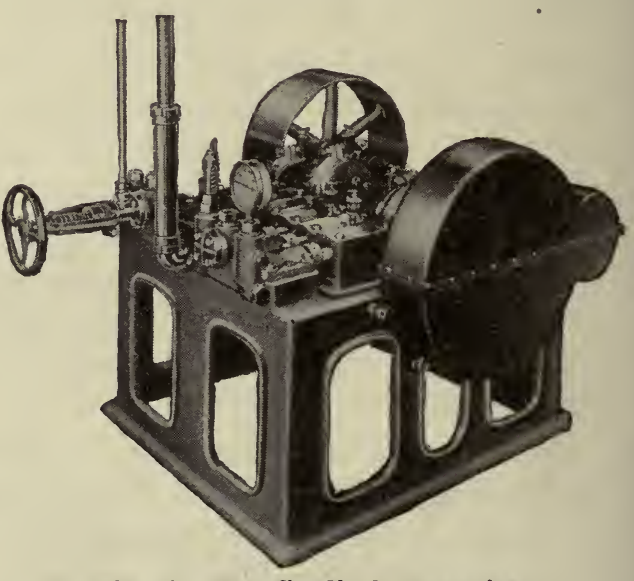

Fig. 47. The Gaulin homogenizer Courtesy of Creamery Package Mfg. Co. 
Kinds of Homogenizers.-There are at this time three makes of homogenizers in use in this country, namely, the "Gaulin" homogenizer, the "Progress" homogenizer and the "Viscolizer."

In the Gaulin homogenizer, the milk is forced, by means of single-acting pumps, against an agate valve which presses against a ground valve seat. The milk has to pass between the ground surfaces of this valve and valve seat.

In the Progress homogenizer the homogenizing principle consists of forcing the milk, by means of single acting pumps, between a series of discs with ground surfaces. The discs lie

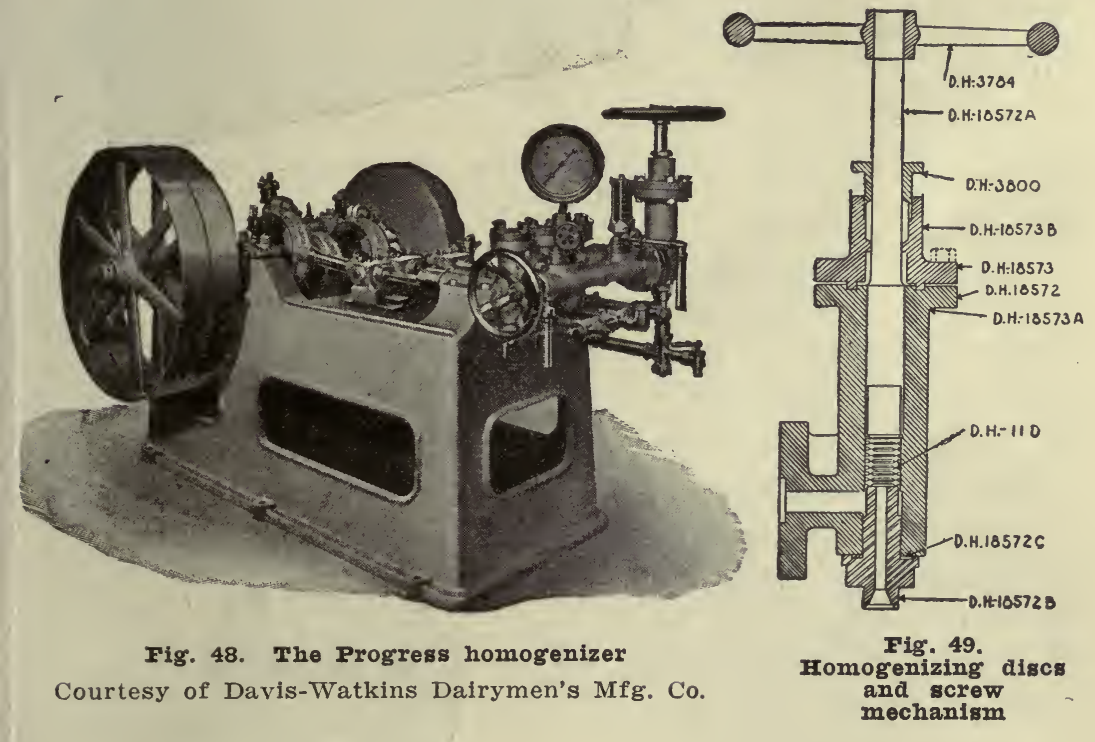

flat one upon the other, they are enclosed in a cylinder and are held in place by a rod running through their center. The discs are pressed against each other by a heavy spiral screw, which regulates the pressure to which the milk is subjected. The milk passes from the center to the periphery of the discs. The discs used in this machine are of two types. One type has very fine irregular grooves. The milk shoots through these grooves against hard shoulders. The other type of discs has smooth surfaces but their area of contact is narrow. The milk passes through these smooth surfaces, 
The Viscolizer.-This homogenizer is equipped with a coneshaped resistance valve of "Viscolite" metal, through which the milk is forced. The conical valve has an accurately fitted guide in the valve seat, for the purpose of lifting squarely from the seat and providing an opening of equal dimensions for the entire circumference. This valve is regulated by a differential screw mechanism in which the travel or advance

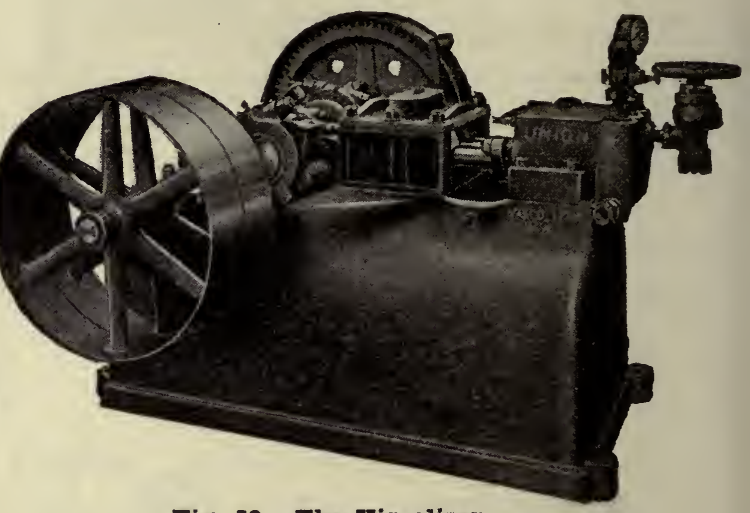

Fig. 50. The Viscolizer Courtesy of John W. Ladd Co. of this screw is reduced 28 times from its normal pitch, making possible a very fine adjustment. One complete turn of the handwheel opens or closes the valve approximately to .001 of an inch. The milk is forced through this valve by a triple pressure pump.

Operation of the Homogenizer.-In order to avoid fat separation it is necessary to subject the milk to enough pressure to reduce the fat globules to at least one-third their original size. If enough pressure is applied to divide the fat globules into much smaller units there is a tendency to also change the properties of the casein to such an ex-

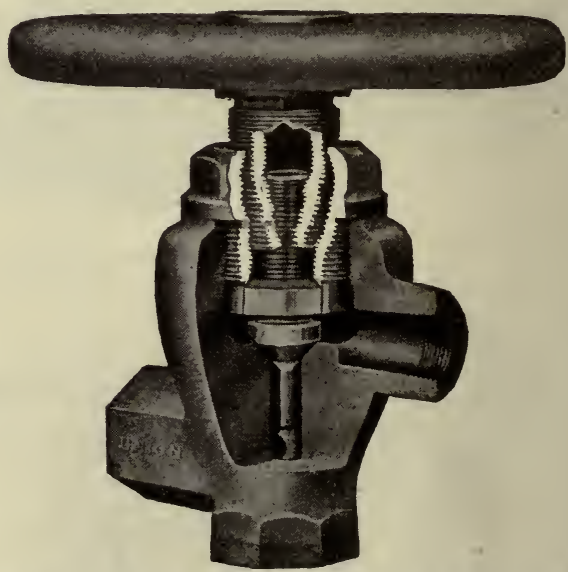

Fig. 51. Atomizing valve and differential screw mechanism of viscolfzer

Courtesy of Union Steam Pump Co. tent as to cause it to give rise to copious precipitation, when the evaporated milk is sterilized, and making the finished product 
curdy and unmarketable. In this case the cure would be more disastrous than the original defect. Great care must, therefore, be exercised, guarding against the use of excessive pressure that would injure the casein. Experiments have shown that a pressure of between one thousand and fifteen hundred pounds per square inch is sufficient to prevent fat separation and is practically harmless as far as its objectionable effect on the casein in the evaporated milk is concerned.

The evaporated milk is run through the homogenizer hot, just as it comes from the vacuum pan or standardizing tank. If the evaporated milk were homogenized cold, the fat globules, instead of being subdivided would unite into butter granules, the milk would churn. The first pailful of milk passing through the machine should be returned to the supply tank, as on the start, the pressure is not uniform and homogenization is incomplete.

The pistons, cylinders, valves and pipes of the homogenizer should be kept in sanitary condition. They are difficult to clean. After homogenizing, the machine should be kept in operation, running water through it, until most of the remnants of evaporated milk are rinsed out; then hot water containing some active alkali should be pumped through; this should be followed by clean hot water and steam. Unless this machine is kept scrupulously clean, it may become a dangerous source of contamination, infecting the evaporated milk with spore forms that are exceedingly resistant and which are liable to pass into the finished product alive, in spite of the sterilizing process, causing the goods to be a complete loss, due to subsequent fermentation.

\section{ChAPTER X.}

\section{COOLING.}

In the cooling of the evaporated milk, no attention need be paid to sugar crystallization. In this class of goods there is plenty of water to keep the milk sugar in ready solution. The evaporated milk can, therefore, be cooled as rapidly as facilities permit. The cooling may be accomplished in similar. ways as are used for cooling fresh milk. From the homogenizer the evaporated milk is run over a surface cooler, or cooling coil. It 
is advisable to cover the coils with a jacket of galvanized iron, tin or copper, so as to avoid undue contamination of the milk from dust, flies, and other undesirable agents. In som? condenseries the hot evaporated milk is forced through double pipes, cold water passing between the inner and outer pipes, or the coils through which the milk passes are submerged in a tank of cold water. The only objection to this system is that the pipes are more difficult to clean than in the case of an open surface cooler. Where this system is used, the pipes should be equipped with sanitary fittings

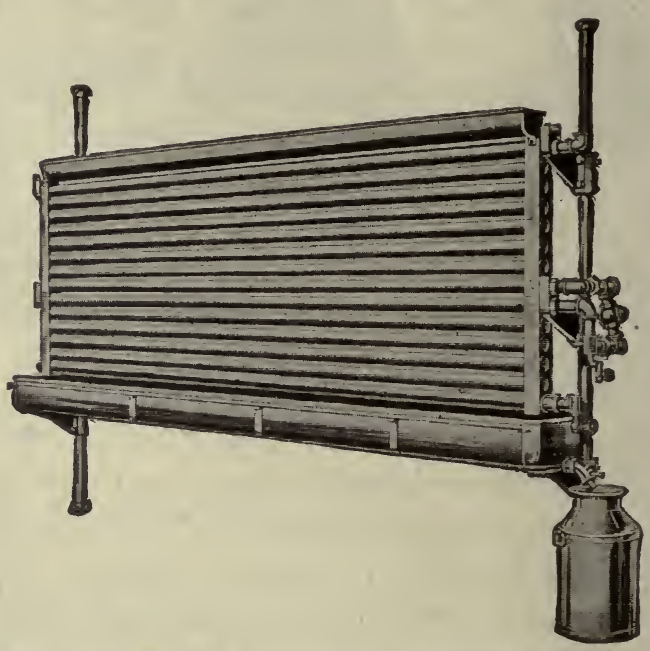

Fig. 52. Surface cooler for evaporated milk Courtesy of Davis-Watkins Dairymen's Mfg. Co. so that they can be readily swabbed out from both ends. In other factories, the evaporated milk is cooled in revolving cans with stationary paddles, similar as described and used for sweetened condensed milk, with the exception that cold water is run into the cooling tank at once. In still other factories the cooling is done in vats or tanks by means of revolving coils which carry the cooling medium. If the evaporated milk is not homogenized, it should be cooled as soon as it leaves the vacuum pan.

Holding Tanks.-The cooling and holding of evaporated milk may be accomplished in the same series of equipment as described and illustrated under cooling of sweetened condensed milk, Fig. 38. The tanks for holding this product are preferably jacketed, so as to make possible the circulation of cold water or brine, in case the evaporated milk must be held for a considerable number of hours in the holding tank. Some of these tanks are equipped with propellers eccentrically located, facilitating 
the agitation of the contents and bringing all parts of the milk in direct contact with the cooling surface.

In factories where these large glass-lined tanks are installed. each successive batch of evaporated milk is transferred, at the conclusion of the process of evaporation and homogenization, to this large holding and cooling tank, where all the batches of the same day's make are conled, mixed and held until the last batch

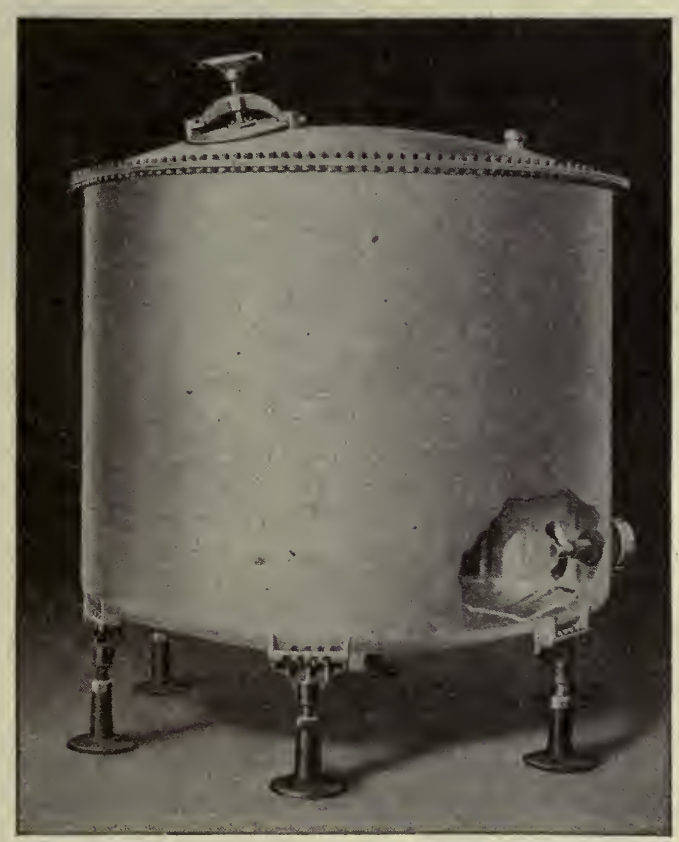

Fig 53. Holding tank for evaporated milk Courtesy of The Pfaudler Co.

is in the tank. The standardization of the evaporated milk may be deferred, until all the batches of one and the same day's make have reached the holding tank and the entire mixture is then standardized to the desired composition by the addition of distilled water, skim milk, or cream, according to needs. The evaporated milk in this tank is usually cooled to and held at 40 to 45 degrees F. until next morning, when the filling into tins commences. See also "Standardization," Chapter XXIX. 
It should be understood that, at this stage of the process, the evaporated milk is not sterile, nor does it contain cane sugar to preserve it, neither is it sufficiently concentrated to be preserved because of the absence of moisture. If exposed to heat, such as summerheat, or even room temperature, its acidity will increase rapidly, thereby rendering the subsequent sterilizing process difficult. Therefore, $\mathrm{unless}$ it is canned and sterilized immediately after it leaves the vacuum pan, or the homogenizer in case it is homogenized, it should be cooled promptly to a temperature low enough to check bacterial development, 40 to 45 degrees $\mathrm{F}$., or below. In the absence of holding tanks or

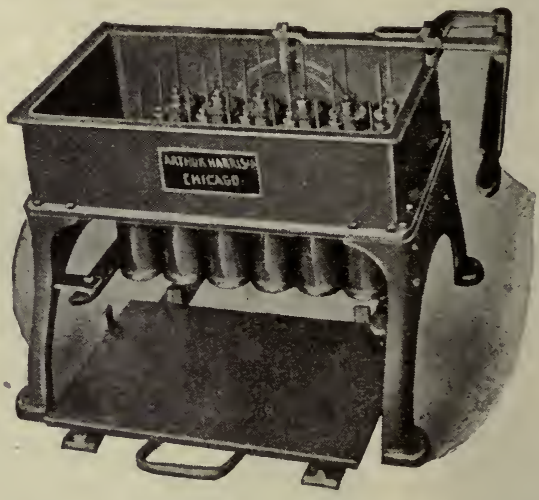

Fig. 54. Hand filling machine for evaporated milk

Courtesy of Arthur Harris \& Co. vats with refrigerating facilities as described above, the cooled evaporated milk may be drawn into 40 quart milk cans, and set in the cold room, or these cans may be submerged in a tank of ice water.

\section{FILLING.}

The cooled evaporated milk is filled into tin cans ranging in size from eight ounces to one gallon. The gallon cans are ustrally filled by hand. The filling of the smaller cans is done by automatic filling machines.

Of late years much progress has been made in the construction of different types of filling machines for evaporated milk. The openings in the cans through which the cans are filled range from the Sanitary can, which is filled with the top of the can entirely removed, to the venthole can with an opening of not more than one-eighth inch in diameter. The filling machines are constructed to fill by gravity, under pressure, or in vacuo. 
These filling machines should be thoroughly washed and freed from all remnants of evaporated milk adhering to the valves and other parts after each use. Remnants of milk left in any part of the filling machine decompose readily and impair the wholesomeness and marketable properties of the product. This is an important point and one too often neglected. Much of the spoiled evaporated milk may be the result of the use of unsanitary and unclean filling machines. The

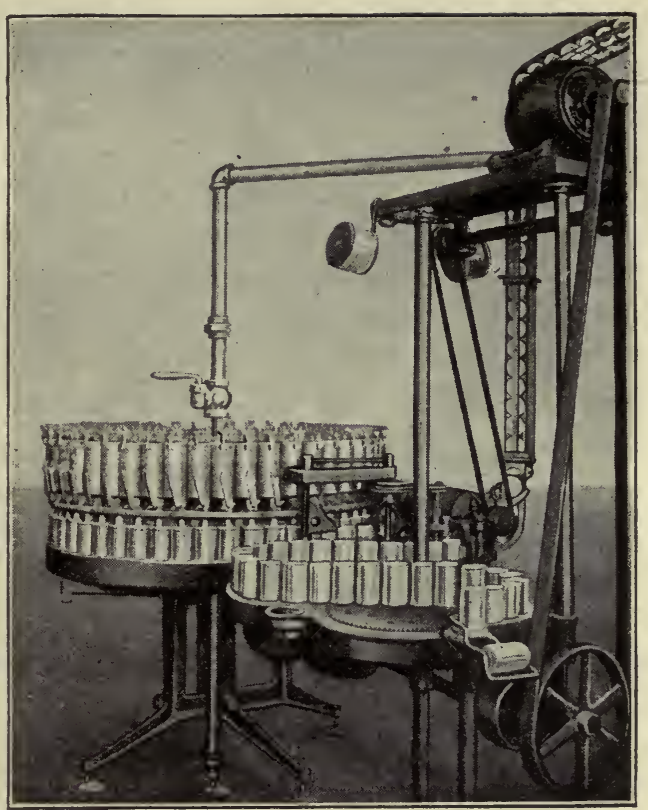

Fig. 55. Venthole filling machine

Courtesy of F. G. Dickerson Company fact, that the evaporated milk is sterilized after it leaves the filling machine, is no excuse for unclean filling machines. The

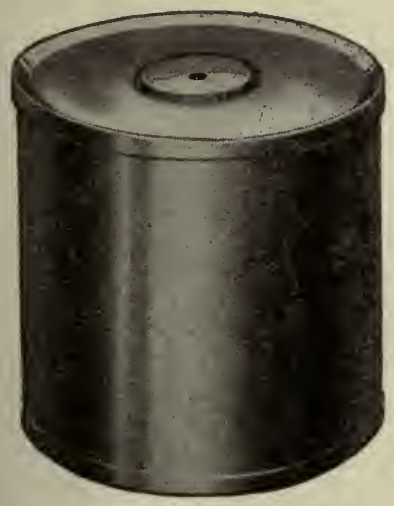

Fig. 56. Venthole can Courtesy of F. G. Dickerson Company operator should bear in mind that the milk running through an unclean filling machine becomes contaminated with millions of bacteria. The more bacteria it contains, the more difficult it is to render it perfectly sterile. Furthermore, sporeforms are prone to develop in the decaying remnants of milk; these spores are very resistant and require excessively high sterilizing temperatures to be destroyed.

- In the filling of the venthole cans the foaming of the evaporated milk frequently causes serious annoyance. This can be avoided by having the milk 
at the proper temperature at the time of filling. Experience has shown that warm milk, or milk with a temperature above about 60 degrees $F$. causes more trouble in this respect than cold milk.

With the rapid and general adoption and use among condenseries of a cold storage system, the evaporated milk usually has a temperature between 40 and 50 degrees $F$., when it reaches the filler, and at these temperatures the tendency to foam is reduced to such an extent that the filling can be done without interference or interruption due to foam.

In order to economize both space and time, it has been found advisable to connect the pipe feeding the filler direct with the holding tank. The extent of elevation of the holding tank over the filler obviously controls the gravity pressure under which the evaporated milk enters the filling machine. If the holding tank is located at a high elevation, therefore, the speed of filling can be materially increased.

\section{SEALING.}

The filled cans should be capped and sealed at once. The seal must be hermetical and strong enough to withstand the strain of the subsequent sterilizing process. With the exception of the "Sanitary can," seals without solder have so far proven unsatisfactory in the canning of evaporated milk. "They are prone to weaken in the sterilizer and cause "leakers." Most of the cans on the market containing evaporated milk are, therefore. sealed with solder. Sealing evaporated milk cans with solder is by far the safest methor. For details of methods of sealing see Chapter VII.

For the sealing or tipping of the renthole cans an automatic tipper is usually attached to the filling machine, so that when the cans leave the filling machine, they have also been sealed.

It is exceedingly important that the sealing be done perfectly, because even minute leaks cause the evaporated milk in the cans to become contaminated causing spoilage. In order to detect cans with imperfect seals all the cans, as they come from the filling and sealing machine, are carefully inspected for leaks. This may be done by the use of a test bath consisting of a narrow 
oblong trough, filled with hot water and through which the cans pass on an endless chain. In the case of leaky cans, the-heat of the hot water bath expands the air in the cans and causes it to escape through the leak in the seal and percolate upward in the water in the form of air bubbles. The operator standing over the test trough picks the cans which expel air bubbles out so that the defective seals can be mended.

Most condenseries manufacturing evaporated milk are now using a hot water bath for testing the sealed cans. But experience has shown that the hot water baths built on the continuous $\mathrm{ch}$ a in principle often fail to give the desired efficiency. This is not the fault of the machine, but it is due to the fact that it

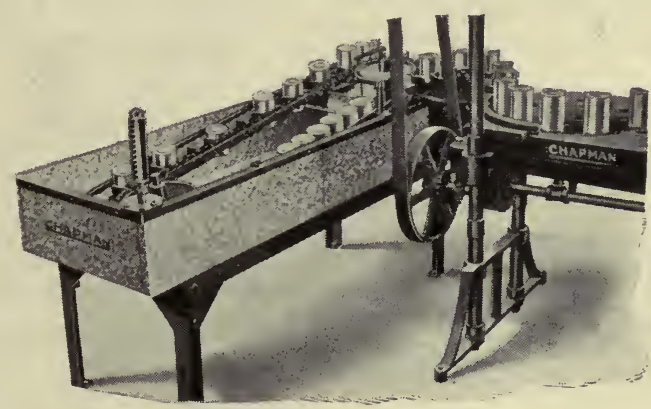

Fig. 57. Chapman automatic can tester Courtesy of Schaefer Mfg. Co.

becomes very tiresome for the inspector to watch the moving line of cans in the water bath and he soon becomes careless and his work inefficient. It has been found that baths constructed and operated on the principle of stbmerging a whole tray full of cans, (usually 24 cans) at a time, give more satisfactory results, relieving the monotony and preserving more successfully the keenness of observation of the inspector.

The venthole filler is simple in construction, economical in operation and easily cleaned and kept in sanitary condition. The milk, from the time it comes within the range of the filler, is no longer exposed to contaminating influences, such as the hands of employes, insects, etc. 'The cans are uniformly filled to within one gram of the guaranteed weight and the vents or pin holes are automatically sealed with the minimum amount of solder. While the quantity of solder must necessarily vary with operating conditions, it is possible to limit the average amount of solder, inder proper conditions, to 5 ounces per 1000 cans. The 
fact that the vent hole or pin hole filler operates by gravity, as to both, the empty cans and the inflowing evaporated milk, reduces the human and mechanical error to the minimum, once the machine is set for operation.

The acknowledged advantages of the venthole filler have made its general adoption and use rapid and it is estimated that today over 90 per cent of the American evaporated milk is being canned by this type of filling machine.

\section{Chapter XI.}

\section{STERILIZING.}

The sealed cans are now ready for the sterilizer. If they cannot be sterilized within an hour or two they should be submerged in ice water or placed in a refrigerating room until the sterilizer is ready for them. This precaution is especially advisable in summer.

Purpose of Sterilization.-The chief purpose of subjecting the evaporated milk to the sterilizing process is to kill all germ life and, therefore preserve the product permanently. When the hermetically sealed cans come from the sealing room, their contents are not sterile. The only means to preserve this milk is to subject it to temperatures high enough to kill all forms of ferments, organized and unorganized, vegetative cells and spores. The success of the manufacture of this product depends to a large extent on the process of sterilization.

Aside from this, the manufacturer aims to gain another commercially important condition, namely, to prevent the separation of the butter fat. Before sterilization, there is nothing to prevent the fat from separating out in the evaporated milk and from churning in transportation, unless the eraporated milk was homogenized. The sterilizing process helps to so change the physical properties of the milk, that this tendency of the fat to separate is greatly minimized. The sterilizing temperatures used, further lend to the evaporated milk a creamy consistency and yellowish color, giving the product a semblance of riçhness, 
Sterilizers.-The predominating apparatus used for sterilizing is a huge, boiler-like, hollow, iron cylinder or box. It opens either at one end or on the side. Its interior is equipped with a revolving framework, steam inlet with a perforated steam distributing pipe in the bottom of the steril-

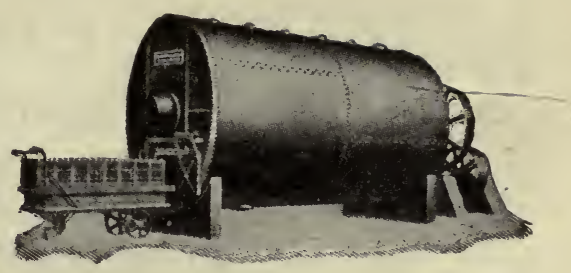

Fig. 58.

Sterilizer for evaporated milk

Courtesy of Arthur Harris \& Co. izer and extending over the entire length of the sterilizer, a water exhaust, a water inlet with a water distributing pipe in the top of the sterilizer and running the entire length of the sterilizer and a water exhanst. The sterilizer carries on its exterior a steam gauge, a vacuum gange, a water gauge, a blowoff valye and a high-temperature thermometer (registering to about 280 degrees $\mathrm{F}$.). In some makes of sterilizers the interior frame-work does not revolve on its axis, but moves back and forth by means of a direct-acting, s t e a mdriven piston, attached to the back end of the sterilizer. The purpose of ke e p ing the cans in motion while heat is applied, is to heat the conte $n$ ts rapidly and uniformly, and to prevent the evaporated milk from baking onto the $\mathrm{sides}$ of the cans. A still

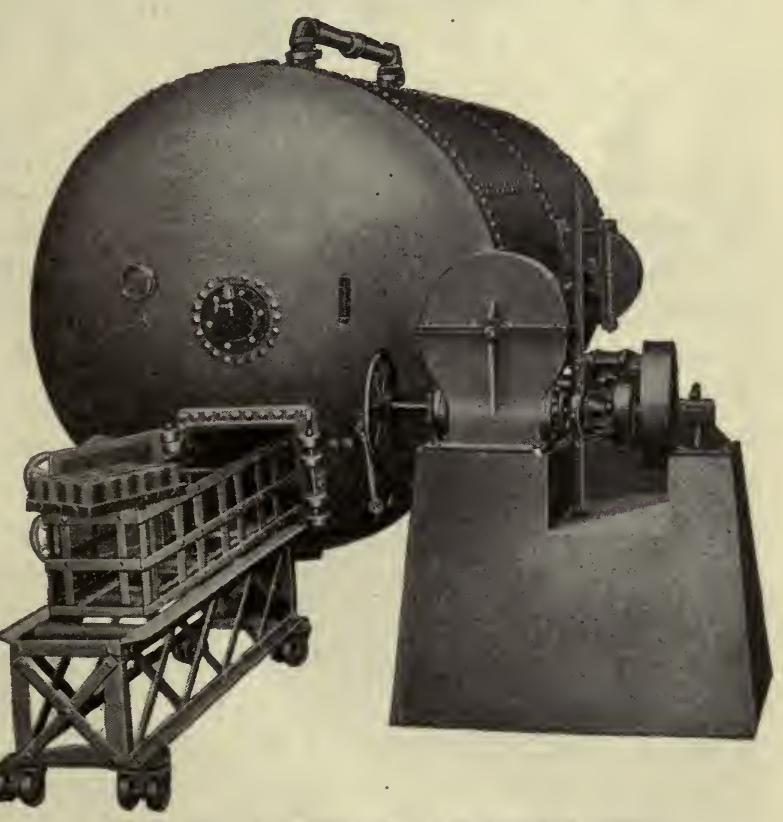

Fig. 59. Sterilizer for evaporated milk Courtesy of The Engineering Company 
other form of sterilizer is the continuous sterilizer in which the unsterilized cans pass into and the sterilized cans escape from the heating chamber in continuous procession.

Loading the Batch-Sterilizer.-The sealed tin cans are placed in heary iron trays, usually holding twenty-four 16-ounce cans or six 1-gallon cans. The loaded trays are slid and locked into the framework in the interior of the sterilizer. The sterilizer is closed with heavy iron doors and the framework is put in motion. In some makes of sterilizers the interior consists of a large perforated iron box revolving on its axis. In this case the cans are simply piled into this box, no trays being used.

Uniform Distribution of Heat.-Where no water is used in the sterilizer during the sterilizing process, it is important that there be a free air space between every two layers of cans, so as to allow the steam to circulate freely and to come in direct contact with every can. When the cans are piled into the sterilizer six to twelve layers deep without any free air space between layers, the cans in the center do not receive as much heat as those at the sides, ends, top and bottom. This causes irregular heating and imperfect sterilization.

A satisfactory means of insuring even distribution of heat is to fill the sterilizer about one-thirdful of water, so that, when the sterilizer is in operation the cans pass through this water, with each revolution of the frame work. Water distributes the heat uniformly, rapidly and there is no danger of the formation of air" pockets between the cans. Since the heat is applied by steam under pressure, the temperature of the water is equal to that of the steam in the sterilizer. This precaution is especially necessary in the case of baby-size cans (eight ounces) which are usually piled in stacks more than two deep. When sterilizing in the absence of water there is danger of lack of uniformity of the amount of heat they receive. The uniform distribution of the steam by the perforated steam distributing pipe in the bottom of the sterilizer is essential for uniform heating of all the cans. If the perforations in this pipe become enlarged due to wear, or in case of an iron pipe due to rusting, or if the cap at the end of the pipe happens to come off, the heat distribution. is bound to lack uniformity. 
It is advisable and important to establish the efficiency of heat distribution in the sterilizer by accurate test. For this purpose the use of cans equipped with automatic thermometers, similar to medical thermometers, but registering sterilizing temperatures, may be found practical. Such cans are placed in different parts in the cages of the sterilizer at the time the sterilizer is loaded, and at the conclusion of the process these

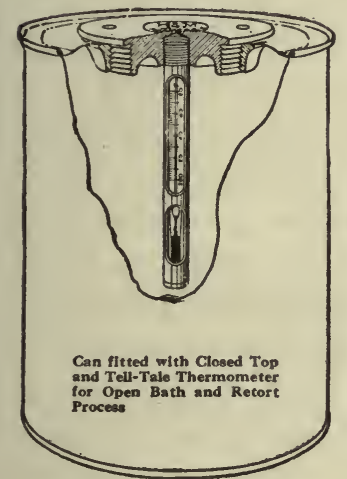

Fig. 60.

Evaporated milk can with tell-tale thermometer, complete

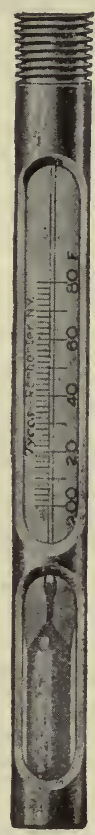

Fig. 61.

Tell-tale thermometer

Courtesy of Taylor Instrument Co.

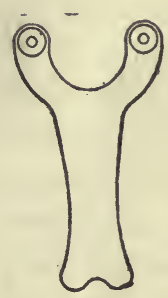

rig. 62.

Wrench for sealing and opening can

thermometers indicate the maximum temperature to which the contents of the respective cans were heated. Unfortunately these thermometers are not always accurate and often they do not function properly. Then again the jars to which they are subjected in the revolving cage and again when the trays containing these cans are removed from the sterilizer, frequently change the position of the mercury column, rendering its readings unreliable and misleading.

Another and very simple and reliable method of testing 
the sterilizer for heat distribution is to test numerous cans from different parts of the sterilizer, after sterilization, for viscosity by means of the Mojonnier viscosimeter or similar device, as described under "Testing Sample Cans for Viscosity," see this chapter, succeeding paragraphs.

Temperature and Time of Exposure.-When the sterilizer is filled with the cans and closed, the frame work is set in motion and steam is turned into the sterilizer. In order to hasten the heating and expel all the air, the exhaust and safety should be left open until the temperature has risen to 212 degrees $F$. This temperature is usually reached in about ten to fifteen minutes. The exhaust and safety are then closed.

From this point on, the process must depend on locality, season of year and condition, properties and concentration of the milk. No formula can be laid down which can be depended on to give uniformly satisfactory results under all conditions. Nor does the proper sterilization depend on one particular formula. There are numerous ratios of temperature, time of exposure and extent of agitation, which when adjusted to local conditions may give satisfactory results. T'he temperature should be high enough and the duration of exposure long enough to insure absolute sterility of the product and to give the milk sufficient body to prevent the separation of the butter fat in subsequent storage. The temperature should not be so high nor the duration of exposure so long, as to cause the formation of a hard, unshakable curd and dark color.

Some processers use a very short process with high temperatures, others raise the heat gradually and not to quite so high a degree. The more gradual heating is preferable, as it gives the product a better body and more viscosity, which is necessary to keep the fat from separating in storage. The author's judgment in this matter is, that it is not safe to raise the temperature to less than 230 degrees $F$. and it is advisable to heat the milk to 234 to 236 degrees F.. provided that the milk is in condition to stand this heat without formation of too firm a curd. Where the maximum temperature to which the milk is raised in the sterlizer is 230 degrees $\mathrm{F}$. or thereabout, the raise of the last ten degrees should occupy from thirty-five to forty- 
five minutes, and this time should be about evenly distributed over the last ten degrees.

Of recent years, the practice of stopping the reel of the sterilizer, either at intervals or when the maximum temperature has been reached, has been adopted by some of the manufacturers. In this case, the temperature usually is rapidly raised to about 240 degrees $F$., and after keeping the reel running at this temperature for a few minutes (about two minutes) the reel is stopped and this temperature is maintained for from 15 to 20 minutes, with the cans lying still. When the "hold" is completed, the cooling proceeds in the usual way. Some condenseries stop the reel for several minutes once or twice when the temperature has been lowered and, before it has dropped to below 212 degrees $F$.

When the stop process of sterilizing is used it is advisable also to superheat the evaporated milk to about 210 degrees $F$. in the vacuum pan; then cool it to about 140 degrees $\mathrm{F}$. and draw it into the standardizing vat where it is standardized to the desired point, then it is homogenized, filled and sterilized. The superheating can also be done in the standardizing vat instead in the pan, by simply blowing steam direct into the evaporated milk.

Mojonnier Bros. Co. recommend that, where the stop process is used, the temperature be raised 3 degrees $\mathrm{F}$. higher (or to 243 degrees F.), than when the reel is kept revolving during the entire process. They further recommend that the temperature be maintained at 243 degrees $F$. for 15 minutes, during the last seven minutes of which the reel be stopped. This refers to a "coming-up time" (from 190 degrees F. to 240 degrees F.) of 10 minutes.

This method of sterilizing, by stopping the reel, has the advantage of developing in the cans a soft, custard-like coagulum, giving the product a very heavy consistency and making it appear rich and creamy. It represents a form of superheating: however, which if not done with great care, may prove disastrous, causing the evaporated milk to spontaneously thicken and become cheesy in consistency upon storage. Most batches of the stop-reel process require shaking.

In his efforts to insure complete sterility the operator should 
understand that the size of the cans may influence the sterilizing efficiency. It takes more time and agitation to sterilize gallon cans than small cans. At a time of the year when the milk contains micro-organisms of relatively high resistance to heat, as is often the case especially in fall and winter, the per cent loss of gallon cans due to "swell heads" may become disastrously large, unless the manufacturer makes a special effort to adjust his process for gallon cans. Gallon size cans require about one degree $\mathrm{F}$. more heat on a 15 minute run of holding than tall-size cans, and tall-size cans require about one degree $\mathrm{F}$. more than family- and baby-size cans.

The installation and efficient use of automatic temperature controllers and recorders is of material assistance for securing uniform results of sterilization. These accessories are made use of in numerous factories, and have proven to be of valuable help to the manufacturer. Aside from the fact that they actually do facilitate the temperature control, they automatically

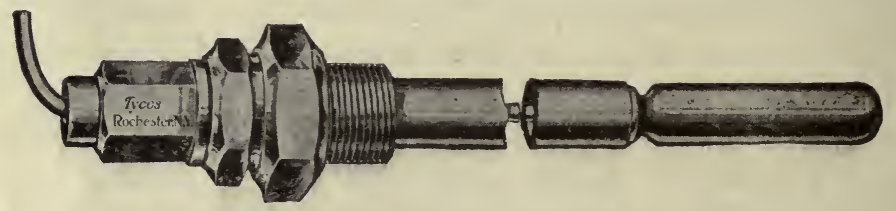

Iig. 63. Bulb for automatic temperature control Courtesy of Taylor Instrument Co.

make for increased efficiency of the operator. The knowledge of the operator that his work is permanently recorded and checked up exerts a beneficial effect on his performance.

The operation of an experimental or pilot sterilizer also has proven a great help in the accurate determination of the amount of heat which the evaporated milk of any batch requires, to produce the desired viscosity, body and color and that it will stand without becoming hopelessly curdy. These machines are of small size, accommodating only a few cans.

A few sample cans of each batch are placed in the pilot sterilizer and run through the process. 'Thus the proper process to be used for the entire batch in the large sterilizer may he adjusted according to the behavior of the contents of the sample cans in the pilot sterilizer.

Qualifications of the Processer,-The operator, or the person 
directing the sterilizing process, should thoroughly appreciate the complexity of the product, understand the cause and effect of the many influencing factors, study the ever-changing conditions and modify the process in accordance with prevailing conditions. He should know that during the exceedingly hot summer days, when the cows suffer from heat and are pestered with flies, the milk will not stand as much heat without badly curdling in the sterilizer as under more favorable conditions. $\mathrm{He}$ should know that toward and during the fall months the organ-

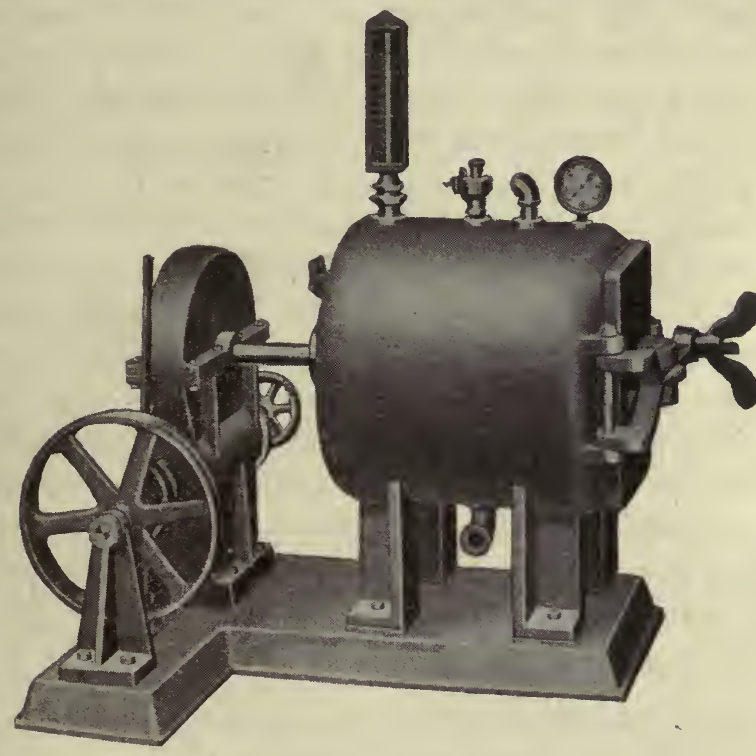

Fig. 64. Pilot sterilizer

Courtesy of The Engineering Company

isms normally present in milk are more resistant and require higher heat to be destroyed, than earliei in the season.

Rapid and Uniform Cooling.-As soon as the required heat has been given the milk in the sterilizer, the steam should be turned off and the exhaust and drain should be opened. When the temperature has dropped to about 220 degrees F., cold water should be turned into the sterilizer while the cans are constantly in motion, until the cans are cool enough to handle. There should be enough cold water available to reduce the tempera- 
ture to 70 or 80 degrees $\mathrm{F}$. in twenty minutes for gallons and in ten to fifteen minutes for small size cans. The water pipe should be so arranged as to distribute the water uniformly over the entire length of the sterilizer.

If the process is to be successful, the processer must have as nearly perfect control of the heat as possible. This means especially, that there must be plenty of water available to insure rapid cooling and the water must be distributed over the cans uniformly. Insufficient water supply and uneven distribution of the water in the sterilizer, means that some of the cans are exposed to the sterilizing heat longer than others, causing lack of uniformity in the smoothness and color of the milk of different cans of the same batch. Delayed cooling, owing to insufficient water supply, has the further disadvantage of causing the cans to bulge badly, owing to the difference in pressure between the interior and exterior of the cans. This is especially noticeable in gallon-size cans, the ends of which may become badly distorted, present an unsightly appearance and their seams and seals may be weakened to the extent of producing "leakers." Excessive bulging and injury to the cans can be avoided by admitting to the sterilizer a sufficient quantity of compressed air at the conclusion of the sterilizing process, to take the place of the steam pressure and thereby equalizing the pressure between the outside and inside of the cans during the cooling process.

Fractional Sterilization.-In the early days of the manufacture of evaporated milk the product was sterilized by fractional sterilization. This method has now been largely abandoned, but is occasionally used when the milk happens to be in very abnormal condition. The milk is heated in the sterilizer to considerably lower temperatures than those stated above, and this heating is repeated on two or three successive days. The principle of this process is to kill all vegetative forms of bacteria during the first heatiag. This gives the spores a chance to develop into vegetative forms by the second and third days, which forms are then destroyed during subsequent heating. This system of sterilization is not practical for general use. It is too great a tax on the capacity of the average factory and increases 
the cost of manufacture. It should, therefore, be made use of only in exceptional cases, when it is known that a certain batch of milk could not be put through the higher sterilizing temperatures without causing the product to become permanently curdy.

Standardization of Properties that Influence Behavior of Evaporated Milk toward Heat of Sterilization.-In the foregoing discussion of the sterilizing process no mention was made of methods to standardize the behavior of evaporated milk toward the sterilizing heat. It was clearly pointed out that, in the absence of such methods, it is impossible to lay down any one formula for sterilization that would give uniformly satisfactory results under diverse conditions of the product to be sterilized. The chemical, physical and physiological properties of milk are ever changing, and even slight changes in these properties often cause wide variations in the amount of heat the product will stand in the sterilizer. This in turn necessitates constant changes and modifications of the process, if a marketable product is to be the result. Too much must be left to the judgment and power of observation of the processer and this situation obviously results in excessive numbers of defective batches and in costly losses and wastes.

The standardization of evaporated milk for percentage of fat and solids alone materially assists in narrowing down the range of variations in the behavior of the milk in the sterilizer, but it fails to adequately control those properties which have the greatest influence on the sensitiveness of this product toward sterilizing heat. This problem has confronted the manufacturer of evaporated milk from the very beginning of the industry. Much experimental work has been done in an effort toward its permanent solution, but the results have largely been of local and temporary success and usefulness only.

Within recent years the Mojonnier Bros. Co. of Chicago have developed and have furnished the industry with a simple, practical and systematic method and suitable equipment, for controlling the properties of this complex product with such a degree of accuracy that the adoption of a standard sterilizing formula has become feasible and practicable. 


\section{THE MOJONNIER METHOD OF EVAPORATED MILK CONTROL.}

Principle of Method.--This method briefly consists of the following outstanding features:

1. The adoption of a standardized process of sterilization designed and adapted for evaporated milk of superior quality

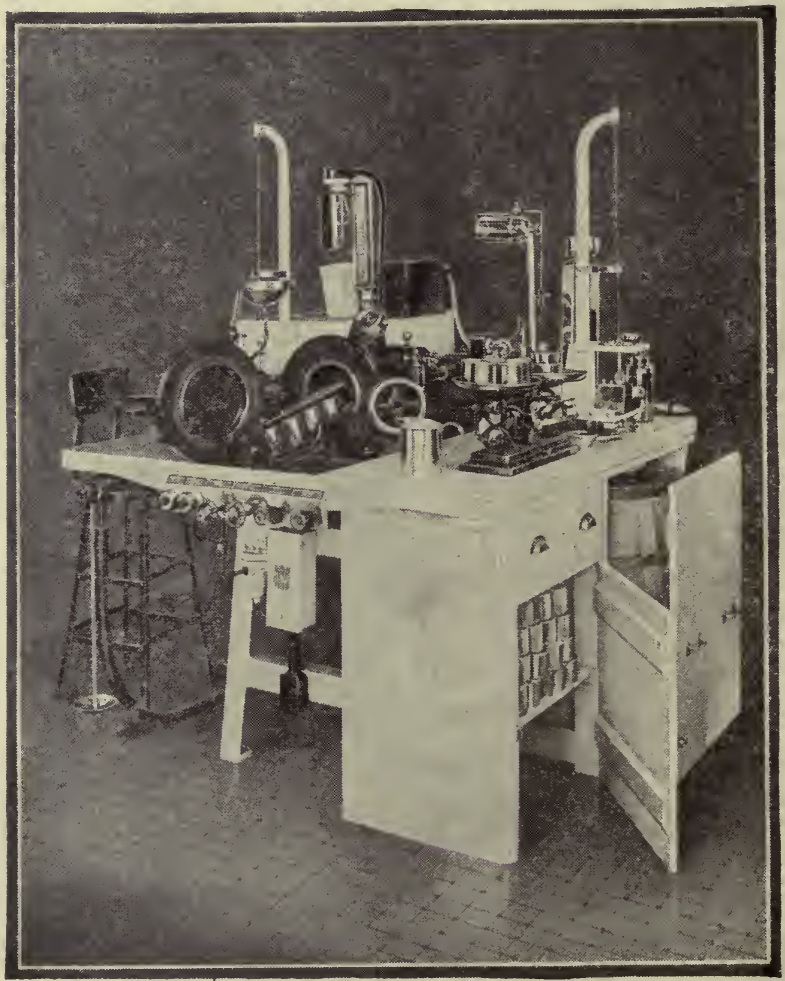

Fig. 65. Mojonnier evaporated milk controller Courtesy of Mojonnier Bros. Co.

for processing. This process provides a very narrow range of variation of temperature and of time of exposure, in order to limit the personal factor with its inevitable uncertainties to the minimum. 
2. A standard method of determining, by means of a pilot sterilizer, a viscosimeter and a color test, the proper viscosity and color that the evaporated milk should have when it comes from the sterilizer; and

3. A standard method of determining the amount of bicarbonate of soda that must be added to any given batch to evaporated milk in case its properties are such, that it is unsafe to subject it, without such treatment, to the temperature conditions that fall within the range of the standardized process of sterilization.

Equipment for Mojonnier Method.--The equipment designed for this method of evaporated milk control, is illustrated in Fig. 65, and consists of the following apparatus:

1. One pilot sterilizer with motor, complete

2. 2 viscosimeters

3. 1 venthole sample can filler

4. Glassware for making up and measuring sodium bicarbonate solution

5. 1 torsion balance

6. Open-top cups and venthole tin cans.

Preparation of $10 \%$ Sodium Bicarbonate Solution.-The bicarbonate of soda is used in this test in the form of a 10 per cent solution. This solution is prepared as follows:

1. Weigh empty bottle to .01 ounce

2. Add 3 ounces bicarbonate to bottle

3. Add 27 ounces warm water to bottle.

Shake thoroughly until the bicarbonate is all dissolved. Draw out as needed into dispensing bottle, filling the same not over half full. Keep remainder tightly corked in the stock bottle until needed. Should the bicarbonate crystallize out, prepare a new lot. The above solution contains exactly 10 per cent sodium bicarbonate.

Adding the Sodium Bicarbonate Solution to Sample Cans.Arrange in a row five open-top cups, marked-X-1-2-3-4 respectively. These cups are furnished with the Controller. Cup marked $\mathrm{X}$ is blank, to which no bicarbonate is added. To cup marked No, 1 add one charge of sodium bicarbonate from the 
dispensing burette. This is the amount contained between the upper two graduations on the burette. To cup marked No. 2 add two charges, to cup No. 3 add three charges, to cup No. 4 add four charges. Dispensing burette furnished with the controller indicates how the above quantities are to be added; the burette is graduated into four separate charges. The unit with one single charge contains the equivalent of one ounce of sodium bicarbonate, to one thousand pounds of evaporated milk. Each successive charge is a multiple of this unit. In dispensing the bicarbonate solution, it is best not to fill the bottle more than half full. When filling the burette, the solution should be allowed to flow into it slowly in order not to trap in the air. If air is trapped into the burette, it is difficult to remove it, and in such a case it is best to run out whatever solution may be in the burette and to put in a new supply.

Whenever the quality of the milk is very abnormal, it may be necessary to add more than above indicated number of charges of bicarbonate solution to the sample cans. In such cases any multiples of the above number of charges may be added. The ratio of ounces of bicarbonate to one thousand pounds of milk will remain the same, being increased simply by the number of charges added to each sample can.

Preparation of the Five Sample Cans for the Sterilizer.After the five open-top cups have been treated with bicarbonate as indicated in the preceding section, they are transferred to the Torsion Balance and exactly six ounces of milk is weighed into each cup. This can be done by taring the entire set of empty cups, and then weighing six ounces of evaporated milk into each separate cup.

One set of five empty cans is now marked in the same manner as the cups to which the bicarbonate solution was added, namely as follows: $\mathrm{X}=$ can containing no bicarbonate; $1=$ can containing equivalent of one ounce bicarbonate per thousand pounds of evaporated milk; $2=$ can containing equivalent of two ounces per one thousand pounds of evaporated milk; $3=$ can containing equivalent of three ounces per one thousand pounds of evaporated milk, and $4=$ can containing equivalent of four ounces per one thousand pounds of evaporated milk.

Next the contents of the five open-top cups are transferred 
to the five tin cans in the crder above indicated. This is done by placing the cans in pairs, under the two-can venthole filler, furnished with the Controller, and the cups with the milk and bicarbonate marked corresponding to the empty cans, are now emptied into the filler. Care must be taken to keep the cans in the proper order.

After filling, the cans are tipped, using preferably rosin solder. Should none of this solder be available, then great care must be exercised not to let any of the flux from the zinc chloride solder enter the cans. Zinc chloride flux has a very bad effect upon the milk, and will completely change the results.

Sterilizing the Five Sample Cans.-The five sample cans, prepared as above directed, are now ready for the sterilizer. Place these in the cage and fasten the lid securely, and also turn down the screws in order to hold all of the cans securely into place. Adjust the cage in the sterilizer by means of the thumb screw on the right hand, side, in order to keep them from having end play. Close the sterilizer door securely so that no steam escapes during the sterilizing process.

Be sure to provide circulation of the steam through the rent on the pipe surrounding the thermometer. This little vent should be kept open during the entire sterilization operation. Fill the small pilot sterilizer with water to a point half way upon the gauge glass. Be sure to turn on the switch to start the motor in operation. Open the "steam start valve" and take five minutes to let the heat reach 190 degrees F. or 3 on the sterilizer scale. Then let the heat come up gradually from 190 degrees to 240 degrees $\mathrm{F}$. or from 3 to 8 on the thermometer, taking one minute for each 5 degrees as indicated in the following table:

\begin{tabular}{c|c|c}
\hline $\begin{array}{c}\text { Actual Temperature } \\
\text { in } \\
\text { Fahrenheit Degrees }\end{array}$ & $\begin{array}{c}\text { Actual Reading } \\
\text { upon } \\
\text { Thermometer Scale }\end{array}$ & $\begin{array}{c}\text { Point at which Mercury } \\
\text { should be at any given } \\
\text { time coming up }\end{array}$ \\
\hline $240^{\circ}$ & 8 points & 20 minutes \\
$230^{\circ}$ & 7 points & 18 minutes \\
$220^{\circ}$ & 6 points & 16 minutes \\
$210^{\circ}$ & 5 points & 14 minutes \\
$200^{\circ}$ & 4 points & 12 minutes \\
$190^{\circ}$ & 3 points & 10 minutes \\
\hline
\end{tabular}


Where sterilizing is done with steam only, without using superheated water, it is recommended to take twenty minutes for coming up. The above table is arranged upon this basis. The table, however, can be readily adapted to a system requiring fifteen minutes for coming up, by taking five minutes to come up to the point marked 10 upon the table, or to 190 degrees $\mathrm{F}$.

It is also recommended that in the pilot sterilizer, the samples be cooked to 243 degrees F. and that the "jump" from 230 degrees to 243 degrees be made in two minutes. It is very important to know the exact second when the mercury column reaches 243 degrees. The milk should be held at this temperature for fifteen minutes to the exact second.

Cooling the Five Sample Cans.-The instant the clock shows that the samples have been sterilized as indicated above, both, discharge valve and cold water valve should be opened simultaneously. It is best to cool the five samples to about 75 degrees $\mathrm{F}$. This should take not to exceed five minutes, depending upon the temperature of the water available. This is something each operator must judge for himself.

Testing the Sample Cans for Viscosity.-As soon as the sample cans are cooled in the sterilizer, as indicated above, the cans are dried on the outside and are then opened and each can is placed in the proper position in the viscosimeter rack. It will be noticed that the same scheme of marking the spaces upon the viscosimeter rack has been observed as in the case of marking the cans. It is very desirable to cool the samples to as nearly $75^{\circ}$ degrees as possible. If this is not done, the viscosity should be corrected for temperature, using the scale of corrections that is furnished with the viscosimeters. Make the viscosity test as follows:

(a) Different sizes of balls are furnished, corresponding to the product that it may be desired to test for viscosity. A special viscosity ball is furnished in the case of evaporated milk, and this is not interchangeable with any other ball for this purpose. Therefore, see that the proper ball is being used.

(b) Fasten one end of the wire in the knurled nut upon the 
top of the bent support, and the other end in the dial. Adjust the vertical position of the dial by raising or low e ring, until the small lug on the bottom of the dial is in the proper position to engage the trip upon the right-hand side of the stand.

(c) Adjust the horizontal position of the dial until zero degrees is in a line with the pointer upon the front of the frame when the dial is balanced in the air. Center the dial in the open circle by means of the adjusting screws on the under side of the frame. Make a test for viscosity directly in the baby-size cans. Properly center the can by means of the automatic arrangement provided for that purpose. As already indicated, be sure to watch the temperature factor very closely.

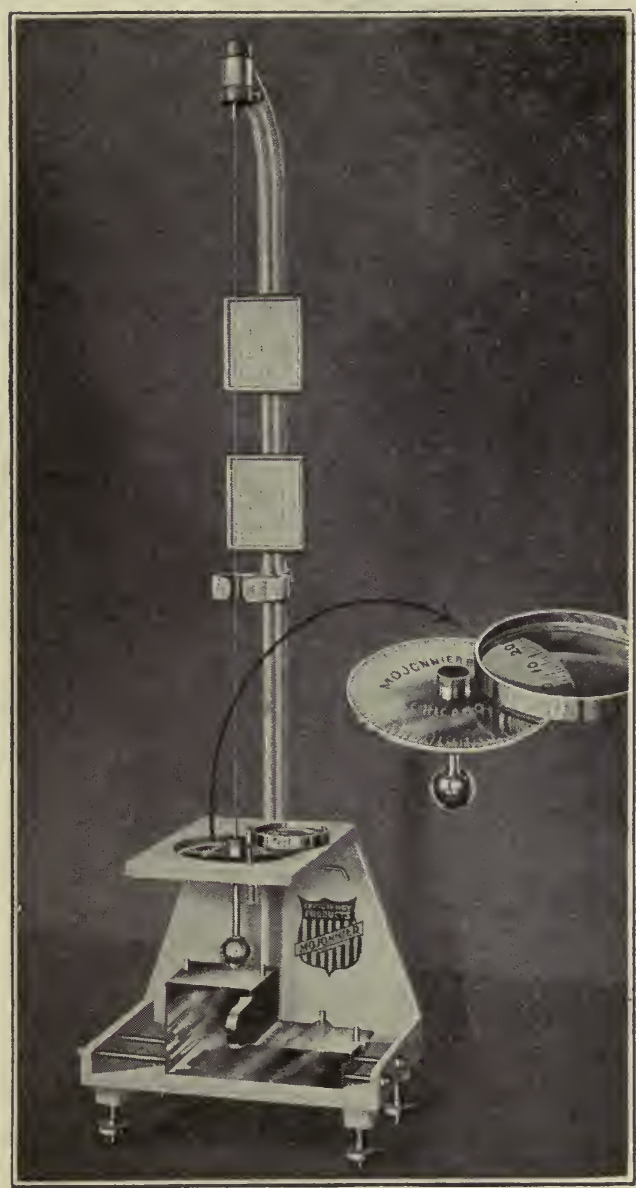

Fig. 66. Mojonnier viscosimeter

Courtesy of Mojonnier Bros. Co.

(d) Lower the ball into the can of milk; turn the dial clockwise one revolution; stopping when zero degrees upon the dial is in line with the pointer upon the front of the frame. Hold the dial in place by means of the lug and trip. When ready, sharply, release the trip, note the degree where the dial stops, just before it starts upon. the return round. This will occur 


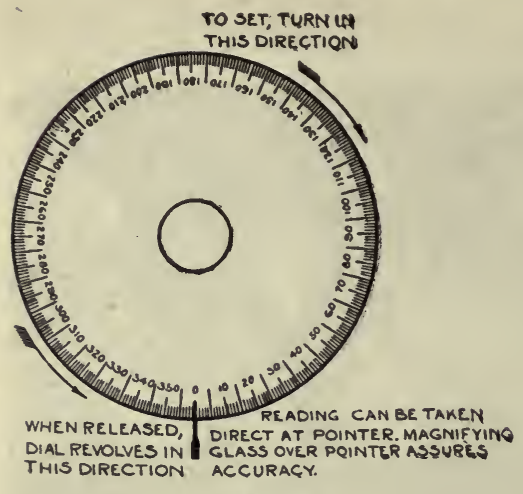

Fig. 67.

Mojonnier-Doolittle viscosimeter dial, graduated to $360^{\circ}$

Courtesy of Mojonnier Bros. Co. after the dial has made one complete, and part of the second revolution. The degree at which the dial stops will represent the viscosity of the sample. The greater the viscosity, the larger the degree reading will be.

Record the viscosity of each of the sample cans tested, as indicated above. Further instructions will follow as to the method of applying the information thus obtained.

Table for Correcting Viscosity of Evaporated Milk to $75^{\circ} \mathrm{F}^{1}$

\begin{tabular}{|c|c|c|c|c|c|c|c|c|c|c|c|}
\hline \multicolumn{6}{|c|}{ STERILIZING ROOM } & \multicolumn{6}{|c|}{ PACKING ROOM } \\
\hline \multicolumn{3}{|c|}{ Take } & & & \multirow{2}{*}{$\begin{array}{l}\text { Add } \\
\text { on } \\
\text { Deg. }\end{array}$} & \multicolumn{3}{|c|}{ Take } & \multicolumn{2}{|l|}{ Add } & \multirow{2}{*}{$\begin{array}{l}\text { Add } \\
\text { on }\end{array}$} \\
\hline $\begin{array}{l}\text { Temp. } \\
\text { Deg. }\end{array}$ & $\begin{array}{l}\text { off } \\
\text { Deg. }\end{array}$ & $\begin{array}{l}\text { Temp. } \\
\text { Deg. }\end{array}$ & $\begin{array}{c}\text { on } \\
\text { Deg. }\end{array}$ & $\begin{array}{l}\text { Temp. } \\
\text { Deg. }\end{array}$ & & $\begin{array}{l}\text { Temp. } \\
\text { Deg. }\end{array}$ & $\begin{array}{l}\text { off } \\
\text { Deg. }\end{array}$ & $\begin{array}{l}\text { Temp. } \\
\text { Deg. }\end{array}$ & $\begin{array}{l}\text { on } \\
\text { Deg. }\end{array}$ & $\begin{array}{l}\text { Temp. } \\
\text { Deg. }\end{array}$ & \\
\hline F. & R. ${ }^{2}$ & F. & R. & F. & $\mathbf{R}$. & F. & R. & F. & $\mathbf{R}$. & F. & R. \\
\hline 65 & 25 & 76 & 2 & 89 & 24 & 60 & 15 & 75 & 0 & 88 & 10.0 \\
\hline 66 & 22 & 77 & 4 & 90 & 25 & 61 & 14 & 76 & 1 & 89 & 10.5 \\
\hline 67 & 19 & 78 & 6 & 91 & 26 & 62 & 13 & 77 & 2 & 90 & 11.0 \\
\hline 68 & 16 & 79 & 8 & 92 & 27 & 63 & 12 & 78 & 3 & 91 & 11.5 \\
\hline 69 & 13 & 80 & 10 & 93 & 28 & 64 & 11 & 79 & 4 & 92 & 12.0 \\
\hline 70 & 10 & 81 & 12 & 94 & 29 & 65 & 10 & 80 & 5 & 93 & 12.5 \\
\hline 71 & 8 & 82 & 14 & 95 & 30 & 66 & 9 & 81. & 6 & 94 & 13.0 \\
\hline 72 & 6 & 83 & 16 & 96 & 31 & 67 & 8 & 82 & 7 & 95 & 13.3 \\
\hline 73 & 4 & 84 & 18 & 97 & 32 & 68 & 7 & 83 & $7.5^{\circ}$ & 96 & 13.6 \\
\hline 74 & 2 & 85 & 20 & 98 & 33 & 69 & 6 & 84 & 8.0 & .97 & 13.9 \\
\hline 75 & 0 & 86 & 21 & 99 & 34 & 70 & 5 & 85 & 8.5 & 98 & 14.2 \\
\hline & 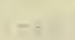 & 87 & 22 & 100 & 35 & 71 & 4 & 86 & 9.0 & 99 & 14.5 \\
\hline & & 88 & 23 & & & 72 & 3 & 87 & 9.5 & 100 & 14.8 \\
\hline & & & & & & 73 & 2 & & & & \\
\hline & & & & & & & 1 & & & & \\
\hline
\end{tabular}

Importance of Proper Viscosity.-The viscosity of evaporated milk determines the body and permanency of the emulsion of the fat and other solid and liquid constituents of the product and it further determines the extent to which the evaporated

1 Courtesy of Mojonnier Bros. Co.

$2 \mathbf{R}$ means degree retardation or viscosity. 
milk may be expected to withstand the sterilizing heat without danger of curdling in a manner that would render the product unmarketable.

The purpose of the viscosity test, of sample cans having passed through the pilot sterlizer or controller is, to determine whether the evaporated milk of the entire batch, without treatment will safely pass through the adopted, standard sterilizing process, or to what extent this process must be modified, or to what extent the product, before sterilization must be treated with bicarbonate of soda to secure a good body, and at the same time insure freedom from the formation of a permanent curd when applying the standard sterilizing process.

A certain degree of viscosity in evaporated milk is desirable and necessary in order to give the product a good body and to prevent the separation of the butter fat.

But, as the viscosity increases a point is reached beyond which it is not safe to go, because of the danger of the formation of a permanent curd that renders the product unmarketable.

The increasing viscosity is due to a change in the physical properties of the protein constituents of evaporated milk resulting from the action of heat. The earlier stages of these changes are desirable, because they result in a product of good body and of increased stability of emulsion. An excessive continuation of these changes precipitates the proteins in the form of visible particles of curd which, if permanent, spoil the product for the market.

Factors which Influence the Viscosity and their Correlation to the Sterilizing Process.-The extent to which heat increases the viscosity of evaporated milk is dependent on many and varying conditions, such as acid of milk, natural stability of proteins in milk as related to their behavior toward heat, degree of concentration of evaporated milk, degree of heat applied in forewarmer, amount of extraneous water in evaporated milk, degree of heat in the sterilizer, duration of exposure to sterilizing heat. The resistance of the proteins to heat, as affected by these several conditions and factors, can be modified and largely controlled if necessary, by the treatment of milk that has an abnormally low resistance to heat, with definite, small quantities of bicarbonate of soda, 
The viscosity test therefore furnishes a measure of the resistance of any given batch of evaporated milk toward sterilizing heat. But in order to enable the operator to correctly interpret the results of this test and to correctly govern his method of handling the evaporated milk according to these findings, he should have a clear understanding of the correlation of the several factors that influence this resistance to heat and that affect the viscosity.

With reference to the direction (increase or decrease of viscosity) in which these several factors influence the viscosity and the tendency to curdle the evaporated milk, the following general facts should be known:

Factors that increase the viscosity and the tendency to curdle the milk decrease the viscosity and the tendency to curdle
1. high per cent acid in milk

2. low stability of proteins

3. high concentration of evaporated milk

4. high sterilizing temperature

5. long exposure to sterilizing temperature

6. high pressure in homogenizer

1. low acidity in milk

2. great stability of proteins

3. low concentration of evaporated milk

4. low sterilizing temperature.

5. short exposure to sterilizing heat

6. high temperature in forewarmer

7. extraneous water in evaporated milk

8. low pressure in homogenizer

9. addition of bicarbonate of soda

The exact quantitative relation of most of these factors to one another and to the viscosity of the evaporated milk has been experimentally determined by Mojonnier Bros. Co. for evaporated milk standardized to 7.8 per cent fat and 25.5 per cent total solids as follows:

A 40 degree retardation or viscosity as determined by the Mojonnier viscosimeter corresponds to:

1. One degree $F$. in sterilizing temperature at the holding point of 240 degrees $F$., when held for 15 minutes and with the same "coming-up" time as given under "Sterilizing the Five Sample Cans." This means that each degree F. above 240 de- 
grees F. under above conditions of holding increases the retardation or viscosity 40 degrees.

2. One minute of time at holding temperature of 240 degrees $\mathrm{F}$. This means that each minute of holding at 240 degrees $\mathrm{F}$. longer than 15 minutes increases the retardation or viscosity 40 degrees and each minute of holding at 240 degrees $F$. less than 15 minutes decreases the retardation or viscosity 40 degrees.

3. Two degrees F. on temperature to which milk is heated in hot well under 212 degrees $F$. This means that for every two degrees $F$. below 212 degrees $F$. in the hot well the retardation or viscosity is increased 40 degrees.

4. 20 pounds of extraneous water per 1000 pounds of evaporated milk. This means that the addition to or presence in evaporated milk of 20 pounds of extraneous water per 1000 pounds of evaporated milk reduces the retardation or viscosity 40 degrees.

5. One ounce of solid sodium bicarbonate per 1000 pounds of evaporated milk. This means that the addition to the unsterilized evaporated milk of one ounce of bicarbonate of soda per 1000 pounds of evaporated milk reduces the retardation or viscosity 40 degrees.

6. When using the above correlation of factors as a guide, it should be borne in mind that, with evaporated milk of a higher degree of concentration the influence of these several factors on the retardation or viscosity is altered and intensified.

The Correct Viscosity for Evaporated Milk.-The experimental study of the viscosity of evaporated milk by Mojonnier Bros. Co. has further demonstrated that a considerable portion of the riscosity, as determined immediately after the evaporated milk comes from the sterilizer, is lost during the handling to which the product is subjected from the time it leaves the sterilizer and until it is ready to leave the shipping department, and again in transport until it reaches the consumer. Also the extent of this loss of viscosity is governed somewhat by the temperature of the milk while it is so handled; the higher the temperature the greater the sacrifice in viscosity.

Accordingly it has been found that for domestic trade a retardation or viscosity of 150 degrees is the correct viscosity for evaporated milk just as it comes from the sterilizer. For 
export purposes the viscosity should be higher, around 200 degrees.

A 150 degrees viscosity of evaporated milk immediately after sterilization is equivalent to a viscosity of from about 80 degrees to 100 degrees by the time the milk is ready to leave the shipping department, and this represents about the correct viscosity for the summer months. For the winter months the viscosity should not exceed about 80 degrees retardation. Excessive viscosity invites the "feathering" or curdling of the evaporated milk when used in hot coffee or when diluted with hot water.

Adding Sodium Bicarbonate to Batch of Evaporated Milk.As soon as the controller and viscosimeter tests are completed, the batch of evaporated milk is ready to be filled into the tin cans. In case it is necessary to add sodium bicarbonate, the following procedure is recommended:

For convenience sake we will assume that can No. 2 in the test showed the correct viscosity, as represented by a retardation of 150 degrees. To this can had been added sodium bicarbonate on the basis of two onnces per 1,000 pounds of milk. The entire batch of milk containing 24,000 pounds evaporated milk, hence $\frac{24,000 \times 2}{1,000} \doteq 48$ ounces of solid sodium bicarbonate are carefully weighed out. This amount of bicarbonate is conveniently placed into a 10-gallon milk can, a small amount of water is added and preferably also a small amount of evaporated milk. This mixture is then heated to a vigorous boil, which can easily be done by means of the steam hose. The boiling should be continued until the greater part of the gas generated has been expelled.

The hot mixture is now added to the entire batch of evaporated milk in the holding tank. It should be added slowly and the evaporated milk should be kept thoroughly agitated, not only while the bicarbonate is added but for from 10 to 20 minutes after its addition.

Adjusting Sterilizing Process to Different Sizes of Cans.As stated elsewhere in this chapter, different sizes of cans require different sterilizing formulas to insure complete sterilization, and a similar effect has been found also with reference to 
viscosity. Thus, tall size cans require one degree more heat on a 15 minute run of holding than the baby size cans. Hence if the record for a baby size batch of evaporated milk calls for 15 minutes at 240 degrees $F$., for tall size cans, the same batch would have to be held for 15 minutes at 241 degrees $F$.

Irregularities in the Reaction and Results of Sodium Bicarbonate.-Generally speaking the Mojonnier formula above given for the use of Bicarbonate of Soda yields reliable results. There are occasionally conditions, however, when the evaporated milk fails to react normally with this ingredient and may yield results exactly opposite those anticipated. Instead of reducing the viscosity of the milk, it increases the viscosity. Abnormal cases of this type suggest that the physical and possibly the chemical make-up of the casein may have undergone material, though not as yet well understood changes.

Such abnormal conditions may be the result of improper forewarming of the milk, the use of excessive pressure in the homogenizer, excessive heat in the sterilizer, mixture of brine with the evaporated milk due to leaky coils in the cooler, or unbalanced relation of the protein and ash constituents of the original milk. See also Chapter XXIII, "Defective Evyaporated Milk" under "Lumps of Curd in Evaporated Milk."

Should Bicarbonate of Soda or any other Chemical be Used at all?-The foregoing directions for the use of the Mojonnier Controller and Viscosimeter should not be interpreted to mean. that this volume advocates the use of bicarbonate of soda in the manufacture of evaporated milk. In fact the availability of this equipment and of these tests materially facilitates the manufacture of evaporated milk without the use of sodium bicarbonate.

It is important to realize, however, that the use of sodium bicarbonate for the purpose of facilitating the process of sterilization has been pretty general for many years prior to the introduction of Mojonnier equipment and methods. It has become a fairly well established practice, accepted by the industry. Its abuse cannot be too strongly condemned and its promiscuous use in the absence of a systematic, scientifically controlled, correct method, is prone to invite its abuse. 
While, in principle, the use of bicarbonate of soda in a product such as evaporated milk cannot be unconditionally recommended, its proper and correct use, where necessary, has proven a decided benefit to the industry, reducing the occurrence of unmarketable though otherwise perfectly good batches of . evaporated milk to the minimum, and thereby avoiding unnecessary economic loss. It is a matter of choosing the lesser of two evils.

Irregularities in the behavior of evaporated milk toward the sterilizing process, that render the product unmarketable are largely due to changes and differences in the chemical composition and physical and physiological properties of the milk. Some of these changes are under the control of the milk producer on the farm, others are under the control of the manufacturer and still others are uncontrollable.

The conditions which can and should be controlled by the producer refer largely to sanitation in the production and care of milk, prompt and proper cooling, frequency of delivery, protection against heat in transit, health of cows and rejection of colostrum milk. The condensery must insist on cleanly production, on proper cooling of the milk on the farm, on daily delivery at the factory (some condenseries, especially those in Europe receive their patrons' milk twice daily), on the proper temperature of the milk upon arrival at the factory, on the proper disposition of milk from sick cows and of milk too close before parturition, and too soon after calving. Much of this can be accomplished by a rigid system of milk inspection on the platform and frequent visits by the inspector to the patrons' farms. In the case of rail shipments the milk often is in transit too long to arrive at the factory in the best condition.

The factors under control of the factory, which influence the behavior of the evaporated milk toward sterilizing heat, refer to sanitation in all departments where milk is handled in the plant and to uses or abuses of the milk in manufacture. All equipment with which milk comes in contact must be kept in a perfect state of cleanliness as outlined earlier in this volume under "Factory Sanitation." The handling of two days' milk must be discontinued, the evaporated milk must not be held excessively long in the storage tanks, and if held at all, it must 
be cooled to a low temperature. All abuses of milk along these and similar lines are bound to cause trouble in the sterilizer, which is avoidable and unnecessary.

Finally there are factors which are not under control but which also exert a very marked influence on the behavior of the product toward sterilizing heat at times. These are invariably associated with changes in the period of lactation, changes in feed and climatic conditions and their effect on the amount and proportion of the protein and ash constituents of milk, as explained in Chapter XXIII, "Defective Evaporated Milk, Lumps of Curd." These conditions are not only not controllable, but their effect on the milk is not determinable by any now known practical method of analyses.

Proper attention to the controllable conditions will go far in making unnecessary the use of bicarbonate in evaporated milk and will at least confine its use, when necessary, to very small amounts. When these conditions have been conscientiously taken care of and, in spite of these precautions, certain batches of milk, because of the above named effect of uncontrollable factors, require the use of bicarbcnate in order to insure safe sterilization and to avoid loss, then the emergency justifies and sound judgment and business efficiency demand recourse to methods that the helping hand of science has made available, so long as these methods do not impair the wholesomeness and food value of the product, although their ethics, in principle at least, cannot be approved for general practice. See also "Effect of Relation of Mineral Constituents of Milk," Chapter XXIII, "Defective Evaporated Milk."

\section{SHAKING.}

Purpose.-The purpose of shaking the evaporated milk is to mechanically break down the curd that may have been formed in the process of sterilization and to give the contents of the cans a smooth and homogeneous body.

The high temperatures to which the evaporated milk is subjected in the sterilizer have a tendency to coagulate the casein. In the case of normal, fresh milk the casein coagulates at a temperature of 269 degrees F. In the evaporated milk, made from perfectly. normal and sweet, fresh milk, the casein curdles at much lower temperatures, and the higher the ratio of concentra- 
tion, the lower the temperature required to precipitate the casein. It seems that the concentration of the milk intensifies the properties of milk to coagulate when subjected to heat. This factor is probably in part at least due to the increase of the per cent of lactic acid in the evaporated milk, due to the concentration. If the fresh milk contains .17 per cent lactic acid, a concentration of two and one-fourth parts of fresh milk to one part of evaporated milk causes the evaporated milk to contain .17 $\times 2.25=.38$ per cent lactic acid. With this amount of acid acting on the casein, it is not difficult to understand why a coagulum is often formed in the sterilizer. While the formation of this coagulum may be partly avoided, under certain conditions it appears in every factory and there are more batches, especially in summer, that come from the sterilizer coagulated than otherwise.

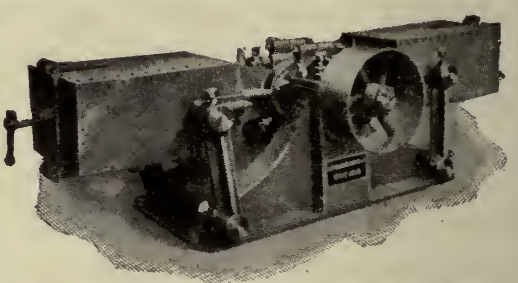

Fig. 68. Evaporated milk shaker Courtesy of Arthur Harris \& Co.

In this condition the product is not marketable. Some means must be provided, therefore, to break up this curd and reduce the contents of the cans to a smooth, homogeneous and creamy body. For this purpose a mechanical shaker is used.

Method of Shaking.-The shaker consists of one or more heavy iron boxes, or iron crates made of black iron pipes. These boxes are attached to an eccentric. The trays. filled with evaporated milk cans are firmly wedged into these boxes. When the shaker is in operation, the

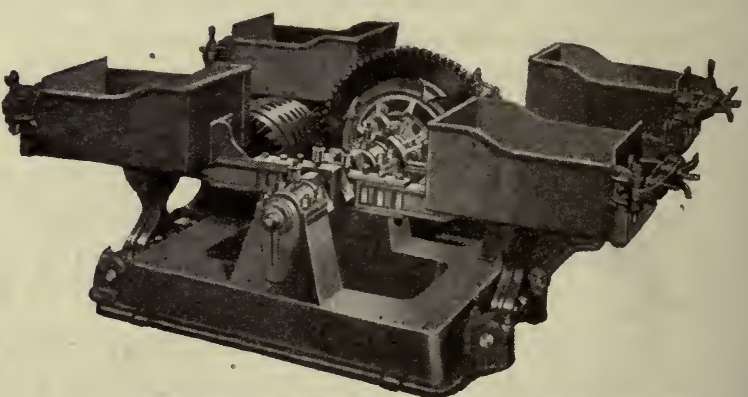

Fig. 69. Evaporated milk shaker Courtesy of The Engineering Co. cans are shaken back and forth violently, causing the curd in the cans to be broken up. 
Speed of the Shaker.--If the shaker is to perform its work properly, it must have long enough a stroke and run fast enough to cause most vigorous agitation. The stroke should be not less than about two and one-half inches and the eccentric should revolve not less than three hundred to four hundred times per minute. In order to accomplish this without wrecking the machine, the shaker must be fastened securely to a solid foundation.

From one-fourth to two minutes' shaking is usually sufficient to completely break down a soft curd. When shaking for five minutes does not produce a smooth milk, the product is usually hopelessly curdy and no amount of additional shaking will remedy the defect.

In some cases it has been possible, however, to improve the curdy product by shaking again after a day or two. Under certain conditions, age seems to have a slight mellowing effect on the curd.

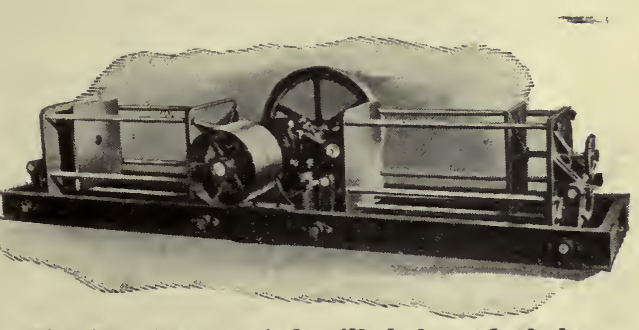

Fig. 70. Evaporated milk balanced shakex Courtesy of Schaefer Mfg. Co.

Formation of Curd not Desirable nor Necessary.-It should be understood that the processor should aim to get only a very

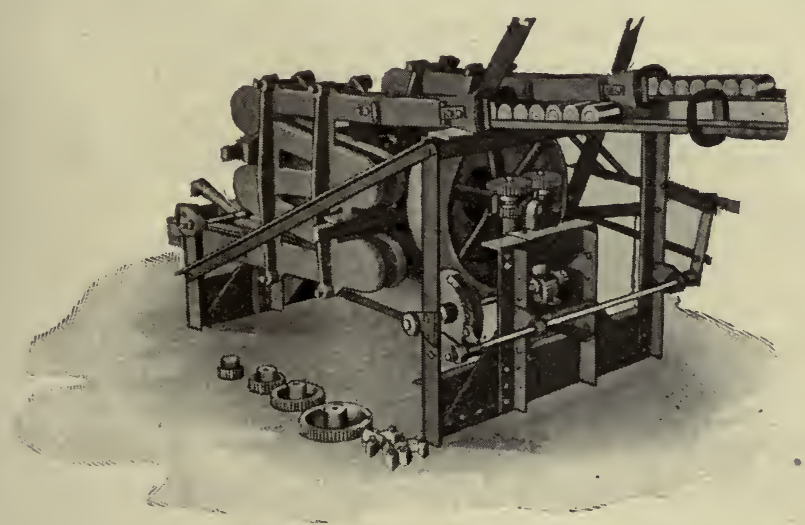

Fig. 71. Atomatic shaker

Courtesy of Schaefer Mfg. Co. 
slight and soft curd in his product, that can be shaken out in the shaker in one-fourth to one-half minute. When the curd produced is firm, even prolonged shaking will not prevent the appearance in the finished product of specks and small lumps of curd. Such milk is rejected on the market.

The formation of curd during the sterilizing process is not desirable and is not necessary as far as the marketable properties of the evaporated milk is concerned. It is unavoidable, however. under many conditions and as long as it can be confined to a soft curd that readily shakes out, no harm is done.

\section{INCUBATING.}

From the shaker, the cans are transferred to the incubating rcom. This is a room with a temperature of 70 degrees to 90 degrees $F$. The evaporated milk remains there ten to thirty days. The purpose of incubation is to detect defective milk and defective cans before they leave the factory. If the contents of any of the cans have not been completely sterilized, or if any cans have the minutest leak, the evaporated milk therein will spoil within the time of incubation. Such milk either sours. curdles or becomes solid, or it undergoes gaseous fermentation, causing the appearance of "swell heads." The more nearly perfect the process of sterilization and the better the construction and seal of the cans, the fewer are the spoiled cans. This incubation process is strictly a preventative measure. It is omitted in many factories where the cans are labeled, packed and shipped to their destination at once, or put in ordinary storage in the factory.

\section{Cinapter XII.}

\section{PLAIN CONDENSED BULK MILK.}

Definition.-This is an unsweetened condensed milk made frum whole milk, or partly, or wholly skimmed milk, condensed in vacuo at the ratio of about three or four parts of fluid milk to one part of condensed milk. It is usually superheated to swell 
and thicken it, and it has the consistency of rich cream. It is sold in 10-gallon milk cans to ice cream factories and in milk bottles to the direct consumer. Plain condensed bulk milk is not sterile, nor is it preserved by sucrose. Its keeping quality is similar to that of a high quality of pasteurized milk.

Quality of Fresh Milk.-The sweeter and purer the fresh milk or skim milk, the better will be the quality of this product. Old milk, or skim milk in which the acid development has made considerable headway, tends to form a lumpy plain condensed bulk milk. However, since this milk is not subjected to sterilizing temperatures and is used up quickly after manufacture, the (quality' of the fresh milk from which it is made, is not of such magnitude as in the case of evaporated milk.

Heating.-In the manufacture of plain condensed bulk milk the heating is accomplished much in the same manner as in the case of sweetened condensed milk and eraporated milk. The milk is usually heated by turning steam direct into it; though many of the more efficient types of milk and cream pasteurizers could be used to excellent advantage for this purpose.

It is advisable, however, to heat this milk only to about 150 to 160 degrees F. in order to secure a nice "liver" (coagulum), when it is stiperheated in the pan. If the milk is heated to the - boiling point in the forewarmers, it does not respond to the superheating in the pan as satisfactorily.

Condensing.- The condensing of plain condensed bulk milk is clone in the vacuum in a similar manner as described under evaporated milk, except that the evaporation is carried farther. See also "Campbell Process" and "Condensing Milk by Continuous Process."

Superheating.-When the condensation is nearly completed the milk in the pan is superheated. This is accomplished by shutting off the steam to the jacket and coils, closing the valve that regulates the water supply of the condenser, stopping the vacuum pump and blowing steam direct into the milk in the pan, for the purpose of swelling and thickening it. During this proc- 

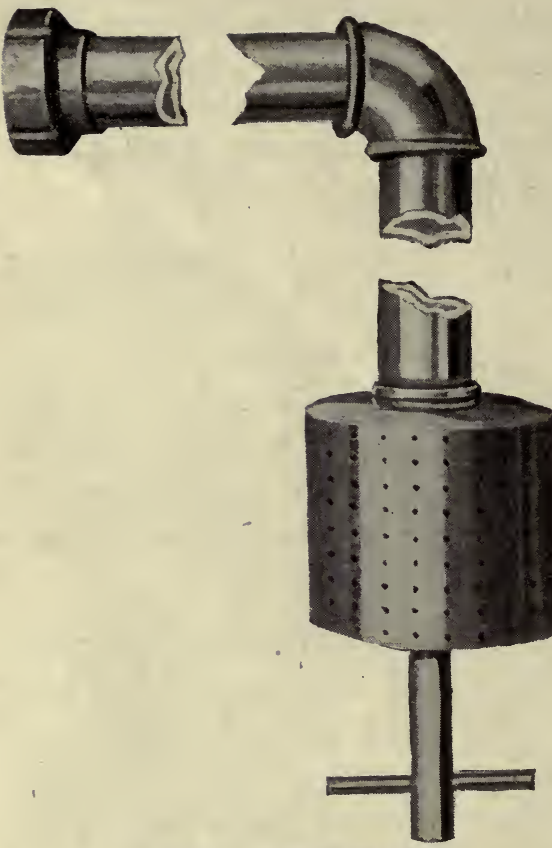

Fig. 72. Superheater

Courtesy of C. E. Rogers ess the temperature rises to between 180 and 200 degrees $F$. iVhen the milk has become sufficiently thick or, in the language of the processor, has produced the "proper liver" (coagulum) the steam is shut off, water is again turned into the condenser and the vacuum pump is started up. As soon as the vacuum has risen to from twenty-five to twenty-six inches and the temperature has dropped to about 130 degrees $F$. the process is complete, the racuum is released and the condensed milk is drawn off. The superheating usually occupies about twenty-five to thirty minutes.

The completion of the superheating, or the point when the superheating should cease, may also readily be detected by the examination of a sample of the product. As soon as the condensed milk begins to show a flaky condition of the curd, the purpose of superheating has been accomplished. The amount of superheating necessary and that the milk will stand, will largely depend, aside from the sweetness of the original milk, on the extent of the concentration. The higher the ratio of concentration, the less superheating is required to secure the desired results.

Striking.-The striking, or sampling and testing for gravity is done with a Beaumé hydrometer, the same, or a similar one. as is used for evaporated milk. The scale should extend to 18 degrees Beaumé. The batch should be struck before and after superheating.

Factories which standardize their product to a certain estab- 
lished density, usually condense the milk to a point slightly beyond that desired. Then, after superheating, they determine the amount of water required to reduce the finished product, and then add the required amount of water before the condensed milk is cooled. It is advisable to use destilled water for this purpose.

Ratio of Concentration.- The ratio of concentration varies largely with the fat content of the milk, although the locality and season of year are also influencing factors. Whole milk is condensed at the ratio of about three parts of milk to one part of condensed milk, while the ratio of concentration for skim milk is about 4 to 1 . The proper density varies somewhat with locality and season of year. Roughly speaking, whole milk has reached the proper density when the Beaumé reading at 120 degrees $F$. is about 10 degrees $B$. and skim milk has reached about the proper density when the Beaume reading at 120 degrees $F$. is about 14 degrees $B$. When the ratio of concentration exceeds 4 to 1 , there is danger of gritty condensed milk due to the precipitation, in this concentrated preduct, of crystals of milk sugar

Cooling.-The plain condensed bulk milk is usually drawn into 40 quart milk cans, placed in cooling tanks containing rerolving cogwheels, as described in Chapter VI, under "Cooling Sweetened Condensed Milk," and is cooled to as near the freezing point as facilities permit.

Recently this crude and laborious method of cooling has been superseded in many of the larger condenseries by more modern ways. While the plain condensed bulk milk becomes tco thick and sluggish during the process of cooling to make possible the use of surface coolers, and internal-tube coolers, it an be readily cooled in vats equipped with revolving discs, or in horizontal coil vats especially constructed for this purpose and in which the lower part of the rat is constricted and the coil sets very low in this constricted part. so as to agitate the milk vigorously and at the same time prevent the incorporation of air. by being completely submerged, or in circular rats equipped with a vertically suspended coil. The vertical coil vat has the further advantage in that it eliminates from the milk, all bearings and glands and it expels, rather than incorporates, air, from the condensed milk.

When cooled the condensed milk is ready for the market. 
If held in the factory, it should be placed in a cold room or should be otherwise protected against temperalures sufficiently high to cause it to sour. When kept at 40 degrees F. or below the danger from souring is largely eliminated. If transported long distances during warm weather, it should be shipped in refrigerator cars.

\section{CuAptiar XIII.}

\section{CONCENTRATED MILK.}

Definition.-Concentrated milk is cow's milk, either whole milk, or partly or wholly skimmed milk, condensed at the ratio of three to four parts of fresh milk to one part of concentrated milk. It is not condensed in vacuo, but in open vats by passing currents of hot air through the milk. It is sold largely in pint and quart bottles for direct consumption. It is not sterile and therefore keeps for a limited time only. Its keeping quality is similar to that of a high grade of properly pasteurized milk. The process by which the concentrated milk is manufactured is known as the "Campbell Process." This process was invented by J. H. Campbell of New York City, in $19 \mathrm{CO}$ and patented in 1901.

Apparatus Needed.-The principa! part.; are: the evaporating vat with hot water jacket and coils, and air blast registers or nozzles near the bottom of the rat; an air blewer which furnishes the air blast; an air heater through which the air blast passes and from which the heated air is conducted into the milk; a water pump circulating hot water through the jacket and coils; an auxiliary evaporating tank for completing the evaporation; and a spray pump which throws the spray of milk drawn from the bottom of the main evaporating vat into the auxiliary tank and for transferring the partly condensed milk from tank 1 to tank 2.

Operation of Campbell Process.-The milk is heated to about 100 degrees $F$. and allowed to How into evaporating tank 1 . Water at temperatures ranging from 100 to 125 degrees $F$. is forcer! through the coils and jacket. Hot air is then passed into the milk. The temperature of the air is regulated so as to keep the temperature of the evaporating milk down to 120 degrees $F$. 
on the start, and to finish the evaporation between 90 and 100 degrees F. The air blast is so introduced as to keep the milk along the heating surface of the jacket and coils in circulation and, therefore, prevent largely the baking of the milk on the heating surface. After the milk has been evaporated to a certain degree of concentration, say $2: 1$, it is transferred to the auxiliary evaporating tank where the condensation is completed. This transfer is not necessary, but is resorted to solely as a convenience, in order to continue treatment of the reduced bulk of material in a smaller tank and leave the larger tank free for treating a fresh batch of milk, and further, because there are no obstructing coils in the auxiliary tank, interfering with the drawing off of the finished and thick condensed milk. In this process, as now used, the milk is usually first separated and the skim milk only is condensed. The cream is subsequently added to the condensed skim milk.

Advantages and Disadvantages of Campbell Process.-The initial cost of installing the necessary machinery is much less than where vacuum evaporation is practiced. The low heat applied makes it possible for the finished product to retain the properties of raw milk, leaving the allumenoids and lime salts in their original and easily digestible form and preserving the antiscorbutic vitamines in active form.

This process is applicable only in the manufacture of unsweetened condensed milk. Lnless subsequentiy sterilized, the product will keep for a short time only. This process has at the present time only very limited use. It can hardly be considered as an important branch of the condensed milk industry.

\section{CIIAPTiR XIV.}

\section{CONDENSING MILK BY CONTINUOUS PROCESS.}

The processes of condensing milk described in preceding chapters, are exclusively confined to the intermittent or batchprinciple of evaporation. 'That is in the case of the vacutrm pair. the fresh.milk runs into the pan until the capacity of the pan is reached and no conciensed milk leaves the pan until the condensaticn of the entire batch is completer. 'Then the pan must be emptied before more milk can be drawn in. In a similar manner, in the Campbell process, evaporation of the entire batch 
must be completed before any of the finished product leaves the evaporating vat or tank. The operation in either case is intermittent and not continuous.

Of more recent years, equipment and processes have been developed that make possible contintous operation. That is, the fresh milk enters the machine and the condensed milk leaves it simultaneously and continuously. So far three types of continuous machines have been perfected sufficiently to make them commercially practical and usable, namely the Buflovak Rapid Circulation Evaporater, invented and manufactured by the Buffalo Foundry and Machine Co., Buffalo, N. Y., the Continuous Concentrator, invented by the By-Products Recovery Co., Toledo, Ohio, and manufactured by the Creamery Package Manufacturing Co., Chicago, and the Ruff Condensing. Evaporator, manufactured by The Cream Production Co., Port Huron, Mich.

\section{BUFLOVAK RAPID CIRCULATION EVAPORATOR.}

This type of Evaporator has been developed from the standard return-flue tubular boiler and adopted for the special purpose of handling foamy and delicate liquors.

Construction.'The Buflorak Rapid Circulation Evaporator consists of a horizontal cylindrical vapor body. 'To this is bolted an inc li ne d cylindrical steam-chest.

The vapor body is equipped with a baffle plate which extends across its cylindrical part and

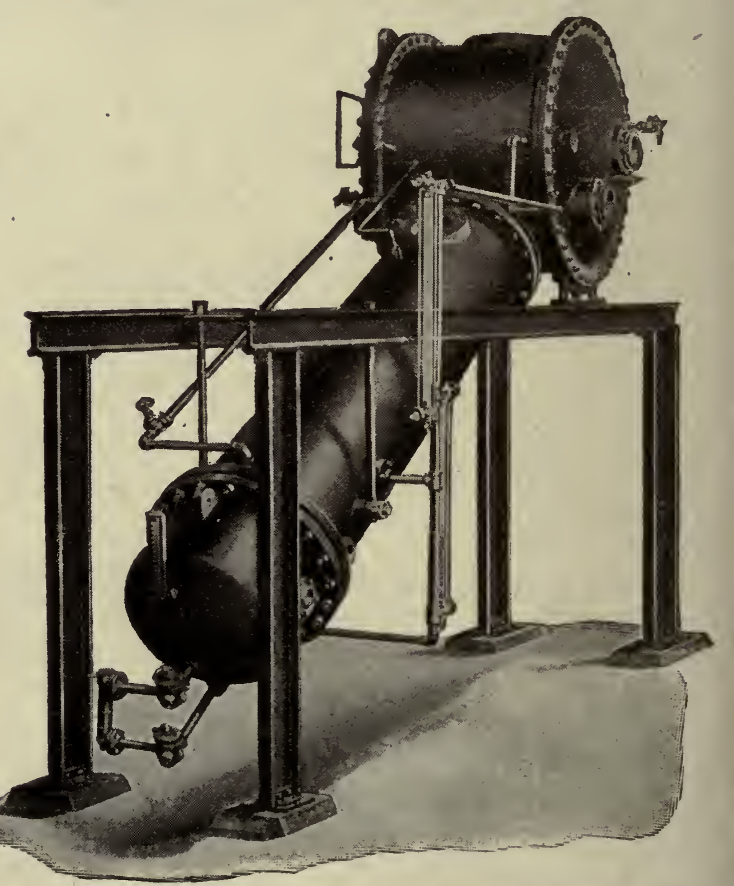

Fig. 73. The Buflovak rapid circulation evaporator Courtesy of Buffalo Foundry \& Machine Co. 
leaves openings at both ends of the vapor body for the vapors to escape, the ends or heads of the vapor body being dished outward. The vapor body also carries the milk inlet, vapor outlet and spy glasses.

The steam chest which is attached to the lower part of the vapor body, is divided by a solid partition into two compartments. The upper and larger compartment is filled with tubes which are expanded in the flue-sheets, closing both ends. The tubes themselves are open at both ends. They are two inches in diameter and from six to eight feet long. The lower and small compartment, called the downtake, is entirely open at both ends. The steam chest is equipped with a steam inlet, a liquor outlet and a condensation outlet or drip. The steam is around the tubes and the milk is inside the tubes.

Operation.-This machine is operated under vacuum of from 26 to 28 inches mercury column, the vapor outlet being connected with a condenser and vacuum pump.

The fluid milk enters the vapor body and flows down into the bottom of the downtake of the steam chest, from where it rises in the tubes and finds its level. The level of the milk in the tubes is kept low, the coefficient of the heat transmission being highest when the milk level in the tubes is about onethird of the tube length above the lower flue-plate, and it is regulated by automatic float controls in the larger machines. The steam that is turned into the steam chest, causes the milk in the tubes to boil. The vapor thus arising from the milk, together with a portion of the milk, rises and passes through the upper part of the tubes at a very high speed, and is thrown with great force against the ribs of the baffle plate which extends across the whole cylindrical length of the rapor body.

The liquid or condensed milk returns through the downtake to the lower part of the steam chest where it escapes from the machine. The vapor passes at both ends of the baffle plate into the vapor space above and from there through the entrainment separator for reclaiming, escaping milk, and then to the condenser attached to the outlet of the vapor body.

The upper part of the tubes becomes covered with a climbing film of milk. This together with the high speed of the 
milk in the tubes (100 feet per second or more) increases the capacity of the heating surface, and the small amount of milk in circulation, together with the low level of the milk in the tubes, reduces the possibility of fnaming, confining the foam to and breaking it up in the upper part of the tubes where film eraporation takes place.

The escape of the condensed milk is continuous and the
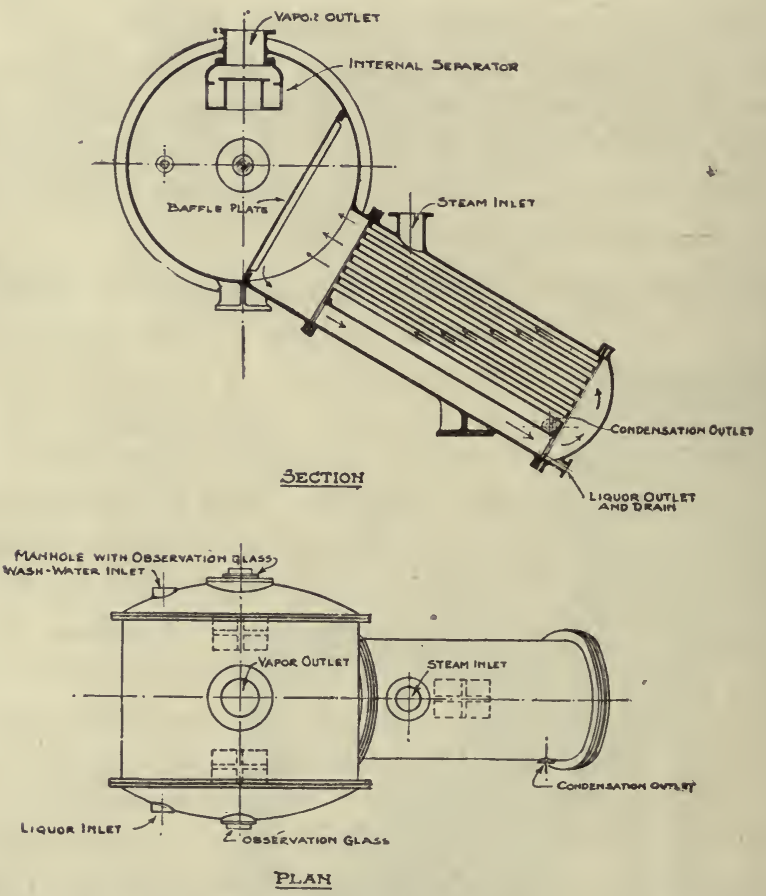

Fig. 74. Cross section of Buflovak rapid circulation evaporator Courtesy of Buffalo Foundry and Machine Co.

degree of concentration is controlled by a valve regulating the outlet. The condensed milk runs by gravity from the steam chest into a reservoir located under the evaporator. In this case the reservoir must be under the same vacu1m as the evaporator. In some cases it. is recommended to have an intermediate storage tank removing the condensed milk from the evaporator by a specially constructed steam pump. 


\section{THE CONTINUOUS CONCENTRATOR.}

The inflow of the fluid milk and the outflow of the condensed milk are continuous. The milk is condensed under atmospheric pressure at 212 degrees $F$. A rapidly revolving agitator throws the milk in a thin film against the steam-heated and continuously polished periphery of a jacketed copper drum. By keeping the heating surface clean and bright, and the milk rapidly moving, the power of the milk to absorb and utilize heat is greatly algmented and the rapidity of evaporation increased.

Description of Continuous Concentrator.-The continuous concentrator consists of a hollow copper drum. The copper shel! is surrounded by a steam jacket which is insulated. The space

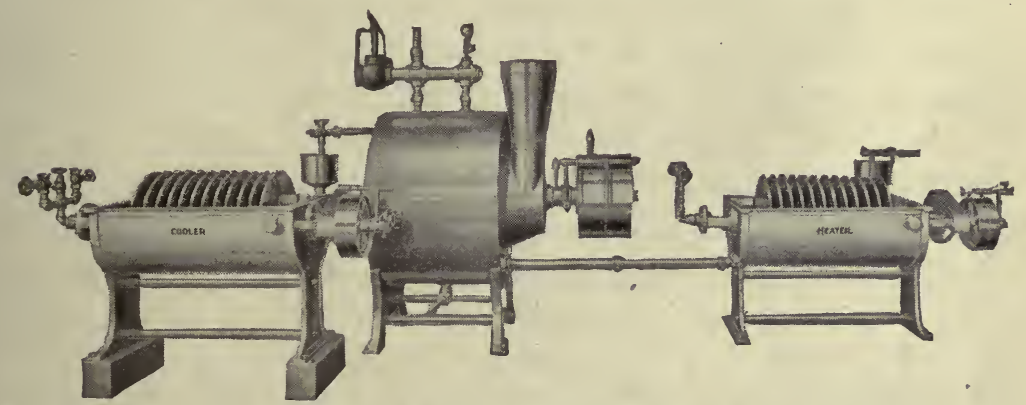

Iig. 75. The continuous concentrator with preheater and cooler

Courtesy of Creamery Package Mfg. Co.

between inner shell and jacket is about one inch.

This drum carries in its interior, a revolving dasher with f.nur or more hlades, according to the size of the machine, and similar to an ice cream freezer or a flash pasteurizer. The edge of these blades comes in direct contact with the inner surface of the shell which is the heating surface, so that when revolving, each blade constantly removes from the heating surface any nilk that adheres to it.

The blades are pressed against the heating surface by the centrifugal force that is generated when the machine is in motion. The arms to which the blades are attached are equipped with stops that control their pressure against the heating surface so as to insure continuous and uniform pressure. The shaft which carries the dasher passes through the front and rear heads 
of the concentrator and carries a pulley hack of the rear head, to which the power is transmitted.

The rear of the concentrator terminates in the exhaust chamber of the condensed milk vapors, which escape throngh a galvanized iron flue to the outside. The vapors are not condensed by water, but escape into the atmosphere. The rear wall is equipped with the intake of the fluid milk. In order to permit the milk to feed the concentrator by gravity, without necessitating inconveniently high elevation of the forewarmer, the intake is located at the bottom.

In the front head, in close proximity to the periphery of the concentrator is located the outlet of the condensed milk. Its distance from the inside wall of the concentrator determines the thickness of the film of condensed milk that is allowed to form on the heating surface, and the amount of milk that is retained in the concentrator. According to the amount of superheating intended, this film may vary from $\frac{1}{x}$ to $\frac{1}{2}$ inch in thickness and the amount of milk retained in the machine may vary from 6 to 12 quarts.

The front head is equipped with a cover which is fastened to the rim with screw bolts and which carries a spy glass through which the operator may watch the process. At the conclusion of the operation this cover is removed and the dasher and blades are taken out, so that both the shell and the dasher can be readily washed. Over the top of the concentrator extends the steam line, a 3 inch pipe, with $1 \frac{1}{2}$ inch laterals, supplying the steam jacket, and insuring uniform distribution of heat. The steam line is also equipped with regulator and steam gauge. At the bottom of the concentrator is located the exhanst and regulating crip valve.

The continuous concentrator is constructed of diverse sizes and capacities, the most common of these sizes are the following:

\begin{tabular}{|c|c|c|c|}
\hline Diameter & Length & $\begin{array}{c}\text { Capacity per Hour } \\
\text { when Concen- } \\
\text { trating at the } \\
\text { Ratio of } 3: 1 \\
\end{array}$ & $\begin{array}{c}\text { Boiler Capacity } \\
\text { Required } \\
\text { H. P. }\end{array}$ \\
\hline 3 feet & 4 feet & 7000 libs. & 100 H. P. \\
\hline 3 feet & 3 feet & - $5000 \mathrm{lbs}$ & 80 H. P. \\
\hline 3 feet & 2 feet & $2000 \mathrm{lbs}$. & $40 \mathrm{H} . \mathrm{P}$. \\
\hline
\end{tabular}


Speed of Agitator.-The proper speed of the continuous concentrator is expressed in terms of rim speed, that is the distance which the blades travel per minute. It has been found that the rim speed which is sufficient to move the film of milk in the machine properly, is about 2500 feet per minute. In order to insure a rim speed of 2500 feet per minute, the blades in a 3 foot dianeter machine must revolve $\frac{2500}{3 \times 3.14}=265$ times per minute. In a six foot diameter wheel, the same rim speed would require $\frac{2500}{6 \times 3.14}=133$ revolutions per minute of the spider.

Again, it has been found that the blades should be not more than about $2 \frac{1}{2}$ feet apart. A three foot diameter concentrator, therefore, requires four blades while concentrators with larger diameter require a larger number of blades in order to keep the distance between blades within the limit of two and one-half feet.

Operation of Continuous Concentrator.-.'The operation of the continuous concentrator is simple and the ratio of concentration of the product can be regulated as desired.

Heating of Milk.--Similar as in case of evaporation in vacuo, it is desirable, if not necessary, to heat the milk before it enters the concentrator. This not only increases the capacity of the machine, but it also prepares the casein in the milk for the superheating to which the milk is subjected in the concentrator. Any method of forewarming or preheating may be used for this purpose, but since the milk flows to and through the concentrator, in a continuous stream, it is preferable to also use a forewarmer of the continuous type. The milk should be heated to about 185 to 200 degrees $F$. and the forewarming should be so arranged that the milk is exposed to this temperature for 5 to 10 minutes before it enters the concentrator.

Condensing.-The concentrator is steamed, the parts of the agitator are assembled and installed in their proper place, the cover is securely bolted over the opening in the front head and the machine is ready for operation. Before starting the agitator a small amount of milk is permitted to flow into the concentrator 
so as to prevent the blades from running over the dry heating surface, cutting the copper. Simultaneonsly with the starting of the agitator the steam is turned into the jacket and then the milk intake valve is opened.

The steam pressure on the jacket is kept uniform, preferably at 40 to $50 \mathrm{lbs}$. of steam. This machine evaporates the milk at atmospheric pressure. The temperature of the milk in the concentrator therefore, is practically the same as that of boiling water-212 degrees F.-at the sea level and varies only with the altitude of the location. The ratio of concentration is regulated by the rate of the milk inflow. As the milk inflow is increased. the ratio of concentration is reduced, because the amount of evaporation being constant, a smaller proportion of the water is taken out of the milk.

The density is determined by the use of the Beaumé hydrometer. If the density is greater than desired. more milk is allowed to flow into the machine. If the density is lower than desired the inflow of milk is reduced.

Cooling of Condensed Milk.-From the discharge spout the condensed milk is run over a continuous cooler from which it escapes ready for packing in whatever form it is intended for. The disc continuous cooler has proven very suitable for this purpose.

No subsequent superheating of the concentrated milk is necessary. This product can be made of any consistency desired, regardless of concentration, according to the thickness of the film that is allowed to form in the concentrator, and this in turn depends on the distance of the discharge from the periphery of the machine.

\section{THE RUFF CONDENSING EVAPORATOR.}

Principle of Machine and Process.-In the "Ruff Condensing Evaporator," similar as in the "Contintous Concentrator," the condensing is accomplished by the film principle, but in the Ruff machine the heating surface consists of one or more steam-heated. revolving drums, and atmospheric air is blown through the mills. This machine is applicable both, for continuous evaporation and for condensing in batches. 
Construction.-The Ruff Condensing Evaporator consists of the following, three main parts :

1. A vat or $\mathrm{t}$ a $\mathrm{n} \mathrm{k}$ holding the milk to be condensed, and equipped with cover. The body of this tank is of steel sheathing, lined on the inside with tinned c op per. The cover or top is fitted with doors.

2. One or more st e a m-

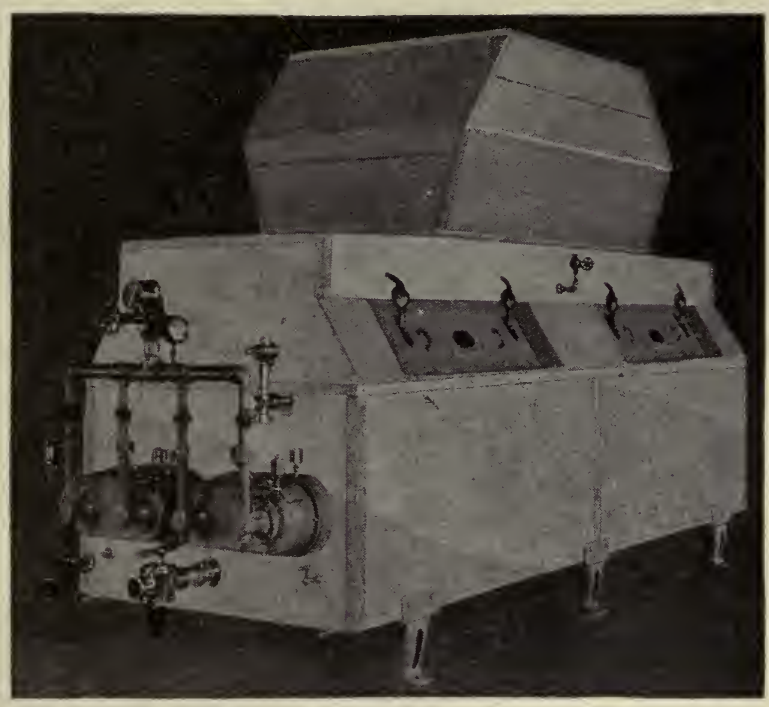

Fig. 76. The Ruff condensing evaporator Courtesy of The Cream Production Co. heated hollow cylinders which revolve in the tank horizontally. These cylinders are constructed of special steel, highly polished. They are equipped with tinned bronze scrapers which remove the film of milk from the heating surface. The cylinders are fitted with a device for the automatic removal of the condensed steam, facilitating the continuous heating with dry steam and therby inhancing the rapidity of evaporation and augmenting the capacity of the machine.

3. An arrangement for blowing atmospheric air into the lower part of the tank, causing it to rise up through the milk and to escape from the tank.

4. Accessories.-The entire unit further comprises such accessories as a dial thermometer, high pressure blower with pipe connections from fan to evaporator and automatic return boiler feed pump, complete.

Operation.-The milk is preheated to 145 degrees $F$. The hot milk runs into the tank by gravity, or is pumped in. In the 
case of continuous evaporation the milk is kept at a constant level, the lower part of the revolving cylinders dipping into it and picking up a film which is automatically scraped off with every revolution of the cylinders.

At the same time air is blown through the hot milk, further assisting in the evaporation and also removing gases and other volatile substances from the milk.

During operation the revolving cylinders are charged with 40 pounds of steam and the temperature of the milk is held at about 145 degrees $F$.

The process of condensing can be carried to almost any degree of concentration and the desired degree of density is determined in a similar manner as in the case of evaporated milk and plain condensed bulk milk.

Capacity.-This machine is constructed in several sizes, with capacities ranging from 900 pounds to 8000 pounds of raw milk per hour, based on a ratio of concentration of two to one, as shown in the following specifications:

\begin{tabular}{c|c|c|c|c|c|c}
\hline \hline $\begin{array}{c}\text { Model No. } \\
\text { 1920 }\end{array}$ & $\begin{array}{c}\text { Number of } \\
\text { Steam } \\
\text { Cylinders }\end{array}$ & $\begin{array}{c}\text { Approximate } \\
\text { Floor Space }\end{array}$ & $\begin{array}{c}\text { Gallons } \\
\text { Tank } \\
\text { Capactity }\end{array}$ & $\begin{array}{c}\text { Pounds Capacity } \\
\text { Condensing } \\
\text { Raw Mnik } \\
\text { to 1 per Hour }\end{array}$ & $\begin{array}{c}\text { Additional H. P. } \\
\text { Required for } \\
\text { Blower and } \\
\text { Evaporator Cyl- } \\
\text { Inders }\end{array}$ & $\begin{array}{c}\text { Required } \\
\text { Boller } \\
\text { Capacity } \\
\text { H. P. }\end{array}$ \\
\hline 2 & 2 & $3^{\prime} \times 5^{\prime}$ & 175 & 900 & 4 & 15 \\
4 & 2 & $3^{\prime} \times 10^{\prime}$ & 300 & 1800 & 7 & 30 \\
6 & 2 & $4^{\prime} \times 14^{\prime}$ & 500 & 2700 & 10 & 40 \\
7 & 4 & $5^{\prime} \times 14^{\prime}$ & 600 & 5400 & 20 & 80 \\
8 & 6 & $7^{\prime} \times 14^{\prime}$ & 1000 & 8000 & 30 & 120 \\
\hline
\end{tabular}

Quality of Products from Continuous Concentrators and Evaporators.-When properly operated and when using a good quality of raw material these continuous concentrators and film evaporators yield a product of excellent flavor and good quality, especialiy suitable for the manufacture of ice cream, but also applicable for the manufacture of sterilized evaporated milk, condensed buttermilk and condensed whey.

\section{ChAPTF:R XV.}

\section{CONDENSED BUTTERMILK.}

The value of buttermilk as a part of the feed ration for chickens, laying hens, pigs and hogs has long been recognized 
and its use for feeding purposes is rapidly growing. Buttermilk not only contains protein and carbohydrates of high quality and great digestibility, but it has biological properties that stimulate growth and gain in weight. and it exerts a physiological action that makes for a healthy condition of the intestines, because of its lactic acid content.

Chicken feeders have found it invaluable in their efforts to accomplish maximum growth and gain in weight of the growing chicks, and because of the superior quality of the meat of buttermilk-fed fowl. And extensive experiments with laying hens have conclusively demonstrated that buttermilk makes for increased egg production.

For similar reasons buttermilk, when properly balanced with other feed, is a most valuable hog feed. In fact it is the foundation of a good hog and is becoming a more and more indispensable part of the ration for growing pigs and fattening hogs.

Composition of Buttermilk. ${ }^{1}$

\begin{tabular}{|c|c|c|c|c|c|c|c|}
\hline \multirow{2}{*}{$\begin{array}{l}\text { Constituents } \\
\text { in } \\
\text { Buttermilk }\end{array}$} & \multicolumn{5}{|c|}{ From Ripened Cream } & \multicolumn{2}{|c|}{ From Sweet Crean } \\
\hline & $\begin{array}{l}\text { Van } \\
\text { Slykke } \\
\%\end{array}$ & $\begin{array}{c}\text { Storch } \\
\%\end{array}$ & $\begin{array}{c}\text { Snyder } \\
\%\end{array}$ & $\begin{array}{c}\text { Vieth } \\
\%\end{array}$ & $\begin{array}{c}\text { Fleisch- } \\
\text { mann } \\
\%\end{array}$ & $\begin{array}{l}\text { Störch } \\
\%\end{array}$ & $\begin{array}{l}\text { Rich- } \\
\text { mond } \\
\%\end{array}$ \\
\hline Water & 90.6 & 90.93 & 90.5 & 90.39 & 91.30 & 89.74 & -90.98 \\
\hline Fat :.. & .1 & .31 & .2 & .50 & .50 & 1.21 & .35 \\
\hline $\begin{array}{l}\text { Casein } \\
\text { Albumin }\end{array}$ & $\begin{array}{r}2.8 \\
.8\end{array}$ & 3.37 & 3.3 & 3.60 & 3.50 & 3.28 & 3.51 \\
\hline Vilk Sugar. & 4.4 & 4.58 & 5.3 & 4.06 & $M$ & 400 & $4.4 ?$ \\
\hline I. actic Ac & .6 & & & .75 & 4.00 & 4.98 & .01 \\
\hline Ash & .7 & .81 & .7 & .80 & .70 & .79 & .73 \\
\hline
\end{tabular}

Specific gravity of sweet-cream buttermilk 1.0331 . Specific gravity of sour-cream buttermilk 1.0314 . Caloric value 165.

Since the great bulk of butter is manufactured during the summer season, the main supply of buttermilk is confined to the summer months. In summer the output of buttermilk far exceeds the demand for this product and much of it goes to waste for lack of a suitable market for it. In winter, on the other hand, the output of buttermilk is small and insufficient to supply the demand.

${ }^{1}$ Hunziker, The Butter Industry, 1920. 
In order to stop this waste of buttermilk in summer, to utilize it economically and profitably and to equalize the supply throughout the year, some of the large creameries of the country have found it practicable and profitable to condense the surplus buttermilk. Information from chicken feeders and hog feeders shows that, when re-diluted to the consistency of the original butternilk, this condensed buttermilk gives equally as satisfactory results as the fresh buttermilk.

Prior to the great war the market value of buttermilk and of condensed buttermilk was considered too limited to justify the relatively high manufacturing expense, incident to the concentration of buttermilk by evaporating from it a large portion of its water. But the food and feed shortage, together with the high prices brought about by the war and since the war, necessitated the more general use of byproducts and raised the valuation of buttermilk to figures that render its manufacture into condensed buttermilk highly profitable.

Manufacture.-There are several methods whereby buttermilk can be and is being commercially reduced in volume. The most common of these are: Removal of water by gravity, removal of water by centrifugal separation, removal of water by evaporation, either in vacuo or under atmospheric pressure.

Removal of Whey by Gravity.-Much of the so-called condensed buttermilk that reaches the market is not the result of evaporation of a portion of the water contained in the buttermilk, but is produced by permitting the curd to settle by gravity and then drawing off and rejecting the whey.

In this case the fluid buttermilk is pumped into a wooden tank, either a horizontal vat or a vertical stave tank. The tank usually contains several outlets with gates, located at different heights, to facilitate the removal of the whey. The tank may or may not be equipped with steam pipes for heating. The buttermilk is heated to boiling point in these tanks either by blowing live steam into it, or by running steam through the pipes installed in the tank. This heat is maintained for sereral hours. This causes the casein to contract and settle to the bottom in the form of fine particles of curd, leaving on top a clear whey. This whey is drawn off through the gates located above the stratum 
of curd. The residue, consisting largely of casein, water and some lactic acid and milk sugar, represents the condensed buttermilk. The concentration, or more correctly speaking, the reduction in volume thus offered, is at the ratio of about 4 to 5 parts of fluid buttermilk to one part of condensed buttermilk. It is obvious that in this form of concentration all of the valuable food elements of the buttermilk are not reclaimed. Most of the milk sugar and much of the lactic acid escape with the whey and are lost. However, the equipment required for this process is very simple and inexpensive and the process requires no special knowledge on the part of the creamery personnel.

Concentration by Centrifugal Separation.-For many years. efforts have been made to remove the water from the buttermilk by centrifugal separation. Machines are now on the market and in use, in which the curd of the buttermilk collects on the walls of a revolving basket while the whey is centrifuged out. These machines are similar in principle to the well-known laundry centrifuge. They have been successfully used by creameries that are engaged in the manufacture of buttermilk cheese. Their operation, hoivever, is intermittent only. When the basket fills 11) with the curd, the machine must be stopped and the curd removed.

For the purpose of handling large volumes of buttermilk daily, these centrifuges are obviously not well adapted. They are too limited in capacity, in speed and in volume of performance. Efforts to derise a centrifuge for continuous operation. similar to the cream separator, have so far failed. The specific gravity of the curd in the buttermilk is so nearly like that of the whey, that the centrifugal separator refuses to discharge a liquid rich in curd and one of practically clear whey. Experiments by the author have demonstrated that, no matter how the ontlets of the discharges are adjusted, both liquids have practically the same composition.

Evaporation in Vacuo.-This method for condensing buttermilk is rapidly gaining in fávor and today vast rolumes of buttermilk are concentrated in this manner. The equipment used and the method of operation are principally the same as those used in the manufacture of condensed milk and evaporated milk. The buttermilk is condensed in the vacuum pan. 


\section{Equipment Necessary to Condense from 5000 to 6000 Pounds} of Buttermilk per Hour:

2 wooden buttermilk storage tanks, capacity 10,000 pounds each, for ripening the buttermilk;

16 -foot vacuum pan with condenser;

1 vacuum pump, vacuum cylinder 18 inches diameter and 20 inches long; if steam driven, steam cylinder, 12 inches diameter and 12 inches stroke;

2 hot wells, 5 feet diameter and 5 feet deep, with 3 inch outlet in bottom. and equipped with brass heater arrangement.

Boiler capacity, $150 \mathrm{H}$. P.

Water requirements; 125 gallons per minute. *

\section{OPERATION.}

Ripening of Buttermilk.-The buttermilk should be sour. the sourer the better, because:

1. The acidity facilitates the process of manufacture. The curd in sweet or only slightly sour buttermilk is viscous and sticky. It adheres to the coils and sides of the pan and its action during the condensing process is sluggish, retarding evaporation, reducing the capacity of the pan and increasing the cost of manufacture.

If the buttermilk is sour, these handicaps are greatly minimized. Upon subsequent heating the curd in the sour buttermilk contracts, loses much of its viscosity and stickiness, and adheres less readily to coils and sicles of the pan. The sour buttermilk is more fluid, boils more vigorously and therefore condenses more rapidly.

2. High acid content is necessary in order to give the condensed buttermilk satisfactory keeping quality. The finished product is not sterile, nor is the temperature at which it is held in storage sufficiently low to inhibit bacterial action and prevent decomposition. The acidity is essential to preserve this product.

3. High acid is adrantageous for feeding purposes. The acid in the buttermilk keeps the fowls. pigs and hogs in healthy condition, and makes them thirsty. They drink more water, which is a valuable asset for best results. 
If the buttermilk comes from sweet cream butter or from neutralized cream churnings, it is usually not sufficiently-sour for ready handling and rapid evaporation. It therefore should be allowed to ripen before it is used. For this purpose it is held in wooden storage tanks for one or more days, where it automatically develops acidity due to the lactic acid bacteria with which it is usually teeming. For most satisfactory operation the buttermilk should have an acidity of approximately .6 per cent. In some cases it may be necessary to inoculate it with lactic acid starter in order to insure the desired acid development.

Heating the Buttermilk.-From the ripening tanks the buttermilk is drawn or pumped into the hot wells, where steam is turned clirect into it until the temperature is raised to the boiling point. This method of heating also keeps it agitated and prevents the ropious settling of the curd.

Condensing.-From the lot wells the boiling-hot buttermilk is drawn into the vacuum pan. The buttermilk is preferably drawn frem the lottom of the hot weils, so as to continuously remore a portion of the settling curd. The buttermilk will drop some of its curd in the hot wells. The operation of the vacuum pan for buttermilk is the same as for milk. For general directions the reader is referred to Chapter V on "Condensing."

The first pans used for condensing buttermilk were tin coated on the inside and had tinned copper coils, so as to minimize the action of the acid on the copper. The tin coating was of very short ruration, however, especially that on the coils, so that it was found impractical and too costly to use tinned vac$111 \mathrm{~m}$ pans. The pans now in use are not tinned.

In the conciensing of a thick and sluggish liquid, such as buttermilk, it is of the greatest importance that the coil arrangement in the vacuum pan be such as to insure maximum circulation of the milk, otherwise the buttermilk is incapable to absorb the heat fast enough and to expose enough surface to evaporation, to make possible rapid concentration, the buttermilk fails to freely boil up, it sluggishly bubbles in the bottom of the pan. evaporation is slow, the capacity of the pan is greatly reduced, and the cost of manufacture is increaserl. For detailed description of the proper coil arrangement see Chapter V on "Description of Vacuum Pan." 
During the early stages of the condensing process the buttermilk boils and behaves in the pan in a similar manner as milk. As the process continues and the buttermilk increases in density, it becomes more sluggish and does not circulate as rapidly, nor boil as vigorously.

Concentration.-The buttermilk should be condensed until it has a concentration of at least $4: 1$. Buttermilk of a lower concentration fails to have the necessary keeping quality to withstand the trials of storage for several months at ordinary temperature. It undergoes decomposition, usually of the putrefactive type, that renders it unfit for feeding purposes.

Testing for Density.-No accurate mechanical method of determining the exact density of the condensed bitttermilk has as yet been worked ont. When a concentration of about $4: 1$ or more has been reached, the buttermilk is very thick, even while hot. It is too thick and viscons to permit of testing it with the Beatumé hydrometer. The density could be determined however by weighing a definitely measured volume or by the adaption of a resistance tester such as the Mojonnier viscosimeter. Ordinarily, however, the determination of the proper degree of concentration is left to the experienced eye and judgment of the pan operator. If he condenses batches of uniform size; the height of the surface of the condensed buttermilk in the pan furnishes an approximate guide. The behavior of the boiling condensed buttermilk, when the proper degree of concentration has been reached, is also noted. And samples taken from the pan and examined for thickness, standing-up properties and transparency or opaqueness, as described under "Methods of Striking" for sweetened condensed milk, Chapter VI, enable the operator to approach a fairly uniform density of the finished product from batch to batch.

When condensed at the ratio of $4: 1$ the buttermilk at the temperature of the pan, or about 120 degrees $F .$. is thick enough so that when a sample is taken into a cun and a portion of it is picked up with a spoon or stick and is allowed to drop back into the cup from a height of about six inches, it does not readily diffuse, but "piles up" on the surface of the sample in the cup.

Condensing Buttermilk by Film Process.-The condensing of buttermilk can be and is accomplished also by film evapora- 
tion as represented by the "Continuous Concentrator" and the "Ruff Condensing Evaporator." These methods have proven a commercially practical proposition. Experiments have demonstrated that a condensed buttermilk of very good quality and of the desired degree of concentration can be made by the use of these continuous machines. In fact some of the condensed buttermilk on the market is their product and it is probable that the future will see many of these machines installed and in operation in creameries for the purpose of condensing buttermilk. See also "Condensing Milk by the Continunus Process," Chapter XIV.

Packing.-The condensed buttermilk is filled into barre!s, holding about 600 pounc's of the finished product. Second hand glucose barrels or copra barrels are generally used for this purpose. Buttermilk intended for bakeries, confectioners and other channels of human consumption, should be filled into new barrels. The barrels should be thoroughly rinsed and steamed out before use and it is advisable to treat them on the inside with sodium silicate.

The barrels are filled with the condensed buttermilk while hot and direct from the pan or other condenser. If allowed to cool, the condensed buttermilk would be too thick to "run."

Storage.-The barrels filled with the condensed buttermilk are storer at ordinary ware house temperature. If made from properly soured buttermilk, condensed at the ratio of not less than $4: 1$, and if the barrels are filled completely full and sealed tightly, the product will keep in good condition, without molding and without appreciable deterioration for many months without artificial refrigeration.

In remnant barrels or In barrels which are subsequently opened and from which a portion of the contents has been removed, the buttermilk molds rapidly on the surface and spoils, because of exposure to air. This can be largely prevented by "slapping" a piece of heavy paper (wrapping paper), large enough to cover the entire exposed surface. on the top of the remaining contents. The condensed buttermilk being of a pasty consistency forms a tight seal with the paper, shutting out the air, and retarding molding and decomposition.

The above statements concerning the keeping quality of 
condensed buttermilk refer only to the prodtict resulting from evaporation of a portion of the water, such as condensing in the vacuum pan, or by the continuous concentrators and evaporators. Where the reduction in rolume is accomplished by removing a portion of the whey, either by gravity or by centrifugal separation, the finished product lacks in keeping quality, it will spoil in a few weeks after manufacture, if held at ordinary temperatures. The reason for this lies in the fact that with the removal of the whey, the finished product is also deprived of much of the lactic acid. There is not high enough a percentage of acid left in it to preserve it.

Composition of Commercial Condensed Buttęrmilk.

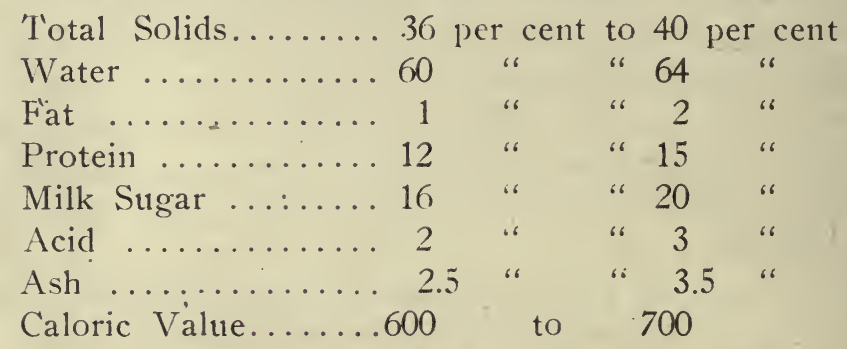

Markets.-The great bulk of condensed buttermilk manufactured in the United States is sold to chicken feeders and for hog feeding. The price obviously fluctuates with season, locality and supply and demand. During the first six months of 1920 it averaged about 4.5 cents per pouncl.

Considerable quantities of condensed buttermilk are also absorbed by bakeries and manufacturers of diverse prepared food products. The price received during the first six months of 1920 , for condensed buttermilk sold to bakeries, etc., averaged about 8.5 cents per pound.

Annual Output of Condensed Buttermilk in United States. -As previously stated the manufacture of condensed buttermilk is rapidly growing. In 1918 the total output amounted to $6,534,023$ pounds; in 1919 it was 22,535,580 pounds.

\section{CONDENSED WHEY, MYSEOST, OR PRIMOST.}

The condensing of whey is a practice which originated in Scandinavia. The original process consisted of straining the 
whey into a kettle or large open pan over a fire. "The albuminous material that precipitates and rises to the surface is skimmed off." The whey is evaporated as rapidly as possible with constant and thorough stirring. When it has reached about onefourth of its original volume the albumin previously skimmed off is returned and stirred thoroughly to break tip all possible lumps. When the whey has attained the consistency of thickened milk it is poured quickly into a wooden trough and stirred with a paddle until cool, to prevent the formation of large sugar crystals. It can then be molded into the desired form for market.

A more rapid method of making primost is to evaporate the whey in the vacuum pan. When the syrup has reached the desired density it is drawn off, allowed to cool and pressed into bricks. The product has a yellowish-brown color, gritty texture and sweetish taste. The evaporation of whey in vacuo is as yet a rare practice and the demand for the finished product is very limited.

Experiments with the "Continuous Concentrator" have demonstrated that condensed whey of good quality can readily be prepared with this machine. The concentration can be carried as far as 15 to 1 ; whey so condensed escapes from the concentrator still in liquid form, but changes to a solid upon cooling, the milk sugar in this supersaturated solution crystallizing completely. If made of sour whey, the product thus obtained has a splendid clean and sharp acid flavor. This product promises to have excellent dietetic properties, and also to lend itself admirably for cooking purposes.

1 United States Department of Agriculture, Bureau of Animal Industry, Bulletin No. $\mathbf{1 0 5 .}$ 


\section{PART IV. \\ FROM FACTORY TO CONSUMER}

\section{ChAPTER XVI.}

Stamping.-Every well regulated condensing factory, selling condensed milk in hermetically sealed tin cans, employs some system of marking the cans. This is important for future reference.

When defective condensed milk is returned to the factory, the marks on the cans tell the manufacturer the date of manufacture, and his own record on file in the factory shows the conditions under which the defective milk was made. In this way defects can usually be traced to their causes and the recurrence of similar trouble can be avoided.

In some factories the batches of condensed milk are numbered from one up, and the cans are stamperl with the respective batch number. This method is simple but may prove undesirable, since it informs the competitors also of the date of manufacture of competing brands. In most factories a code of letters and figures is used, designating the factory, the date, and the number of the batch of each day.

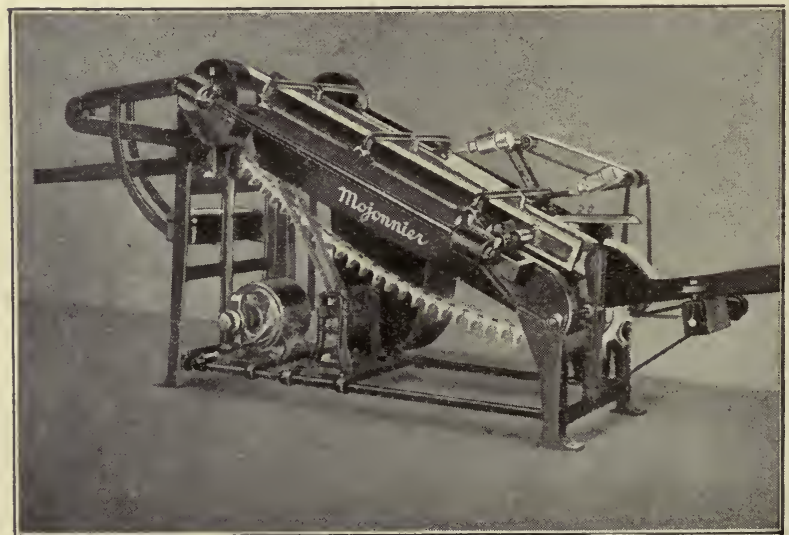

Fig. 78. Mojonnier evaporated milk can polisher Courtesy Mojonnier Bros. Co.
The cans are usually stamped on the bot.tom, that is, on the end which carries the cap. The stamping is done by the sealer. S $\mathrm{m}$ a 11 interchangeable rubber letters and figures are us ed. The stamping in k should contain 
a drier and be waterproof. In small factories the stamping is done by hand. It can be done very rapidly. In large factories an automatic stamping outfit is attached to the filling, sealing or labeling machine and the cans are stamped automatically while they are being filled, sealed or labeled.

Inspecting.-The sealed and stamped cans are placed, with caps down, in wooden trays holding twenty-four medium-sized cans. All trays of one batch are stacked together. A card indicating number and date of batch and number of cans in the batch is attached to the stack and a copy of the same is filed in the office. The cans are placed with their caps down in order to detect "leakers" (cans with defective seals). Before labeling, the trays should be taken down, the cans turned over and examined for leaky seais. Unless the factory is behind in filling orders the cans will have bcen in stock at least twenty-four hours or usually longcr. In the case of sweetened condensed milk, if any seals are defective, a little condensed milk will have oozed out by that time. Inexpericnced sealers are prone to cause a high percentage of leaky cans. A careful sealer may reduce the number of leakers to 1 per cent.

In the case of evaporated milk (unsweetened, sterilized) all cans coming from the inculating room should be individually shaken by hand. All cans showing no signs of bulging, and the contents of which shake with the characteristic sound and hehavior of a liquid, pass inspection. If the ends of the cans are bulging or the contents do not respond to the shaking with the characteristic sound of normal milk. they are rejected, as the evaporated milk in them has either undergone gaseous or curdling fermentation, and is spoiled.

\section{LABELING.}

Labeling Machines.-In the early days of the milk condensing industry, the labeling of the cans was done by hand, involving much time and considerable expense. Today, especially constructed labeling machines are almost exclusively used for this purpose. The efficiency and quality of work of these machines are such, that they have become a permanent fixture in practically every condensery selling canned goods. The labeling ma- 
chines are adjustable to various sizes of cans and can be operated by hand, motor. or belt power.

Principle of Labeling Machines.-The cans are placed into a chute from which they roll into the machine by gravity. They are caught by two endless belts which draw them through the machine. They first pass over revolving metal discs that touch each can with a trace of "pick-up". cement. From here the can rolls over the label table which is loaded with a stack of labels. face-down. The touch of "pick-up" cement on the cans causes each can to pick up one label, which is automatically wrapped

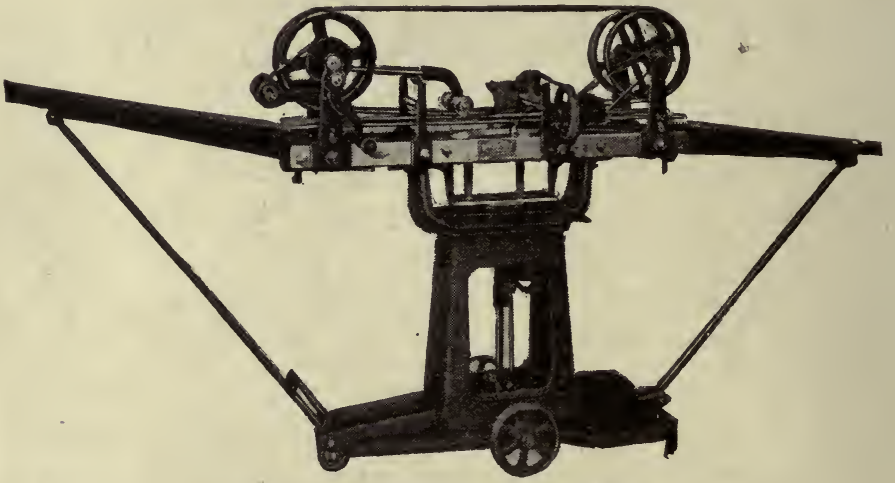

Fig. 79. Burt labeling machine

Courtesy of Burt Machine Co.

around the can as it rolls on. An endless belt passing through a paste box applies a small strip of paste to the lap of the label and a curling rod stretches the label tant and gives its lap an inward curl, making it to conform to the shape of the can and ensuring a perfect seal.

The label table is equipped with an automatic feeding arrangement which pushes the stack of labels up as fast as the labels are being used.

Wrinkles and Rust Spots on Labels.--In the latest models of labeling machines no paste touches the cans proper. The "pick-up" cement used on the cans, is moisture-proof and is applied hot. This is a great advantage from the standpoint of ensuring freedom from rust spots on labels. The cement, being applied hot, dries instantly and having no corrosive action on the 
can, is a reliable safeguard against wrinkles and rust spots, which are so prone to appear where paste is used exclusively, and which mar the attractiveness and neatness of the package. The labeled cans which now leave the machine over a chute slanting from it, can be cased immediately without risk. The use of tables and fans to dry the labels, often found necessary in the case of mechanically applied paste, is made superfluous, and time, labor and space are saved.

Capacity of Labeling Machines.-In the latest improved types of labeling machines the capacity has been greatly increased over that of the older models. One properly operated hand-driven machine will now label on an average from 40,000 to 50,000 cans and a power-driven machine will average from 60,000 to 70,000 cans per ten-hour day.

\section{PACKING.}

The labeled cans are packed in cases holding from six to ninety-six cans, according to the size of the cans. (One case holds six 1-gallon cans; forty-eight 14-, 15-, 16-, and 20-ounce cans; or seventy-two to ninety-six 8-ounce cans.)

The sides, bottom and to̊p of the cases should be of material about three-eighths of an inch to one-half inch thick, the ends three-fourths of an inch to seven-eighths of an inch thick. The cases are usually bought in the "knock-down" shape and are made up in the factory. Sixpenny cement-coated wire nails are most suitable for this purpose. The cases are most economically nailed by the use of nailing machines, which nail one entire side or one side and one end simultaneously. The cans are usually placed into the cases direct from the labeling machine. In some factories, packing machines, which pack twenty-four mediumsize cans in one operation, are used. Formerly condensed milk cans were packed exclusively in wooden cases. Within the last few years the use of paste-board and fibre boxes has been adopted in many condenseries. These boxes are proving very serviceable for domestic trade, and prior to the price advance on paper material caused by the world war, they made possible a considerable saving in the cost of the package.

Mechanical can casers, operating with the labeling machine, are now available and are used to adrantage in many condens- 
eries. The can caser receives the labeled cans from the labeling machine, stacks them into layers, places the layers of cans in to the case and antomatically pushes off the filled case, while a new layer of cans is pushed forward. It is obvious that the mechanical can caser makes the work of packing the cans easier and accelerates its speed.

Marking the Cases.-One end of each case is stenciled with the number of the batch; over the other end is pasted a case label, representing, enlarged, the brand of the label on the cans within. In the place of the case label, the respective brand may be printed on or burnt into the wood. The burnt stenciling is

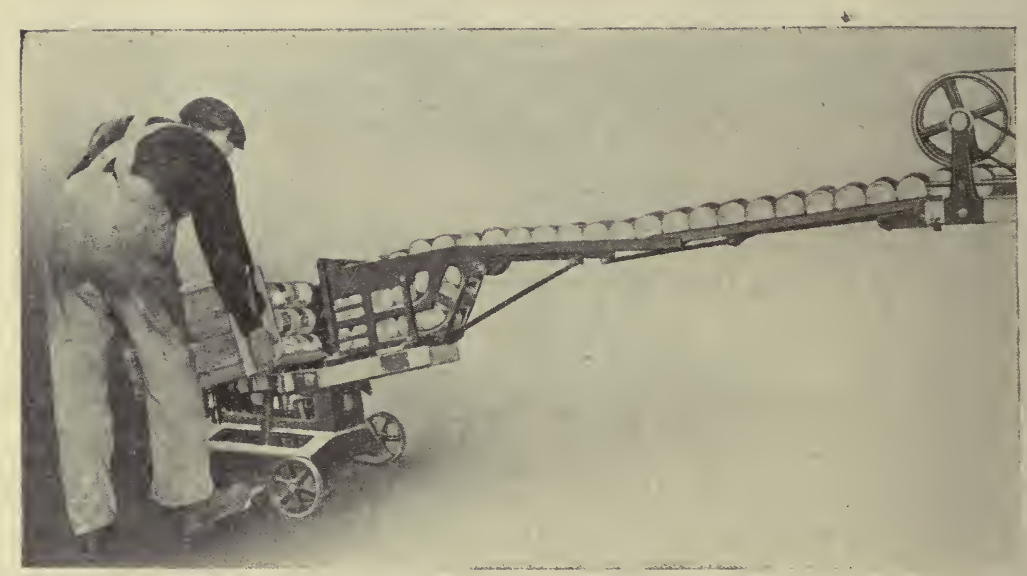

Fig. 80. Burt caser

Courtesy of Burt Machine Co.

usually done by the manufacturer of the shooks. One side of each case is usually marked "Condensed Milk" or "Evaporated Milk," as the case may be; the other "Keep in cool, dry place." If sweetened condensed milk is exposed to excessive heat for a considerable length of time, as is often the case in storehouses or in the hold of steamers, where the cases may be stowed against the boiler room, it becomes brown, thickens rapidly and develops a stale flavor. Evaporated milk also darkens when exposed to heat and depreciates in flavor. It should, therefore, be kept in a cool place. The humidity of the storage room has no effect on the condensed milk proper, the cans being hermetically sealed. 
Prolonged exposure to dampness, however, will dampen and wrinkle the labels, rust the cans and invite the appearance of rust and mold spots.

Packing Condensed Milk for Export.-In the case of condensed milk bought by the United States Government, the cans are dipped in a solution of shellac before they are labeled, or the tin plate or empty cans are bought by the manufacturer already lacquered. Cans for export trade and in many instances for the home market, are wrapped into heary, soft paper, bearing on the outside a copy of the respective brand. This wrapping paper takes up the space beetween the cans and prevents the cans from being damaged on their long journey and by rough usage. This wrapping is usually done by hand. Some makes of labeling machines, however, have an attachment for wrapping the cans so that when the cans leave the machine they are wrapped as well as labeled. The cases are reinforced with a band of strap iron around each end. Where the cases have to be loaded and unloaded numerous times, as is the case with export shipment. they are in danger of being torn to pieces, unless such special precautions are taken.

\section{CH.MPTFR XVTI.}

\section{STORAGE.}

Purpose of Storing.--'The purpose of storing condensed milk is largely the same as that of storing butter and other produce. namely. to keep the product from the time of large supply and low prices, to the time of small supply and high prices. In summer time, the market is usually flonded with condensed milk throwghout the country, the demand for it is at ebb tide and the prices are low. In winter. there is usually a great shortage of condensed milk. the demand far exceeds the supply and prices soar high. The storing of summer milk may be necessary, also. in order to enable the manufacturer to fill his contracts and supply his trade in winter. This is especially true where the factories of a concern are located in new territories where the patrons produce an excessively small amount of winter milk.

Plain condensed milk and concentrated milk which are not sterile and contain no cane sugar to prcserve them, keep but a 
few days at ordinary temperatures and should, therefore, be sold and used as soon as possible after manufacture. If their storage is unavoidable, they should be held as near the freezing point as possible. For prolonged storage it might be advantageous to freeze them. However, reliable data on this phase of the industry are lacking.

Evaporated milk, sold in hermetically sealed cans, is supposed to be entirely sterile, and, if made properly, will keep indefinitely. There is a constant tendency. however, for the fat to separate out, which naturally is augmented by prolonged storage. Again, the lactic acid in the evaporated milk gradually acts on the can. causing the tinplate to become dull and the contents to acquire a disagreeable metallic flavor. When stored for an excessively long time this chemical action may be sufficient to cause the evolution of considerable quantities of hydrogen gas. swelling the cans.

Sweetened condensed milk which is preserved by about 40 per cent of sucrose. will keep apparently unchanged for a considerable length of time. It is best, however, when fresh. Bacteriological examinations have shown that, while moderate agc does not change the outward appearance of this condensed milk. the bacteria in it gradually increase and the milk gradually develops a stale flaror. White and yellow "buttons." lumps, or nodules of a cheesy texture and flavor. due to fungus growth, are also prone to appear in the condensed milk. Age, also, causes it to become darker in color. These defects are especially apparent in old milk which has not been kept at a low temperature. Again, sweetened condensed milk made in May and June has a strong tendency to thicken with age and to become entirely solid.

In sone cases a part of the sweetened condensed milk marle during the summer months is stored in large cylindrical wooden or iron tanks sunk into the ground, or installed in the basement of the factory, where the condensed milk remains at an even temperature. As the demand for the product increases and the supply of fresh milk decreases. condensed milk is drawn from these tanks to fill the increasing orders.

Effect of Storage Temperature.-Most, if not all the changes which condensed milk is prone to undergo in storage are retarded. if not entirely prevented, when stored at the proper temperature. 
Temperatures of 60 degrees $\mathrm{F}$. or above are too high for satisfactory storage for a prolonged period of time and the higher the temperature the greater the resulting defect.

Temperatures below the freezing point of water are also undesirable. The evaporated milk freezes and while so doing it expands sufficiently to swell the cans. Although this swelling disappears when the contents of the cans dissolve again, yet the swelling action tends to weaken the cans and may give rise to subsequent leakers. Again, the melted evaporated milk is prone to be grainy as the result of freezing. This is due to the fact that when freezing, the watery portion separates from the curd and the latter contracts. When the milk thaws up the curd remains contracted and fails to form a smooth emulsion with the remainder of the milk.

The sweetened condensed milk does not freeze, because it contains so concentrated a sugar solution that its freezing point is usually far below the refrigerating temperature. If it is packed in solder-sealed cans there is usually no bad effect from cold storage. However, when packed in cans sealed with the friction cap or the burr cap, difficulties may arise. These seals are not air-tight. Excessively low storage temperatures cause the contents to shrink appreciably. Suction is formed and air is drawn in through the seal. When these cans again warm up, the viscous milk in the cans seals the microscopic openings, the air and the liquid expand but the air finds no exit. This causes the cans to swell. While the quality of the milk in these cans is not impaired in the least, the swelled cans suggest gaseous fermentation, which means spoiled milk and which is invariably rejected on the market.

The temperatures at which condensed milk can be stored with least objectionable results, range between 32 and 50 degrees $\mathrm{F}$.

Advisability of Storing.-A heavy stock of condensed milk is a severe drain on the working capital of the condensery, involving the cost of the fresh milk, cane sugar, tinplate, boxes, solder, labels, coal and labor.

Unless the manufacturer has successfully overcome and mastered all of the principal condensed milk defects, and, unless his experience justifies him in believing that his goods will stand 
the trials of storage, he will find it advisable not to manufacture more than he can promptly dispose of. Even at best, the condensed milk will be from three to six months old before it is all consumed, and, if it is at all subject to deterioration, the sooner it is consumed the better.

\section{TRANSPORTATION.}

The plain condensed bulk milk and concentrated milk are highly perishable products. If shipped considerable distances they should be placed in refrigerator cars.

The evaporated milk and sweetened condensed milk in hermetically sealed cans, and the latter also in barrels, can safely be shipped in ordinary box cars. The cases weigh from fifty to six-five pounds, and the barrels from three hundred to seven hundred pounds. Care should be taken that the cars used for this purpose are clean and did not previously carry goods with strong and obnoxious odors, such as fertilizers, as these odors are prone to follow the condensed milk to its destination. Strong box cars, in good repair only, should be used. Even at best, the cases and cans suffer more or less damage in transportation. Cars with leaky roofs should be condemned, as transportation in them may cause the package to suffer in appearance. If shipped on steamboats, it should be specified to stow the cases away from the boiler room, as prolonged exposure to high temperatures causes the condensed milk to deteriorate.

\section{Chapter XVIII.}

\section{MARKETS.}

A large proportion of the canned condensed milk, both sweetened and unsweetened, supplies localities, territories and countries where the dairy industry is yet in its infancy, or where geographic and climatic conditions bar the profitable husbandry of the dairy cow. Thus, we find some of the best condensed milk markets in the tropics, in the arctic regions, in the army and navy, on ocean liners and in mining and lumber camps. In these markets condensed milk has, in many cases, become as great a necessity as fresh milk is to the inhabitants within the temperate zone. The wastage and the decreased 
production of diverse food products caused by the war has opened vast new markets for, and has caused the demand and consumption of condensed milk to grow by leaps and bounds. The consumption of canned condensed milk in our home markets has, also, been increasing rapidly within recent years, and is today assuming astonishing proportions. This increase has occurred, in part at least, at the expense of the consumption of fluid milk. While conclusive statistics on this subject are not available, the trend toward larger domestic consumption of condensed milk accompanied by decreased consumption of fluid milk is suggested in the following tables, in which Prof. J. O. Jordan, ${ }^{1}$ President of the International Association of Dairy and Milk Inspectors, shows the situation in the city of Boston, Mass.:

Consumption of Condensed Milk in Boston, Mass.

\begin{tabular}{|c|c|c|c|c|}
\hline \multirow{2}{*}{ Source of Statistics } & \multicolumn{4}{|c|}{ Cases of Condensed Milk by Years } \\
\hline & $\begin{array}{l}1916 \\
\text { Cases }\end{array}$ & $\begin{array}{l}1917 \\
\text { Cases }\end{array}$ & $\begin{array}{c}1918 \\
\text { Cases }\end{array}$ & $\begin{array}{l}1919 * \\
\text { Cases }\end{array}$ \\
\hline $\begin{array}{l}\text { Business of a firm } \\
\text { operating } \mathrm{ch} \text { a in } \\
\text { stores ….......... } \\
\text { Receipts according }\end{array}$ & 30,500 & 52,700 & 76,500 & 77,000 \\
\hline $\begin{array}{c}\text { Receipts according } \\
\text { to records of Board } \\
\text { of Trade ....... }\end{array}$ & 762,446 & 880,072 & $1,237,647$ & $1,647,264$ \\
\hline
\end{tabular}

Daily Consumption of Fluid Milk in Boston, Mass.

\begin{tabular}{|c|c|c|c|}
\hline Year & $\begin{array}{l}\text { Quarts of M il k } \\
\text { actually c o n - } \\
\text { sumed daily }\end{array}$ & $\begin{array}{l}\text { Quarts of M ilk } \\
\text { wh } \mathrm{h} \text { ch should } \\
\text { have been con- } \\
\text { sumed d a ily } \\
\text { based on esti- } \\
\text { mated population } \\
\text { and quarts used } \\
\text { in } 1916 \text { by esti- } \\
\text { ma te popula- } \\
\text { tion }\end{array}$ & $\begin{array}{l}\text { Estimated } \\
\text { Population }\end{array}$ \\
\hline $\begin{array}{l}1916 \ldots \ldots \\
1917 \ldots \ldots \\
1918 \ldots \ldots \\
1919 * \ldots \ldots \ldots\end{array}$ & $\begin{array}{l}347,735 \\
342,244 \\
342,451 \\
333,506\end{array}$ & $\begin{array}{l}353,209 \\
358,617 \\
364,157\end{array}$ & $\begin{array}{l}760,400 \\
772,370 \\
784,340 \\
796,310\end{array}$ \\
\hline
\end{tabular}

1 Jordan, Address, Eighth Annual Convention International Association Dairy and Milk Inspectors, 1919.

1919 figures are for ten months only. 
The rapid growth of the ice cream industry has further developed a splendid and ever-increasing market for plain condensed bulk milk. Additional impetus has been lent this development since the advent of national prohibition, which caused a vast increase in the consumption of ice cream and of soft drinks of which ice cream constitutes an integral part. Manufacturers of condensed milk estimate that this has resulted in an increase of their production of plain condensed bulk milk amounting to from 15 to 20 per cent.

Market Prices of Condensed Milk.-The price of condensed milk is not controlled by the general market of dairy products, nor by any board of trade; there is no consistent uniformity of price throughout the country as is the case of butter and cheese. The price of condensed milk does not necessarily follow the rise and fall of the butter and cheese markets, but in the long run it is usually affected by abrupt fluctuations of prices of these other dairy products, largely on account of the influence of such fluctuations on the supply to the condensery of fresh milk. It is chiefly governed by local conditions of supply and demand, conposition of product and reputation of the individual brand. Condensed milk is sold under hundreds of different brands or labels. While one and the same concern may sell scores of different brands, the brand itself has very little, if anything, to do with the quality or composition of the contents of the can. Each brand usually sells at its own special price, although the various brands put on the market by the same concern often contain the same quality of milk and may be filled with condensed milk from one and the same batch. It is customary in most factories to fill the cans before they are labeled and the orders for different brands of condensed milk are filled from the same general stock. The brands serve largely as an instrument to increase the sales and "dodge" competitors.

Sweetened condensed milk, packed in hermetically sealed cans, sells from about $\$ 3.25$ to $\$ 5$ per case of 48 sixteen-ounce cans and the cans retail at from 5 to 20 cents each, according to the size of the cans and market conditions.

Evaporated milk, unsweetened condensed milk in hermetically sealed cans, sells from $\$ 2.25$ to $\$ 4.00$ per case, according tq the size of the cans and market conditions. 
Bulk milk, both sweetened and unsweetened, goes direct from the manufacturer to the purchaser who buys it at priees agreed upon by the contracting parties. The sweetened condensed milk is sold in barrels holding from three hundred to seven hundred pounds (usually about six hundred pounds) to candy and caramel factories, bakeries and confectioners. The price varies from four to ten cents per pound according to the per cent of fat, demand and supply. When there is a general "epidemic" of bad canned condensed milk, this spoiled condensed milk is usually turned into candy shops and bakeries, where it is sold for "a song." This condition has always a depressing influence on the price of sweetened condensed bulk milk, which, during such seasons, may have to be sold at a loss. Some milk condensing concerns operate their own candy shops which take care of the condensed milk that is rejected on the market.

Plain or unsweetened condensed milk is sold in 1-gallon to 10 -gallon cans to ice cream factories, the price varying from twenty-five to ninety cents per gallon, according to fat content, concentration and market conditions. The market for this class of goods is not very constant, but the profits are generally high. It reaches ebbtide in winter when the demand for ice cream is small. Limited quantities of plain condensed bulk milk are also sold in milk and cream bottles for direct consumption. The concentrated milk finds the same markets as the plain condensed bulk milk.

The above range of prices of the several types of condensed milk refers to the market conditions which prevailed while the industry was protected against competition with goods from abroad by an import tariff of $2 \mathrm{c}$ per pound or $\$ 1.00$ per case of condensed milk, and to conditions prior to the advent of the European war in 1914.

In 1913, the United States, by Act of Congress, removed the import tariff, placing condensed milk on the free list. This Act became effective in the fall of the same year. Its immediate effect was a rapid increase in the importation of European condensed milk, which was offered for sale at relatively low prices, 
decreased the sale of domestic goods and caused the holdings of condensed milk to accumulate in large quantities. Condensed milk prices depreciated rapidly throughout 1914 and reached the bottom.in the fall of that year when financial limitations compelled many concerns to move their goods at any price. At that time the bottom prices of condensed milk were approximately as follows:

Sweetened condensed milk per case.......\$2.50

Ėvaporated milk per case.............. 1.90

The losses suffered by this slımp in the condensed milk market, caused by the influx of cheap foreign goods in the absence of a protective tariff, were enormous and caused bankruptcy of numerous of the financially limited concerns. The outlook for the future of the industry looked very uninviting at best, but the situation was saved and market conditions reversed by the urgent food requirements of the Allied nations in the European war, and after the entrance of the United States into the war, by large orders for the American army and navy.

The extraordinary and very urgent demand for condensed milk by the U. S. Government and by its allies during the war and the enormous demand for exports to Europe after the armistice, boosted the prices of this product to a level not attained since the Civil War. While Government regulations tended to hold price advances within reasonable bounds and while lack of shipping facilities and other factors caused temporary fluctuations downward, the price advance in general continued until the spring of 1919, and reached the following maximum figures per case :

Sweetened condensed milk per case........\$9.25

Evaporated milk, per case............. 6.50

Exports and Imports.-Canned condensed milk only need be considered here.

The United States Bureau of Statistics reports the following imports and exports of condensed milk for the years 1911 to 1919, inclusive : 
Exports and Imports of Condensed Milk and Evaporated Milk for the Years 1911 to 1919, inclusive. ${ }^{1}$

Exports

\begin{tabular}{rrrrr} 
Years & Pounds & \multicolumn{1}{c}{ Dollars } & \multicolumn{1}{c}{ Pounds } & \multicolumn{1}{c}{ Dollars } \\
1911 & $12,180,445$ & 936,105 & 630,308 & 46,088 \\
1912 & $20,642,738$ & $1,651,879$ & 698,176 & 61,671 \\
1913 & $16,525,918$ & $1,432,848$ & $1,778,044$ & 135,724 \\
1914 & $16,209,082$ & $1,341,140$ & $14,599,339$ & $1,089,440$ \\
1915 & $37,235,627$ & $3,066,642$ & $33,624,189$ & $2,556,787$ \\
1916 & $159,577,620$ & $12,712,952$ & $18,174,505$ & $1,515,354$ \\
1917 & $259,102,213$ & $25,129,983$ & $18,375,698$ & $1,746,446$ \\
1918 & $553,439,554$ & - & $29,926,931$ & - \\
1919 & $852,275,264$ & - & $16,509,239$ & -
\end{tabular}

Prior to 1914 the United States exported condensed milk chiefly to North America, Oceanica and Asia, small quantities were also exported to South America, Africa and Europe. About 60 per cent of all the export condensed milk went to countries of the North American Continent, Canada and Panama being the leading markets. During the last few years, immediately preceding the world war, our exports to Canada had fallen off very rapidly. In 1911 the exports to Canada amounted to only about 15 per cent of the total exports of condensed milk to the same country in 1908. The rapid development of the milk condensing industry in Canada, within the last decade was largely responsible for this situation. From 1907 to 1911 there was an annual decrease in the total exports of the United States. In 1907 they amounted to $\$ 2,191,000.00$ as against $\$ 936,105.00$ in 1911.

Prior to 1913, the imports of condensed milk into the United States were likewise very limited. This was largely due to the protective tariff on imported goods, which was an effective agent to exclude foreign brands from American markets.

In the fall of 1913, Condensed Milk was placed on the "free list." This resulted in an immediate and rapidly growing influx of condensed milk from European countries, such as Switzerland, Denmark, Holland, Sweden, Norway, Germany and Eng-

1 United States Department of Commerce and Labor, Bureau of Statistics for 1811 to 1919 . 
land. At first the bulk of the influx consisted of sweetened condensed milk, but later evaporated milk also arrived in increasingly large quantities, causing havoc in our domestic markets, and an almost unprecedented depression in the industry in the Fall of 1914. At the same time, the exports further decreased and ceased almost entirely.

In 1915 the food shortage in the allied countries and their need of condensed milk for their armies and navies began to counteract the effect of the removal of the protective tariff. Imports decreased while large and repeated contracts for exports to the Allies brought about an unprecedented growth of our export trade of condensed milk at attractive prices. Our exports were further increased by the fact that the war deprived noncombatant countries in South America, Asia and Africa of their usual imports of this commodity from the then warring countries, opening up the world markets to the United States.

The exports continued to increase after the armistice was declared; the volume exported being limited largely only by the shortage of transatlantic transportation facilities. After the first six months of 1919 the increasingly unfavorable rate of exchange of foreign moneys commenced to make itself felt and since then there has been a steady decline in exports. Early in 1920 isolated shipments of condensed milk began to arrive in this country, foreign manufacturers being attracted by and taking advantage of the high exchange value of the American dollar, our high domestic prices and the absence of tariff on condensed milk imported into the United States.

\section{Chapter XIX.}

\section{CHEMICAL COMPOSITION AND STANDARDS OF CONDENSED MILK.}

Sweetened Condensed Milk.--Sweetened condensed milk contains all the constituents of fresh milk and considerable but varying quantities of sucrose. Its composition, therefore, depends on such factors as: composition of the fresh milk from which it is made; the degree of condensation and per cent. of cane sugar added. As all of these factors vary in milk from different localities, and in milk of the same factory at different 
seasons of the year, no hard and fast rule can be given. The following figures merely show the average composition of sweetened condensed milk as obtained from the results of analyses of a large number of different brands.

\section{Average Composition of Sweetened Condensed Milk.}

Vater

Milk solids $\left\{\begin{array}{l}\text { fat } \\ \text { proteids } \\ \text { milk sugar } \\ \text { ash }\end{array}\right.$

Cane sugar
26.5 per cent.

$$
\left.\begin{array}{r}
9.0 \text { per cent. } \\
8.5 \text { per cent. } \\
13.3 \text { per cent. } \\
1.8 \text { per cent. }
\end{array}\right\}
$$

32.6 per cent.

40.9 per cent.

Total

\section{0 per cent.}

Water.-The water content is largely governed by the degree of condensation and the per cent. of cane sugar. American brands average from 24 per cent. to 28 per cent. water. In exceptional cases milk has been found to contain as low as 21 per cent. and as high as 34 per cent. water.

Milk Solids.-The per cent. of milk solids is largely governed by the per cent. of milk solids in fresh milk and the degree of condensation. In the majority of brands the solids fluctuate between 28 and 34 per cent.; in extreme cases analyses have shown less than 28 per cent. and as high as 40 per cent. milk solids. The relative proportion in which the various solid constituents are present is the same as that in the fresh milk from which the condensed milk is made, provided that the fresh milk was not skimmed previous to condensing.

The fact that the U. S. standard requires not less than 28 per cent. milk solids and the introduction of perfected methods of standardizing have an unmistakable tendency toward keeping the percentage of milk solids down to 28 per cent.

Butter Fat.-The butter fat in sweetened condensed whole milk fluctuates from about 8 to 12 per cent., according to locality, season of year and degree of condensation. Sweetened condensed milk sold in barrels is usually partly or wholly skimmed and is, therefore, low in fat. It has been suggested that a small portion of the milk fat is lost during the process of condensation, 
and this theory is frequently resorted to by condensed milk men to explain why their milk is low in fat. It has been claimed by some that the volatile fats (volatile fatty acids) are lost during the process of condensation. This claim is not well founded, since repeated experiments ${ }^{1}$ have conclusively demonstrated that condensed milk contains the normal amount of volatile fatty acids. It has further been experimentally proven that the condensed milk, when made properly and from whole milk, contains fat equal in amount to that found in the fresh milk used. A reasonable allowance should be made, however, for loss of milk due to spilling and wasting in pipes and retainers. Experience has shown that this loss amounts to about fifty to one hundred pounds of milk per average batch under normal conditions.

Proteids.-The per cent. of proteids in the condensed milk varies with the per cent. of proteids in the original milk and the degree of concentration. It fluctuates usually between 7.5 and 9 per cent. The heating previous to condensing coagulates a portion of the milk albumin and alters the casein to the extent that it is not precipitated in the normal way, when rennet is added to the diluted condensed milk.

While, in most analyses of sweetened condensed milk, the per cent. of proteids nearly equals that found in the fresh milk multiplied by the degree of concentration, there is a tendency toward a slight loss of this constituent due to precipitation in the forewarmers.

Milk Sugar.-Sweetened condensed milk contains from about 12.5 to 15 per cent. of milk sugar, the amount varying according to the degree of concentration and per cent. of milk sugar in the fresh milk. The milk sugar is not known to undergo any material changes as the result of the condensing process. If condensed milk is recondensed, it assumes a darker color which is largely due to the caramelizing of a part of the milk sugar, caused by the action of prolonged exposure to heat. The milk sugar in condensed milk crystallizes very readily and causes the condensed milk to become sandy and settled. Chemical analyses of this sugar sediment show that it consists principally of milk sugar. The primary cause of this property lies in the

Hunziker and Spitzer, Indiana Agricultural Experiment Station Bulletin No. 134, 1909. 
fact that sweetened condensed milk contains so little water (about 26.5 per cent.) that the milk sugar is present in the form of a supersaturated solution; therefore, any condition which favors sugar crystallization will tend to produce this defect: ${ }^{1}$ Milk sugar requires from five to six times its weight of water at ordinary temperatures for complete solution. In sweetened condensed milk the milk sugar has access to only about twice its weight of water (12.5 to 15 per cent. lactose to 25 to 27 per cent. water).

Ash.-The per cent. of ash is largely dependent on the degree of condensation. It usually varies from 1.5 to 2 per cent. It is quite constant in fresh milk. (normal fresh milk contains uniformly about . 7 per cent. ash). The per cent. of ash in sweetened condensed milk may serve, therefore, as a reasonably reliable factor in determining the degree of condensation. The heating of milk, before condensing, precipitates and renders insoluble a portion of the mineral solids, principally the lime salts.

Sucrose.--The purpose of the presence of sucrose in this product is to preserve it. Most of the sweetened condensed milk on the market contains from 37 to 44 per cent. sucrose, or cane sugar. Wider variations, however, are not infrequent. In some cases analyses showed as low as 30 per cent. and in others as high as 48 per cent. cane sugar. Cane sugar dissolyes in one half its weight of water, so that under normal conditions there is sufficient water in the condensed milk to keep the sucrose in solution. The amount of sucrose in milk does not appreciably affect the power of the milk to dissolve milk sugar, nor does the per cent. of lactose present materially affect the power of the milk to dissolve sucrose.

When the sweetened condensed milk has a concentration of about $2.5: 1$, the manufacturer usually aims to have it contain about 40 per cent. sucrose. When it is condensed sufficiently only to contain 28 per cent. milk solids it is necessary to add sufficient sucrose to bring the percentage of sucrose up to about 44 , in order to insure the necessary keeping quality.

1 For further detalls on causes of settled sweetened condensed milk see Chapter XXII. 
Specific Gravity.-The specific gravity of sweetened condensed milk falls within the limits of 1.24 to 1.35 . Foreign brands average somewhat higher in specific gravity than American brands. The specific gravity of sweetened condensed milk is controlled by the degree of condensation, the per cent. of fat and the per cent. of cane sugar. Milk condensed at the ratio of about 2.5 parts of fresh milk to 1 quart of condensed milk and containing about 9 per cent. fat and 40 per cent. cane sugar, has a specific gravity of about from 1.28 to 1.29 . The specific gravity of sweetened condensed skim milk may go as high as 1.35 , and, if it contains an excess of cane sugar, it may be still higher.

Chemical Analyses of Sweetened Condensed Milk of Eighteen Different Brands.

\begin{tabular}{|c|c|c|c|c|c|c|c|}
\hline Brand & $\begin{array}{c}\text { Mnlk } \\
\text { solids } \\
\text { per } \\
\text { cent. }\end{array}$ & $\begin{array}{c}\text { Water } \\
\text { per } \\
\text { cent. }\end{array}$ & $\begin{array}{l}\text { Fat } \\
\text { per } \\
\text { cent. }\end{array}$ & $\begin{array}{c}\text { Pro- } \\
\text { teids } \\
\text { per } \\
\text { cent. }\end{array}$ & $\begin{array}{l}\text { Lac- } \\
\text { tose } \\
\text { per. } \\
\text { cent. }\end{array}$ & $\begin{array}{c}\text { Ash } \\
\text { per } \\
\text { cent. }\end{array}$ & $\begin{array}{l}\text { Sucrose } \\
\text { per } \\
\text { cent. }\end{array}$ \\
\hline Ires" Condens & 31.90 & 28.68 & 8.40 & 9.12 & 12.56 & 1.91 & 40.38 \\
\hline Borden's Con & 31,08 & 25.99 & 8.72 & 8.15 & 12.35 & 1.83 & 42.93 \\
\hline Truro dondens & 31.23 & 27.33 & 9.56 & 8.32 & 13.42 & 1.80 & 41.44 \\
\hline Bordens' Cond & 36.57 & 21.67 & 10.07 & 9.35 & 15.00 & 2.15 & 41.76 \\
\hline Borden's Cond & 31.74 & 24.84 & 8.23 & 8.57 & 13.02 & 1.92 & 43.42 \\
\hline Mohawk Cond & 32.84 & 24.07 & 9.31 & 8.71 & 12.95 & 1.87 & 43.09 \\
\hline Wisconsin Con & 31.15 & 26,83 & $8.00^{\circ}$ & 8.49 & 12.87 & 1.79 & 42.02 \\
\hline American Conc & 35.56 & 26.50 & 9.31 & 9.50 & 14.80 & 1.95 & 37.94 \\
\hline Mohawk Conde & 34,78 & 27.14 & 11.07 & 7.92 & 14.03 & 1.76 . & 38.64 \\
\hline Borden's. Conde & 30.82 & 24.76 & 8.88 & 8.06 & 12.07 & 1.81 & 4297 \\
\hline Borden's Conde & 31.98 & 26.32 & 8.64 & 7.84 & 13.50 & 2.00 & 4200 \\
\hline Michigan Conde & 30.00 & 27.63 & 8.60 & 7.07 & 12.60 & 1.73 & 41.00 \\
\hline Anglo-Swiss Cor & 35.69 & 25.65 & 9.65 & 8.78 & 15.17 & 2.09 & 38.68 \\
\hline The Manitoba D & 29.40 & 32.15 & 9.62 & 8.61 & 11.30 & 1.85 & 33.45 \\
\hline Baldwin Conden & 32.24 & 26.69 & 11.50 & 8.50 & 12.35 & 1.80 & 41.07 \\
\hline Canid Milk $\mathrm{Co}$ & 31.61 & 30.84 & 10.61 & 8.47 & 12.40 & 1.81 & 37.55 \\
\hline Henfy Nestle & 32.91 & 28.04 & 8.08 & 7.68 & 15.23 & 1.94 & 89.05 \\
\hline o. S. Condensed & 33.65 & 27.88 & 8.80 & 8.34 & 14.66 & 1.85 & 3847 \\
\hline
\end{tabular}

${ }^{2}$ Spitzer, Indiana Agricultural Experiment Station, 1910.

2 McGill, Inland Rev. Dept., Ottawa, Bulletin No. 144, 1908.

- Cochran, Special Report of Analysis of Condensed Milks and Infants' Foods, Pennsylvania Dept. of Agriculture, 1905. 
Evaporated Milk.-The same factors which control the chemical composition of sweetened condensed milk, also govern that of the unsweetened product, with the exception that the cane sugar is absent.

The following figures represent, in round numbers, the average composition of evaporated milk as obtained from analyses of a large number of American brands.

Average Composition of Evaporated Milk

Water

$$
\text { Milk solids }\left\{\begin{array}{ll}
\text { fat } & 8.3 \text { per cent. } \\
\text { proteids } & 7.5 \text { per cent. } \\
\text { lactose } & 9.7 \text { per cent. } \\
\text { ash } & 1.5 \text { per cent. }
\end{array}\right\} 27 \text { per cent. }
$$

The chemical and physical properties of the various ingredients in unsweetened condensed milk are affected to a greater extent than in the case of sweetened conderised milk. This is largely due to exposure of the evaporated milk to high temperatures in the sterilizer.

Water and Solids are governed by the degree of concentration and the relative per cent. of the same constituents in the fresh milk. The per cent. of solids admissible in evaporated milk is largely dependent on the chemical and physical properties of the milk and the sterilizing temperatures employed. Excess in solids in this product jeopardizes its marketable properties, owing to the tendency of the proteids to form hard lumps of curd during the sterilizing process. Evaporated milk very low in solids tends toward the separation of its butter fat in storage.. Analyses show a range of from 23 to 31 per cent. solids. Since the per cent. of solids necessary and possible to be contained in marketable evaporated milk, largely depends on the properties of milk, and, since these properties again are principally controlled by locality, season of year, crop, feed and weather conditions and the quality of the fresh milk, the solids in milk from any given season of the year may vary very considerably. In some localities and at certain times of the year the best results may be obtained with evaporated milk containing 28 per cent 
solids. In other localities it may be difficult at certain seasons of the year, to incorporate more than 24 per cent. solids without injuring or destroying the marketable properties of the product. ${ }^{1}$

Butter Fat.-The fat varies with the per cent. of fat in the fresh milk and with the degree of concentration. No fat is lost during the process of condensing and sterilizing. ${ }^{2}$ It has been claimed by some that in the process of manufacture, the volatile fatty acids escape and that the evaporated milk therefore contains less fat than the fresh milk from which it is made, times the degree of concentration. If this were true the loss of fat in the evaporated milk would not exceed .25 of 1 per cent. But analyses show that the fat in the evaporated milk is entirely normal in composition and contains the same proportion of volatile fatty acids as the fat in the fresh milk.

The Composition of Milk Fats in Evaporated Milk. ${ }^{2}$

\begin{tabular}{|c|c|c|c|c|}
\hline $\begin{array}{l}\text { Date of } \\
\text { Manufacture }\end{array}$ & $\begin{array}{l}\text { Reichert } \\
\text { Meissl } \\
\text { Number }\end{array}$ & $\begin{array}{l}\text { Iodine } \\
\text { Number }\end{array}$ & $\begin{array}{l}\text { Melting Point of } \\
\text { Mixed Fats }\end{array}$ & $\begin{array}{l}\text { Melting Point of } \\
\text { Insoluble Fatty } \\
\text { Acids }\end{array}$ \\
\hline $\begin{array}{l}\text { August, } 1908 \ldots \ldots \ldots \ldots \\
\text { November, } 1908 \ldots \ldots \ldots\end{array}$ & $\begin{array}{l}28.48 \\
29.52\end{array}$ & $\begin{array}{l}33.64 \\
33.60\end{array}$ & $\begin{array}{l}33.3 \text { degrees C. } \\
33.4 \text { degrees C. }\end{array}$ & $\begin{array}{l}41.0 \text { degrees C. } \\
41.2 \text { degrees C. }\end{array}$ \\
\hline
\end{tabular}

In the evaporated milk there is a strong tendency for the fat to separate out during storage and to churn in transportation. This is largely avoided by the proper adjustment of the sterilizing process and by use of the homogenizer.

Proteids.-The proteids vary with the per cent. of total proteids in the fresh milk and the degree of concentration. Similar to the case of sweetened condensed milk, there is a tendency of a slight loss of proteids in evaporated milk due to mechanical adhesion of a part of the precipitated curd to the heating surfaces in the forewarmers and in the vacuum pan.

Most of the coagulable milk albumin is precipitated. Fresh milk contains about .16 per cent. of albumin that is not coagulable by heat. ${ }^{3}$ The relation of soluble and insoluble curd is

1 Hunzlker, Indiana Agricultural Experiment Station, Twenty-first Annual Report, 1908, pages 67-68.

2 Hunziker and Spitzer, Indiana Agricultural Experiment Station, Bulletin No. 134 .

Hunziker, Indiana Agricultural Experiment Station, Bulletin No. 143. 
shown in the following table which represents analyses of different brands of evaporated milk:

\section{Soluble and Insoluble Curd in Evaporated Milk. ${ }^{1}$}

\begin{tabular}{|c|c|c|c|}
\hline Brand & $\begin{array}{l}\text { Insoluble } \\
\text { Curd } \\
\text { Per Cent. }\end{array}$ & $\begin{array}{c}\text { Soluble } \\
\text { Albumin } \\
\text { Per Cent. }\end{array}$ & $\begin{array}{c}\text { Total } \\
\text { Protelds } \\
\text { Per Cent. }\end{array}$ \\
\hline 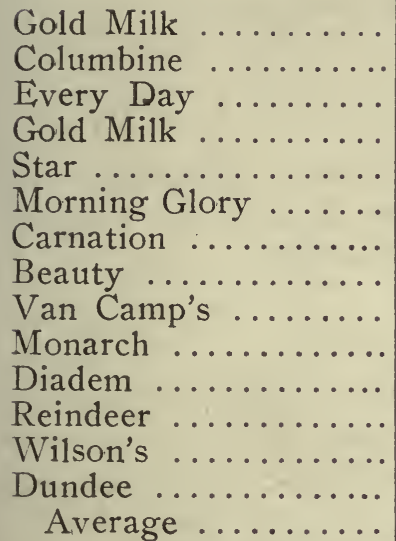 & $\begin{array}{l}8.44 \\
7.41 \\
7.54 \\
7.37 \\
7.86 \\
8.28 \\
6.49 \\
8.39 \\
7.52 \\
6.77 \\
7.06 \\
6.88 \\
6.89 \\
7.21 \\
7.436\end{array}$ & $\begin{array}{l}.46 \\
.49 \\
.46 \\
.33 \\
.30 \\
.34 \\
.52 \\
.39 \\
.42 \\
.52 \\
.42 \\
.52 \\
.49 \\
.44 \\
.429\end{array}$ & $\begin{array}{l}8.90 \\
7.90 \\
8.0 \\
7.70 \\
8.16 \\
8.62 \\
6.91 \\
8.78 \\
7.94 \\
7.29 \\
7.48 \\
7.40 \\
7.38 \\
7.65 \\
7.865\end{array}$ \\
\hline
\end{tabular}

The above figures show that, in the evaporated milk, practically all of the coagulable albumin is changed to insoluble curd. The brands analysed contained evaporated milk condensed at the ratio of 2 to 2.4 parts of fresh milk to 1 part of evaporated milk. The soluble albumin found corresponds with the albumin not coagulable by heat, normally found in fresh milk, times the ratio of concentration.

The casein is largely precipitated by the sterilizing heat, but is present in the form of very finely divided particles. This is due to the mechanical shaking to which the evaporated milk is subjected in the sterilizer and in the shaker. In many batches of evaporated milk the precipitation of the casein during sterilization is so fine that the product is perfectly smooth without shaking. The casein in evaporated milk does not respond to the action of rennet as does the casein in fresh milk.

${ }^{2}$ Hunziker, Indiana Agricultural Experiment Station, Bulletins Nos. 134 and 143. 
Milk Sugar.-The milk. sugar is present in per cent. corresponding with that of the original milk, times the degree of concentration. A portion of it has undergone oxidation (caramelization) due to the high sterilizing temperatures. It gives to the evaporated milk a yellow to light brown color. The higher the sterilizing temperature and the longer the exposure of the evaporated milk to this heat, the darker is its color.

Ash.-The mineral constituents also are present in nearly the same proportion to the other solids, as in fresh milk. They are largely rendered insoluble by the sterilizing process. The lime constituents frequently are found in the bottom of the cans in the form of hard, whitish, insoluble granules. For discussion of relation of ash constituents to stability of casein, stee Chapter XXIII on "Lumpy and Curdy Evaporated Milk."

Since the ash in normal fresh milk is practically constant, averaging about .70 per cent., the per cent. of ash in the evaporated milk is frequently used as a factor in determining the degree of concentration. The results may, however, be very misleading, since, when the ash is precipitated in the form of granules, it is practically impossible to mix it back into the milk in order to obtain a representative sample for analysis.

The Specific Gravity ranges from 1.05 to 1.08 , according to the degree of concentration and the specific gravity of the original milk. It averages about 1.065 .

Plain Condensed Bulk Milk is of very varying composition, depending largely on the degree of concentration and the per cent. of fat present. It is usually made from partly or wholly skimmed milk and is condensed at the ratio of 3 to 4 parts of fresh milk to 1 part of condensed milk. The same fact applies to the composition of concentrated milk. 
Chemical Analyses of Twenty-four Different Brands of Evaporated Milk. ${ }^{1}$

\begin{tabular}{|c|c|c|c|c|c|c|c|}
\hline Brand & Solids & Water & Fat & Curd & $\begin{array}{l}\text { Itac- } \\
\text { tose }\end{array}$ & Ash & Total \\
\hline Gold Milk. & 29.25 & 70.75 & 9.42 & 8.44 & 9.75 & 1.54 & 99.90 \\
\hline Columbine & 24.63 & 75.37 & 7.45 & 7.41 & 8.56 & 1.36 & 99.98 \\
\hline Every Day. & 26.20 & 73.80 & 8.07 & 7.54 & 9.10 & 1.47 & 100.15 \\
\hline Gold Milk. . & 27.18 & 72.82 & 9.07 & 7.39 & 9.23 & 1.49 & 100.00 \\
\hline Star $\ldots \ldots \ldots \ldots$ & 29.04 & 70.90 & 8.35 & 7.86 & 10.37 & 1.62 & 99.16 \\
\hline Morning Glory & 31.08 & 68.92 & 10.48 & 8.26 & 10.47 & 1.67 & 99.82 \\
\hline Carnation .... & 23.81 & 76.19 & 8.05 & 6.49 & 7.55 & 1.24 & 99.49 \\
\hline Beauty ... & 28.38 & 71.62 & 8.47 & 8.39 & 9.94 & 1.56 & 99.98 \\
\hline Van Camp's & 27.89 & 72.11 & 8.69 & 7.52 & 9.66 & 1.54 & 99.52 \\
\hline Wilson's . . & 25.23 & 74.77 & 8.70 & 6.53 & 8.68 & 1.37 & 100.05 \\
\hline Monarch & 26.70 & 73.30 & 8.09 & 6.77 & 10.35 & 1.44 & 99.95 \\
\hline Diadem & 24.96 & 75.04 & 8.16 & 7.06 & 7.92 & 1.33 & 99.51 \\
\hline Reindeer & 26.66 & 73.34 & 8.08 & 6.88 & 10.21 & 1.45 & 99.96 \\
\hline Dundee ...... & 27.04 & 72.96 & 8.73 & 7.21 & 9.36 & 1.48 & 99.74 \\
\hline Sundry samples & 28.02 & 71.98 & 893 & 7.68 & 9.86 & 1.61 & 100.06 \\
\hline $2 \ldots$ & 31.99 & 68.01 & 9.68 & 8.49 & 11.88 & 1.69 & 99.75 \\
\hline 3. & 26.01 & 73.99 & 8.18 & 6.77 & .9 .24 & 1.46 & 99.64 \\
\hline & 27.33 & 72.67 & 9.04 & 6.93 & 9.42 & 1.51 & 99.57 \\
\hline & 29.37 & 70.63 & 9.71 & 7.34 & 10.52 & 1.56 & 99.76 \\
\hline & 21.12 & 78.88 & 7.30 & 5.78 & 6.78 & 1.12 & 99.86 \\
\hline & 23.25 & 76.75 & 7.98 & 6.19 & 7.96 & 1.25 & 100.13 \\
\hline 8. & 25.48 & 74.52 & 8.68 & 6.34 & 8.67 & 1.35 & 99.56 \\
\hline $9 \ldots \ldots$ & 26.62 & 73.38 & 9.20 & 7.00 & 9.18 & 1.37 & 100.13 \\
\hline
\end{tabular}

${ }^{3}$ Hunziker and Spitzer, Indiana Agricultural Experiment Station, Bulletin No. 134, 1909. 
Condensed Milk Standards.-Federal condensed milk standards were first assembled in connection with the Federal Food and Drugs Act, passed June, 1906, and which went in force January 1, 1907. These standards provided that both, sweetened condensed milk and unsweetened condensed milk shall contain not less than 28 (twenty-eight) per cent milk solids, of which not less than 27.5 (twenty-seven and five-tenths) per cent. shall be milk fat.

These standards have been modified repeatedly since their introduction. ${ }^{1},{ }^{2},{ }^{3}$ The standards which have superseded them and their earlier modifications, and which are now in force are as follows:

"Sweetened condensed milk, sweetened evaparated milk, sweetened concentrated milk, is the product resulting from the evaporation of a considerable portion of the water from the whole, fresh, clean, lacteal secretion obtained by the complete milking of one or more healthy cows, properly fed and kept, excluding that obtained within fifteen days before and ten days after calving, to which sugar (sucrose) has been added. It contains, all tolerances being allowed for, not less than twenty-eight per cent. $(28 \%)$ of total milk solids, and not less than eight per cent. $(8 \%)$ of milk fat. ${ }^{3}$

"Unsweetened condensed milk, evaporated milk, concentrated milk, is the product resulting from the evaporation of a considerable portion of the water from the whole, fresh, clean, lacteal secretion obtained by the complete milking of one or more healthy cows, properly fed and kept, excluding that obtained within fifteen days before and ten days after calving, and contains, all tolerances being allowed for, not less than twenty-five and five-tenths per cent. $(25.5 \%)$ of total solids and not less than seven and eight-tenths per cent. $\left(7.8 \%\right.$ ) of milk fat. ${ }^{1}$

"Sweetened condensed skimmed milk, sweetened evaporated skimmed milk, sweetened concentrated skimmed milk, is the product resulting from the evaporation of a considerable portion of the water from skimmed milk to which sugar (sucrose) has

${ }^{1}$ U. S. Department of Agriculture, Circular No. 19; also Hunzlker, Purdue Bulletin No. 143, 1910.

2 U. S. Department of Agriculture, Food Inspection Decislons Nos. 131 $1911 ;{ }^{2} 158,1915 ;{ }^{8} 170,1917$.

${ }^{8}$ U. S. Department of Agriculture, Food Inspection Decision No. 158, April 2, 1915. 
been added. It contains, all tolerances being allowed for, not less than twenty-eight per cent. (28\%) of milk solids. ${ }^{2}$

"Unsweetened condensed skimmed milk, evaporated skimmed milk, concentrated skimmed milk, is the product resulting from the evaporation of a considerable portion of the water from skimmed milk, and contains, all tolerances being allowed for, not less than twenty per cent. (20\%i) of milk solids." ${ }_{2}$

Requirements of Condensed Milk for Export to the Allied Nations.-Condensed milk shall contain not less than 9.2 per cent. butter fat.

In order to meet the high butter fat requirement in condensed milk furnished to the Allies, American condenseries which receive largely low-testing milk are compelled to reinforce their product with butter fat. This is done either by removing a portion of the skim milk, or by the addition to the milk of butter fat in the form of cream or unsalted butter.

\section{ChAPTER XX.}

\section{SANITARY PURITY, DIGESTIBILITY AND VITAMINE PROPERTIES OF CONDENSED MILK.}

Sanitary Purity.-From the point of view of freedom from pathogenic and other harmful micro-organisms, most forms of conflensed milk are superior to the average market milk. In the first place, the manufacture of a marketab!e condensed milk makes essential eternal vigilance in the control of the quality of the fresh milk. It is safe to state that in no milk plants does the quality of the fresh milk accepted, receive more careful attention and average higher than in the milk condensery. The foundation of the condensed product, the fresh milk, therefore, is of a relatively high standard of purity.

Again, the temperature to which the milk is subjected is sufficiently high to destroy the germs of practically all milk-borne diseases; so that, unless the condensed milk becomes infected with pathogenic germs after condensing and before the tin cans are hermetically sealed, practically all danger from disease germs is eliminated. In the case of evaporated milk the marketable

2 U. S. Department of Agriculture, Food Inspection Decision No. 170, March $31,1917$. 
product is free from all forms of germ life. The only exception to this rule would apply to concentrated milk, in the manufacture of which the milk is not heated to temperatures detrimental to the life of bacteria.

Digestibility.-In this discussion of the digestibility of condensed milk it is assumed, that the condensed milk, unless used in admixture with other foods, is diluted to approximately the consistency of normal milk. If consumed as a drink, similar to milk but without proper dilution, its concentration, and consequent excessive richness, would obviously seriously interfere with digestion. While there are no experimental data available concerning the digestibility of condensed milk, the results of feeding experiments with heated, pasteurized or sterilized milk vs. raw milk, may furnish a logical guide as to the dietetic effect of condensed milk. Milk pasteurized at high temperatures, or sterilized, may be considered comparable, as far as the effect of heat is concerned, to condensed milk.

Doane and Price ${ }^{1}$ report the following experimental results: "Raw milk is more easily digested when fed to calves than either pasteurized, or cooked milk. Contrary to theory, cooked milk, when fed to the calves used in these experiments, caused violent scouring in the majority of trials. A majority of physicians in charge of children's hospitals corresponded with, favored the use of raw milk for infants when the milk is known to be in perfect condition, but favored pasteurized milk under ordinary conditions. With one exception all the physicians corresponded with, discouraged the use of cooked, or sterilized milk for infant feeding."

Rosenau* states that "Comparative observations upon infants under the same conditions show that they flotirish quite as well upon heated milk as upon raw milk. Laboratory experiments as well as clinical observations coincide with the view, that heated milk is quite as digestible as raw milk. In fact it is now claimed to be more so. Metabolism experiments indicate that the utilization of calcium and iron in the body is more complete in children fed upon boiled cow's milk, than in those fed upon raw cow's milk.

\footnotetext{
${ }^{1}$ Doane and Price, Maryland Agricultural Experiment Station, Bulletin No. 77,1901 .

- Rosenau, United States Department of Agriculture, Bureau of Animal Industry, Circular No. 153, 1910.
} 
Stutzer ${ }^{1}$. who conducted experiments of artificial digestion reports in favor of boiled milk, while similar investigations made by Ellenberger and Hofmeister ${ }^{2}$ showed no difference in the digestibility between raw and cooked milk.

Rodet $^{3}$ who experimented with dogs noticed a slight difference in favor of boiled milk. Bruning ${ }^{4}$ fed dogs, pigs, rabbits, and guinea pigs with raw and sterilized milk and reports that all results were in favor of the sterilized milk. Bruckler's ${ }^{5}$ experiments with dogs showed that the animals gained more in weight on sterilized milk than on raw milk, but that their general health, vigor and vitality was better when fed raw milk. Variot ${ }^{6}$ observed no difference in the effect on infants between raw and boiled milk.

The foregoing citations suggest that our knowledge of the digestibility of heated or boiled milk is exceedingly limited and that the resilts obtained and conclusions drawn by the various investigators are at variance. In experiments with the living organism, and confined to so few.specimens as seems to have been the case in the work reported, the factors of individuality and environment are a constant stumbling block, magnifying the limit of experimental error and weakening the conclusiveness of the results. On the basis of our present knowledge it seems reasonable to conclude that, as far as the digestibility of its inherent ingredients is concerned, condensed milk, when consumed in properly diluted form, varies but little, if any, from raw milk. The absence in condensed milk of ferments, such as enzymes, which are destroyed in the process and which may assist digestion, may be considered the most important defect of condensed millk from the point of view of digestibility.

In the case of sweetened condensed milk, however, the nutritive ratio of the normal milk is decisively disturbed by the presence of large quantities of sucrose. Even when diluted to far beyond the composition of normal and original fluid milk, the

1 Stutzer, Landw. Versuchs-Stationen, 40, p. 307.

2 Ellenberger \& Hofmeister, Bericht ueber das Veterinarwesen Koenigreich Sachsen, 1890.

3 Rodet, Compt. rend. soc. biol., 48, p. 555.

- Bruning, Muenchner Mediz., Wochenschrift, No. 8, 1905.

- Bruning, Zeitschrift fuer Tiermed, 10, p. 110, 1906.

- Bruckler, Jahrbuch fuer Kinderheilk, 66, p. 343, 1907.

- Variot, Comp. rend., 139, p. 1002, 1904. 
per cent of cane sugar is still high, causing the nutritive ratio of such milk to be abnormally wide and unbalanced. The carbohydrates are present far in excess of the protein, fat and ash. If fed to infants exclusively and for a prolonged period of time, the growing organism is bound to suffer from malnutrition and at the expense of muscular development.

Furthermore, it is conceded by the medical profession that sucrose is not a suitable form of carbohydrates for infants. It is not as digestible as lactose, it changes the bacterial flora of the intestines, enhancing the development of butyric acid and other gas-forming and putrefactive germs at the expense of Bacillus bifidus, which is the natural inhabitant of the intestine in normal, milk-fed babies.

Sweetened condensed milk is generally highly advertised by the manufacturer as a suitable food for babies; it is frequently recommended by physicians and in some instances, it is claimed to have agreed with babies who were unable to take care of milk in any other form. It is not improbable that in these extremely isolated cases of baby feeding, when all other feeds failed, the true virtue attributed to the sweetened condensed milk, lay in the fact that the mothers carefully followed the directions on the label for dilution. The directions specify that the condensed milk be diluted with ten to sixteen parts of water. The majority of cases of digestive disorders in bottle-fed babies are undoubtedly the result of the natural tendency of the mother to feed her child too much milk or too rich milk. When we consider that the ratio of concentration in sweetened condensed milk is only about 2.5 to 1 , it is obvious that a dilution of 10 or 16 to 1 is a great relief to the over-taxed digestive organs of infants, previously fed on milk too rich for normal digestion. The immediate change of the health and disposition of these babies for the better, as the result of turning from a prolonged siege of too rich food to the very dilute condensed milk, is therefore not surprising.

The manufacturer of sweetened condensed milk in this country is inclined to load his product excessively with sucrose. $\mathrm{He}$ does this largely in an effort to increase the keeping quality and to guard against development of fermentations in the finished article that ruin the goods for the market. While a certain 
amount of sucrose is necessary to preserve this milk, yet, if the product is manufactured from a good quality of fresh milk, as it should be, and when the proper sanitary conditions are maintained in all departments of the factory, sixteen pounds of cane sugar per one hundred pounds of fresh milk is entirely sufficient. He should bear in mind that sweetened condensed milk is used and accepted by the consumer as a substitute for market milk, and it is the manufacturer's moral duty to retain in this substitute the normal properties and composition of the product which it is supposed to replace, as nearly as is consistent with the production of a wolesome and marketable product.

Vitamine Properties.-Recent discoveries by nutrition experts ${ }^{1},{ }^{2}$ have revealed and conclusively demonstrated the presence of vitamines, or chemically unknown substances of food origin, that are essential for the normal performance of the function of animal life. Extensive feeding experiments have shown, that before complete growth can occur in a young animal, or for prolonged maintenance, or for the prevention of certain diseases, the diet, besides being adequate as regards its content of proteins, carbohydrates, fats and mineral salts, must contain certain, at present unidentified accessory substances, popularly called vitamines.

Hart and his co-workers enumerate three of these vitamine substances, namely, water-soluble vitamines or antineuritic vitamines; fat soluble vitamines or antixerophthalmic vitamines; and antiscorbutic vitamines. The absence in the diet of each, or all of these vitamine substances causes stunting of growth and the development of certain characteristic diseases.

Water-Soluble Vitamine.-The absence of this vitamine in the diet retards and stunts growth and leads to such diseases as polyneuritis and beriberi (paralysis). The water-soluble vitamine is present in a variety of foods and constitutes an inherent part of the non-fatty portion of milk.

Fat-Soluble Vitamine.-The absence of this substance in the diet retards and stunts growth and leads to the disease of xerophthalmia (an eye disease culminating in blindness). The

1 McCollum, The Newer Knowledge of Nutrition, 1918.

2 Hart, Steenbock and Smith, Studies of Experimental Scurvy, Journal Biological Chemical Chemistry, Vol. XXXVIII, No. 2, 1919. 
fat-soluble vitamine is present abundantly in a very limited list of foods, namely, in butter fat, egg fat, cod liver oil, the fats of the vital organs and in the leaves of plants. It is not contained in ordinary animal fats such as lard, nor in any of the vegetable fats.

Antiscorbutic Vitamine.-The absence of this vitamine substance in the diet causes the development of scurvy and similar scorbutic diseases and skin diseases. The antiscorbutic vitamine appears to be present in many foods, similar to the watersoluble vitamine, and it is abundantly present in raw milk.

Effect of Heat Employed in the Manufacture of Condensed Milk on These Vitamines.-The heat to which condensed milk is subjected in the process of manifacture does not rob the condensed milk of the water-soluble and fat-soluble vitamines, so far as our knowledge, based on data now available, is concerned. This applies to all kinds of condensed and evaporated milk made from whole milk. From the standpoint of these two growthpromoting and curative vitamines, all forms of condensed whole milk are, therefore, equally desirable for infant feeding, for children and for the adult, as is whole milk.

On the other hand, skim condensed milk is not a satisfactory food for the growing young. It lacks the indispensable fatsoluble accessory and unless supplemented by egg yolk, cod liver oil or butter, its consumption by the young in the place of whole milk, or in the place of condensed milk made from whole milk, will prove disastrous to the growth and well-being of those who are restricted to such a diet.

Nor does imitation condensed milk, such as the "Hebe" product, in which the butter fat has been replaced by a vegetable fat, supplement the lacking fat-soluble vitamine substance. The public should clearly understand that in milk or condensed milk, there is no substitute for butter fat and when the butter fat is removed the product no longer can take the place of milk. See also "Addition of Artificial Fats," Chapter XXIV.

The antiscorbutic vitamine, on the other hand appears to be destroyed in the process of manufacture of evaporated milk, as shown by Hart in experiments with guinea pigs. Hart found that commerçial unsweetened condensed milk (meaning 
evaporated milk), had lost its antiscorbutic properties when used in quantities equivalent to an amount of raw milk which would prevent scurvy in guinea pigs on a diet of rolled oats and dried hay.

Hart's results agree with those of many other investigators in the fact that the exposure of milk to sterilizing temperature, deprives the product of its antiscorbutic properties. On the basis of these facts evaporated milk cannot be recommended as an exclusive milk diet for babies and children. If evaporated milk must be used for infant feeding, some antiscorbutic supplementary food, such as orange juice, should be fed in conjunction with the exclusive use of evaporated milk or similar heated milk product.

To what extent the antiscorbutic properties of milk are preserved or destroyed in the manufacture of sweetened condensed milk, has not as yet been experimentally demonstrated. This product is not exposed to sterilizing temperatures and yet it is heated at least to the boiling point. The safer course to follow here, too, if sweetened condensed milk must take the place of normal raw or pasteurized milk, is to feed it in conjunction with a known antiscorbutic supplementary food, such as orange juice.

\section{ChAPTFR XXI.}

\section{COST OF MANUFACTURE.}

General Discussion.--The cost of manufacture varies, in a general way, with the organization and size of the factory, capacity of machinery and the amount of the output. These variations are further modified by the cost of available labor, the price of milk, cane sugar, tin cans, box shooks, coal and other supplies, etc.

In a properly organized plant the cost of manufacture per case of finished product decreases with the increase of the output, provided that the capacity of the machinery is sufficient to take care of such increase. When the plant is forced beyond its capacity, the factory operates at a disadvantage, and the extra labor and possible waste and losses tend to increase the cost per case. When the output drops below 100 to 150 cases 
per day, profitable manufacture becomes difficult, the overhead expense is out of proportion with the business, the factory cannot take advantage of rebates in the purchase of supplies, the factory labor is relatively high, because skilled men have to do manual labor, and occasional losses due to spoiled goods devour the profits of a comparatively large portion of the entire output.

The price of milk fluctuates with season and proximity and strength of competing markets. The pre-war fluctuations embraced a range of from $\$ 1.00$ to $\$ 2.00$ per one hundred pounds of fluid milk, or twenty-five to fifty cents per pound of butter fat. Maximum war prices and post-war prices up to and including January 1,1920 , reached the figure of $\$ 4.17$ per 100 pounds of milk.

Cane sugar varies in price largely with the season and with the success or failure of the sugar cane crop. Sugar prices usually reach their climax in fall and their minimum price in late winter or early spring. Pre-war variations usually fell within the limits of $\$ 4.00$ and $\$ 6.50$ per one hundred pounds of sugar. Since the war and up to January 1, 1920, the price of sugar has risen to 17 cents per pound.

Tin cans vary in price with style of can and whether made in the condensery or bought from a can-making concern. Some factories are paying more or less heavy royalties for the privilege of using certain patents of cans. Cans intended to be sealed without the use of solder, but which are guaranteed to make a hermetical seal, are generally higher in price than those in the sealing of which solder is used. This difference in price, however, is offset, in part at least, by the cost of the solder and gasoline. Cans purchased from can-making concerns usually are more expensive than cans manufactured in the condensery. This holds true only where the tin-shop of the condensery is properly equipped and efficiently manned. In normal times the cost of cans bought from can-making concerns is about 45 cents per case of 14 ounce cans and 55 cents per case of tall size cans, varying somewhat with size and style of can; when made in the condensery the price may be lowered from 10 to 20 per cent. January 1, 1920, prices for cans were about 88 cents 
per case of 48 14-ounce cans and about 99 cents per case of 48 cans for tall-size cans.

The cost of coal varies with quality and locality. Under average conditions, the condensing and packing of one pound of fluid milk requires about three-tenths of a pound of coal or thirty to forty pounds per case. A good quality of "mine run" can be laid dow'n at the factory in states near the coal region, like Indiana and Illinois for about $\$ 2.50$ per ton, or in northern states, like Wisconsin, for about $\$ 3.30$ per ton. The cost of coal per case, therefore, may vary from about three and eight-tenths to six and a half cents per case. Where natural gas or refuse from lumber mills is available, the cost of fuel may be reduced materially by the use of these substitutes for coal. Maximum war price raised the cost of coal to about 9 cents per case.

Solder and gasoline for sealing the cans average about three and a half cents per case. The price of solder is about twentyseven cents per pound and the solder used per case of fortyeight cans, amounts to about one-tenth of a pound. Maximum war price raised it to about $7 c$ per case.

For venthole cans the amount of solder needed is from .3 to .5 of one ounce per case, making the cost in normal times about seven-tenths of one cent for tall size cans.

In the case of the sanitary can and other cans with solderless seals this item drops out entirely.

The labels vary in price according to quality of paper, and elaborateness of printing. The average cost of labels is about four cents per case. Maximum war price about 8 cents per case.

The box shooks and nails per case cost about eight to ten cents. January 1, 1920, the price of box shooks per case for 14 ounce cans was about 23 cents and per case for tall size cans about 26 cents. In the case of fibre boxes the cost per case is about 18 cents.

The factory labor for pre-war conditions was about 12 to 1.5 cents per case and the administration expense about 5 to 10 cents per case, varying widely, of course, with the type of organization and volume of business. January 1, 1920, the factory labor was about 20 to 25 cents per case and the administration expense about 10 cents per case. 
Under pre-war conditions the freight and other transportation ranged from about 10 to 25 cents per case averaging about 12 to 15 cents. January 1,1920 , the freight and other transportation charges would average 35 cents per case.

Before the war the investment in factory, equipment and operating expense for a plant with a capacity of about 500 cases per day amounted to about $\$ 75,000$, placing the interest and insurance at about 3 cents per case. January 1, 1920, a factory of similar capacity would involve an investment in building, equipment and operating expense of about $\$ 175,000$, placing the interest and insurance at about 7 cents per case.

The selling expense varies widely ranging from less than 10 cents to 20 cents per case.

The following tabulated summary may serve to bring out the approximate relative expense per case of sweetened condensed milk and evaporated milk more clearly:

\section{Sweetened Condensed Milk.}

Cost per case of forty-eight cans. These cans weigh 14 ounces net per can or 42 pounds net per case. They are known in the trade as 14 ounce cans.

1913. 1920.

105 lbs. milk (concentration

$2.5: 1) \ldots \ldots \ldots \ldots \ldots \ldots @ \$ 1.50$

16.8 lbs.sugar(16 lbs.per 100)@5.00

Tin cans (sanitary) ................. 45

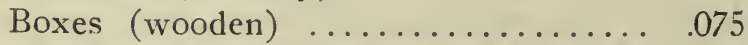
Jan. 1.

Labels ....................... $\quad .040$

Coal ........................ .045

Factory labor ......................

Administration expense ............ .07

Freight ........................ .14

Selling expense ............... .10

$\$ 3.78$

Interest and insurance on investment and on operating capital.......... .03 @ $15.75 \quad 2.64$

@ $\$ 3.60$




\section{Evaporated Milk.}

Cost per case of forty-eight tall size cans, weighing forty-eight pounds net.

1913.

$$
\text { (a) } \$ 1.50 \$ 1.59
$$

106 lbs. milk

Cans (vent hole) .55

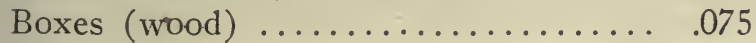

Labels

Soider and gasoline (vent hole cans)... .007

Coal ........................ . . . .

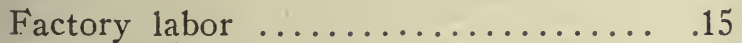

Administration expense $\ldots \ldots \ldots \ldots . .07$

Freight .....................

Selling expense ................ 10

Interest and insurance on investment and on operating capital...........03

@ $\$ 3.60 \$ 3.816$

Jan. 1.
$\$ 3.816$
.988

.262

.053

.014

.09

.23

.10

.35

.12

.07

Total cost per case......... \$2.797

$\$ 6.093$ 


\section{PART V. \\ CONDENSED MILK DEFECTS, THEIR CAUSES AND PREVENTIONS}

\section{Chapter XXII. \\ CLASSIFICATION OF DEFECTS.}

Many are the defects which cause condensed milk to be rejected on the market and numerous are the arenutes that may lead to the manufacture of defective milk. The milk faults may be of mechanical, physical, chemical, or bacteriological origin, or they may be due to a combination of two or more of these forces. In some instances the defects can be detected in milk during; or immediately after the process, in which case they may be remedied, or their recurrence prevented. But more often, several weeks may pass before abnormalities develop and before the manufacturer realizes that something is wrong with the milk. In the meantime, the conditions which originally produced the milk defect may have so changed, that it is exceedingly difficult to locate the seat of the original trouble. .

\section{DEFECTIVE SWEETENED CONDENSED MILK.}

The following are the chief and most common defects of sweetened condensed milk:

1. Sandy, rough or gritty

2. Settled

3. Thickened and cheesy

4. I umpy, white or yellow buttons

5. Blown or fermented Es contan

6. Rancid

7. Putrid

8. Brown

9. Metallic. 


\section{Sandy, Rough or Gritty Sweetened Condensed Milk.}

General Description.- - This is condensed milk in which a portion of the milk sugar has been precipitated in the form ( f large crystals, the size of the crystals depending on the conditions causing crystallization. First-class sweetened condensed milk is smooth and velvety: Such milk is not entirely free from sugar crystals, but they are so minute in size that they do not rob the condensed milk of its natural smoothness. In sandy or gritty condensed milk the crystals are very numerous and large enough to grind between the teeth, similar to salt crystals in gritty butter. The presence of these crystals is also noticeable to the naked eye; the milk looks candied.

Causes and Prevention.--The sugar crystals which render the condensed milk rough and sandy consist largely of milk sugar. 'The solubility of milk sugar is relatively low. Milk sugar requires about six times its weight of water at ordinary temperature for complete solution. Condensed milk contains from 12.5 to 15 per cent milk sugar and only about 26.5 per cent water. The ratio of milk sugar to water in sweetened condensed milk, therefore, is $1: 2$, while for complete solution it should be $1: 6$. The milk sugar in this product is present in a supersaturated solution and any condition which favors sugar crystallization strongly tends to precipitate this milk sugar, because there is more of it present in the milk than the available water is capable of readily keeping in solution. The chief factor that prevents the milk sugar from precipitating very badly is the great viscosity of the condensed milk. This is largely due to the caseous matter and the cane sugar.

Cane Sugar Content.-It has been argued that the large amount of sucrose which sweetened condensed milk contains, is the principal cause of sandy milk and of sugar sediment in the bottom of the tin cans, and that a reduction in the amount of sucrose lessens the tendency of the sugar to crystallize and the milk to become sandy. This line of reasoning is erroneous. The presence, in water, of sucrose in solution does not materially lessen the power of the water to dissolve milk sugar, provided that the sucrose solution is not a saturated one. Sweetened condensed milk, contains about 35 to 45 per cent strcrose and 
24 to 28 per cent water. Sucrose dissolves in one half its weight of water. The sweetened condensed milk does not, therefore, contain a saturated solution of sucrose.

Incomplete Solution of Sucrose.-If the finished product is to be smooth and free from sandiness, it is essential that the sucrose which is added to the hot, fresh milk be thoroughly dissolved before the mixture reaches the vacuum pan. Undissolved sugar crystals in a medium as highly concentrated as sweetened condensed milk have much the same effect in a physical way, as have bacteria in fresh milk in a biological way; they multiply rapidly. Therefore, if all the sugar added to the fluid milk is not completely dissolved, the undissolved sugar crystals give rise to wholesale precipitation of the milk sugar in this product after manufacture, and since the crystals of undissolved cane sugar are relatively large, their presence also gives rise to the formation of milk sugar crystals of large size. Hence the sandy condition of the condensed milk. Complete solution of the cane sugar can best be accomplished by heating the liquid, milk or water, in which the sugar is to be dissolved, to the boiling point and by boiling the mixture for several minutes; or by placing the sugar on a large wire mesh strainer (ahout eighty meshes to the inch) which stretches across the sugar well and allowing hot milk to run over this sugar into the well below. In this way the sugar crystals must dissolve before they can reach the sugar well.

One of the safest methods of insuring complete solution of the cane sugar is to dissolve it in a separate kettle in a sufficient quantity of boiling water (preferably distilled water) and boiling the syrup for five to fifteen minutes. If the syrup thus made is given a few minutes rest it should become perfectly clear; by. its clearness, the purity of the sugar can also be observed. If a scum forms at the top it should be removed; then the hot sugar syrup is drawn into the pan. Care should be taken that the milk already condensing in the pan has not become too concentrated, otherwise sugar crystallization may set in. It is advisable to inject the sugar syrup gradually, rather than to wait until nearly all the milk is in the pan.

Excessive Chilling in the Pan.-The cause of grittiness of condensed milk may lie in the pan itself. Where the water used for condensing is very cold, and where one end of the spray 
pipe in the condenser is very close to the goose neck of the pan, as is the case with most of the vacuum pans in use, which are equipped with horizontal spray condenser, the chilling of the vapors and of the spray of milk rising from the pan is so sudden, that sugar crystals are prone to form in the spray and along the walls of the pan. These crystals either stick to the side of the pan, or fall back into the milk where they later multiply and cause the milk to become sugary. Trouble from this source can be avoided by either raising the temperature of the water that goes to the condenser which is, however, not practical under most conditions, or by closing the holes in that portion of the spray pipe which is nearest the pan. This can easily be done by wrapping a piece of galvanized iron or tinplate around the portion of the spray pipe to be closed, or by filling the holes with solder, or by replacing the old spray pipe by a new and shorter one, properly constructed.

Superheating at End of Batch.--Sometimes the manufacturer is persistently troubled with the apprearance of crystals in the condensed milk of monstrous size, as large as rice kcrnels; this condition arrives usually very gradually. During the first few days after manufacture, only a few of these large crystals may appear in some of the cans. In the course of a few weeks, all of the cans may contain specimen of these "rice crystals" which increase in number until the entire contents of the cans are one mass of "rice crystals," rendering the milk unsalable. The direct causes of this particular kind of sugar crystallization are excessive concentration of the condensed milk, the use of too much steam pressure in the coils and jacket when condensation is near completion, delay in the drawing off of the condensed milk from the pan, and leaky steam valves in the pipes leading to jacket and coils.

Toward the end of the condensing process the milk becomes heavy, thick and syrupy, and boils with much less violence. If, at this stage of the process, excessive steam pressure is used in the jacket and coils, the milk is superheated, often causing the precipitation of "rice crystals." Again, where the finished condensed milk is drawn from the pan very slowly, either owing to too small an outlet in the bottom of the pan, or because the milk is forced to run through a strainer attached to the outlet, or 
because the finished condensed milk is retained in the pan as the result of an accident, in all of these cases there is danger of superheating, and therefore, of the production of these large crystals. This danger is especially great, where the valves of the steam pipes leading to the jacket and coils are leaking, as is often the case. The avoidance of excessive.concentration and the removal of any conditions that tend to expose the finished or the nearly finished condensed milk to excessive heat will - usually prevent further trouble of this sort.

Experimental results by C. S. Hudson, ${ }^{1}$ on the solubility and crystallization of milk sugar also show that milk sugar crystals of large size were obtained by evaporation of a solution of milk sugar at 95 degrees C. (203 degrees F.).

Excessive Concentration.-In as much as the initial cause of the precipitation of a portion of the milk sugar which leads to the production of sandy condensed milk lies in the fact that the milk sugar is present in this product in the form of a supersaturated solution, it is obvious that the danger of sugar crystallization and sandiness in this product increases with the increase in concentration. This is fully borne out by practical experience. The higher the ratio of concentration the more difficult it becomes to manufacture a smooth condensed milk. The danger here is further augmented by the fact that in the very highly concentrated product the tendency of superheating is augmented. And the superheating gives rise to very large crystals wilich render the product exceedingly coarse. The superheating is due to the increased sluggishness of the very thick condensed milk in the pan, it ceases to boil vigorously enough and is therefore excessively exposed to the hot coils. It is further due to the slowness with which this product leaves the hot pan.

Improper Cooling.- The method used for cooling the sweetened condensed milk after it leaves the vacuum pan is another important factor determining the smoothness or grittiness of the finished product. The chief principles involved here are the rapidity and extent of cooling and the amount of agitation to which the condensed milk is subjected.

In order to fully appreciate the importance of strict atten-

${ }^{1}$ Hudson, The Hydration of Milk Sugar in Solution, Jour. Am. Chem. soc., Vol. XXVI, No. 9, 1904. 
tion to details in the cooling process of sweetened condensed milk, it should be understood, that the formation of large sugar crystals in concentrated solutions is enhanced by sudden chilling and by excessive agitation of these solutions. In the case of cooling in 10 gallon cans as described under "Cooling of Sweetened Condensed Milk," Chapter VI., the sudden and irregular chilling of a part or all of the sweetened condensed milk in the cooling cans is the result of the use of badly dented cans, poorly fitting paddles, a warped condition of the pivots on which the cog wheels in the bottom of the cooling vat revolve, too cold water, and the application of too much cold water.

The paddles must scrape all parts of the sides of the cans, from top to bottom. This is possible only when the cans are intact and their sides are smooth and free from indentations. The paddles must be adjusted properly so that their edges fit snugly against the sides of the cans, they must be firmly fastened to the cross bars and forced against the sides of the cans by springs. In order that the cans may run true they must properly fit into the rim of the cog wheels in the bottom of the cooling vat and the pivots on which the cog wheels revolve must be perpendicular. If the pivots are warped, the cog wheels cannot run true and the cans wobble; this causes uneven and incompiete scraping of the sides of cans by the paddles.

The water in the cooling vat should not be cold, but have a temperature of about 90 degrees $F$. when the cans, filled with the hot condensed milk, are set into the vat. The cold water should flow into the vat slowly and be evenly distributed throughout the vat. This is best accomplished by the installation of a perforated pipe running the entire length of the vat. The cooling must be gradual. See also "Excessive Stirring."

Excessive Stirring.-The cans should revolve slowly. Rapid revolution causes excessive agitation of the condensed milk, which stimulates the formation of crystals. About five revolutions per minute is satisfactory. In order to make more effective the proper scraping of the cans by the paddles when the cans revolve slowly, it is advisable to install two paddles in each can, touching the periphery of the can on opposite sides.

When the milk has been cooled to between 60 and 70 de- 
grees F., the water should be drawn from the cooling vat, or the cans should be removed at once.

In the newer method of cooling, in which the hot condensed milk is forced under pressure through a $1 \frac{1}{4}$ to $1 \frac{1}{2}$ inch coil submerged in a tank of cold water, there appears to be a happy relation of rapidity of cooling and type of agitation, that assists in avoiding the formation of crystals sufficiently large to cause sandiness. While the cooling here takes place with relatively great rapidity, the agitation appears to be such as to prevent, in a large measure, the production of excessively large crystals. If this cooled condensed milk, leaving the cooling coil, is subsequently further subjected to slow agitation for several hours, the formation of small crystals is encouraged and the prevention of a sandy condition of the product is facilitated. For detailed description of this method of cooling see "Cooling Sweetened Condensed Milk," Chapter VI.

Warming Up of Too Cold Condensed Milk.-Finally, if the condensed milk is cooled to too low a temperature, either by mistake, or as the result of the cans of cooled milk standing in a very cold room over night, so that the condensed milk is too thick to run through the filling machine, it is best to warm it up by simply allowing it to stand in a warm room. The practice of setting the cans back into the cooling tank and revolving them in warm water is objectionable, since this stirring of the milk, while it is warming, seems invariably to produce. wholesale sugar crystallization, and therefore, causes the condensed milk to become very gritty. (See also Settled Condensed Milk.)

\section{Settled Sweetened Condensed Milk.}

General Description.-By the term "settled milk" the condensed milk man refers to condensed milk which has precipitated and thrown down a portion of its sugar, forming a deposit of sugar crystals in the bottom of the can or barrel. This deposit may vary in amount from a very thin layer to a layer an inch deep or more, according to the character and age of the milk. The nature of this sediment also differs in different cases of settled milk. It may be soft, and upon stirring may mix in and dissolve readily, or it may be very dry and hard, in which case it sticks to the bottom of the can with great tenacity, and 
can be removed and mixed into the milk with difficulty only. Like gritty milk, settied milk is a very common condensed milk defect. Though it does not render the product less wholesome, it is an undesirable characteristic. Such milk is usually rejected on the market and results in a partial loss to the manufacturer.

Causes and Prevention.--It is obvious, for reasons above referred to, that the conditions leading up to the production of settled milk, are closely related to those that cause milk to become gritty. Condensed milk cannot diop its milk sugar, unless the latter is present in the form of crystals. The absence of crystals then, means that condensed milk will not settle but experience has shown that it is a practical impossibility to manufacture sweetened condensed milk which contains no sugar crystals. Sugar crystals are always present in it, and the fact that the milk is not sandy or gritty, does not necessarily mean that it will not settle. Nevertheless, the removal of conditions conducive of sandy or gritty milk, diminishes the tendency of the formation of sugar sediment. The successful and uniform production of condensed milk that does not settle, however, involves additional conditions that are not controlled by the factors causing gritty milk.

Effect of Density on Sugar Sediment.-One of the chief of these conditions is the density of the condensed milk. The thinner the condensed milk, the greater the difference between the specific gravity of the liquid portion and that of the sugar crystals; therefore, the more readily will the crystals sink to the bottom. The viscosity of thin condensed milk, also, is less than that of thick milk, offering less resistance to the force of gravity of the crystals. In the manufacture of sweetened condensed milk that has the proper density, about 2.5 parts of fresh milk are condensed into one part of condensed milk. If the evaporation is stopped sooner, so that the ratio is much less than 2.5 to 1 , the condensed milk is usually too thin to hold its sugar crystals in suspension unless its specific gravity and viscosity are increased by the addition of more sucrose.

Effect of Fat Content on Sugar Sediment.-The per cent of fat in milk, also, influences the specific gravity of the condensed milk, and therefore, has some effect on the settling of the sugar 
crystals, although to a relatively slight. degree. Nevertheless, sweetened condensed skimmed milk will settle less readily than sweetened condensed whole milk.

Effect of Cane Sugar Content on Sugar Sediment.-The per cent of cane sugar materially influences the specific gravity and viscosity of the condensed milk. Milk with a high per cent of sucrose is heavier, more viscous and drops its sugar crystals less readily than milk with a low per cent of sucrose.

Turning the Cans to Prevent Sugar Sediment.-Concerns who have been continually troubled with settled milk often resort to the practice of turning their cases daily, or at other regular intervals. This keeps the precipitated crystals in motion, but it does not prevent the settling entirely. Moreover, milk destined to settle, as the result of defects in the process, cannot be prevented from dropping its crystals after it leaves the factory. Some concerns have stooped to printing on their labels statements similar to the following: "A sediment in the bottom of this can indicates that this condensed milk is absolutely pure and free from harmful ingredients." Advice of the above denomination is obviously ridiculous as well as untrue.

Adding Powdered Milk Sugar.-It has been explained that after the condensed milk is cooled it contains sugar crystals. If those crystals are large, their cubic content is relatively great in proportion to their surface. Their buoyancy is, therefore, sufficient to overcome the resistance of the surrounding liquid and they will drop to the bottom, forming a sediment. If these crystals are very small and fine they are not objectionable and they usually do not cause settled milk, because their gravity force is insufficient to overcome the resistance of the viscous syrup. It has been further shown that the size of the sugar crystals is largely determined by the size of the first crystals present. Experience has demonstrated that the addition to the condensed milk before cooling, of very fine sugar crystals, such as powdered milk sugar contains, encourages the formation of very small crystals and tends to guard against the development of large and coarse crystals during subsequent cooling. Hence sugar sediment may be greatly minimized, if not entirely prevented, by adding to the hot sweetened condensed milk, a small amount of powdered milk sugar. at the rate of a tea- 
spoon full of milk sugar per one hundred pounds of condenserl milk. The milk sugar must be added as soon as the condensed milk comes from the pan, if the milk is allowed to cool before the milk sugar is added, its effectiviness is largely lost.

In order to insure the full desired action of the added powdered milk sugar, this powder must be transferred to the condensed milk in such a manner as to prevent its formation into lumps. It must be evenly and finely distributed over and in the condensed milk. The use of a flour sifter has been found most suitable for this purpose.

\section{Thickened and Cheesy Sweetened Condensed Milk.}

General Description.-.The term "thickened and cheèsy" condensed milk applies to condensed milk that has become thick and in some cases solid. This is a very common trouble with milk manufactured in late spring and early summer. The milk thickens soon after its manufacture and continues thickening until it assumes the consistency of soft cheese, without the development of acid. In this condition it usually has a peculiar stale and cheesy flavor, disagreeable to the palate. Such milk is invariably rejected on the market.

Causes and Prevention: Effect of Colostrum on Thickening. -It has been suggested that this spontaneous thickening is due to the presence in the fresh milk of colostrum milk, because this defect appears at a time when the majority of the cows supplying the condensery freshen. This explanation can hardly be considered correct and there is no experimental evidence available substantiating it. If the presence of colostrum milk were the cause of it, the thickening would take place during the process, as the result of the action of heat on the albuminoids. This is not the case. This thickening begins some days and often some weeks after manufacture and increases as the milk grows older.

Effect of Cow's Feed on Thickening.-Again, the cause of this defect has been attributed to the change in feed, the cows being turned from dry to succulent feed at the time when this tendency of the condensed milk to thicken occurs. 'There is no reliable evidence, however, of how the succulent pasture 
grasses on which the cows feed can bring about this thickening action in the condensed milk.

Effect of Bacteria on Thickening.-A third and far more reasonable explanation is that this thickening is the result of a fermentation process. It is quite probable that the thickening of sweetened condensed milk is closely related to the sweetcurdling fermentation in fresh milk. The sweet-curdling of fresh milk is a fermentation characteristic of, and frequent during late spring and summer. It is caused by certain species of bacteria which are capable of producing a rennet-like enzyme, which has the powier to curdle milk in the sweet state. These bacteria are known to be closely associated with dirt and filth, especially from the feces, and gain access to the milk usually on the farms where the production and handling of milk is not accomplished under most sanitary conditions.

It is further known, as the result of analyses that, in spite of the large per cent of cane sugar which sweetened condensed milk contains, the bacteria in it increase with the age of the milk. The thickening of the sweetened condensed milk in early summer, therefore, very probably is the result of a slow curdling of its casein, caused by enzymes which are produced by bacteria. It has further been demonstrated that condensed skim milk thickens more readily than condensed whole milk, which may be explained by the fact that condensed milk without butter fat represents a more favorable medium for bacterial growth. Furthermore, it has been conclusively demonstrated by the writer and others that the addition of cane sugar to condensed milk, in excess of that present in normal condensed milk, greatly retards thickening. This fact suggests that the higher per cent of sucrose has an inhibiting effect on the enzyme-producing bacteria, and perhaps, on the action of the enzyme itself. This condensed milk defect can be prevented entirely by using, during the summer months, eighteen pounds of sucrose per one hundred pounds of fresh milk, so that the condensed milk contains about 45 per cent sucrose.

Effect of Finishing in Pan With High Steam Pressure on Thickening.-Abnormally thick condensed milk is also the result of overheating the condensed milk in the vacuum pan toward the close of the process. The batch should be finished with low 
steam pressure in the jacket and coils, not to exceed five pounds of pressure, and the milk should be drawn from the pan at once after condensation is completed. The superheating to which the condensed milk is subjected in the pan, when finishing with a high steam pressure in jacket and coils, or when the milk is not drawn from the pan promptly when the vacuum pump is stopped, or when an effort is made to condense to a very high degree of concentration, is almost sure to cause the finished product to spontaneously thicken with age and this tendency is especially pronounced in the spring and early summer.

Effect of Age on Thickening.-Finally, all sweetened condensed milk has a tendency to thicken with age. Exposure to high storage temperature (summer heat) hastens this action. The rapidity of thickening in storage increases with the increase in temperature. This tendency is very much reduced, therefore, by protecting the goods from high temperatures and by storing them below 60 degrees F. (See Chapter XVII on "Storage," page 191.)

\section{Lumpy Sweetened Condensed Milk.}

General Description.-Lumps of varying denominations are not infrequently found in sweetened condensed milk. They may be soft and permeate the contents of the can throughout, or may appear especially in the form of a "smear" along the seams of the can; or again, they may float on the surface, in which case they are usually hard and cheesy, and either white or yellow in color. Their presence gives the contents of the can an unsightly appearance at best, and in many cases, they spoil its flavor. They naturally suggest to the consumer that something is wrong with the condensed milk, and cause him to reject the whole package.

Causes and Prevention.-The chief causes of lumpy condensed milk are: poor quality of fresh milk, unclean pipes in factory, milk from fresh cows, acid flux in tin cans, and unclean and contaminated tin cans.

Poor Quality of Fresh Milk and Unclean Factory Conditions.-Upon opening the can of condensed milk, even shortly after it is filled, the lid is covered with large and small lumps and specks sticking to the tin, presenting a very uninviting appear- 
ance. This condition can usually be traced back to a poor quality of fresh milk, containing too much acid. Very often, too, the cause lies in the factory itself, where it is due to lack of cleanliness. A thorough inspection of milk pipes and pumps generally shows accumulations of remnants of milk which get into the milk of the succeeding batch. Where this condition exists, it is noticeable that the first batch of the day contains more specks and lumps than the succeeding ones. These lumps do not, as a rule, grow larger in size nor increase in number with the age of the condensed milk, but they injure its appearance to the eye, and certainly cannot add to the wholesomeness of the milk. They might easily be accompanied by the formation of ptomains. A more rigid inspection of all the fresh milk as it arrfves at the factory and thorough scouring of all milk tanks and milk pumps, pipes and conveyors usually prevents the recurrence of this defect.

Milk from Fresh Cows.-During early spring there is a strong tendency of the jacket and coils in the vacuum pan to become coated with a thick layer of gelatinous and lumpy milk. This is probably due to the fact that milk during these months comes largely from freshened cows and may contain some colos. trum milk which coagulates when subjected to heat, or that the proteids of milk from these fresh cows are abnormally sensitive to heat. This thickened material usually does not leave the pan until most of the condensed milk has been drawn off. It, therefore, appears in the last one or two cooling cans. If the milk in these cans is mixed with the rest of the condensed milk, the lumps will appear again in the tin cans. The last cans drawn from the pan should, therefore, be kept separate. The contents of these remnant cans may be redissolved in hot water and should be recondensed in a succeeding batch. In this way the manufacturer sustains practically no loss. In order to prevent these lumps from getting into the cooling cans, some factories attach a strainer to the outlet of the pan. This practice is as unnecessary, as it is damaging to the milk in the pan. The straining greatly retards the removal of the milk from the pan, and the milk is held in the hot pan so long, as to cause partial superheating which is otherwise detrimental to its quality. 
Comparative Composition of Gelatinous Coating of the Jacket. and Coils and of Normal Condensed Milk of the Same Batch, Made April 23, 1908.

Coating of Jacket and Coils

Moisture

Lactose

Fat

Curd

Ash

Acid

Sucrose
24.76 per cent

13.12

9.50

8.14

1.42

.33

41.36

98.63 per cent
Normal Condensed

Milk

30.34 per cent

13.16 " “

7.44 “

7.30 “

1.80 “

.40 “

40.02 “

100.46 per cent

The above analyses were made in order to determine the difference in chemical composition between that part of the batch which, in the spring of the year, forms a gelatinous coating on the jacket and coils and that part which remains normal. The figures do not show as great a difference, as the physical comparison of the two products would suggest. Possibly the most significant point these analyses show is that, while the proteids in the coating are higher, the ash is lower than in the normal condensed milk.

A large portion of the ash of milk is present in chemical combination with the casein, which does not curdle by heat, while the albumin, which is coagulated by heat, contains only a very small amount of ash. Therefore, the fact that an increase in the proteids of this gelatinous coating is accompanied by a decrease in the ash content, would suggest that the proteids. of the coating of the jacket and coils consist of more albumin and less casein than the proteids of the normal condensed milk of the same batch. Since this coating of the jacket and coils occurs only in the spring of the year, when most of the cows freshen, it is reasonable to assume that this coating is the result of the acceptance at the factory of milk too soon after calving and which contains excessive quantities of proteids and other sub- 
stances which are highly sensitive to heat, such as albumin, colostrum, etc.

Excess of Acid in Condensed Milk and Acid Flux in Tin Cans.-The presence in the condensed milk of organic and mineral acids, in excess of the amount which normal fresh milk contains, is conducive of the formation of lumps.

Excessive amounts of acid in condensed milk may be the result of fermentations, usually due to a poor quality of stgar, or of the use of acid flux in the making and sealing of the tin cans. Condensed milk that shows acid or gaseous fermentation usually contains lumps. The acid which it develops as the result of the fermentation, curdles the casein with which it comes in contact.

One of the most common channels through which condensed milk may become contaminated with acid mechanically, is the use of cans. in the manufacture and sealing of which acid flux was used. The acid flux generally used contains zinc chloride. The flux precedes the solder and some of it is bound to sweat through the seams into the interior of the cans. This type of lumps usually has a pink or brownish-red color, especially in the case of considerable quantities of acid flux. Zinc chloride is a highly poisonous product and its use in the manufacture of tin cans, which are intended for receptacles of human food, should be prohibited by law. Aside from its injurious effect on the health and life of the consumer, its presence, even in small quantities in condensed milk, is a detriment to its market value. In such cans there accumulate, usully along the seams, lumps and smeary substances which have been found to consist of casinate of zinc.

Most commercial soldering fluxes consist largely of zinc chloride and are highly acid, although many of these are advertised as acid-free fluxes. In order to avoid the appearance in condensed milk of lumps from this source, cans should be used, in the manufacture of which a strictly acid-free flux is used and which are sealed with acid-free flux. Dry, powdered resin or resin dissolved in alcohol or gasoline are harmless in this respect and are just as effective fluxes, as acid flux, 
Buttons in Sweetened Condensed Milk.-Buttons, as known to the condensed milk manufacturer, represent a type of lumps, different from those previously described. Buttons are lumps of curd of a firm and cheesy consistency. They usually float on top of the condensed milk in the can or barrel. They are sufficiently firm units so they can be readily removed and washed free from the condensed milk. They are of varying sizes, depending on the age of the condensed milk and the temperature at which it was stored. The older the milk and the higher the

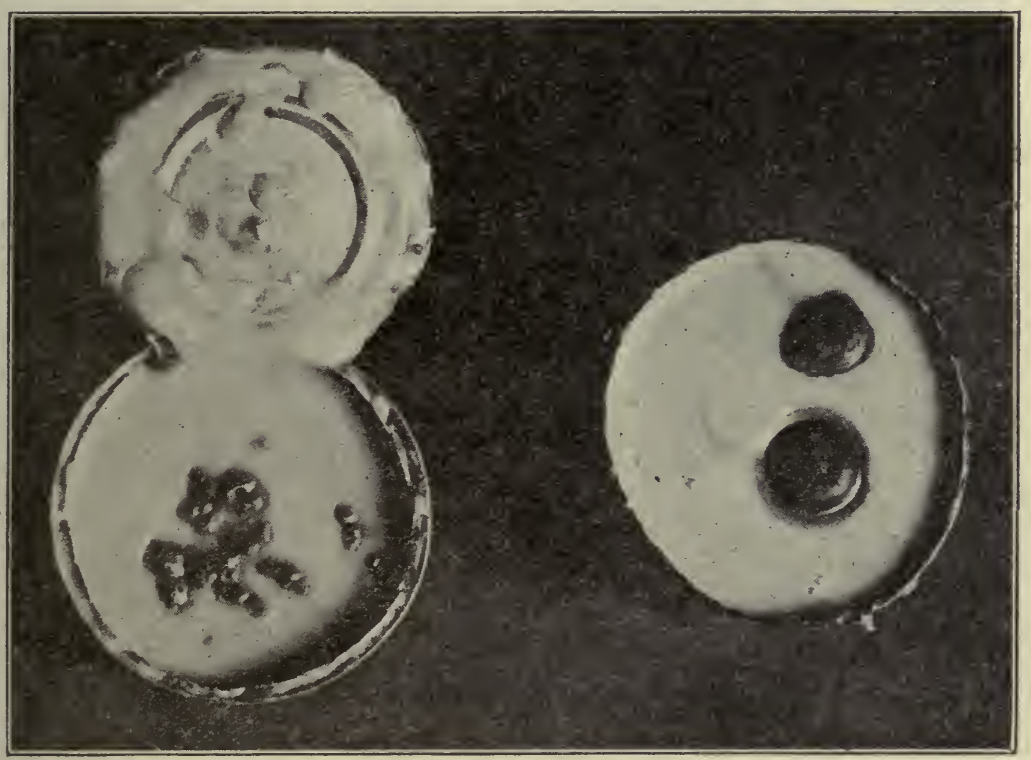

Fig. 81.

Typical buttons of different sizes-All signs of mold have disappeared Courtesy of L. A. Rogers, U. S. Dairy Division

storage temperature, the larger the buttons. Most of the buttons are about one half inch in diameter but frequently they are of sufficient size to cover the entire surface of milk in the can.

These buttons have a whitish-brown to yellowish or reddishbrown appearance. They appear in old sweetened condensed milk more frequently than in milk that has been in storage for a short time only. They are entirely absent in freshly made con- 
densed milk. They themselves have, and they give the condensed milk, a cheesy, stale flavor and lend the entire product an unsightly appearance. They depreciate the market value of sweetened condensed milk.

Causes of Buttons.-Experience has demonstrated that buttons are most prone to appear in stored condensed milk, in the parking of which no attention was given to sanitary conditions in the factory and of the cans or barrels, and that the use of clean sterile cans and barrels and a high standard of sanitation in the handling of the product before packing greatly minimizes this defect. That they are the result of biological action, direct or indirect, is fairly obvious, and the fact that the milk during the process of manufacture is heated to temperatures destructive to most vegetative types of germlife, strongly suggests, that they are the product of recontamination of the finished product.

Rogers, Dahlberg and Evans ${ }^{1}$ of the United States Dairy Division investigated the causes and control of buttons experimentally. They found that the buttons are caused by the growth of the mold Aspergillus repens, and possibly by other molds; that the development of the mold colony is restricted by the exhaustion of the oxygen in the can or barrel, and that the button itself is probably due to enzyme action, continued after the death of the mold.

These findings corroborate earlier experimental results by the author, who was unable to develop growing mold colonies in normal sweetened condensed milk from inoculations with fullgrown buttons.

Rogers and his co-workers demonstrated that the time required for the development of the various stages resulting in button formation varies with temperature, amount of air available and possibly other factors. The mold colony usually appeared in 5 to 10 days. Mold growth is supposed to cease in two to three weeks on account of the exhaustion of the air. In one month a reddish-brown discoloration became quite evident and at the end of two months the button had usually assumed

1 L. A. Rogers, A. O. Dahlberg and Alice C. Evans, The Cause and Control of Buttons in Sweetened Condensed Milk, Jour. Dairy Science, Vol. III, No. 2,1920 . 
definite form. The disintegration of the mold hyphae (filament) proved to be a slow process, extending over 5 to 6 months.

\section{Prevention of But-} tons.-The prevention or control of hese buttons may be accomplished by: 1. exclusion of contamination, 2. low temperature, 3 . exclusion of oxygen.

\section{Exclusion of Con-} tamination.-Contamination of the condensed milk with button-forming molds is most likely to occur during the cooling, holding and filling operations and as the result of contaminated cans and barrels.

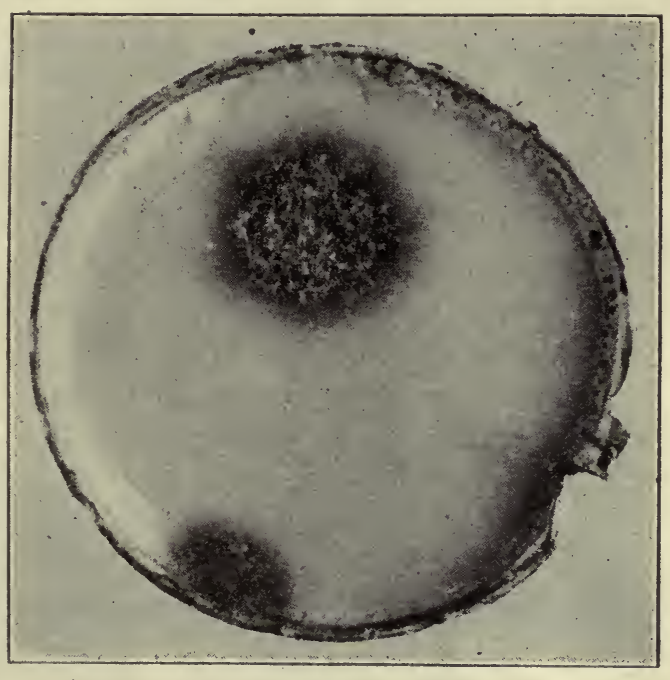

Fig. 82.
Button in growing state, molds still very evident

Courtesy of L. A. Rogers, U. S.

In condenseries where the milk is cooled by the old method -in open 10-gallon cans, revolving in a cold water tank and stirred with wooden paddles-it is not difficult to understand the reason for buttons. In this system the condensed milk is exposed to the air for hours, the 10-gallon cans and the wooden paddles are never sterile and are an almost sure source of contamination, unless special precautions concerning the sanitary condition of equipment and of the air are observed.

In condenseries which use the continuous plan of cooling and holding of the sweetened condensed milk, the product is protected against the atmosphere of the factory from the time it leaves the vacuum pan until it enters the tin cans, and if this equipment is kept clean and is steamed out thoroughly before use, which is readily and quickly done with this type of equipment, contamination should be very largely eliminated and buttons guarded against. 
The empty tin cans in many of the plants are kept under undesirable conditions. They are exposed to diverse channels of contamination during transportation to the factory and during storage in the factory. If these contaminated cans are subsequently filled with the condensed milk, contamination is unavoidable and buttons are likely to follow.

The tin cans should therefore be protected against avoidable contamination, or better yet, they should be sterilized before filling.

A practical sterilizer of empty cans may be readily devised by permitting the cans to pass bottom-side-up over a series of gas flames, under a hood. This method is used successfully in some of the European condenseries and has for them solved, in a large measure, the prevention of buttons. The caps and filling machines obviously should receive such treatment as to prevent them from becoming sources of contamination. Barrels should be steamed till piping hot and then paraffined, before filling.

In factories with wooden floors where the filling and sealing is done, the danger of mold contamination is much greater than in the case of concrete floors.

According to Thom and Ayres ${ }^{1}$ the spores of the mold Aspergillus repens, as well as of most other common molds, are killed in 30 minutes at 140 degrees $F$. The preheating of the milk in the hot wells, which is done at 180 degrees to 200 degrees $F$., and again evaporation in the vacuum pan at 135 to 150 degrees F. are, therefore, sufficient to destroy any mold present in the original milk, so that the cause must be confined very largely to contamination after the finished product leaves the vacuum pan.

Low Temperature.-The growth of most molds is retarded, if not entirely inhibited at low temperatures. This also is the case with the button-forming mold Aspergillus repens. Rogers et al., state that this mold grows very poorly, at temperatures of 68 degrees $\mathrm{F}$. or below. They report that they have never

1 Thom and Ayres, Effect of Pasteurization on Mold Spores, Jour. Agr. Res., Vol. VI, 153-166, 1916. 
observed buttons on condensed milk held at 68 degrees F. or below. These temperature limits are not corroborated by experiments by Hunziker, nor by the experience of the manufacturer. In commercial manufacture, the storage of sweetened condensed milk at 68 degrees $\vec{F}$. will show copious button formation, if such milk contains button-forming spores. Reasonably sure prevention of buttons-may be secured by holding the sweetened condensed milk at about 50 degrees $F$. or below.

Exclusion of Oxygen.-Molds need air for their life and growth. They cannot develop in the absence of oxygen. Accord-

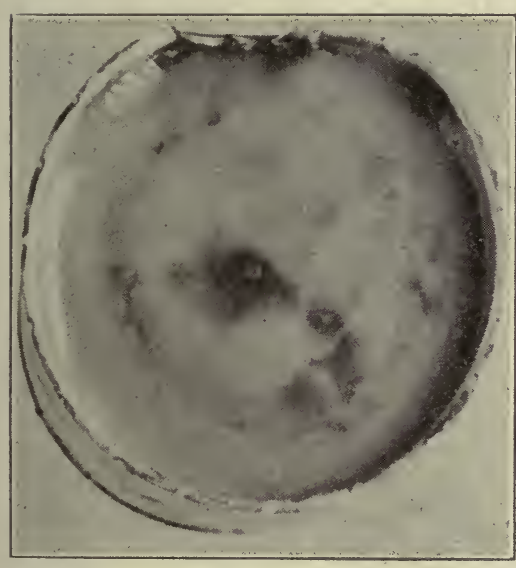

Iig. 83.

Button development under atmosperic pressure

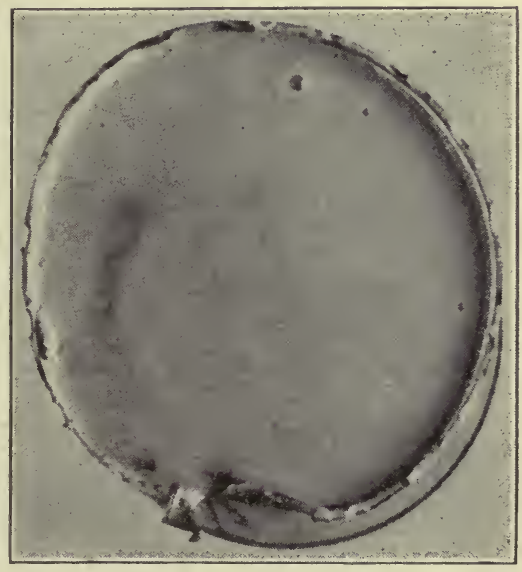

Fig. 84.

Absence of buttons in 20-inch vacuum

Courtesy of L. A. Rogers, U. S. Dairy Division

ingly Rogers et al., by careful experimenting, found that by sealing the cans under a vacuum of 20 inches or more, button-formation in condensed milk contaminated with button-forming. molds could be entirely prevented.

It is probable that a similar effect, if practicable, could be accomplished also by charging the cans with an inert gas to the exclusion of atmospheric oxygen. 


\section{Blown, or Fermented Sweetened Condensed Milk.}

General Description.-One of the most disastrous troubles in the manufacture of sweetened condensed milk is the appearance of "swell heads." This term is applied to cans of condensed milk, the contents of which have undergone gaseous fermentation, the resulting pressure causing the ends of the cans to bulge or swell, and frequently to burst open the seams. In the case of barrel goods, the pressure may cause the barrel head to blow out. This gaseous fermentation is usually, though not always, accompanied by the development of acid and the formation, of lumps.

This fermented milk is worthless for any purpose and means a total loss to the manufacturer. The loss is generally augmented by the fact that this trouble does not become noticeable at once; its development requires several weeks, so that large quantities of condensed milk may have been manufactured before it is apparent that the milk is defective. Some of the goods may have reached the market before the cans begin to swell, in which case the reputation of the respective brand is jeopardized. In some instances entire batches show this defect, while in others only a few cans or cases of èach batch are blown.

Causes and Prevention.-This defect may be brought about through various channels. In most cases it is due to contamination of the milk, on the farm or in the factory, with specific micro-organisms which are capable of fermenting one or more of its ingredients, in spite of the preservative action of the sucrose; or the condensed milk may contain highly fermentable substances such as glucose or invert sugar, so that the germs normally present in the condensed milk become active and produce gas; or the milk may not be condensed to a sufficient degree of concentration, or may not contain adequate quantities of sucrose, to render it immune to the bacteria normally present. The cans may also bulge without bacterial action, as the result of exposure to a wide range of temperatures, causing mechanical contraction and expansion of the contents.

Contamination with Specific, Gas-Producing Bacteria and Yeast.-This is by far the most common cause of blown milk. While the micro-organisms which, under normally sanitary pro- 
duction of milk and factory conditions, gain access to the condensed milk, are largely inhibited and do not ferment the sweetened condensed milk, there are certain specific forms of bacteria and yeast whose growth is not retarded by the concentrated sugar solution of this product. Contamination of the condensed milk with these specific organisms is usually the result of highly unsanitary conditions in the handling of the condensed milk.

The products of fermentation depend on the particular type and species of micro-organisms involved. In most cases the sucrose is the chief constituent attacked, but the lactose, also, is capable of gaseous fermentation, thoughainstances of lactose fermentation in sweetened condensed milk are not common.

The gaseous fermentation of lactose is largely caused by bacteria, yeast and molds which contain the lactose-splitting enzyme "lactase," which has the pow'er of hydrolizing the lactose. While the species of organisms which cause lactic acid fermentation from lactose are very numerous, those containing the enzyme lactase and thereby causing gaseous fermentation from lactose, are less frequent, at least, as far as their access to milk and condensed milk is concerned. It is generally understood, though not experimentally proven, that species of microorganisms which do not contain the enzyme lactase have no gas-producing action on lactose.

The great majority of cases of gaseous fermentation of sweetened condensed milk are the result of the action of microorganisms on the sucrose, especially those which contain the enzyme "invertase." The majority of yeasts secrete invertase and ferment sucrose, producing alcohol and carbon dioxide to the same extent as in the case of glucose fermentations. The process is considerably slower, however, especially at the start, owing to the fact that inversion of the sucrose must precede fermentation. For this reason gaseous fermentations of sweetened condensed milk do not become noticeable until the product is one or several weeks old.

Contamination with Yeast on the Farm.-In most cases of yeast fermentations of sweetened condensed milk, the source of contamination lies in the factory. While such contamination may and often does occur on the farm, the yeast cells, though they may be spore-bearing, are destroyed by the heat to which 
the fresh milk is subjected in the forewarmers and before it reaches the vacuum pan. The thermal death point of all forms of yeast which have come to the attention of the writer in connection with a vast number of investigations of fermented condensed milk was below 180 degrees $F$. If all the milk is properly heated in the forewarmers to 190 degrees $\vec{F}$. or over, there is, therefore; little danger of fermented milk, caused by contamination of the fresh milk on the farm with yeast. If, however, the heating is incomplete, or if some of the milk passes into the vacuum pan without having been properly heated, there is dan. ger of milk, contaminated with these yeasts, to result in fer- mented condensed milk.

Contamination with Yeast in the Factory.-As* previously stated, yeast fermentation of condensed milk can almost in-

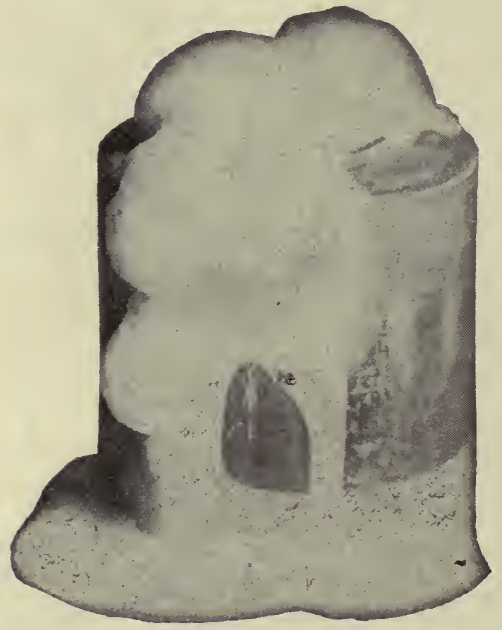

Fig. 85. Gaseous fermentation in sweetened condensed milk ${ }^{1}$

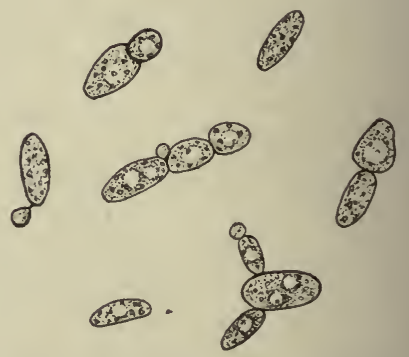

Fig. 86. Yeast cells causing gaseous fermentation

This species is capable of fermenting sugar solutions containing $85 \%$ sucrose. ${ }^{1}$

variably be traced back to contamination in the factory. After the milk leaves the forewarmers, or hot wells, it is never again heated to temperatures high enough to destroy these destructive yeast cells. The channels through which yeast contamination may occur in the factory are many.

1 Hunziker, A Study of the Causes of Fermented Sweetened Condensed Milk, 1910. 
Contaminated Sugar.-The sucrose itself may be contaminated with yeast. This is frequently the case and especially so if the sugar is exposed to dampness, and if flies, bees, ants or cockroaches have access to it.

Again, the sugar may reach the milk through a sugar chute. The lower end of the chute is usually located directly over the steaming milk in the hot well. The vapors arising from below may be condensed in the chute, causing its inside walls to become damp, and sugar will adhere to the damp surface, forming a crust. If the crust is not removed daily, its contamination with yeast and other dangerous micro-organisms is almost inevitable and whenever this crust peels off and drops into the milk, the contamination may be carried into the finished product, giving rise to gaseous fermentation.

Contaminated Machinery and Milk Conveyors.-Remnants of milk may lodge in the condenser, in the vacuum pan, in the pipes conveying the milk and condensed milk, in the cooling cans or coils, in the supply tank of the filling machine, or the filling machine itself. These remnants are all subject to contamination and may become the source of fermented condensed milk. The strictest attention to scrupulous cleanliness and continuous inspection of all parts of conveyors and apparatus which come in contact with the milk are the only consistent safeguards against trouble from this source.

Contamination Through "Cut-opens."-It is customary to empty the contents of samp!e cans which are cut open for any purpose, back into the condensed milk of succeeding batches. If these samples happen to be contaminated with the fermenting germs, the defect is naturally propagated from batch to batch and it is exceedingly difficult to locate the source of the trouble. It is obvious that all suspicious "cut-opens" should be rejected and that all "cut-opens" that are utilized should be emptied into the hot well where their contents are boiled up again.

Dangerous Effect of Poor Quality of Sugar.-Sweetened condensed milk is not sterile. There is no part of the process that would render it sterile and, from the time it leaves the vacuum pan to the time when the tin cans are hermetically sealed, it is exposed to contamination with microbes, even 
though the factory observes the most rigid attention to scrupulous sanitation and cleanliness. Most of these microbes are harmless and their growth is inhibited by the preservative action of the cane sugar. If, however, a poor quality of sucrose is used, which may contain traces of invert sugar, or acid, etc., many of these common species of micro-organisms, harmless in normal condensed milk, find an opportunity to develop and cause gaseous fermentation. The presence of invert sugar makes unnecessary the action of invertase in order to start fermentation; thus, microbes which do not secrete invertase and are otherwise harmless, may become detrimental in the presence of invert sugar, added to the milk in the form of a poor quality of cane sugar. In. a similar way the nse in condensed milk of commercial glucose, as a substitute of a part of the cane sugar, and in order to reduce the cost of manufacture, is bound to cause disastrous results. Nothing but the best refined, granulated sucrose should be used, the best is the cheapest.

Dangerous Effect of High Acid in Milk.-Acids have the power of inverting sucrose. The inversion by acid is especially active in the presence of heat. The milk in the vacuum pan is condensing at 130 to 150 degrees $F$. These temperatures are most favorable to inversion of a portion of the sucrose in the presence of acid. The higher the acid content of the milk, the more active is the inversion. Since invert sugar is the very ingredient necessary to cause bacterial action in the finished product, it is essential that the acidity of the milk to be condensed, should be held down to the minimum in order to avoid trouble from this source.

Contamination with Butyric Acid Bacteria.-Frequently the troublesome microbe is not a yeast, but helongs to a species of bacteria highly resistant to heat, and which fail to be destroyed by heating the milk to the boiling point. In this case, the contamination usually originates on the farm. Organisms of this kind, which infest the milk on the farm in this connection, largely belong to the butyric acid group. The most prominent among them are Granulobacillus saccharo-butyricus mobilis or Bacillus saccharobutyricus, Bacillus esterificans, Bacillus dimorphobutyricus. The putrefactive forms of butyric acid organisms, 
such as Bacillus putrificus, Plectridium foetidum, Plectridium novirm, etc., do not seem to thrive in sweetened condensed milk.

The contamination may occur from dust of hay and other fodder, grain, bedding, or the unclean coat of the udder and surrounding portions of the animal, or from milking with wet and unclean hands, or from remnants of milk in unclean utensils.

It is noticeable that the great majority of cases of blown milk appear during late summer and early fall, when the crops are harvested and the air in the barn is frequently loaded with dust from the incoming crops. Gelatin plates exposed in the stable before and during the filling of silos showed an enormous increase of colonies on the plates exposed during the filling of the silos. Milk drawn under such conditions is naturally subjected to excessive contamination, unless special precautions are observed.

A very common source of these butyric acid organisms also is remnants of milk in pails, strainers, coolers, cans and any other utensils with which the milk may come in contact, also polluted water used for rinsing the utensils. The cheese-cloth strainer, owing to the fact that it is difficult to thoroughly clean and that it is very seldom really clean, is a very serious menace in this respect. Under average farm conditions, unless a new cloth strainer is used at each milking, it is safe to condemn it entirely and to recommend the use of a fine wire mesh strainer containing about eighty meshes to the inch. On some farms the milk is held in a set of old cans which are kept on the farm and which never reach the can washer at the factory. Just before hauling time these cans are emptied into the clean cans from the factory. These old cans are often not washed properly and sometimes not at all. The remnants of milk $\cdot$ in these cans breed these undesirable germs and contaminate the fresh milk. It is obvious that such a practice is bound to jeopardize the quality and life of the finished product and may constitute a continuous cause of blown milk.

Effect of Amount of Sucrose.-Since the sucrose contained in sweetened condensed milk is the chief agent preserving it, it is obvious that enough of it must be added to insure adequate preservative action. Experience has shown that about 39 to 40 per cent of sucrose is required to preserve the condensed milk 
under average conditions. A higher per cent of sucrose would naturally intensify the preservative action and inhibit the growth of the bacteria normally present more completely; but if enough sugar were added to also inhibit the growth of and make harmless those violent gas-producing butyric acid bacteria and yeast cells, which thrive in sweetened condensed milk containing 40 per cent sucrose, the product would be objectionable from the consumer's point of view. The logical avoidance of "swell heads" as the result of these undesirable germs, therefore, must ever lie in prevention, rather than cure. The sanitary standard of production on the farm and of the process in the factory must be raised to and maintained on a leve! where the milk is protected from contamination with these micro-organisms.

The writer ${ }^{1}$ has isolated yeast from fermented sweetened condensed milk that produced vigorous gas formation in media containing as high as 85 per cent sucrose (600 grams sucrose in $100 \mathrm{cc}$. whey bouillon).

Effect of Too Thin Condensed Milk.-Condensed milk that is too thin is, also, prone to start fermenting, since it is deficient in the chief preserving agents, i. e., density and per cent of sucrose. It is not safe to put goods on the market, with a ratio of concentration much less than $2.5: 1$, unless the amount of cane added is sufficient to raise the cane sugar content of the finished product to 44 per cent or above.

Effect of Excessively Low Temperatures.-The cans of sweetened condensed milk may also bulge in the case of cans with non-hermetical seals, exposed successively to excessive cold and to room temperature. In this case, the condensed milk is entirely normal and unaffected, and the bulging is the result of mechanical contraction and expansion by cold and heat. This is possible only where the seal of the cans is not entirely hermetical. In the case of the Gebee seal with the burr cap, and the McDonald seal with the friction cap, the seal is not absolutely air-tight. While the pores between cap and can are microscopic in size, and not large enough to permit the contents from leaking out, they are sufficient to admit air. The cans are usually filled with the condensed milk at a temperature of about 70 de-

\footnotetext{
${ }^{1}$ Hunziker, Results not published.
} 
grees $\mathrm{F}$. If the filled and sealed cans are exposed to a very low temperature, as may be the case in winter, in store houses or in transit, the milk and the air in the cans contract. This contraction is intensified by the fact that the sweetened condensed milk does not freeze. Its concentration is so great that its freezing point is usually below the most extreme cold storage temperature. This contraction of milk and air in the cans produces a partial vacuum, causing air to be drawn into the cans through the microscopic openings of the seal. When the cans are subsequently moved into places with a more moderate temperature, the milk and the air in the cans expand, but the milk on the inside of the cans forms a seal preventing the escape of the surpluts air. 'The result is that the ends of the cans bulge. This phenomenon has been experimentally determined by the author. ${ }^{1}$ While the contents of such cans are perfectly normal, the package suggests fermented milk and may be rejected on the market.

It is evident, from the above data, that the swelling of the cans, as the result of exposure to excessively low temperatures, can readily be avoided, either by protecting the cans against excessive cold, or by using cans that are sealed with solder. The solder-seals are hermetical so that no air can be drawn into the cans when a partial vacuum is formed in their interior as the result of the contraction of air and milk.

\section{Rancid Sweetened Condensed Milk.}

General Description.-Sweetened condensed milk may develop a distinctly rancid flavor and odor, a defect which renders it unmarketable.

According to the best authority, there are many agents which may be active in the production of rancidity. The fact that in rancid butter are usually found to predominate certain species of organisms, such as the fungi of Penicilium Glaucum, Penicilium Roqueforti, Cladosporium butyri, Oidium lactis, Actinomycoces odorifora, yeast and various bacterial species, such as Bacterium fluorescens, Bacterium prodigiosum, Bacillus mesentericus, etc., and that these species are capable of making butter rancid, has led to the conclusion that they may be the cause of rancidity, either by direct action, or by the secretion of fat-splitting

${ }^{1}$ Hunziker, Results not published. 
enzymes. It is, therefore, quite possible that some of these species, or similar groups of species, may be instrumental in developing rancidity in sweetened condensed milk. It has been further found that the milk products from certain individual cows, or cows under certain physiological conditions are more prone to develop a rancid flavor, than milk products from other cows or cows under other conditions.

Relation of Polluted Water to Rancidity.-Polluted and filthy water is usually contaminated with fungi and bacteria belonging to the species cnumerated above and which have been found to be able to produce rancidity. It is, therefore, not improbable, where such water is used in the factory in the washing of cans, conveyors, kettles, pipes, etc., in the condegnser of the vacuum pan and in the cooling tanks, as is frequently the case, that the contamination of milk with it may result in the development of rancidity.

Relation of Climate to Rancidity.-It is frequently claimed that condensed whole milk shipped to the tropics turns rancid. owing to exposure of this milk, rich in fat to a warm climate. Advantage is sometimes taken of this argument, to justify violations of the law by skimming all, or a part of the milk before condensing. This matter has been thoroughly investigated. All experimental results show that sweetened condensed milk, made properly and in conformance with the law, and containing all the butter fat of the original whole milk, does not turn rancid at any temperature.

\section{Putrid Sweetened Condensed Milk.}

General Description.-Sweetened condensed milk is best when fresh. With age it gradually develops a stale flavor which frequently develops into a putrid odor and flavor.

Causes and Prevention.-The purer the fresh milk and the cane sugar, and the more careful the processor, the longer will the condensed milk retain its pleasant flavor, provided that it is stored at a reasonably low temperature. Age, however, will cause the best, sweetened condensed milk to become stale. The appearance of the stale flavor is usually hastened when heating the fresh milk with direct steam; also, where the fresh milk is not heated to a sufficiently high temperature (below 176 de- 
grees $\mathrm{F}$.) the condensed milk will break down rapidly with age, usually developing a putrid flavor and odor. This defect rarely appears where the fresh milk is heated to 180 degrees $F$. or above. This phenomenon is probably due to the presence in milk of active enzymes, such as galactase, gradually decomposing the proteids. The action of most of these enzymes is destroyed when the milk is heated to 176 degrees F. or above.

\section{Metallic Sweetened Condensed Milk.}

General Description.-Sweetened condensed milk frequently is pregnant with a very distinct metallic flavor suggesting copper.

Causes and Prevention.-This can usually be traced back to an unsanitary condition of the dome of the vacuum pan. The sugar and acid in the boiling milk in the pan tend to cause the formation of copper oxide and copper salts, on those sections of the interior surface of the pan which are not daily completely cleansed.

The dome of the pan is neglected in many condenseries from the standpoint of thorcugh cleaning. If it is permitted to go uncleansed for a considerable period of time, it becomes coated with copper salts and when the pan is again in operation, the boiling milk and its spray wash these metallic salts down, incorporating them in the condensed milk.

That the copper in the dome is being acted on can be very readily determined by wiping the inside surface of the dome off with a wet sponge, then analyzing the expressed liquid that the sponge has absorbed. This liquid will be found to contain varying amounts of copper, according to the state of cleanness of the dome.

In order to avoid metallic flavor in sweetened condensed milk, the dome should be washed down daily with similar care as is given the cleansing of the jacket, body and coils, and each morning, before the milk is allowed to enter the pan, the entire pan, including dome and gooseneck, should be thoroughly rinsed down with plenty of clean water.

\section{Brown Sweetened Condensed Milk.}

General Description.-Some of the sweetened condensed milk on the market has a brown color, suggesting chocolate pudding. In this condition it is usually rejected by the consumer. 
Causes and Prevention.-All sweetened condensed milk not held at a low temperature grows darker in color with age. If manufactured properly and not exposed to unfavorable conditions, this brown color appears very gradually and not until the condensed milk is many months old. If exposed to high temperature in storage or transportation, when stowed against the boiler room in the hold of the steamer, or lying on the shelves of the warm grocery store or drug store, etc., it turns brown rapidly. Condensed milk in cold storage retains its natural color indefinitely. Where milk is recondensed (the condensed milk is redissolved either in water or in fresh milk and condensed a second time), the product is always darker in color. This brown color is due to the oxidizing action of heat on both, the lactose and the sucrose, a portion of the sugar caramelizing. Experience has shown that the sugar is more sensitive to the oxidizing action of the heat of recondensing, than when condensed the first time.

\section{Chapter XXIII.}

\section{DEFECTIVE EVAPORATED MILK AND PLAIN CONDENSED BULK MILK.}

The following are the chief defects of unsweetened condensed milk: curdy, grainy, separated and churned, blown or fermented, brown, gritty, metallic.

\section{Curdy, Plain Condensed Milk and Evaporated Milk.}

General Description.-Curdy, unsweetened condensed milk is a term used for milk in which a part of the casein is precipitated in the form of lumps of various sizes. The appearance of lumps of curd in this product is a defect that may render the goods unsalable.

Causes and Prevention.-Lumps are usually due to a poor quality of fresh milk, the use of excessive heat in the sterilizing process and too high a degree of concentration.

Lumps in Plain Condensed Bulk Milk.-Lumps are prone to appear in plain condensed bulk milk, as this class of gocds is usually made from fresh milk that may be slightly sour, as is the case in creameries and in milk plants where the surplus and the 
returned milk is often manufactured into plain condensed bulk milk. This defect can be avoided by neutralizing the milk before heating, with an alkali (sodium bicarbonate or lime water), heating less intensely, or by not carrying the condensing process quite so far. If the plain condensed bulk milk comes from the pan in lumpy condition, it can usually be reduced to a smooth body by passing it through an ice cream freezer at ordinary temperatures.

Lumps of Curd in Evaporated Milk.-The danger of lumpiness, or curdiness in evaporated milk is greatly augmented by the fact that, in addition to the causes named under plain condensed bulk milk, the sterilizing process must be dealt with. The high sterilizing temperature used, tends to precipitate the proteids of milk, and the temperature cannot be reduced below certain limits without impairing the keeping quality of the product. Most of the evaporated milk, after sterilization, is subjected to the shaking process in which the coagulum in the cans is reduced to a homogeneous creamy fluid, provided that the curd is not too hard. A curd will form in the sterilizer in the majority of cases. If it is soft enough, so that it can be completely broken up. no harm is done. If it is so firm that mechanical shaking fails to cause it to disappear, then the evaporated milk will reach the market in lumpy condition and is difficult to sell.

Effect of Quality of Fresh Milk.-The quality of fresh milk is all important in preventing lumpy evaporated milk. The milk must come from healthy cows in good, normal physical condition. It must not contain colostrum milk nor be stripper milk and it must receive the best of care on the farm and reach the factory. perfectly sweet. Milk that is not of high quality in every respect should not be received at the factory.

The acidity of milk due to acid fermentation, lowers the curdling point of the milk, partly by changing the reaction and partly by lowering the citric acid content. High acidity therefore is one of the causes of curd formation in evaporated milk. If abnormal curdling is to be prevented, one of the first and fundamental essentials is that the milk reach the condensery in as fresh and sweet a condition as possible.

Effect of Relation of Mineral Constituents of Milk.-More recent studies of the heat coagulation of milk, however, by Som- 
mer and Hart, ${ }^{1}$ and by Rogers ${ }^{2}$ show that the titratable acidity of fresh milk is not the only, and often not the really important factor, controlling the coagulation of milk, but that the stability of the casein, or its resistance to the coagulating effect of exposure to heat, depends on the relation of certain ash constituents.

Sommer and Hart conclude that maximum stability of the casein demands a proper balance of calcium and magnesium with the phosphates and citrates, while the sodium and potassium chlorides in the concentrations present do not have any marked influence on the coagulating point. Thus these investigators state, the coagulation of milk on heating may be due either to an excess or a deficiency of calcium and magnesium. The calcium in the milk distributes itself between the casein, citrates, and phosphates chiefly. "If the milk is high in citrate and phosphate contents, more calcium is necessary in order that the casein may retain its optimum calcium content after competing with the citrates and phosphates. If the milk is high in calcium, there may not be sufficient citrate and phosphate to compete with the casein to lower its calcium content to the optimum. In such a case the addition of citrates or phosphates makes the casein more stable by reducing its calcium content. The magnesium functions by replacing the calcium in the citrates and phosphates.

"In most cases the coagulation is due to an excess of calcium and magnesium. It is possible to balance this excess by citrates, phosphates, carbonates and other salts." See also Chapter XI on "Sterilizing," Mojonnier Viscosity Controller.

The factors of relation of ash constituents are influenced and largely controlled by such conditions as breed, period of lactation, health and feed of the cows. And this fact in turn may be accepted to explain, why there is a vast difference in the ability of milk produced in different localities, to withstand different degrees of concentration and sterilization without developing a permanent and objectionable curd. It is a well

1 H. H. Sommer and E. B. Hart, The Heat Coagulation of Milk, Jour. Biol. Chemistry, Vol. XL, No. 1, 1919.

2 L. A. Rogers, Address, Milk Section National Canners' Association, Cleveland, O., 1920 . 
known fact, established by practical experience in processing, and by analyses of different brands of evaporated milk, that in some European countries, milk can be condensed to a much higher degree of concentration than in most sections of this country, without becoming permanently curdy.

Effect of Forewarming or Preheating on Curdling.-As explained in Chapter XI on "Sterilizing," under "Factors that Decrease Viscosity of Evaporated Milk," the readiness with which milk coagulates in the sterilizer is diminished by lengthening the period of preheating in the forewarmer, or by raising the temperature of preheating, or both. And vice versa, the shorter the period of preheating and the lower the temperature (below 210 degrees $\mathrm{F}$.) to which the milk is forewarmed, other conditions being the same, the greater the danger of curdling in the sterilizer.

It is not improbable that here again the modification of the balance of the calcium and magnesium with the phosphates and citrates, may be the fundamental cause of these phenomena. In this case the longer exposure to the forewarming heat, or the higher temperature of forewarming, or both, may have the effect of lowering the soluble calcium content by precipitating part of it as insoluble calcium phosphate. If coagulation is due to an excess of calcium or magnesium, as it usually is, then this lowering of the calcium content, as the result of preheating, will mini. mize the danger of coagulation in the sterilizer.

Effect of Addition of Water on Curdling.-Addition of extraneous water to the evaporated milk lessens the intensity of coagulation in the sterilizer. This is a matter pretty generally understood by the experienced operator, as pointed out in Chapter $\mathrm{XI}$ on "Sterilizing" under "Factors which Decrease Vliscosity and Tendency to Curdle." It is due to the dilution of both the casein and the serum in milk.

Effect of Concentration.- The more concentrated the evaporated milk, the greater the danger of lumpiness. All the conditions causing lumpiness are intensified by the degree of concentration. ${ }^{1}$ The manufacturer must, therefore, study the be-

1 For detailed discussion of relation of quality of fresh milk to curdiness of evaporated milk see Chapter VIII on "M'anufacture of Evaporated Milk," "Quality of Fresh Milk." 
havior of his product at different degrees of concentration, and then decide how much evaporation it will stand without developing subsequently a permanent curd in the sterilizer. ${ }^{1}$

It is obvious that any excess or deficiency of calcium, or any excess of acid present in the original milk, is magnified in direct proportion as the concentration increases. Therefore, the higher the concentration, the more difficult it is to put the evaporated milk through the sterilizing process without the formation of a permanent curd.

Effect of Sterilization.-The coagulum is formed in the sterilizer. The higher the temperature, other conditions being the same, the firmer the curd. The lowest temperature that will efficiently sterilize the evaporated milk should, therefore, be used. Since the sterilizing temperature to be maintained cannot be modified below certain limits, it is necessary, when the milk is very sensitive to the heat, to lower the degree of concentration. In some factories fractional sterilization is resorted to with batches of milk that are suspicious. By so doing, lower temperatures can be used effectively, but this process calls for much more labor, increases the cost of manufacture and decreases the capacity of the factory.

Effect of Fractional Curdling.-Experience has shown that, if the proteids in evaporated milk are partly precipitated by heat before the milk reaches the sterilizer, the curd or lumps formed in the sterilizer are less firm and can be shaken out more readily. It is, therefore, advisable to heat the milk in the forewarmers to as near the boiling point as possible and to hold it at that temperature for at least five minutes before it is drawn into the pan. The superheating of the evaporated milk before it leaves the pan is an additional safeguard against the formation of excessive curd in the sterilizer.

Effect of Homogenizing Evaporated Milk.-Excessive pressure in the homogenizer tends to so change the physical properties of the casein as to render it more sensitive to the sterilizing process. Evaporated milk, homogenized under excessive pressure almost invariably forms a firm, unshakable curd in the

1 For detalled discussion see Chapter VIII, on "Striking," and Chapter XI, on "Sterillzing." 
sterilizer. The homogenizing pressure should be kept down to one thousand to fifteen hundred pounds. ${ }^{1}$

Effect of Addition of Bicarbonate of Soda.-As shown in Chapter XI on "Sterilizing" the addition to the evaporated milk of bicarbonate of soda diminishes the viscosity and tendency to curdle in most cases.

This is due to the fact, that in most cases, the coagulation is due to an excess of calcium and magnesium, which lowers the stability of the casein. The addition of carbonates in the form of bicarbonate of soda reduces the excess of calcium and magnesium, assists in balancing these mineral constituents, and thereby makes the casein more stable.

Occasionally it happens, however, that the addition of sodium bicarbonate increases, instead of decreases, the viscosity and coagulability of the evaporated milk, and in such cases, the difficulty increases in direct proportion with the amount of bicarbonate added. In this case the viscosity and coagulability of the evaporated milk are undoubtedly due, not to an excess of calcium as is usually the case, but to a deficiency of calcium. Under such conditions a soluble calcium or magnesium salt should be added in the place of bicarbonate, in order to diminish the viscosity and to render the casein more stable.

Acid Flux in the Cans Causes Lumps.-Similar as in the case of the sweetened condensed milk, the presence of acid flux in the cans of evaporated milk causes lumpiness. The acid that reaches the interior of the cans causes the milk coming in contact with the seams to curdle. Only acid-free flux should be used in the manufacture and sealing of the cans.

\section{Grainy Evaporated Milk.}

General Description.-This term is sometimes applied to lumpy milk, in which case it means the same. By grainy milk, however, is generally understood milk which contains a sediment of a white granular appearance, which is insoluble.

Causes and Prevention.--This granular sediment is largely found in the hermetically sealed cans after the sterilizing process. It is due to excessively high sterilizing temperatures or too long

1 For detalied discussion of the effect of homogenizing on curdiness see Chapter IX on "Homogenizing" and Chapter XXIII on "Separated and Churned Evaporated Milk." 
exposure of the milk to the process. It consists largely of the mineral matter of milk, rendered insoluble and precipitated by heat. The use of lower sterilizing temperatures or the shortening of the period of sterilization will help to avoid this defect.

Evaporated milk in the condensation of which the "Continuous Concentrator" was used, has a tendency to show slight grainy condition, though this is barely perceptible.

\section{Separated and Churned Evaporated Milk.}

General Description.- This is a very common defect. A portion of the butter fat of the contents of the hermetically sealed cans, has separated and appears in the form of lumps of cream or of churned butter, on top of the evaporated milk. While this separated evaporated milk is normal in quality and wholesomeness, its appearance condemns it.

Causes and Prevention.-As explained in Chapter IX on "Homogenizing," the fundamental cause of separated and churned evaporated milk lies in the difference of the specific gravity between the butter fat and the rest of the milk constituents. The fat globules, being lighter than the serum, tend to rise to the surface, forming a layer of thick cream. When this separated evaporated milk is subjected to agitation, as is the case in transportation, this cream churns into lumps of butter. This tendency of the fat to separate in storage and churn in transportation, increases with the increase of the size of the fat globules, because the larger the globules, the larger is their cubic content in proportion to their surface. This fact is based on the well known physical law, that the surfaces of two spheres are to each other as the squares of their diameters, and the cubic contents of two spheres are to each other as the cubes of their diameters. The cubic contents determine the gravity force, or buoyancy, while the surfaces control the resistance force. Therefore, the larger the fat globules the greater is their buoyancy and the weaker is the relative resistance which they must overcome in their upward passage.

Effect of Locality and Season.-Since the predominating size of fat globules in milk, varies with breed and period of lactation of the cows, the ease with which evaporated milk 
separates and the difficulty of overcoming this defect, differ greatly with locality and season of year. The fat globules in milk from the Channel Island breeds, average two to three times as large as those in milk from the Holsteins and Ayrshires. Therefore, factories located in Holstein and Ayrshire territories are not troubled nearly as much with fat separation in evaporated milk, as factories in localities where Jerseys and Guernseys predominate.

Again, the fat globules are largest at the beginning of the period of lactation and decrease in size as the period of lactation advances.

In order to equalize the output of evaporated milk throughout the year, condensing concerns make every effort to induce their patrons to time the breeding of their cows in such a way that the fresh cows are distributed throughout the year. The result of this practice is, that the milk supply of these factories represents at all times a mixture of milk from cows at all stages of their period of lactation. This naturally equalizes the behavior of the finished product as far as separation of the fat is concerned, facilitating the control of this separation. On the other hand, in localities of factories, newly established, summer milk is largely produced and the majority of cows freshen in the spring. This canses a marked increase of the size of the average fat globules in early summer, rendering the manufacture of evaporated milk, that does not separate its fat, more difficult.

Effect of Degree of Concentration.-- Other conditions being the same, the more concentrated the product, the less the danger of fat separation in the finished product. The 1 eason for this lies in the fact that with the concentration the viscosity and the resistance force of the evaporated milk increase, hindering the fat globules in their upward passage. This is partly offset by the increase in the specific gravity of the product, but the increase of the resistance force exerts a stronger influence against separation of the fat, than the increase of the gravity force exerts in favor of fat separation.

However, as the concentration increases, the evaporated milk becomes more sensitive to the sterilizing process and beyond certain limits it would be necessary to reduce the temperature or the length of exposure to heat, or both, in order to 
prevent the more highly concentrated milk from becoming permanently curdy. If, in order to increase the viscosity, the degree of concentration is carried so far that the sterilizing process has to be shortened, nothing is gained but much may be lost. It is obvious, therefore, that the degree of concentration does not furnish a practical basis for controlling fat separation.

Effect of the Sterilizing Process.-Prolonged exposure of the evaporated milk to the sterilizing heat tends to so change the physical properties of the albuminoids, as to render the product more viscous. Within the limits of the necessary sterilizing heat, long exposure to moderate heat is more effective in this respect than short exposure to a high degree of heat. Since the greater viscosity tends to keep the fat globules from rising; the use of a prolonged sterilizing process, in which the heat is applied slowly, is more effective in preventing fat separation in the evaporated milk than a rapid, short process, in which the temperature used is very high.

It should be understood from the discussion in previous chapters that, in regulating the process of sterilization, the processor should be governed by the condition and behavior of the milk and that on the one hand the degree and duration of heat should always be sufficient to insure absolute sterility of the product, while on the other he must guard against the formation of an unshakable curd. ${ }^{1}$

Effect of Superheating.-The superheating of the milk before sterilization and the stopping of the reel of the sterilizer as explained under "Sterilization," also tend to so increase the viscosity of the evaporated milk as to minimize its tendency to separate its fat. But here again good judgment is required, ntherwise there is danger of spontaneous thickening of the product after manufacture.

Turning the Cans in Storage.-Many manufacturers, in an effort to avoid fat separation, have adopted the practice of turning their goods in storage at regular intervals. This operation naturally interferes with and retards the rising of the fat to the surface, as long as the goods remain in the factory. After they leave the factory this control must of necessity cease and if the

${ }^{1}$ For detailed discussion see Chapter XI on "Sterilizing." 
evaporated milk, owing to the process of manufacture and the condition of the product, is destined to separate its fat, the turning of the cases, while at the factory, cannot permanently prevent separation. Where the goods are consumed immediately after they leave the factory, this practice may serve the purpose; but, since the large bulk of evaporated milk manufactured, is exposed to prolonged storage, its advantage is very limited.

Effect of Homogenizing.-Under average conditions careful attention to the precautions above discussed will greatly minimize and often prevent fat separation. At best, however, much of the evaporated milk on the market shows signs of separation after sixty to ninety days and some of it even after two weeks, for the fundamental cause of separation, the difference in gravity between the fat globules and the rest of the milk constituents, is still present; then again, under less favorable conditions. even the above precautions may not prove adequate to keep the fat from separating.

The introduction of any agent or process, therefore, capable of permanently removing this fundamental cause, must prove a lasting benefit to the manufacturer of evaporated milk. This agent has been found in the homogenizer. The homogenizer makes it possible to divide the fat globules so finely, that their buoyancy or gravity force is not great enough to overcome the resistance of the surrounding liquid. They are unable to rise to the surface, but remain in homogeneous emulsion.

It is quite probable that aside from the reduction of the size of the fat globules, the efficiency of the homogenizer to prevent fat separation is due also to the physical change of the casein as the result of homogenization. The casein becomes more viscous.

The chief objection to the use of the homogenizer is its effect on the casein of the milk, when subjected to excessive pressure. Beyond certain limits of pressure homogenization so affects the casein, that the latter is more prone to curdle in the sterilizer. However, experience has amply shown that the maximum pressure required to prevent fat separation in the finished product, is not great enough to seriously affect the behavior of the casein during sterilization. Hence, the proper regulation of 
the pressure and the intelligent use of the homogenizer, furnish a satisfactory and reliable means to prevent fat separation. ${ }^{1}$

\section{Fermented Evaporated Milk.}

General Description.-Fermented evaporated milk is evaporated milk, which after sterilization, has undergone fermentation. The type of fermentations found in this product varies with locality, season of year and factory conditions. The contents of the cans may have soured with curd formation, or a curd may have formed without acid development, or the fermentation may be gaseous, in which case the cans bulge, and these gaseous fermentations may be accompanied by acid formation or by putrefactive products. In all cases of fermented milk the product is entirely worthless. These defects are usually, though not always, detected during the period of incubation.

Fermented evaporated milk is the result, either of incomplete sterilization, or of leaky cans. The causes of fermented evaporated milk differ with the specific type of fermentations produced; they will be discussed separately and as relating to the respective types of fermentations.

\section{Acid Fermentation, Sour, Curdled, Evaporated Milk.}

General Description.-Upon opening the cans the contents are found to be sour and curdy.

Causes and Prevention.-This condition is the result of the presence of acid-producing species of micro-organisms, "usually of the lactic acid type, which sour the milk, and the acid produced curdles the casein. Since the majority of the lactic acid bacteria are not resistant to heat and are destroyed at relatively low heat, this defect is not usually caused by incomplete sterilization. The temperature of sterilization, though it might be insufficient to kill spore forms, is high enough to make it impossible for lactic acid bacteria to pass the process alive.

The only way in which this defect can occur is through sul)sequent contamination of the contents of the cans with these germs, and the only possible channel, through which this subsequent contamination may occur, is leaky cans, or leaky seals.

${ }_{1}^{1}$ For details on the use of homogenizer see Chapter IX on "Homogeniz- 
A careful examination of the cans of sour, curdled evaporated milk usually shows faulty cans or faulty seals.

\section{Bitter Curd.}

General Description.-When the cans are opened the contents present a solid coagulum, generally noticeably white in color and very bitter to the taste, similar to the bitterness of dandelions. There is a separation of practically clear whey, the curd does not break down readily upon shaking and the acid reaction of the mixture of curd and whey is about .35 to .40 per cent, which is normal for evaporated milk.

Causes and Prevention.-Microscopic examinations under high magnification of cultures in sterile milk show the presence of very small bacilli. The milk forms a firm coagulum in five to seven days and when over one week old the curd has the same strong, bitter taste as that in the cans. The bitterness increases with agc. These bacilli grow best at 90 degrees $F$. They are facultative anaerobes, developing both, in aerobic and anaerobic media, but prefer anaerobic conditions.

In the cases under observation no spores were detected and exposure for fifteen minutes to 212 degrees $\mathrm{F}$. destroyed these germs. The above findings do not exclude the possibility of spore formation under conditions very unfavorable to growth and life.

The presence of this species of bitter curd organisms suggests incomplete sterilization of the evaporated milk. The striking whiteness of the curd in all cases that have come to the writer's attention, is further proof of the correctness of this deduction. It indicates that these cans received relatively little heat in the sterilizer, otherwise the curd would have a darker color. This defect usually does not show up in all the cans of one and the same batch, but only in a limited portion of each batch. This fact suggests that the distribution. of heat in the sterilizer is not uniform, some cans getting less heat than others.

This defect occurs generally in summer, a fact which may be due to one or both of the following conditions:

While it is well known that there is a group of species of bacteria, yeast and torula that are capable of producing a bitter curd, either direct, or through the secretion of casein-curdling 
enzymes, and while these different species of micro-organisms come from a variety of sources, the most common sources are, the soil, pasture, water and the udder itself. It is a noteworthy fact that this defect is most commonly found in milk and milk products when the cows are on pasture. It is, therefore, probable that, in most cases, this troublesome germ is carried in to the milk on the farm.

Again, in summer, at a time when this defect generally occurs, the effect on the cows of the summer heat and flies, and the tendency toward high acid in milk, render the milk most sensitive to the sterilizing heat. The operator finds it difficult to avoid the formation of a disastrous curd in the sterilizer. In order to guard against this trouble he is tempted to either lower the temperature, or shorten the duration of the sterilizing process. This tends towards incomplete sterilization. A very frequent result of this incomplete sterilization in the late summer months, is the formation of a bitter curd. When the processor returns to the proper sterilizing process, the occurrence of bitter curd in the cans disappears and the product is normal.

A further safeguard against the recurrence of this trouble lies in providing for uniform distribution of heat in the sterilizer. If the cans have to be stacked in deep tiers, which is undesirable and should be avoided, slats should be placed over the top of every second row of cans. This will make possible the free access of steam to at least one end of each can. If the circulation of steam in the sterilizer is poor, the uniform distribution of heat can be facilitated by filling the sterilizer about onethird full of water so that, with every revolution of the framework, the cans have to pass through this water once. The water reaches every nook in the interior of the sterilizer, distributing the heat much more uniformly than the steam. Uneven distribution of the heat may also be due to an improper condition of the steam-distributing pipe located in the bottom of the sterilizer. Some of the perforations in this pipe may have become too large by wear, or may have become clogged with scale or the cap at the end of the pipe may have come off. In all of these cases the distribution of the heat in the sterilizer is found to be irregular, interfering with the uniformity and dependability of the process of sterilization. The processer should make sure, by daily in- 
spection, that the steam-distributing pipe is in proper operating condition. If these precautions fail to remedy the trouble, then the entire process is inadequate and either more heat, or longer exposure to the same heat is necessary.

Spitzer and Epple ${ }^{1}$ investigated a case of bitter evaporated milk, in which the troublesome organism appears to have been of a different type than was the case in the bitter evaporated milk epidemics under observation by Hunziker, as described above. Spitzer and Epple found the bitterness to be due to the presence in the evaporated milk, of an organism that corresponds with Migula's (1900) classification of Bacillus panis as described. by $L_{\text {awrence }}$ and Laubach. ${ }^{2}$

This organism is a non-motile bacterium, rod-shape, witl rounded ends and measuring about .4 by 2.0 microns. It is sporebearing, the spores forming readily in 48 to 72 hours and appearing usually near the center of the rod. The organism is capsulated and is very resistant to heat. Spitzer and Epple found it to survive a temperature of 250 degrees $F$. for 8 minutes, but was destroyed at the same temperature upon 10 minute exposure. The organism does not form gas, it does not swell the cans, nor does it coagulate the casein. The contents of the cans appear perfectly normal to the eye, the only change noticeable is the intensely bitter taste. It is an active proteolytic germ capable of secreting enzymes which are proteolytically active, rapidly breaking down the proteids of milk into large quantities of peptones and lower nitrogenous compounds of complex nature. The authors suggest that the excessive peptonizing function of this organism may be the primary cause of the bitterness.

The description of the cultural characteristics and thermal death-point of this organism suggests that the presence of this germ in the evaporated milk, and the spoilage of the product, are not due to a faulty process of sterilization, but are the result of conditions in the factory that permit this germ to lodge and to contaminate the milk. Unsanitary condition of pipes, pumps, homogenizer, filling machine, etc., would be the most likely breeding places and sources of contamination.

1 Spitzer and Epple, Bitterness in Evaporated Milk, Journal of Dairy Science, Vol. III., 1920.

2 Lawrence and Laubach, Studies on Aeroblc, Spore-bearing, Non-pathogenic Bacteria, Journal of Bacteriology, Vol. I., p. 493. 


\section{Blown Evaporated Milk (Gaseous Fermentation).}

General Description.-The ends of the cans bulge out very noticeably, frequently so much so that the seams of the cans burst open. This is due to gaseous fermentation causing high pressure in the cans. The pressure is often so great that upon opening the cans, most of the contents are blown out with tremendous force. In some cases of blown evaporated milk, the contents have an acid odor, pleasant and aromatic. In most instances, however, they give off very foul odors and suggesting hydrogen sulfide, not unlike aggravated cases of Limburger cheese. These odors are exceedingly penetrating and difficult to remove from anything they come in contact with.

Causes and Prevention.-.'The bacteria causing gaseous fermentations in evaporated milk usually belong to the anaerobic group of butyric acid species and in most cases, though not always, the putrefactive types prevail, such as Bacillus putrificus, Plectridium novum and Plectridium foetidum, especially the latter, because of its extraordinary power of resistance to heat. Plectridium foetidum is an obligatory anaerobe and it absolutely refuses to grow under aerobic conditions. It is an actively motile, medium-sized organism with flagella and spores. At one end it has an Indian club-like enlargement, in which appears the spore. The bacillus resembles a kettle-drum stick similar to B. tetani. Under strictly anaerobic conditions, and incubated at 90 degrees F., it ferments milk in four days. The milk first curdles, then gradually the curd dissolves (digests) completely, leaving a clear yellow liquid, similar in appearance to butter oil. The fermentation is accompanied by the evolution of a penetrating foul odor. This organism survives exposure for 15 minutes to 245 degrees F. Its thermal death point lies between 245 and 250 degrees F.1

Plectridium foetidum, as well as most of the other species of anaerobic, spore-bearing butyric acid bacilli and bacteria, is present abundantly in cultivated soil, in field crops and even on the kernels of the grain. Since this type of evaporated milk defect is characteristic, especially, of the product manufactured during the late summer and early fall months, it is very probable that the dust incident to the harvesting of the field crops, fur-

\footnotetext{
${ }^{1}$ Hunziker, A Study of Gaseous Fermentation in Evaporated Milk.
} 
nishes the chief source of contamination of the milk, though it is quite possible that contamination with these germs may also result from the use of unclean equipment in the factory.

In order to avoid the occurrence of blown, fermented, evaporated milk, therefore, it is necessary to employ the highest sterilizing temperatures, or the longest exposure to the sterilizing heat, or both, consistent with freedom of the milk from curdiness. Experience has shown that the use of the ranges of temperature and

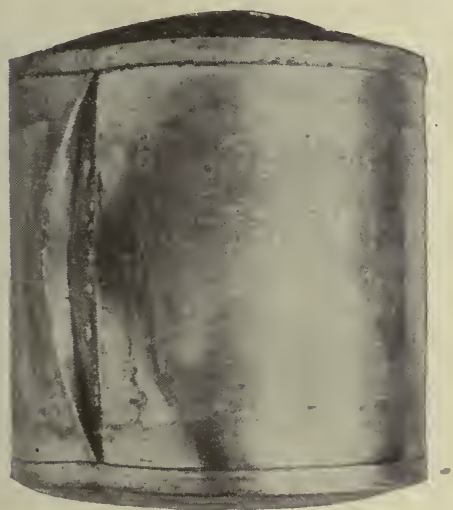

Eig. 88. The result of gaseous fermentation

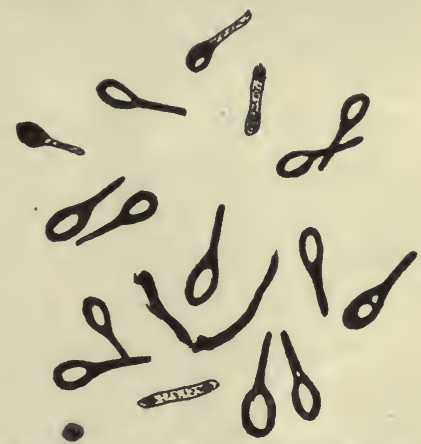

Fig. 89. Plectridium foetidum a highly resistant species of anaerobic micro-organisms, causing" "swell heads" of evaporated milk

time of exposure, given under Chapter XI on "Sterilizing," guard effectively against this defect.

Blown Evaporated Milk Due to Freezing.-If the evaporated milk is exposed to storage temperatures below the freezing point of water, the contents of the cans will freeze. While freezing, the contents expand sufficiently to cause the ends of the cans to bulge. When the cans are subsequently transferred to warmer temperatures, so that their contents melt again, the milk contracts and the cans resume their normal shape.

While the wholesomeness and flavor of the product are not affected by the freezing process, the remelted evaporated milk is usually less smooth and often slightly grainy. This is due to the fact that, during the process of freezing, there is a partial separation of the watery portion from the caseous material. The casein contracts and the watery portion freezes. When melted, the emulsion is less complete than it was before freezing. The 
casein remains in its contracted form and robs the product of its original smoothness.

\section{Blown Evaporated Milk Due to Chemical Action.-While} properly processed evaporated milk is perfectly sterile, and from the biological point of view, keeps indefinitely, the cans of very old evaporated milk may bulge, as the result of the action of the acid in the milk on the container. Evaporated milk contains from .35 to .50 per cent acid (calculated as lactic acid). When the tin cans are filled with the evaporated milk, the tinplate is bright and untarnished, both, inside and out. After the sterilizing process, the inside surface of the cans is dark and dull. This is caused by the combined action of acid and heat, which seems to weaken the timplate. This phenomenon is further illustrated by the fact that where creameries pasteurize their skimmilk and return it to the patrons in the milk cans hot, the milk cans arè short-lived; they soon corrode and begin to leak.

The acid in the evaporated milk continues to act on the tinplate of the can after manufacture and in the case of very old evaporated milk, the acid may decompose a considerable part of the iron. This action is accompanied by the evolution of hydrogen gas, which causes the cans to bulge. This action is hastened by continued exposure of the goods to high temperatures (summer heat). This fact was experimentally demonstrated, ${ }^{1}$ also, by scratching the bottom of tin cans on the inside with a file, then filling the cans with a .4 per cent solution of lactic acid and acetic acid, respectively. After sealing, the cans were sterilized in the autoclave, so as to avoid any possibility of bacterial action. After cooling, these sterilized cans were incubated for some time at 90 degrees $F$. The cans containing the dilute acid began to swell, while the check cans, containing distilled water only, remained normal.

Blown Evaporated Milk Due to Change in Altitude.-Cans of evaporated milk when filled in factories located at a low altitude (near the sea level) may bulge when transferred to a high altitude. The danger from this source is intensified, if the evaporated milk happens to be cold at the time of filling, and when the

${ }^{1}$ Hunziker and Wright, Indiana Agricultural Experiment Station. Results not published. 
temperature to which the cans are exposed at the high altitude is high.

This type of swelled cans obviously has nothing to do with the quality of the contents, nor is it the result of fermentation or chemical changes. It is caused by the fact that the pressure in a can sealed at the sea level is somewhat greater than the atmospheric pressure surrounding the can when transferred to a high altitude. If, at the same time, the milk packed at the sea level goes into the can at a low temperature and the atmospheric temperature at the high altitude, to which the sealed cans are shipped, happens to be high, the difference in pressure between the interior and exterior of the can is further increased, due to the expansion of the milk and of the air in the can. The combination of these factors is sufficient to cause the ends of the can to bulge, making it erroneously appear that the package contains fermented goods.

This has actually happened in the case of one factory filling a Government war contract, the whole shipment of evaporated milk being rejected by the Government, because of the bulged cans.

Occurrences of this type can be prevented by filling cans, intended for markets in high altitudes, with the evaporated milk while warm.

\section{Brown Evaporated Milk.}

General Description.-It is the aim of the processor to so govern the sterilizing process as to give the evaporated milk a rich, yellow, creamy color. Frequently, this color limit is overstepped to the extent of imparting to the evaporated milk a brown color, suggesting coffee with milk in it. In this condition evaporated milk fails to appeal to the consumer.

Causes and Prevention.-The dark color in evaporated milk is due to the oxidizing action of excessive heat on the milk sugar, causing the milk sugar to caramelize. This can be avoided by reducing the sterilizing temperature, or shortening the sterilizing process, or both. The storing of evaporated milk at high temperatures (summer heat) also tends to deepen its color with age. 


\section{Gritty Plain Condensed Bulk Milk.}

General Description.-Grittiness in the unsweetened goods appears usually only in the plain condensed bulk milk. It is a defect which renders the product undesirable for ice cream making.

Causes and Prevention.-The chief cause of this defect is too great concentration. Plain condensed bulk milk which is not condensed over 3.5 parts of fresh milk to 1 part of condensed milk does not become gritty. When the concentration exceeds $4: 1$, the milk sugar begins to crystallize out, making the product gritty. Milk sugar requires about six times its weight of water for complete solution in cold water. When condensed at the ratio of $4: 1$ or over, the plain condensed bulk milk contains considerably less than five parts, by weight, of water to one part of milk sugar. This high concentration, together with the practice of storing this product at refrigerating temperatures in order to preserve it, is responsible for the grittiness. This trouble can, therefore, easily be prevented by not condensing to quite as high a degree of concentration.

\section{Metallic Evaporated Milk and Plain Condensed Bulk Milk.}

General Description.-Both, evaporated and plain condensed bulk milk may show a metallic and puckery flavor, though this defect is rather rare.

Causes and Prevention.-The metallic flavor may be due to the same cause as metallic sweetened condensed milk, i. e., an unsanitary condition of the vacuum pan, in which case its recurrence can be readily avoided by thoroughly cleaning all parts of the pan including the dome and the goose neck, and rinsing down the whole pan thoroughly with clean water each morning before operations begin.

Unsweetened condensed milk made by the use of the "Continuous Concentrator" may have a metallic flavor when the scrapers in this machine are improperly adjusted, causing them to cut into the copper walls and thereby incorporating metallic copper in the product. This source of metallic flavor can be removed by proper adjustment of the revolving spider and its essential parts. 
Evaporated milk may also show a metallic flavor as the result of chemical action of the acid in the milk on the can. This occurs usually only upon prolonged storage. Very old evaporated milk is very prone to have a metallic flavor from this source and particularly when stored at a rather high temperature. This can best be avoided by endeavoring to move the goods sufficiently rapidly to limit the age of the milk to a reasonable period of time and by avoiding high storage temperatures.

Cans, in the manufacture and sealing of which an acid flux is used, are prone to give the contents a puckery, metallic flavor, due to the zinc chloride and hydrochloric acid present. This can be avoided by using cans only in the manufacture of which a non-acid flux, such as gasoline-resin flux, is used, and by using a non-acid flux for sealing the filled cans.

\section{Cinapter XXIV.}

\section{ADULTERATIONS OF CONDENSED MILK.}

It is the sense of the Federal Pure Food Act that the addition to condensed milk of any substance except sucrose, and the abstraction of any substance from milk except water, is an adulteration.

Skimming.-Condensed milk made from partly or wholly skimmed milk must be labeled and sold as condensed skimmed milk in order to comply with the Pure Food regulations. However, it is possible for condenseries receiving fresh milk, rich in butter fat, to skim a part of that milk and have their product still conform with the food standards.

Skimmed sweetened condensed milk can readily be detected by its whitish color, while condensed whole milk has normally a rich yellow color. When diluted, to the consistency of ordinary milk, skimmed condensed milk, both the sweetened and the unsweetened, foams very profusely when shaken, while diluted condensed whole milk behaves similar to ordinary whole milk. ${ }^{1}$

Addition of Artificial Fats.-In order to lower the cost of manufacture, attempts have occasionally been made to skim the

${ }^{1}$ For chemical tests of butter fat in condensed milk see Chapters XXXI and XXXII. 
fresh milk and substitute the abstracted fat by artificial fats of animal or vegetable origin.

Recent improvements in the method of manufacture have made it possible to manufacture evaporated milk, made from skim milk to which foreign fats, especially vegetable oils, such as cocoanut oil, have been added. 'This milk has every appearance of, and will commercially keep as well as genuine evaporated milk. A representative of this imitation evaporated milk is the "Hebe" product. This product consists of skim milk to which have been added vegetable fats to replace the butter fat. The mixture is homogenized in order to form a complete emulsion, then it is evaporated, filled in cans and sterilized in a similar manner as the genuine evaporated milk.

The Federal law requires that the composition and ingredients of these imitation products appear plainly on the label of the package.

It should be clearly understood by the manufacturer, the dealer and the consumer that this imitation milk is inferior to the genuine evaporated milk, in the fact that it lacks the important growth-promoting and curative properties which are inherent in whole milk. If sold on its own merits, and in accordance with the Federal law, there can be no logical objection to the imitation product, but if offered to the consumer as the genuine article, the manufacture and sale of imitation evaporated milk is a heinous crime against humanity.

Experiments conducted at Ohio State University, by Mr. J. L. Hutchison, instructor in the Department of Agricultural Chemistry under the direction of Professor O. Erf, Chief of Department of Dairy Husbandry and Dr. J. F. Lipman, Professor of Agricultural Chemistry, demonstrated that "Hebe" milk, when fed to young white rats, resulted in malnutrition accompanied by stunted growth, sore eyes and death of some of the experimental rats, in a similar manner as did other rations in which the fat soluble vitamines were lacking.

The volume of "filled" evaporated milk manufactured in this country is assuming large proportions and is growing annually as shown below: 
Annual Output of Imitation Evaporated Milk, Made from Wholly or Partly Skimmed Milk to Which Foreign Fats had been Added. ${ }^{1}$

\begin{tabular}{c|r|r|r}
\hline \hline Year & $\begin{array}{c}\text { Case Goods } \\
\text { Pounds }\end{array}$ & \multicolumn{1}{c|}{$\begin{array}{c}\text { Bulk Goods } \\
\text { Pounds }\end{array}$} & \multicolumn{1}{c}{$\begin{array}{c}\text { Total } \\
\text { Pounds }\end{array}$} \\
\hline $1916 \ldots \ldots \ldots \ldots$ & 12,000 & $14,134,712$ & $14,146,712$ \\
$1917 \ldots \ldots \ldots \ldots$ & 18,504 & $17,487,064$ & $17,505,568$ \\
$1918 \ldots \ldots \ldots \ldots$ & $41,033,855$ & $7,591,182$ & $48,625,037$ \\
$1919 \ldots \ldots \ldots \ldots$ & $62,262,221$ & $2,748,120$ & $65,010,341$ \\
\hline
\end{tabular}

Mothers who buy evaporated milk for feeding infants and children should be cantioned to observe carefully whether or not they receive the genuine article. Imitation evaporated milk is not a baby food. Babies and growing children need butterfat for their best development. If canned milk is used for infant feeding, it should be made from whole milk only. (See also Chapter XX on "Vitamine Properties of Condensed Milk.")

Addition of Commercial Glucose.-Commercial glucose belongs to a group of starch products in which dextrose is the leading constituent. It is manufactured by the action of dilute acids in starch and starchy matter, or occasionally woody fibre. In this country it is almost whọlly made from maize starch.

Starch glucose occurs in commerce in several forms, varying from the condition of pure anhydrous dextrose, through inferior kinds of solid sugar, to the condition of a thick syrupy liquid, colorless and transparent, resembling molasses in consistency and glycerine in appearance; it contains a large proportion of dextrin. In connection with the manufacture of condensed milk the term "glucose" refers to this thick, syrupy liquid. It is added to the condensed milk with a view of substituting a portion of the sucrose and thus reducing the cost of manufacture. It has also been suggested that the presence of commercial glucose in condensed milk prevents the precipitation of sugar crystals. Experiments have shown, however, that condensed milk containing varying amounts of glucose, will become sandy just as readily as normal condensed milk.

That glucose cannot be used as a substitute for sucrose, is

1 The Market Reporter, U. S. Bureau of Markets, Vol. I, No. 18, 1920. 
obvious from the fact that its presence defeats the very object for which sucrose is added. Instead of serving as a.preservative, as is the case with the best refined, granulated cane sugar, glucose acts as a most effective fermentative. It has been explained that the presence in sucrose of traces of invert sugar, or levulose and glucose, causes condensed milk to ferment. Glucose belongs to the monosaccharides. Its chemical formula, like that of levulose, is $\mathrm{C}_{6} \mathrm{H}_{12} \mathrm{O}_{6}$, it oxidizes readily and under the influence of yeast and other micro-organisms it ferments, yielding mainly alcohol and carbon dioxide. Its presence in condensed milk, therefore, is prone to start fermentation, and the manufacturer who uses it with a view of lessening the cost of manufacture of condensed milk is, indeed, practicing poor economy. There is ne adulteration of sweetened condensed milk that will produce such inevitable disaster as the addition to it of glucose. Aside from this fact, the law prohibits the addition of anything except sucrose.

\section{Addition of $\mathrm{Bi}$-Carbonate of Soda, Ammonium Hydroxide,} Lime Oxide and Lime Hydrate and Other Alkali.-These alkalies and alkaline earths are frequently added to evaporated milk, for the purpose of neutralizing excess of acid, or balancing the ash constituents, in order to diminish the viscosity and tendency to curdle, to facilitate the sterilizing process, and to prevent the milk from curdling when exposed to heat. If used in reasonable quantities, they interfere in no way with the quality and healthfulness of the product, and may in exceptional cases prevent great loss. If used in excess, the milk will foam very badly in the vacuum pan, which renders the process of condensing a difficult one and the finished product has a bitter flavor. Under ordinary conditions, their use is entirely unnecessary and simply means additional labor and expense. The above agents and also viscogen, are sometimes used with the view of thickening sweetened condensed milk and increasing the output. Experimental results, ${ }^{1}$ however, showed that these agents cannot be used in large enough quantities to produce the above results without materially lowering the quality of the product.

Addition of Cream of Tartar.-Cream of tartar is used extensively in the manufacture of candies and caramels. Its purpose

${ }^{1}$ Hunziker, experiments not published. 
is to make the sugar in these products precipitate in the form of very fine and soft crystals. Condenseries, which have been continually troubled with sugar crystallization and sugar sediment, have tried to overcome this defect by adding cream of tartar to the sweetened milk in the vacuum pan. Cream of tartar is an acid salt (acid potassium tartrate, $\mathrm{KH} . \mathrm{C}_{4} \mathrm{H}_{4} \mathrm{O}_{6}$ ), and it is this acid which in the manufacture of candy causes the fine and soft grain of the sugar. It is obvious that if enough cream of tartar were added to condensed milk to produce the desired effect on the sugar, the acid present would curdle the milk. Its use is of no value to the manufacturer of condensed milk.

Addition of Starch.-The pasty and thick consistency of sweetened condensed milk frequently suggests to the public that it contains starch. This is erroneous, for it is doubtful if condensed milk is ever adulterated with starch. There would be nothing gained by so doing, and the presence of starch in condensed milk could be readily detected with iodine. Iodine gives the starch cells a deep blue color. 


\title{
PART VI. MANUFACTURE OF MILK POWDER
}

\author{
Chapter XXV.
}

\section{DEFINITION.}

Milk powder, dry milk, pulverized milk; dehydrated milk, desiccated milk, milk flour, is made from cow's whole milk, or partly or wholly skimmed milk, or from whole milk that has been enriched by additional butterfat, to which sugar, or wlkalies, or both may, or may not have been added, and which has been evaporated to dryness, either under atmospheric pressure, or in vacuo. Powders made from cream containing 18 per cent butterfat or more, are called cream powders.

\section{KINDS.}

The milk powders on the market vary chiefly in their solubility and fat content. The bulk of the milk powders is produced from wholly or partly skimmed milk. Most of the milk powders of the early days of this industry contained added cane sugar and alkalies. The purpose of the addition of alkalies was to lend greater solubility to the proteids.

The process of manufacture, however, has been improved to the extent to where the solubility of the proteids can now be preserved without the admixture of alkalies. Most of the milk powders put on the market in this country are free from admixture of any substances foreign to normal milk.

\section{HISTORY AND DEVELOPMENT OF INDUSTRY.}

The origin and history of the milk powder industry are very closely related and intimately connected with those of the condensed milk industry. The fundamental purpose of the two products is one and the same, i. e., to preserve milk as nearly as possible in its natural condition, and to reduce its bulk to the minimum, so as to make possible its economical transportation to all parts of the world. 
The difference between milk powder and condensed milk is mainly one of degree of concentration. It is not surprising, therefore, that the inventions of processes of manufacture of the two products date back to about the same period, the middle of last century, and in most cases the inventors of the one product had also in mind and gave due consideration to the possibilities of the other.

The first commercially usable process was invented by Grimwade who secured a patent from the British Government in 1855 . His process consisted briefly of first adding carbonate of soda or potash to the fresh milk, then evaporating in open jacketed pans and with constant agitation, until a dough-like substance was obtained; then adding cane sugar; the mixture was then pressed between rollers into ribbons, further dried and then pulverized. The alkali, in the form of carbonate of soda or potash, was added in order to render the casein more soluble, and the purpose of the admixture of the sugar was to produce granulation of the dough toward the end of the process facilitating the removal of moisture during the later stages of the drying process. The evaporation in open pans was later superseded by the use of the vacuum pan. The Grimwade process of manufacturing milk powder was in practice for some years.

Since the introduction of the Grimwade process, several modifications thereof have been patented, and numerous new processes for desiccating milk, that involve principles entirely different from the Grimwade process, have been invented, have found wide commercial application and have practically superseded the use of the earlier inventions.

The perfection of processes suitable for the commercial manufacture of dried milk is of relatively recent origin and dates back largely to the closing years of the nineteenth century and the first decade of the twentieth centry. Up to that time the annual output of milk powder was comparatively small. But within the last score of years rapid progress has been made and the world war has lent this industry additional impetis. Today the annual production is assuming large proportions, especially that of powdered skim milk, though considerable quantities of powdered whole milk, powdered cream and powdered buttermilk are also manufactured, as show'n below. 
Annual Production of Skim Milk Powder, Whole Milk Powder and Cream Powder in the United States. ${ }^{1}$

\begin{tabular}{|c|c|c|}
\hline \multirow{2}{*}{ Kind of Product } & \multicolumn{2}{|c|}{ Pounds by Years } \\
\hline & 1918 & 1919 \\
\hline Skim milk powder . . . . . . . . . & $25,432,007$ & $33,076,131$ \\
\hline Whole milk powder...... & $4,164,334$ & $8,660,785$ \\
\hline Cream powder .......... & 654,360 & 592,070 \\
\hline
\end{tabular}

According to Potts, ${ }^{2}$ the number of firms manufacturing powdered milk products in the United States is as follows:

Skim milk powder................ 47

Whole milk powder............... 15

Cream powder ................. 3

\section{Description of the Principal Processes of Manufacture.}

The processes of desiccating milk, which have proven commercially successful and have found wide application, may be conveniently grouped into three fundamental categories, according to the predominating principle upon which they are based. These are:

1. Dough-drying processes.

2. Film-drying processes.

3. Spray-drying processes.

For detailed discussion of the more outstanding principles covered in some of the patents of these processes the reader is referred to the following brief description and illustrations.

\section{Dough-drying Processes.}

To this group largely belong the earlier and cruder processes. The milk is condensed in any manner, either by heating in open pans under atmospheric pressure and usually with the help of mechanical agitation; or in the vacuum pan with or without mechanical agitation; or in open vats by blowing heated air through the milk, to a high degree of concentration and to a dough-like consistency. The concentrated product is then

1 The Market Reporter, U. S. Bureau of Markets, Vol. I., No. 14, 1920.

2 Potts. Data furnished by correspondence. 1920. 
spread on trays or other similar containers, and dried to a hard substance in vacuum chambers or in other vaults or drying apparatus, provided with heating devices or currents of hot air. The dried product is subsequently ground to a fine powder. Examples of this type of milk-drying processes are the Wimmer process, the Campbell process and others.

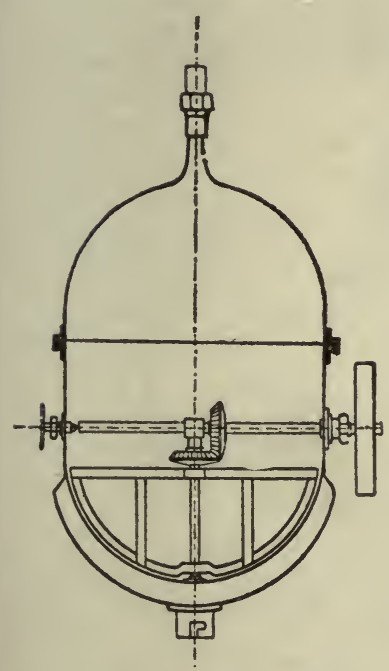

Fig. 90. The Wimmer milk powder machine

The Wimmer Process.-The milk is boiled in a vacuum pan similar to that used in the manufacture of condensed milk. The vacuum pan has a deep steam jacket for heating, but in the place of the usual coils, the pan is equipped with a mechanical stirrer. The milk is condensed at a relatively low temperature and the stirrer revolves until the water content of the milk is reduced to about 30 per cent and the milk has become porous and crumbly, though it still forms a compact mass. The drying is then completed in the open air and without additional heating. The product is then ground to a powder. This is the process invented by Ole Bull Wimmer of Copenhagen, Denmark.

The Campbell Process.-This process was invented, patented and improved by J: H. Campbell of New York City, U. S. patent Nos. 668,159 and 668,161, February 19, 1901 ; U. S. patent No. 718,191, January 13, 1903; U. S. patent No. 762,277, June 14, 1904; and by J. H. and H. C. Campbell, U. S. patent No. 668,162, February 19, 1901; and by C. H. and P. T. Campbell, U. S. patent No. 771,609, October 4, 1904.

The Campbell process consists essentially of concentrating milk to a high degree of concentration by blowing heated air through it in an open vat. The milk is reduced to a very thick consistency, resembling a batter. The concentrated milk is then removed from the evaporating tank, is reduced mechanically to small units by means of a pugging or shredding machine, or 
otherwise. This subdivided product is then placed on shelves or trays and dried in a chamber heated to a temperature below the coagulating point of the albumen.

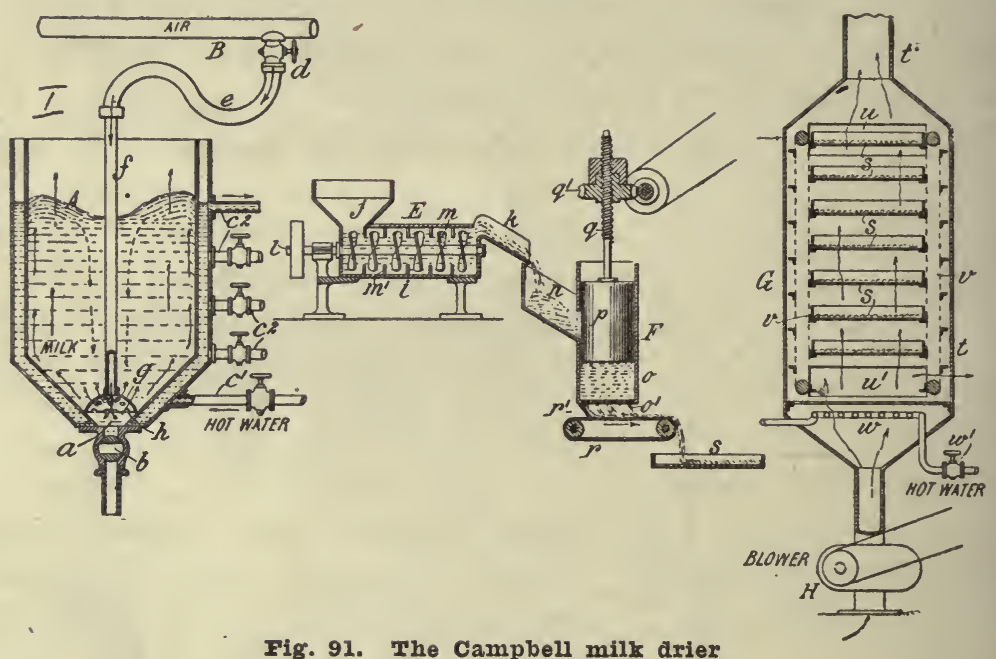

I. A concentrating vessel, a outlet, $b$ valve, $c$ hot water jacket, $c^{1}$ hot water pipe, $c^{2}$ discharge of jacket, $B$ air pipe, e connecting hose, $f$ stand pipe, g air-distributing disc, $t$ air chamber.-II. $E$ pug mill, i cylinder, $j$ hopper, $\mathrm{k}$ chute, 1 horizontal shaft, $\mathrm{m}$ blades for stirring, $\mathrm{m}^{\prime}$ projections for scraping blades, $F$ Vermicelli-machine, $n$ hopper, o cylindrical chamber, $p$ piston, $q$ spiral screw, $q^{\prime}$ worm-wheel, $o^{\prime}$ small holes, $x^{\prime}$ endless traveling apron, $s$ tray with perforated bottom.-III. G drier, $t$ body of drier, $H$ blower, $t^{\prime}$ flue, $u$ opening to insert trays, $u^{\prime}$ opening for removing trays, vv endless chains with projections for supporting trays, w coil heater, w' pipe circulating hot water.

In the processes of the dough-drying principle of desiccation, the dried product is reduced to a marketable powder by grinding it and then bolting or or sifting it.

\section{Film-Drying Processes.}

To this group belong the numerous processes in which the milk, with or without previous, concentration, is dried on the surface of one or more steam-heated, revolving drums. The milk is either picked up by the revolving drums, or it is sprayed onto these drums, forming a thin film which dries rapidly. The film of dried milk so formed is atomatically removed with each revolution of the drum by means of a mechanical scraper. In some of the processes of the film-drying type the drying cylinders operate in the open, under atmospheric pressure, in others 
the drying drums are incased in a vacuum chamber and the drying is accomplished under reduced pressure. Some of the U. S. patents of the film-drying process that have found wide commercial application are described below.

The Just Process.-This process appears to be the first of its type that found wide application in the desiccating of milk. It was invented and patented by John A. Just of Syracuse, New York, U. S. patent No. 712,545, November 4, 1902.

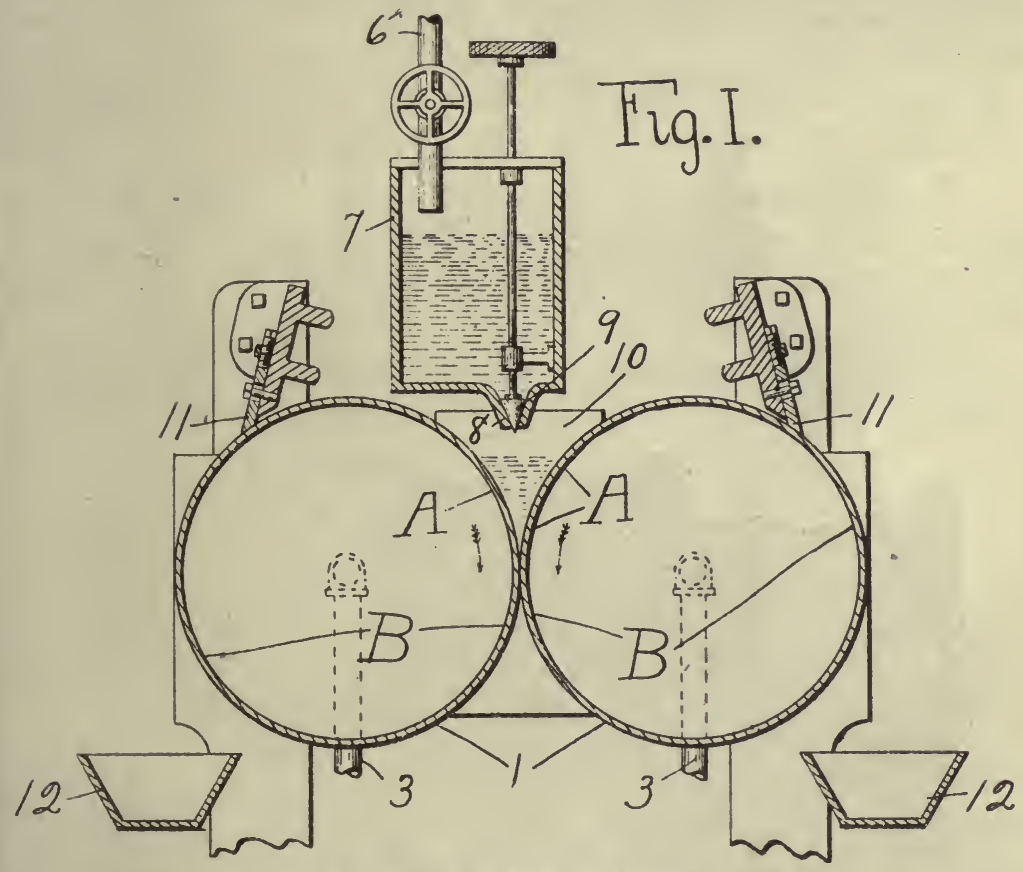

Fig. 92. The Just milk drier

The essential equipment involved in the Just process consists of two horizontal steam-heated revolving metal cylinders. These cylinders are installed sufficiently close to each other so that there is contact at their periphery. A milk destributing tank (7) with adjustable discharge (8 and 9) in the center over and between the two cylinders. Scrapers or knives (11) which remove the dried film of milk from the cylinders; and receptacles (12) which receive the finished powder. 
The patent claims of the Just process cover the treatment of the milk with calcic chloride $\left(\mathrm{CaO}+\mathrm{Ca} \mathrm{Cl}_{2}\right)$, or with the double salt of sodium and calcium citrate, to reduce the acidity of the milk, and with alkaline hypochlorite for the purpose of preserving the fatty acids in the finished product, the heating and boiling of the milk by bringing it in contact with a heating surface of a temperature above 212 degrees $F$. and below 270 degrees $F$., allowing the thus treated and heated milk to flow in regulated quantities on the surface of the steam heated revolving metal cylinders, where it is dried in the form of a film and from which it is removed by mechanical scrapers. The temperature of the heating surface on the cylinders is to exceed 212 degrees $F$. and to be below 270 degrees $F$.

The high temperature to which the milk is heated obviously reduces the solubility of the finished powder. The purpose of neutralizing the acidity of the milk, before drying, is to minimize the solubility-destroying action of the high heat.

The Hatmaker Process.-This is similar to the Just process. James R. Hatmaker of London, England, purchased the Just

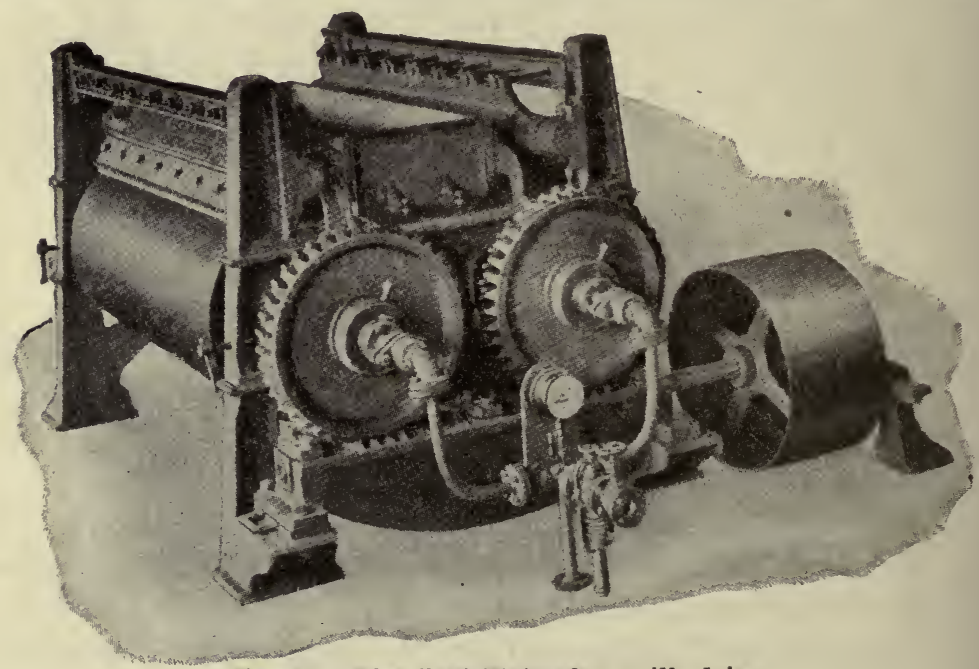

Fig. 93. The Just-Hatmaker milk drier

process for operation in Europe and later secured a patent of his own, which represents a modification of the original Just process, and which is known as the Just-Hatmaker process. 
The Gathmann Process.-This process and equipment was invented and patented by Louis Gathmann of Washington, D. C., U. S. patent No. 834,516, October 30, 1906.

In this process, similar as in the Just process, the milk is dried in the form oi a film on a revolving, steam-heated drum, under atmospheric pressure. In this case, however, only one drum is used, the drum (A) is cone-shape instead of cylindrical and its surface is spirally grooved or corrugated (a) and the adjacent surface against which the cone revolves is also similarly corrugated but the spiral grooves $\left(b^{1}\right)$ running in the opposite

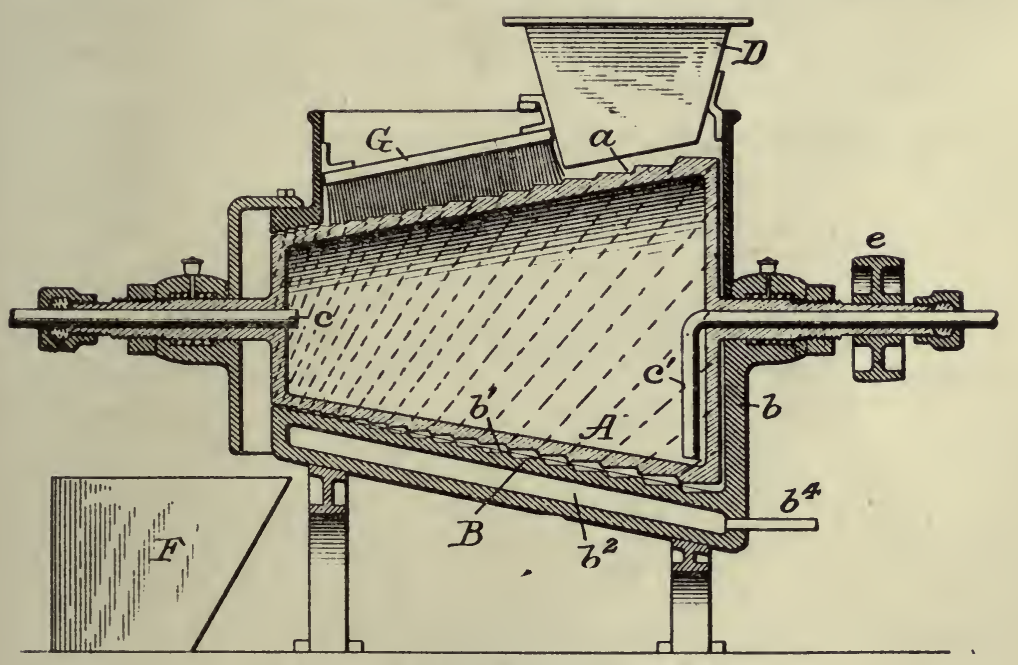

Fig. 94. The Gathmann milk drier

direction from those on the cone, as is common in grindingmills. Hence when the cone revolves the drying milk is kneaded and ground between the two surfaces and is gradually carried or pushed by the corrugated surface of the revolving cone to the smaller, or discharge end of the machine.

The adjacent corrugated surface against which the surface of the cone grinds, and which incases the lower half of the surface of the cone, is steam jacketed $\left(b^{2}\right)$, so that the milk is between two heated surfaces.

A hopper (D) regulates and feeds the flow of the milk to the cone at its larger end and a brush $(G)$ located near the smaller end of the cone removes such parts of the dried milk 
as may adhere to the grinding surface. Baffle boards or dash boards are provided to receive such of the milk, as may splash from the cone.

The patent claim covers the drying of the milk by feeding it to a continuously moving, heated surface, where it is permitted to form a comparatively thin layer, heating it to evaporate the water, and simultaneously subjecting it to a kneading, which gradually changes to a grinding action, as the milk solidifies, and forms a powder.

The temperature of the heating surface is recommended to be that of boiling water, but may be between 212 degrees $F$. and 270 degrees $F$. The milk enters the hopper without preheating and without other treatment.

The Passburg Process.-This process was invented and

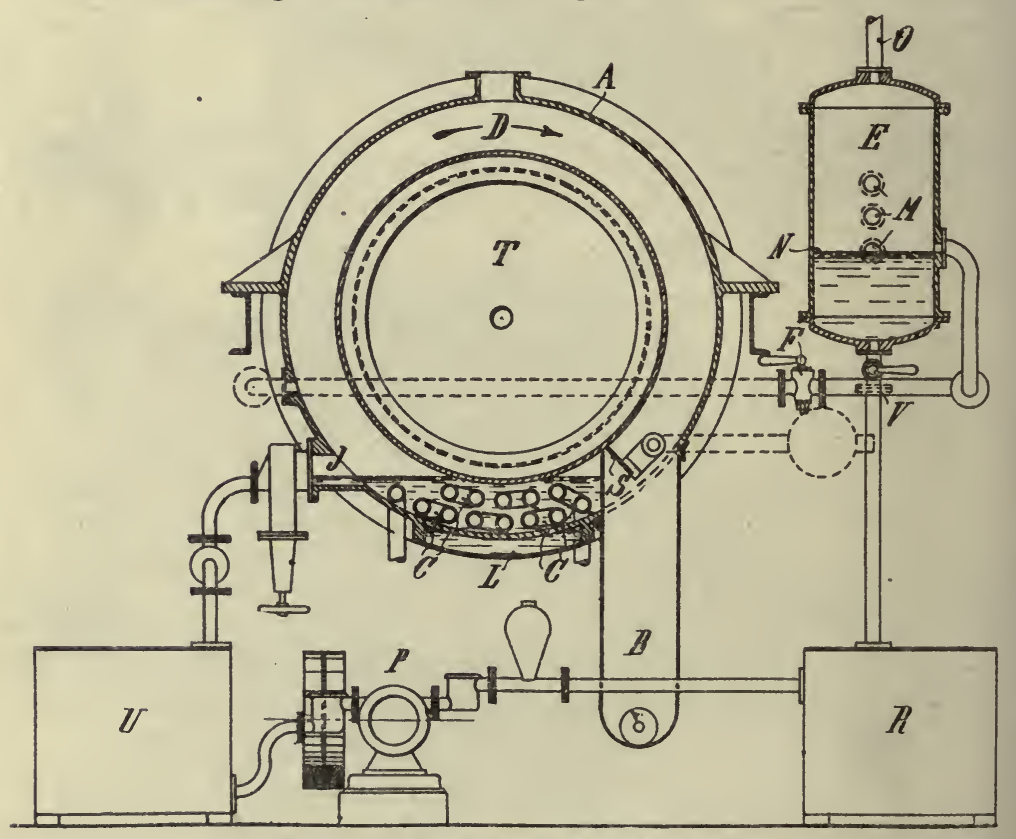

Fig. 95. The Passburg milk arier

patented by Emil Passburg of Berlin, Germany, U. S. patent No. 726,742, April 28, 1903. This film dryer operates under reduced pressure. It consists of an outer casing (A) in which revolves one steam heated, metal drum ( $T$ ), an automatic milk 
supply regulating feed $(\mathrm{E})$ which keeps the milk in the vacuum casing at a constant level, an overflow aperture $(\mathrm{J})$ that regulates the thickness of the film, a vacuum pump, a scraper (S) to remove the film of dried milk from the revolving drum and an evacuated receiver (B) for the dried substance.

The milk is drawn into the drum casing or vacuum chamber by the force of the vacuum in this chamber. By. the proper adjustment of the feed valve and the overflow valve, the milk rises to a given level and stays at that level while operation is in progress. The revolving steam-heated drum slightly dips into the milk in the vacuum chamber and picks up a film of milk which dries under reduced pressure while the drum makes one revolution. The dried film is removed by the automatic scraper and the finished dried milk is discharged into the receiver, while the moisture-laden air and vapors escape through a condenser located outside of the drying apparatus.

The Ekenberg Process.- This is also a film drier operating in vacuo. This process was invented by Martin Ekenberg of Stockholm, Sweden, in the year 1899 and is covered by a number of United States patents, some of the earlier of which are patent No. 764,995, 1904, and No. 785,600, March 21, 1905. The patents covering this process are owned by the Ekenberg Company of Cortland, N. Y., who are operating numerous milk drying factories in the States of New York and Michigan.

The Ekenberg milk drier is called exsiccator. It consists of a revolving, steam heated nickel drum, inclosed in a vacuum chamber. 'The ends of the drum form bell-shaped bowls, dished outward. The drum is equipped with knives or scrapers, which remove the film of dried milk that gathers on the drum. Attached to the vacuum chamber there is a smaller chamber which serves to receive the dried milk as it is scraped from the drum. This is separated from the large vacuum chamber by a series of air locks, so that the material may be removed without breaking the vacuum in the large chamber.

The milk, as it enters the vacuum chamber, is sprayed into the concave ends of the drum. In this manner it is fore-condensed. It is then withdrawn from the vacuum chamber by a pump, and returned again, this time being sprayed upon the 
periphery of the drum. The milk remains on the drum only long enough for it to make three-quarters of a revolution.

After the dried milk is removed from the exsiccator, it is placed in a special drying chamber at a temperature of 90 degrees F. where it remains long enough for the milk sugar to crystallize. This is usually accomplished in about an hour. After this it is ground and sifted in a similar manner as is the case in the milling

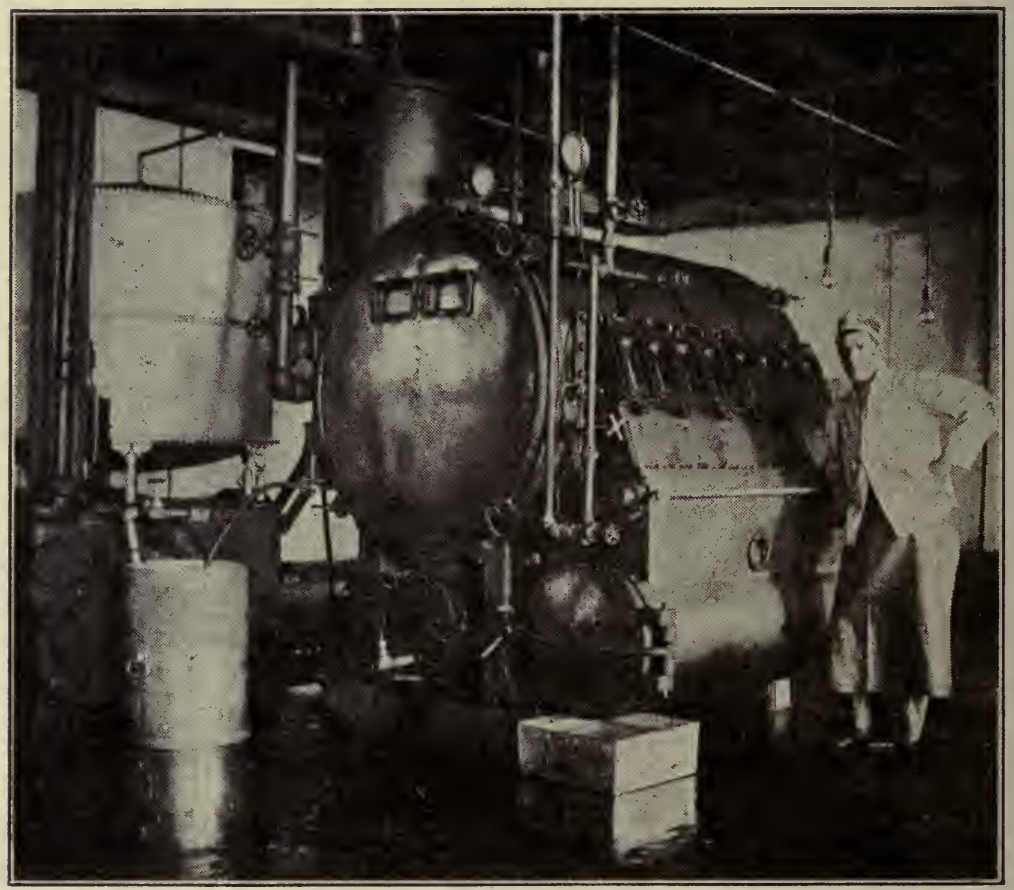

Fig. 96. The Ekenberg exsiccator Courtesy of Ekenberg Co.

of wheat flour. It is then ready for the market, which it reaches packed in either tins, boxes, or barrels.

The fact that the milk is evaporated under reduced pressure makes it possible to accomplish the drying at a relatively low temperature, although the film of drying milk is naturally exposed for a very brief time to the direct heat of the drum, and which obviously varies with the steam pressure in the drum. The manufacturers claim that the drying of the milk takes place 
at a temperature of about 100 degrees $F$. and that the milk at no time reaches temperatures higher than 120 degrees $\mathrm{F}$.

The Govers Process.-This process and equipment was invented and patented by Francis X. Govers, of Owego, New York, U. S. patent No. 939,495, November 9, 1909.

In the Govers patent the milk is dried on two revolving, hollow cylinders (5) located at such proximity to each other

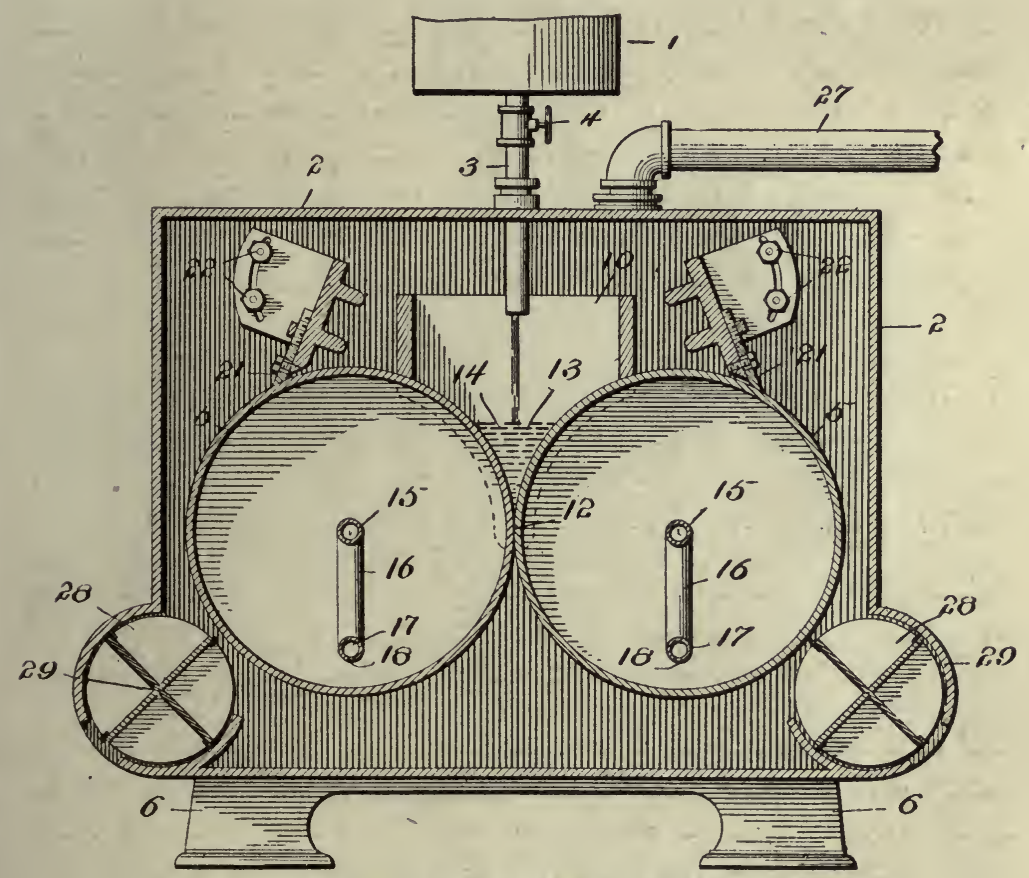

Fig. 97. The Govers milk drier

that there is practical contact at the periphery of the two cylinders, in a similar manner as is the case with the Just process. These revolving cylinders, however, are inclosed and operated in an outer casing which serves as a vacuum chamber (2), which connects with a vacuum pump through pipe (27). There is a milk supply tank (1) with regulating valve (4), feeding the milk to the vacuum chamber through pipe (3). Plates (10) which bear against the opposite ends of the cylinders (5) form with the revolving cylinders a receptacle (13) to receive and retain a 
small quantity of the milk to be desiccated. The cylinders are charged with hot water through pipes (16). Scrapers (21) remove the dried milk from the cylinders, and a rotating valve arrangement (28 and 29) is provided to catch the dried milk as it is scraped from the cylinders and to carry it from the vacuum chamber without breaking the vacuum.

In the operation of this machine it is aimed to maintain a partial vacuum, sufficient to cause the milk to boil at a temperature of about 157 degrees $F$. Through the revolving metal cylinders passes a continuous flow of hot water at a temperature somewhat higher than 157 degrees $\mathrm{F}$. but below 212 degrees $\mathrm{F}$., so that the milk is never exposed to 212 degrees $F$. nor over.

In the small receptacle of milk at (13) to which the milk is continually supplied from the outside, and as rapidly as it evaporates, the milk is heated, to about 157 degrees $\mathrm{F}$. by the revolving cylinders. It is partly condensed and a thin film of this condensed milk coats the surface of the cylinders where it dries, the dried film is removed from the cylinders by the scrapers and discharged to the outside of the apparatus through the vanes of the four-winged valves (28), located near the bottom on both sides of the vacuum chamber.

The Buflovak Process.-The principle of drying milk and other liquids on a steam- or hot water-heated revolving drum has been put to extensive application through the activities of the Buffalo Foundry \& Machine Co., Buffalo, N. Y. This company has, during the last decade, invented, constructed and perfected the "Buflovak" vacuum drum drier. Patents were granted their engineer, Mr. O. S. Sleeper, by the United States Government in 1911, 1913, 1914, 1915 and 1916. All these patents were assigned to the Buffalo Foundry \& Machine Co.

These patents pertain to the drum drier as used for whole milk, skim milk, buttermilk and milk products in general. They are applicable to other products as well as to milk, but for milk they are made specially accessible for cleaning and for sanitary control.

The Buflovak drier consists of a casing in which revolves a steam-heated, polished drum. The milk is fed to the surface or periphery of this drum by a pan located beneath the drum and placed lightly against the drum. The pan has an overflow 
along one side for the automatic removal of the surplus milk not taken up by the drum. To the bottom of this casing is supplied a quantity of milk. This is pumped to the supply pan under the drum, the overflowing milk running back into the lower portion

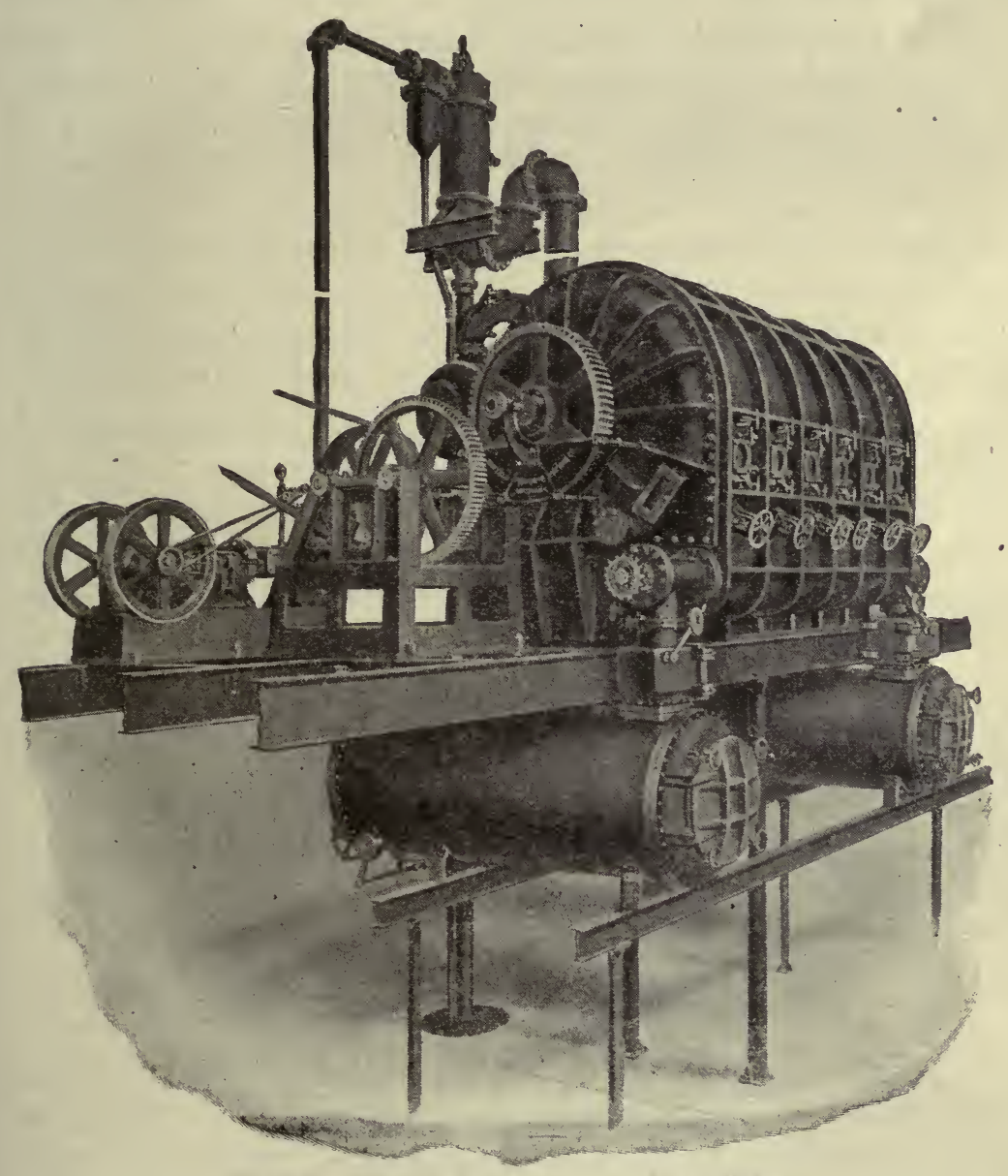

Fig. 98. The Buflovak vacuum drum drier

Courtesy of Buffalo Foundry \& Machine Co.

of the casing. There is slight pressure in the supply pan which causes the drum to take up a heavy and even coating. Near the supply pan is installed a leveling arrangement which levels off and equalizes the layer of milk on the drum. As the drum 
revolves and the layer of milk reaches what is termed the front of the machine it is continuously removed in the form of a dry film by a stationary scraper. At this point the machine is provided with a breaker which consists of a shaft with a number of rods projecting through the same, which revolves to break up the film of dried milk as it leaves the drum. This does not reduce the film to a powder, but causes the material to be sufficiently broken up to allow it to fall into the receiver where it can be easily handled for removal.

The receiver is a large cylindrical pan placed below the scraper at the front of the machine. Observation glasses are placed so that all internal parts may be seen while being operated. The receiver is equipped at each end with a door of the full width of the receiver, facilitating the rapid removal of the dried milk.

Aside from the circulating pump for supplying the milk to the feed pan, there is a condenser and a dry vacuum pump. Before the vapors reach the condenser, they pass through a dust collector. This is water-sealed and prevents the accumulation in the vapor pipe of any dust that may escape from the drum and pass to the condenser.

This drier is operated under a high vacuum, permitting rapid evaporation at a relatively low temperature. The actual drying time of the film of milk on the drum is about 6 to 7 seconds. The operation is continuous and at the conclusion of the day's run the machine is washed out. If subsequently closed up and evacuated for a few minutes, the entire interior will be dry, insuring a sanitary condition of the machine.

\section{Spray-Drying Processes.}

To this group belong the several processes in which milk is desiccated by atomizing it into a fine spray and in an atmosphere or current of heated air. The small particles of the milk spray surrender their moisture quickly and drop to the bottom of the drying chamber in the form of flakes of dried milk while the moistureladen air escapes to the exterior, screens or other forms of dust collectors being provided to recover such parts of dried milk as may escape from the drying chamber with the expelled air. The principle of desiccating fluid substances by atomizing them into an atmosphere 
of heated air dates back to the invention of Samuel R. Percy in 1872.

The Percy Process. - This process was invented and patented by Samuel R. Percy of New York City, U. S. patent No. 125,406, April 9, 1872. The process embraces in its claims, a process of atomizing and desiccating fluid and solid substances, also any viscid substance containing water, by the use of dried, heated or cooled air or gas, which forces the substance into atoms; the atoms are thrown - forward, and forced into a chamber and dried in consequence of the dried or heated air which propels them into the chamber and also, owing to the dried and heated state of the chamber into which they are thrown.

The Stauf Process. - The Stauf process represents the first commercially successful application of the desiccation of milk by

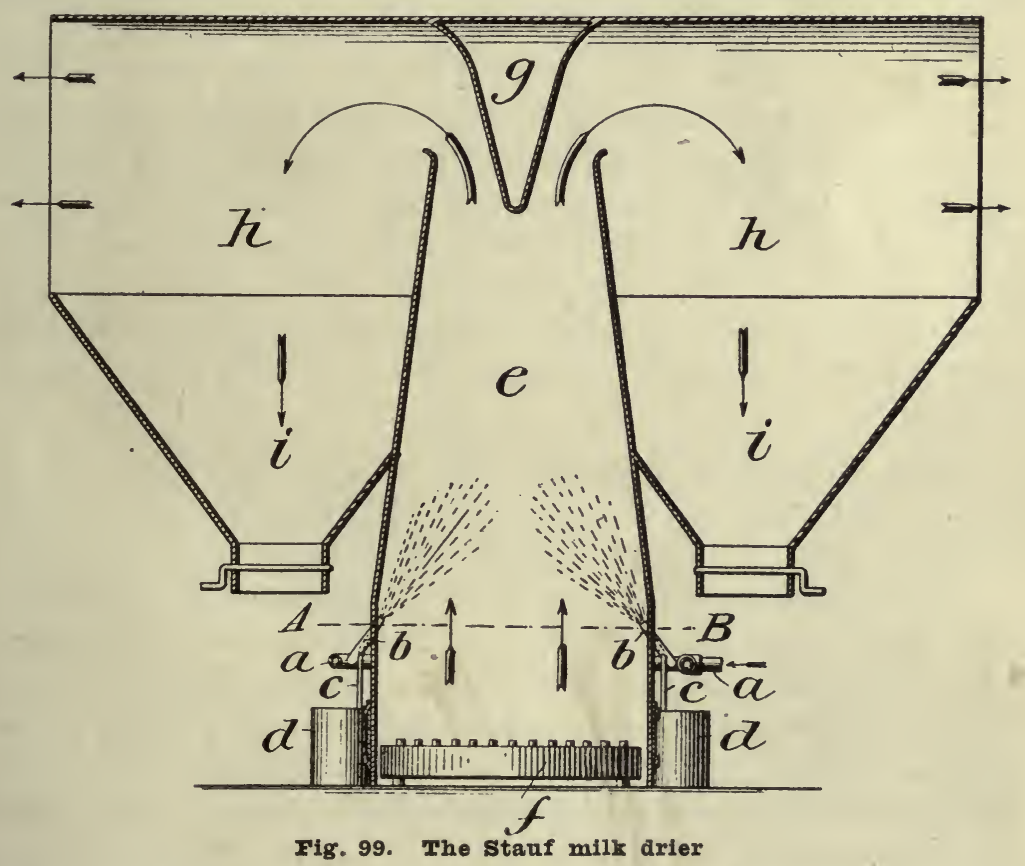

the spray-drying principle invented by Percy. The Stauf process was patented by Robert Stauf of Posen, Germany, U. S. patent No. 666,711, January 29, 1901.

The patent claims are as follows: "The process of obtaining 
the solid constituents of liquids, such as blood, milk and the like, in the form of powder, said process consisting in converting the liquid into a fine spray, bringing such spray or atomized liquid into a regulated current of heated air, so that the liquid constituents are completely vaporized, conveying the dry powder into a suitable collecting space away from the air current, and discharging the air and vapor separately from the dry powder."

The Stauf patent shows a vertical drying chamber (e) into which the liquid (milk) to be desiccated is atomized through jets or nozzles (b) under pressure, into a fine spray. A current of heated air is admitted at the bottom of the drying chamber ( $f$ ) running in the same direction as, and mixing with, the spray of milk, and evaporating the watery constituents of the spray. The steam and dried particles are carried upward by the heated air, retaining the atoms momentarily in the current of hot air and causing them to surrender substantially all the remaining moisture in the form of vapor, and the product is prevented by the cooling effect of such evaporation from undergoing chemical change. The vapors and dried atoms are guided by a cone $(\mathrm{g})$ extending downward from the top into the drying chamber, into collecting chambers $(h)$ where the desiccated milk or dry powder gathers in hoppers (i) away from the vaporizing current. The moisture-laden air or gas is separated from the dry powder and escapes through the sides of the collecting chamber, which consist of mill gauze, woolen fabric or like pervious material.

The McLachlan Process.-This process was patented by John C. McLachlan of Chicago, Ill., U. S. patent No. 806,747, December 5, 1905. This process is a modification of the Stauf process.

McLachlan uses a tall vertical drying chamber (B) surrounded on its sides by a jacket or casing (A), containing steam heating coils (G) with intake, and outlet of steam; a circular, perforated pipe (M) is installed near the top of the chamber for the purpose of discharging into the chamber heated air, an atomizing jet $\left(\mathrm{O}^{5}\right)$ enters through the side of the drying chamber near the top, an air pump (O) forcing heated air into the atomizing nozzle $\left(\mathrm{O}^{5}\right)$, a slide door (D) at the bottom of the drying chamber for the discharge of the dried powder through opening (E), and a perforated covering $(\mathrm{K})$ over the top of the drying chamber for the escape of the moistureladen air. 
In this apparatus the spray of the milk enters into the upper part of the drying chamber and is permitted to drop through an atmosphere of heated air. As the atoms of drying milk descend, they surrender more and more of their moisture and at a certain point toward the bottom they have discharged substantially all their mois-

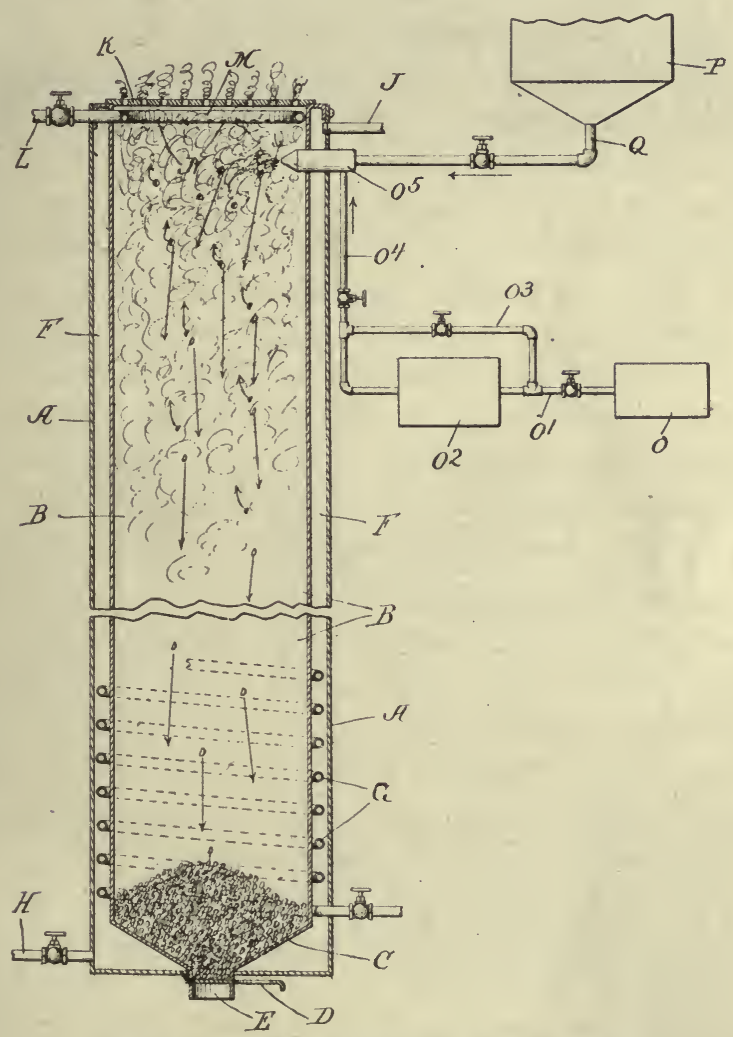

Fig. 100. The McIachlan milk drier

ture and are deposited in the form of a dry powder in the bottom of the drying chamber, from where they are discharged by a slide door. In the meantime the vapors pass freely up and out of the upper or open end of the chamber.

This process differs from the Stauf process essentially only in the fact that the milk descends through an atmosphere of heated air and that the drying chamber and the collecting chamber are one and 
the same, while in the Stauf patent the milk spray ascends and is carried into separate collecting chambers.

In a later design, U. S. patent No. 1,038,773, September 17, 1912, McLachlan causes the heated air to be forced into the drying chamber through a rotating discharge head located in the center of the drying chamber. The rotating discharge head directs the air currents radially outward toward a deflecting ring.

The milk is blown into the drying chamber through multiple supply nozzles or atomizers. These supply nozzles enter through the periphery of the deflecting ring. They discharge in a horizontal plane and incline to the radius in such a manner as to cause maximum commingling of the finely divided particles of the milk with the heated air. The dried powder, deposits in the bottom of the drying chamber, a belt conveyor discharges it into a screw conveyor pocket, whence it is removed to any suitable storage container.

The moisture-laden air leaves the drying chamber through drums near the bottom and top of the drying chamber. These discharge drums are equipped with suitable arrangement to recover such parts of the powder as are deposited on their surfaces.

The Merrell-Merrell-Gere Process.--This process is similar to the Stauf process except that the patent covering the MerrellMerrell-Gere process specifically refers to the desiccation of previously condensed milk, while the Stauf patent makes no specific reference to the use of condensed milk, although the term "milk" may have been intended to embrace all kinds of milk regardless of the degree of concentration prior to desiccation.

The Merrell-Soule Co., of Syracuse, N. Y., purchased the Stauf patent in 1905 and two years later L. C. Merrell, I. S. Merrell and W. B. Gere, of Syracuse, N. Y., assignors to Merrell-Soule Co. patented the process as applied to desiccating condensed milk, U. S. patent No. 860,929, July 23, 1907. Their patent claims read as follows :

1. "The process of obtaining the solid constituents of liquids and semi-liquids, in the form of powder, which process consists in concentrating the substance by removing a large percentage of the water therefrom, converting the concentrated mass into a fine spray, bringing such spray into a current of dry air or gas having an avidity for moisture so that substantially all the remaining liquid constituents are separated thereby, 
conveying the dry powder into a suitable collecting space away from the air or gas current, and discharging the air or gas separately from the dry powder.

2. "The process of obtaining the solid constituents of liquids and semi-liquids, in the form of powder, which process consists in concentrating the substance by removing a large percentage of water therefrom, converting the concentrated mass into a spray, bringing such spray into a current of dry heated air or gas having an avidity for the moisture of the substance treated. retaining the atoms momentarily in said current so that substantially all the remaining moisture is converted into vapor

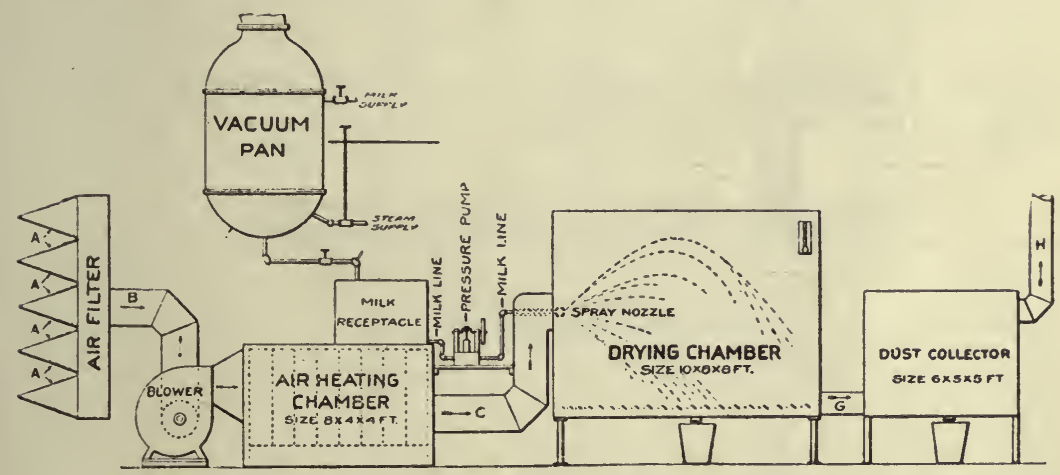

Fig. 101. The Merrell-Soule milk arier ${ }^{1}$

and the product is prevented by the cooling effect of such evaporation from undergoing chemical change, conveying the dry powder into a suitable collecting space away from the vaporizing current, and discharging the air or gas separately from the dry powder."

The Merrell-Soule Co. are operating numerous powdered milk factories, with headquarters in Syracuse, N. Y. This company has subjected the spray-drying process to much experimental study in efforts to perfect the process and to improve the quality and keeping properties of the product.

Obviously, during the life of the Stanf patent, which expired January 29, 1918, no one could make milk powder by the spray-drying process, whether from milk uncondensed, or from

${ }^{1}$ From Plaintiff's Record in the U. S. District Court. Merrell-Soule Co. vs. Rico Milk Products Co. 
milk previously condensed without paying tribute to the owners of this patent, the Merrell-Soule Co.

The C. E. Rogers Process.-This process was patented by Charles E. Rogers of Detroit, Mich., U. S. patent No. 1,226.001, May 15, 1917, and No. 1,243,878, October 23, 1917.
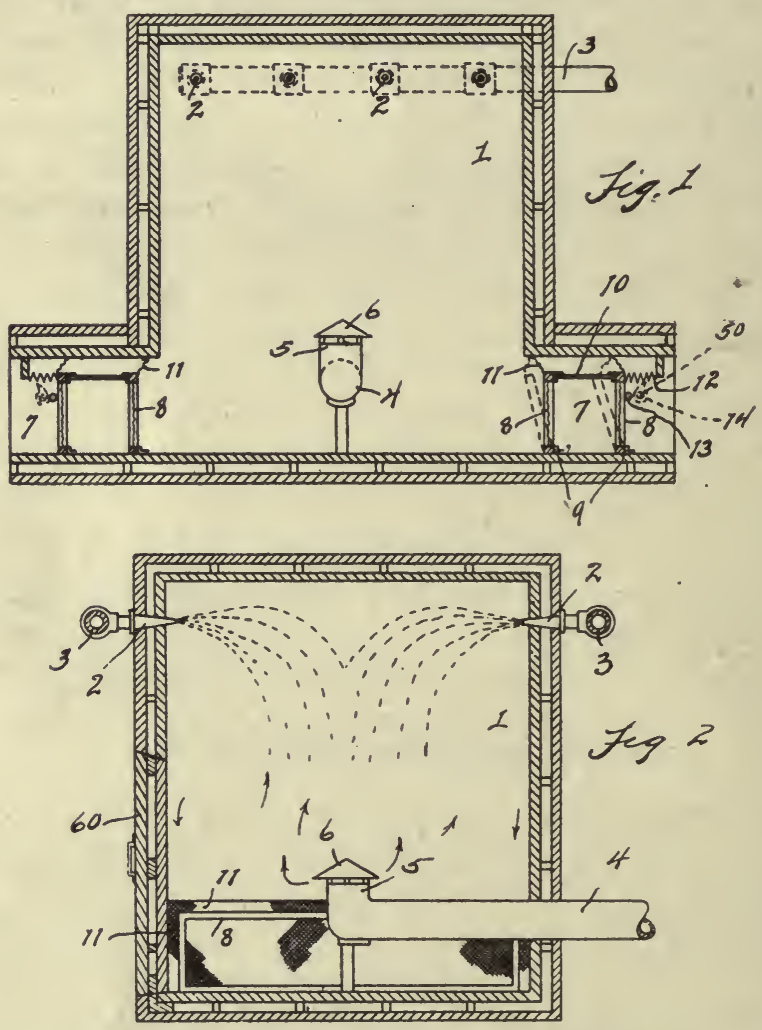

Fig. 102 and Fig. 103. Rogers milk arier

Courtesy of C. E. Rogers

${ }^{1}$ desiccating chamber, ${ }^{2}$ spray nozzles, ${ }^{3}$ spray pipes, ${ }^{4}$ hot air inlet conduit, ${ }^{8}$ end of air conduit, 8 deflector, 7 air discharge conduits, 8 recovery screens, ${ }^{2}$ pivots, $10 \mathrm{bar},{ }^{11}$ loose screens for vibrating, 12 springs, 13 rods contacting with ${ }^{14}$ cams.

The patent claims cover the desiccation by the spray-drying process of fluids including condensed milk. The apparatus consists of a large drying chamber, the spray nozzles are located near the top on all four sides of the chamber. The hot air is 
adimitted near the bottom in the center of the drying chamber, means for heating the air, blowing it into the drying chamber and screens located near the bottom at the periphery of the chamber for discharging the spent air are provided.

In this apparatus the sprayed milk falls from near the top of the drying chamber through an ascending current of heated air. The milk spray entering on all sides causes an even distribution of the spray particles and a consequent even deposit of the dried milk particles on the bottom of the drying chamber. The previously condensed milk is sprayed into the drying chamber while heated to a temperature of 140 degrees $\mathrm{F}$., the temperature of the air in the drying chamber ranges from 180 to 200 degrees F. The distance over which the spray falls through the ascending current of heated air being sufficient to permit the removal from the milk particles of substantially all the remaining moisture.

The Gray Process.-Chester Earl Gray of Eureka, Calif., and Aage Jensen of Oakland, Calif., U. S. patent No. 1,078,848, November 18, 1913, Chester Earl Gray, Assignor of one-half to Aage Jensen, U. S. patent No. 1,107,784, August 18, 1914, and Chester Earl Gray, U. S. patent No. 1,157,935, October 26, 1915, and U. S. patent No. 1,266,013, May 14, 1918, subjected the possibilities of spray drying to extensive study and invented and patented successive improvements and new principles relating to desiccation of milk and other liquid substances.

Gray patent No. $1,107,784$ involves an apparatus with a circular desiccating chamber $\mathrm{A}$, having a cone-shape lower section $\mathrm{B}$, terminating in a discharge opening for the dried substance, and a discharge opening $\mathrm{C}$ for the moisture-laden air. The heated air is introduced into the desiccating chamber peripherally in a tangential direction, by means of a blower D. Between the blower and the drying chamber there is an inclosed heating coil (steam coil) over and around which the air is blown into the drying chamber. The tangential entry of the heated air into the circular chamber sets up a cyclonic current therein and this effect is augmented by introducing the air at several different points through tangential openings a. The milk to be desiccated enters under pressure through a spray nozzle $\mathrm{H}$, located in the 
center of the chamber and is atomized. The distinctive features of this process are:

1. The heated air enters at the periphery, forms a cyclonic current moving tangentially toward the center where the moistureladen air escapes at $\mathrm{C}$.

2. The atomized milk enters at the center of the cyclonic air current, partakes of the rotary movement of the air current, but because of their greater specific gravity the particles of drying milk influenced by centrifugal force are caused to travel in

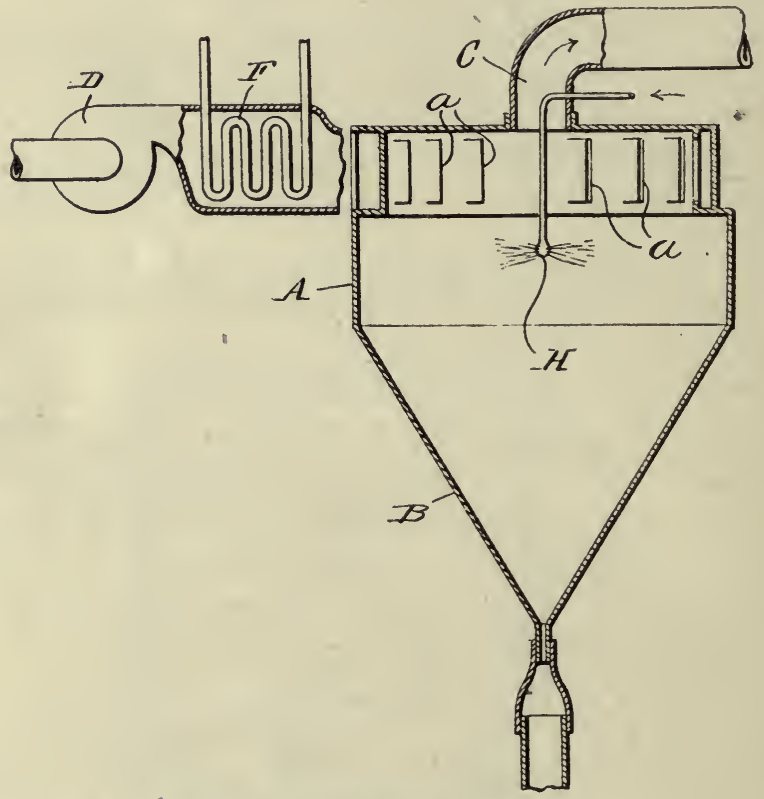

Fig. 104. The Gray milk drier

spiral lines outwardly through the current of air and are finally arrested by the confining walls of the chamber down which they fall to the discharge end at the bottom.

3. The exhaustiveness of the removal of moisture from the particles of milk is augmented by the fact that the heated air moving through the spray of milk spirally toward the center, where it escapes, has taken up its maximum charge of moisture by the time it reaches the center, which is the point of its discharge and it is dryest near the periphery. The spray of milk 
being discharged into the cyclonic current at the center, carries its maximum moisture content at that point, gradually surrenders it to the air, as it moves outward to the periphery of the cyclonic current. The completion of the drying is accomplished in the zones of incoming heated air which carry the least humidity. Therefore, as the outwardly moving particles of milk surrender more and more of their moisture, they pass through dryer zones of heated air. This obviously both accelerates the speed of drying and enhances the completeness of the removal of moisture.

4. Inasmuch as the danger of the solubility-destroying effect of heat is greatest while the milk is still in the liquid state, and this effect is practically completely absent in milk from which the bulk of moisture has been removed, this process has the additional advantage of maximum preservation of the solubility in the finished product. The temperature of the cyclonic air current is lowest when it reaches the center where the moisture content of the milk is greatest. By the time the particles of milk come in contact with the hottest air (at the periphery) their moisture content is lowest.

5. This process tends to facilitate maximum recovery of the milk powder. The moisture-laden air escapes in the center, where the particles of milk are heaviest, and where their greater specific gravity causes them to partake of the centrifugal motion moving them outward until when completely dried, they strike the steeply tapered confining walls of the drying chamber and fall to the bottom of this chamber.

Gray patent No. 1,157,935 involves, in addition to the new and advantageous features established under patent No. 1,107,784. and explained above, apparatus and a method for supporting the milk or other substance to be desiccated on and by the introduction of a solid, sheet-like, or finely divided substance. In the case of milk, the supporting or absorbing material used may be previously desiccated milk.

'The desiccating chamber A described in this patent is similar to the desiccating chamber shown under patent No. 1,107.784. and the intake of the heated air B and discharge of the moistureladen air $\mathrm{C}$ are unchanged. The intake of the milk and supporting material into the desiccating chamber is located in the center 
near the top of this chamber. The milk and supporting material enter through an inlet duct $E$, through which a shaft $F$ extends

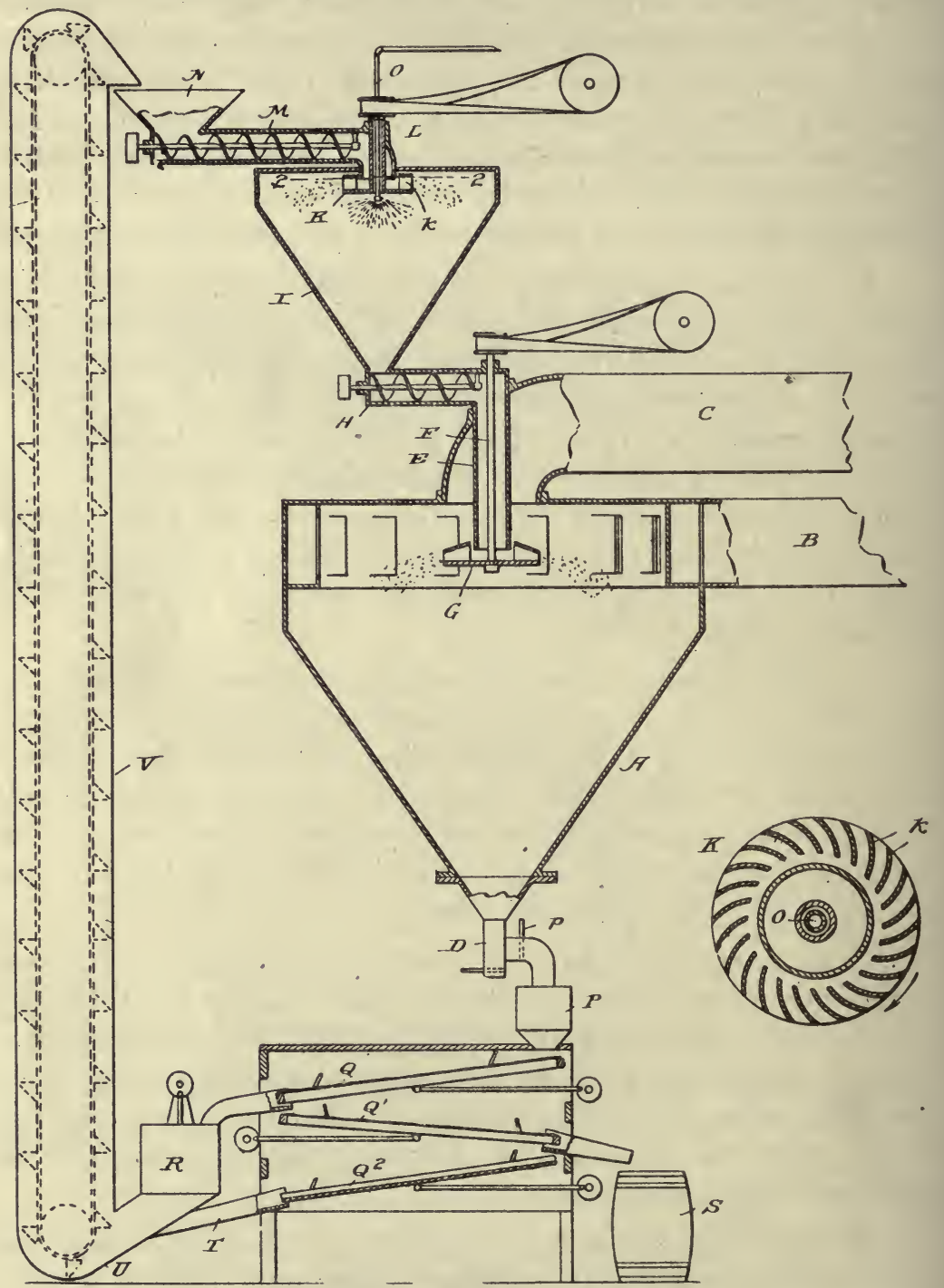

Fig. 105. The Gray milk drier

down to a vaned distributer $\mathrm{G}$, which is revolved by any suitable power mechanism. The material to be dried enters the duct $\mathrm{E}$ 
at the upper end being fed thereto by a screw conveyor $\mathrm{H}$, which receives the product from the coating chamber I which is located above the drying chamber. The coating chamber is cone shape. At the upper end of this chamber there is provided a means for introducing the nucleus mass or supporting material, in this case the previously desiccated milk, and distributing the same in the chamber, as well as a means for maintaining in this chamber an atmosphere which carries the milk to be desiccated in comminuted form. The nucleus mass or supporting material is fed to a rotary distributer $\mathrm{K}$ by a screw conveyor $\mathrm{M}$, receiving its material from a hopper N. Extending down through a hollow shaft $\mathrm{L}$ is a pipe $\mathrm{O}$ terminating in an atomizing nozzle and the milk to be desiccated is forced through the pipe and nozzle under pressure. By this arrangement the comminuted milk and the comminuted supporting material come into intimate contact whereby the particles of the supporting material become coated with the milk to be desiccated.

At the bottom of the desiccating chamber a grading mechanism is provided consisting of shaking screens $Q$ and $Q^{1}$ and a hopper $\mathrm{P}$ which separate the desiccated milk into three grades. Shaking screen $Q$ is of relatively large mesh. It is designed to remove only the larger particles which pass from this screen to a pulverizing apparatus $\mathrm{R}$ where they are reduced to a finer condition. The material passing through screen $Q$ drops on screen $Q^{1}$, the mesh of which is of such size as to permit the passage of only the finer particles, while the intermediate sized particles are discharged into receptacle $S$ as the finished product. The finer particles pass down onto a shaking floor $Q^{2}$ and from there into a receiver $U$, which may also receive the pulverized material from pulverizer $\mathrm{R}$. A conveyor $\mathrm{V}$ carries the material from receiver $\mathrm{U}$ up into hopper $\mathrm{N}$, this material constituting the nucleus mass or supporting material used for desiccating the milk. There is no drying action in the coating chamber.

This apparatus and process may be operated continuously and after it is once in operation the output is claimed to be equal to or greater than would be possible, with an apparatus in which the liquid milk itself is sprayed into the current of heated air.

This process yields a product having particles of appreciable size, which facilitates ease and completeness of solution in water. 
It is superior in this respect to the fine state of division of the product of other processes, in which state the particles are more difficult of mixture and solution, though they may be equally soluble.

Gray patent No. 1,266,013 deviates in principle from No. $1,157,935$, in that the liquid to be desiccated is distributed on a desiccating supporting surface, and the dried milk is removed from this surface in finely divided form. The operation is made continuous by causing the spraying or depositing devices to travel in unison with the devices for removing the dried material. but so as to deposit the liquid on the supporting surface after the same has been cleaned of the dried substance.

The desic c ating chamber is of large size and cone-shape. The inclined or tapering sides A form the supporting surface. It terminates at its bottom in a suitable discharge opening $\mathrm{B}$, regulated by a valve $b$. At the top in the center there is an exit $\mathrm{C}$ for the moisture-laden air, and peripheral inlet openings $\mathrm{D}$ for the heated air, similar as in the apparatus of the two previous patents, and so arranged as to create in the drying chamber a $\mathrm{cyclo}$ o i c action, whereby any particles heavier than

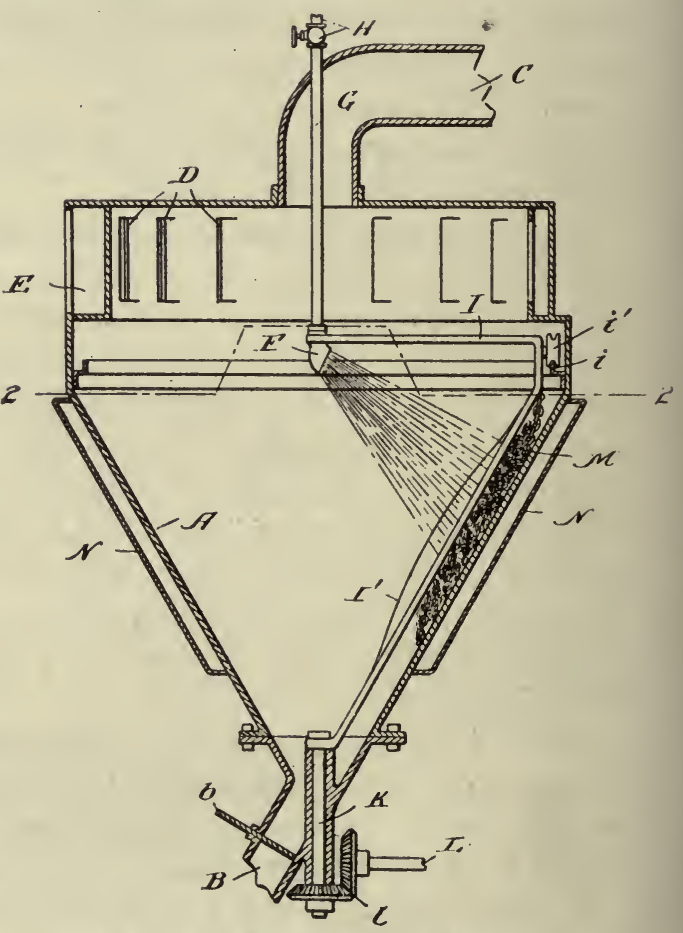

Fig. 106. The Gray milk drier the air are caused to seek the walls of the chamber and be deposited thereon. In the center of the upper portion of the drying chamber is a rotary spray nozzle $F$, arranged to direct the milk in a fan-shaped spray against the inclined wall $\mathrm{A}$. The 
milk reaches the spray nozzle under pressure through pipe $G$. The nozzle rotates by means of a traveler I supported by a track $i$ and a roller arrangement $i^{1}$. The traveler extends down through the desiccating chamber, with driving attachment $\mathrm{K}$ and $\mathrm{L}$ near bottom. The traveler is provided with a brush made of a mass of chain links $M$, depending from the traveler and resting in contact with the inner surface of the inclined wall A. This brush insures the removal of the dried material from the surface in finely divided form.

If it is desired to control the temperature of the supporting surface A during the drying operation, the supporting wall may be jacketed, thereby forming a surrounding chamber $\mathrm{N}$ through which a circulating medium of the desired temperature may be passed to effect the proper control of the temperature of the surface.

The design and arrangement of the apparatus covered by the above patent is such that while the major portion of the surface is constantly exposed to the drying effect of the cyclonic current of the heated air, the brush and the traveler which propels it, advance around the chamber so as to remove the dried milk from each portion of the surface in succession and the spray nozzle operates in such a manner as to direct the spray of milk against the surface in the rear of the traveler and brush. or on that portion of the surface from which the dried milk has been removed. ${ }^{1}$

\section{Chapter XXVI.}

\section{COMMERCIAL MANUFACTURE OF MILK POWDER BY THE SPRAY PROCESS.}

Pre-heating of Milk.-It has been demontrated that in order to preserve maximum solubility of the finished product, the fluid milk should not be heated above 150 degrees $F$.

Accordingly the practice has been generally adopted in plants drying milk by spray-drying to heat the milk to from 140 to 150 degrees $F$. For this purpose similar equipment is used as in the manufacture of condensed milk.

Pre-condensing of Milk.-While, in the early days of the use of the spray-drying principle for desiccating milk, the fluid

${ }^{3}$ See also Dick process, page 335 . 
milk, without precondensing, was sprayed, and while this procedure is entirely feasible, it was soon found that it was more economical to remove a considerable portion of the water of the fluid milk and to reduce the product to a concentration of about $4: 1$ or $4.5: 1$ before spraying. This is accomplished by condensing the fluid milk by any of the methods for condensing as described under the "Manufacture of Condensed Milk" in this volume. In general practice the vacuum pan is used for this purpose in most of the milk powder plants.

Effect of Pre-condensing on Economy of Manufacture.The chief advantage and purpose of pre-condensing, instead of spraying the fluid, or uncondensed milk, lies in the greater economy of operation in the case of pre-condensing. *

The fluid milk contains more water than the condensed milk; more water must be removed during the spraying process, hence less milk can be desiccated in equipment of the same capacity and in the same space of time than in the case of spraying pre-condensed milk. The pre-condensing therefore means greater capacity of the available equipment- shorter hours and greater economy of operation.

Again, the fuel requirements are greater in the process of desiccating by the spray method than by evaporation in the vacuum pan or the film method. The comparative efficiency of evaporating water by means of air and in vacuum, is well understood. The heat-transmitting coefficient of air is much lower than that of steam and metal heating surfaces. The heat applied in the form of heated air is less completely utilized than the heat applied in the form of steam in copper jackets and coils, hence in evaporation by heated air there is greater waste of heat and fuel. The various factors which enter into the drying by means of air and the resulting losses of heat transferred are discussed in detail by $\mathrm{E}$. Hausbrand ${ }^{1}$ in his revised treatise entitled "Drying by Means of Air and Steam."

Effect of. Pre-condensing on Bulkiness of Spray Milk Powder.-Other conditions, such as orifice of spray nozzle, pressure of milk, and temperature to which the milk is preheated being the same, the milk powder made by spraying fluid or uncondensed milk, is somewhat more bulky than that made by

${ }^{1}$ Hausbrand. "Drying by Means of Air and Steam," 1901. 
pre-condensing the milk before spraying. The spraying of uncondensed milk appears to produce a more flaky powder while the spraying of condensed milk results in a more granular powder. The flake shape does not pack as closely together as the granular shape. This is obviously an advantage in favor of pre-condensing.

However, the physical shape and condition of the powdered milk can be controlled to a considerable extent by modification of the coarseness or fineness of the spray. In fact, by such modification it is possible to make a distinctly granular product from uncondensed milk, and a decidedly flaky product from the precondensed milk.

The finer the spray the more flaky the milk powder; the coarser the spray the more granular the milk powder. The fluid milk makes a finer spray than the condensed milk; therefore the more flaky condition of the powder from the former.

Aside from the concentration of the milk to be sprayed, the fineness or coarseness of the spray can be regulated by the size of the orifice of the spray nozzles and by the pressure of the milk. The larger the orifice or the lower the pressure, or both, the coarser will be the spray and consequently the more granular the milk powder. Therefore, in order to reduce the flakiness and bulkiness of milk powder made from uncondensed milk, and to make this milk powder more granular, the orifices of the spray nozzles must be relatively large or the pressure of the milk must be relatively low, or both. Superheating of the milk (hoiling it at 212 degrees $\vec{F}$.) by turning steam direct into it also assists in minimizing the fluffiness and bulkiness of the resulting milk powder but it diminishes the solubility of the product.

\section{Effect of Pre-condensing on Keeping Quality of Spray Milk} Powder.-Inasmuch as the spray milk powder that is now commercially manufactured does not contain enough moisture, when properly desiccated and protected from dampness, to sustain bacterial action, the keeping quality of this product does not materially depend on bacterial decomposition or freedom therefrom.

Milk powder does became stale with age, however, and much of it gradually develops a tallowy flavor and odor. This 
must be attributed to chemical changes, one of the chief of which is oxidation. While there are numerous agents, which come in contact with, or enter into, the composition of milk powder, that may bring about, or may invite oxidation, air is one of the most likely factors to play an important role.

Air, as is well known, acts as an oxidizing agent. Since there is a noticeable tendency of the product from uncondensed milk to be flakier and bulkier than the product from condensed milk, it appears that with this increased bulkiness, there may be more air in a given bulk, varying somewhat with the method of packing.

But experience has shown that there is enough air contained both, in a package of milk powder made from uncondęnsed milk and in a like package of milk powder made from condensed milk, to cause deterioration, when other conditions, such as light, or temperature, or both, are favorable, or when there is present in the product enough moisture.

There are no experimental results available that show any difference in the keeping quality of the two products and the experience of the commercial manufacturer points to the conclusion that the milk powder made from uncondensed milk keeps as well as the product made from pre-condensed milk.

Effect of Pre-condensing on Solubility of the Spray Milk Powder.-The flaky and fluffy powder of the uncondensed milk goes into solution at the start somewhat slower than the more granular powder made of condensed milk. This is due to the fact that the flaky particles with their relatively large exposed surfaces, coming in immediate contact with the water, dissolve and take up water so rapidly, that they run together and paste, forming a coating around the remaining mass of the product, which renders the penetration of the water into the mass somewhat slower at the start. However, this is no indication that the flaky powder is less soluble than the granular powder, in fact the flaky powder, because of the large relative surfaces of its particles and, therefore, the greater area of contact, does dissolve more rapidly when it actually comes in contact with water.

Experiments conducted by Hunziker indicate that the difference in speed of solution between the two products is very slight 
and that the total solubility is very slightly greater in the case of the more flaky milk powder made from uncondensed milk. In these experiments the amount of milk powder, the amount and temperature of the water and the kind and amount of mechanical agitation were exactly alike. At the end of one minute from the time the milk powders were put into the water, the amount of solids dissolved was practically the same in the case of the flaky powder made from uncondensed milk as it was in the case of the granular powder made from pre-condensed milk. And after that the percentage of total solids dissolved from the powder made from uncondensed milk was slightly greater than the percentage of total solids dissolved at the end of the same respective periods of time from the powder made from pre-condensed milk.

Here again it should be understood that uncondensed milk may be so atomized and dried (large orifice of spray nozzle and low pressure) to increase the size and granular condition of the particles of the resulting powder sufficiently, so that for all purposes for which milk powders are used commercially and domestically the ease or difficulty of solution is no longer any factor.

Effect of Pre-condensing on Recovery of Spray Milk Powder. -The finer, lighter and more fluffy the milk powder the greater is the tendency of a portion of the powder to escape from the drying chamber. Hence it is obvious that the product from uncondensed milk, when desiccated in such a manner as to intensify the flakiness at the expense of a granular condition (small orifice of spray nozzle and high pressure), will tend to escape from the drying chamber more profusely than the more granular powder made from pre-condensed milk. Pre-condensing facilitates maximum recovery.

It should be borne in mind, however, that the fineness of some of the particles of dried milk made from either uncondensed or pre-condensed milk, makes necessary the use of an efficient dust collector. Without such a dust collector, a portion of the finer and lighter particles will be lost in either case. In the case of the flakier and finer product of uncondensed milk, the dust collector must be such as to collect a product of that 
fineness, in order to be efficient and to accomplish maximum recovery.

The percentage of recovery of the solids of milk in the form of milk powder in any given desiccating arrangement then is largely a matter of efficiency of the dust collector, and the efficiency of dust collectors must increase as the fineness and flakiness of the product increases. The recovery may be materially facilitated, however, by such an arrangement of the desiccating apparatus, as will cause the particles of drying milk to travel in a direction opposite to that of the escaping air, as indicated in the Gray patents.

Heating the Air.-This is done either by the installation and operation of a furnace, similar in principle to hot air furnaces, or by steam coils installed in a closed, insulated vault.

The hot air furnace makes possible the heating of the air to higher temperatures and it is claimed to be somewhat more economical from the standpoint of fuel consumption. Its disadvantages are that the temperature is somewhat more difficult to control, it fluctuates rapidly with the condition of the fire. There is also more or less danger of impure air, because in the case of even slight leaks between the fire box and the hot air chamber, soot and ashes tend to be drawn into the heated air and are thus blown into the drying chamber where they mix with and deposit in the milk powder.

Steam coils, enclosed in a vault, have been found less objectionable in this respect. While it is more difficult to attain quite as high a degree of heat by this method, the heated air can be maintained more easily at a uniform temperature and there is no danger of impurities leaking into the air.

The air is drawn into the furnace or hot air vault from the atmosphere. It may be, but usually is not, filtered by admitting it through an air filter, located at the intake, into the hot air vault. Absorbent cotton or other similar pervious material may be used for this purpose.

The earlier patents also cover an air drying arrangement installed before the air reaches the hot air vault. This greatly assists in controlling and making uniform the results of the drying process from one day to another, neutralizing the disturbing ef- 
fect of the uncontrollable fluctuations in the humidity of the atmospheric air, as affected by weather conditions. However, in commercial operation the artificial drying of the atmospheric air is generally omitted.

The air may be blown into the desiccating chamber by a blower fan, in which case a suction fan is frequently also installed to draw the moisture-laden air from the desiccating chamber; or the injection of the air into the drying chamber may all be taken care of by a strong suction fan located at the air exhaust end of the desiccating chamber. It is claimed that the double arrangement of blowing in and drawing out of the heated air, requiring less powerful suction at the exhaust end, minimizes the escape of milk powder with the moisture-laden air and thereby facilitates the recovery. The speed of the drying action and the exhaustiveness of desiccation may be augmented by introducing the air in such a manner as to produce a cyclonic air current moving spirally toward the center of the drying chamber, where it escapes while the milk spray issues from the center, is acted on by the centrifugal force and moves tangentially toward the periphery as shown in the Gray patents.

The temperature of the air as it enters the desiccating chamber is generally held at from $250^{\circ}$ to $300^{\circ} \mathrm{F}$., the temperature of the moisture-laden air discharging from the drying chamber ranges from $150^{\circ} \mathrm{F}$. to $200^{\circ} \mathrm{F}$.

Spraying and Desiccating.-The drying is accomplished by forcing the milk or condensed milk, in the form of an atomized spray, into the current of heated air in such a manner, that the fluid milk particles, or atoms of the milk spray, remain in suspension sufficiently long to cause them to surrender substantially all of their moisture. The dried particles or flakes of milk are allowed to deposit at the bottom or sides of the drying chamber or in a separate collecting chamber, from where they are removed for sifting and packing through a hopper, while the moisture-laden air escapes separately to the outside.

The Desiccating Chamber.--The desiccating chambers in commercial use vary considerably in size and in shape, as well as in arrangement of spray nozzles and intake and outlet of heated air. 
Most of these chambers are rectangular, measure from about 12 feet in length, width and height upward to much larger dimensions. Some are longer than they are wide and others are much higher than they are wide and long. Still others are of the circular type, resembling small silos, and some are cone-shape.

The desiccating chambers are usually completely lined with tin plate on the inside, making them air tight or nearly so. In order to prevent waste of heat by radiation through the walls, top and bottom, they must be properly insulated. This is generally done with asbestos sheeting.

Spray Nozzles.-The milk enters the desiccating chamber through one or more spray nozzles, under a pressurê of about 3,000 pounds. The spray nozzles are generally located in the side of the drying chamber in close proximity to the top, so as to give the spray particles as far a distance to fall through the heated air as the height of the chamber permits. Or the spray nozzle may be located in or near the center of the drying chamber, in its upper portion, in which case the spray issues outward radially, or is blown out of the nozzle tangentially by giving the spray nozzle a rotary motion.

When more than one spray nozzle is used, the multiple nozzles are either arranged in a straight row along one side, or they may be distributed over two or over all four sides of the desiccating chamber.

Different types of spray nozzles or atomizers are used. In some hot air under pressure, or steam, propels and blows the milk through the nozzle on a similar principle as the boiler water injector. In other cases the spray nozzle consists of a heavy black iron cap, about one and one-quarter inch long and with a one-half inch threaded bore. This cap is screwed on to the end of the milk pipe, or its laterals. In the center of the closed end, the cap has a very fine opening with a diameter of from one-half to one millimeter (.02 to .04 inch). A small brass disc, about one-quarter inch thick and snugly fitting into the iron cap, lays against the closed end of the cap and covers the small orifice. This brass disc carries two minute spiral grooves at its periphery, through which the milk under pressure is forced between disc and cap 
and escapes through the small orifice in the cap, forming a fine spray or mist.

The small orifice through which the milk spray enters the desiccating chamber increases in size by usage due to wear, and necessitates the frequent replacing of the old caps or nozzles by new ones. When in operation, these spray nozzles at times become clogged and must be changed for cleaning. It is necessary, therefore, for the operator to supervise the process continually, making sure that all the spray nozzles function properly, so as to secure maximum efficiency and speed of desiccation.

In order to facilitate the changing of spray nozzles while desiccation is in progress, the nozzles are so placed as to connect with the milk pipe on the outside of the desiccating chamber, the nipples carrying the spray nozzles connecting with the milk supply pipe by means of Barco joints (loose joints), can be turned in all directions sufficiently to withdraw the nozzles from the desiccating chamber independently and at any time during the desiccating operation.

Spray Pumps.-In order to maintain a uniform efficiency of desiccation and to secure a uniform fineness of spray, it is important that the pressure of the milk should be uniform. To accomplish this requires a special type of pump. The pumps best

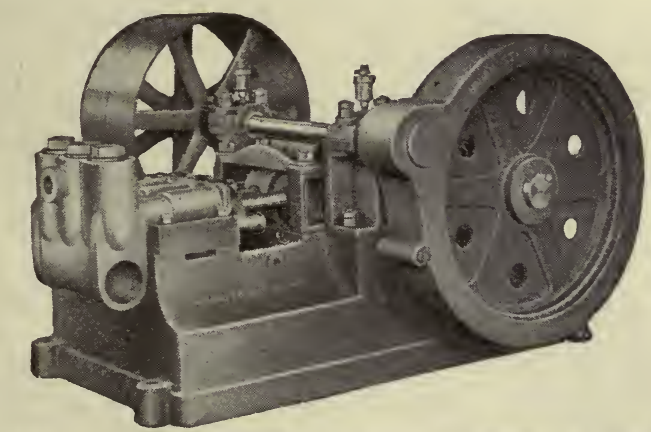

Fig. 107. High pressure pump for spraying milk Courtesy of Union Steam Pump Co.

suited for this purpose are three cylinder pumps with large, heavy valves and with extra deep stuffing boxes that can be packed with one-half inch packing rings, and special, heavily bolted glands that can be readily adjusted when the pump is running.

The triple cylinder arrangement insures a steady pressure 
and continuous flow through the spray nozzles and the deep stuffing boxes enhance the tightness of the seal. The hardening of condensed milk on the plungers is prevented by an open pot waterseal which completely merges the stuffing boxes, the water serving to both cool and lubricate the packing and to prevent its being hardened by absorbing condensed milk. While the pump is in operation a small stream of cold water is allowed to run into this water pot and to-overflow through a suitable opening.

These pressure pumps should also be provided with proper relief or overflow valves, so as to avoid the danger of excessive pressure and variation in the spray, in case several of the spray nozzles should become clogged simultaneously.

At the finish of the run of milk, a quantity of water should be pumped through these high pressure pumps and pipes and it is advisable to allow the pumps and pipes to stand full of water when they are not in use, so as to loosen and remove remnants of condensed milk, preventing their accumulation in the cylinders and avoiding difficulties incident to plugging. and clogging.

The pressure used at which the milk is forced through the spray nozzles varies from 800 to 3,500 pounds per square inch, the usual range of pressure employed fluctuates between 2,000 and 3,000 pounds. The multiple nozzles with the fine openings require less pressure to secure the same atomizing effect than when fewer or one large nozzle is used.

Hot Air Intake and Discharge.-The heated air enters the drying chamber at points varying with different types of chambers. Where the spray issues forth from nozzles located all on one side, the heated air often is admitted through a slot located directly under the spray nozzles and the air travels in the same direction as the spray and mixes with it.

In desiccating chambers in which the spray nozzles are installed on all sides, the heated air may enter near the bottom in the center of the desiccating chamber, pass up through and mixing evenly with the spray that issues from all sides toward the center. Or the heated air may enter at the top and pass downward with the spray. Or it may enter at the periphery at various points near the top, in the form of a cyclonic current moving spirally toward the center, and escaping in the center through the top of the desiccating chamber. 
The arrangement of the exit of the moisture-laden, spent air also differs with different drying chambers. In many cases, especially where the heated air and spray enter at one side, the exit of the moisture-laden air is on one side, in this case on the side opposite that of the intake. In other cases the spent air escapes at the top and in still others near the bottom of the desiccating chamber.

Hausbrand ${ }^{1}$ points out that the air always enters the desiccating room hotter than it leaves and that the spent air is usually more completely moisture-saturated than the incoming air. The density of the spent air therefore is greater than that of the air at the intake. The spent air is heavier. It has, consequently, an inclination to pass downward. Hausbrand accordingly holds, that in vertical drying rooms the direction of the currents of air should be from top to bottom, since the movement is then more uniform than when the heated air enters below and at once takes the shortest path to the upper exit, without coming in contact with all the drying material.

It is important that the drying room be protected against the entry of air from outside. The walls must be free from leaks, the peep holes or sight glasses, the doors and the shutters in the hopper at the bottom, must fit tightly.

The outgoing air, in a properly operating desiccating chamber, should have a temperature considerably lower than the incoming air. As previously stated, it usually is, and it is desirable that it should be below $200^{\circ} \mathrm{F}$., and preferably not above about $150^{\circ} \mathrm{F}$. The lowering of the temperature of the heated air in the desiccating chamber is due to the cooling effected by the rapid evaporation of the moisture from the spray of milk. This cooling effect in turn protects the milk solids against changes resulting from contact with the hot air, and assists in preserving their original solubility.

Recovery of Desiccated Milk.-Because of the extreme fineness and lightness of the milk powder made by the spray process of desiccating milk, a certain portion of the most flaky and fluffy particles escapes from the desiccating chamber with the outgoing air. As previously stated, the proportion of powder that thus escapes varies greatly with the degree of flakiness or granulation

${ }^{1}$ Hausbrand, Drying by Means of Air and Steam, 1901. 
of the product. But even in the case of quite granular powders a very appreciable portion leaves the desiccating chamber. Again, efforts have been made to prevent this escape of milk powder by extending the length of the desiccating chamber, thereby augmenting the distance between the intake and exit of the hot air. This arrangement subjects the dried particles over a longer distance to the gravity force, their opportunity to drop to and deposit on the bottom of the desiccating chamber before being caught in the outgoing air current is augmented, and the tendency for escape is diminished. In other cases, see Gray patent, the intake and discharge of the air and the direction of the particles of milk are so arranged that the moisture-laden air escapes in the center while the milk spray moves tangentially toward the periphery, thus making for minimum escape and maximum recovery of the powder.

At best, however, there is need of provisions to recover milk powder carried off in the air currents escaping from the desiccating chamber, and diverse contrivances have been designed and are in use in milk powder factories for this purpose.

These arrangements for the purpose of reclaiming or recovering the milk powder are known as "dust collectors." They are similar in principle to those used in flower mills. Some of these dust collectors now in commercial use are guaranteed to accomplish 99.9 per cent recovery of such products as corn starch, wheat flour and the like.

They chiefly consist of vaults or drums or other containers into which the suction fan, located at the air exit end of the drying chamber, discharges the outgoing air. 'These vaults are equipped with a series of canvas screens or bags on which the particles of milk powder floating in the outgoing air, are deposited, and from which by mechanical shaking or otherwise. the escaping milk powder is reclaimed and recovered.

In some factories a part of the recovery equipment consists of a so-called cyclone. This is usually a cylindrical receptacle with cone-shaped bottom. The air escaping from the drying chamber is blown into this cyclone with great force and, being thrown against its walls, drops at least a portion of the fine, dust-like milk powder it contains. 
Bolting.- The powdered milk resulting from the spray dry ing process of desiccation requires no grinding. It is very floury in its physical make up, and after sifting it is ready to be packed.

Packing of Milk Powder.-The dried milk is put on the market in packages of various types, such as fibre containers, tin cans and barrels. The sizes vary from 8 ounce packages to 200 pound barrels. Of the small size packages the 10 pound can with friction top predominates. The barrels vary some in net weight with the process of manufacture used, the granular product of the dough-drying and film-drying processes being heavier than the flaky product of the spray-drying process.

The bulk of milk powder reaches the market in barrels; these are paper lined, sinilar as sugar barrels.

Chapter XXVII.

\section{COMPOSITION AND PROPERTIES OF MILK POWDERS.}

Chemical Composition of Milk Powders.-The chemical composition of milk powders varies principally with the percentage composition of the original milk from which the powder is made, and to some extent with the process of desiccating.

The percentage composition of the fluid milk is controlled primarily by locality and season of year, as determined by breed, period of lactation and feed of the cows. For these reasons milk powders made by the same process, but in different localities and at different seasons of the year, often show very considerable variations in their percentage composition.

Effect of Atmospheric Conditions.--The atmospheric condition, especially with reference to humidity of the air, has a further, frequently quite material effect on the chemical composition of the powder from the standpoint of dryness or moisture content. Experience has amply demonstrated that when there is a high degree of humidity in the atmosphere, the resulting milk powder shows a higher per cent moisture than when made on a clear, dry day. 
Effect of Process of Manufacture.-The influence of the process of manufacture on the composition of the milk powder refers primarily to modifications of the milk prior to desiccation, although the method of desiccation itself also exerts a limited effect.

The greater the percentage of butterfat to which the original milk has been standardized or modified, the lower must necessarily be the percentage of solids not fat, and this same fact is true also of the finished powder. Hence the milk powders may vary from say one per cent of fat and possibly over 95 per cent of solids not fat in the case of skim milk powder, to over 70 per cent of fat and less than 30 per cent of solids not fat in the case of cream powder. Whole milk powders generally contain from about 26 to 29 per cent fat.

The degree of dryness, or per cent of moisture, aside from atmospheric conditions is largely governed by the process of desiccation. Generally speaking, milk powders manufactured by the spray-drying process contain less moisture than those made by the film-drying and dough-drying processes.

The spray-drying process, at its present state of perfection, makes possible the removal of all but a very small percentage of moisture. Spray powders containing as low as one per cent moisture are quite possible; in fact, the moisture content of these powders, as found in commerce, ranges from about .5 per cent to 3.5 per cent, averaging about 1.5 to 2.5 per cent.

The powders resulting from the film-drying processes generally contain from about 3 to 6 per cent moisture.

Some milk powders, especially certain brands of foreign manufacture, and particularly those of the dough-drying process, also contain added sucrose. 
Chemical Composition of Milk Powders.

\begin{tabular}{|c|c|c|c|c|c|c|}
\hline $\begin{array}{l}\text { Analyses Made or } \\
\text { Reported by }\end{array}$ & $\underset{\%}{\text { Water }}$ & \begin{tabular}{|} 
Butter- \\
fat \\
$\%$
\end{tabular} & $\begin{array}{l}\text { Protein } \\
\%\end{array}$ & $\underset{\substack{\text { Mugar } \\
\text { Milk }}}{\text {. }}$ & $\underset{\%}{\text { Ash }}$ & $\begin{array}{l}\text { Cane } \\
\text { Sugar } \\
\%\end{array}$ \\
\hline \multicolumn{7}{|l|}{ Whole milk powders: } \\
\hline mond $^{1}$ & 6.39 & 27.35 & 27.48 & 31.42 & 6.00 & \\
\hline & & & & & & 1.25 \\
\hline & & 29. & 26. & & & \\
\hline & 2 & 26. & 32.06 & 31.90 & 5.67 & \\
\hline White ${ }^{3}$ & 40 & 29. & 26.92 & 36.48 & 6.00 & \\
\hline & 4.0 & 25.0 & 24.84 & 35.75 & 620 & $3.13^{a}$ \\
\hline Ierrell-Soule Co. ${ }^{5}$ & 1.50 & 28.20 & 26.67 & 37.88 & 5.75 & $\cdots$ \\
\hline \multicolumn{7}{|l|}{$\begin{array}{l}\text { Part skim milk } \\
\text { powders: }\end{array}$} \\
\hline & 5.15 & 19.90 & 31.10 & 34.96 & 7.11 & \\
\hline & & 15. & & & & \\
\hline $\mathrm{H}$ & 30 & 13. & & & 7.28 & \\
\hline White ${ }^{3}$. & 5.00 & 15.1 & & 39. & 6.5 & \\
\hline & 5.46 & 21. & 25. & 40.93 & 5.7 & $1.16^{6}$ \\
\hline & & 17 & & 40. & & 5.08 \\
\hline & & 15 & & 40. & 6.06 & $1.46^{\mathrm{a}}$ \\
\hline [errell-Soule Co. ${ }^{5}$. & 2.12 & 14.20 & 32.26 & 44.41 & 7.01 & \\
\hline \multicolumn{7}{|l|}{ Skim milk powders: } \\
\hline Richmond $^{1} \ldots \ldots$ & 3.5 & 2.55 & & & 7.89 & 2.80 \\
\hline & 7.40 & 1.00 & & & 8. & \\
\hline & 7.0 & 1. & & 47 & 8.0 & \\
\hline Ota & 7.1 & $1.3^{3}+x+a+n$ & & & 8.03 & \\
\hline & & & & & & \\
\hline $\mathrm{r} \mathrm{B}$ & 3.3 & .1 .2 & & & 7.87 & \\
\hline Bros. Co. ${ }^{6}$. & & 1.15 & & & 8.03 & \\
\hline nier Bros. Co. ${ }^{6}$. & 1.0 & 1.97 & 34.75 & 51.92 & 8.24 & \\
\hline & & & & & & \\
\hline & .00 & & & & & \\
\hline Merrell-Soule Co. ${ }^{5}$ & .56 & 71.15 & 11.12 & 14.74 & 2.43 & \\
\hline
\end{tabular}

${ }^{1}$ Richmond, Dairy Chemistry, 1914.

${ }^{2}$ C. Huyge. La Poudre du lait, Revue générale du lait. V ol 3, No. 14, 1904. Also Leach Food Analyses.

s Larsen \& White. Dairy Technology, 1913.

- Otakar Laxa. Berichte der laktologischen Anstalt der k. k. böhmischen technischen Hochschule in Prag, Vol. VIII., 1917.

5 Merrell-Soule Co. Descriptive Bulletin Concerning Merrell-Soule Powdered Milk, 1918; also Stocking, Manual of Milk Products, 1919.

- Mojonnier Bros. Co. Analysis by request of author, 1919.

a Hydrocarbons in ash. 
Solubility of Milk Powders. If milk powders are to take the place of fresh milk or condensed milk on the table of the consumer, and for most of the industrial uses to which they are being put, they must be readily soluble. One of the greatest obstacles in the progress of the milk powder industry has been that the dried milk of most of the processes failed to be readily and completely soluble. Earlier processes prescribed the admixture to the milk of alkalies in order to preserve the solubility of the proteids, which otherwise were rendered insoluble by the high heat of the respective processes. It is obvious that a dried milk, the solubility of 'which can be retained only by the admixture of alkalies, is a poor substitute for milk, and the very principle of adding chemicals to a food product like milk, is contrary to our ideal of successful manufacture of high quality of product.

The term "Solubility" is here used in the broader sense of the word. Milk is not a true solution. It is part solution and part emulsion. "Solubility" here implies a powder, in which those constituents which are in complete solution in normal fluid milk, have retained their original solubility, such as the sugar of milk, and in which those constituents which are present in normal fluid milk in the form of an emulsion, as is the case with the casein, fat and part of the ash, have retained their original emulsifying power. In short, the term "solubility," as used in this discussion, means those attributes of the milk powder that enable the powder, when mixed with water, to again form a solution and emulsion of a character, physically and mechanically, similar to that of normal fluid milk.

The solubility of milk powders varies principally with the quality of the fluid milk and with the process of manufacture.

By quality of milk, as here referred to, is meant chiefly the acidity. The combination of the heat of desiccation and of high acidity, tends to rob the protein and ash constituents of the resulting powder of their natural solubility. The higher the degree of acid in the fluid milk, the lower "will be the solubility of the powder. The fresher and sweeter the milk at the time of desiccation, the more soluble will be the powder, other factors being the same.

For this reason many milk powder factories are endeavoring 
to receive their fluid milk twice daily, and some are using alkaline neutralizers in order to reduce the acidity of the milk before desiccation.

One fundamental reason why even slight increases in acidity do very markedly reduce the solubility of the finished powder, lies in the fact that the high degree of concentration necessarily multiplies the percentage of acid, and with it the solubility-destroying effect of the heat of desiccation.

The process of manufacture controls the solubility of the milk powder chiefly by the degree of heat to which the milk is exposed and by the manner in which the heat is applied.

In the film process of drying, for instance, the milk is exposed to the heated cylinder charged with steam under pressure, and consequently it is subjected to temperatures far exceeding that of the boiling point of water. This high heat does materially reduce the solubility of the resulting powder, though this unfavorable effect may be minimized to some extent by having the cylinders operate in a vacuum chamber under reduced pressure.

In the case of the spray-drying process, the milk is not exposed to a steam-heated metal surface. The fact that the air entering the spray-drying chamber may have, and usually does have, a temperature of from 275 degrees $F$. to over 300 degrees $F$., appears to not materially affect the solubility of the resulting powder.

In the spray-drying process the evaporation of the moisture in the atomized spray is so rapid that it brings about a marked cooling effect, and it is believed that the milk solids are kept in a relatively cool condition until they have surrendered substantially all of their moisture.

This protection of the milk against the solubility-destroying action of heat appears to be especially insured by the process of the Gray patent, in which the coolest strata of the heated air only come in contact with the incoming moisture-laden milk, and by the time the milk particles enter the zone of the hot incoming air they have surrendered the bulk of their moisture.

That a marked cooling effect does take place in the drying chamber is further borne out by the fact that the moisture-laden air escaping from the drying chamber has a temperature very much lower than the entering air. The outgoing air of a properly operated 
spray-drying chamber usually has a temperature of from 150 to about 180 degrees $\mathrm{F}$.

In the spray-drying process it is customary to heat the fluid milk or the condensed milk to not to exceed 150 degrees $F$., and it appears that when this is done the milk solids are not exposed to temperatures materially higher than 150 degrees $F$. until they have given off their moisture; in fact, it is possible that at least during the early stages of desiccation they are actually cooled by their rapid surrender of moisture.

Experimental study has demonstrated that, when a certain degree of concentration has been exceeded, exposure to high heat destroys the solubility of the protein constituents of the milk. This is a matter of common knowledge to the operator of the sterilizer in the manufacture of evaporated milk. In the spray-drying process the change from high concentration of the milk in the liquid state, to complete dryness, is so instantaneous that no damage is done and when once dry, exposure to heat does no further harm.

The solubility of the powder resulting from the spray-drying process may be materially reduced, however, if the fluid milk. prior to desiccation, is heated to temperatures considerably in excess of 150 degrees $F$.

The powders of the properly operated spray-drying process are practically completely soluble in cold water. The powders of the film-drying process require hot water for their solution and even in hot water they fall short slightly, but unmistakably, of complete solution.

The relative solubility of spray- and film-dried powders is shown in the following table: 
Solubility of Milk Powders of Film-Drying Process, and of Spray-Drying Process.

\begin{tabular}{|c|c|c|c|c|}
\hline \multirow[b]{2}{*}{ Process of Desiccation } & \multicolumn{2}{|c|}{$\begin{array}{c}\text { In Cold Water } \\
78.5^{\circ} \mathrm{F} .\end{array}$} & \multicolumn{2}{|c|}{$\begin{array}{c}\text { In Hot Water } \\
210^{\circ} \mathrm{F} \text {. }\end{array}$} \\
\hline & $\begin{array}{c}\text { Per Cent } \\
\text { in } \\
\text { Solution }\end{array}$ & $\begin{array}{c}\text { Per Cent } \\
\text { of } \\
\text { Powder } \\
\text { Dissolved }\end{array}$ & $\begin{array}{c}\text { Per Cent } \\
\text { in } \\
\text { Solution }\end{array}$ & $\begin{array}{c}\text { Per Cent } \\
\text { of } \\
\text { Powder } \\
\text { Dissolved }\end{array}$ \\
\hline & \multicolumn{4}{|c|}{ Total Solids } \\
\hline 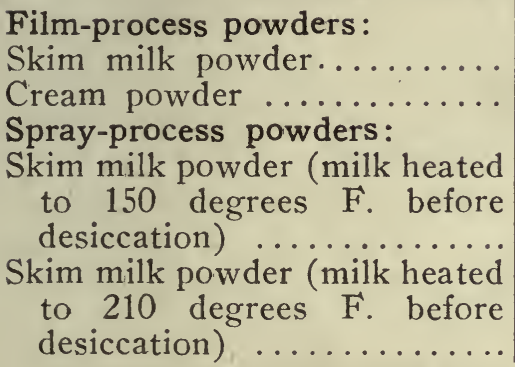 & $\begin{array}{l}3.94 \\
3.46\end{array}$ & $\begin{array}{l}69.61 \\
61.13\end{array}$ & $\begin{array}{l}4.42 \\
4.53\end{array}$ & $\begin{array}{l}78.09 \\
80.03\end{array}$ \\
\hline
\end{tabular}

Protein

Film-process powders:

Skim milk powder ..........

Cream powder ..............

Spray-process powders:

Skim milk powder (milk heated to 150 degrees $\mathrm{F}$. before desiccation $) \ldots \ldots \ldots \ldots . . . .$. Skim milk powder (milk heated to 210 degrees $F$. before desiccation) (n)

The solubility tests, the results of which are recorded in the foregoing table, were made as follows:

Two samples of film-process powders and two samples of sprayprocess powders were used. Twelve grams of each powder was added to $200 \mathrm{cc}$. of water at a temperature of 78.5 degrees $\mathrm{F}$. The four samples were placed into a mechanical shaker and shaken for ten minutes.

After shaking, $100 \mathrm{cc}$. of each lot was poured through a paper filter and the filtrate analyzed for percentage of total solids.

The remaining $100 \mathrm{cc}$. of each lot was heated to the boiling 
point and held there for five minutes. The water lost by evaporation was replaced. The hot solutions were then filtered and analyzed for total solids.

The results of the above tests show that the spray-process powder when made from milk that was not heated above 150 degrees $\mathrm{F}$. before desiccation, had the power of returning into an emulsion in cold water that would filter in a similar manner and would pass through the filter with a similar degree of completeness as ordinary milk. The powder was substantially completely soluble.

When made from milk that had been heated to the boiling point, the spray-process powder lost slightly over 10 per cent of its solubility. About one-half of this loss was recovered upon heating the water and powder mixture to the boiling point.

The film-process powder in cold water went into a filterable emulsion to the extent of from 60 to 70 per cent of the powder added, and in hot water to the extent of from 78 to 80 per cent of the powder added.

The very marked difference in solubility of the powders from the two processes could be readily observed also without chemical analysis. When the solutions of the film-process powders were allowed to remain at rest in test tubes there would always gather a very considerable deposit of solid matter in the bottom. This was the case in both hot and cold water, but the deposit was very considerably more voluminous in the cold mixture than in the hot mixture.

In the case of the spray-process powders no such deposit of solid matter could be detected, neither in the hot nor in the cold mixtures.

It is further interesting to note that the percentage of protein found in the filtrates from all the powders with the exception of the hot solution from the film-process cream powder, followed very closely the percentage of total solids in the same filtrates. This suggests very obviously that the degree to which the solubility, or better the power of the milk powder to return to the character of the original milk, is impaired by the process of desiccation, is largely controlled by and depends on the extent to which the process of desiccation changes the physical properties of the protein of milk.

Miscibility and Readiness of Solution of Milk Powders.The rapidity and readiness with which milk powders go into so- 
called solution is a factor which does not always depend on their actual solubility.

Other conditions being the same, it is obvious that the finer the particles of the powder the more rapidly will it dissolve. This fact is based on the well-known physical law that the smaller a body the larger is its surface in proportion to its cubic contents. The surfaces of two spheres are to each other as the squares of their diameters and the cubic contents of two spheres are to each other as the cubes of their diameters. This is clearly demonstrated in the following example:

One sphere has a diameter of 2 inches and the other sphere has a diameter of 4 inches. The surfaces and the cubic contents of these spheres are as follows:

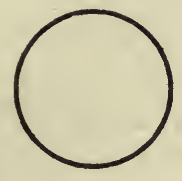

Fig. 108.

Sphere with

2 -inch dia.

Surfaces $=2 \times 2=4$

Cubic contents $=2 \times 2 \times 2=8$

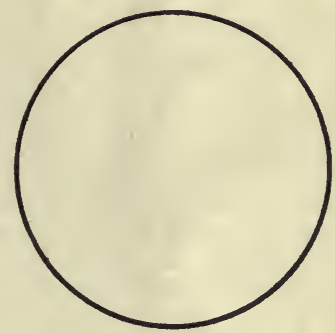

Sphere with 4 -inch dia.

$4 \times 4=16$

$4 \times 4 \times 4=64$

The surface of the sphere with the 4 -inch diameter is four times as large as the surface of the sphere with the 2-inch diameter. But the cubic content of the sphere with the 4-inch diameter is eight times as great as the cubic content of the sphere with the 2 -inch diameter.

And again, the cube and circular shape of a body has a smaller surface than the oblong and flake shape body.

The greater the area or surface of a body with a given cubic content, the more surface is exposed to the solvent and the more rapidly will it dissolve. Therefore, the finer and more flaky the particles of milk powder, the more readily and more rapidly will they dissolve.

The spray-process powders usually are finer and more flaky 
than the film-process powders, hence the former should go in solution more rapidly than the latter.

The above facts concerning the relation of fineness and flakiness of milk powder to ease and speed of solution prevail to a certain point. When that point is exceeded mechanical handicaps enter into the results that tend to retard solution, at least in the beginning. In the case of excessively fine and flaky milk powders, the exposed surfaces are so great and the particles so small that when the powder is placed into water, the rapid solution of the powder that comes into immediate contact with the water causes the powder to run together and paste, forming a pasty coating around the remainder of the powder. This coating hinders and retards the penetration of the powder by the water and thereby renders complete solution slower, at least at the start.

This difficulty is generally not experienced with the film-process powders, which are of a granular nature. It can be largely avoided in the case of the spray-process powders by so adjusting the orifice of the spray nozzles and the pressure of the milk, as to increase the coarseness of the spray. The coarser the spray the less flaky, and the more granular the powder. High pressure and small orifice in spray nozzles produce a very fine spray and a flaky powder. Low pressure and large orifice in spray nozzles produce a less fine spray and a more granular powder.

The concentration of the milk at the time of spraying also influences the coarseness or fineness of the spray to a considerable extent. Other conditions being the same, the higher the concentration of the milk at the time of spraying the coarser the spray and the less flaky and the more granular the resulting milk powder. When the milk is sprayed before previously condensing it, a finer and flakier powder is produced than when the milk is first condensed at the ratio of about $4: 1$, and the condensed milk is sprayed, always assuming, however, that other conditions, such as orifice of spray nozzle and pressure of milk be the same. It is possible, even by spraying the fluid, uncondensed milk, to produce a powder that is distinctly granular, by the proper adjustment of the above factors.

The miscibility of the dried milk with water depends, aside from its solubility, readiness of solution and character of the protein, on the physical condition of its butter fat. If the process employed is such as to destroy the globular form of the fat globules, it is 
impossible to reduce the dried milk to a homogeneous fluid, similar to normal fresh milk. The fat in such milk will rise to the surface quickly, similar to the fat in a mixture of oil and water.

\section{Keeping Quality of Milk Powders.}

Moisture Content.-One of the fundamental reasons for which milk is reduced to a dry powder lies in the efforts of the manufacturer to preserve it.

Bacteria and other micro-organisms require moisture to grow, thrive and accomplish their work of decomposing the substances in which and on which they live. In the absence of moisture bacterial action ceases.

In properly desiccated milk powders, such as are now manufactured and placed upon the market, the percentage of moisture has been reduced to a point that precludes the possibility of bacterial decomposition. If these desiccated milk powders are packed and stored in such a manner as to protect them against dampness, they may reasonably be expected to keep indefinitely insofar as their keeping quality depends on freedom from bacterial action. Milk powders with excessive moisture content and milk powders that are exposed to dampness, on the other hand, are prone to become lumpy, moldy and to develop diverse undesirable flavors.

Air, Light and Heat; Relation to Stale Flavor, Tallowy and Rancid Flavor.- In spite of the fact that the low moisture content renders milk powders practically immune to bacterial action, they are subject to deterioration with age when certain other conditions, such as air, light and heat are favorable, or when metals and metallic salts are present, or both, and experience has amply demonstrated that practically all milk powders made from the usual quality of milk under the present methods of manufacture and packing, and usual conditions incident to storage, develop a disagreeable stale flavor, which often degenerates into a tallowy or socalled rancid flavor with age.

Exact data showing the fundamental changes which these powders undergo are not available, but the findings of Rogers, Hunziker and others, ${ }^{1}$ as the result of extensive experimental studies of the keeping quality of butter strongly suggest, that these changes are of chemical rather than of biological nature and that oxidation of

${ }^{1}$ Hunziker. The Butter Industry, 1920. 
one or more of the constituents of these products plays an important role. Success in the manufacture of milk powders of superior keeping quality, therefore, demands also the protection of the product against agencies that invite oxidation. ${ }^{1}$

Exclusion of Air.-The oxidizing power of air is well known. Milk powder exposed to atmospheric air will not keep. It soon develops a stale flavor, and if it contains a considerable percentage of butterfat it becomes tallowy.

For this reason milk powder should be, and usually is, packed in such a manner as to exclude the outside air as much as possible. The powder packed in bulk is sealed in barrels lined with heavy paper. Smaller packages consist of tin cans, or fibre cans with tin ends and friction caps.

Unfortunately the body of the milk powder itself is not entirely free from air, so that unless packed under vacuum there always is some air in the package. While protection against free exposure to outside air, by proper packing, greatly minimizes the deteriorating action, and does distinctly enhance the keeping quality of the powder, the air present in the sealed package is sufficient to cause slow deterioration when other conditions, such as heat or metallic salts, or both, are present. The packing of milk powder in vacuo would undoubtedly assist in preserving the milk powder.

Exclusion of Light.-The rays of light intensify the oxidizing action of the air. It is, therefore, important that milk powder be kept in the dark. This is automatically accomplished by sealing it in the usual commercial packages. If the powder must be held in the factory for a considerable number of hours before packing, it should be kept in covered containers. Remnant barrels, or other broken packages in the home or in industrial establishments using milk powder should be kept tightly covered.

Effect of Heat.-Heat, similar as light, intensifies the oxidizing action of air and of other oxidizers and catalizers. Milk powder kept at relatively high temperatures becomes stale and develops other defects quicker than milk powder kept in the cold.

Metals and Metallic Salts.-Certain metals and their alloys

1 The sensitiveness of most of the spray process milk powders toward oxidizing agents is augmented by the fact the atomizing process under high pressure causes a subdivision of the fat globules, depriving the fat of at least a portion of the protective gelatinous layer which surrounds each original fat globule, thereby exposing the fat more directly to the destructive oxidizing agents. 
and salts are most active oxidizers. This is especially the case of copper and its alloys, such as brass and German silver; also the salts of copper. Iron, while not inert from the standpoint of oxidation, is much less active and its salts exert but a slight oxidizing action. Tin and nickel have no oxidizing action.

On the basis of these facts it is not improbable, that the holding, heating and condensing of milk in copper containers, and the use of copper drums in film-drying and of brass nozzles in spray-drying, are factors contributory to the deterioration of the resulting milk powders.

Continuous, or flash heaters through which the milk passes rapidly and to the metal surfaces of which it is exposed for a very short time only, are a negligible factor in this respect. Even if these surfaces are of untinned copper, there is but very remote danger of damage to the product.

But not so with containers in which the milk is held for hours, or in which it is condensed prior to desiccation. Here the time and conditions of exposure are sufficient to invite chemical action of the acid and lactose of the milk on the copper surface of the container. If the holding tanks are of copper. they should be heavily tinned; or in their place glass enameled tanks should be used.

The copper vacuum pan is another menace to keeping quality. Salts of copper are especially likely to form on the inner surface of the dome which is exposed to the spray and to the volatile acids of the boiling milk. After each day's work the dome, as well as all the other parts of the interior of the pan, should be scrupulously cleaned to prevent any accumulation of copper salts, which would otherwise become a part of the next batch and of the milk powder made therefrom.

In the manufacture of whole milk powder, particularly, due to the action of the copper of the vacuum pan on the butterfat, the tendency to cause damage to the finished product; is great. It is advisable to skim the whole milk, condense the skim milk only and add the cream after condensing, in order to minimize this danger.

Sandblasted iron pipes are preferable to so called sanitary pipes, unless the inside copper surface of the sanitary pipes is properly tinned and the tin coating is reasonably permanent. 
To what extent the brass nozzles jeopardize the keeping quality of the powider is difficult to say. But it is well known that they suffer considerable wear as the result of the spraying, and this means that the atomized spray carries off particles of brass which later become a part of the finished powder.

The metal drums used in the film-drying process are generally constructed of metal other than copper. Many are of highly polished steel and some are nickel plated. The desiccating equipment used in this process is therefore not exposing the product to copper and copper salts, thereby largely avoiding the possibility of injuring the keeping quality of the resulting milk powder through this channel.

Insects in Milk Powder.-Milk powder may, and «1nder certain conditions does, become infested with insect life, such as maggots, weevil, etc. This infection may take place in the factory itself, but more often it is the result of contamination after it leaves the factory.

Such contamination is generally due to a faulty package. Whenever the seal is broken the danger of insect invasion is very great. Manufacturers have found also that packages sent to the tropics are especially prone to succumb to this nuisance, the prevention of which necessitated the packing of the powder destined for the tropics, in hermetically sealed cans.

Lumpy Milk Powder.-As previously stated, milk powder exposed to dampness invariably becomes lumpy, and even when exposed to atmospheric air of normal humidity it will gradually form lunips, owing to the highly hygroscopic properties of the milk powder. In order to prerent lumpiness, the powder must be stored in a dry place and packed in a manner to protect it against direct contact with atmospheric air.

At best milk powder has an inherent tendency to "lump up." This is especially true of flaky powders. The more granular powters yield less readily to this defect.

In order to minimize the tendency toward lumpiness, the milk powder should be allowed to cool, after desiccation and before sifting and packing. If sifted and packed while still warm, the soft condition of the fat causes the particles to lump together after sifting. If sifted and packed after the milk powder has surrendered its heat, the fat has had an opportunity to 
solidify and harden and after sifting the particles remain separate and granular and do not so readily stick together in the form of lumps.

\section{COST OF MANUFACTURE.}

The approximate cost of manufacture of whole milk powder and skim milk powder is, indicated below:

\section{Cost of Whole Milk Powder.}

100 lbs. whole milk . . . . . . . . . . . . . . . \$3.350

Barrels and liners per 100 lbs. milk.......... .100

Labor per 100 lbs. milk.................... . . . . . .

Futel (condensing and drying) per $100 \mathrm{lbs}$. milk. . .089 Overhead per 100 lbs. milk............... .074 Interest, insurance, etc., per $100 \mathrm{lbs}$. milk...... .050

Total cost per 100 lbs. milk............ \$3.856

Total cost per pound of whole milk powder, calculated on basis of 12.5 pounds of powder made from 100 pounds of whole milk, when price of whole milk is $\$ 3.35 \ldots \ldots \ldots \ldots \ldots 0.3085$

\section{Cost of Skim Milk Powder.}

100 lbs. skim milk....................\$1.13

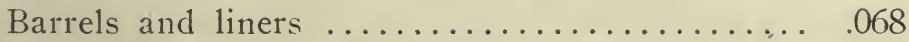

Fuel (condensing and drying) per 100 lbs. skim milk ............................ . . . . . .

Labor per 100 lbs. skim milk.............. . . . . .

Overhead per 100 lbs. skim milk........... . .074 Interest, insurance, etc., per 100 lbs. skim milk. . .040

Total cost per 100 lbs. skim milk........\$1.594

Total cost per pound of skim milk powder, calculated on basis of 8.5 pounds powder made from 100 pounds skim milk, when price of skim milk is $\$ 1.13$ .$\$ 0.1875$

\section{MARKETS.}

The uses of milk powder are very diversified.' Whole milk powder is widely advertised for infant food and for general family 
use. Considerable quantities are used by market milk dealers for "reconstituting" milk for market milk purposes, especially at times of shortage of the fluid milk supply. Large quantities of whole milk powder are absorbed also by chocolate factories in the manufacture of milk chocolate, the butterfat being one of the essential components on which the milk chocolate depends for its superior smoothness and flavor.

Skim milk powder is used in the consumer's kitchen, in bakeries and confectioners' establishments, in the manufacture of ice cream, fermented milk beverages, and starters used for cream ripening where milk and skim milk are not available; in the preparation of baking powders, of pure cultures of lactic acid bacteria, of drugs, choice toilet soaps, etc. In European countries the chocolate factories purchase vast quantities of skim milk powder in the manufacture of milk chocolate and allied products, and manufacturers of diverse prepared food products, such as cereals, soups, noodles, and vegetables, furnish additional markets for this valuable dairy product.

\section{Chapter XXVIII.}

\section{DRIED BUTTERMILK AND DRIED WHEY.}

These by-products of the creamery and cheese factory can be reduced to a powder in a similar way and by the same processes and machinery as are used in the manufacture of dried milk and dried skim milk.

Dried buttermilk makes a splendid chicken feed, both for egg production and for fattening chickens, and it is used also to make up a part of the ration for feeding hogs and young stock. It is best diluted to about the original buttermilk (one part powder in ten parts water) and mixed with the grain feed into a mush.

Like fresh buttermilk, so is dried buttermilk a wholesome, nutritious and easily digested food and recommends itself especially to persons with weak digestion. When properly made, buttermilk powder keeps indefinitely and may, therefore, be available for immediate use at all times.

The following analyses show the composition of buttermilk powder and of the fresh buttermilk from which it was made: 


\section{Composition of Buttermilk Powder.}

Fresh buttermilk

Butterfat

Proteids

Lactose

Ash

Acidity

Water

Total
1.17 per cent

3.00 per cent

2.97 per cent

.85 per cent

.60 per cent

91.63 per cent

100.22 per cent
Buttermilk powder

11.70 per cent

36.24 per cent

35.50 per cent

8.25 per cent

6.00 per cent

4.32 per cent

1 The buttermilk of which the composition is shown in the above table was made at the plant of the Buffalo Foundry and Machine Company, Buffalo, N. Y., under the supervision of the writer. The machine used was of the Buflovak type. The buttermilk was furnished by Schlosser Bros., of Frankfort, Indiana. This batch of buttermilk happened to be abnormally high in butterfat; therefore the large butterfat content of the finished product. About thirty pothds of steam pressure were used in the drying drum, the temperature in the vacuum chamber was 125 degrees $F$. and the vacuum twenty-five to twenty-six inches of the mercury column.

This buttermilk powder had a nice, clean, acid taste, it was much relished by all who sampled it and, when fed to chickens for fattening, produced satisfactory gains in weight.

The annual production of buttermilk in the United States was 4,341,157 pounds in 1918 and 5,278,827 pounds in 1919 .

The chief obstacle to extensive production of buttermilk powder lies in the fact that the manufacturing cost involved in reducing buttermilk to dryness is very high in proportion to the market value of the finished product, when used for hog and chicken feeding.

Buttermilk powder can be manufactured by any of the processes described under the manufacture of milk powder. However the spray process is not as well suited for the desiccation of buttermilk as is the film, or roller process.

In the spray process there is a considerable tendency for the milk to clog the spray nozzles. Again, the cost of manufacture by the spray process is greater than that by the film process. As stated under the manufacture of milk powder, heat in the form of

${ }^{1}$ Hunziker, Indiana Agricultural Experiment Station, Twenty-sixth Annual Report, 1913. 
heated air, is not as economically and as efficiently utilized as heat in the form of steam applied in steamed-heated metal drums.

While, as previously shown, the spray-drying process is the only process of desiccating milk, that preserves the original solubility of the milk, this advantage is lost in the case of buttermilk. The acid in the buttermilk has changed the casein from its fine emulsion, such as it represents in normal milk, to a condition which renders the particles of casein, or curd, incapable of permanently remulsifying. The curd in commercial buttermilk does not stay in emulsion, but settles to the bottom. Hence nothing is gained by drying the buttermilk by the more expensive process of spray-drying. The film process, which is the more economical, is therefore better adapted for the manufacture of buttermilk powder than the spraydrying process.

It is advisable to precondense the buttermilk, before desiccating, at the ratio of about $2: 1$.

One gallon of buttermilk yields about .72 pounds of buttermilk powder, or the manufacture of one pound of powder requires about 1.39 gallons of buttermilk. The cost of manufacture is estimated at about 2 cents per pound of buttermilk powder or about 1.44 cents per gallon of buttermilk.

Whey powder is nianufactured in a similar manner. Its chief value lies in its usefulness in the diet of infants and invalids, with whom the consumption of casein produces digestive disturbances. Since fresh whey is often not obtainable, the whey powder, the good keeping quality of which permits of keeping it on hand, furnishes an admirable substitute. When made from sour whey, it offers many advantages in cooking and baking and should be especially well suited for such dishes as pan cakes, etc.

\section{MALTED MILK. ${ }^{\text {I }}$}

Definition.-The product known as malted milk is that resulting from the combination of whole milk with the extract of malted barley and wheat flour, and the mixture is reduced to a dry form by desiccation in vacuo.

History of Malted Milk Industry.-The process of the manufacture of malted milk was invented by Mr. William Horlick, of

1 Information on Definition, History and Process of Manufacture, received through the courtesy of Horlick's Malted Milk Co., Racine, Wis., March 8, 1918 . 
Racine, Wis., in the year of 1883 . The product was first placed on the market under the name of "Malted Milk," given it by its inventor, in 1887.

Prior to the advent of Horlick's malted milk Mr. Horlick was making "Horlick's Food.". It was through suggestions of members of the medical profession, who complained that it was almost impossible to obtain first class, pure, clean, wholesome, whole milk, that Mr. Horlick took up the idea of malted milk. In consultation with Dr. R. C. Hindley, then Professor of Chemistry at the Racine College, who later became Chief Chemist and Superintendent for Mr. Horlick, the manufacture of malted milk was subjected to considerable experimenting by its inventor before the product reached the market in its perfected form.

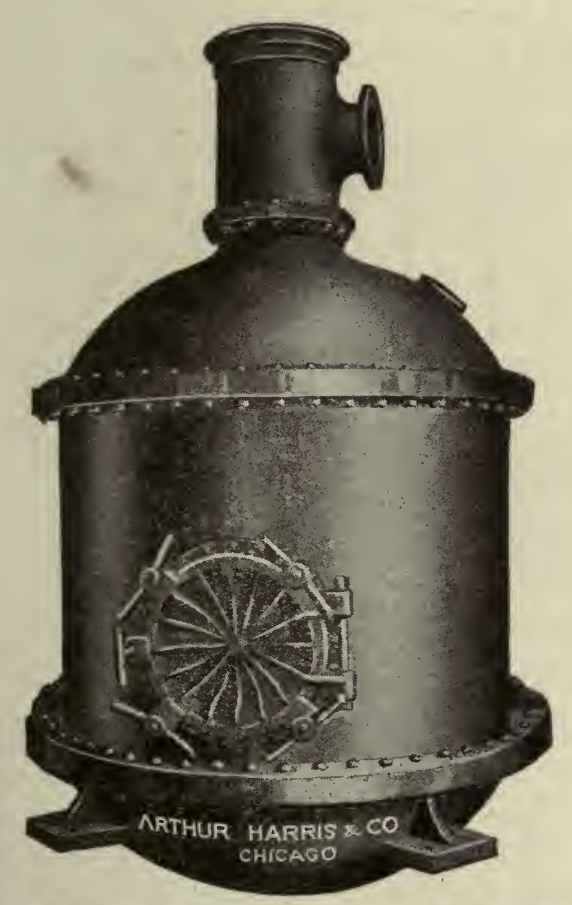

Fig. 109. Vacuum pan for malted milk

Courtesy of Arthur Harris \& Co.

The convenience, nutritive value and digestibility of this product recommended themselves to and were appreciated by the medical profession, and its relishing properties appealed to the public. The industry grew rapidly and is today assuming large proportions.

\section{Manufacture of Malted} Milk.-A mash is prepared by mixing wheat flour with barley malt of good diastatic quality. This mash is raised to the proper temperature for a sufficient length of time to insure the complete conversion of the insoluble starch into the soluble malt sugàrs dextrin and maltose. This conversion is closely akin to starch digestion in the human system, hence the resulting liquid is essentially a predigested product, claimed to be of much value as a special food for infants and invalids. 
This extract is combined with whole milk and reduced to a dry powder in a vacuium at such a low temperature as will thoroughly pasteurize the malted milk and yet preserve its digestibility.

Keeping Quality of Malted Milk.--Malted milk is the only milk powder made from whole milk that will keep indefinitely in any climate. Those who have subjected the manufacture of malted milk to most intensive study hold, that the keeping quality of malted milk is due to the fact that the fat globules are very finely divided and are surrounded by a coating or envelope of gluten, sugars and salts, which protects the fat against the deteriorating action of the air.

In dried whole milk the volume of fat is too great and the proportion of other solids too limited, to cause the fat globules to be properly coated, the air therefore has more or less access to the fat, causing such changes as are prone to lead to the development of a tallowy flavor and rancidity.

The use of wheat flour, while originally a survival of "The Horlick's Food," from which malted milk was developed, may also be responsible, in part at least, for the keeping quality of malted milk. Its large amount of gluten may assist in yielding an effective coating for the protection of the fat globules. Experiments made with flour of other cereals gave results that did not warrant their use in the place of wheat flour.

Again, it has been experimentally found that malted milks made by mere mechanical mixing of the required ingredients, also become stale and rancid rapidly, and that the only product that has permanent keeping quality is that in the manufacture of which scientific use is made of the action of enzymes and other ferments, etc.

Uses of Malted Milk.-Malted milk is a food of acknowledged high degree of food value and of superior digestibility. Being a whole milk food, it also contains the indispensable growth-promoting and curative properties contained in whole milk.

It is placed on the market both in powder and in tablet form. Its high digestibility, nutritive value and health-protective properties render it most valuable as a wholesome food for infants and invalids, and its compactness and keeping quality facilitate its transportation to and use in all parts of the globe. Malted milk, therefore, is of special merit for use in countries and territories which are 
barred by their geographical location and climate from the profitable husbandry of the dairy cow, and where the limitations of transportation render the availability of fluid milk difficult or impossible.

The annual output of maited milk in the United States was 15,654,243 pounds in 1918, and 17,495,887 pounds in 1919.

Federal Standards for Milk Powder, Skim Milk Powder and Malted Milk. ${ }^{1}$ - The following standards of dried milk products were adopted by the United States Department of Agriculture March 16, 1917, and became effective March 31, 1917, as per Food Inspection Decision 170:

"DRIED MILK is the product resulting from the removal of water from milk, and contains, all tolerances being allowed for, not less than twenty-six per cent $(26 \%)$ of milk fat, and not more than five per cent $(5 \%)$ of moisture.

DRIED SKIMMED MILK is the product resulting from the removal of water from skimmed milk and contains, all tolerances being allowed for, not more than five per cent $(5 \%)$ of moisture.

MALTED MILK is the product made by combining whole milk with the liquid separated from a mash of ground barley malt and wheat flour, with or without the addition of sodium chlorid, sodium bicarbonate and potassium bicarbonate in such a manner as to secure the full enzymic action of the malt extract, and by removing water. The resulting product contains not less than seven and one-half per cent $(7.5 \%)$ of butter fat and not more than three and one-half per cent $(3.5 \%)$ of moisture."

Dick Process. ${ }^{2}-$ S. M. Dick invented and patented a spraydrying apparatus for milk, U. S. patent No. 1,298,470, 1919, similar to the McLachlan patent No. 806,747 . In the Dick dryer the milk enters by gravity and is sprayed and distributed by a revolving disc arrangement. Part of the heated air enters at the top and part at the bottom of the desiccating chamber.. The air entering at the bottom is hotter than that entering at the top.

1 United States Department of Agriculture, Food Inspection Decision 170, March 31, 1917.

2 This process came to the author's attention too late for detailed diseussion in this volume. 


\title{
PART VII.
}

\section{STANDARDIZATION, TESTS AND ANALYSES OF MILK, CONDENSED MILK AND MILK POWDER}

\author{
ChAPTER XXIX.
}

\section{STANDARDIZATION.}

Prior to the enactment of the Federal Food and Drugs Act, which became effective January 1, 1907, the milk condensing factories made no special effort to place on the market a product of any definite and specific composition. The milk was condensed, either as whole milk, no matter what the original composition of the fluid milk was, without modification, or it was partly skimmed or wholly skimmed, before condensing. If any effort towards modification of the composition was made, such effort was practically wholly confined to the regulation of the fat content of the finished product and even in such cases wide fluctuations were quite frequent.

With the enforcement of the Federal Food and Drugs Act, the milk condenseries found themselves called upon to manufacture a product that would comply with the Federal standards established and which prescribed the minimum per cent of fat and milk solids permissible in condensed milk.

It became necessary therefore to guard against the production of condensed milk, the per cent fat and milk solids of which fell below the specified standard. And later, with the rapid development of the condensed milk industry, competition gradually compelled the individual concerns to not only avoid the manufacture of an illegal product by causing its valuable components to fall short of the percentage required by the standard, but to so modify the composition as to not have the finished product materially exceed the required standard, in order to keep down the cost of manufacture. Furthermore, in the case of bulk condensed milk, which goes to confectioners and 
ice cream manufacturers, the buyer often specifies in his order the desired composition of the product, necessitating standardization to meet these special demands.

These factors and conditions inevitably led to the adoption of the practice of carefully standardizing condensed milk for fat and milk solids. The details of methods used for standardizing vary considerably with different manufacturers. The principle upon which standardization is based, however, is obviously very much the same under all conditions, and variations in details affect the results largely only with reference to the degree of accuracy.

Some manufacturers standardize the fluid milk before condensing, others prefer to standardize after evaporation only, while still others standardize both, the fluid milk and then again the finished product just prior to canning. Each of the three methods is practical and the double method of standardizing before and after condensation is obviously the most exact. In the case of sweetened condensed milk standardization before condensation is preferable inasmuch as the admixture to the finished product of water, skim milk or cream is not advisable from the standpoint of keeping quality, unless these products have been previously properly pasteurized. In the case of evaporated milk, which is much thinner, more miscible and which is subsequently sterilized, these objections are largely removed.

The materials generally used for standardizing are skim milk, condensed skim milk, cream, butter and water. Water is used only to lower the per cent total solids, or the degree of concentration, and is of service only after condensation of the milk.

The calculations employed for standardization are identical for all forms of condensed milk and milk powder, both sweetened and unsweetened. The addition of cane sugar to the fluid milk does not alter the ratio of fat to milk solids, since the added sugar merely displaces a portion of the water in the finished product.

The per cent total solids in the condensed milk is controlled primarily by the degree of concentration as determined by the Beaumé hydrometer or by gravimetric analysis and it may be 
further modified by the addition of water to the finished product in case condensation has passed beyond the desired point.

Aside from this, the fundamental effort of standardization is confined to securing the desired proportion of butter fat to milk solids not fat. When this is accomplished all that is necessary to insure the required composition is to subject the product to the necessary degree of concentration.

Standardizing the Fluid Milk.-In order to properly standardize the fluid milk it is necessary to know the required per cent fat and solids not fat in the finished product and the per cent fat and solids not fat in the milk to be standardized and then to calculate the proportion of fat and solids not fat needed in the fluid milk. This calculation is most conveniently made by allegation. This then shows the amount of fat or solids not fat, as the case may be, that must be added to secure the desired proportion of these ingredients and from this the amount of cream, or butter, or skim milk that must be used for standardizing can be readily determined.

\section{Example 1.}

The standard for evaporated milk is 7.8 per cent fat and 25.5 per cent total solids, or $(25.5-7.8)=17.7$ per cent solids not fat.

Amount fluid milk in batch, 7,000 pounds.

Fat in fluid milk, 3.3 per cent.

Solids not fat in milk, 9.0 per cent.

Fat wanted in evaporated milk, 7.8 per cent.

Solids not fat wanted in evaporated milk, 17.7 per cent.

What per cent fat should fluid milk contain?

How much cream, testing 25 per cent fat, must be added? Answer: s. n. f. in c. m. : s. n. f. in r. m. $=$ f. in c. m. : $X$; $=\times \% \mathrm{f}$. required in $\mathrm{r} . \mathrm{m}$.

$$
\begin{aligned}
& \text { s. } \mathrm{n} . \mathrm{f} .=\text { solids not fat. } \\
& \text { f. }=\text { fat. } \\
& \text { c. } \mathrm{m} .=\text { condensed milk. } \\
& \text { r. } \mathrm{m} .=\text { raw or fluid milk. }
\end{aligned}
$$

$17.7: 9 .=7.8: \times ; \times=3.966 \%$ fat.

The raw milk must contain $3.966 \%$ fat. 
How much $25 \%$ cream is required to raise the per cent fat in the 7,000 pounds of milk testing $3.3 \%$ fat to $3.966 \%$ ?

3.3

25.

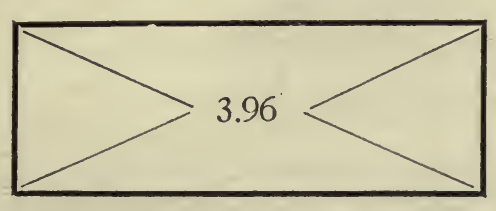

21.04

.66

$\overline{21.70}$

Enough $25 \%$ cream must be added to the raw milk so that each 21.7 pounds of standardized milk contains .66 pounds of added cream and 21.04 pounds of the original milk. Hence $21.7: .66=7000: X ; X=213$. lbs. of cream.

Total batch, 7000 pounds.

$25 \%$ cream, 213 pounds.

$3.3 \%$ milk, 6787 pounds.

\section{Example 2.}

Amount of fluid milk in batch, 7,000 pounds.

Fat in fluid milk, 4.5 per cent.

Solids not fat in fluid milk, 8.5 per cent.

Fat wanted in evaporated milk, 7.8 per cent.

Solids not fat wanted in evaporated milk, 17.7 per cent.

How much fat should fluid milk contain? How much skim milk must be added?

Answer: $17.7: 8.5=7.8=X ; X=3.75 \%$. The fluid milk must contain $3.75 \%$ fat.

How much skim milk must be added to lower the per cent fat in the fluid milk to $3.75 \%$ ?

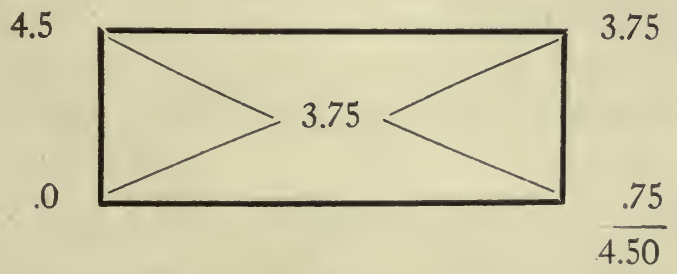

Enough skim milk must be added to the fluid milk so that each 4.5 pounds of standardized milk contains .75 pounds of 
added skim milk and 3.75 pounds of original milk. Hence $4.50: .75=7000: X ; X=1167$ pounds of skim milk.

Total batch, 7000 pounds.

Skim milk, 1167 pounds.

$4.5 \%$ milk, $\overline{5833}$ pounds.

Standardization of Finished Product.-In a similar manner standardization may be accomplished after condensation. In this case the proportion of solids is best increased or the proportion of fat reduced by the addition of condensed skim milk in the place of ordinary skim milk, while the proportion of fat is increased by the addition of cream as explained under Standardization of Fluid Milk.

If it is desired to lower the total solids in the finished product, without affecting the proportion of solids not fat to fat, the necessary amount of water required is determined as follows :

\section{Example 3.}

Evaporated milk in batch, 3000 pounds.

Total solids in evaporated milk, $27 . \%$.

Total solids desired, $25.5 \%$.

How much water must be added?

Answer:

27.

0.

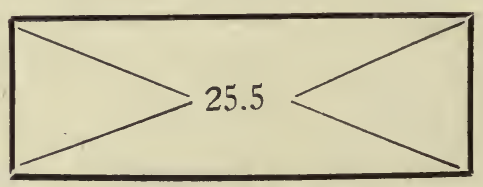

25.5

To each 25.5 pounds evaporated milk must be added 1.5 pounds water. Hence $25.5: 1.5=3000: X ; X=176.5$ pounds of water.

Original batch evaporated milk, 3000 pounds.

Water added, 176.5 pounds.

Standardized evaporated milk, $\overline{3176.5}$ pounds.

The results of standardization in which cream is used to alter the proportion of fat to solids not fat, are not absolutely mathematically accurate, because of the fact that the per cent 
of solids not fat in the cream is somewhat lower than in milk. This causes a slight shortage of solids not fat in the standardized product. This error is so slight, however, that it may be considered within the limits of the experimental error and for all practical purposes this method of standardization may be accepted as reliable and accurate.

Standardization of Sugar (Sucrose) in Sweetened Condensed Milk.-This is most readily accomplished by standardizing the proportion of sugar to the per cent total solids in the fresh milk.

If it is desired to secure a sweetened condensed milk, the milk solids of which merely comply with the Federal standard of 28 per cent, it is clesirable and necessary, from the standpoint of keeping quality, to add enough sugar (sucrose) so as to have the finished product contain at least 44 per cent sucrose.

\section{Example 4.}

Amount of fluid milk in batch, 15,000 pounds.

Fluid milk contains 12 per cent total solids.

How much sugar must be added in order to insure the sweetened condensed milk to contain 44 per cent sucrose, when the milk has been condensed sufficiently to contain 28 per cent milk solids?

Answer: $28: 44=12: \times: X=18.87$.

To every 100 pounds of fluid must be added 18.87 pounds sicrose.

To 15,000 pounds fluid milk must be added

$$
\frac{18.87 \times 15,000}{100}=2830.5 \text { pounds sucrose. }
$$

If it is desired to produce a sweetened condensed of heavy body and containing a high per cent of milk solids, as for instance, 32 per cent milk solids, the per cent sugar contained in the finished product may be considerably reduced. Such sweetened condensed milk may contain, say 40 per cent sucrose.

\section{Example 5.}

Amount of fluid milk in batch is 15,000 pounds.

Fluid milk contains 12 per cent total solids.

How much sugar must be added to insure the sweetened con- 
densed milk to contain 40 per cent sucrose when the milk has been condensed sufficiently to contain 32 per cent milk solids?

Answer: $32: 40=12: \times: X=15$.

To every 100 pounds of fluid milk must be added 15 pounds of sugar.

To 15,000 pounds fluid milk must be added

$$
\frac{15 \times 15,000}{100}=2250 \text { pounds of sucrose. }
$$

\section{Chapter XXX.}

\section{CHEMICAL TESTS AND ANALYSES OF MILK, SWEET- ENED CONDENSED MILK, EVAPORATED -MILK AND MILK POWDERS.}

In assembling these methods of analyses, preference has been given the "Official and Provisional Methods of Analysis," published by the American Association of Official Agricultural Chemists. ${ }^{1}$ The official methods have been modified and supplemented by other methods in numerous cases wherever, in the judgment of the writer and others, such modifications and substitutions are better adapted for analysis of these special products. A special effort has further been made to include in this chapter modifications and abbreviations of tests and analyses, adapted for the use of the factory operator, whose knowledge. skill, facilities and time are too limited to enable him to successfully follow the directions of the official methods, or to execute delicate and difficult chemical analyses.

For practical factory tests of fresh milk on the receiving platform, determining its fitness for condensing, the reader is referred to Chapter III, "Inspection of Milk at the Condensery."

\section{MILK.}

\section{Specific Gravity.}

Aerometric Method by Means of the Quevenne Lactometer. --Use an accurate Quevenne lactometer with thermometer attachment and a lactometer cylinder about ten inches high and

1 United States Department of Agriculture, Bureau of Chemistry, Bulletin No. 107, 1912. Also Journal of the Assn. of Official Agr. Chemists, Vol. II, No. 3, Nov. $15,1916$. 
one and one-half inches wide. Fill the cylinder with milk at a temperature between 55 and 65 degrees F. Insert the lactometer and when it has found its equilibrium, note the point on the scale at the surface of the milk. The correct temperature is 60 degrees F. For every degree Fahrenheit above 60 add one-tenth point to the observed reading, and for every degree Fahrenheit below 60 deduct one-tenth point from the observed reading. This rule holds good only when the range of temperature is within the limits of 55 degrees and 65 degrees $\mathrm{F}$.

'The specific gravity is calculated by adding 1,000 to' the lactometer reading and dividing the sum by 1,000. Example: Lactometer reading is 31 at 65 degrees $F$. Corrected reading is 31.5 ;

$$
\text { specific gravity is } \frac{31.5+1000}{1000}=1.0315 \text {. }
$$

Gravimetric Determination.-This consists of the filling of a perfectly dry picnometer or other graduated flask of known measure with milk at the standard temperature (60 degrees F., or 15.5 degrees $\mathrm{C}_{\text {.) }}$ and weighing the flask and contents. The weight of the flask is then deducted from the weight of the flask plus contents and the difference is divided by the weight of an equal volume of water at standard temperature. The result is the specific gravity of the milk.

The Westphal balance method furnishes another accurate means of determining the specific gravity. Both the gravimetric method and the Westphal balance method, while accurate when operated by the skillful chemist, require considerable time. Experimental comparisons have demonstrated that for all practical purposes the Quevenne hydrometer, when accurately graduated, yields correct results, and the simplicity and rapidity of its operation render its use in the determination of the specific gravity of milk highly advantageous and satisfactory.

\section{Total Solids.}

By Means of the Babcock Formula.-For rapid and reasonably accurate work the total solids of milk may be determined by the use of the Babcock formula, which is as follows:

$$
\text { Total solids }=\frac{\mathrm{L}}{4}+1.2 \times \mathrm{f}
$$




\section{$\mathrm{L}=$ Quevenne lactometer reading. \\ $\mathrm{f}=$ per cent of fat.}

Example: Lactometer reading is 32 ; per cent fat is 4 .

$$
\text { Total solids }=\frac{32}{4}+1.2 \times 4=12.8 \text { per cent. }
$$

Gravimetric Method.--" Heat from three to five grams of milk at the temperature of boiling water until it ceases to lose weight, using a tared flat dish of not.less than 5 c.c. diameter. If desired, from fifteen to twenty grams of pure, dry sand may be previously placed in the dish. Cool in a desiccator and weigh rapidly to avoid absorption of hygroscopic moisture."

Ash.

"Weigh about twenty grams of milk in a weighed"dish, add 6 c.c. of nitric acid, evaporate to dryness and ignite at a temperature just below redness until the ash is free from carbon."

\section{Total Nitrogen.}

Place about five grams of milk in a Kjeldahl digestion flask and proceed, without evaporation, as described under "Gunning Method" for the determination of nitrogen. Multiply the percentage of nitrogen by 6.38 to obtain nitrogen compounds.

\section{Gunning Method.}

\section{Apparatus.}

(a) Kjeldahl flasks for both digestion and distillation.These are flasks having a total capacity of about 550 c.c., made of hard, moderately thick and well-annealed glass. When used for distillation the flasks are fitted with rubber stoppers and bulb tubes, as given under distillation flasks.

(b) Kjeldahl digestion flasks.-These are pear-shape, roundbottomed flasks, made of hard, moderately thick, well-annealed glass, having a total capacity of about 250 c.c. They are 22 c.m. long and have a maximum diameter of $6 \mathrm{c} . \mathrm{m}$., tapering gradually to a long neck, which is $2 \mathrm{c.m}$. in diameter at the narrowest part and flared a little at the edge.

(c) Distillation flasks.-For distillation a flask of ordinary shape, of about 550 c.c. capacity may be used. It is fitted with a 
rubber stopper and with a bulb tube above to prevent the possibility of sodium hydrate being carried over mechanically during distillation. The bulbs may be about $3 \mathrm{c} . \mathrm{m}$. in diameter, the tubes being of the same diameter as the condenser and cut off obliquely at the lower end, which is fastened to the condenser by a rubber tube."

\section{Preparation of Reagents.}

(a) Potassium sulphate.- This reagent should be pulverized before using.

(b) Sulphuric acid.-The sulphuric acid should have a specific gravity of 1.84 . It should be $\mathrm{C}$. P., containing no nitrates nor ammonium sulphate.

(c) Sulphuric acid.- N-10 solution.

(d) Standard alkali solution.-The strength of this solution relative to the acid must be accurately determined, $\mathrm{N}-10$ solution.

(e) Metallic mercury or mercuric oxid.-If mercuric oxid is used it should be prepared in the wet way, but not from mercuric nitrate.

(f) Granulated zinc or pumice stone.-One of these reagents is added to the contents of the distillation flasks, when found necessary, in order to prevent bumping.

(g) Potassium sulphid solution.-A solution of forty grams of commercial potassium sulphid in one liter of water.

(h) Sodium hydroxid solution.-A saturated solution of sodium hydroxid free from nitrates.

(i) Indicator.-A solution of cochineal is prepared by digesting and frequently agitating three grams of pulverized cochineal in a mixture of 50 c.c. of strong alcohol and 200 c.c. of distilled water for a day or two at ordinary temperatures. The filtered solution is employed as indicator."

\section{Determination.}

Place the substance to be analyzed in a digestion flask, employing from 0.7 to 3.5 grams, according to its proportion of nitrogen. Add 10 grams of powdered potassium sulphate and from 15 to 25 c.c. (ordinarily about 20 c.c.) of sulphuric acid. Conduct the digestion by starting with a temperature below boiling point and 
increasing the heat gradually until frothing ceases. Digest for a time after the mixture is colorless, or nearly so, or until oxidation is complete. Do not add either potassium permanganate or potassium sulphid. Dilute, neutralize, distil and titrate with standard alkali. In neutralizing, it is convenient to add a few drops of phenolphthalein indicator, by which one can tell, when the acid is completely neutralized, remembering that the pink color, which indicates an alkaline reaction, is destroyed by a considerable excess of strong fixed alkali.

\section{Casein and Albumin.}

“(a) Casein.-The determination should be made when the milk is fresh, or nearly so. When it is not practicable to make this determination within twenty-four hours, add one part of formaldehyde to twenty-five hundred parts of milk and keep in a cool place. Place about 10 grams of milk in a beaker with about 90 c.c. of water at 40 degrees to 42 degrees C., and add at once 1.5 c.c. of a 10 per cent acetic acid solution. Stir with a glass rod and let stand from three to five minutes longer. Then decant or filter, wash two or three times with cold water by decantation and transfer precipitate completely to filter. Wash once or twice on filter. The filtrate should be clear, or nearly so. If it be not clear when it first runs through, it can generally be made so by two or three repeated filtrations, after which the washing of the precipitate can be completed. Determine nitrogen in the washed precipitate and filter by the Gunning method. To calculate the equivalent amount of casein from the nitrogen multiply by 6.38 .

In working with milk which has been kept with preservatives, the acetic acid should be added in small proportions, a few drops at a time, with stirring, and the addition continued until the liquid above the precipitate becomes clear or very nearly so.

(b) Albumin.-Exactly neutralize with caustic alkali the filtrate obtained in the preceding operation (a), add 0.3 c.c. of a 10 per cent solution of acetic acid and heat the liquid to the temperature of boiling water until the albumin is completely precipitated, collect the precipitate on a filter, wash and determine the nitrogen therein. Nitrogen multiplied by 6.38 equals albumin," or 
'Io the filtrate of the casein determination add 0.3 c.c. of 10 per cent acetic acid, boil until the albumin is completely precipitated and proceed as directed in previous paragraph.

In the place of the above methods the per cent of albumin may he determined by subtracting the per cent of casein from the per cent of total nitrogen.

\section{Milk Sugar (Lactose). Optical Method. \\ Preparation of Reagents.}

“(a) Acid mercuric nitrate--Dissolve mercury in double its weight of nitric acid, specific gravity 1.42 , and dilute with an equal volume of water. One cubic centimeter of this reagent is sufficient for the quantities of milk mentioned below. Larger quantities may be used without affecting the results of polarization.

(b) Mercuric iodid with acetic acid.--Mix 33.2 grams of potassium iodid, 13.5 grams of mercuric chlorid, 20 c.c. of glacial acetic acid and 640 c.c. of water."

Determine the specific gravity of the milk by means of a delicate hydrometer, or, if preferred, a pycnometer. The quantity of sample to be taken for the determination varies with the specific gravity and is to be measured at the same temperature at which the specific gravity is taken. The volume to be measured is indicated in the following table, which is based upon twice the normal weight of lactose (32.9 grams per 100 metric c.c.) for the Ventzke sugar scale.

Place the quantity of milk indicated in the table in a flask graduated at 102.6 c.c., add 1 c.c. of the acid mercuric nitrate solution or 30 c.c. of the mercuric iodid solution (an excess of these reagents does no harm), fill to the mark, shake, filter through a dry filter and polarize. It is not necessary to heat before polarizing. If a $200 \mathrm{~m} . \mathrm{m}$ tube is used, divide the polariscope reading by 2 ( or, if a $400 \mathrm{~m} . \mathrm{m}$. tube is used, by 4) to obtain the per cent of lactose in the sample. 
Volume of Milk Corresponding to a Lactose Double Normal Weight.

\begin{tabular}{|c|c|c|c|}
\hline $\begin{array}{l}\text { Specific Gravity } \\
\text { of Milk }\end{array}$ & $\begin{array}{c}\text { Volume of Milk } \\
\text { for a Lactose } \\
\text { Double Normal } \\
\text { Weight Ventzke } \\
\text { Scale }\end{array}$ & $\begin{array}{l}\text { Specific Gravity } \\
\text { of Milk }\end{array}$ & $\begin{array}{c}\text { Volume of Milk } \\
\text { for a Lactose } \\
\text { Double Normal } \\
\text { Weight Ventzke } \\
\text { Scale }\end{array}$ \\
\hline $\begin{array}{l}1.024 \\
1.025 \\
1.026 \\
1.027 \\
1.028 \\
1.029 \\
1.030\end{array}$ & $\begin{array}{l}\text { C. C. } \\
64.25 \\
64.20 \\
64.15 \\
64.05 \\
64.00 \\
63.95 \\
63.90\end{array}$ & $\begin{array}{l}1.031 \\
1.032 \\
1.033 \\
1.034 \\
1.035 \\
1.036\end{array}$ & $\begin{array}{l}\text { C. C. } \\
63.80 \\
63.75 \\
63.70 \\
63.65 \\
63.55 \\
63.50\end{array}$ \\
\hline
\end{tabular}

Low's Volumetric Method Modified.

Preparation of Reagents.

“(a) Copper sulphate solution.-Dissolve 34.639 grams of $\mathrm{CuSO}_{4} .5 \mathrm{H}_{2} \mathrm{O}$ in water and dilute to 500 c.c.

(b) Alkaline tartrate solution.-Dissolve 173 grams of Rochelle salts and 50 grams of sodium hydroxid in water and dilute to 500 c.c.

(c) Mixed solution.-Mix equal volumes of solutions (a) and (b) immediately before use.

(d) Standardization of the thiosulphate solution.-Prepare a solution of sodium thiosulphate, dissolving 24.659 grams of pure crystals to 1,000 c.c. Weigh 6.36 grams copper foil. Dissolve by warming in minimum amount of nitric acid and water required. Boil to expel the red fumes, add 160 c.c. strong bromine water and boil until the bromine is thoroughly expelled. Renove from the heat and add a slight excess of strong ammonium hydroxid; 223 c.c. is about the right amount. Again boil until the excess of ammonial is expelled, as shown by a change of color of the liquid, and partial precipitation. Now add a slight excess of strong acetic acid (100 to 130 c.c. of 80 per cent acid) and boil for a minute. Cool to room temperature and dilute to 1,000 c.c. Titrate a known amount ( 10 to 15 c.c.) of the copper solution, to which 10 c.c. of a 25 per cent solution of pure potassium iodid has been added, with the 
thiosulphate solution until the brown tinge has become weak, then add sufficient starch liquor to produce a marked blue coloration. Continue the titration cautiously until the color due to free iodin has entirely vanished. The blue color changes toward the end to a faint lilac. If at this point the thiosulphate be added drop by drop and a little time be allowed for complete reaction after each addition, there is no difficulty in determining the end point within a single drop. One cubic centimeter of the thiosulphate solution will be found to correspond to .00636 grams of copper."

\section{Determination of Copper.}

"After washing the precipitated cuprous oxid, cover the gooch with a watch glass and dissolve the oxid by means of 5 c.c. of warm nitric acid $(1: 1)$ poured under the watch glass with a pipette. Catch the filtrate in a flask of 250 c.c. capacity, wash watch glass and gooch free of copper; 50 c.c. of water will be sufficient. Boil to expel red fumes, add 5 c.c. of bromine water, boil off the bromine and proceed exactly as in standardizing the thiosulphate."

\section{Determination of Lactose.}

Place 50 c.c. of the mixed copper reagent in a beaker and heat to the boiling point. While boiling briskly add 100 c.c. of the lactose solution containing not more than 0.300 grams of lactose and boil for six minutes. Filter immediately through asbestos and wash. Obtain the weight of lactose equivalent to the weight of copper found from the following table: 
"Table for the Determination of Lactose (Soxhlet-Wein)."

\begin{tabular}{|c|c|c|c|c|c|c|c|c|c|}
\hline $\begin{array}{l}\text { Minu- } \\
\text { grams } \\
\text { of } \\
\text { copper }\end{array}$ & $\begin{array}{l}\text { Mill- } \\
\text { grams } \\
\text { of } \\
\text { bactose }\end{array}$ & $\begin{array}{l}\text { Mmi- } \\
\text { grams } \\
\text { of } \\
\text { copper }\end{array}$ & $\begin{array}{l}\text { Mnil- } \\
\text { grams } \\
\text { of } \\
\text { stctose }\end{array}$ & $\begin{array}{l}\text { Mill- } \\
\text { grams } \\
\text { of } \\
\text { copper }\end{array}$ & $\begin{array}{l}\text { Milli- } \\
\text { grams } \\
\text { of } \\
\text { lactose }\end{array}$ & $\begin{array}{l}\text { Milli- } \\
\text { grams } \\
\text { of } \\
\text { copper }\end{array}$ & $\begin{array}{l}\text { Milli- } \\
\text { grams } \\
\text { of } \\
\text { Iactose }\end{array}$ & $\begin{array}{l}\text { Mill! } \\
\text { grams } \\
\text { of } \\
\text { copper }\end{array}$ & $\begin{array}{c}\text { Mill. } \\
\text { grams } \\
\text { of } \\
\text { lactose }\end{array}$ \\
\hline $\begin{array}{l}100 \\
101 \\
102 \\
103 \\
104\end{array}$ & $\begin{array}{l}71.6 \\
72.4 \\
73.1 \\
73.8 \\
74.6\end{array}$ & $\begin{array}{l}160 \\
161 \\
162 \\
163 \\
164\end{array}$ & $\begin{array}{l}116.4 \\
117.1 \\
117.9 \\
118.6 \\
119.4\end{array}$ & $\begin{array}{l}220 \\
221 \\
222 \\
223 \\
224\end{array}$ & $\begin{array}{l}161.9 \\
162.7 \\
163.4 \\
164.2 \\
164.9\end{array}$ & $\begin{array}{l}280 \\
281 \\
282 \\
283 \\
284\end{array}$ & $\begin{array}{l}208.3 \\
209.1 \\
209.9 \\
210.7 \\
211.5\end{array}$ & $\begin{array}{l}340 \\
341 \\
342 \\
343 \\
344\end{array}$ & $\begin{array}{l}255.7 \\
256.5 \\
257.4 \\
258.2 \\
259.0\end{array}$ \\
\hline $\begin{array}{l}105 \\
106 \\
107 \\
108 \\
109\end{array}$ & $\begin{array}{l}75.3 \\
76.1 \\
76.8 \\
77.6 \\
78.3\end{array}$ & $\begin{array}{l}165 \\
166 \\
167 \\
168 \\
169\end{array}$ & $\begin{array}{l}120.2 \\
120.9 \\
121.7 \\
122.4 \\
123.2\end{array}$ & $\begin{array}{l}225 \\
226 \\
227 \\
228 \\
229\end{array}$ & $\begin{array}{l}165.7 \\
166.4 \\
167.2 \\
167.9 \\
168.6\end{array}$ & $\begin{array}{l}285 \\
286 \\
287 \\
288 \\
289\end{array}$ & $\begin{array}{l}212.3 \\
213.1 \\
213.9 \\
214.7 \\
215.5\end{array}$ & $\begin{array}{l}345 \\
346 \\
347 \\
348 \\
349\end{array}$ & $\begin{array}{l}259.8 \\
230.6 \\
261.4 \\
262.3 \\
263.1\end{array}$ \\
\hline $\begin{array}{l}110 \\
111 \\
112 \\
113 \\
114\end{array}$ & $\begin{array}{l}79.0 \\
79.8 \\
80.5 \\
81.3 \\
82.0\end{array}$ & $\begin{array}{l}170 \\
171 \\
172 \\
173 \\
174\end{array}$ & $\begin{array}{l}123.9 \\
124.7 \\
125.5 \\
126.2 \\
127.0\end{array}$ & $\begin{array}{l}230 \\
231 \\
232 \\
233 \\
234\end{array}$ & $\begin{array}{l}169.4 \\
170.1 \\
170.9 \\
171.6 \\
172.4\end{array}$ & $\begin{array}{l}290 \\
291 \\
292 \\
293 \\
294\end{array}$ & $\begin{array}{l}216.3 \\
217.1 \\
217.9 \\
218.7 \\
219.5\end{array}$ & $\begin{array}{l}350 \\
351 \\
352 \\
353 \\
354\end{array}$ & $\begin{array}{l}233.9 \\
264.7 \\
265.5 \\
263.3 \\
267.2\end{array}$ \\
\hline $\begin{array}{l}115 \\
116 \\
117 \\
118 \\
119\end{array}$ & $\begin{array}{l}82.7 \\
83.5 \\
84.2 \\
85.0 \\
85.7\end{array}$ & $\begin{array}{l}175 \\
176 \\
177 \\
178 \\
179\end{array}$ & $\begin{array}{l}127.8 \\
128.5 \\
129.3 \\
130.1 \\
130.8\end{array}$ & $\begin{array}{l}235 \\
236 \\
237 \\
238 \\
239\end{array}$ & $\begin{array}{l}173.1 \\
173.9 \\
174.6 \\
175.4 \\
176.2\end{array}$ & $\begin{array}{l}295 \\
296 \\
297 \\
298 \\
239\end{array}$ & $\begin{array}{l}220.3 \\
221.1 \\
221.9 \\
222.7 \\
223.5\end{array}$ & $\begin{array}{l}355 \\
356 \\
357 \\
358 \\
359\end{array}$ & $\begin{array}{l}268.0 \\
268.8 \\
269.6 \\
270.4 \\
271.2\end{array}$ \\
\hline $\begin{array}{l}120 \\
121 \\
122 \\
123 \\
124\end{array}$ & $\begin{array}{l}86.4 \\
87.2 \\
87.9 \\
88.7 \\
89.4\end{array}$ & $\begin{array}{l}180 \\
181 \\
182 \\
183 \\
184\end{array}$ & $\begin{array}{l}131.6 \\
132.4 \\
133.1 \\
133.9 \\
134.7\end{array}$ & $\begin{array}{l}240 \\
241 \\
242 \\
243 \\
244\end{array}$ & $\begin{array}{l}176.9 \\
177.7 \\
178.5 \\
179.3 \\
180.1\end{array}$ & $\begin{array}{l}300 \\
301 \\
302 \\
303 \\
304\end{array}$ & $\begin{array}{l}224.4 \\
225.2 \\
225.9 \\
226.7 \\
227.5\end{array}$ & $\begin{array}{l}350 \\
361 \\
362 \\
363 \\
364\end{array}$ & $\begin{array}{l}272.1 \\
272.9 \\
273.7 \\
274.5 \\
275.3\end{array}$ \\
\hline $\begin{array}{l}125 \\
.126 \\
127 \\
128 \\
129\end{array}$ & $\begin{array}{l}90.1 \\
90.9 \\
91.6 \\
92.4 \\
93.1\end{array}$ & $\begin{array}{r}185 \\
186 \\
187 \\
188 \\
189\end{array}$ & $\begin{array}{l}135.4 \\
136.2 \\
137.0 \\
137.7 \\
138.5\end{array}$ & $\begin{array}{l}245 \\
246 \\
247 \\
248 \\
249\end{array}$ & $\begin{array}{l}180.8 \\
181.6 \\
182.4 \\
183.2 \\
184.0\end{array}$ & $\begin{array}{l}305 \\
306 \\
307 \\
308 \\
309\end{array}$ & $\begin{array}{l}228.3 \\
229.1 \\
229.8 \\
230.6 \\
231.4\end{array}$ & $\begin{array}{l}365 \\
366 \\
367 \\
368 \\
369\end{array}$ & $\begin{array}{l}276.2 \\
277.1 \\
277.9 \\
278.8 \\
279.6\end{array}$ \\
\hline $\begin{array}{l}130 \\
131 \\
132 \\
133 \\
134\end{array}$ & $\begin{array}{l}93.8 \\
94.6 \\
95.3 \\
96.1 \\
96.9\end{array}$ & $\begin{array}{l}190 \\
191 \\
192 \\
193 \\
194\end{array}$ & $\begin{array}{l}139.3 \\
140.0 \\
140.8 \\
141.6 \\
142.3\end{array}$ & $\begin{array}{l}250 \\
251 \\
252 \\
253 \\
254\end{array}$ & $\begin{array}{l}184.8 \\
185.5 \\
186.3 \\
187.1 \\
187.9\end{array}$ & $\begin{array}{l}310 \\
311 \\
312 \\
313 \\
314\end{array}$ & $\begin{array}{l}232.2 \\
232.9 \\
233.7 \\
234.5 \\
235.3\end{array}$ & $\begin{array}{l}370 \\
371 \\
372 \\
373 \\
374\end{array}$ & $\begin{array}{l}280.5 \\
281.4 \\
282.2 \\
283.1 \\
283.9\end{array}$ \\
\hline $\begin{array}{l}135 \\
136 \\
137 \\
138 \\
139\end{array}$ & $\begin{array}{r}97.6 \\
98.3 \\
99.1 \\
99.8 \\
100.5\end{array}$ & $\begin{array}{l}195 \\
196 \\
197 \\
198 \\
199\end{array}$ & $\begin{array}{l}143.1 \\
143.9 \\
144.6 \\
145.4 \\
146.2\end{array}$ & $\begin{array}{l}255 \\
256 \\
257 \\
258 \\
259\end{array}$ & $\begin{array}{l}188.7 \\
189.4 \\
190.2 \\
191.0 \\
191.8\end{array}$ & $\begin{array}{l}315 \\
316 \\
317 \\
318 \\
319\end{array}$ & $\begin{array}{l}236.1 \\
236.8 \\
237.6 \\
238.4 \\
239.2\end{array}$ & $\begin{array}{l}375 \\
376 \\
377 \\
378 \\
379\end{array}$ & $\begin{array}{l}284.8 \\
285.7 \\
286.5 \\
287.4 \\
288.2\end{array}$ \\
\hline $\begin{array}{l}140 \\
141 \\
142 \\
143 \\
144\end{array}$ & $\begin{array}{l}101.3 \\
102.0 \\
102.8 \\
103.5 \\
104.3\end{array}$ & $\begin{array}{l}200 \\
201 \\
202 \\
203 \\
204\end{array}$ & $\begin{array}{l}146.9 \\
147.7 \\
148.5 \\
149.2 \\
150.0\end{array}$ & $\begin{array}{l}260 \\
261 \\
262 \\
263 \\
264\end{array}$ & $\begin{array}{l}192.5 \\
193.3 \\
194.1 \\
194.9 \\
195.7\end{array}$ & $\begin{array}{l}320 \\
321 \\
322 \\
323 \\
324\end{array}$ & $\begin{array}{l}240.0 \\
240.7 \\
241.5 \\
242.3 \\
243.1\end{array}$ & $\begin{array}{l}380 \\
381 \\
382 \\
383 \\
384\end{array}$ & $\begin{array}{l}289.1 \\
239.8 \\
290.8 \\
291.7 \\
292.5\end{array}$ \\
\hline $\begin{array}{l}145 \\
146 \\
147 \\
148 \\
149\end{array}$ & $\begin{array}{l}105.1 \\
105.8 \\
.106 .6 \\
107.3 \\
108.1\end{array}$ & $\begin{array}{l}205 \\
206 \\
207 \\
208 \\
209\end{array}$ & $\begin{array}{l}150.7 \\
151.5 \\
152.2 \\
153.0 \\
153.7\end{array}$ & $\begin{array}{l}265 \\
266 \\
267 \\
.268 \\
269\end{array}$ & $\begin{array}{l}196.4 \\
197.2 \\
198.0 \\
198.8 \\
199.5\end{array}$ & $\begin{array}{l}325 \\
326 \\
327 \\
328 \\
329\end{array}$ & $\begin{array}{l}243.9 \\
244.6 \\
245.4 \\
246.2 \\
247.0\end{array}$ & $\begin{array}{l}385 \\
386 \\
387 \\
388 \\
389\end{array}$ & $\begin{array}{l}293.4 \\
294.2 \\
295.1 \\
236.0 \\
236.8\end{array}$ \\
\hline $\begin{array}{l}150 \\
151 \\
152 \\
153 \\
154\end{array}$ & $\begin{array}{l}108.8 \\
109.6 \\
110.3 \\
111.1 \\
111.9\end{array}$ & $\begin{array}{l}210 \\
211 \\
212 \\
213 \\
214\end{array}$ & $\begin{array}{l}154.5 \\
155.2 \\
156.0 \\
156.7 \\
157.5\end{array}$ & $\begin{array}{l}270 \\
271 \\
272 \\
273 \\
274\end{array}$ & $\begin{array}{l}200.3 \\
201.1 \\
201.9 \\
202.7 \\
203.5\end{array}$ & $\begin{array}{l}330 \\
331 \\
332 \\
333 \\
334\end{array}$ & $\begin{array}{l}247.7 \\
248.5 \\
249.2 \\
250.0 \\
250.8\end{array}$ & $\begin{array}{l}390 \\
391 \\
392 \\
393 \\
394\end{array}$ & $\begin{array}{l}277.7 \\
298.5 \\
299.4 \\
300.3 \\
301.1\end{array}$ \\
\hline $\begin{array}{l}155 \\
156 \\
157 \\
158 \\
159\end{array}$ & $\begin{array}{l}112.6 \\
113.4 \\
114.1 \\
114.9 \\
115.6\end{array}$ & $\begin{array}{l}215 \\
216 \\
217 \\
218 \\
219\end{array}$ & $\begin{array}{l}158.2 \\
159.0 \\
159.7 \\
160.4 \\
161.2\end{array}$ & $\begin{array}{l}275 \\
276 \\
277 \\
278 \\
279\end{array}$ & $\begin{array}{l}204.3 \\
205.1 \\
205.9 \\
206.7 \\
207.5\end{array}$ & $\begin{array}{l}335 \\
336 \\
337 \\
338 \\
339\end{array}$ & $\begin{array}{l}251.6 \\
252.5 \\
253.3 \\
254.1 \\
254.9\end{array}$ & $\begin{array}{l}395 \\
396 \\
397 \\
398 \\
399 \\
\\
400\end{array}$ & $\begin{array}{l}302.0 \\
302.8 \\
308.7 \\
304.6 \\
305.4 \\
306.3\end{array}$ \\
\hline
\end{tabular}




\section{Butter Fat. The Babcock Test. Standard Glassware. ${ }^{1}$}

(a) Standard milk test bottles, graduated to 8 per cent and with sub-divisions of .1 per cent.

(b) Standard pipette graduated to 17.6 c.c.

(c) Acid measure graduated to 17.5 c.c.

(d) Centrifuge-Babcock tester.

(e) Water bath for reading at 130 to 140 degrees $F$.

(f) Calipers for measuring fat column.

(g) Sulphuric acid, specific gravity 1.82 to 1.83 .

\section{Determination.}

Pipette 17.6 c.c. of the properly mixed sample of milk into the milk test bottle. Add 17.5 c.c. of acid and shake until all the curd is completely dissolved. Both milk and acid should have a temperature of 55 to $70 \mathrm{de}$ grees F. If milk and acid are too warm, set the sample bottles and the acid jar into a trough or tub of water at 55 to 70 degrees $\mathrm{F}$. for thirty minutes before testing. The test bottles containing the mixture of milk and acid are then whirled in the Babcock tester for five minutes at about one thousand revolutions per minute, in the case of a tester with a twelveinch diameter wheel. Fill the test bottles to the bottom of the neck with hot water. The

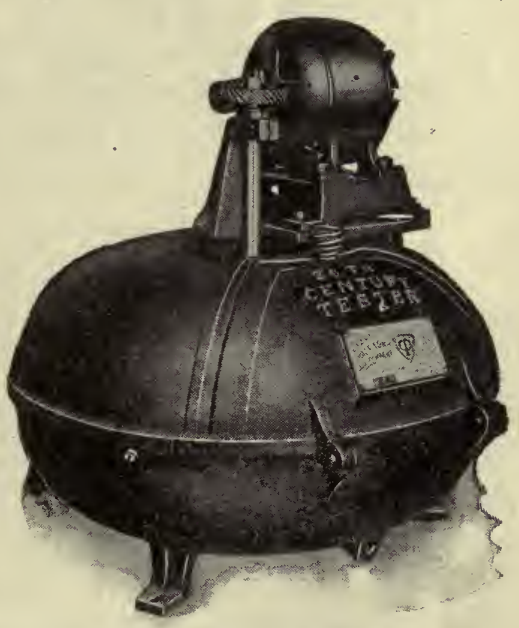

Fig. 110. Babcock tester

Courtesy of Creamery Package Mfg. Company water should be soft, preferably rain water or distilled water. If hard tap water is used it should be boiled to precipitate the carbonates, otherwise the test may be difficult to read, owing to the presence of bubbles of gas on top of the fat column. Revolve 1914.

${ }^{1}$ Hunziker, Indiana Agricultural Experiment Station, Circulars 41 and 42 , 
again at full speed for two minutes, fill the test bottles to near the top of the graduation with hot water. Whirl in the centrifuge for one minute. Now set the test bottles in the water bath at 135 degrees $F$. for five minutes. The test is now ready to be read. The figures on the test bottles represent per cent. In the case of the 8 per cent standard milk test bottle the sub-divisions represent tenths per cent. Read from the bottom of the lower curve to the top of upper curve of the fat column, including the meniscus in the reading.

\section{Gravimetric Method-Paper Coil.}

"Make coils of thick filter paper, cut into strips 6.25 by 62.5 c.m., and thoroughly extract with ether and alcohol, or correct the weight of the extract by a constant obtained for the paper. From a weighing bottle or weighing pipette, transfer about 5 grams of milk to the coil, care being taken to keep the end of the coil held in the fingers, dry. Dry the coil, dry end down, on a piece of glass at the temperature of boiling water; transfer to an extraction apparatus and extract with absolute ether or petroleum ether boiling at about 45 degrees C.; dry the extracted fat and weigh."

\section{Roese-Gottlieb Method.}

"Weigh 10-11 grams of the milk into a Röhrig tube or some similar apparatus, add 1.25 c.c. of concentrated ammonium hydroxid ( 2 c.c. if the sample is sour) and mix thoroughly. Add 10 c.c. of 95 per cent alcohol by volume and mix well. Then add 25 c.c. of washed ether and shake vigorously for thirty seconds, then 25 c.c. of petroleum ether (redistilled slowly at a temperature below 60 degrees C.) and shake again for thirty seconds. Let stand twenty minutes, or until the upper liquid is practically clear. Draw off as much as possible of the ether-fat solution (usually $0.5-0.8$ c.c. will be left) into a weighed flask through a small quick-acting filter. The flask should always be weighed with a similar one as a counterpoise. Re-extract the liquid remaining in the tube, this time with only 15 c.c. of each ether, shake vigorously thirty seconds with each and allow to settle. Draw off the clear solution through the small filter into the same flask as before and wash the tip of spigot, the funnel and the filter with a few c.c. of a mixture of the two ethers in equal parts. 
For absolutely exact results the re-extraction must be repeated. This third extraction yields usually not more than about $1 \mathrm{mg}$. of fat (about 0.02 per cent on a 4 gram charge) if the previous ether-fat solutions have been drawn off closely. Evaporate the ethers slowly on a stean bath, then dry the fat in a boiling water oven to constant weight.

Confirm the purity of the fat by dissolving in a little petroleum ether. Should a risidue remain, remove the fat completely with petroleum ether, dry the residue, weigh and deduct the weight. Finally correct this weight by a blank determination on the reagents used."

\section{SWEETENED CONDENSED MILK.}

\section{Preparation of Sample.}

Pour the contents of the can into a bowl or on a glass plate. Scrape out the can thoroughly, removing all the sugar sediment from the top and bottom of the can. Mix thoroughly with pestle or spatula until a homogenous emulsion is secured. This is important, as it is exceedingly difficult to secure a representative sample otherwise.

If it is desired to use a 40 per cent solution as directed in the determination of the individual ingredients, weigh accurately 40 grams of the properly mixed contents of the can into a 100 c.c. graduated flask. Add 60 c.c. of water. The sweetened condensed milk mixes somewhat difficultly with the water. Complete solution is facilitated by adding the water in several installments, shaking after each addition until condensed milk sediment adheres no longer to the bottom and sides of the flask.

\section{Spec:fic Gravity.}

\section{Aerometric Method by Means of Beaumé Hydrometer. Apparatus.}

Beaumé Hydrometer.- - ise a specially constructed Beaumé hydrometer with mercury bulb, and a scale of 30 to 37 degrees B., graduated to tenths degrees. Length over all, twelve inches; length of spindle, six inches; length of empty bulb, four and 
one-quarter inches; width of empty bulb, thirteen-sixteenths of one inch.

Hydrometer Jar.-Use a glass or tin cylinder with substantial base, minium length twelve inches, minimum width one and a half inches.

\section{Determination.}

Use the original undiluted condensed milk. The Beaumé hydrometer is graduated to read correctly at 60 degrees F. (15.5 degrees C.). At this temperature the sweetened condensed milk is too viscous for rapid and accurate work. Warm the condensed milk to 100 degrees $\mathrm{F}$. or above and correct the Beaumé reading by adding to the observed reading .025 points for every degree Fahrenheit above 60 . At a temperature of 100 degrees $F$. or above, the reading can be made in fifteen minutes or less, after the hydrometer is inserted in the milk.

The specific gravity is determined by the use of the following formula :

$$
\text { Specific gravity }=\frac{144.3}{144.3-\mathrm{B}} .
$$

$\mathrm{B}=$ Beaumé reading at 60 degrees $\mathrm{F}$.

Example: Observed Beaumé reading at 120 is 31.6.

Corrected reading $=31.6+[(120-60) \times .025]=33.1$.

$$
\text { Specific gravity }=\frac{144.3}{144.3-33.1}=1.2977 \text {. }
$$

The following table shows the specific gravity of sweetened condensed milk when the Beaumé reading is known. 


\begin{tabular}{c|c||c|c||c|c}
\hline Beaume & $\begin{array}{c}\text { Specific } \\
\text { Gravity }\end{array}$ & Beaume & $\begin{array}{c}\text { Specific } \\
\text { Gravity }\end{array}$ & Beaumé & $\begin{array}{l}\text { Specific } \\
\text { Gravity }\end{array}$ \\
\hline & & & & & \\
0 & 1.000 & 16.5 & 1130 & 29.7 & 1.260 \\
0.7 & 1.005 & 17.1 & 1.135 & 30.2 & 1.265 \\
1.4 & 1.010 & 1.77 & 1.140 & 30.6 & 1.270 \\
2.1 & 1.015 & 18.3 & 1.145 & 31.1 & 1.275 \\
2.7 & 1.020 & 18.8 & 1.150 & 31.5 & 1.280 \\
3.4 & 1.025 & 19.3 & 1.155 & 32.0 & 1.285 \\
4.1 & 1.030 & 19.8 & 1.160 & 32.4 & 1.290 \\
4.7 & 1.035 & 20.3 & 1.165 & 32.8 & 1.295 \\
5.4 & 1.040 & 20.9 & 1.170 & 33.3 & 1.300 \\
6.0 & 1.045 & 21.4 & 1.175 & 33.7 & 1.305 \\
6.7 & 1.050 & 22.0 & 1.180 & 34.2 & 1.310 \\
7.4 & 1.055 & 22.5 & 1.185 & 34.6 & 1.315 \\
8.0 & 1.060 & 23.0 & 1.190 & 35.0 & 1.320 \\
8.7 & 1.065 & 23.5 & 1.195 & 35.4 & 1.325 \\
9.4 & 1.070 & 24.0 & 1.200 & 35.8 & 1.330 \\
10.0 & 1.075 & 24.5 & 1.205 & 36.2 & 1.335 \\
10.6 & 1.080 & 25.0 & 1.210 & 36.6 & 1.340 \\
11.2 & 1.085 & 25.5 & 1.215 & 37.0 & 1.345 \\
11.9 & 1.090 & 26.0 & 1.220 & 37.4 & 1.350 \\
12.4 & 1.095 & 26.4 & 1.225 & 37.8 & 1.355 \\
13.0 & 1.100 & 26.9 & 1.230 & 38.2 & 1.360 \\
13.6 & 1.105 & 27.4 & 1.235 & 38.6 & 1.365 \\
14.2 & 1.110 & 27.9 & 1.240 & 39.0 & 1.370 \\
14.9 & 1.115 & 28.4 & 1.245 & 39.4 & 1.375 \\
15.4 & 1.120 & 28.8 & 1.250 & 39.8 & 1.380 \\
16.0 & 1.125 & 29.3 & 1.255 & 40.1 & 1.385 \\
& & & & & \\
\hline
\end{tabular}

\section{Gravimetric Determination.}

Dilute a measured portion of a 40 per cent solution with an equal volume of water, use 5 c.c. of the diluted mixture, corresponding to 1 gram of the condensed milk and proceed as directed under "Milk."

\section{Total Solids.}

Dilute a measured portion of a 40 per cent solution with an equal volume of water, measure 5 c.c. of the diluted mixture, corresponding to 1 gram of the condensed milk into an eva!)orating dish containing 15 to 20 grams of pure dry sand and proceed as directed under "Milk."

\section{Ash.}

Ignite the total solids at very low redness, cool, and weigh. See "Milk."

\section{Proteids.}

Determine nitrogen in 5 c.c. of the 40 per cent solution 
according to the Gunning method, see "Milk," and multiply the results by 6.38 .

\section{Lactose.}

Dilute five grams of a 40 per cent solution to about 40 c.c. and add 6 c.c. of Fehling's copper solution. Nearly neutralize with sodium hydroxide, make up to 100 c.c., filter through dry filter and determine lactose in an aliquot as directed under "Milk-Determination of Lactose."

\section{Fat.}

\section{Modified Babcock Test.}

Weigh eighteen grams, or measure 16.1 c.c. of the 40 per cent solution into a standard Babcock milk test bottle. Add 4 c.c. of commercial sulphuric acid, specific gravity 1.82 to 1.83 . Shake immediately until acid is thoroughly mixed with the milk. Whirl in Babcock tester for six minutes at full speed. The centrifuge must run smoothly. Stop the tester gradually and remove the bottles carefully so as not to break the layer of floating curd. Decant the clear whey by slowly inclining the bottle. Now add two-thirds of a 17.6 c.c. pipette full of water. After thoroughly shaking to emulsify the curd and to wash it free of sucrose, add 4 c.c. sulphuric acid, shake, whirl and decant as before. Then add one 17.6 c.c. pipette full of water, 17.5 c.c. of sulphuric acid and complete the Babcock test in the usual way as directed under "Milk." Multiply the reading by 2.5 .

This method yields very satisfactory results with sweetened condensed milk containing not less than 4 to 5 per cent fat. With condensed milk of a lower fat content the decanting of the clear whey is difficult, since the curd in the partly skimmed product is too heavy to float in the form of a firm cheese.

\section{The Roese-Gottlieb Method.}

As practiced in the Dairy Laboratory, Bureau of Chemistry, Department of Agriculture.

"Weigh out 4 to 5 grams of the homogeneous sample of condensed milk into a Röhrig tube (Zeit. Unters. Nahr. u. Genussm., 1905, 9:531) or some similar apparatus and dilute with water in the tube to about 10.5 c.c.-or, if preferred, weigh into 
the tube 10 to 11 grams of a 40 per cent solution of the substance -add $1 \frac{1}{4}$ c.c. of concentrated ammonium hydroxid (2 c.c. if the sample be sour) and mix thoroughly with the milk. Add 10 c.c. of 95 per cent alcohol and mix well. Then add 25 c.c. of washed ethyl ether and shake vigorously for half a minute, then add 25 c.c. of petroleum ether (redistilled slowly at a temperature below 60 degrees $C$. preferably) and shake again for half a minute. Let stand 20 minutes or until the upper liquid is practically clear and its own lower level constant. Draw off of the ether solution as much as possible-usually 0.5 to 0.8 c.c. will be left-into a weighed flask through a diminutive quick acting filter, of selected paper. The flask should always be weighed with a similar one as counterpoise.

"Re-extract the liquid remaining in the tube, this time with only 15 c.c. of each ether, shaking vigorously half a minute with each, and allow to settle.

"Draw off the clear solution through the small filter into the same flask as before and wash the tip of the spigot, the funnel and the filter with a few c.c. of a mixture of the two ethers in equal parts (previously mixed and free from deposited water).

"For perfectly exact results the re-extraction must be repeated. This extraction yields usually not more than about a nilligram of fat, if the previous ether-fat-solutions have been drawn off closely - an amount averaging about .02 per cent on a 4-gram charge.

"Evaporate the ether slowly on a steam bath, then dry the fat in a boiling water oven until loss of weight ceases.

"Prove the purity of the fat by dissolving in a little petroleum ether. Should a residue remain, wash the 'fat out completely with petroleum ether, dry the residue, weigh, and deduct the weight. (This should not often be necessary.)

"Finally deduct the weight obtained by blank determination on the chemicals used.

"By this method practically absolute results can be obtainecl."

\section{Sucrose.}

Determine by difference, deducting the milk solids (ash plus proteids plus lactose plus fat) from the total solids, or 
invert the sucrose, determine, the total invert sugar, deduct from this the lactose calculated as invert sugar and calculate the difference as sucrose.

\section{Milk Solids.}

Deduct the per cent sucrose from the per cent total solids. The difference represents the per cent milk solids.

\section{EVAPORATED MILK.}

\section{Preparation of Sample.}

Shake the can of evaporated milk vigorously before opening. If, upon opening the can, separated cream or small lumps of butter are found to adhere to the seams and around the junction of the ends and the body, set the can in a water bath at 130 degrees F. for ten minutes or until all fat is completely dissolved. Then pour the entire contents into $a_{0}$ beaker and pour back and forth several times until a homogeneous mixture is secured. If it is known before opening the can that the contents are separated, submerge the whole can in a water bath at 130 degrees F. for ten minutes, then shake, open and proceed as above.

If it is desired to use a 40 per cent solution, as directed under the determination of the individual ingredients, weigh accurately 40 grams of the properly mixed contents of the can into a 100 c.c. graduated flask. Add 60 c.c. water and mix thoroughly by shaking or stirring.

\section{Specific Gravity. Aerometric Method. \\ Apparatus.}

Beaumé hydrometer.-Use a special Beaumé hydrometer with a scale ranging from five to twelve points, graduated to tenths degrees and mercury-weighted. Length over all eleven inches, length of spindle six inches, length of empty bulb four inches and width of empty bulb seven-eighths inch.

Hydrometer jar:- Use a glass or tin cylinder with substantial base. Minimum height ten inches and minimum width one and a half inches.

\section{Determination.}

The Beaumé hydrometer is graduated to read correctly at 60 degrees F. (15.5 degrees C.). For every degree Fahrenheit 
above 60 add .0313 points to the observed reading. For every degree Fahrenheit below 60, deduct .0313 points from the observed reading.

The specific gravity is determined by the use of the following formula :

$$
\text { Specific gravity }=\frac{145.5}{145.5-\mathrm{B}}
$$

$\mathrm{B}=$ Corrected Beaumé reading.

Example: Beaumé reading at 80 degrees $\mathrm{F}$. is 7.8 .

Corrected reading $=7.8+\lceil(80-60) \times .0313\rceil=8.43$.

Specific gravity $=\frac{145.5}{145.5-8.43}=1.0615$.

Equally good results may be obtained by diluting the evaporated milk with an equal weight of water. Then take the Quevenne lactometer reading at 60 degrees $F$. Multiply the reading by 2 , add 1000 , and divide by 1000 .

\section{Gravimetric Determination.}

Dilute the evaporated milk with four times its weight of water and proceed as directed under "Milk."

\section{Total Solids.}

\section{By Means of Specific Gravity and Babcock Formula.}

Determine the specific gravity as above directed. Multiply by 1000 and substract 1000 . Then use the following formula:

$$
\frac{\mathrm{L}}{4}+1.2 \times \mathrm{f}
$$

$L_{1}=$ The figure derived from the specific gravity by above calculations.

$\mathrm{f}=$ per cent fat.

Example: Evaporated milk tests 7.8 per cent fat and has a specific gravity of 1.0615 .

$$
\begin{aligned}
& \mathrm{L}=(1.0615 \times 1000)-1000=61.5 . \\
& \quad \text { Total solids }=\frac{61.5}{4}+1.2 \times 7.8=24.74 \text { per cent } .
\end{aligned}
$$

For rapid determination of the total solids of evaporated milk the factory operator is referred to the following tables from which the per cent total solids may be read at a glance when the Beaumé reading at 60 degrees $F$. and the per cent fat are known. 


\section{Per Cent Solids of Evaporated Milk.}

The Beaumé Degrees at 60 Degrees F. are Indicated in the Horizontal Line at the Top. The Per Cent of Fat is Shown in the Vertical Column at the Left.

\begin{tabular}{|c|c|c|c|c|c|c|c|c|c|c|}
\hline \multicolumn{11}{|c|}{ Beaumé reading at 60 degrees Fahrenheit } \\
\hline & 8.0 & 8.1 & 8.2 & 8.3 & 8.4 & 8.5 & 8.6 & 8.7 & 8.8 & 8.9 \\
\hline $\begin{array}{c}\text { PER } \\
\text { CENT }\end{array}$ & $\begin{array}{c}\text { Solids } \\
\text { per } \\
\text { cent. }\end{array}$ & $\begin{array}{c}\text { Solids } \\
\text { per } \\
\text { cent. }\end{array}$ & $\begin{array}{c}\text { Solids } \\
\text { per } \\
\text { cent. }\end{array}$ & $\begin{array}{c}\text { Solids } \\
\text { per } \\
\text { cent. }\end{array}$ & $\begin{array}{l}\text { Solids } \\
\text { per } \\
\text { cent. }\end{array}$ & $\begin{array}{c}\text { Solids } \\
\text { per } \\
\text { cent. }\end{array}$ & $\begin{array}{c}\text { Solids } \\
\text { per } \\
\text { cent. }\end{array}$ & $\begin{array}{c}\text { Solids } \\
\text { per } \\
\text { cent. }\end{array}$ & $\begin{array}{c}\text { Solids } \\
\text { per } \\
\text { cent. }\end{array}$ & $\begin{array}{c}\text { Sollds } \\
\text { per } \\
\text { cent. }\end{array}$ \\
\hline $\begin{array}{l}6.0 \\
6.2 \\
6.4 \\
6.6 \\
6.8\end{array}$ & $\begin{array}{l}21.75 \\
21.99 \\
22.23 \\
22.47 \\
22.71\end{array}$ & $\begin{array}{l}21.94 \\
22.18 \\
22.42 \\
22.66 \\
22.90\end{array}$ & $\begin{array}{l}22.13 \\
22.37 \\
22.61 \\
22.85 \\
23.09\end{array}$ & $\begin{array}{l}22.32 \\
22.56 \\
22.80 \\
23.04 \\
23.28\end{array}$ & $\begin{array}{l}22.52 \\
22.76 \\
23.00 \\
23.24 \\
23.48\end{array}$ & $\begin{array}{l}22.71 \\
22.95 \\
23.19 \\
23.43 \\
23.67\end{array}$ & $\begin{array}{l}22.90 \\
23.14 \\
23.38 \\
23.62 \\
23.86\end{array}$ & $\begin{array}{l}23.10 \\
23.34 \\
2358 \\
23.82 \\
24.06\end{array}$ & $\begin{array}{r}23.29 \\
23.53 \\
23.77 \\
24.01 \\
24.25\end{array}$ & $\begin{array}{l}23.49 \\
23.73 \\
23.97 \\
24.21 \\
2445\end{array}$ \\
\hline $\begin{array}{l}7.0 \\
7.2 \\
7.4 \\
7.6 \\
7.8\end{array}$ & $\begin{array}{l}22.95 \\
23.19 \\
23.43 \\
23.67 \\
23.91\end{array}$ & $\begin{array}{l}23.14 \\
23.38 \\
23.62 \\
23.86 \\
24.10\end{array}$ & $\begin{array}{l}23.33 \\
23.57 \\
23.81 \\
24.05 \\
24.29\end{array}$ & $\begin{array}{l}23.52 \\
23.76 \\
24.00 \\
24.24 \\
24.48\end{array}$ & $\begin{array}{l}23.72 \\
23.96 \\
24.20 \\
24.44 \\
24.68\end{array}$ & $\begin{array}{l}23.91 \\
24.15 \\
24.39 \\
24.63 \\
24.87\end{array}$ & $\begin{array}{l}24.10 \\
24.34 \\
24.58 \\
24.82 \\
25.06\end{array}$ & $\begin{array}{l}24.30 \\
24.54 \\
24.78 \\
25.02 \\
25.26\end{array}$ & $\begin{array}{l}24.49 \\
24.73 \\
24.97 \\
25.21 \\
25.45\end{array}$ & $\begin{array}{l}24.69 \\
24.93 \\
25.17 \\
25.41 \\
25.65\end{array}$ \\
\hline $\begin{array}{l}8.0 \\
8.2 \\
8.4 \\
8.6 \\
8.8\end{array}$ & $\begin{array}{l}24.15 \\
24.39 \\
24.63 \\
24.87 \\
25.11\end{array}$ & $\begin{array}{l}24.34 \\
24.58 \\
24.82 \\
25.06 \\
25.30\end{array}$ & $\begin{array}{l}24.53 \\
24.77 \\
25.01 \\
25.35 \\
25.49\end{array}$ & $\begin{array}{l}2472 \\
24.96 \\
25.20 \\
25.44 \\
25.68\end{array}$ & $\begin{array}{l}24.92 \\
25.16 \\
25.40 \\
25.64 \\
25.88\end{array}$ & $\begin{array}{l}2511 \\
25.35 \\
25.59 \\
25.83 \\
26.07\end{array}$ & $\begin{array}{l}25.30 \\
25.54 \\
25.78 \\
26.02 \\
26.26\end{array}$ & $\begin{array}{l}25.50 \\
25.74 \\
25.98 \\
26.22 \\
26.46\end{array}$ & $\begin{array}{l}25.69 \\
25.93 \\
26.17 \\
26.41 \\
26.65\end{array}$ & $\begin{array}{l}25.89 \\
26.13 \\
26.37 \\
26.61 \\
26.85\end{array}$ \\
\hline $\begin{array}{l}9.0 \\
9.2 \\
9.4 \\
9.6 \\
9.8\end{array}$ & $\begin{array}{l}25.35 \\
25.59 \\
25.83 \\
26.07 \\
26.31\end{array}$ & $\begin{array}{l}25.54 \\
25.78 \\
26.02 \\
26.26 \\
26.50\end{array}$ & $\begin{array}{l}25.73 \\
25.97 \\
26.21 \\
26.45 \\
26.69\end{array}$ & $\begin{array}{l}25.92 \\
26.16 \\
26.40 \\
26.64 \\
26.88\end{array}$ & $\begin{array}{l}26.12 \\
26.36 \\
26.60 \\
26.84 \\
2708\end{array}$ & $\begin{array}{l}26.31 \\
26.55 \\
26.79 \\
27.03 \\
27.27\end{array}$ & $\begin{array}{l}26.50 \\
26.74 \\
26.98 \\
27.22 \\
2746\end{array}$ & $\begin{array}{l}26.70 \\
26.94 \\
27.18 \\
27.42 \\
27.66\end{array}$ & $\begin{array}{l}26.89 \\
27.13 \\
27.37 \\
27.61 \\
27.85\end{array}$ & $\begin{array}{l}27.09 \\
27.33 \\
27.57 \\
27.81 \\
28.05\end{array}$ \\
\hline $\begin{array}{l}10.0 \\
10.2 \\
10.4 \\
10.6 \\
10.8\end{array}$ & $\begin{array}{l}26.55 \\
26.79 \\
27.03 \\
27.27 \\
2751\end{array}$ & $\begin{array}{l}26.74 \\
26.98 \\
27.22 \\
27.46 \\
2770\end{array}$ & $\begin{array}{l}26.93 \\
27.17 \\
27.41 \\
27.65 \\
27.89\end{array}$ & $\begin{array}{l}27.12 \\
27.36 \\
27.60 \\
27.84 \\
28.08\end{array}$ & $\begin{array}{l}27.32 \\
27.56 \\
27.80 \\
28.04 \\
28.28\end{array}$ & $\begin{array}{l}27.51 \\
27.75 \\
27.99 \\
28.23 \\
28.47\end{array}$ & $\begin{array}{l}27.70 \\
27.94 \\
28.18 \\
28.42 \\
28.66\end{array}$ & $\begin{array}{l}27.90 \\
28.14 \\
2838 \\
28.62 \\
28.86\end{array}$ & $\begin{array}{l}28.09 \\
28.33 \\
28.57 \\
28.81 \\
29.05\end{array}$ & $\begin{array}{l}28.29 \\
28.53 \\
28.77 \\
29.01 \\
29.25\end{array}$ \\
\hline $\begin{array}{l}11.0 \\
11.2 \\
11.4 \\
11.6 \\
11.8\end{array}$ & $\begin{array}{l}2775 \\
27.99 \\
28.23 \\
28.47 \\
28.71\end{array}$ & $\begin{array}{l}27.94 \\
28.18 \\
28.42 \\
28.66 \\
28.90\end{array}$ & $\begin{array}{l}28.13 \\
28.37 \\
28.61 \\
28.85 \\
29.09\end{array}$ & $\begin{array}{l}28.32 \\
28.56 \\
28.80 \\
29.04 \\
29.28\end{array}$ & $\begin{array}{l}28.52 \\
28.76 \\
29.00 \\
29.24 \\
29.48\end{array}$ & $\begin{array}{l}28.71 \\
28.95 \\
29.19 \\
29.43 \\
29.67\end{array}$ & $\begin{array}{l}28.90 \\
29.14 \\
29.38 \\
29.62 \\
29.86\end{array}$ & $\begin{array}{l}29.10 \\
29.34 \\
29.58 \\
29.82 \\
30.06\end{array}$ & $\begin{array}{l}29.29 \\
29.53 \\
29.77 \\
30.01 \\
30.25\end{array}$ & $\begin{array}{l}29.49 \\
29.73 \\
29.97 \\
30.21 \\
30.45\end{array}$ \\
\hline
\end{tabular}


Per Cent Solids of Evaporated Milk (Continued).

The Beaumé Degrees at 60 Degrees F. are Indicated in the Horizontal Line at the Top. The Per Cent of Fat is Shown in the Vertical Column at the Left.

Beaumé reading at 60 degrees Fahrenheit

\begin{tabular}{|c|c|c|c|c|c|c|c|c|c|c|}
\hline \multirow{2}{*}{$\begin{array}{c}\text { FAT } \\
\text { PER } \\
\text { CENT }\end{array}$} & 9.0 & 9.1 & 9.2 & 9.3 & 9.4 & 9.5 & 9.6 & 9.7 & 9.8 & 9.9 \\
\hline & $\begin{array}{c}\text { Solids } \\
\text { per } \\
\text { cent }\end{array}$ & $\begin{array}{c}\text { Solids } \\
\text { per } \\
\text { cent. }\end{array}$ & $\begin{array}{c}\text { Solids } \\
\text { per } \\
\text { cent. }\end{array}$ & $\begin{array}{c}\text { Solids } \\
\text { per } \\
\text { cent }\end{array}$ & $\begin{array}{c}\text { Solids } \\
\text { per } \\
\text { cent. }\end{array}$ & $\begin{array}{c}\text { Solids } \\
\text { per } \\
\text { cent. }\end{array}$ & $\begin{array}{l}\text { Solids } \\
\text { per } \\
\text { cent. }\end{array}$ & $\begin{array}{c}\text { Solids } \\
\text { per } \\
\text { cent. }\end{array}$ & $\begin{array}{l}\text { Solids } \\
\text { per } \\
\text { cent }\end{array}$ & $\begin{array}{l}\text { Solids } \\
\text { per } \\
\text { cent }\end{array}$ \\
\hline 6.0 & 23.68 & 23.88 & 24.08 & 24.27 & 24.47 & 24.66 & 24.86 & 25.06 & 25.26 & 25.45 \\
\hline 6.2 & 23.92 & 24.12 & 24.32 & 24.51 & 24.71 & 24.90 & 25.10 & $2 \zeta .30$ & 25.50 & 25.69 \\
\hline 6.4 & 24.16 & 24.36 & 24.56 & 24.75 & 24.95 & 25.14 & 25.34 & 25.51 & 25.74 & 25.93 \\
\hline 6.6 & 24.40 & 24.60 & 24.80 & 24.99 & 25.19 & 25.38 & 25.58 & 25.78 & 25.98 & 26.17 \\
\hline 6.8 & 24.64 & 24.84 & 25.04 & 25.23 & 25.43 & 25.62 & 25.82 & 26.02 & 26.22 & 26.41 \\
\hline 7.0 & 24.88 & 25.08 & 25.28 & 25.47 & 25.67 & 25.86 & 26.06 & 26.26 & 26.46 & 26.65 \\
\hline 7.2 & 25.12 & 25.32 & 25.52 & 25.71 & 25.91 & 26.10 & 26.30 & 26.50 & 26.70 & 26.89 \\
\hline 7.4 & 25.36 & 25.56 & 25.76 & 25.95 & 26.15 & 26.34 & 26.54 & 26.74 & 26.94 & 27.13 \\
\hline 7.6 & 25.60 & 25.80 & 26.00 & 26.19 & 26.39 & 26.58 & 26.78 & 26.98 & 27.18 & 27.37 \\
\hline 7.8 & 25.84 & 26.04 & 26.24 & 26.43 & 26.63 & 26.82 & 27.02 & 2722 & 27.42 & 27.61 \\
\hline 8.0 & 26.08 & 26.28 & 26.48 & 26.67 & 26.87 & 27.06 & 27.26 & 27.46 & 27.66 & 27.85 \\
\hline 8.2 & 26.32 & 26.52 & 26.72 & 26.91 & 27.11 & 27.30 & 27.50 & 27.70 & 27.90 & 28.09 \\
\hline .4 & 26.56 & 26.76 & 26.96 & 27.15 & 27.35 & 27.54 & 27.74 & 27.94 & 28.14 & 28.33 \\
\hline 8.6 & 26.80 & 27.00 & 27.20 & 27.39 & $\begin{array}{l}27.59 \\
27.82\end{array}$ & 27.78 & 27.98 & 2818 & 28.38 & 28.57 \\
\hline 8.8 & 27.04 & 27.24 & 27.44 & 2763 & 27.83 & 28.02 & 28.22 & 2842 & 28.62 & 28.81 \\
\hline 9.0 & 27.28 & 27.48 & 27.68 & 27.87 & 28,07 & 28.26 & 28.46 & 28.66 & 28.86 & 29.05 \\
\hline 9.2 & 27.52 & 27.72 & 27.92 & 28.11 & 28.31 & 28.50 & 28.70 & 28.90 & 29.10 & 29.29 . \\
\hline 9.4 & 27.76 & 27.96 & 28.16 & 28.35 & 28.55 & 28.74 & 28.94 & 29.14 & 29.34 & 29.53 \\
\hline 9.6 & 28.00 & 28.20 & 28.40 & 28.59 & 28.79 & 28.98 & $29: 18$ & 29.38 & 29.53 & 29.77 \\
\hline 9.8 & 28.24 & 28.44 & 28.64 & 28.83 & 29.03 & 29.22 & 29.42 & 29.62 & 29.82 & 30.01 \\
\hline 10.0 & 28.48 & 28.68 & 28.88 & 29.07 & 29.27 & 29.46 & 29.66 & 29.86 & 30.06 & 30.25 \\
\hline 10.2 & 28.72 & 28.92 & 29.12 & 29.31 & 29.51 & 29.70 & 29.90 & 30.10 & 30.30 & 30.49 \\
\hline 10.4 & 28.96 & 29.16 & 29.36 & 29.55 & 29.75 & 29.94 & 30.14 & 30.34 & 30.54 & 30.73 \\
\hline 10.6 & 29.20 & 29.40 & 29.60 & 29.79 & 29.99 & 30.18 & 30.33 & 3058 & 30.78 & 30.97 \\
\hline 10.8 & 29.44 & 29.64 & 29.84 & 30.03 & 30.23 & 30.42 & 30.62 & 30.82 & 31.02 & 31.21 \\
\hline 11.0 & 29.68 & 29.88 & 30.08 & 30.27 & 30.47 & 30.66 & 30.86 & 31.06 & 31.26 & 31.45 \\
\hline 11.2 & 29.92 & 30.12 & 30.32 & 30.51 & 30.71 & 30.90 & 31.10 & 31.30 & 31.50 & 31.69 \\
\hline 11.4 & 30.16 & 30.36 & 30.56 & 30.75 & 30.95 & 31.14 & 3134 & 31.54 & 31.74 & 31.93 \\
\hline 11.6 & 30.40 & 30.60 & 30.80 & 30.99 & 31.19 & 31.38 & 3158 & 31.78 & 31.98 & 32.17 \\
\hline 11.8 & 30.64 & 30.84 & 31.04 & 31.23 & 31.43 & 31.62 & 31.82 & 32.02 & 32.22 & 3241 \\
\hline
\end{tabular}


Per Cent Solids of Evaporated Milk (Continued).

The Beaumé Degrees at 60 Degrees F. are Indicated in the

Horizontal Line at the Top. The Per Cent of Fat is Shown in the Vertical Column at the I,eft.

\begin{tabular}{|c|c|c|c|c|c|c|c|c|c|c|}
\hline \multicolumn{11}{|c|}{ Beaumé reading at 60 degrees Fahrenheit } \\
\hline \multirow{2}{*}{$\begin{array}{c}\text { FAT } \\
\text { PER } \\
\text { CENT }\end{array}$} & 10.0 & 10.1 & 10.2 & 10.3 & 10.4 & 10.5 & 10.6 & 10.7 & 10.8 & 10.9 \\
\hline & $\begin{array}{l}\text { Solids } \\
\text { per } \\
\text { cent. }\end{array}$ & $\begin{array}{c}\text { Solids } \\
\text { per } \\
\text { cent. }\end{array}$ & $\begin{array}{c}\text { Solids } \\
\text { per } \\
\text { cent. }\end{array}$ & $\begin{array}{l}\text { Solids } \\
\text { per } \\
\text { cent. }\end{array}$ & $\begin{array}{c}\text { Solids } \\
\text { per } \\
\text { cent. }\end{array}$ & $\begin{array}{c}\text { Solids } \\
\text { per } \\
\text { cent. }\end{array}$ & $\begin{array}{c}\text { Solids } \\
\text { per } \\
\text { cent. }\end{array}$ & $\begin{array}{c}\text { Solids } \\
\text { per } \\
\text { cent. }\end{array}$ & $\begin{array}{c}\text { Solids } \\
\text { per } \\
\text { cent. }\end{array}$ & $\begin{array}{c}\text { Solids } \\
\text { per } \\
\text { cent. }\end{array}$ \\
\hline 6.0 & 25.65 & 25.85 & 26.05 & 26.25 & 26.45 & 26.65 & 26.85 & $27.05^{\circ}$ & 27.25 & 27.45 \\
\hline 6.2 & 25.89 & 26.09 & 26.29 & 26.49 & 26.69 & 26.89 & 27.09 & 27.29 & 27.49 & 27.69 \\
\hline & 26.13 & 26.33 & 26.53 & 26.73 & 26.93 & 27.13 & 27.33 & & & 27.93 \\
\hline 6.6 & 26.37 & 26.57 & 26.77 & 26.97 & .27 .17 & 27.37 & 27.57 & 27.77 & 27.97 & 28.17 \\
\hline 6.8 & 26.61 & 26.81 & 27.01 & 27.21 & 27.41 & 27.61 & 27.81 & 28.01 & 28.21 & 28.41 \\
\hline 7.0 & 26.85 & 27.05 & 27.25 & & & 27.85 & 28.05 & & & 28.65 \\
\hline 7.2 & 27.09 & 27.29 & 27.49 & 27.6 & 27.8 & 28.09 & 28.29 & & & 28.89 \\
\hline & 27.33 & 27.53 & 27.73 & 27.93 & 28.13 & 28.33 & 28.53 & 28.73 & 28 . & 29.13 \\
\hline & 27.57 & 27.77 & 27.97 & 28.17 & 28.37 & 28.57 & 28.77 & 28. & 29 & 29.37 \\
\hline 7.8 & 27.81 & 28.01 & 28.21 & 28.41 & 28.61 & 28.81 & 29.01 & 29.21 & 29.41 & 29.61 \\
\hline 8.0 & 28.05 & & & & & & & & & \\
\hline 8.2 & 28.29 & 28.49 & 28.69 & 28.89 & 29.09 & 29.29 & 29.49 & 29 & 29.89 . & 30.09 \\
\hline 8.4 & 28.53 & 28.73 & 28.93 & 29.13 & 29.33 & 29.53 & 29.73 & 29.93 & 30.13 & 30.33 \\
\hline & 28.77 & 28.97 & 29.17 & 29.37 & 29. & 29 & 29.97 & & & 30.57 \\
\hline 8.8 & 29.01 & 29.21 & 29.41 & 29.61 & 29.81 & 30.01 & 30.21 & 30.41 & 30.61 & 30.81 \\
\hline 9.0 & 29.25 & 29.45 & 29.65 & 29.85 & 30.05 & 80.25 & 30.45 & 30.65 & 30 & 31.05 \\
\hline 9.2 & 29.49 & 29.69 & 29.89 & 30.09 & 30.29 & 80.49 & 30.69 & & & 31.29 \\
\hline 9.4 & 29.73 & 29.93 & 30.13 & 30.33 & 30.53 & 80.73 & 30.93 & 31.13 & 31.33 & 31.53 \\
\hline & 29.97 & 30.17 & 30.37 & 30. & & & 31.17 & & & 31.77 \\
\hline 9.8 & 30.21 & 30.41 & 30.61 & 30.81 & 31.01 & 31.21 & 31.41 & 31.61 & 31.81 & 32.01 \\
\hline 10.0 & 30.45 & 30.65 & 30.85 & 31.05 & 31.25 & 31.45 & 31.65 & & 32.05 & 32.25 \\
\hline & 30.6 & 30.89 & 31.09 & 31.2 & 31.49 & 81. & 31.89 & 9 & 32.2 & 32.49 \\
\hline 10.4 & 30.93 & 31.13 & 31.33 & 31.53 & 31.73 & 81.93 & 32.13 & 32.33 & 32.53 & 32.73 \\
\hline 10.6 & 31.17 & 31.37 & 31.57 & 31.77 & 31.97 & 32.17 & 32.37 & 32.57 & 32.77 & 32.97 \\
\hline 10.8 & 31.41 & 31.61 & 31.81 & 32.01 & 32.21 & 32.41 & 32.61 & 32.81 & 33.01 & 33.21 \\
\hline 11.0 & 31.65 & 31.85 & 32.05 & 32.25 & 32.45 & 32.65 & 32.85 & 33.05 & 33.25 & 33.45 \\
\hline .11 .2 & 31.8 & 32.09 & 32.29 & 32.49 & 32.69 & 32.89 & 33.09 & 33.29 & 33.49 & 33.69 \\
\hline 11.4 & 32.13 & 32.33 & 32.53 & 32.73 & 32.93 & 33.13 & 33.33 & & 33.73 & 33.93 \\
\hline 11.6 & 32.37 & 32.57 & 32.77 & 32.97 & 33.17 & 33.37 & 33.57 & 33.77 & 33.97 & 34.17 \\
\hline 11.8 & 32.61 & 32.81 & 33.01 & 33.21 & 33.41 & 33.61 & 33.81 & 34.01 & 34.21 & 34.41 \\
\hline
\end{tabular}




\section{Gravimetric Determination.}

Dilute a measured portion of a 40 per cent solution with an equal volume of water, use 5 c.c. of the diluted mixture, corresponding to 1 gram of the evaporated milk and proceed as directed under "Milk."

\section{Ash.}

Ignite the total solids at very low redness, cool, weigh, see "Milk."

\section{Proteids.}

Use 5 c.c. of a 40 per cent solution, determine nitrogen according to the Gunning method as directed under "Milk," and multiply result by 6.38 .

\section{Lactose.}

Dilute 10 grams of a 40 per cent solution to about 40 c.c. and add .6 c.c. of Fehling's copper solution; nearly neutralize with sodium hydroxide, make up to 100 c.c., filter through dry filter, and determine lactose in an aliquot as directed under "Milk."

\section{Fat.}

\section{The Modified Babcock Method. ${ }^{1}$}

Carefully weigh 4.5 grams of well-mixed evaporated milk into the 8 per cent test bottle. Add one 17.6 c.c. pipetteful of water. Add 17.5 c.c. of sulphuric acid and shake until the curd in the test bottle is completely dissolved. Whirl at usual speed (one thousand revolutions per minute) for five minutes. Mix equal portions of water and sulphuric acid in glass beaker. For one or two tests, one pipetteful of water and one acid measure full of acid are sufficient. Fill test bottle to slightly below the bottom of the neck with the hot diluted acid. Whirl for two minutes. If the fat collected at the base of the neck is not clear, shake the bottle until all the curdy matter is completely dissolved, fill the bottle to about the 8 per cent mark with hot mater, whirl for one minute and read the test at 135 degrees $\mathrm{F}$. The fat column must be read from the top of the upper meniscus to the bottom of the lower meniscus. Multiply the reading by 4 . This gives the correct per cent of fat.

Instead of weighing 4.5 grams into the test bottle, a 4.3 c.c. 1 Hunziker and Spitzer, Indiana Agricultural Experiment Station, Bulletin
No. 134, 1909. 
pipette may be used. After emptying the pipette into the bottle it should be rinsed twice and the rinsings discharged into the test bottle.

For making numerous tests from the same sample it is advisable to dilute the evaporated milk with equal parts of water, by weight; then weigh nine grams of this dilution into the test bottle and add one-half pipetteful of water.

The Roese-Gottlieb Method.

Proceed as directed under "Sweetened Condensed Milk."

\section{MILK POWDER.}

\section{Total Solids.}

Weigh 5 grams of the milk powder in a drying bottle or evaporating dish and place in drying oven at 100 to 105 degrees C. until constant weight is secured.

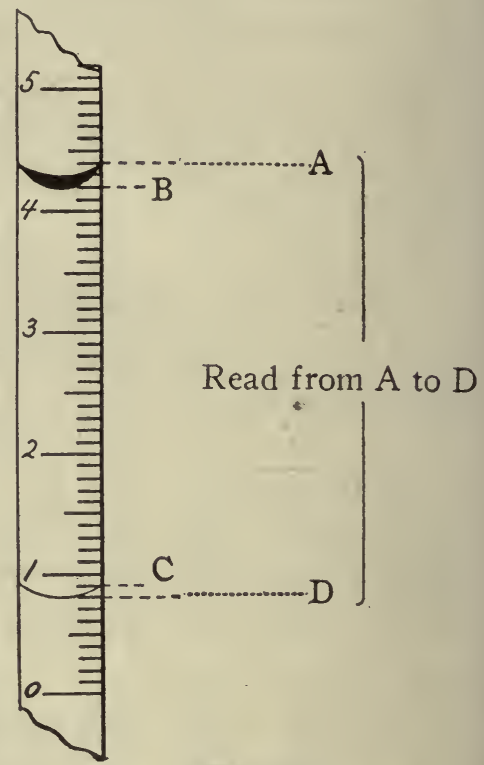

Fig. 111

Reading the Babcock test

Ash.

Weigh two grams of the milk powder in a weighed platinum dish and proceed as directed under "Milk."

\section{Proteids.}

Use five grams of the milk powder and proceed as directed under "Milk."

\section{Milk Sugar (Lactose).}

Dissolve ten grams of milk powder in 90 c.c. of water. Warm and stir until a satisfactory solution is effected and proceed as directed under "Milk," and multiply result by 10 .

\section{Sucrose.}

For the determination of sucrose proceed as directed under "Sweetened Condensed Milk." 
Fat.

The Babcock Test Method.-Dissolve ten grams of milk powder in 90 c.c. of water. Warm and mix until a complete solution is effected. Then proceed as directed under "Milk," and multiply the result by 10 .

"Roese-Gottlieb Method.-Weigh one gram of the powder in a 30 c.c. lipped beaker. Rub up with 9 c.c. of water and 2 c.c. of concentrated ammonium hydroxid, digest on steam bath until the casein is well softened and the whole resembles milk. Cool, transfer to Röhrig tube or similar apparatus, using 10 c.c. of 95 per cent alcohol for rinsing, followed, after shaking contents of tube, by 25 c.c. of washed ethyl ether. Shake vigorously for one-half minute and proceed as in the determination of fat in sweetened condensed milk."

\section{Chapter XXXI.}

\section{THE MOJONNIER TEST FOR FAT -AND SOLIDS. ${ }^{1}$}

The Mojonnier test for fat and solids in milk and milk products represents the use of chemical apparatus and mechanical devices of a high degree of precision, ingeniously invented, scientifically modified and especially adapted for accurate tests of dairy products. It offers methods of fat and solids estimations that combine the accuracy of official chemical analysis with the rapidity of factory tests. It has been introduced in and is successfully used by most of the progressive milk-condensing factories in the country, and it is admirably filling a long-felt demand for reliable and accurate methods of testing milk, condensed milks and milk powders and for standardizing these products under factory conditions.

\section{EQUIPMENT.}

Install the tester on a solid foundation in a room protected against excessive fluctuations in temperature.

1. Tester for butter fat.

2. Tester for total solids.

3. Fat extraction flasks.

${ }^{1}$ Directions furnished through courtesy of Mojonnier Bros. Co., Milk Engineers, Chicago. 
4. Eight $3 \frac{1}{2}$-inch aluminum dishes without covers and with tall counterpoise which tares the eight dishes, for fat tests.

5. Eight 3-inch aluminum dishes with covers and short counterpoise, for solids tests.

6. Fat oven. Keep temperature at $135^{\circ} \mathrm{C}$.

7. Cooling chamber.

8. Solids oven. Keep temperature at $100^{\circ} \mathrm{C}$.

9. $250^{\circ} \mathrm{C}$. thermometer for solids oven. Have mercury bulb

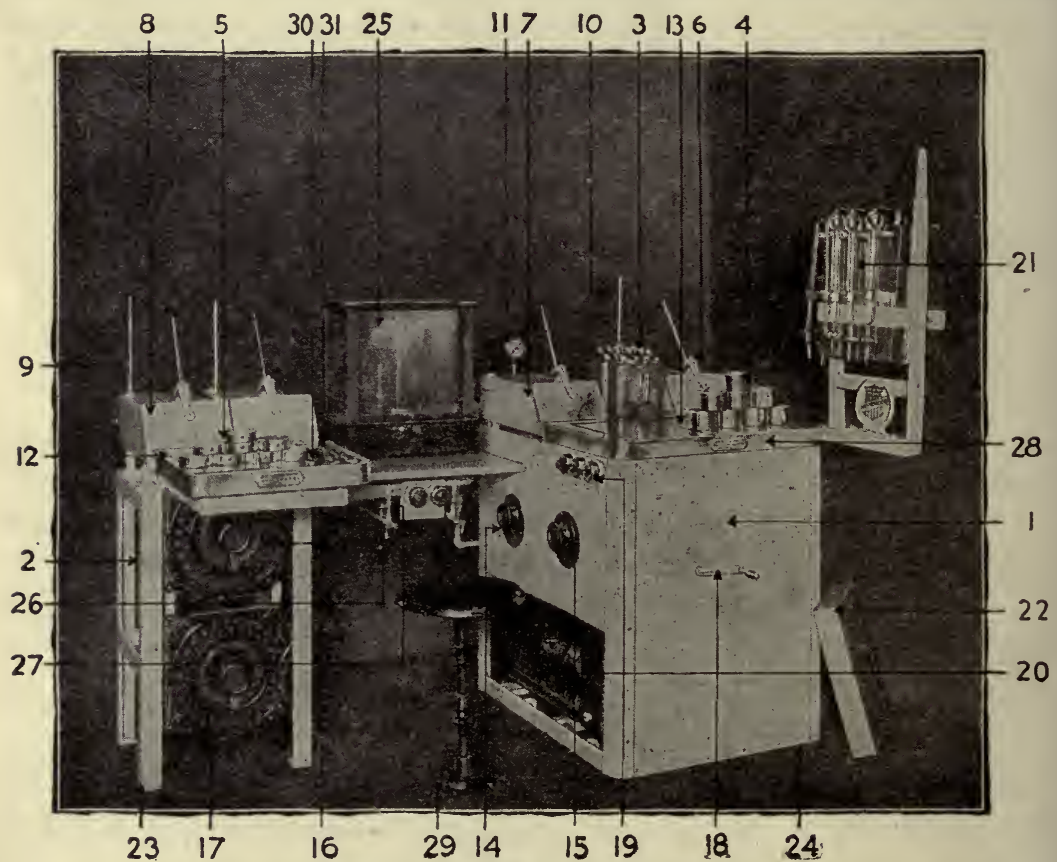

IIg. 112. The Mojonnier tester

Courtesy of Mojonnier Bros. Company

fit snugly into brass mercury well. Brass mercury well must always form good contact with hot plate.

10. $250^{\circ} \mathrm{C}$. thermometer for fat oven. Observe same precautions as in (9).

11. Vacuum gauge on main suction line, registers either or both ovens.

12. Solids plate. Must be level and held at $180^{\circ} \mathrm{C}$.

13. Fat plate. Hold at $135^{\circ} \mathrm{C}$. 
14. Rheostat for fat plate. Lever must make good contact with one button, not with two at a time. When right button has been found that maintains constant temperature, mark this point on rheostat rim. When starting tester each day, turn handle on full until temperature has risen to within right point, then turn back to previously marked button. (14).

15. Rheostat for fat oven. Observe same precautions as in

16. Rheostat for solids oven. Observe same precautions as in (14).

17. Rheostat for solids plate. Observe same precautions as in (14).

18. Handle for centrifuge.

19. Snap switches for each hot plate showing temperature and time for treating samples at various points.

20. Power unit, consisting of vacuum pump, water circulating pump and motor for same. Keep pump filled to air cock with oil furnished with tester.

21. Automatic burettes and cans holding the water, ammonia, alcohol, ethyl ether and petroleum ether, placed in the order in which they are used. Each division on burettes delivers the proper amount of the desired reagent for a single extraction.

22. Hood, to be placed over fat dishes when evaporating off ether.

23. Legs, to be fastened to floor with lag screws.

24. This side need not be fastened to floor. If necessary to take out power unit disconnect connections in rear of machine and move this part of machine forward.

25. Chemical balance. Keep level, clean and handle carefully. Raise knife edges gradually and with care. Clean balance daily. Keep weights clean. When weights show signs of wear, order new. ones.

26. Cock, to exhaust vacuum from oven when cock (27) is closed. Must be kept closed when vacuum is turned on oven.

27. Cock, that switches vacuum from main line into vacuum oven. Set of cocks at right is for solids oven, set of cocks at left is for fat oven.

28. Hole in top of fat plate holder, communicating with suction 
fan, on power unit. Run exhaust pipe on suction fan out of window and keep hood over the dishes in order to drive all ether fumes from room.

29. Stool, to be screwed to floor.

\section{DIRECTIONS FOR OPERATING MOJONNIER TEST.}

Preliminary directions for tests of both Fat and Solids.

(1) Wash solids dishes with warm water and fat dishes with gasoline. Dry with a towel and place into heated vacuum oven for five minutes with vacuum on. At the end of five minutes put these dishes into cooler and, with the pump still running, keep them there for five minutes before weighing. Do not turn off motor until last dish is weighed out of cooling chaniber.

(2) While dishes are being heated and cooled, wash pipettes with water, alcohol and ether and dry by applying vacuum at exhaust cock upon tester. Always use clean and dry pipettes for each different sample. Aim to clean pipettes as well as all glassware, immediately after using.

(3) It is very important to keep extraction flasks clean. Wash these with warm water immediately after extraction is finished. Wash with washing powder and shot when necessary.

(4)) After aluminium dishes have been in cooler for at least five minutes, weigh accurately to .0001 gram, using the proper counterpoise. WVeigh solids dishes with cover on. Fat dishes do. not have covers. Fat dishes should be cooled for seven minutes before being weighed.

(5) Use weighing pipettes as follows: Fill five-gram pipette up to five-gram mark for butter fat, and one-gram pipette up to one-gram mark for total solids. If duplicates are to be run fill two pipettes from the same sample. As pipettes are filled place lower end into cleaned and dry rubber tubes which are pressed upon knobs at ends and center of weighing cross. Either five or less samples for butter fat or five or less for total solids may be pipetted out.

(6) Weigh the cross with the pipettes containing the milk on chemical balance accurately to .0001 gram. Run milk from pipette into proper flask, or 3-inch dish if making solids test. The pipettes may be distinguished by the number upon each 
cross. Replace pipette and weigh again. Difference in weight gives weight of sample. Repeat until all samples are run into proper flasks, and into weighed solids dishes if solids are determined along with the fat.

For fat in Sweetened Condensed Milk use a five-gram sample. The five-gram pipette delivers approximately five grams between the five-gram mark and the base of the bowl of the pipette.

Some operators prefer to mix 200 grams of sweetened condensed milk with 200 grams of water, weighing these carefully upon a Harvard trip scale sensitive to .1 gram. In this case care must be exercised to obtain the exact weight of both milk and water and to stir these thoroughly with glass or metal rod before taking sample. A tall tumbler, a one-pound bottle or a quart cup make good containers in which to make mixture. A tengram sample of this mixture is used. This is best weighed out by using two five-gram pipettes on weighing cross.

For total solids weigh out $1 / 2(.5000)$ to $3 / 4$ (.7500) gram of this mixture. If the undiluted milk is used take as nearly (.2500) gram as possible.

For regular 8 per cent plain bulk condensed milk use same size samples and treat same as evaporated milk. For 12 per cent superheated condensed milk mix 100 grams milk with 300 grams water upon Harvard trip scale. Weigh ten-gram sample of this mixture into flask for fat and a two-gram sample into solids dish for solids. Multiply percentages obtained by four for correct percentages, when a 1 to 4 dilution is made.

\section{FRESH MILK, SKIM MILK, WHEY, BUTTERMILK.}

\section{Butter Fat Determination.}

(1) Use the ten-gram pipettes for measuring out ten grams of milk into cleaned but not necessarily dried Mojonnier extraction flask. Use only ten-gram pipettes furnished with tester and do not use 10 c.c. pipettes. The pipette is graduated to deliver ten grams of milk after allowing all milk to run out and letting it drain for fifteen seconds longer, then blowing gently to remove last drop. The pipette must be perfectly clean and dry before being used. Wash frequently with sulphuric acid, water, alcohol and ether to insure having a clean pipette. 
(2) Make extractions exactly as in test for butter fat in condensed milk, excepting that in second extraction only 15 c.c. of each ether need be used.

(3) Percentage butter fat is obtained by multipling the weight of the extracted butter fat by 10 .

(4) If any of these products have soured badly, double the quantity of ammonia in the regular extraction and shake until all particles are dissolved.

\section{Total Solids Determination.}

(1) Determine total solids às in evaporated milk, excepting that a two-gran sample is weighed out, and no water need be added to spread the milk over the bottom of the dish.

\section{SWEETENED CONDENSED MILK, EVAPORATED MILK AND CONDENSED BULK MILK.}

\section{Butter Fat Determination.}

(1) Remove flask from holder and run 4 c.c. water (one charge on water burette) into each flask. Be careful not to add more. Shake well until all of sample is mixed with water. This can be done without inserting cork.

For Sweetened Condensed Milk, if not diluted with water, add 6 c.c. of hot water with a pipette. To get hot water place fat dish filled with distilled water upon solids plate. If sweetened milk has been previously diluted with water and a ten-gram sample has been used, it is not necessary to add water.

It is very necessary to shake the flasks containing the sweetened condensed milk very thoroughly after the addition of each reagent. Sweetened condensed milk requires more shaking than any other liquid milk product.

(2) Before replacing flask into holder, add $1 \frac{1}{2}$ c.c. c.p. ammonia. Shake well so that all of sample is well mixed with ammonia. This can be done without inserting cork.

(3) Add 95 per cent alcohol up to base of top bulb of extraction flask. Insert cork, using best quality corks only. Replace flask into flask holder. Shake thoroughly and see that no milk adheres to any part of flask undissolved. In case particles of milk stick to side of flask, shake thoroughly until these are 
washed away. It is of the utmost importance to shake thoroughly at this point.

(4) Add 25 c.c. ethyl ether, insert cork and shake vigorously, lengthwise of flask, with liquid in large bulb of flask, and small bulb extended upward. Stop shaking at end of five seconds until all liquid has run into large bulb and repeat vigorous shaking for four five-second periods.

(5) Add 25 c.c. petroleum ether and shake in same way.

(6) Place extraction flasks into centrifuge and whirl for thirty turns at speed of about 600 R. P. M. Double time for sweetened condensed milk.

(7) Place four $3 \frac{1}{2}$-inch dishes in line on shelf adjoining hot plate, keeping them in order in which their weights were posted upon record sheet. Aim to have numbers on flasks correspond with number of dishes.

(8) Pour ether extraction to dividing line into proper dishes and slide dishes over onto hot plate, which should be held at a temperature of 135 degrees C., as indicated by thermometer inserted in nickel plated mercury well.

(9) Repeat the extraction, adding first alcohol enough to bring line close up to top of small neck of flask, then 25 c.c. ethyl ether, and then 25 c.c. petroleum ether, and shake vigorously after the addition of each of above three reagents for four 5 -second periods.

(10) Whirl in centrifuge for thirty turns.

(11) Move aluminum dishes back upon shelf adjoining hot. plate and pour the second extraction into proper dishes. Never pour extraction into hot dish. Remove dish from hot plate as soon as ether is all evaporated.

(12) When all of ether has evaporated place dishes into vacuum oven, which should have a temperature of 135 degrees centigrade. Keep them there for five minutes after the vacuum gauge shows at least twenty-two inches of vacuum.

(13) Place dishes into cooler for seven minutes, with pump outfit running. See that water is running through cooling plates.

(14) Place counterpoise for dish and the approximate weight for fat on right hand balance pan. 
(15) Transfer dish to left hand balance pan and weigh quickly to 0.10 milligram (0.0001 gr.).

"(16)" 'Weight of fat divided by weight of sample taken. multiplied by 100 , represents per cent butter fat.

\section{Total Solids Determination.}

(1) The temperature of the hot plate in the solids vacuum oven must be 100 degrees $\mathrm{C}$. The temperature of the outside solids plate must be 170 degrees to 180 degrees $\mathrm{C}$.

(2) 'To weighed milk' in solids dish add about 1 c.c. water and distribute mixture evenly over bottom of dish. For sweetened condensed milk use hot water.

(3) Place not more than two dishes at once upon hot plate, which must be perfectly level. Allow all visible moisture to evaporate. During the evaporation turn the dishes around with crucible tongs, slowly, so as to produce an even boiling over the whole bottom surface of the dishes. The dishes must be watched carefully during the evaporation. This step should require not more than two minutes. The end point is reached when bubbling and crackling ceases and sample shows first trace of brown. Vigorous boiling without spattering and complete evaporation are fundamentally essential.

(4) Place dishes into vacuum oven, which must be at 100 degrees C., and turn on the vacuum. Heat for ten minutes. In the case of sweetened condensed milk keep it for twenty minutes in vacuum oven The gauge should register not less than twenty-two inches of vacuum. If for any reason you cannot obtain at least twenty-two inches of vacuum then leave dishes in oven for twice the regular time.

(5) Remove from oven and place into cooler. Allow dishes to cool for five minutes.

(6) Weigh dishes with covers on in the same manner that the butter fat dishes were weighed, being careful: to weigh quickly and very exactly.

(7) Weight of dry solids divided by weight of milk taken, multiplied by 100 represents per cent total solids. 


\section{POWDERED MILK AND MALTED MILK.}

\section{Method of Sampling.}

Mix the sample thoroughly, making sure that it is sufficiently pulverized and representative of the entire lot to be tested. Transfer the pulverized sample promptly to a sealed jar. Mix before removing portions for testing.

\section{Butter Fat Determination.}

(1) Weigh out rapidly, to prevent absorption of moisture from the air, about one gram of milk powder into butter boat. In case of malted milk, weigh out a 0.5 gram sample.

(2) Add 8.5 c.c. of hot water to flask. Insert cork. Heat flask in water bath and shake thoroughly until the sample is well mixed.

(3) Add 1.5 c.c. (one charge) ammonia, and shake thoroughly.

(4) Add alcohol up to line on small neck of flask. Insert cork. Replace flask into flask holder. Shake flask thoroughly with cork inserted. Use best quality cork only.

(5) Cool flask by running cold water over lower end of extraction flask, if flask is very hot. This is not ordinarily necessary.

(6) Add 25 c.c. ethyl ether. Insert cork, shake vigorously until all butter is dissolved out of boat. Then add 25 c.c. petroleum ether and repeat operation.

(7) Centrifuge flasks, turning handle thirty turns after centrifuge has reached a speed of about 600 R. P. M.

(8) Pour off extractions into proper, weighed $3 \frac{1}{2}$-inch aluminum dishes. Repeat above extraction, adding first alcohol, then 25 c.c. of each ether. Excepting for very accurate work a third extraction is not necessary.

The second extraction will remove all but .10 to .15 per cent of the butter fat. For factory control work this would be a good margin of safety.

(9) Evaporate off ether at 135 degrees C. on "fat plate," and when all of ether is off, dry fat in fat oven held at 135 degrees C. for five minutes after the vacuum has reached at least twenty-two inches.

(10) Cool, weigh and calculate per cent butter fat. 


\section{Total Solids Determination.}

(1) Use .3000 gram sample. Add 2 c.c. distilled water to the sample in this dish. Mix milk powder and water thoroughly with the blunt rod.

(2) Continue the determination as under evaporated milk. but continue heating in the vacuum oven for twenty minutes.

\section{Chapter XXXII.}

\section{BACTERIOLOGICAL ANALYSES.}

While it is obviously beyond the scope and purpose of this volume to discuss in detail the technique of bacteriological analyses and microscopic preparations of the milk products described herein, it is deemed advisable to offer some suggestions that may serve for guidance of those who are not familiar with bacterial fermentations in condensed milk.

Sampling.-Take samples of all products contained in open receptacles, such as fluid milk, plain condensed bulk milk, barreled sweetened condensed milk and milk powder, in sterile, cotton plugged test tubes, or in small sterile glass-stoppered bottles, and keep them in a cool place, preferably not above 35 degrees F. until ready to use. Keep canned condensed milk sealed in the original package until ready to use. If already open, invert a petri dish or a beaker over the can to avoid contamination from the air.

Dilution for Numerical Counts.-Make dilutions in 250 c.c. glass-stoppered flasks. Before opening sealed cans, thoroughly wipe off the entire top with a sterile piece of cheese cloth soaked in a saturated solution of mercuric bichloride or a 5 per cent solution of carbolic acid and flame the top of the can. Open evaporated milk cans by punching a hole into their top, large enough to insert the discharge end of a graduated pipette. Open sweetened condensed milk cans with a sterile knife or a sterile can opener.

In the case of fluid milk and evaporated milk, measure with a sterile graduated pipette two cubic centimeters of the product and 198 cubic centimeters of sterile water into the 250 c.c. flask. In the case of plain condensed bulk milk, sweetened condensed 
milk and milk powder, use tared flasks holding about 150 cubic centimeters, weigh into them two grams of the product and add enough sterile water at a temperature of 98 degrees $\mathrm{F}$. to make up 100 cubic centimeters. Use a sterile spoon or spatula to transfer the product to this flask. A wide-mouth flask is preferable.

The above represents the first dilution. The flask should be carefully shaken until a homogeneous mixture is obtained and the soluble portions have been completely dissolved.

From this dilution further dilutions are made in sterile water in glass-stoppered flasks, according to requirements. The dilutions should be sufficient to limit the number of colonies on the plates to about 50 to 100 per plate. Whole milk, as it arrives at the factory, usually shows from 100,000 to $1,000,000$ bacteria per c.c. Evaporated milk should be practically sterile unless the can shows signs of fermentation in which case the number of bacteria present will depend on the age of the sample can; dilutions as high as $1: 1,000,000$ are recommended in such cases. Plain condensed bulk milk when fresh contains from about 1,000 to 100,000 bacteria per c.c., when several days old and in the absence of refrigeration, its germ content is often much greater. Swectened condensed milk averages from about 500 to 500,000 bacteria per c.c.

Plating.-For plating the following media are recommended:

Media for Total Counts and also for acidifiers

4 grams beef extract

10 grams peptone

30 grams lactose

4 grams sodium chloride

12 grams thread agar

1000 c.c. distilled water.

Acidity 0.1 per cent.

For acidifiers add 1 c.c. of sterile litmus solution to each plate before pouring the agar.

Media for Liquefiers

4 grams beef extract

10 grams peptone 
30 grams lactose

4 grams sodium chloride

150 grams gelatin

1000 c.c. distilled water. Acidity 0.1 per cent.

Media for Yeasts and Molds

4 grams beef extract

10 grams peptone

12 grams agar

1000 grams whey Acidity 0.2 per cent.

Add 1 c.c. of sterile one per cent tartaric acid solųtion to each plate before pouring the medium over the dilution.

Incubation.-Incubate agar, litmus agar and whey agar plates at 35 degrees C. (95 degrees F.) for at least three days before making counts. Incubate gelatin plates at 21 degrees $C$. (70 degrees F.) for four to five days before making counts.

Making Counts.-The colonies on the plates are counted most conveniently by placing the plates over a standard counting plate. In the absence of such a plate, place the petri dish upside down on a dark surface and draw, with a blue crayon, radial lines, dividing the field into segments. For plates containing not to exceed 100 colonies eight to sixteen segments are sufficient for easy counting.

Qualitative Determinations.-Numerical counts on the four kinds of media recommended above usually furnish a fair general idea of the types of bacteria present.

For the detection of gas-producing species, nutrient bouillon containing three per cent lactose and three per cent sucrose, respectively, in fermentation tubes, or nutrient agar containing three per cent lactose and three per cent sucrose, respectively, in test tubes, are serviceable.

Cans of sweetened condensed milk that show gaseous fermentation (swell heads) are usually due to certain species of yeast, which thrive best in media containing sucrose.

Cans of evaporated milk that show gaseous fermentation (swell heads) are usually caused by anaerobic putrefactive bac- 
teria, of which Plectridium foetidum is a most frequent representative, see "Blown Evaporated Milk," Chapter XXIII. This type of micro-organisms requires strictly anaerobic cultural conditions. Under limited laboratory facilities the anaerobic conditions are best produced by the use of oxygen-absorbing chemicals, such as pyrogallol to which potassium hydroxide is added. Use dry commercial pyrogallol and potassium hydroxide sticks, in proportion of 1 gram pyrogallol to .7 gram potassium hydroxide, dissolved in about 2 c.c. of water.

Place 50 grams of pyrogallol into the bottom part of a large size desiccator. Have the rim of the desiccator and the corresponding rim of the cover covered with a mixture of half paraffine and half bee's wax. Pour into the pyrogallol in the desiccator 100 c.c. of water and then throw in 35 grams of potassium hydroxide. Quickly insert culture tubes, or plates, and close the desiccator with the cover, turning the cover so as to secure a perfect seal. Apply three permanent screw clamps.

Anaerobic germs of the type of Plectridium foetidum grow best in freshly sterilized milk. In the case of Plectridium foetidum the milk. first curdles, then digests, forming a clear yellow liquid. The digestion begins at the surface and proceeds downward. These cultures develop a most penetrating foul odor, resembiing that of spoiled eggs. ${ }^{1}$

The technique and methods for determining the bacteriological flora with reference to cultural and morphological characteristics of individual species of microbes present, are identical to those used in the bacteriological study of milk and other similar products, and which are fully described in standard manuals on bacteriology.

1 For further details on the technique of Anaerobic Cultures see Hunziker Review of Existing Methods for Cultivating Anaerobic Bacteria. Journal of Applied Microscopy and Laboratory Methods, Vol. V, Nos. 3, 4, 5, 6. 


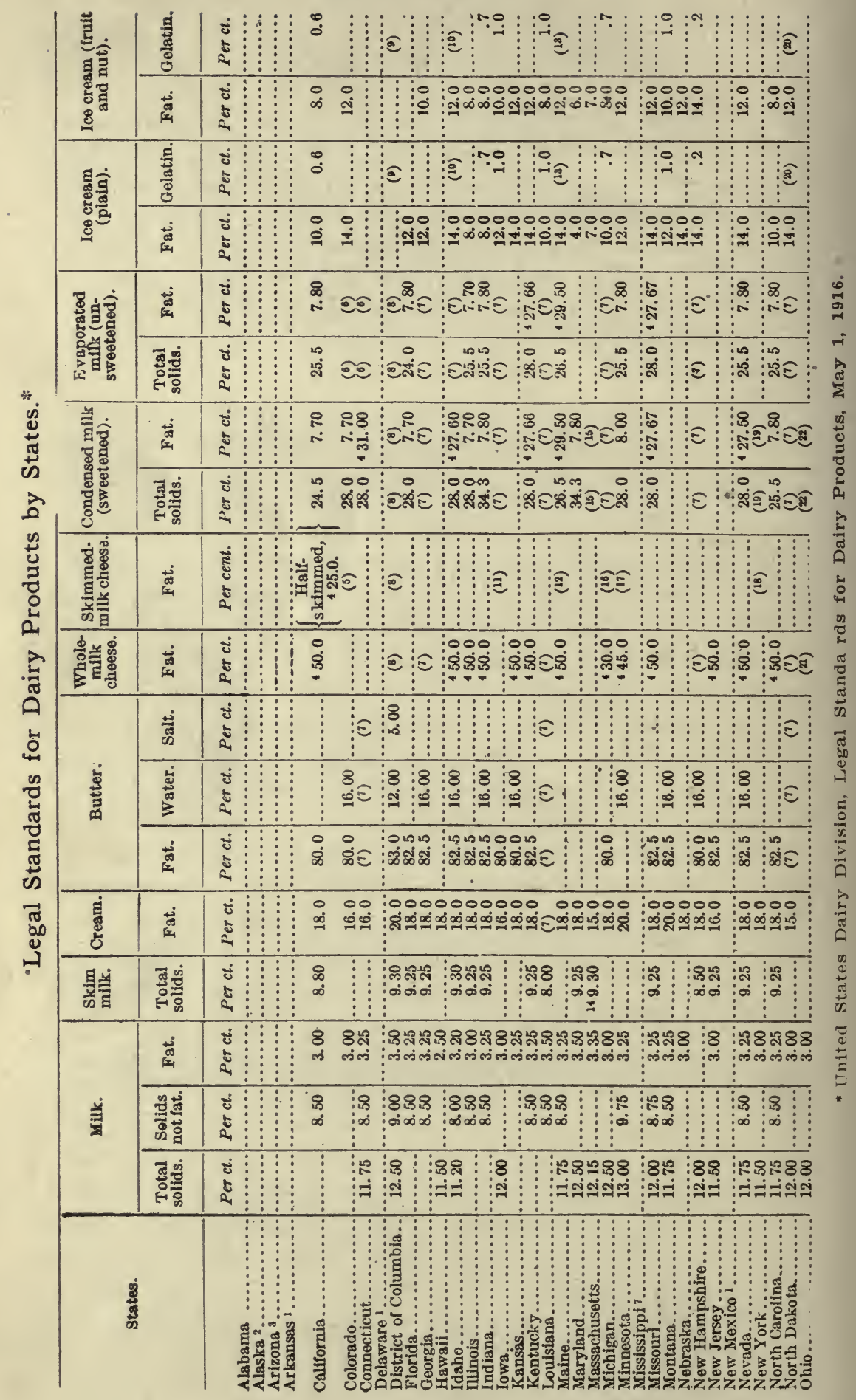




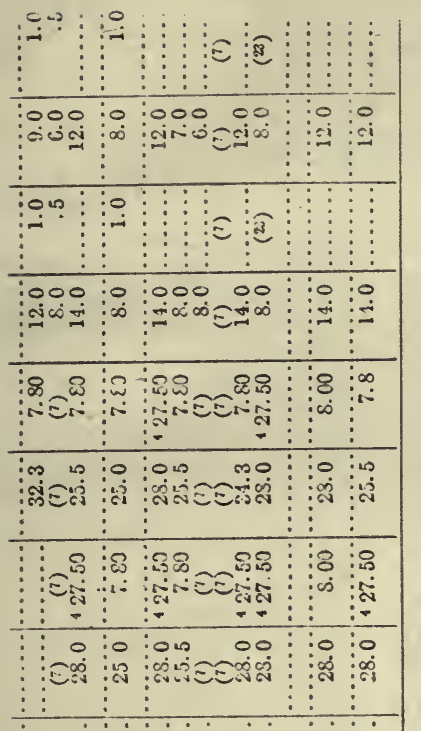

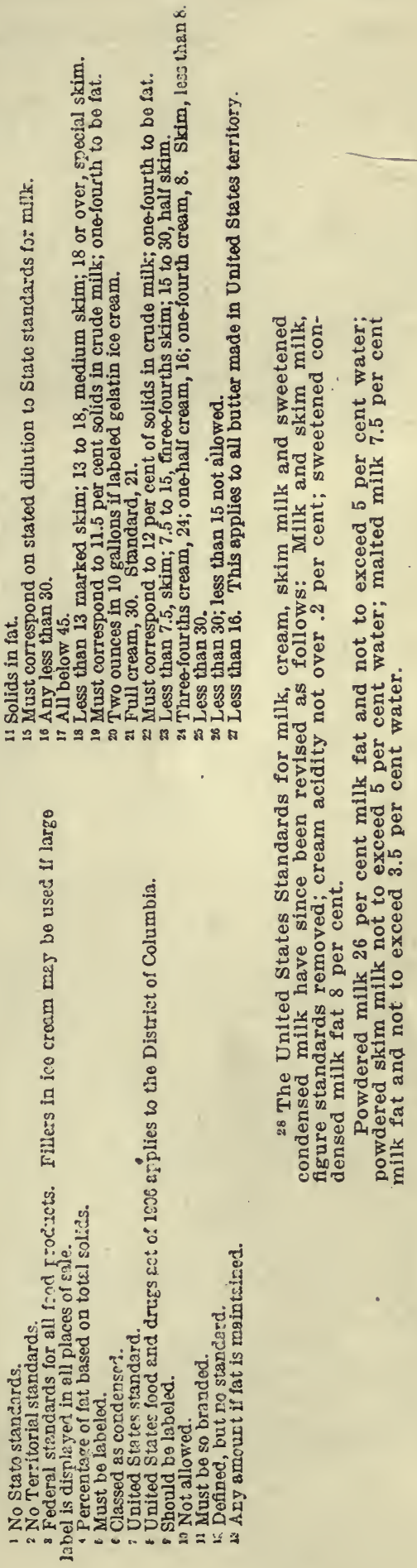




\section{N D E X}

\section{A}

Accidents, prevention of......... 95

Acknowledgments ............... 14

Acid tests ...................... 50

Addition of sugar.............6 63

Adulterations .................271

Advertisements ..............384-424 $\left.\begin{array}{c}\text { Agitation of sweetened } \\ \text { condensed milk }\end{array}\right\} .106,107,108$

Air discharge ..................312

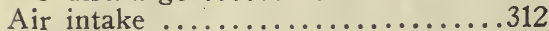

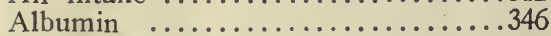

Altitude $\ldots \ldots \ldots \ldots \ldots \ldots \ldots . .68,89,90$

Anaerobic cultures .............377

Anglo-Swiss Condensed Milk Co...2 21

Annual production of-

buttermilk powder .............331

condensed buttermilk ............184

condensed milk ..............26, 29

cream powder ..............278

malted milk .................335

milk powder ................278

Antineuritic vitamines ...........215

Antiscorbutic vitamines ..........216

Antixerophthalmic vitamines .....2215

Arrangement of machinery .......41, 42

Ash........203, 208, 344, 355, 363, 364

Aspergillus repens ..............238

Atmospheric pressure ..........88, 89

\section{B}

Bacillus panis ...............265

Bacterioligical analyses ...........374

Bacteriological media .............375

Babcock test ..............351, 365

Barometric condenser ............. 77

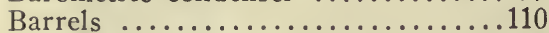

Beet sugar .................63, 64

Beaumé hydrometer...$\ldots \ldots \ldots \ldots$

$99,100,101,122,353,358$

Beriberi ....................215

Bicarbonate of soda........147, 156, 157

Bitter evaporated milk...........263

Blow-down valve ............... 76

Boiling point at different vacua...86, 87

Boiling test ................ 51

Bolting ...........................

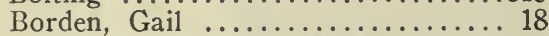

Borden's Condensed Milk Co...... 21

Borden patent ................ 18

Brands of condensed milk..........196

Brown evaporated milk...........269

Brown sweetened condensed milk...251
Buflovak process ................288

Buflovak rapid circulation evapora-

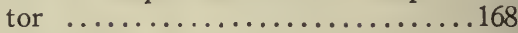

Building and equipment for con-

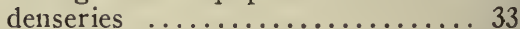

Bulk milk ....................162

Butterfat

201, 206, 351, 356, 363, 365, 369, 370, 373

Butterfat test .............. 54

Buttermilk, composition ..........177

Buttermilk powder ...............330 annual output ....................331

composition $. . \ldots \ldots \ldots \ldots \ldots . . . .331$

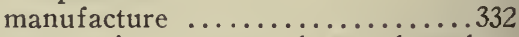

Buttons in sweetened condensed milk ...................237, 241

Buying milk ................ 43

By-Products Recovery Co......... 25

\section{C}

Calcium in milk...............253

Campbell process ............166, 279

Cane sugar ...............63, 203

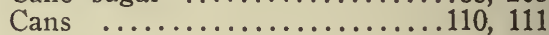

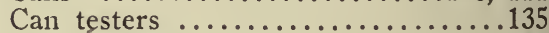

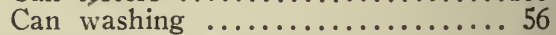

Care of milk in factory............ 57

Casein ........................346

Casing machines ...............189

Catch-all ......................... 82

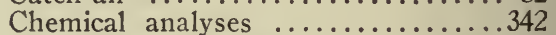
of evaporated milk ........358, 370

of malted milk ................373

of milk ...................342, 369

of milk powder ...........364, 373

of sweetened condensed milk.353, 370

Citrates in milk...............253

Coils in pan.............72, 73, 74

Composition of-

buttermilk ..................177

buttermilk powder ....................331

condensed buttermilk .............184

evaporated milk ..............205

milk powders ..................315

plain condensed milk............208

sweetened condensed milk.......200

Concentrated milk ...............166

Concentration, ratio of....96, 165, 182

Condensed buttermilk ...........176

Condensed milk-

annual production in U. S.....26, 28

in different countries............ 29

cost of manufacture...............217

defects $\ldots \ldots \ldots \ldots \ldots \ldots \ldots \ldots \ldots \ldots \ldots \ldots \ldots 222$ 
digestibility $\ldots \ldots \ldots \ldots \ldots \ldots \ldots .212$

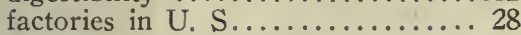

history and development........ 17 purity .....................211 standards ...................210 vitamine properties ...........215 Condensers .................76-82 Condensery floors $\ldots \ldots \ldots \ldots \ldots \ldots 33$ Condensing....68, 119, 163, 173, 179-184 Continuous concentrators...25, 167, 171 Cooling ............103, 129, 165, 174 Cooling in sterilizer..............143 Correction of Beaumé.........100, 122 Cost of manufacture.........219, 329 Cream Production Co.............25 Curdy evaporated milk.......253, 259

\section{D}

Defective plain condensed milk....252 lumpy ...................252

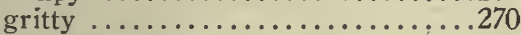

Defective evaporated milk........252 bitter ....................263 brown .......................269

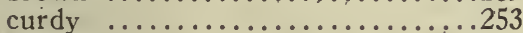
fermented ................258 grainy ....................257

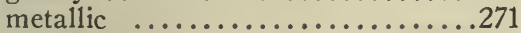
separated $\ldots . \ldots \ldots \ldots \ldots \ldots . . . .258$

Defective sweetened condensed milk.222 blown ......................242

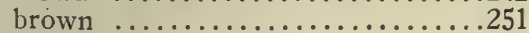
buttons in ...............237 cheesy ....................231 fermented .....................242 lumpy $. . . \ldots \ldots \ldots \ldots \ldots \ldots \ldots \ldots . . .233$ metallic ....................251 putrid ....................250 rancid ......................249 sandy .....................223 settled .....................228 thick ......................231

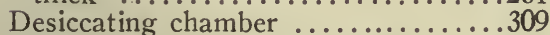

Distribution of heat in sterilizer.....138

Dome ..................... 75 Dough-drying processes ..........278 Drainage in condenseries......... 35 Dried buttermilk ..............330

\section{$\mathbf{E}$}

Ekenberg process ..............286 Equipment for condenseries.........39-41 Evaporated milk ................117

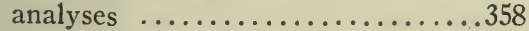
behavior toward heat.............158 composition ..................205

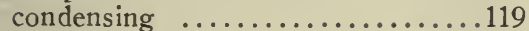
control .....................146 cooling .......................129

cost of manufacture...........221

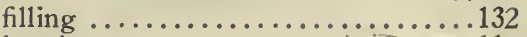

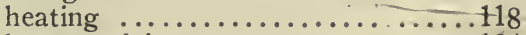

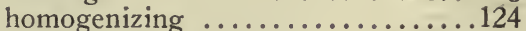

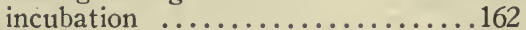

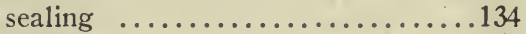

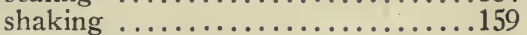

standards ...................210

standardizing $\ldots \ldots \ldots \ldots \ldots . .123,339$

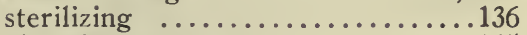

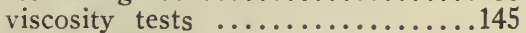

Expansion tank ..............8 82

Exports ...............198, 199

\section{$\mathbf{F}$}

Factory sanitation ............. 54

Fat-soluble vitamines ...........215

Fat standard for export..........211

Federal standards........210, 335, 378

Fermentation tests .............. 53

Fermented evaporated milk.........262

Fermented sweetened condensed

milk ......................242

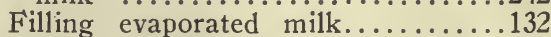

Filling machines ................110

Film-drying processes ...........280

Floor plans ..................35-39

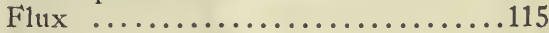

Fractional sterilization ..........144

\section{G}

Gaseous fermentations......242, 266-268

Gas generators ...................... 115

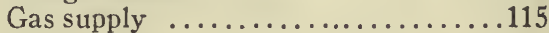

Gathmann process .............283

Gaulin homogenizer ..........126, 127

Gebee seal .................111

Glass-lined tanks ......47, 57, 58, 131

Glucose .....................273

Govers process ...............2287

Grainy evaporated milk...........257

Gray processes ...........297, 299, 302

Grimwade process ..............277

Gritty plain condensed milk........270

Gunning method ...............344

\section{$\mathbf{H}$}

Hatmaker process .............282

Heating milk .............59-62, 118

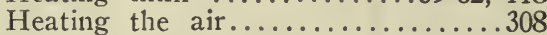

Hebe product ............216, 272

Helvetia Milk Condensing Co...... 22

High pressure pumps..............107

Holding tanks ................... 131

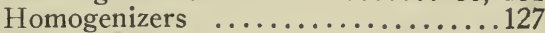

Homogenizing $\quad . . \ldots \ldots \ldots \ldots . . .124,129$

Hotwells ..................6 61 


\section{I}

Imitation evaporated milk........216

annual output ..............273

Imports ................... 198, 199

Incubation $\ldots \ldots \ldots \ldots \ldots \ldots \ldots \ldots . . .162,376$

Index to advertisers...............384

Inder to contents..............380-383

Insects in milk powder...........328

Inspection of cans.............187

Insulation of piping........... 42

\section{$\mathbf{J}$}

Jacket in pan.............. 71

John Wildi Evaporated Milk Co.... 24

Just process ................281

\section{$\mathbf{K}$}

Keeping quality ofmalted milk

milk powder .325-328

\section{L}

Labeling .187

Labeling machines ..............187 Lactose.....202, 208, 347, 356, 363, 364

Legal standards of dairy products by states

379

Loading the sterilizer.............138

Locations for condenseries........ 29

Lumpy milk powder.............328

Lumpy sweetene, condensed milk...

233-236

\section{M}

McDonald seal .................111

McLachlan process ............292, 294

Making bacterial counts...........376

Malted milk ...............332-335

Marking cases ...................190

Market prices .................196

Markets ........184, 194, 195, 329, 334

Mercury column .............. 75

Merrell-Merrell-Gere process .....294

Metallic evaporated milk..........270

Metallic sweetened condensed milk..251

Meyenberg, John B. ........... 23

Milk analyses ................342

Milk inspection ................... 49

Milk powder ..............276-335

Milk powder factories............278

Milk prices ................. 45

Milk quality .................... 48

Milk solids ............201, 205, 358

Milk sugar .....202, 208, 347, 363, 364

Milk supply ................30, 43

Milk trap .................... 82

Mineral matter .............203, 208
Miscibility $\ldots \ldots \ldots \ldots \ldots \ldots \ldots . \ldots \ldots 20$

Modified Babcock test.........356, 363

Mojonnier evaporated milk control..145

Mojonnier test for fat and solids....365

\section{$\mathbf{N}$}

Nailing machines ................189

Nestle-Cham Condensed Milk Co...21

New York Condensed Milk Co...20, 21

i itrogen determination ...........343

0

Operation of pan.............. 94

$\mathbf{P}$

Packing..............183, 189, 315

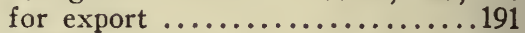

Passburg process .................284

Percy process .................291

Phosphates in milk.............253

Pilot sterilizer .............142, 143

Plain condensed bulk milk.162-165, 208

Plating .........................375

Plectridium fœetidum .............267

Polyneuritis ....................215

Precondensing for drying........303-307

Preface ....................... 8

Preheating ..................... 173, 303

Progress homogenizer ...........127

Proteids ....145, 202, 207, 354, 363, 364

Putrid sweetened condensed milk. ...250

Q.

Quality of milk..........117, 163, 253

Quevenne lactometer ...............342

$\mathbf{R}$

Rancid sweetened condensed milk..249 Rapidity of evaporation..........91 Ratio of concentration.....96, 165, 182 Retardation .................152 Recovery ...................307, 313 Rim speed ....................173

Rogers process ..............296 Reese-Gottlieb method.352, 356, 364, 365 Ruff condensing evaporator.........174 Rust spots on labels..............188

\section{$\mathbf{S}$}

Sampling sweetened condensed milk.102 Sandy sweetened condensed milk... 223-228

Sanitary can $\ldots \ldots \ldots \ldots \ldots \ldots \ldots \ldots, 111,112$

Science and practice of evaporation in vacuo .................... 85

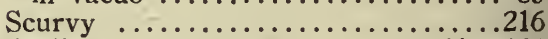
Sealing $\ldots \ldots \ldots \ldots \ldots \ldots \ldots \ldots \ldots \ldots \ldots \ldots \ldots \ldots \ldots \ldots, 134$

Sediment test $\ldots \ldots \ldots \ldots \ldots \ldots \ldots \ldots, 52$ 
Separated evaporated milk.....258-261 Settled sweetened condensed milk.. $107,228-230$

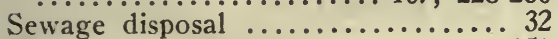

Shaking .....................159

Shakers ....................160

Size of cans in sterilizer.......142, 156

Solder ........................114

Soldering devices ..............113

Soldering flux ................... 115

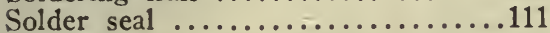

Solubility of milk powders.........318

Sour, curdled evaporated milk.....262

Specific gravity $.101,123,204,208,342,353,358$

Spray-drying processes ........290-315

Spraying milk .................309

Spray nozzles ........................

Spray pumps ..................311

Spy glasses .................. 75

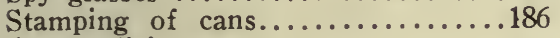

Standardizing-

evaporated milk ...........123, 336

fluid milk ......................339

sweetened condensed milk.118, 340,341

Standardization of sterilizing process .........................143

Starting the pan............... 94

Stauf process ...............291

Sterilizers .....................137

Sterilizing process ..............136

Sterilizing sample cans.............149

Stopping reel in sterilizer..........141

Storage ...................183-193

Striking $\ldots \ldots \ldots \ldots \ldots \ldots \ldots . . .6 \%, 120,164$

Sucrose $\ldots \ldots \ldots \ldots \ldots \ldots \ldots 203,357,364$

Sugar ..............63-67, 203

Superheating. 120,141, 163, 225, 232, 261

Surface condenser ............. 76

Sweetened condensed milk-

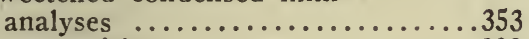

composition ................200

cooling .....................103

cost of manufacture...........220

defects ....................222

drawing off $\ldots \ldots \ldots \ldots \ldots \ldots \ldots . . . . .103$

filling $\ldots \ldots \ldots \ldots \ldots \ldots \ldots \ldots \ldots$

manufacture ................ 59

sampling ...................102

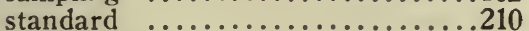

striking $. . . \ldots \ldots \ldots \ldots \ldots . \ldots 96$
T

Table of contents...............9-14

Tell-tale thermometers ...........139

Temperature of storage...........193

Temperature in sterilizer.........140

Testing for density..............178

Testing for viscosity............150

Thermometer for vacuum pan..... 76

Thick and cheesy sweetened con-

densed milk ..............231-233

Tin shop equipment............41

Total solids

$343,355,359,364,370,372,374$

Total solids tables.............360-362

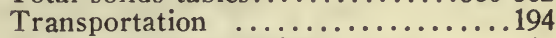

Transportation facilities .......... 31

\section{V}

Vacuo, science and practice of evaporation in .................. 85

Vacuum breaker .................... 76

Vacuum gauge $. . . \ldots \ldots \ldots \ldots \ldots \ldots . \ldots 75$

Vacuum pan .................. 68

Vacuum pump .................83-85

Vapor belt .................... 72

Venthole cans ..................133

Venthole fillers ................133

Ventilation in condenseries........ 34

Viscolizer ......................128

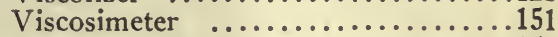

Viscosity correction ..............152

$\mathrm{V}$ iscosity, factors influencing.....153-155

Viscosity tests ................150

Vitamine properties ...........215-216

\section{W}

Water .................201, 205

Water-soluble vitamines ............215

Water supply .................. 30

Wet-vacuum spray condenser....... 78

Wimmer process .................279

Wrinkles on labels............... 188

$\mathbf{x}$

Xerophthalmia ................215

$\mathbf{Y}$

Yeast $\ldots \ldots \ldots \ldots \ldots \ldots \ldots \ldots \ldots \ldots \ldots \ldots$ 


\section{INDEX TO ADVERTISERS}

Page

American Can Co., New York..................... 385

Alois Aufrichtig Copper and Sheet Iron Mfg. Co., St. Louis, Mo. 386

Bausch and Lomb Optical Co., Rochester, N. Y.......... 386

Buffalo Foundry and Machine Co., Buffalo, N. Y......... 387

Burt Machine Co., Baltimore, Md.................. 388

By-Products Recovery Co., Toledo, O............... 389

J. G. Cherry Co., Cedar Rapids, Ia................ 390

Colonial Salt Co., Akron, O.................... 411

Creamery Package Mfg. Co., Chicago................ 391

Cream Production Co., Port Huron, Mich............... 392

Davis-Watkins Dairymen's Mfg. Co., Chicago.......394, 395, 397

F. G. Dickerson Co., Chicago................. 393

Dry Milk Engineering Co., Chicago................. 398

Engineering Co., Fort Wayne, Ind............... 399

J. B. Ford Co., Wyandotte, Mich................. 400

General Laboratories, Madison, Wisc............... 401

Groen Mfg. Co., Chicago..................... 402

Arthur Harris \& Co., Chicago.................4404, 405

Jensen Creamery Machinery Co., Long Island City, N. Y... . 403

John W. Ladd Co., Detroit, Mich.................... 423

Lathrop Paulson Co., Chicago................... 406

Milk Drying Machinery Co., Chicago.............. 407

Mojonnier Bros. Co., Chicago................. 408

Louis F. Nafis, Chicago....................... 409

Pfaudler Co., Rochester, N. Y................. 410

C. E. Rogers, Detroit, Mich..................412, 413

Rice and Adams Corporation, Buffalo, N. Y............ 411

E. H. Sargent \& Co., Chicago..................... 414

Schaefer Manufacturing Co., Berlin, Wisc............. 414

Sharples Separator Co., West Chester, Pa............. 415

L. Sonneborn Sons, New York................. 416

Spray Drying Corporation, New York............. 417

Sturges and Burn Mfg. Co., Chicago............... 420

C. J. Tagliabue Mfg. Co., Brooklyn, N. Y.............. 418

Taylor Instrument Companies, Rochester, N. Y.......... 419

Torsion Balance Co., New York................ 420

Union Steam Pump Co., Battle Creek, Mich.......421, 422, 423 
CONTAINERS for

Condensed Milk

\section{Evaporated Milk}

\section{Powdered Milk}

\section{AMERICAN CAN COMPANY 120 Broadway, New York, N. Y. \\ CHICAGO, ILL. Monroe Bldg. \\ PORTLAND ORE. \\ SAN FRANCISCO, CAL. Mills Bldg.}




\section{Efficiency and Economy}

ARE COMBINED IN THE NATIONALLY KNOWN "AUFRICHTIG" VACUUM PAN

Our Standard " 6 ' 6 "” Pan will condense 10,000 pounds of milk in one hour with two coil and 12,000 pounds with three coil system.

Investigate the economically operated Jacketed Hot Wells.

We manufacture complete equipment used in Milk Condenseries and Dairies.

Highest grades of materials and best of workmanship is put into our equipment.

Write for specifications and prices.

Alois Aufrichtig Copper \& Sheet Iron Mfg. Co. Third and Lombard Streets Saint Louis, Missouri

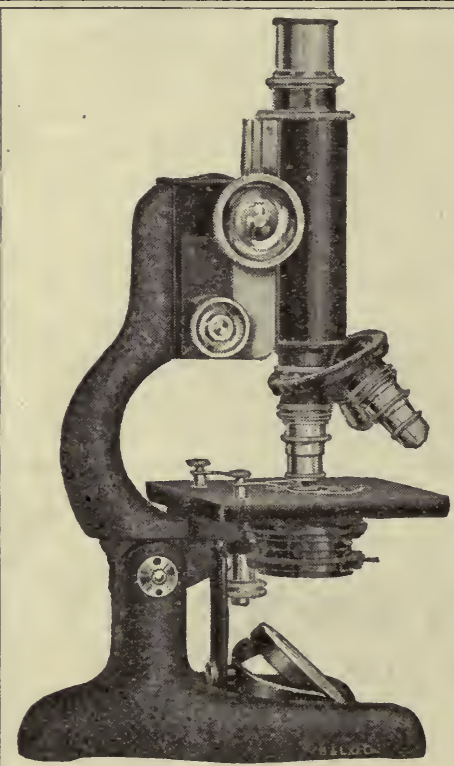

Model FFS 8

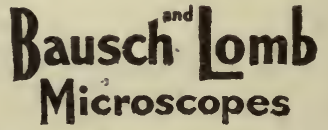

Standards of Optical and Mechanical Efficiency

Model FFS 8 is especially suitlogical work Has coarse and fine focusing adjustments, with adjustment heads on side of arm; two iris diaphragms, three objectives-including oil immersion-in revolving nosepiece; two eyepieces and an Abbe condenser in quick-acting screw substage. Number of magnifications obtainable ranges from 50 to 1260 . Construction is rugged, and black crystal finish on arm and base unusually durable.

Write for catalog describing this and other models.

Bausch E Lomb Optical @. NEW YORK WASHINGTON SAN FRANCISCO CHICAGO ROCHESTER, N. Y. LONDON 


\section{Dry Milk Products}

Manufactured in

\section{"Buflovak" Apparatus}

The "Buflovak" Vacuum Drum Dryer is the ideal apparatus for converting milk into powder form. The milk is dried without the slightest danger of overheating or. contamination. Every part of the interior is accessible, and can be easily cleaned-a distinctive feature of the "Buflovak" Dryer.

When considered in the light of steam consumption, drying speed, output, quality and drying cost, it is the most economical milk dryer on the market. Dries skim milk, buttermilk, malted milk and other liquids containing solids.

The "Buflovak" Rapid Circulation Evaporator is especially adapted for evaporating milk and other delicate liquids.

Vacuum Shelf Dryers for drying casein and other products in pans or trays.

Catalog showing all types of "Buflovak" Dryers and Evaporators will be mailed on request.

\section{Buffalo Foundry \& MachineCo.}

20 Winchester Avenue BUFFALO, N. Y. 


\section{THIS MACHINE Plays an Important Part in Milk Canning}

It labels as many cans a day as you require.

Orders are filled promptly and Storage facilities never overtaxed.

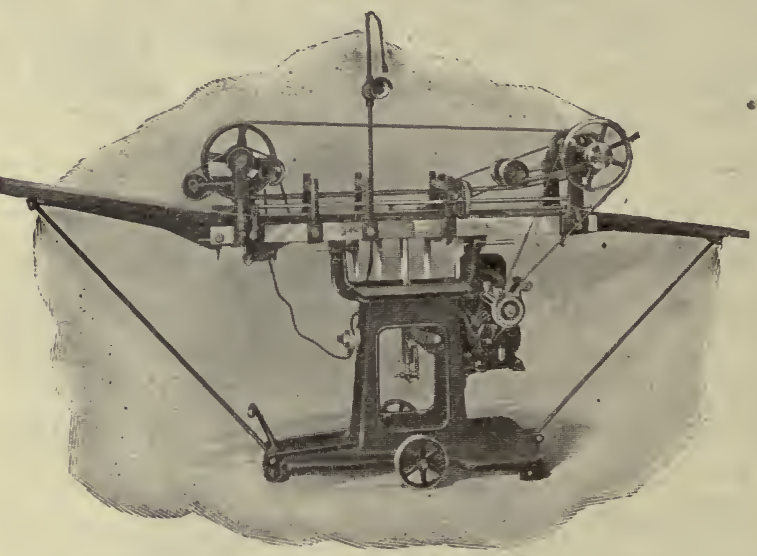

\section{THE BURT LABELING MACHINE}

Is used in the small as well as the largest plants because there is no other way to label cans so fast, neat and cheap.

It applies the label with a hot moisture-proof cement which sets instantly, thus preventing the label from slipping while being wrapped around the can and ensuring it always being applied tight and matched evenly at lap. No paste is put on the can, so there's no possibility of the label discoloring-it always looks as though just from the printer-that increases the sales value of goods.

Let us tell you more about the Burt Labeler-what it does and why you should not be without it. Just state size of cans used.

\section{BURT MACHINE COMPANY}

Labeling, Wrapping and Casing Machines BALTIMORE, MD. 
The By-Products Recovery Company 109 Chamber of Commerce Building Toledo, Oh io

\section{Milk Products Department}

Automatic Concentrators for "Evaporated" Milk, "Preserved" Milk, Dry Milk and

Sugar of Milk Factories

Whole Milk, Skim Milk, Buttermilk and Whey Rapidly and Economically Reduced to High Concentrates Without the Aid of Vacuum Pumps, Condensers, Water or Expert Labor

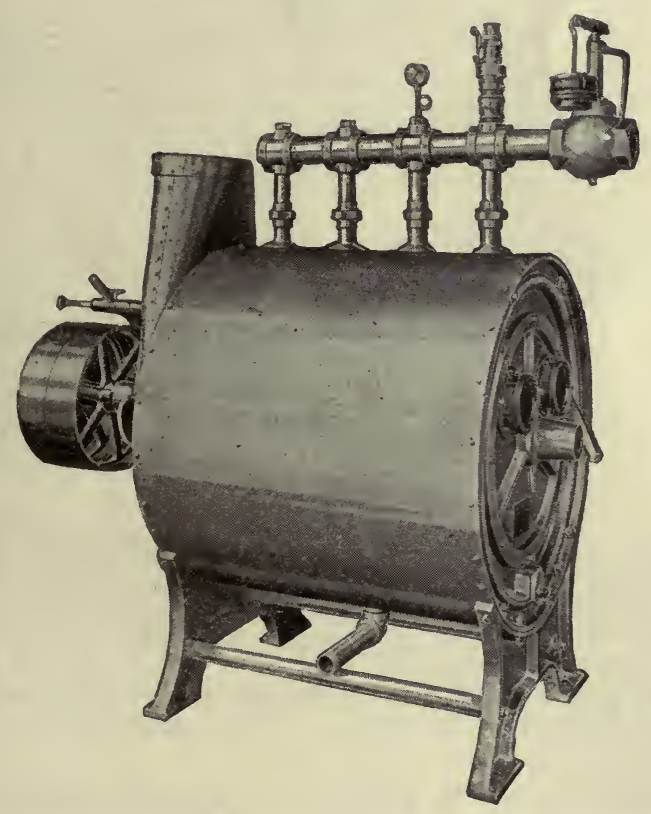

It is More Economical

It is Less Complicated It is More Simple to Operate

No Water Requirements Excepting for Cooling More than 100 Machines Now in Use

For Particulars Write

The By-Products Recovery Co., Toledo, O. 


\section{T H E \\ Cherry Condensed Milk Cooler}

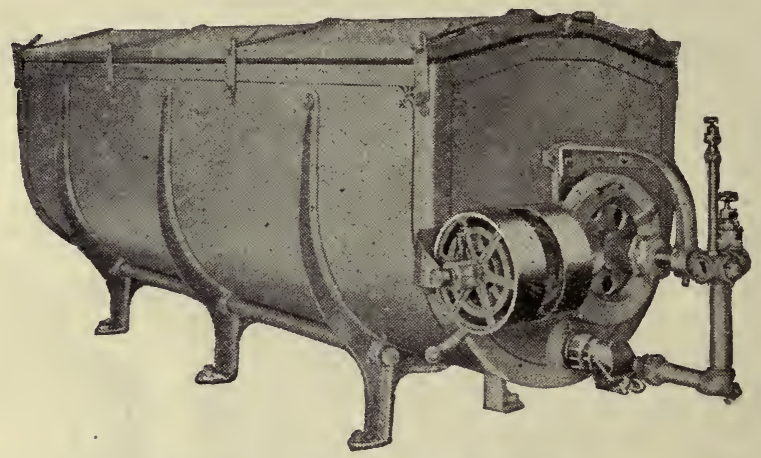

\section{Three Special Features} Coil.

1. It is equipped with the justly famous Cherry Twin

2. The coils are of special diameter to assure their being entirely submerged at all times, thus preventing the incorporation of air into the product.

3. It is equipped with a two-speed drive. This drive is a clutch pulley through steel cut gears. This equipment provides for operating the coil on high speed for evaporated or plain condensed and on low speed for sweetened condensed milk. This feature is exclusive on this type of cooling vat.

\section{A Dependable Outfit}

Where condensed milk is concerned the requirements call for a cooling system enabling the operator to maintain the desired variation in temperature between the product and the cooling medium and to save every minute of time it is possible to save in handling the product. The Cherry Condensed Milk Cooler is designed to accomplish this purpose and has proven its efficiency in some of the largest plants in the country.

\section{BUTTER MAKING EQUIPMENT}

For the Condensery needing a complete Butter Making Outfit there is the Cherry Line of Creamery Equipment to cover every requirement.

If you are considering the manufacture of butter, let us quote you prices on your needs. Ask for our special catalog.

\section{J. G. CHERRY COMPANY} CEDAR RAPIDS, IOWA

St. Paul, Minn.

Tama, Iowa

Peoria, Ill. 


\section{The

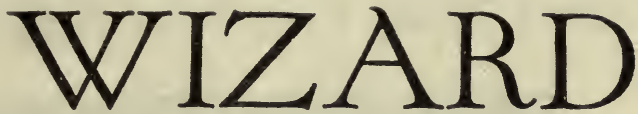 Condensed Milk Cooler}

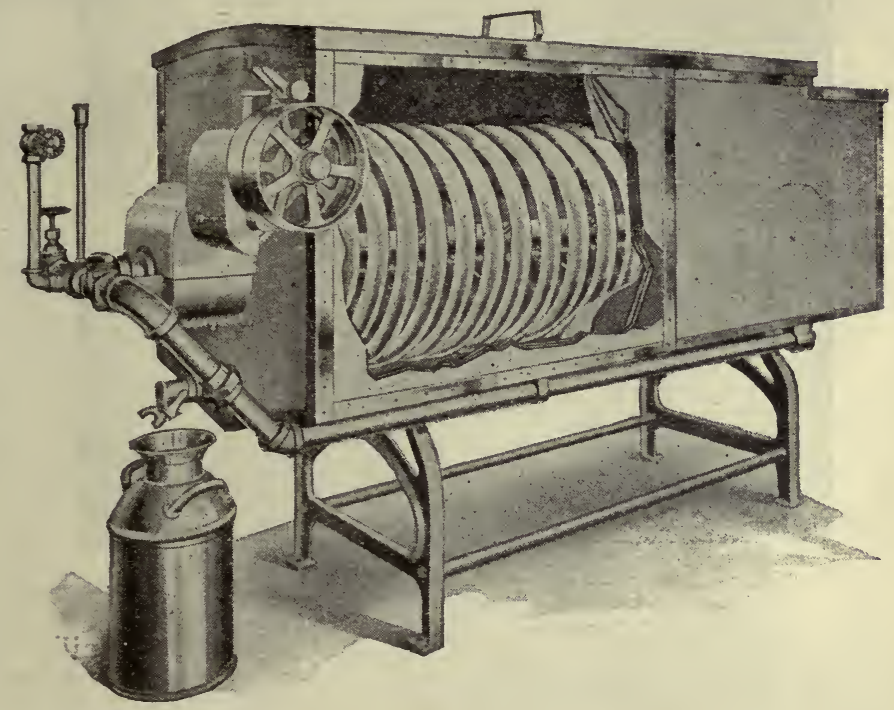

DESIGNED particularly for the condensed milk trade. It is made extra deep. Coil is entirely submerged, thus preventing the incorporation of air with the product made.

Coil has two speeds, composed of shifting cut gears so that coil can be run on high speed for evaporated or plain condensed and on low speed for sugared condensed.

Built either with legs high enough to permit a 10 gallon can beneath gate valve or on standard height legs as desired.

It has the patented Wizard Multiple Feed Coil either $2^{\prime \prime}$ or $2^{1 / 2^{\prime \prime}}$ diameter as desired; large built-in brine box; and the latter can be fitted with direct expansion coils when desired. Made in sizes from 300 to 1000 gallons, equipped for motor or belt drive.

\section{The Creamery Package Mfg. Company 61-7 W. Kinzie St., Chicago Sales Branches Everywhere}




\section{Ruff Milk Condensing Evaporator}

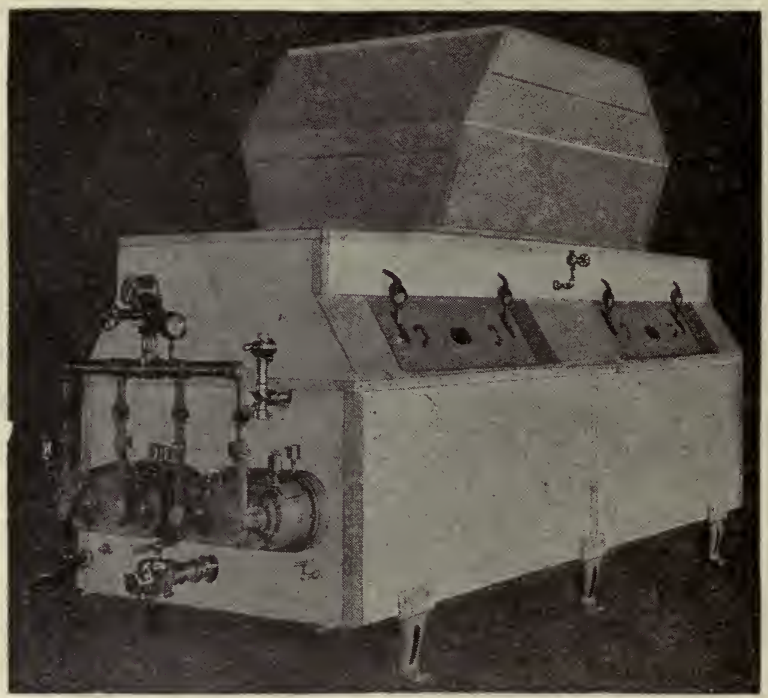

1920 MODEL NO. 7

The Ruff Milk Condensing Evaporator condenses milk at 145 degrees temperature without use of vacuum, leaving the albumin milk solids soluble.

Will make a superior quality condensed milk of all grades sold on the market, such as plain condensed and superheated, sugared condensed milk, sugared milk condensed for the chocolate trade, unsweetened evaporated, precondensing for milk powder, also buttermilk.

A world beater in connection with your pan to pre-heat milk to 210 degrees for making sugared and unsweetened evaporated, a saving of 15 per cent to 18 per cent moisture, which is generally added when milk is heated with live steam.

This evaporator is built of the best material, neat in appearance, has a large capacity, economical in power and steam, and is a money-maker to ice cream manufacturers, condenseries and creameries. The saving on water and power to pump would soon pay for this entire equipment.

$$
\text { Apply to }
$$

\section{THE CREAM PRODUCTION CO.} PORT HURON, MICHIGAN Mfgs. for United States

\section{B. TRUDEL \& CO.}




\section{The Dickerson Vent Hole Filler and Sealer}

\section{Baby Machine for 6 oz. cans \\ Combination Machine for 16 and $12 \mathrm{oz}$.}

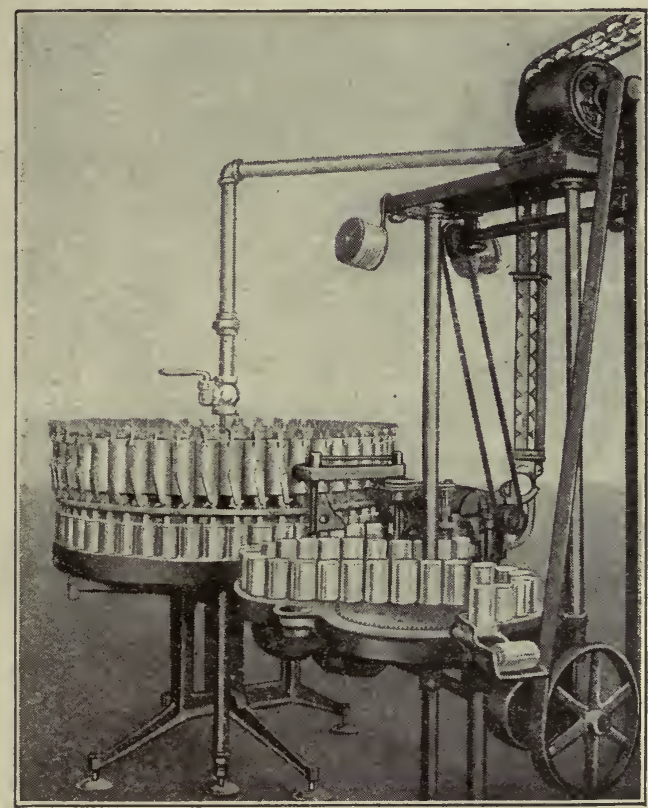

TALL SIZE 


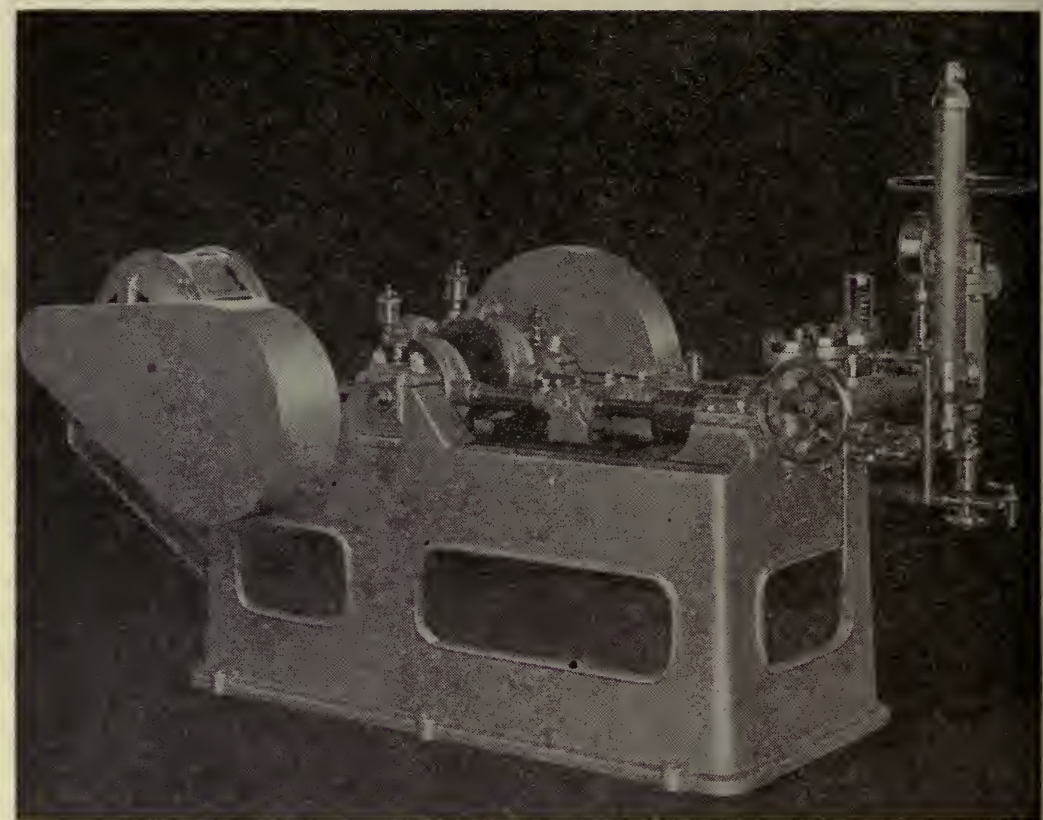

\section{Progress Homogenizer}

Progress Homogenizers are built in four sizes. Number 1 handles 90 gallons per hour; Number 2, 200 gallons; Number 4, 400 gallons; Number 8, 800 gallons. Each machine is built full rated capacity, and it will do the work it is intended for at snall expense and to excellent advantage.

This machine quickly pays its cost, and oftimes it results in a saving equal to many times its cost in a very short time. You manufacturers of evaporated milk must avoid the waste which may be occasioned by "separated" milk. The Progress Homogenizer so breaks up the fat globules that the cream cannot possibly separate. It will not injure the casein.

Write to our nearest office for full information and prices on the size you need. Many plants have several of these machines. Tell us about the size of your-business so we can judge as to your requirements. "The Davis-Watkins Line" includes everything needed in the manufacture of Dairy Products. Let us quote you prices and co-operate with you.

\section{Davis-Watkins DAIRYNens MFG.Co. \\ ADDRESS NEAREST SALES OFFICE}

NORTH CHICAGO, ILL. JERSEY CITY. N.J. KANSAS CITY. MO
DENVER, COLO.

SAN FRANCISCO, CAL. 


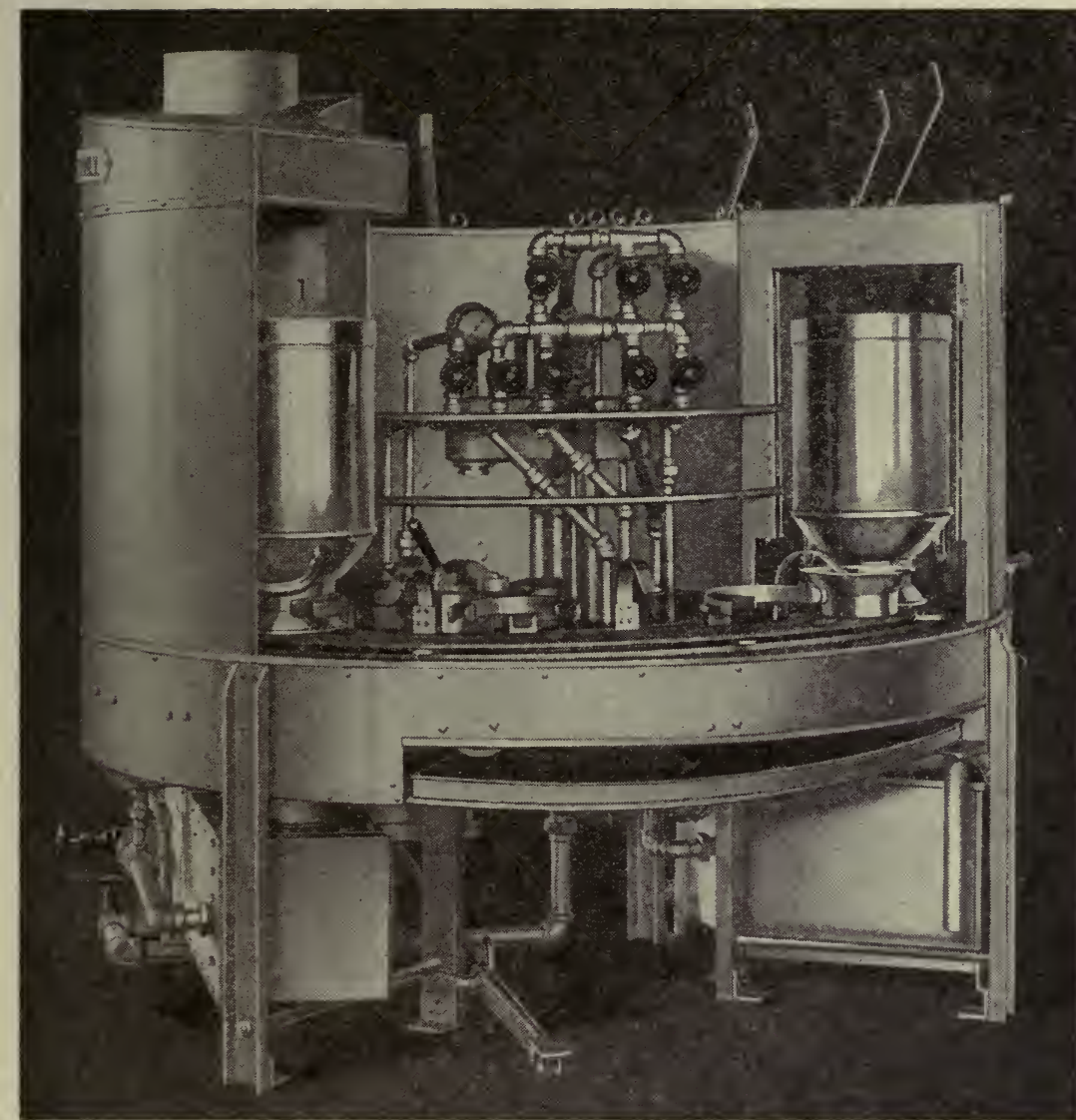

\section{Progress Circular Milk CanW asher}

Every valve is accessible and easily flushed. Each can and cover is drained, washed, rinsed, sterilized and dried inside and outside; all in a few minutes, too, and with a reasonable amount of steam and power. You can't beat it for efficient, economical results.

You save on the keeping qualities of your milk by reducing the bacteria count to the minimum. You save milk-can money because none of the tin is scraped off, and they don't rust so badly. You save labor expense in your plant. The Progress can washer will do all these things for you. Figure out what this service is worth to you.

\section{DAVIS-IVATKINS DAIRYMENS MFG.Co. \\ ADDRESS NEAREST SALES OFFICE}

NORTH CHICAGO, ILL.

JERSEY CITY, N. J.

KANSAS CITY, MO.
DENVER, COLO.

SAN FRANCISCO, CAL. 


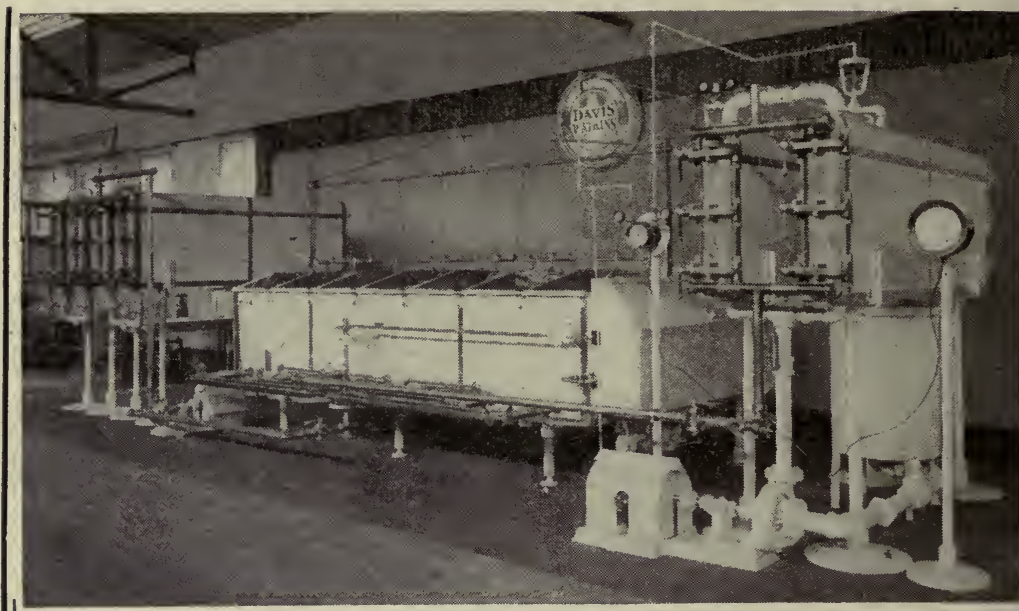

\section{"Davis Pasteurization"}

This is an efficient line of our machinery which will properly pasteurize large quantities of milk at low operating cost. With this equipment you are insured a natural raw taste, the big Davis cream line and a low bacteria count. These are the three big things so essential to the proper building of any milk business.

"Davis Pasteurization" machinery is automatic in operation, easily cleaned, requires little power expense and occupies small floor space. It needs practically no attention while operating. The milk is all inclosed so there is no loss from evaporation and no chance of contamination. The right temperatures are applied in the right way.

This equipment will solve your pasteurization problem in the simplest way, insure you against competition and cut your cost of handling to a minimum. Write our nearest office for complete information. Tell us how much milk you handle daily. Let our experts help you with your problems. Such action on your part obligates you in no way, and it may help you more than you think. Do it NOW.

\section{DAVIS-WATKINS DAIRYMENS MFG.Co.} ADDRESS NEAREST SALES OFFICE

NORTH CHICAGO, ILL. JERSEY CITY. N. J. KANSAS CITY, MO.

DENVER, COLO.

SAN FRANCISCO, CAL. 


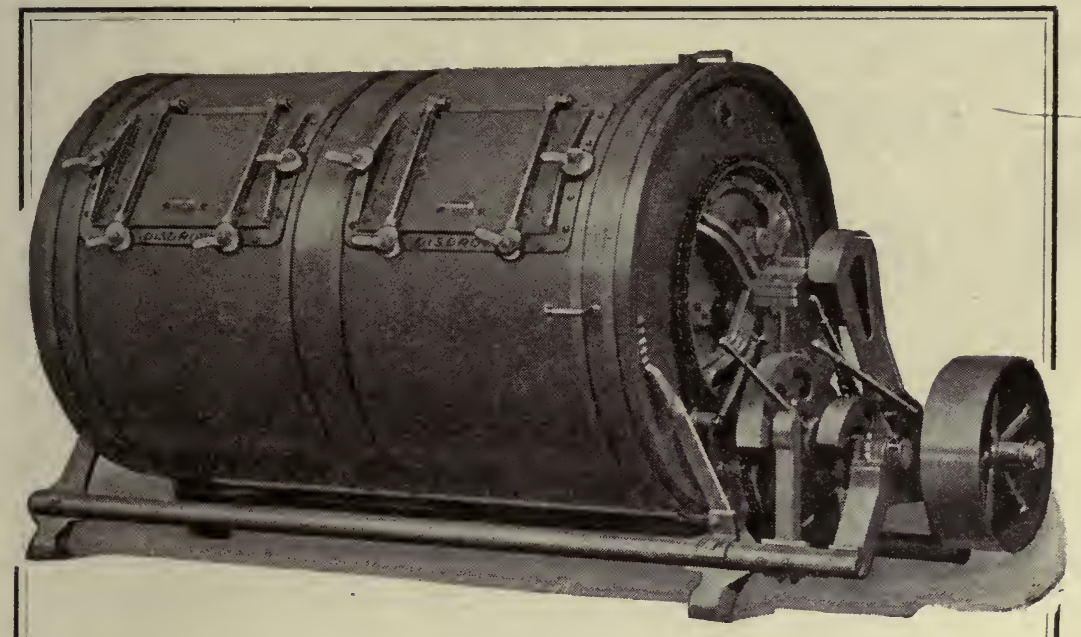

\section{A Reliable Butter Maker}

Once a Disbrow Owner, always a Disbrow Booster. Buttermakers everywhere proclaim the superiority of the Disbrow. Built strong and sturdy, it will stand up well under heavy loads. The quality is there. It is like a pure-bred animal, worthy of its name at all times.

For large capacity and continuous work you need the Number Eight Heavy Duty or the Number Eight Giant. The Giant barrel is a little larger in diameter; the castings and chain are a little heavier. Both barrels are eight feet long on the inside.

If you are interested in knowing the detailed information of this wonderfully efficient, combined churn and worker, write for "The Disbrow Churn Book." It is free and there is no obligation. There are smaller sizes, if the Number Eight is too large. The free book shows pictures and gives complete information on the Disbrow Churn your business needs. Send for it NOW.

\section{DAVIS-WATKINS DAIRYMENS MFG.Co. \\ ADDRESS NEAREST SALES OFFICE}

NORTH CHICAGO, ILL. JERSEY CITY, N.J. KANSAS CITY, MO.
DENVER, COLO. SAN FRANCISCO. CAL. 


\section{DRY BUTTERMILK OR}

\section{BUTTERMILK POWDER}

is in constantly increasing demand at a price that means

\section{BIG PROFITS}

to the wide-awake creameryman equipped to manufacture same.

\section{Dry Milk Engineering Co.}

is building and installing successful

\section{Buttermilk Drying Plants}

in Dairy sections everywhere that are simple, efficient and economical to maintain and operate, require but little space and power and insure

\section{MORE REAL PROFIT}

than any other method of

Buttermilk disposal.

Full details and suggestions by our Dry Milk Experts and Engineers are yours for the asking.

DRY MILK ENGINEERING CO. 139 N. CLARK ST., CHICAGO 


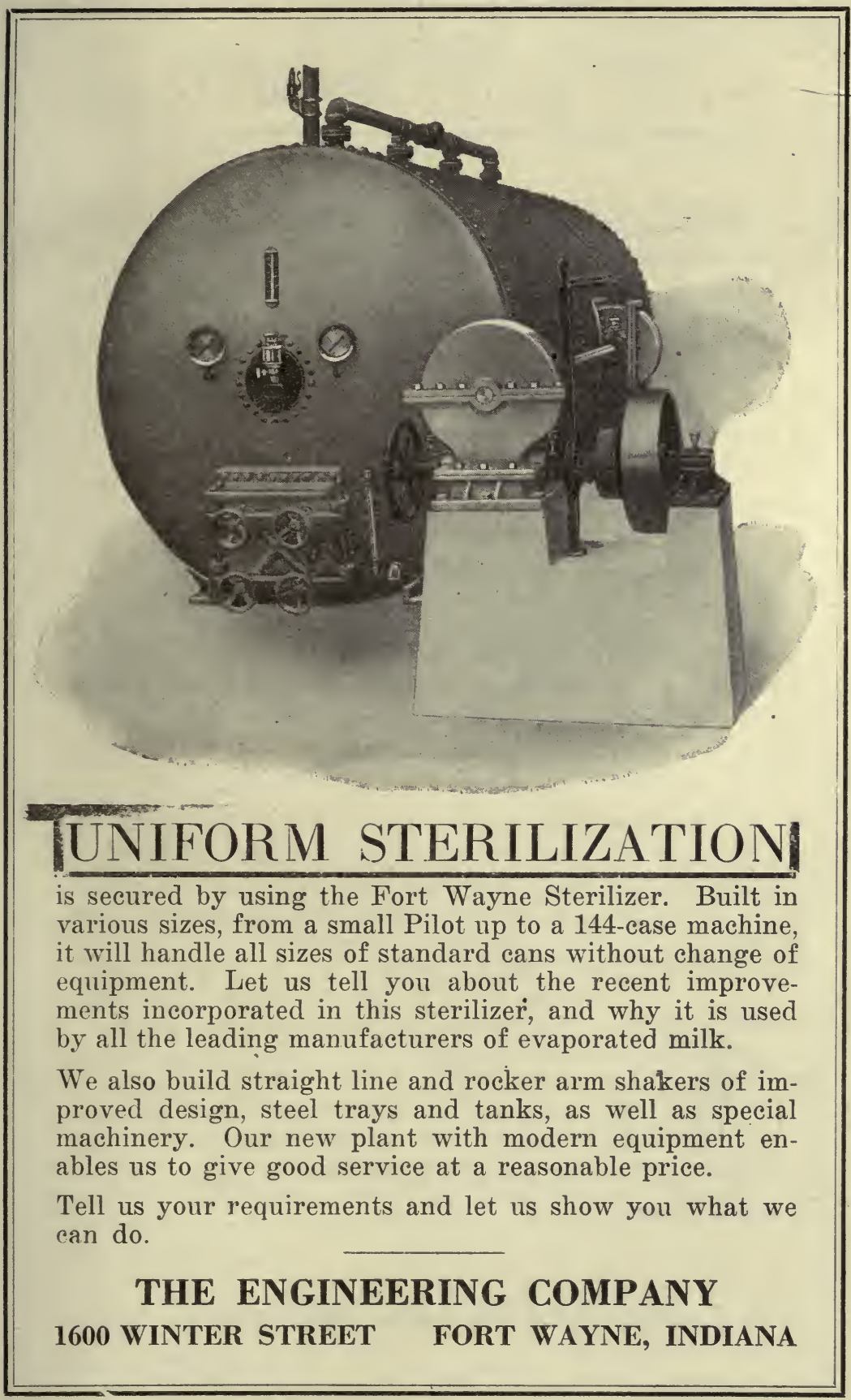




\section{Neither Is of Recent Origin}

The condensed milk and milk powder industry is not new, yet little has been written on the subject to enlighten the manufacturer on its many complexities. Nevertheless, it has always been the opinion of those engaged in milk and milk product production that sanitary cleanliness must prevail. Due to the persistent demand for cleanliness, and assisted by the never failing service rendered by

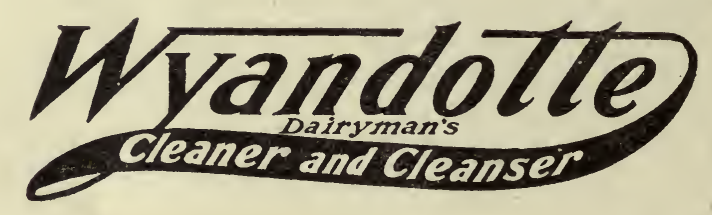

the milk and milk powder industry has reached a very high development.

This cleaner not only appeals to the producer of milk and milk products because it establishes the most sanitary and cleanly conditions, but also because it does this so much more easily, quickly, economically and profitably than other cleaners.

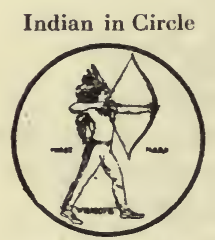

Your supply house will fill your order on our money back guarantee.

It Cleans Clean.

in every package.

The J. B. Ford Co., Sole Mfrs., Wyandotte, Mich. 


\section{WHAT}

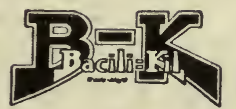

DOES

\section{THREE FUNDAMENTAL PRINCIPLES}

The different uses for BK are based on three fundamental principles. When these are understood it gives an appreciation of BK and a knowledge that enables manufacturers and handlers of dairy products to apply it in many ways to lighten labor and produce purer products.

These principles are:

\section{High bacteriacidal power \\ 2. Solvent Action \\ 3. Harmlessness}

The bacteria-destroying power of $\mathrm{BK}$ is high, so that it kills the bacteria on coming in contact with them.

The solvent action of BK on albumins-milk casein, etc., softens the accumulations on coils, heaters, pasteurizers, pipes, etc., making the cleaning operation easier. Where the metal parts of equipment are not already coated with casein the application of BK before the daily run prevents a milk film from adhering and also dissolves any thin albuminous film that might be there. This solvent action also exposes the bacteria to prompt destruction.

These two functions of BK insure a high degree of sterilization and cleansing-also great economy of labor.

BK is a harmless hypochlorite such as used by the most experienced medical men in and on the human body -adopted by the great surgeons of the allied armies after trying over 150 different articles for protection of health and foods of the armies.

The amount of BK needed to make an effective sterilizing solution is very small and the amount of BK left on the equipment after using is infinitesimal and negligible. Authoritative Experiment Station bulletins prove this point conclusively in their tests on chemical sterilizing.

$\mathrm{BK}$ is easy to use everywhere for purifying, deodorizing and disinfecting. BK has stood the test of time-it has made good. Those who learn its helpfulness become constant users.

\section{GENERAL LABORATORIES}




\section{GROEN}

Vertical Condenser Copper Vacuum Pans

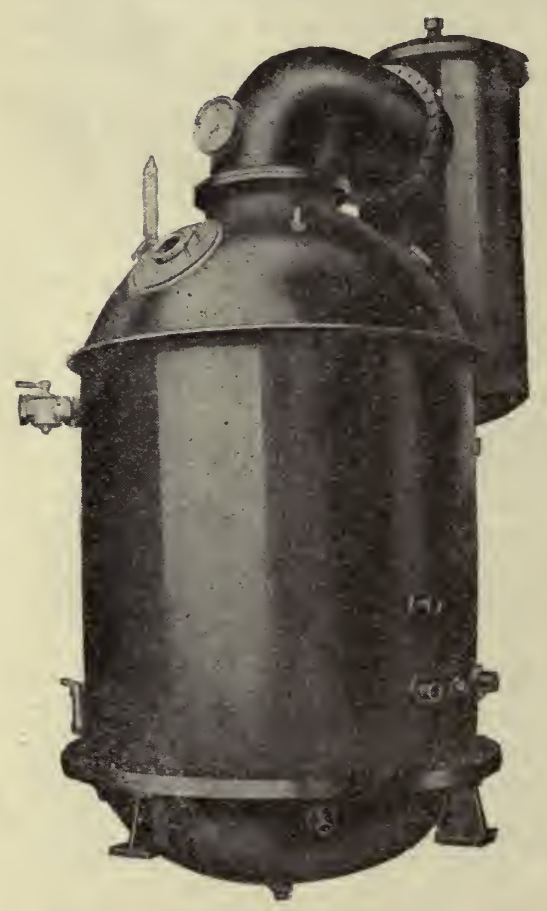

Built in

$3,4,5,6$ and $.7 \mathrm{ft}$. Sizes.

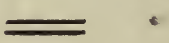

Large Coil Inlets and Outlets for

Exhaust Steam.

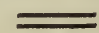

Write for Blueprint Specifications and Prices.

Deliveries made as promised.

Manufacturers of Copper Vacuum Pans, Hotwells, Steam Jacketed Kettles and Special Coppersmith Work.

\section{GROEN MFG. CO., Inc.}

Coppersmiths 


\section{Jensen Vertical Coolers}

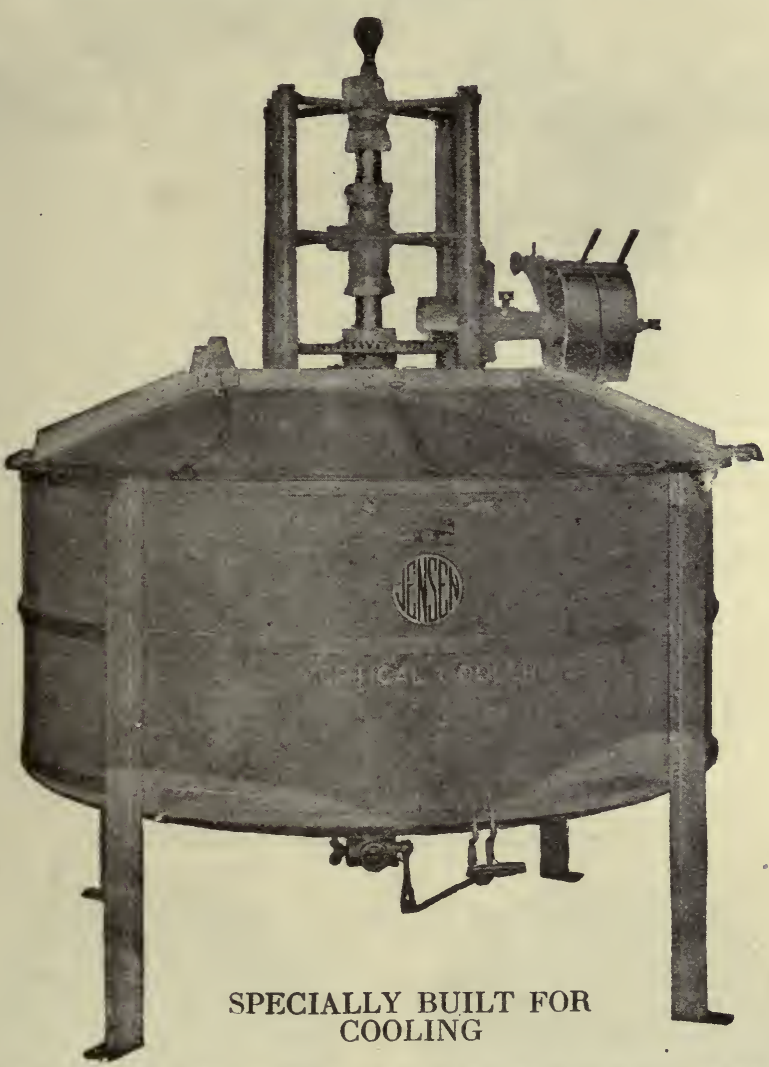

\section{CONDENSED AND EVAPORATED MILK}

\section{ELIMINATE CRYSTALLIZATION.}

Furnish Correct Amount of Agitation to Produce a Smooth

Product. Eliminate Air and Gases Thru Rotation of Double Helical Coil During Cooling Process.

$$
\text { PREVENT CONTAMINATION }
$$

as all Packing and Stuffing Boxes are Outside and Above the Machine.

ASK FOR CATALOG No. 20 A.

Jensen Creamery Machinery Company Long Island City, N. Y. Oakland, California 


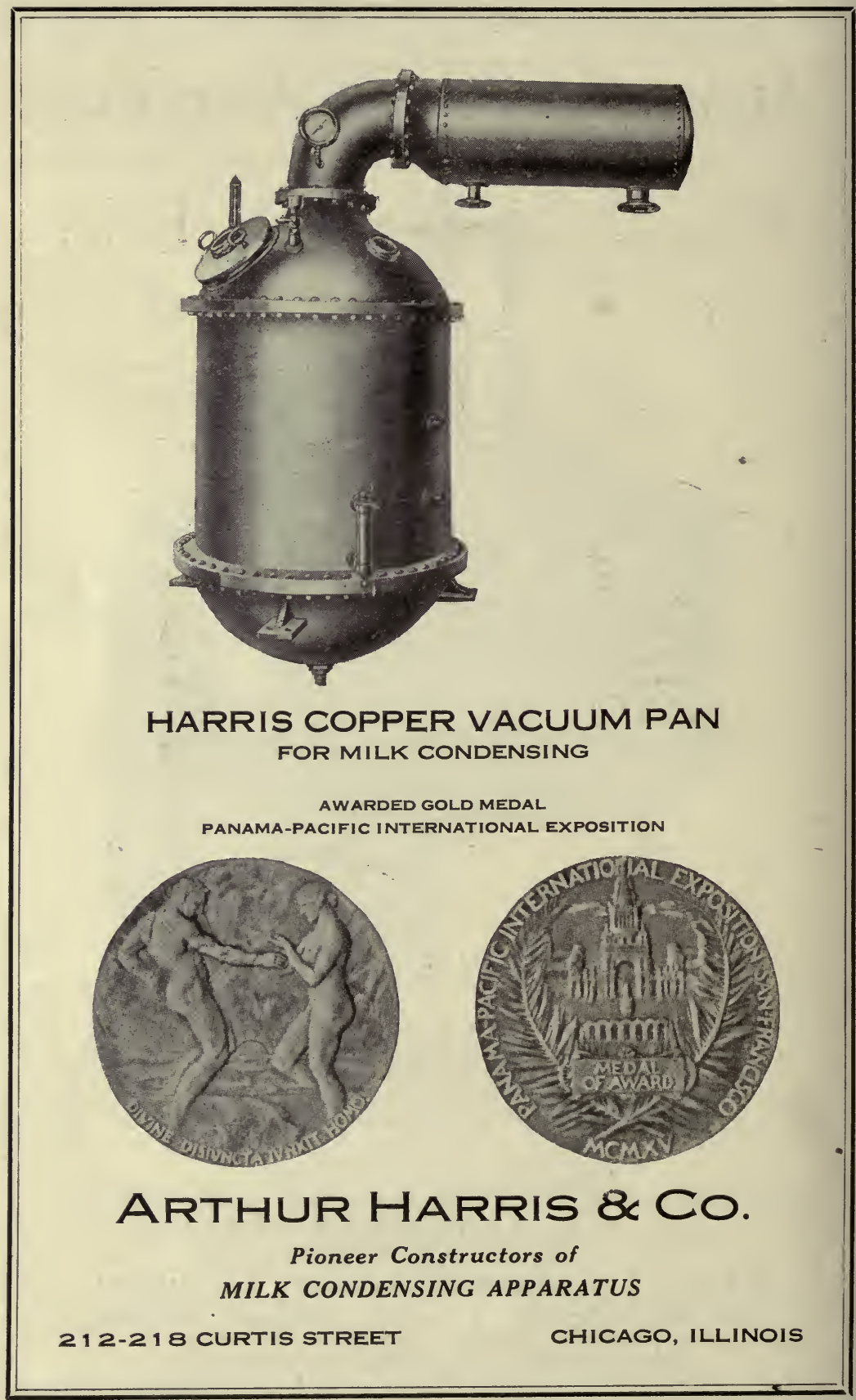




\section{Harris Copper Vacuum Pans \\ AND}

Milk Condensing Machinery

Have been our Specialty for over 30 years. Over this period we have continuously produced High Grade Apparatus which has given most gratifying results both in production and service. Large capacity Harris Copper Vacuum Pans in service today total in the hundreds.

We Solicit Your Inquiries for

VACUUM PANS FOREWARMERS

VACUUM PUMPS

COOLING MACHINES

PIPE COOLERS

RECEIVING TANKS

STORAGE TANKS

FILLING MACHINES
STERILIZERS

SHAKERS

LABELING MACHINES

RUBBER PACKED COCKS

SAMPIERS

SUPERHEATER BULBS

COOLING COILS

WEIGH SCALE TANKS

PEEPHOLE GLASSES, ETC.

\section{Arthur Harris \& Co.}

Established 1884

212-218 Curtis St.

Chicago, Illinois 


\section{The Lathrop-Paulson Company has Perfected}

Can Washer of Super-Success. No Waste, Less Work, Bigger:and

This Now I-P Entirely Automatic Machine has Capacity up to 700 Cans and Covers per hour. Practical and efficient

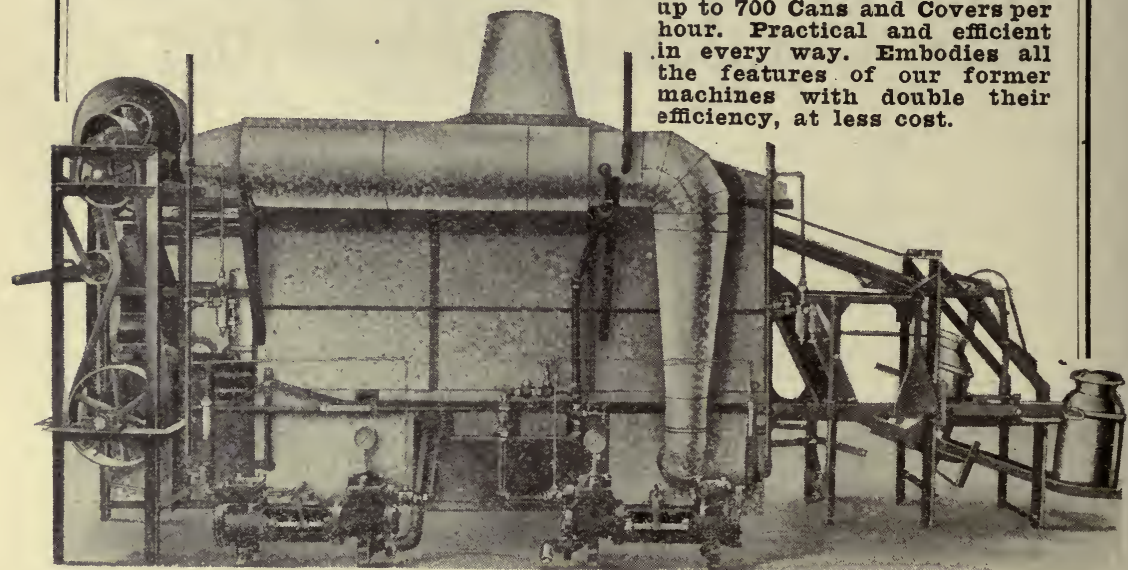

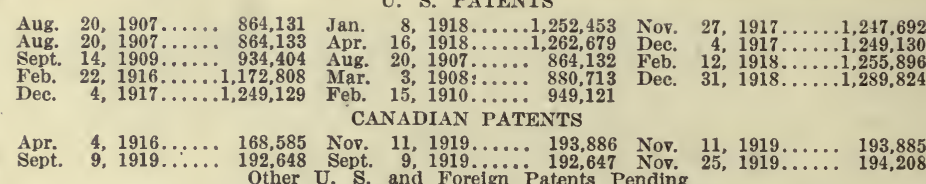
NOTABLE IMPROVED FEATURES:

Does not require even one man to operate.

Machines are END FED, most convenient for disposal of can by milk dumper.

Driven by motor or steam turbine of less than one and onehalf horse power.

Less than one-quarter horse power consumed in automatic machine drive.

Water consumption cut seventyfive per cent.

Drying capacity DOUBLED. Fan delivering 1800 cubic feet of dry, sterile, super-heated air per minute.

WARM SODA SOLUTION WASH - under pressure of 80 to 100 pounds.

CLEAR SCALDING WATER WASH immediately following under pressure of 80 to 100 pounds.

STEAM STERILIZATION under complete control, any amount you desire.

Operating at the rate of 700 cans and covers per hour. IACH and FVIRY CAN receives THREE to FIVE minutes of bacteria-destroying sterilization.

Insures Clean, Dry, Sterile receptacles for the conveyance of product from producer to manufacturer at lowest possible cost.

Machines have the unique feature of handling cans as fast or as slow as desired, depending solely on the speed they are fed to machine, and cannot be crowded beyond capacity.

The Lathrop-Paulson Company are Milk Can Washing Machine Specialists and Solicit Your Inquiries and Requirements

\section{THE LATHROP-PAULSON COMPANY} 2459 West 48 th Street, Chicago, Illinois 


\section{Milk and Egg \\ Drying Machinery}

W ${ }^{\mathrm{E}}$ have over one hundred plants $V$ in successful operation using our spray process in United States and Foreign Countries.

We supply and install complete Milk or Egg drying plants of any required capacity, guaranteeing the highest efficiency at the lowest cost, and that our finished products are freely soluble.

We build a tray albumen Egg Drier, which produces a crystal or flake product. Also a Buttermilk Drier, other than the spray process. Price and particulars on application.

Write for Catalogue

\section{Milk Drying Machinery Company}

Designers, Manufacturers and Builders of Milk and Egg Drying Machinery. Patented in U. S. and Foreign Countries. Established in 1903.

138 North Clark Street, Chicago, Illinois 


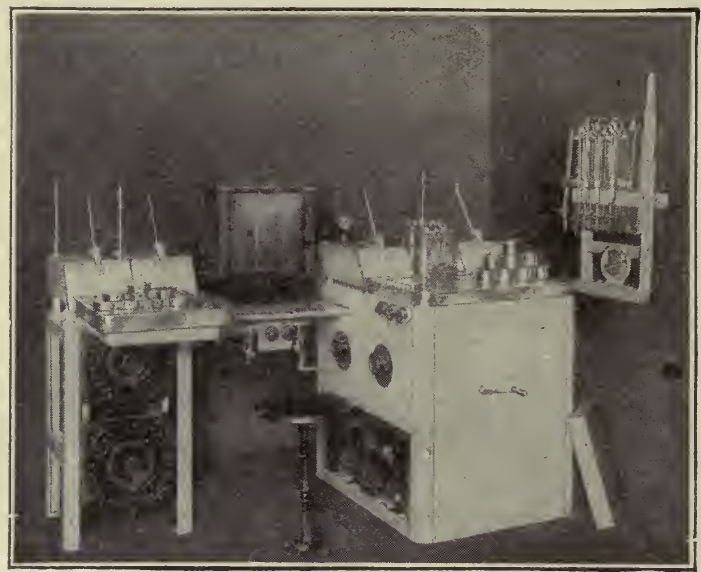

Mojonnier Milk Tester for Butter Fat and Total Solids

(Process patented April 3, 1917; Apparatus patented February 5, 1918; April 9, 1918; June 11, 1918, and August 5, 1919.)

\section{Standard Equipment}

in all up-to-date ice cream, condensed and evaporated milk plants and the larger fresh milk plants includes the

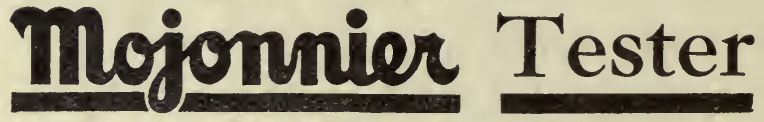

It is used by a large majority of the manufacturers of evaporated milk, and with it they standardize their product to within a few hundredths of 1 per cent of any standard desired upon both butter fat and total solids.

OTHER MOJONNIER PRODUGTS:

Mojonnier Ice Cream Overrun Tester.

Mojonnier Culture Controller.

Mojonnier Evaporated Milk Controller.

Mojonnier Evaporated Milk Can Polisher.

Mojonnier Evaporated Milk Can Opener.

Mojonnier Composite Sample Bottles.

Mojonnier Steam Pressure Copper Kettles.

Extensive line of scientific apparatus and laboratory supplies for chemical and bacteriological control of milk products

Further information cheer ully furnished on any of the above products.

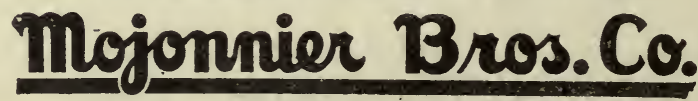

MILK ENGINEERS

739 WEST JACKSON BLVD., CHICAGO

Eastern Office 200 Fif th Avenue, New York, N. Y.

Southern Office $: 0^{\circ} \cdot{ }^{4}{ }^{\circ} 31$ Margaretta Avenue, St. Louis, Mo

Western Office . : : : 2679 McAllister Street, San Francisco, Callf. 


\section{Are You Getting the Highest Efficiency From Your Testing Room?}

\section{NAFIS \\ SCIENTIFIC GLASSWARE.}

WILL HELP YOU TOWARDS THAT GOAL BECAUSE OF ITS

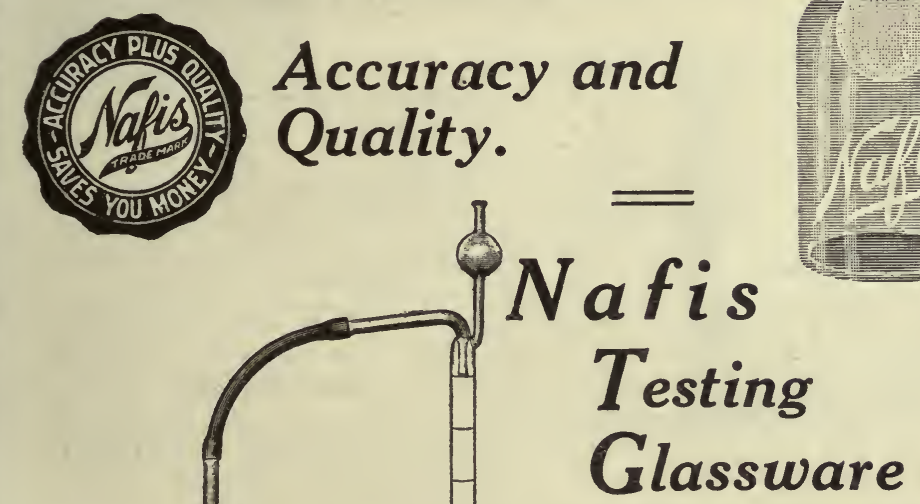

is the result of years of experience and scientific study. It is made to conform with the specifications of the United States Bureau of Standards as well as those of the different states.

Test Bottles are made in either the regular or the Circled Graduation style.

Send in a trial order and judge for yourself.

If your dealer cannot supply you with Nafis Glassware, write for our illustrated catalogue and list of our distributors.

\section{Nafis} Louis F. Nafis, Inc.

Automatic Acid Bottle Manufacturers of Scientific Glassware for Testing Milk and Its Products

542-548 Washington Boulevard CHICAGO, U. S. A. 


\section{PFAUDLER \\ GLASS LINED STEEL CONDENSED MILK EQUIPMENT}

This Tank is used in Condenseries and Bottled Milk Plants to reduce the temperature of incoming milk. It is jacketed for brine circulation, may be equipped with either Air or Mechanical Agitating Device, and the Milk Inlets are provided with spreading devices which spread the milk in a thin film over the brine-chilled tank wall, reducing it at once to a low temperature. Sizes, capacities and prices on request.

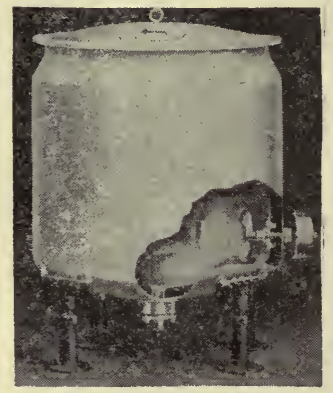

Pfaudler Glass LIned Steel Jacketed Forewarmer

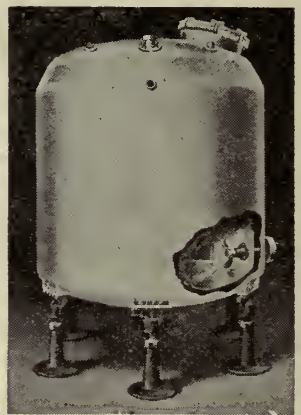

Pfaudier Glass Lined Steel Milk Storage Tank ers are made in the single-shell type or with jacket and side agitator, as illustrated. With the latter the major part of the preheating operation may be carried out without the introduction of steam and finished by the injection of live steam with the regular type of steam header. It may be had with or without the copper cover illustrated. Sizes, capacities and prices on request.

This Milk Truck Tank is divided 1 through the center by a partition head which is open at the top and bottom and acts as a baffle to minimize churning of the contents. The interior, including both sides of the partition head, is lined with Pfaudler Glass Enamel, which extends to the outer edges of the manhole flanges and to the end of the outlets located at the underside of the tank.

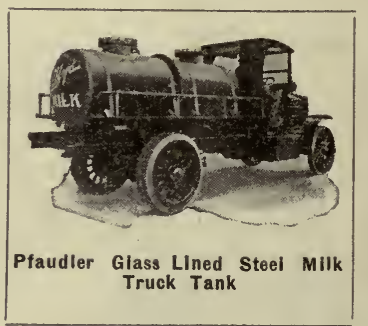

Write for Dairy Equipment Bulletin

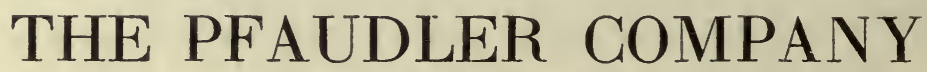

ROCHESTER, N. Y.

NEW YORK

CHICAgo

ST. LOUIS

SAN FRANCISCO 


\section{How To Prevent Streaks and Mottles in Butter}

Prof. Hunziker asserts that streaks and mottles in butter are caused by:

(1) Incomplete fusion of salt and water in butter.

(2) Faulty Mechanical condition of the butter workers.

(3) Overloading of the machine.

Not one of these causes but what may be overcome by any buttermaker who takes pride in his product. With Colonial Salt the buttermaker will never be troubled with incomplete fusion. The other two causes are mechanical and can be easily remedied. Flake salt dissolves quicker than cube salt of the same size grain. Colonial Salt is the only all flaked Butter Salt on the market. It will produce over-run, color, flavor and body. Try it in your next batch of butter.

THE SALT THAT MELTS LIKE SNOW FLAKES AND DISSOLVES LIKE MIST

\section{THE COLONIAL SALT CO.}

AKRON, OHIO BUFFALO

R \& A Hydraulic Can Washer, Sterilizer and Drier for Clean, Dry Sterile Cans

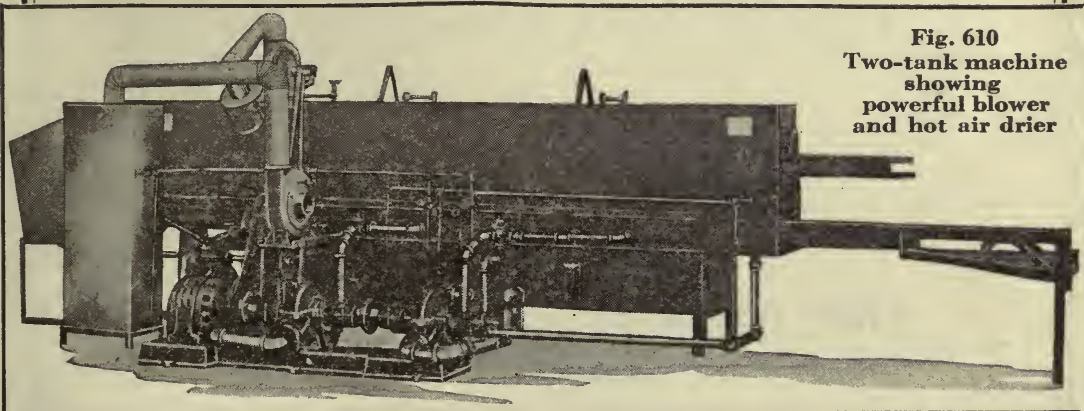

RICE \& ADAMS, Inc.

166-182 CHANDLER STREET BUFFALO 


\section{STERILIZERS}

$\underline{\underline{\text { In All Standard Capacities }}}$

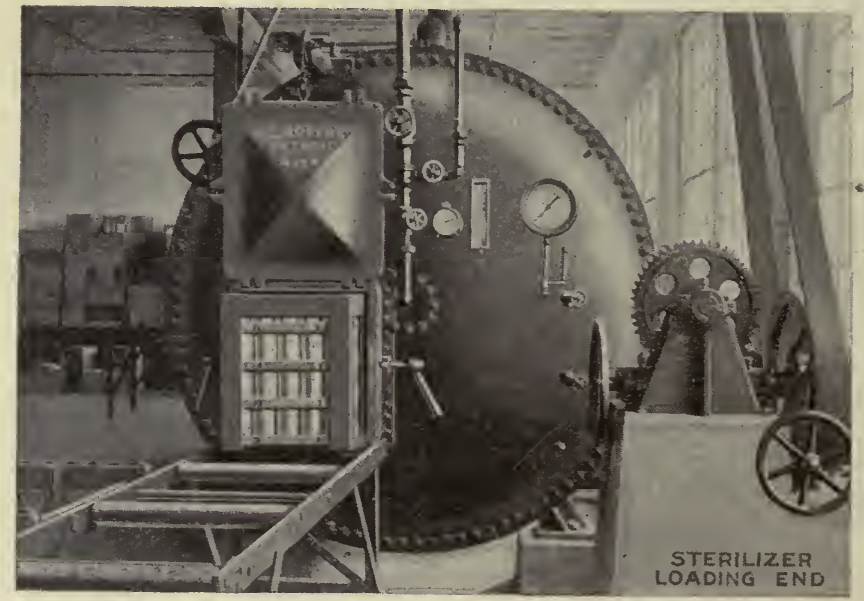

Equal Heat Distribution

RAPID LOADING AND UNLOADING

Our Shakers are also good

C. E. ROGERS

8731 Witt Street

Detroit, Michigan 


\section{HIGH TYPE COPPER}
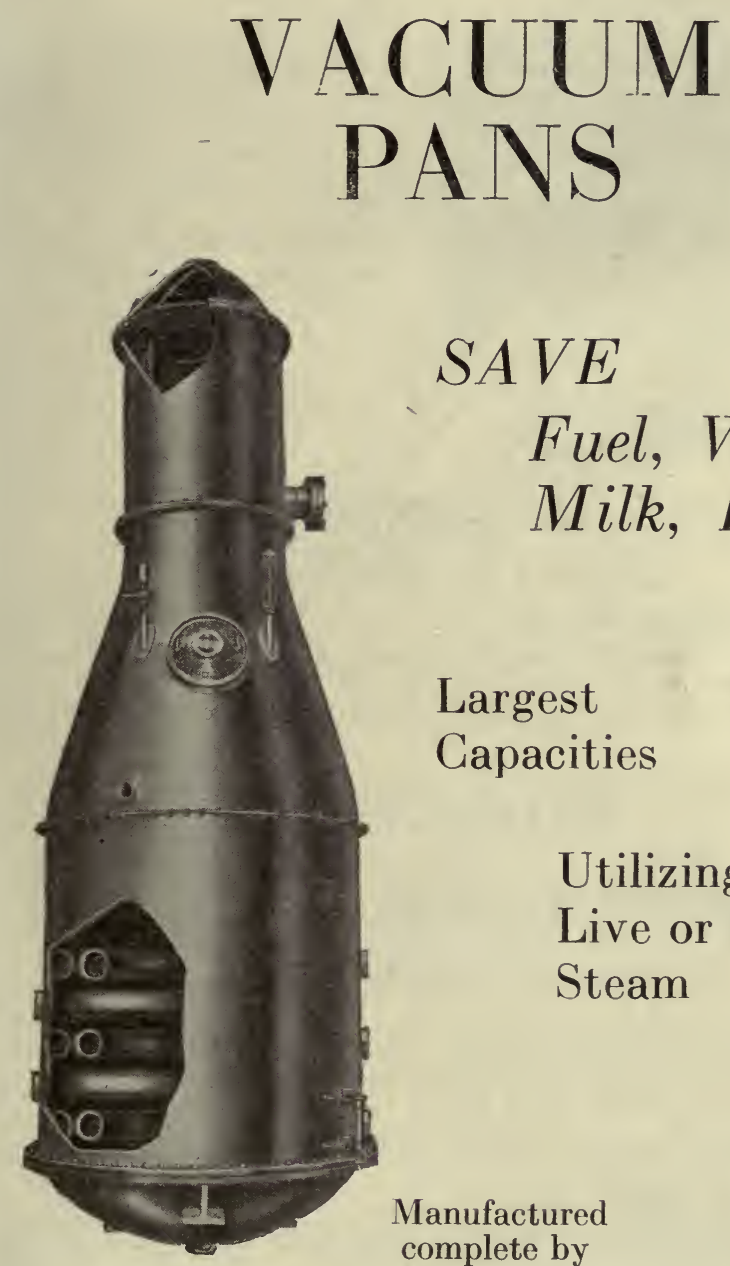

$S A V E$

Fuel, Water Milk, Labor

Largest

Capacities

Utilizing either Live or Exhaust Steam

Manufactured complete by

\section{E. ROGERS}

8731 Witt Street

Detroit, Michigan 


\section{SARGENT'S ELECTRIC DRYING OVEN}

(PATENTFD)

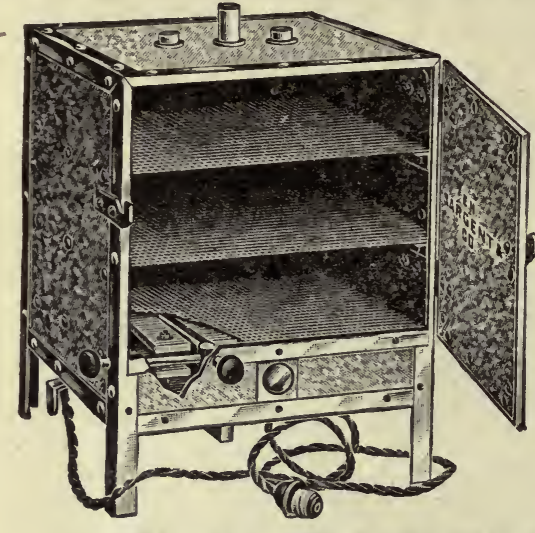

May be set for any temperature from $70^{\circ} \mathrm{C}$. to $150^{\circ} \mathrm{C}$. and will maintain that temperature indefinitely. Almost a necessity in Milk Product Laboratories where the maintenance of the lowest usable temperature is 7) imperative.

Price complete with six-foot cord, plug and thermometer, $\$ 35.00$. Wound for 110 - or 220-volt current.

Complete catalogues furnished upon application.

\section{E. H. SARGENT \& CO.}

Manufacturers, Importers, Dealers in Chemicals and Chemical Apparatus of High Grade only.

155-165 East Superior Street

C H I C A G O

\section{Schaefer \\ Manufacturing Company}

BERLIN, WISCONSIN

Manufacturers of

Condensed and Evaporated

Milk Machinery

Sterilizers

Shakers

Test Sterilizers

Fillers
Automatic

Machinery

Can Conveyors

Testers
Can Coolers and

Special Machinery

for Special

Purposes 


\title{
Make Your Own Cream
}

THE Sharples Emulsifier enables you 1 to make every day, the exact amount of cream needed. No shortage. No surplus. With butter, skim milk powder and water you make your own cream in proper quantities at the proper time with this machine.
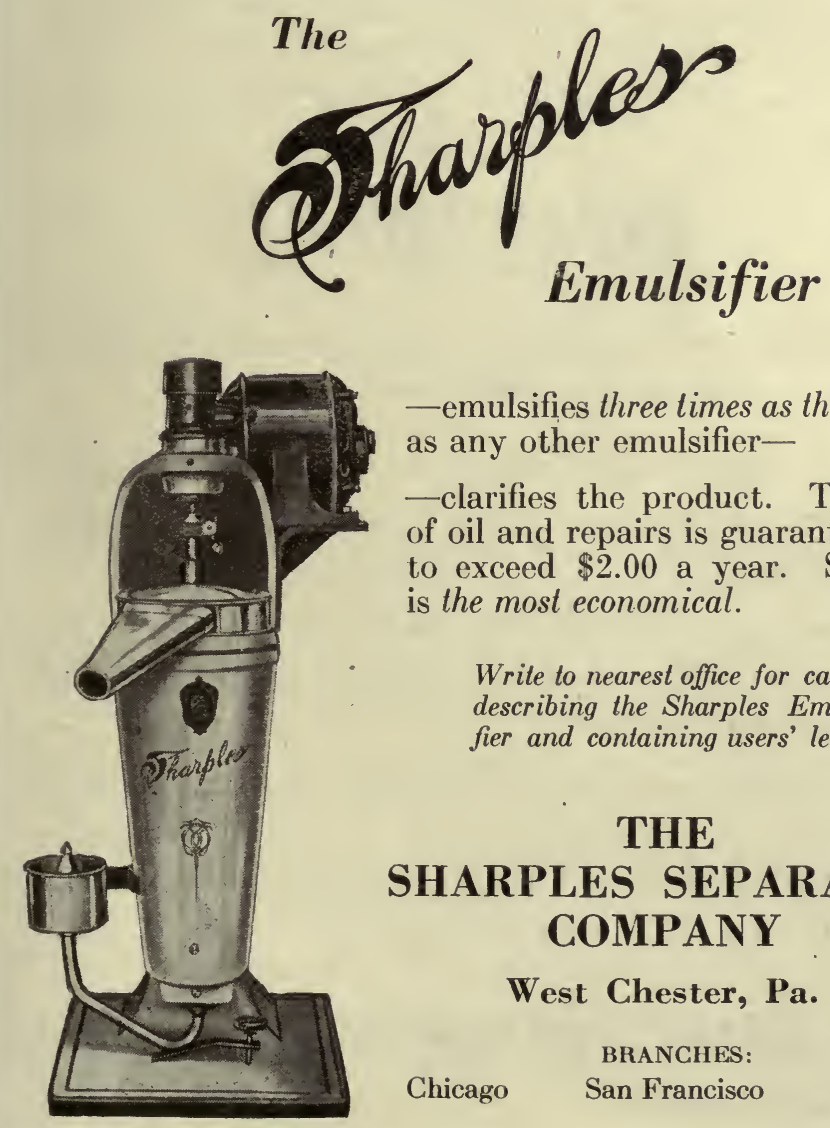

- emulsifies three times as thoroughly as any other emulsifier-

-clarifies the product. The cost of oil and repairs is guaranteed not to exceed $\$ 2.00$ a year. Sharples is the most economical.

Write to nearest office for catalog describing the Sharples Emulsifier and containing users' letters.

\section{THE SHARPLES SEPARATOR COMPANY}

\author{
West Chester, Pa.
}

BRANCHES:

Chicago San Francisco Toronto 


\section{Cemcoat}

\section{White Sanitary Washable Interior Coating}

Cemcoat is a snow-white coating applied like paint. It is glossy and mirror-like and increases the light by reflecting it from every angle. Paint on the light in your Condensery-Cemcoat your walls. The Boston Bio-chemical Laboratory after an exhaustive test finds that Cemcoat affords no ground for accumulation of bacteria and fungi. Heat and cold does not affect Cemcoat - it is water-proof.

\section{LAPIDOLLTH}

\section{Dust-proofs and wear-proofs concrete} floors by chemical action

Lactic acid in milk causes deterioration of concrete floors. Prevent these conditions by flushing on Lapidolith, the liquid hardener.

A chemical combination is effected through the action of Lapidolith on the cement, making the floor granite-like and non-absorbing.

Many dairies and condenseries have thoroughly tested Lapidolith for a number of years. We will refer you to these satisfied users and send samples and complete information.

\section{Sonneborn Sons, Inc.}




\section{Are you going to make

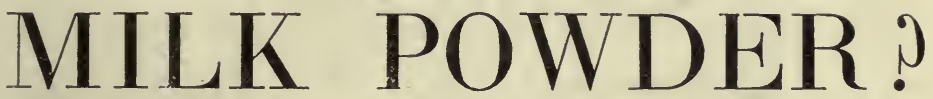 \\ If you are, your logical choice of drying equipment is that of the}

SPRAY DRYING CORPORATION

\section{WHY?}

BECAUSE all the milk powder is recovered within the spray chamber, and not in a succession of secondary equipment.

BECAUSE no milk powder escapes with the outgoing air, a common fault with spray dryers.

BECAUSE it eliminates any need for collecting the powder by means of cyclone dust separators and great, rambling, unsanitary baffle chambers.

BECAUSE of the low fuel power and labor cost.

BECAUSE of the automatic discharge of powder directly into the barrels without conveying machinery or hand shoveling.

BECAUSE the space occupied is only a fraction of that of other spray systems.

BECAUSE no high pressure pump is required for spraying the milk, steam pressure furnishing the force with which the milk is sprayed.

BECAUSE we install these dryers at your plant complete in every detail, and set in operation and relieve you of any concern in the matter.

BECAUSE the powder is freely soluble in cold water.

BECAUSE there is no royalty to pay.

We build these dryers to operate either with fluid milk or condensed milk. In asking us for estimates please tell us how much milk you wish to dry.

\section{Spray Drying Corporation}

50 VESEY STREET

NEW YORK CITY 
YOU U TAG-ROESCH Time-Temperature Controllers-

\section{Because:}

Perfect sterilization of every batch of milk becomes a daily and natural occurrence with practically no labor or attention;

Regardless of a skilled labor shortage, the quality and the quantity of production are safeguarded forever, because an inexperienced workman, after 30 minutes of instruction, can efficiently handle a number of sterilizers;

A rich creamy appearance and uniformly heavy consistency of the finished product are developed-despite the fact that the condition, properties, and concentration of the milk are fixedbecause the time and temperature

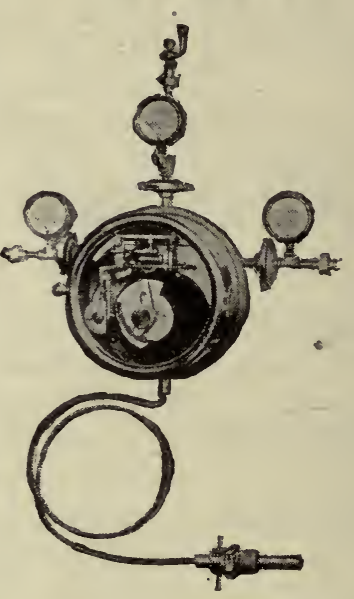
cycles are adhered to rigidly;

A satisfactory product is assured-seven days in the week and 52 weeks in the year-in exact accordance with the pre-determined specifications, because the vital factors of time and temperature are no longer a "hit or miss" proposition;

No separation of the milk when subsequently placed in storage, because the milk always obtains sufficient body or viscosity;

Hard, unshakable curds are avoided, also dark color formation, due to the fact that excessive time and temperature exposures are eliminated;

Considerable labor and steam are conserved, which savings often are sufficient to more than pay for the controllers in one year;

TAG-ROESCH Time-Temperature Controllers can be profitably employed in any milk condensery because this device can be furnished to handle automatically, any combination of time and temperature-no matter how unusual or complicated the sterilizing process may be.

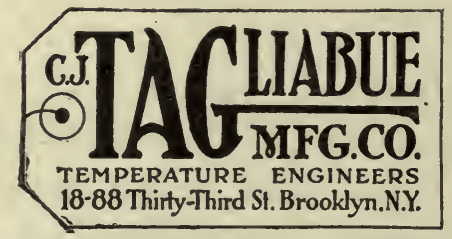

Write for Catalog $\mathrm{H}-460$ and include details of your sterilizing requirements. 


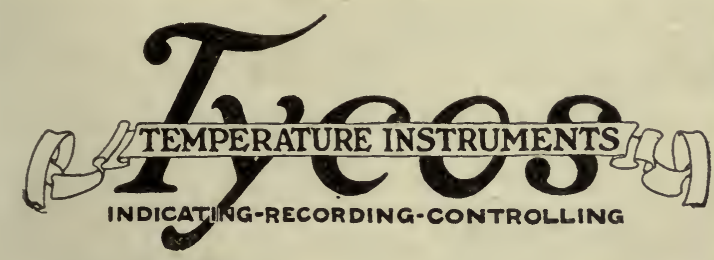

cover every need in temperature equipment of condensed milk and milk powder plants. The executive who needs temperature instruments will find in the list of Tycos products just what he requires for each especial application.

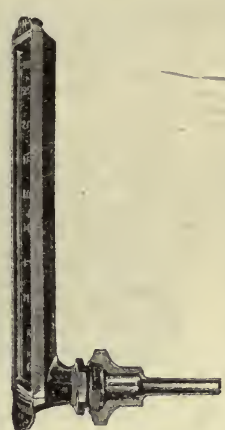

ANGLE STEM THERMOMETER

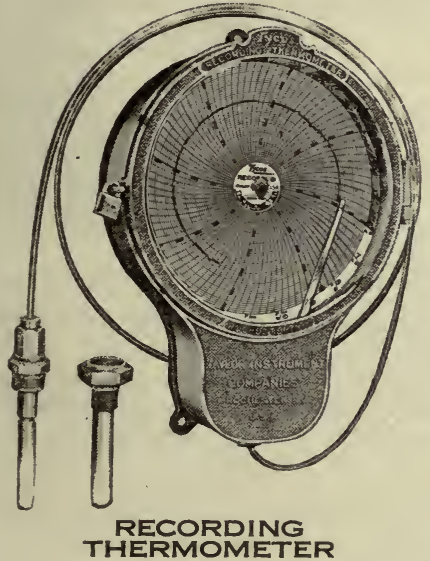

Instruments for every Temperature Need Angle and Straight Stem Thermometers

Engraved Stem Thermometers

Paper Scale Dairy Thermometers Dial Thermometers

Recording and IndexThermometers Temperature and Pressure Regulators

Recording Pressure and Vacuum Gauges

Hydrometers

\section{Bi-Record Recording Thermometer}

Tycos instruments are made for every purpose in the Milk Industry from the time milk enters the hot well until it is ready to be removed from the condenser or vacuum pan.

It will be a privilege for us to send carefully prepared literature, giving valuable information. Simply ask for it. No obligation.

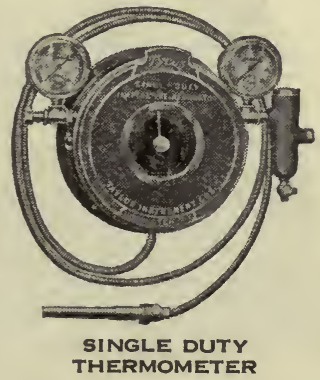

\section{TAYLOR INSTRUMENT COMPANIES} ROCHESTER, N. Y.

There is a Tycos and Taylor Thermometer for Every Purpose 


\section{Why the Leading Condensed Milk Makers Choose Sturges Cans}

-because they are accurate-absolutely true to measure. Sanitary-easy to clean and keep clean. Built extra strong to withstand long service.

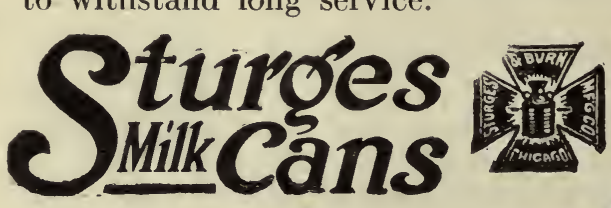

are built of the highest grade of steel plate, carefully tinned. Seams soldered smooth as a china bowl, no places for milk to lodge and sour. Write for catalog No. 111.

STURGES \& BURN MFG. CO. "Leaders Since 1865"

CHICAGO, - ILLINOIS

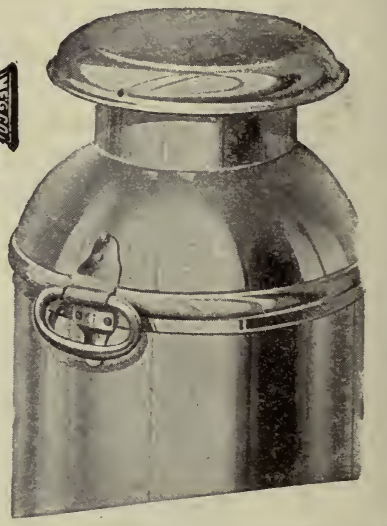

\section{Torsion Balance Creamery Scales}

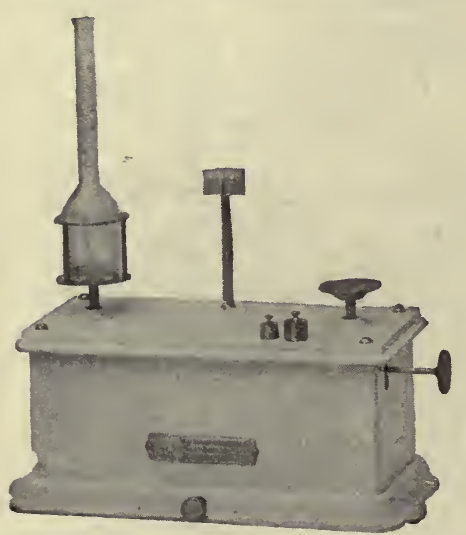

No Knife-Edges - No Friction No Wear

SENSITIVE and ACCURATE

Tares and balances in one operation.

No loose parts to shift. Working parts practically in one piece.

Torsion Balance bottle Cream Test Scale, Style 1500, used by collection stations, creameries, etc., on account of its extreme accuracy.

Your profits depend on your tests as much as anything else, probably more so.

\section{Christian Becker Analytical Balances}

\section{The Torsion Balance Co.}

Head Office: 92 Reade Street NEW YORK, N. Y. Factory: 147-153 Eighth Street JERSEY CITY, N. J. 


\section{GONDENSERY and Powder Plant Pumps}

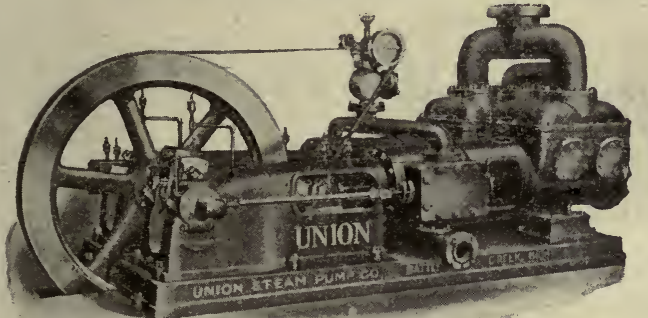

Wet Vacuum Pumps for exhausting Milk Pans manufactured in all required sizes and styles.

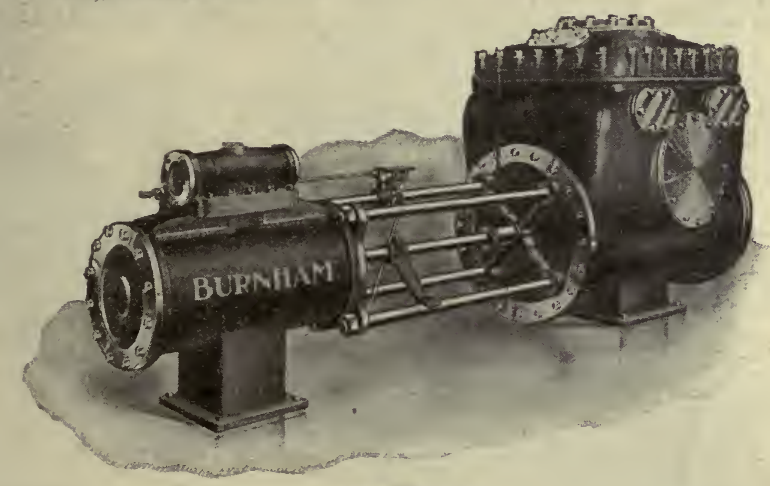

S.P.E.CI.A.L

HIGH

PRESSURE

PUMPS FOR

Cooling

Sweetened Condensed Milk OR Spraying into Drying Cabinets

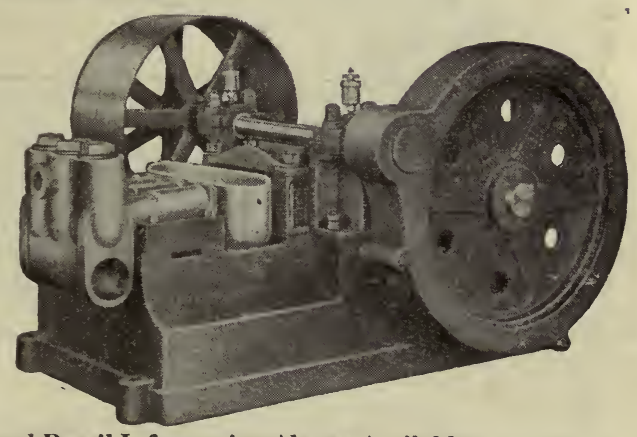

Bulletins and Detail Information Always Available

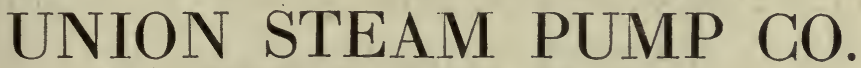
BATTLE, CREEK, MICH. 


\section{COMPLETE \\ Pumping Equipment FOR}

Condensed Milk and Milk Powder Plants

STEAM, BELT OR MOTOR DRIVEN FOR ANY SERVICE; CAPACITY OR PRESSURE

WELL PUMPS

TANK PUMPS

\section{BOILER PUMPS}

Spray Pumps

BRINE PUMPS

VACUUM PUMPS

FILTER PUMPS

Viscolizers

MILK PUMPS

COOLING PUMPS

All listed and described in Bulletin No. 57

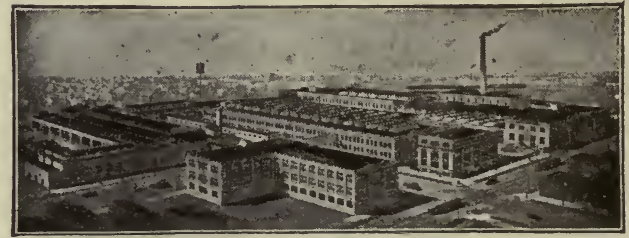

THE FACTORY BEHIND THE GOODS

\section{UNION STEAM PUMP CO.}

BATTLE CREEK, MICH. . 


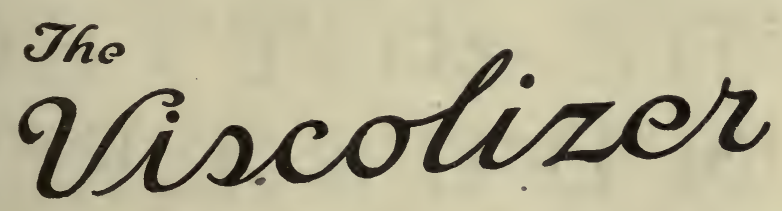

The Highest Development in the Art of Treating Evaporated Milk to Prevent the Separation of Butter Fat without disturbing the Natural Emulsion of Casein and Albumin

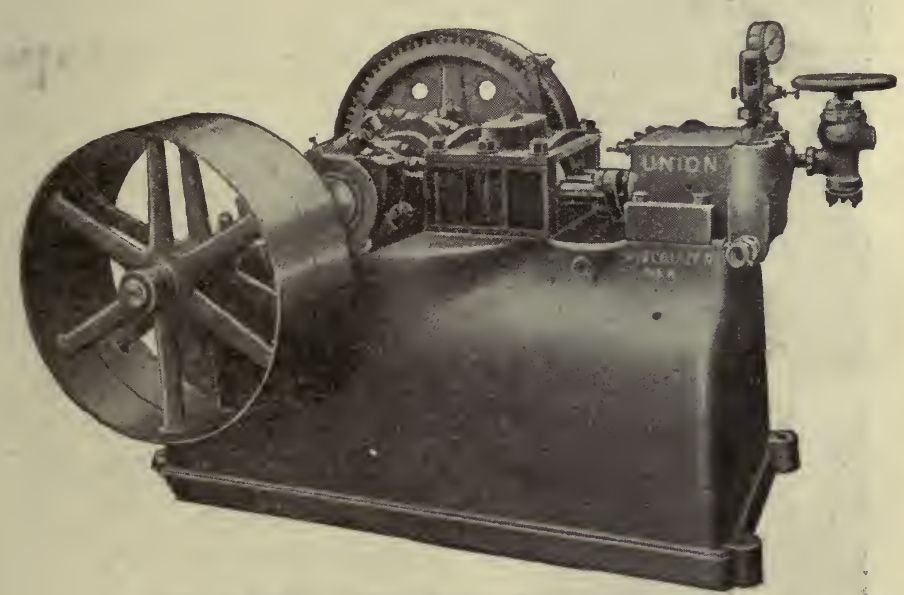
NO. 4 VISCOLIZER-8OO-GALLON CAPACITY

Specially Constructed for Condenseries

Designed as High Pressure Pumps Should be BUILT-PATENTED-GUARANTEED BY Union Steam Pump Co., Battle Creek, Mich.

SALES AND SERVICE BY John W. Ladd Co., Detroit-Cleveland Cherry-Bassett Co., Baltimore-Philadelphia 


\section{THE BUTTER \\ I N D U S T R Y}

B Y O. F. H U N Z I K E R

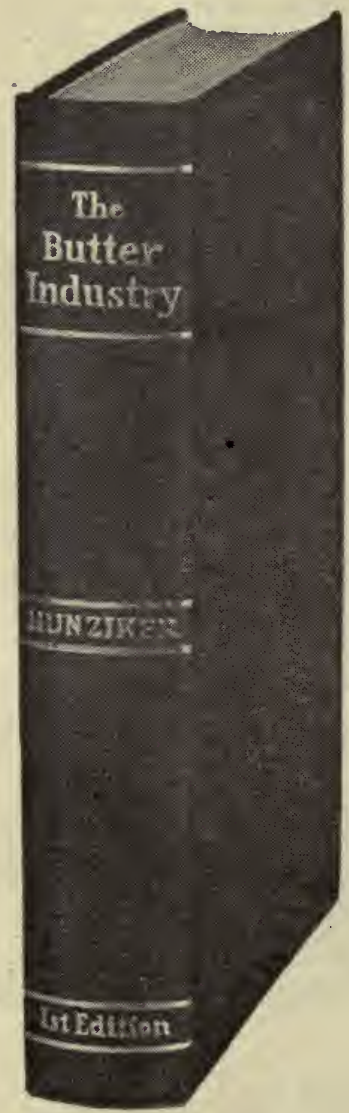

712 pages and over Ioo illustrations.

The information contained in this book is new and not generally known even among the most progressive creameries and milk products factories.

PUBLISHED BY THE AUTHOR. 

THIS BOOK IS DUE ON THE LAST DATE STAMPED BELOW

AN INITIAL FINE OF 25 CENTS WILL BE ASSESSED FOR FAILURE TO RETURN THIS BOOK ON THE DATE DUE. THE PENALTY WILL INCREASE TO 50 CENTS ON THE FOURTH DAY AND TO \$1.00 ON THE SEVENTH DAY OVERDUE.

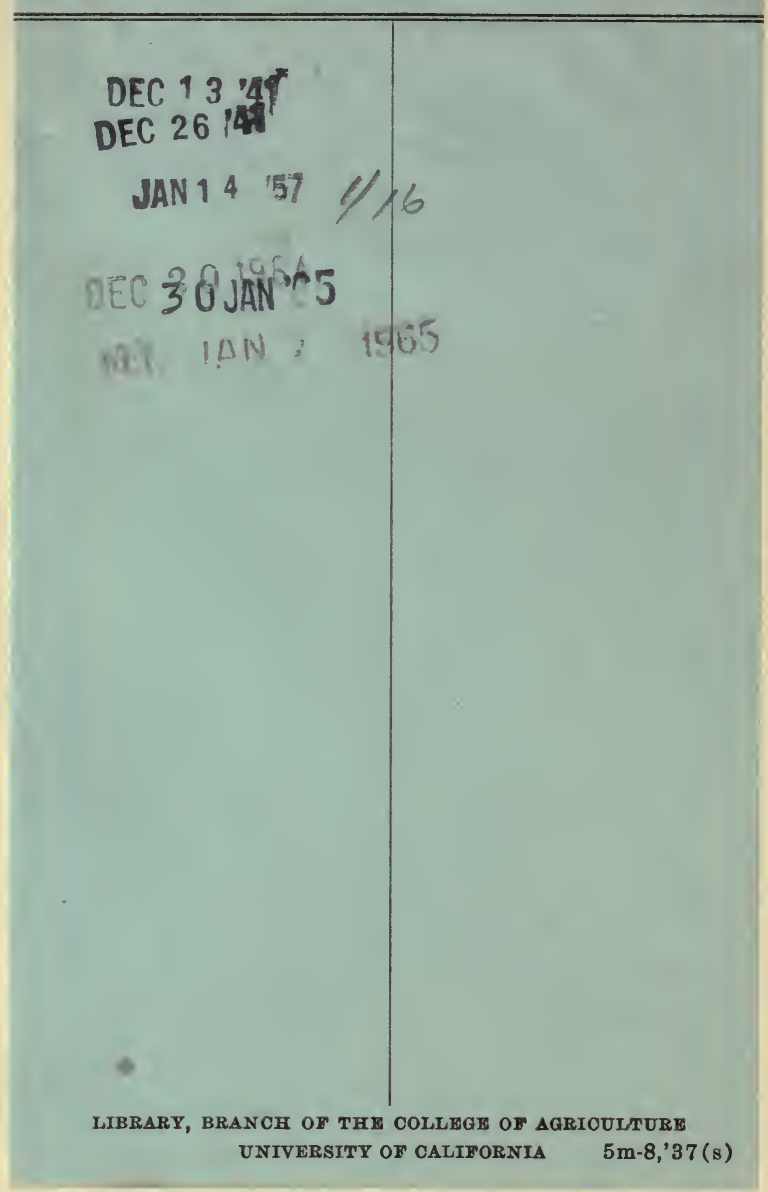


